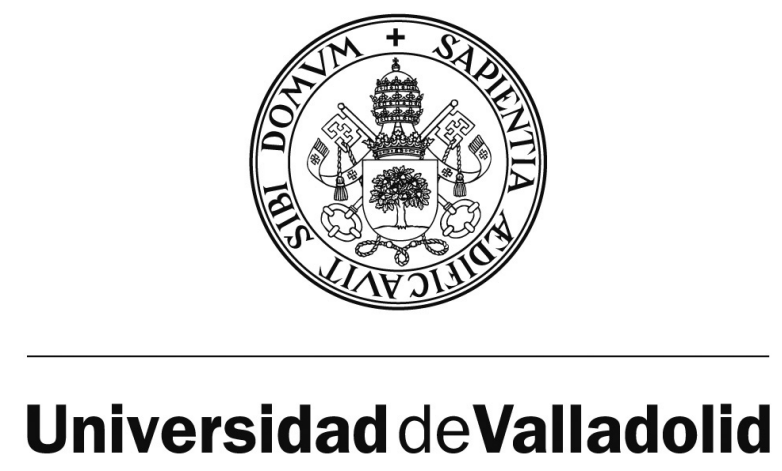

FACULTAD DE EDUCACIÓN Y TRABAJO SOCIAL

DEPARTAMENTO DE DIDÁCTICA DE LA EXPRESIÓN MUSICAL, PLÁSTICA Y CORPORAL

TESIS DOCTORAL:

\title{
LA EXENCIÓN (IN)VISIBLE DE LA EDUCACIÓN FÍSICA EN LA E.S.O. Y EL BACHILLERATO DE PRINCIPIOS DEL SIGLO XXI
}

Presentada por Julio César Rodríguez de la Cruz para optar al grado de Doctor por la Universidad de Valladolid

Dirigida por:

Dr. José Ignacio Barbero González

Dr. Nicolás Julio Bores Calle

Valladolid 2015 

La redacción de esta tesis se ajusta a las normas ortográficas establecidas en la última edición de la ortografía de la lengua española (Real Academia Española, 2010). lectura.

Hemos utilizado el género masculino única y exclusivamente con el deseo de hacer más fluida la 



\section{DEDICATORIA}

A la memoria de Virginia,

ideal de lucha y tesón. 



\section{AGRADECIMIENTOS}

A $\mathrm{M}^{\mathrm{a}}$ Jesús, siempre presente. Mi mejor y gran amiga. Compañera inseparable y apoyo ilimitado a lo largo de toda mi vida.

A mis padres, sin los cuales nada hubiese sido. Su esfuerzo y sacrificio nunca serán recompensados.

A Paula y Julia, a las que las he robado horas de compañía para dedicárselas a esta tesis. Espero que algún día os podáis sentir orgullosas de mí.

A Antonio Diez, el fogonero que ha alimentado la marcha de esta tesis. Un gran consejero, compañero y profesional.

A mis directores, por el asesoramiento, consejos y trabajo infatigable. La ayuda definitiva en la sombra.

A Chema Lera y Fernando "Ministro", con los que me adentré en el mundo de la investigación. Sin un buen inicio, no habría un final digno.

A la familia y amigos de Virginia. Su colaboración y atención son merecedoras de elogio indefinido.

A Vicente Martínez de Haro y Agustín Romero, por su generosa predisposición a ayudarme.

A los compañeros y compañeras que tuve en el IES Santo Tomás de Aquino (Íscar), con los que compartí once años y los momentos más importantes de mi vida. Celia, Charuca, Rosa, Moi, Israel, Carmen, Jesús..., estáis entre estas líneas. 
A Puri, Pilar y Susana, compañeras de penas y fantásticas escuchantes. Mis confesoras y guías en los últimos años.

A los compañeros con los que compartí cursos. Sus sugerencias y colaboraciones han sido fundamentales. 
ÍNDICE 



\section{CAPÍTULO 1.- INTRODUCCIÓN}

1.1.- EL AUTOR EN LA ENCRUCIJADA DE LA FORMACIÓN PERMANENTE

\section{CAPÍTULO 2.- ORIGEN Y JUSTIFICACIONES}

CAPÍTULO 3.- MIS PUNTOS DE PARTIDA. DUDAS Y DILEMAS QUE SE ME PRESENTAN

\section{CAPÍTULO 4.- OBJETIVOS Y LÍMITES DE LA TESIS}

4.1.- OBJETIVOS.

4.1.1.- PIEZAS DE LA VIDRIERA.

4.2.- LÍMITES DE LA TESIS

4.2.1.- LÍMITES ESPACIALES.

4.2.2.- LÍMITES TEMPORALES.

Cronograma

4.2.3.- CARACTERÍSTICAS SINGULARES

\section{CAPÍTULO 5.- APRECIACIONES METODOLÓGICAS}

5.1.- REFERENTES METODOLÓGICOS

5.2.- TÉCNICAS PARA LA OBTENCIÓN DE INFORMACIÓN.

5.2.1.- ANÁLISIS DE CONTENIDO (O ANÁLISIS DOCUMENTAL)

5.2.2.- CUESTIONARIOS 
5.2.4.- HISTORIA DE VIDA................................... 56

5.2.5.- OBSERVACIÓN PARTICIPANTE........................ 57

Cuaderno de trabajo.................................... 58

Diarios de campo...................................... 58

Cuaderno de notas.................................... 58

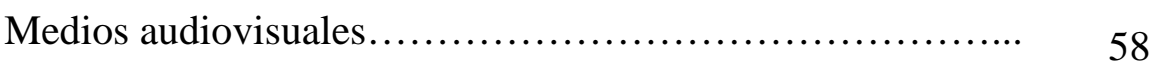

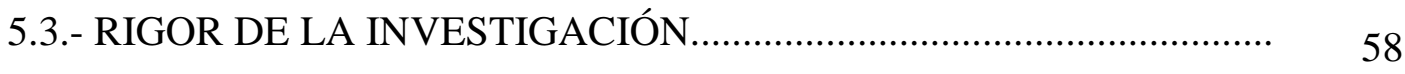

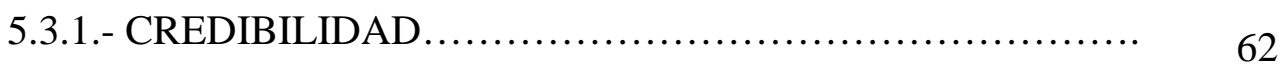

5.3.2.- TRANSFERABILIDAD................................ 64

5.3.3.- DEPENDENCIA...................................... 65

5.3.4.- CONFIRMABILIDAD ................................ 65

5.4.- ÉTICA DE LA INVESTIGACIÓN........................................................ 66

\section{CAPÍTULO 6.- CONFIGURACIÓN DEL MARCO TEÓRICO-LEGAL DE LA EXENCIÓN}

6.1.- MARCO LEGAL: DE LA "DISPENSA" A LA ADAPTACIÓN CURRICULAR (E.S.O.) Y LA "EXENCIÓN"

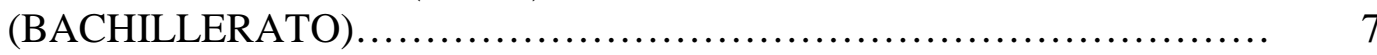

6.1.1.- ACOPIO DE LA LEGISLACIÓN.

6.1.2.- Orden 31 de julio de 1961 (Mº. Educ. Nac.). INSTITUTOS NACIONALES DE ENSEÑANZA MEDIA. Dispensas de educación física. (BOE 15-09-1961)

6.1.3.- ORDEN de 10 de julio de 1995 por la que se regula la adaptación del currículo de la Educación Física para los alumnos con necesidades educativas especiales en el Bachillerato Unificado y Polivalente, en la Formación Profesional de primer y segundo grados y en la educación secundaria, así como la dispensa de la misma para los mayores de veinticinco años (BOE 15-071995)

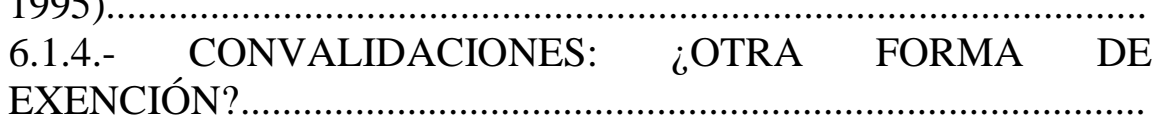

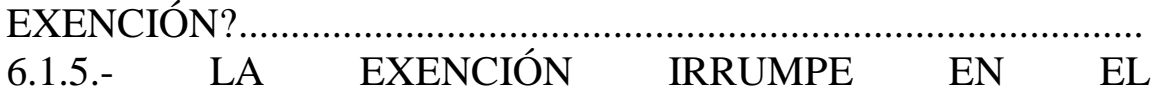

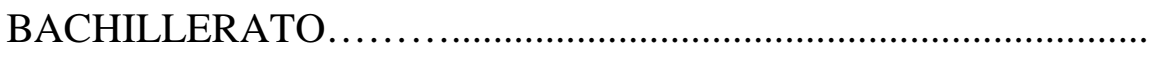


6.1.6.- POCAS VARIACIONES EN LAS NORMAS AUTONÓMICAS .............................................................. 86

Exención de la Educación Física en el Bachillerato.................................................................. 86

Graduación de la exención: parcial y total................... 88

La compatibilidad y convalidación como otra forma de exención...............................................

6.1.7.- PORMENORES DE LA EXENCIÓN DE LA EDUCACIÓN FÍSICA EN EL BACHILLERATO EN CASTILLA Y

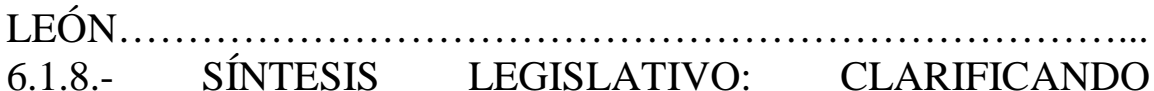
CONCEPTOS Y SACANDO A LA LUZ PARADOJAS Y CONTRADICCIONES.

Glosario terminológico

Paradojas y contradicciones.

6.2.- EL CONCEPTO DE EXENTO: USOS HABITUALES EN LAS FUENTES DE INFORMACIÓN

6.2.1.- ANTECEDENTES: LA EXENCIÓN COMO OBJETO DE ESTUDIO

6.2.2..- LA EXENCIÓN EN EDUCACIÓN FÍSICA: UN PROCEDIMIENTO MANTENIDO EN EL MARCO DE LAS ADAPTACIONES CURRICULARES

6.2.3.- EXENCIÓN EXCLUSIVAMENTE DE LA PRÁCTICA PARA ATENDER A LA DIVERSIDAD.

6.2.4.- EL PODER DE LOS "PAPELES" MÉDICOS Y PATERNOS EN LA APLICACIÓN DE LA EXENCIÓN.

6.2.5.- RESPUESTAS EDUCATIVAS QUE LA EDUCACIÓN FÍSICA OFRECE A ESTOS ALUMNOS

6.2.6.- LA DISPENSA POR APOYO EDUCATIVO

6.2.7.- ¿LA FORMACIÓN DEL PROFESOR DE EDUCACIÓN FÍSICA COMO EXCUSA PARA LA EXENCIÓN?.

6.2.8.- LA EXENCIÓN EN LOS MEDIOS SOCIALES DIGITALES.....

El exento en Educación Física

Solicitud de convalidación de la Educación Física.

6.2.9.- EPÍLOGO CONCEPTUAL

Glosario terminológico. 


\section{CAPÍTULO 7.- APROXIMACIÓN A LA RESPUESTA QUE DA LA EDUCACIÓN FÍSICA: REVISIÓN DE LAS PROGRAMACIONES DIDÁCTICAS}

7.1.- CUESTIONES EN TORNO AL PROCESO

7.2.- METODOLOGÍA UTILIZADA

Diseño de las fichas de análisis

7.3.- PRIMER FILTRO: INFORMACIÓN GENERAL Y AJUSTE A LA NORMA

a) Aspectos generales y de presentación.

b) Aspectos normativos.

b.1) Nombre del Departamento Didáctico

218

b.2) Cuestiones que deben contener las programaciones didácticas según la normativa.

b.3) Normativas recogidas en las programaciones

c) Cómo se articula la evaluación.

7.4.- SEGUNDO FILTRO: MEDIDAS DE ATENCIÓN A LA DIVERSIDAD.

a) Desarrollo de la atención a la diversidad y de las adaptaciones curriculares.

a) La exención: práctica mantenida.

b) Gestión de los casos extremos

c) Respuestas ofrecidas a estos alumnos.

d) Evaluación.

e) Contradicciones que aparecen.

7.6.- OTRAS PROGRAMACIONES DIDÁCTICAS.

a) Más de lo mismo.

b) ¿Qué hay de nuevo?: Cortapisas e impedimentos para los alumnos. 
Piezas de la vidriera

\section{CAPÍTULO 8.- APROXIMACIÓN A LA VISIÓN QUE TIENE EL PROFESORADO}

8.1.- INTRODUCCIÓN

8.2.- RECONSTRUCCIÓN DEL PROCESO DE ELABORACIÓN DEL CUESTIONARIO

Objetivos.

Tipo de preguntas.

Organización y administración

Pasos en la confección.

Tratamiento estadístico.

Muestra.

Centros de interés.

Cuestiones anecdóticas procedimentales

\section{3.- INTERPRETACIÓN DE LOS DATOS}

a) Creencias del profesorado sobre el tema.

b) Niveles de concreción del currículo: cómo se contemplan estos supuestos.

c) Cómo se gestionan estos casos.

d) Lo que se pide o espera de estos alumnos

e) Respuestas de los alumnos implicados

f) Cómo se manifiesta el resto de alumnos

g) Implicación o papel desempeñado por los familiares.

h) Formación y conocimiento sobre el tema

i) Valoración del trabajo y de los medios docentes. 
8.4.- EPÍLOGO

Algunas ideas contradictorias

Piezas de la vidriera

CAPÍTULO 9.- LA EXENCIÓN VISTA A TRAVÉS DE LA FORMACIÓN

301

9.1.- ANTES DE NADA

304

9.2.- LOS ANTECEDENTES

9.3.- SITUANDO LOS RELATOS DE VIDA EN MI INVESTIGACIÓN

9.5.- LA FORMACIÓN INICIAL: PREPARANDO EL CAMINO HACIA LA ENSEÑANZA DE LA EDUCACIÓN FÍSICA.

9.6.- PRIMEROS PASOS EN LA ENSEÑANZA DE LA EDUCACIÓN FÍSICA

9.7.- MI INTERÉS POR SEGUIR FORMÁNDOME

Relatos de mi formación permanente.

Un punto y seguido a mi formación permanente

9.8.- OFERTA FORMATIVA DE LOS CENTROS DE FORMACIÓN E INNOVACIÓN EDUCATIVA DE VALLADOLID (CFIEs).

Metodología y proceso de recogida de la información.

Análisis e interpretación de los datos

9.10.- TODAVÍA FALTAN PIEZAS

Piezas de la vidriera

CAPÍTULO 10.- ANÁLISIS DE UNA REALIDAD EN TORNO A LOS DOCUMENTOS MÉDICOS Y JUSTIFICANTES PATERNOS QUE PRESENTAN LOS ALUMNOS PARA ESTAR EXENTOS 
Contextualización de la investigación

10.2.- DOCUMENTOS MÉDICOS

¿Qué valor hay que dar a los documentos médicos?

Recogida de datos y tabla de documentos

Núcleos de atención: análisis e interpretación.

a)

Formato

b) Información aportada y autoría.

c) Exención: total y parcial.

d) La "no práctica" como tratamiento

e) Visión (reduccionista y tradicional) de la Educación Física. ...

f) Recomendaciones y vuelta al trabajo.

g) Actuación del profesorado: descripción de una realidad.

Conclusiones

Recogida de datos y tabla de documentos

Núcleos de atención: análisis e interpretación.

a) Formato

b) Información aportada y autoría.

c) Recomendaciones a seguir

d) Visión de la Educación Física.

e) Actuación del profesorado: descripción de una realidad.

Conclusiones

10.4.-

Piezas de la vidriera 
CAPÍTULO 11.- LA RESPONSABILIDAD DEL PROFESOR DE EDUCACIÓN FÍSICA: ¿COARTADA PARA LA EXENCIÓN?

11.1.- LA RESPONSABILIDAD DE LOS DOCENTES

11.2.- RIESGOS Y RESPONSABILIDAD EN LA EDUCACIÓN FÍSICA..

11.3.- UNA CUESTIÓN QUE DESPIERTA MI INTERÉS PERSONAL....

11.4.- PERCEPCIÓN DEL RIESGO Y LA RESPONSABILIDAD EN LAS AULAS.

11.4.1.- INTRODUCCIÓN.

11.4.2.- RECONSTRUCCIÓN DEL PROCESO DE ELABORACIÓN DEL CUESTIONARIO 2 ....................

Objetivos 455

Tipo de preguntas

Organización y administración. 456

Pasos en la confección. 456

Tratamiento estadístico 457

Muestra.

11.4.3.- RESULTADOS E INTERPRETACIÓN

Información y formación.

Sobre la Educación Física.

11.5.- EPÍLOGO.

Piezas de la vidriera

CAPÍTULO 12.- ANÁLISIS RETROSPECTIVO DE UN CASO EXCEPCIONAL: LA EDUCACIÓN FÍSICA ATRAVÉS DE LOS OJOS DE VIRGINIA 


\section{CAPÍTULO 13.- CONCLUSIONES GENERALES}

13.1.- ANÁLISIS GLOBAL DE LA TESIS.

13.4.- LAS PROGRAMACIONES DIDÁCTICAS: CONCRECIÓN DEL CURRÍCULO Y DE ASUNTOS PROPIOS DE LA EXENCIÓN.

13.5.- LOS PROFESORES DE EDUCACIÓN FÍSICA SE MANIFIESTAN SOBRE LA EXENCIÓN

13.6.- LA EXENCIÓN IRRUMPE EN EL TRAYECTO DE MI FORMACIÓN PERMANENTE

13.7.- EL PODER DE LOS PAPELES MÉDICOS Y FAMILIARES

13.8.- LA EXENCIÓN MANTENIDA POR LA RESPONSABILIDAD QUE ASUME EL DOCENTE

13.9.- LA EXENCIÓN VISTA POR LOS IMPLICADOS Y SUS FAMILIARES. 


\section{ANEXOS}

ANEXO 1: ORDEN DE 10 DE JULIO DE 1995

ANEXO 2: MODELO DE SOLICITUD DE EXENCIÓN DE MATERIAS DE BACHILLERATO SEGÚN LA ORDEN EDU/490/2014.

ANEXO 3: CARTA DEL DEPARTAMENTO DE E. F. A LOS PADRES PARA LOS CASOS DE EXENCIÓN TOTAL O PARCIAL.

ANEXO 4: IMPRESO DE SOLICITUD DE DISPENSA O EXENCIÓN DE ACTIVIDADES PRÁCTICAS EN LA ASIGNATURA DE EDUCACIÓN FÍSICA .

ANEXO 5: MODELO FAMILIAR E INFORME MÉDICO SEGÚN LA FUENTE [36]

ANEXO 6: FICHA DE EXENTOS DE LA PARTE PRÁCTICA

ANEXO 7: MODELO DE CARTA QUE ENVÍA EL INSTITUTO AL MÉDICO (LÓPEZ, 1996).

ANEXO 8: CARTA AL MÉDICO (PERELLÓ, 2004).

ANEXO 9: FICHA DE INFORMACIÓN GENERAL Y AJUSTE A LA NORMA (PRIMER FILTRO DEL ANÁLISIS).

ANEXO 10: FICHA SOBRE MEDIDAS DE ATENCIÓN A LA DIVERSIDAD (SEGUNDO FILTRO DEL ANÁLISIS).

ANEXO 11: FICHA DEL CONCEPTO Y USO DE LA EXENCIÓN (TERCER FILTRO DEL ANÁLISIS).

ANEXO 12: CUESTIONARIO DE AUTOCUMPLIMENTACIÓN.

ANEXO 13: CORREO ENVIADO A LOS CENTROS DOCENTES. 
ANEXO 14: TABLAS DE FRECUENCIAS ABSOLUTAS (Fi) DEL CUESTIONARIO DE PROFESORES DE E.F

ANEXO 15: REPRESENTACIONES GRÁFICAS.

ANEXO 16: CURSO ATENDER A LA DIVERSIDAD A TRAVÉS DE LOS CONTENIDOS DE EDUCACIÓN FÍSICA.

ANEXO 17: CURSO INTERVENCIÓN DEL DOCENTE ANTE PEQUEÑOS ACCIDENTES ESCOLARES Y ALUMNADO ENFERMO.

ANEXO 18: JORNADAS REGIONALES DE INTERCAMBIO DE EXPERIENCIAS DE EDUCACIÓN FÍSICA.

ANEXO 19: CURSO ESTRATEGIAS DIDÁCTICAS DE EDUCACIÓN FÍSICA EN LA ESCUELA RURAL

ANEXO 20: SOLICITUD DE INDEMNIZACIÓN POR RESPONSABILIDAD PATRIMONIAL

ANEXO 21: COMUNICACIÓN DE ACCIDENTE ESCOLAR

ANEXO 22: CURSO RIESGOS, ACCIDENTES Y RESPONSABILIDAD EN LA PRÁCTICA DOCENTE DE LA EDUCACIÓN FÍSICA.

ANEXO 23: CURSO CONTROL DE LESIONES Y ACCIDENTES EN LA PRÁCTICA EDUCATIVA. RESPONSABILIDAD DOCENTE.

ANEXO 24: CARTA DIRECCIÓN PROVINCIAL DE VALADOLID......

ANEXO 25: FICHA MÉDICA INDIVIDUAL PARA E.F.

ANEXO 26: CUESTIONARIO ACERCA DE ASUNTOS RELACIONADOS CON LA RESPONSABILIDAD DEL PROFESORADO

ANEXO 27: FICHA PARA LA RECOGIDA DE DATOS DEL CUESTIONARIO ACERCA DE ASUNTOS RELACIONADOS CON LA RESPONSABILIDAD DEL PROFESORADO 


\section{ÍNDICE DE FIGURAS}

FIGURA 1: LÍMITES ESPACIALES DE LA TESIS.................. 40

FIGURA 2: VECTORES QUE CONFIGURAN LA "EXENCIÓN INVISIBLE” EN LAS FUENTES DE INFORMACIÓN.

FIGURA 3: FILTROS POR LOS QUE HAN PASADO LAS PROGRAMACIONES DIDÁCTICAS...............................

FIGURA 4: EJEMPLO DE CÓMO SE HAN TRABAJADO LAS FICHAS.

FIGURA 5: EPÍLOGO A LA REVISIÓN DE LAS PROGRAMACIONES DIDÁCTICAS

FIGURA 6: LA EXENCIÓN EN MI FORMACIÓN PERMANENTE.

\section{ÍNDICE DE GRÁFICAS}

GRÁFICA 1: COLABORACIÓN DE LOS IES EN LA ENTREGA DE LAS PROGRAMACIONES DIDÁCTICAS.

GRÁFICA 2: PARTICIPACIÓN DEL PROFESORADO EN LA REALIZACIÓN DEL CUESTIONARIO

GRÁFICA 3: COLABORACIÓN DE LOS IES EN LA REALIZACIÓN DEL CUESTIONARIO.

GRÁFICA 4: NUESTRA ÁREA ES EMINENTEMENTE

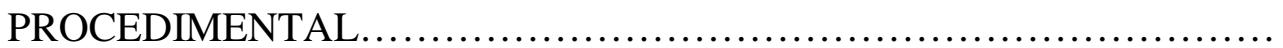

GRÁFICA 5: LA LEGISLACIÓN REFERENTE A ESTOS TEMAS, SOBRE TODO EN NUESTRA ÁREA, ES ESCASA...

GRÁFICA 6: ¿SE PODÍAN PONER EN PRÁCTICA MÁS ACTIVIDADES DE LAS QUE SE HACEN DIRIGIDAS A FAVORECER LA PARTICIPACIÓN DE ESTOS ALUMNOS?...

GRÁFICA 7: ¿CONSIDERAS JUSTIFICADO QUE HAYA ALUMNOS "EXENTOS" SI SU GRADO DE MINUSVALÍA O DISCAPACIDAD ES ELEVADO? 
GRÁFICA 8: EL PEC DE TU INSTITUTO RECOGE ALGO RELACIONADO CON ESTA TEMÁTICA.

GRÁFICA 9: LES REALIZAS UN DOCUMENTO INDIVIDUAL DE ADAPTACIÓN CURRICULAR.

GRÁFICA 10: ESTE TIPO DE ALUMNO APARECE EN TU PROGRAACIÓN COMO "EXENTO" O "EXENTO DE LA PRÁCTICA".....

GRÁFICA 11: SUS INTERESES Y OPINIONES SE TIENEN EN CUENTA A LA HORA DE DISEÑAR LAS ADAPTACIONES Y/O ACTIVIDADES.

GRÁFICA 12: ¿PERMITES QUE NO PARTICIPEN EN UNA TAREAS POR LO MAL QUE LO PASAN?

GRÁFICA 13: ¿PERMITES QUE NO VAYAN A TUS CLASES DEBIDO A SERIOS PROBLEMAS DE DESPLAZAMIENTO Y/O ESTADO ANÍMICO QUE PRESENTAN?

GRÁFICA 14: PARA APLICAR CUALQUIER MEDIDA SE PIDE UN CERTIFICADO MÉDICO OFICIAL

GRÁFICA 15: LA ADAPTACIÓN QUE LES APLICAS, LA REFLEJAS POR ESCRITO.

GRÁFICA 16: EL DEPARTAMENTO DE ORIENTACIÓN COLABORA CON EL TUYO PARA REALIZAR LAS ADAPTACIONES A ESTOS ALUMNOS....

GRÁFICA 17: DEBEN TOMAR PARTE ACTIVA (DE LA FORMA QUE SEA) EN TODAS LAS SESIONES.

GRÁFICA 18: ESTOS ALUMNOS COLABORAN EN LA COLOCACIÓN Y RETIRADA DEL MATERIAL .........................

GRÁFICA 19: ¿PUEDEN REALIAR DURANTE TUS CLASES DE EDUCACIÓN FÍSICA SUS PROPIOS PROGRAMAS DE REHABILITACIÓN MOTRIZ?.

GRÁFICA 20: ¿OBSERVAS PROBLEMAS DE ADAPTACIÓN DE ESTOS ALUMNOS AL RESTO DEL GRUPO?

GRÁFICA 21: ¿TE HAS ENCONTRADO CON ALGÚN ALUMNO DE ESTE TIPO QUE SE HAYA NEGADO A PARTCICIPAR EN ALGUNA SESIÓN? 
GRÁFICA 22: ¿SE PRODUCEN O SE HAN PRODUCIDO SITUACIONES DE CONFLICTOS ENTRE LOS INTERESES DEL GRUPO Y LAS ADAPTACIONES CURRICULARES REALIZADAS A ESTOS ALUMNOS?.

GRÁFICA 23: ¿OBSERVAS CONDUCTAS INADECUADAS EN EL RESTO DE LOS COMPAÑEROS HACIA ESTE TIPO DE ALUMNOS?

GRÁFICA 24: ¿ALGÚN FAMILIAR HA MOSTRADO SU DISCONFORMIDAD A QUE HAGAN PRÁCTICA O ASISTAN A TUS CLASES Y QUE POR ELLO SEAN EVALUADOS?.

GRÁFICA 25: ¿CONOCES LA NORMATIVA QUE REGULA ESTE TIPO DE SITUACIONES?

GRÁFICA 26: ¿HAS ASISTIDO A CURSOS, CONFERENCIAS O SEMINARIOS SOBRE ESTE TEMA?

GRÁFICA 27: ¿TE ENCUENTRAS VERDADERAMENTE SATISFECHO CON LA MANERA DE ABORDAR ESTAS CUESTIONES EN TU PROGRAMACIÓN DIDÁCTICA?...........................

GRÁFICAS DE LA 28 A LA 67

GRÁFICA 68: ACTIVIDADES FORMATIVAS DE EDUCACIÓN FÍSICA. PERIODO 1995-96 AL 2003-04.

GRÁFICA 69: ACTIVIDADES FORMATIVAS DE EDUCACIÓN FÍSICA OFERTADAS POR LOS CFIES DISTRIBUIDAS POR CENTRO Y AÑOS

GRÁFICA 70: ALUMNOS QUE HAN CURSADO EDUCACIÓN FÍSICA DURANTE EL PERIODO DE INVESTIGACIÓN....

GRÁFICA 71: DOCUMENTOS MÉDICOS RECIBIDOS

GRÁFICA 72: DOCUMENTOS MÉDICOS Y VARIABLE SEXO

GRÁFICA 73: JUSTIFICANTES FAMILIARES Y VARIABLE SEXO...

GRÁFICA 74: PARTICIPACIÓN DEL PROFESOR EN LA REALIZACIÓN DEL CUESTIONARIO 2................................ 
GRÁFICA 75: PERCEPCIÓN ENTRE LOS DOCENTES DE SUFRIR UN ACCIDENTE EN ALGUNAS MATERIAS.

GRÁFICA 76: PERCEPCIÓN ENTRE LOS DOCENTES DE EDUCACIÓN FÍSICA DE SUFRIR UN ACCIDENTE EN ALGUNAS MATERIAS.

464

\section{ÍNDICE DE ILUSTRACIONES}

ILUSTRACIÓN 1: LA EXENCIÓN EN LAS NORMAS LEGISLATIVAS DE CASTILLA Y LEÓN DESDE LA APARICIÓN DE LA ORDEN DE 31 DE JULIO DE 1961

ILUSTRACIÓN 2: ORDEN DE TRATAMIENTO A ENFERMERAS Y PRACTICANTES (MODELO OTEP)

ILUSTRACIÓN 3: PARTE DE CONSULTA Y HOSPITALIZACIÓN (PARTE CH).....

ILUSTRACIÓN 4: LA EXENCIÓN (IN)VISIBLE EN LA EDUCACIÓN FÍSICA ESPAÑOLA ENTRE 1995 Y PRINCIPIOS DEL SIGLO XXI ......

\section{ÍNDICE DE TABLAS}

TABLA 1: TÉRMINOS CONVENCIONALES Y ALTERNATIVOS DE CRITERIOS DE CALIDAD EN LA INVESTIGACIÓN CUALITATIVA.

TABLA 2a: LAS RESPUESTAS EN EDUCACIÓN FÍSICA A LOS ALUMNOS CON NECESIDADES EDUCATIVAS ESPECIALES

TABLA 2b: LAS RESPUESTAS EN EDUCACIÓN FÍSICA A LOS ALUMNOS CON NECESIDADES EDUCATIVAS ESPECIALES.

TABLA 2c: LAS RESPUESTAS EN EDUCACIÓN FÍSICA A LOS ALUMNOS CON NECESIDADES EDUCATIVAS ESPECIALES

TABLA 2d: LAS RESPUESTAS EN EDUCACIÓN FÍSICA A LOS ALUMNOS CON NECESIDADES EDUCATIVAS ESPECIALES

TABLA 2e: LAS RESPUESTAS EN EDUCACIÓN FÍSICA A LOS ALUMNOS CON NECESIDADES EDUCATIVAS ESPECIALES.

TABLA 2f: LAS RESPUESTAS EN EDUCACIÓN FÍSICA A LOS ALUMNOS CON NECESIDADES EDUCATIVAS ESPECIALES. 
TABLA 3: CAMBIOS DE ROL EN LA EDUCACIÓN FÍSICA.............

TABLA 4: REVISIÓN DE LA INFORMACIÓN OBTENIDA CON LA "FICHA DE INFORMACIÓN GENERAL Y AJUSTE A LA NORMA"....

TABLA 5: NOMBRE DEL DEPARTAMENTO

TABLA 6: AJUSTE A LA NORMATIVA DE LAS PROGRAMACIONES DE EDUCACIÓN FÍSICA ......................

TABLA 7: NORMATIVAS APARECIDAS EN LAS PROGRAMACIONES.

TABLA 8: DESARROLLO DE LA EVALUACIÓN.

TABLA 9: LA ATENCIÓN A LA DIVERSIDAD Y LAS ADAPTACIONES CURRICULARES

TABLA 10: RESUMEN DE LAS VENTAJAS E INCONVENIENTES DE LOS CUESTIONARIOS POR CORREO

TABLA 11: OBJETIVOS DEL CUESTIONARIO.

TABLA 12a: BIOGRAMA DE TRAYECTORIA FORMATIVA 1995-96 Y 2005-06.

TABLA 12b: BIOGRAMA DE TRAYECTORIA FORMATIVA 1995-96 Y 2005-06.

TABLA 13: CURSOS REALIZADOS RELACIONADOS CON EL ASUNTO

TABLA 14: DOCUMENTOS MÉDICOS RECOGIDOS EN LA INVESTIGACIÓN (1 ${ }^{\mathrm{a}}$ DE 9$)$.

TABLA 14: DOCUMENTOS MÉDICOS RECOGIDOS EN LA INVESTIGACIÓN (2a DE 9).

TABLA 14: DOCUMENTOS MÉDICOS RECOGIDOS EN LA INVESTIGACIÓN (3 ${ }^{\mathrm{a}}$ DE 9).

TABLA 14: DOCUMENTOS MÉDICOS RECOGIDOS EN LA INVESTIGACIÓN (4a DE 9). 
TABLA 14: DOCUMENTOS MÉDICOS RECOGIDOS EN LA INVESTIGACIÓN (5a DE 9).

TABLA 14: DOCUMENTOS MÉDICOS RECOGIDOS EN LA INVESTIGACIÓN (6a DE 9).

TABLA 14: DOCUMENTOS MÉDICOS RECOGIDOS EN LA INVESTIGACIÓN (7ª DE 9)

TABLA 14: DOCUMENTOS MÉDICOS RECOGIDOS EN LA INVESTIGACIÓN (8 DE 9)....

TABLA 14: DOCUMENTOS MÉDICOS RECOGIDOS EN LA INVESTIGACIÓN (9a DE 9).

TABLA 15: MOTIVOS DE LOS INFORMES Y VOLANTES MÉDICOS

TABLA 16: JUSTIFICANTES Y DOCUMENTOS FAMILIARES RECOGIDOS EN LA INVESTIGACIÓN (1ª DE 3$)$

TABLA 16: JUSTIFICANTES Y DOCUMENTOS FAMILIARES RECOGIDOS EN LA INVESTIGACIÓN (2ª DE 3).

TABLA 16: JUSTIFICANTES Y DOCUMENTOS FAMILIARES RECOGIDOS EN LA INVESTIGACIÓN (ÚLTIMA DE 3).

TABLA 17: FORMATOS DE JUSTIFICANTES FAMILIARES PRESENTADOS.

TABLA 18: MOTIVOS DE LOS JUSTIFICANTES FAMILIARES

TABLA 19: RESUMEN COMPARATIVO DE LOS RESULTADOS OBTENIDOS EN EL ESTUDIO DE LOS DOCUMENTOS MÉDICOS Y LOS JUSTIFICANTES PATERNOS

TABLA 20: OBJETIVOS DEL CUESTIONARIO 2. 





\section{CAPÍtULO}

1 


\section{1.- EL AUTOR EN LA ENCRUCIJADA DE LA FORMACIÓN PERMANENTE}

Mi formación universitaria, en lo relativo a asignaturas relacionadas con la docencia, en el entonces llamado Instituto Nacional de Educación Física de Castilla y León (adscrito a la Universidad de León), y casi la mitad de mi experiencia profesional ha transcurrido en el marco legislativo establecido por la LOGSE ${ }^{1}$. En esta ley la formación del profesorado aparecía como uno de los factores que propician la calidad y mejora de la enseñanza. De hecho, en su artículo 56, apartado dos, establecía que la formación permanente es un derecho y una obligación de todo el profesorado, recayendo la responsabilidad de la misma en las Administraciones educativas. Asimismo, en el artículo 59, apartado uno, ponía de manifiesto, entre otros detalles, que dichas Administraciones educativas fomentarán la investigación.

En la misma línea se encontraba la $\operatorname{LOCE}^{2}$ que establecía como unos de los principios de calidad el fomento y la promoción de la investigación, la experimentación y la innovación educativa (artículo 1). Y aún más, en el artículo 56, "Funciones del profesorado", recogía que una de estas deberá ser la investigación, la experimentación y la mejora continua de los procesos de enseñanza correspondiente.

Con la entrada en vigor de la $\mathrm{LOE}^{3}$ la cuestión cambiaba muy poco. El artículo 102, apartado 1, recoge ese derecho y obligación del profesorado. Asimismo, en el

\footnotetext{
${ }^{1}$ Ley Orgánica 1/1990, de 3 de octubre de 1990, de Ordenación General del Sistema Educativo (BOE 0410-1990).

${ }^{2}$ Ley 10/2002, DE 23 de diciembre, de Calidad de la Educación (BOE 24-12-2002).

${ }^{3}$ Ley Orgánica 2/2006, de 3 de mayo, de Educación (BOE 04-05-2006).
} 
apartado 3 de ese mismo artículo, se recoge que a las Administraciones educativas les corresponde fomentar programas de investigación.

Finalmente, de entre las normas legislativas que aún se mantienen vigente durante el periodo que abarca esta investigación, la más explícita es la LOPEGCE $^{4}$ ya que en sus artículos 32 y 33 desarrolla la formación permanente y la innovación e investigación educativas, respectivamente.

De lo que no cabe ninguna duda es que la formación del profesorado de la Educación Secundaria, especialmente la de carácter permanente, ocupa un lugar privilegiado en nuestro ámbito y ha sido una línea de investigación muy recurrente en múltiples ocasiones (Calderón y Martínez, 2014). Que los docentes actualicen los conocimientos y estrategias didácticas que suelen utilizar en su labor educativa se nos antoja como imprescindible. De alguna manera, esto implica reconocer que la formación de los docentes no concluye con la obtención de un título universitario, y que los problemas y dificultades que pudieran aparecer lo son menos con la formación adecuada (Mendoza, 2009).

Esta renovación profesional, tanto académica como didáctica, tiene mucho que ver con la inquietud y ambiciones de mejora y superación que a título personal muestren los profesores. Otra cosa sería que verdaderamente la Administración desarrollara y pusiera en práctica una política que promoviera e incentivara dicha formación. Pero este asunto no es el que ahora nos interesa.

En este sentido, esta tesis es la consecuencia de un cúmulo de preocupaciones personales y profesionales tales como el desarrollo y avance en mi práctica docente, la mejora de la posición y consideración profesional y, sobre todo, el deseo de indagar en torno la temática del trabajo que desempeñamos desde el área de la Educación Física con un determinado tipo de alumno con dificultades de aprendizaje asociadas a discapacidad motriz (tradicionalmente conocidos como acnees). En concreto me centro en descubrir qué indicios, hechos o prácticas contribuyen a que la exención de cursar la

\footnotetext{
${ }^{4}$ Ley Orgánica 9/1995, de 20 de noviembre de la Participación, la Evaluación y el Gobierno de los Centros Docentes (BOE 21-11-95)
} 
Educación Física para estos alumnos, en sus “casos extremos”, sea una realidad que aún perdura pero que es camuflada lingüísticamente (o de cualquier otra forma) para pasar inadvertida y no ir en contra de leyes y principios pedagógicos elementales y saber disciplinar "esperado", y cuál es la opinión y el sentir de estos alumnos y de sus familiares sobre su inclusión y participación en las clases de Educación Física.

\section{2.- ESTRUCTURA DE LA TESIS}

En todo momento hemos pretendido que la tesis sea de lectura llana y clara. Para ello, el lenguaje empleado, aunque hacemos uso de tecnicismos propios del área y del argot educativo, no es extraño para un lector "genérico", ni supone un impedimento para la comprensión del estudio. En la medida de lo posible, se ha procedido a emplear multitud de tablas, gráficos e ilustraciones que permiten una lectura y comprensión rápida de la información. Asimismo, la estructura está diseñada para ir desmenuzando y avanzando lenta pero progresivamente hacia la consecución de los objetivos propuestos.

En el Capítulo 2 encontramos las razones que hicieron que me decantara definitivamente por este asunto, fruto de una relación profesional mantenida con una alumna con necesidades educativas especiales durante los cursos académicos 2000-01 y 2001-02.

Todas mis dudas, dilemas y puntos de partida son explicitados de la mejor manera posible en el Capítulo 3. Este capítulo se posiciona como clave para la posterior lectura e interpretación de la tesis. Aclarar los conflictos e incertidumbres que rodean mi intervención pedagógica en estos casos son el motor de arranque con el que comienzo a neutralizar mi subjetividad.

El Capítulo 4 está dedicado a la concreción de los objetivos perseguidos en esta tesis doctoral enmarcada dentro del Departamento de Didáctica de la Expresión 
Musical, Plástica y Corporal de la Facultad de Educación y Trabajo Social de la Universidad de Valladolid.

Posteriormente, en el Capítulo 5, realizamos una descripción de los métodos y técnicas de investigación utilizadas en el trabajo. En el caso de estas últimas, lo hacemos de manera un tanto elemental ya que el momento elegido para detallarlas ampliamente será el capítulo en el que sean manejadas.

El Capítulo 6 forma lo que podíamos denominar el marco teórico en el que se sustenta la tesis. En primer lugar se aborda el tratamiento legislativo que regula este asunto. Seguidamente se revisan los antecedentes literarios del saber disciplinar, así como otras fuentes de información no tan "científicas" que tratan la atención a la diversidad y, más en concreto, la exención en Educación Física para los alumnos con discapacidad motriz.

A continuación, en el Capítulo 7 se presentan los resultados conseguidos de la revisión y ulterior análisis de las programaciones didácticas del área de Educación Física de los IES públicos de Valladolid y provincia, y en el Capítulo 8 los de los cuestionarios formalizados por su profesorado. En estos capítulos se explican detenidamente los instrumentos utilizados y el proceso seguido en la obtención de los datos.

Mis relatos de vida, revisando y analizando los ámbitos de mi formación inicial y permanente, configuran el Capítulo 9. Un repaso que irá desde mis primeros contactos hacia la Educación Física hasta desembocar en la formación continua recibida a lo largo de un buen número de actividades formativas, sin dejar pasar de largo la formación inicial universitaria. Como se apreciará, la exención en alguna de las formas que iremos descubriendo a lo largo de la tesis y otros asuntos relacionados, emergerán en algún momento durante este largo recorrido.

El estudio del lugar que ocupan los documentos médicos y los papeles familiares en la concesión o no de la exención de la práctica de nuestra asignatura, 
tendrá su cabida en el Capítulo 10. Una recogida de datos durante tres cursos académicos nos aproximará a la realidad de estos escritos que los alumnos presentan a sus profesores de Educación Física y el caso que se les hace.

Otro asunto de especial relevancia es el factor de la responsabilidad que, "presuntamente", asumimos dando clase de una asignatura tan corporal. Este delicado tema será abordado en el Capítulo 11. Las fuentes documentales legislativas y del saber disciplinar, la opinión del colectivo de profesores (no solo la del específico de la asignatura, sino también la de nuestros compañeros de otras asignaturas) y la información aparecida en prensa servirán para hacernos una idea al respecto.

El Capítulo 12 es un pequeño homenaje a Virginia, la persona que hizo que me decantara por investigar sobre estos temas. En él se refleja lo más llamativo de su cuaderno de clase de Educación Física y se resume lo más significativo de una entrevista mantenida con su madre y una de sus amigas de la infancia y de toda su andadura escolar.

En el Capítulo 13 reunimos las conclusiones básicas que se desprenden de todo el proceso llevado a cabo y que, de un modo u otro, se han ido presentando a lo largo de la tesis. Además planteamos distintas posibilidades de futuras líneas de acción relacionadas con el trabajo para continuar ahondando en este tema arduo y complicado para la Educación Física.

Tras indicar las fuentes bibliográficas (libros, leyes, órdenes y direcciones de Internet) que hemos consultado para la elaboración del estudio, se sitúan los anexos, entre cuyos documentos figuran las fichas utilizadas para la revisión de las programaciones didácticas, cuestionarios empleados, correo enviado a los centros docentes, tablas de resultados, representaciones gráficas, información sobre cursos...

Como podrá observarse, todos los capítulos tienen una estructura en común. Al principio hay una introducción que presenta sucintamente su contenido. Esta introducción se encuentra recogida en un formato diferente. Al término de casi todos los 
capítulos hay un epílogo o equivalente a modo de conclusiones que congrega lo fundamental de lo que se haya acometido. Para llamar más la atención del lector, algunos de estos epílogos aparecen en forma de tablas o dibujos ilustrativos.

De igual forma, cada capítulo acaba con un apartado en el que se muestran de forma visual las principales ideas que subyacen tras su desarrollo y exposición (vid.: página 38).

Asimismo, en algunos de los capítulos trato de describir con detalle algunos de las situaciones y acontecimientos (algunos de ellos ciertamente anecdóticos y surrealistas) que han tenido lugar en determinados momentos o procesos de elaboración de dichos episodios. El propósito principal que se persigue con este apartado es el de narrar, con la mayor riqueza posible de referencias, parte del proceso seguido en la investigación de cara a situarnos mejor en el contexto y momento particular en el que tuvo lugar su elaboración. 


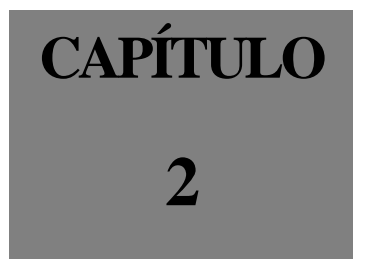


En este capítulo recogeré, muy brevemente, el proceso por el que he pasado desde el comienzo de los cursos del Programa de Doctorado, hasta la elección final del asunto en torno al cual elaborar esta tesis doctoral. Asimismo, reflejaré los motivos personales y profesionales que hicieron que la balanza se inclinara finalmente hacia el tema elegido, y no otro.

En el curso 2000-2001, cuando decidí realizar el Programa de Doctorado "Didáctica de la Educación Artística: Educación Musical, Educación Plástica y Educación Corporal" del Departamento de Didáctica de la Expresión Musical, Plástica y Corporal de la Universidad de Valladolid, vislumbraba la elaboración de una tesis doctoral como algo muy lejano y, en algunos momentos, de difícil consecución, bien por su complejidad, bien por la gran dedicación temporal que implicaba. De hecho, decidí realizar los 20 créditos del Período de docencia en dos cursos académicos.

A pesar de que durante esos dos años algunos de los profesores que impartían los cursos del programa de Doctorado nos animaban y aconsejaban a que nos decidiéramos cuanto antes por un argumento sobre el que investigar, no tenía aún claro el tema en torno al cual centrar mi investigación, ni tampoco el enfoque ni la metodología a utilizar en todo el proceso.

Los asuntos sobre los que se podía investigar en el campo educativo me parecerían variados y amplísimos, pero no es menos cierto que me sentía limitado en experiencias y por ello no quería precipitarme en mi decisión. Así, decidí seguir reflexionando sobre el tema de mi tesis. 
Buscaba algo que verdaderamente me interesase, motivase y supusiese un avance en mi formación y experiencia como profesor. Este era un punto que tenía claro: debía estar relacionado con mi práctica docente en el campo de la Educación Física en la Educación Secundaria Obligatoria y el Bachillerato.

A medida que iba participando en los cursos del programa de doctorado, distintas posibilidades fueron tomando una forma más concreta y factible. Entre ellas se encontraban la evaluación en la Educación Física (en alguna de sus parcelas o posibilidades) y el cuaderno de clase del alumno como medio educativo o como posible elemento de evaluación formativa.

La última idea que surgió, y que poco a poco fue adquiriendo más peso y valor, es la que gira en torno a los alumnos con algún tipo de minusvalía, déficit o impedimento físico permanente (aunque se podría extender a los de tipo temporal) que les incapacita para realizar con total y absoluta "normalidad" el seguimiento y práctica de las clases de Educación Física.

Esta idea surgió en el curso 2001-02 a raíz de los comentarios y de las anotaciones reflejadas en los cuadernos de clase por varios alumnos que no podían realizar las sesiones, digamos, con normalidad. El caso que más me impactó fue el de Virginia, una alumna de $4^{\circ}$ de E.S.O. con graves problemas físicos provocados por una enfermedad ósea degenerativa que le impedían realizar la mayoría de las prácticas físicas con sus compañeros, y que ya en el curso anterior le afectaba notablemente. De forma esporádica, me expresaba su malestar y desánimo por no poder realizar lo que hacían el resto de sus amigos y compañeros, chavales todos ellos de su misma edad; en definitiva, era consciente de que no era igual que sus amigas y, lo peor de todo, que jamás lo sería. Esto le provocaba emociones de impotencia y desesperación, asociadas a un sentimiento de inferioridad por su menor capacidad.

“...pienso que cuando he podido participar lo he hecho y el interés no ha faltado porque cuando no haces Educación Física tienes tantísimas ganas de realizarla que, aunque no puedas, lo intentas (casi siempre en vano) [...] intento realizar ejercicios que por mi circunstancia me son imposibles, aunque a veces pierda mi 
paciencia y me desmoralice." (Cuaderno de clase de Virginia, $3^{\circ}$ E.S.O., 14 de marzo de 2001).

Otros días, los menos, la satisfacción sentida por participar activamente en clase le desencadenaba un estado de ánimo eufórico que le hacía sentirse plenamente orgullosa consigo misma, sus compañeros y su trabajo desarrollado.

"La clase de hoy ha sido "super especial», pues he participado en ambos deportes y eso me ha hecho mucha ilusión (ha sido una fuente de energía que me ha hecho ver que puedo realizar más cosas de las que pensaba). He participado como portera en el balonmano y como jugadora en el voleibol, y he podido percibir bastante compañerismo por parte de mis compañeros, y eso siempre es positivo" (Cuaderno de clase de Virginia, $3^{\circ}$ E.S.O., 9 de mayo de 2001).

Sin embargo, la situación predominante era la primera, la cual era de alguna forma "sobrellevada" por ella con el apoyo de todos, compañeros y profesor, haciéndole participar y tomar parte activa en todo aquello que estuviera al alcance de sus escasas posibilidades físicas y de movimiento. Incluso, a pesar de sus negativas, quizás provocadas por su baja autoestima o el poco convencimiento en sus facultades reales, éramos muchos los que intentábamos convencerle de que su participación sí era posible.

Posteriormente, la enfermedad avanzó de manera terrible y el consiguiente tratamiento médico aumentó su debilidad. Todo esto provocó al principio la nula participación en mis clases y, poco tiempo después, su falta de asistencia a la totalidad de las áreas y materias.

Por desgracia para todos, el final fue el más trágico de los esperados. El 2 de abril de 2002 Virginia fallecía consumida por el cáncer de huesos que años atrás se le había diagnosticado, no sin antes dejar constancia entre nosotros de sus ganas de vivir y su gran capacidad de lucha.

Los comentarios que Virginia y otros alumnos registraban en sus cuadernos de clase me hicieron plantearme lo que estaba haciendo con este tipo de alumnos, tanto desde la perspectiva del profesional de la Educación Física, como desde el terreno de lo personal, pues veía de alguna forma su sufrimiento por no poder emular o imitar en 
alguna tarea, juego o actividad a sus amigos y compañeros. Era como si "asumiera" (si es que eso es posible) que nunca iba a ser igual a los demás y que, por mucho que se lo propusiera, nunca llegaría a realizar lo que los demás hacen. De hecho, muchas veces su "participación" se lograba a través de tareas y actividades bastante diferentes a las realizadas por sus compañeros (adaptaciones curriculares con mayor o menor grado de significatividad).

Al final, marcado por la afable personalidad, encantadora sencillez y especiales circunstancias que rodearon a Virginia, me decanté por conocer más a fondo el tratamiento que los profesionales de la Educación Física proporcionamos a estos "casos extremos" de alumnos con necesidades educativas especiales asociadas a cualquier tipo de discapacidad, centrándome en el estudio de unos objetivos que serán detallados con posterioridad en el Capítulo 4.

Esta tesis absorbe el trabajo de investigación con el que obtuve la Suficiencia Investigadora por la Universidad de Valladolid, con fecha 11 de noviembre de 2003, en el área de conocimiento de Didáctica de la Expresión Corporal. El trabajo llevaba por título: “¿Tiene sentido negar la «exención» en la Educación Física? De las luces de la teoría, a las sombras de la práctica". Su diseño y realización sirvió como proceso de aprendizaje y "entrenamiento" para la realización de esta tesis. Al final de este trabajo proponía unas futuras líneas de investigación que surgían a la vista de los resultados conseguidos. Algunas de esas líneas han sido abordadas ahora, al igual que otras que en su momento no aparecieron.

En cierto modo, el trabajo abrió vías que merecía la pena investigar en relación a la Educación Física y la exención, en cualquiera de sus formas, incluida la que denomino (in)visible. Y es (in)visible porque parece no verse, o no se quiere ver, en nuestro marco educativo cuando aplicamos o desarrollamos algunas actuaciones acordes a la legalidad enmascarándolas de forma lingüística. El propio saber disciplinar científico de los expertos -expresado a través de artículos, manuales y leyes- nos dicen que no ha lugar a su existencia pero, como se comprobará a lo largo de esta tesis, sigue presente en multitud de documentos propios de la Educación Física, en la opinión que 
en ocasiones estos mismos expertos nos dan en cursos o congresos y, de manera especial, en la propia práctica de los que nos dedicamos a impartirla en los centros.

Así pues, la justificación en la se asienta la elaboración de todo el proceso de investigación que da lugar a la tesis es indagar sobre la realidad (in)visible acerca del uso y concepto de la exención en Educación Física. Digamos que para este investigador se ha convertido en una necesidad saber cómo está este tema, cómo es percibido en diferentes colectivos, si realmente existe alguna posibilidad de que ese suceso aún se perpetúe como respuesta a los alumnos con necesidades educativas especiales asociadas a cualquier tipo de discapacidad motriz y, más concretamente, a los "casos extremos".

Como se habrá podido comprobar, el periodo transcurrido entre el término del trabajo de la Suficiencia Investigadora, como paso previo para la elaboración de la tesis, y la propia presentación de la misma es muy amplio. Pudiera incluso parecer excesivo para desarrollar todo lo que a continuación se expondrá. Y lo es. Estoy plenamente convencido que ha pasado mucho tiempo entre uno y otro suceso. Pero las vidas, como suele ser habitual, no tienden a ir por los caminos que uno quisiera. No todo es recto y sin baches; no todo es sencillo y accesible al primer intento.

Pero precisamente esta es otra de las causas que me han impulsado a seguir trabajando para alcanzar lo que ya se ha convertido en un sueño. Soy de carácter obstinado, casi terco, y durante estos casi 12 años nunca he dejado la tesis al margen de mi vida. Siempre ha estado presente: en la búsqueda de datos, en la lectura, en la formación, en mi quehacer diario, en las conversaciones con compañeros y otros que no lo son tanto. Poco a poco, sacando ratos de aquí y de allá, cuando mi vida familiar y profesional me lo permitían, he ido completando fases, cerrando estudios, leyendo documentos, abriendo nuevos capítulos o apartados, ideando diferentes formas de planteamientos...

Así pues, la tesis ha formado parte de mi vida como un cabo suelto que tenía que amarrar para poder intentar centrarme en otras cuestiones. De hecho, la tesis, aparte de por el alcance y satisfacción personal que supone para mí, sería una forma de poner un 
listón más en mi formación que daría paso a otras búsquedas profesionales, aunque para nada alejadas del ámbito educativo. Me gusta lo que hago, con quien lo hago y donde lo hago. Pero creo que es positivo no "estancarse", entendiendo esta expresión en términos de habituarse o convertir el trabajo en un asunto rutinario (Blández, 2010, utiliza la expresión "rutina profesional" para referirse a este asunto). No me gusta pensar que no lo estoy haciendo lo mejor que sé que puedo hacerlo. Prefiero una retirada a tiempo que asentarme en una posición cómoda pero estéril en cuanto a aportación (recíproca).

Por otra parte, comparto con Blández (op. cit.) que el hecho de investigar me ha sido útil de cara a mejorar mi docencia, pues conozco mejor el asunto y su tratamiento; me ha servido para hacer paradas en el estresante camino del día a día, buscando momentos para la reflexión y el análisis crítico; ha supuesto todo un proceso formativo sumamente enriquecedor, con altibajos, con momentos de euforia y otros de desesperación; y, finalmente, creo que me ha servido para adaptarme a los tiempos que corren, innovando y mejorando mi labor docente.

Además, entiendo que la investigación en educación también deber servir para mejorar las condiciones de desarrollo de nuestros alumnos (González Ballesteros, 2003, p. 11). Entre las diversas causas que me han llevado a decantarme por investigar -este tema-, está la de intentar enriquecer la experiencia vital de un determinado sector del alumnado a través del cuestionamiento de algunas respuestas educativas ofrecidas desde la Educación Física.

"Aprendemos a ser sabios más por el fracaso que por el éxito. Con frecuencia hallamos lo que convendrá, descubriendo lo que no conviene y, probablemente, el que no cometió nunca un error, nunca descubrirá nada." (Samuel Smiles citado por Tierno, 2006, p. 181)

“...La mayoría de nosotros hemos crecido en culturas en las que resulta mucho más fácil señalar a los demás lo que han hecho mal que elogiarlos cuando han alcanzado un éxito...” (Rath y Clifton, 2005, p. 47) 


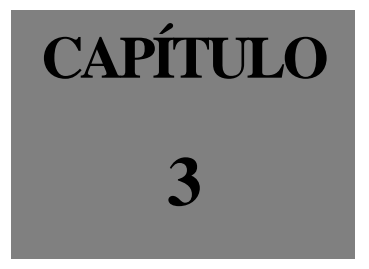

\author{
MIS PUNTOS DE PARTIDA.
}

DUDAS Y DILEMAS QUE SE ME PRESENTAN 
En este capítulo, trataré de explicitar todo lo que el tema elegido supone para mí con el propósito, entre otros, de ver cuál está siendo mi evolución personal y profesional en la manera de enfocar y tratar este asunto al estudiarlo con más profundidad y detenimiento.

Los puntos que desarrollaré abarcarán desde lo que entiendo por un alumno con necesidades educativas especiales, mis convencimientos iniciales sobre cómo tratar a estos alumnos, el origen de tales convencimientos, su evolución, y las dudas y dilemas que se me plantean cuando, ya contando con esa experiencia anteriormente narrada, vuelva a tener que atender a un alumno con discapacidad (del tipo que sea) en un "grado extremo" que no le permita seguir el "normal" desarrollo de las clases de Educación Física.

Con el propósito de clarificar conceptos, entiendo que un alumno deficiente motórico es, como señala Martín-Caro (1996, p. 8), "todo aquel que presenta de manera transitoria o permanente alguna alteración en su aspecto motor, debido a un deficiente funcionamiento en el sistema óseo-articular, muscular y/o nervioso, y que en grados variables limita algunas de las actividades que pueden realizar el resto de los niños de su misma edad”. Este tipo de alumno es, aplicando la nomenclatura de la LOGSE-LOE, el llamado alumno con necesidad educativa especial ${ }^{5}$, pero, al igual que López Melero

\footnotetext{
${ }^{5}$ En la LOE (BOE 04-05-2006), este alumnado está englobado dentro de la categoría genérica alumnado con necesidad específica de apoyo educativo. En el artículo 73 señala que el alumnado que presenta necesidades educativas especiales es aquel que requiera, por un periodo de su escolarización o a lo largo de toda ella, determinados apoyos y atenciones educativas específicas derivadas de discapacidad o trastornos graves de conducta.
} 
(1996, p. 18-19), opino que con esta expresión no se están aceptando las diferencias individuales como elemento de valor personal.

Si a este tipo de alumno le hacemos poseedor de unas necesidades educativas especiales debidas a su escaso o nulo potencial físico-motriz, estamos dando por sentado que el resto de alumnos no las tienen, pasando a considerarlos y tratarlos como si fueran un grupo homogéneo. Sin embargo, la singularidad de cada uno de ellos les hace, también, totalmente "especiales". Por ello, prefiero emplear el término de alumnos con dificultades de aprendizaje asociadas a discapacidad motora, pero entiendo que la nomenclatura "alumno con necesidad educativa especial" está tan arraigada en nuestro saber y quehacer profesional, en el que me incluyo, que su uso será ineludible.

Mi ideal de Educación Física para estos alumnos con dificultades de aprendizaje asociadas a discapacidad motora que hasta ahora se me han presentado (sobre todo de tipo temporal), ha sido el de intentar sacar provecho a sus potencialidades, minimizando los déficits y reduciendo sus efectos negativos. Ello lo pretendo conseguir adecuando las tareas y aprendizajes a su nivel de competencia individual, ya sea a través de adaptaciones de las propuestas dirigidas al conjunto de la clase, o a través de otras específicas para ellos. Esta línea de pensamiento tiene mucho que ver con lo que Ríos ${ }^{6}$ (2001a) denomina el paradigma competencial, en contraposición con el paradigma individual centrado en el déficit. Algunas de las ideas clave de este paradigma competencial, que comparto y transcribo, son:

- El énfasis en una perspectiva pedagógica que valora más las capacidades que las limitaciones o carencias.

- Una concepción de la inteligencia, a partir de las teorías cognitivas, que incide en el desarrollo de los procesos mentales más que en sus resultados. De este modo, todas las personas son consideradas educables, susceptibles de mejoras a todos los niveles: personal, cognitivo, afectivo y social, según su propio ritmo y posibilidades.

\footnotetext{
${ }^{6}$ Ríos lo recoge de López Melero (1995) y Porras (1998).
} 
- La importancia del contexto y la interacción social entre iguales como factor integrador para el desarrollo de la persona, tanto por su incidencia en el desarrollo cognitivo como social, que son interdependientes.

Por lo tanto, entiendo que a cualquier alumno debe facilitársele la posibilidad de intentar participar activamente en las clases de Educación Física con "absoluta" normalidad, independientemente de su problema o discapacidad (en este trabajo, de tipo motora). A este respecto, como docentes hemos de tener presente los déficits del alumno y sus posibilidades de movimiento, pero evitando percibir la globalidad de la persona a partir de sus características más desfavorables.

"Uno de los principios básicos de la reforma educativa es la atención a la diversidad, la individualización de la enseñanza. Este principio exige a los centros y al profesorado proporcionar a cada alumno y alumna la intervención educativa necesaria y conveniente con relación a sus capacidades, motivaciones, intereses y ritmos de aprendizaje para un desarrollo óptimo." (López González, 1997, p. 13)

Aunque en los años que llevo trabajando he tenido algunos alumnos que durante un período concreto de tiempo han sufrido lesiones de relativa gravedad, mi experiencia previa con alumnos con grandes discapacidades había sido, hasta que me encontré con Virginia, prácticamente nula ${ }^{7}$. Mi única relación con este asunto tuvo lugar durante mi formación académica en el INEF de León en dónde cursé, entre otras, las asignaturas de "Fundamentos Pedagógicos y Didácticos de la Educación Física Especial", "Educación Física para Minusválidos Sensoriales" y "Educación Física para Minusválidos motores". En ellas se trataban de forma teórica las etiologías, evoluciones, procesos de rehabilitación, etc., de diferentes tipos de minusvalías y, de forma práctica, realizábamos simulacros de deficiencias físicas o sensoriales, contenidos que versan directamente con ellas, favoreciendo la participación de "cualquier" alumno en las clases de Educación Física independientemente de su minusvalía o déficit físico y/o sensorial. Quizás sea esa la fuente de la que manaban mis convencimientos.

\footnotetext{
7 En el Capítulo 9 abordo parte de los relatos de mi vida en relación al asunto de la formación permanente.
} 
Como veremos más adelante (Capítulo 6), la exención de la Educación Física no está permitida por ley en la E.S.O. para los alumnos con necesidades educativas especiales, es decir, no hay ni puede haber exentos $^{8}$. Este hecho es el que propicia que alumnos como Virginia deban de asistir a las sesiones de Educación Física y ser evaluados conforme a las adaptaciones curriculares significativas de carácter individual confeccionadas por el profesor de Educación Física y Deportiva. Es decir, es el propio profesor, en colaboración con el departamento de Orientación, el que determina la adaptación pertinente en lo referente a los objetivos que estos alumnos pueden llegar a conseguir, así como los contenidos y metodología a través de los cuales lo harán, junto con los criterios de evaluación empleados para su evaluación.

El caso de Virginia supuso una auténtica provocación que originó el replanteamiento de todos mis esquemas y convencimientos. Percibía que en el ámbito físico-motor no se producía ningún tipo de mejora o avance, aunque sí es verdad que la Educación Física le reportó en algunos momentos puntuales un claro beneficio en el plano de las emociones y sentimientos. Pero no es menos cierto que la amargura de sus palabras, que no hacían más que demostrar su indiscutible e inamovible realidad, sus negativas reiteradas a participar en algunas de las actividades de clase o en la realización de prácticas adaptadas para ella, su escasa confianza en sí misma y en sus posibilidades $\mathrm{y}$, como pude comprobar recientemente en palabras de su madre, su amargura en mis clases de Educación Física, me han quitado una venda que no me dejaba ver otra cosa que no fuera el que en mis sesiones se podía y debía participar, y que ello era lo acertado y positivo para el alumno. Pero, ¿es realmente positivo el que siempre deban participar en clase?, ¿es una imposición que puede generar tensiones, resentimientos, frustraciones..., experiencias negativas?, ¿dónde quedan los intereses, sentimientos, emociones, etc., de estos alumnos?

"Creo que sería interesante, también, saber la actitud y los intereses del alumno hacia la asignatura. No todos los alumnos con discapacidad responden igual frente a la actividad física y el deporte. Esta situación personal podría hacer variar la adaptación curricular dependiendo de cada persona. Dos personas con la misma discapacidad y con el mismo grado de afectación dependiendo de

\footnotetext{
${ }^{8}$ Salvo en la etapa del Bachillerato y, como se comprobará en el Capítulo 6, hay algunas excepciones que nada tienen que ver con este tipo de alumnado.
} 
su motivación, podrían tener una respuesta muy diferente y, por tanto, podría no ser efectiva la misma adaptación curricular para las dos y una de ellas podría no alcanzar los objetivos establecidos." (Calverol, 2000, p. 42)

Me pregunto si, por el bagaje acumulado en torno a la integración del alumnado que supuso la puesta en escena de la LOGSE, los profesores de Educación Física de Educación Secundaria nos empeñamos (o nos vemos obligados) en buscar dicha integración sin más pretexto que el meramente normativo, sin pararnos a pensar lo suficiente en cómo hay que llevarla a cabo o en los beneficios que puede estar aportando al alumno en cuestión. En otras palabras, me replanteo si nuestra área debe o no formar parte del currículo de un alumno de estas características sin ni tan siquiera molestarnos en conocer su opinión, intereses y sentimientos; si es verdaderamente necesario "hacerle pasar" por nuestras enseñanzas y aprendizajes para luego, en el supuesto de que curse Bachillerato, se le declare exento...

“... lo que suele ocurrir es que el alumno con una determinada discapacidad, acuda al patio o al gimnasio con sus compañeros y se «integre» con su presencia física pero no participativa en las tareas o los juegos que allí se desarrollan. El profesor y sus compañeros aceptan de buen grado su presencia y así «se cumple» con el principio y el deber de llevar a efecto la integración..." (Arráez, 1998, p. 27)

Sospecho que muchos profesores buscamos la inclusión y la participación "activa" de este tipo de alumnado a través de la petición de trabajos escritos (que luego pueden ser expuestos en clase) o de apuntes sobre contenidos de tipo deportivo, de entrenamiento o acondicionamiento físico, de salud, de actividades en la naturaleza o de juegos y deportes populares. También se les suele solicitar que elaboren sesiones o calentamientos para que, dirigidos por ellos mismos, sean realizados por los demás compañeros. Pienso, lo cual evidentemente no es generalizable, que la demanda de este tipo de tareas no es sino una posible justificación de la presencia de la Educación Física en el currículo de estos alumnos. Creo que todo ello puede estar desencadenando procesos contrarios a los de integración recogidos en las normas educativas de alto rango (LOGSE en su día y ahora la LOE), llegando a convertir a estos alumnos en "exentos invisibles", o provocando la comúnmente denominada "falsa integración" (Ríos, 1998b, p. 30), en la que el alumno con algún tipo de discapacidad suele adoptar 
roles pasivos (Lleixá, 2003, p. 127), reduciendo notablemente su participación normalizada en cualquier actividad, lo cual no deja de ser "una forma encubierta de exclusión” (ibídem, p. 31).

Téngase también presente que algunos alumnos, sin sufrir una discapacidad motriz, forman parte de un reducido grupo de individuos frágiles a los que les resulta imposible acceder al grupo del elitismo motriz tan bien valorado en nuestra materia, llegando a convertirse en objetores de la Educación Física (Barbero, 1996, p. 28).

En consonancia con lo dictado en estas normas, también pudiera estar ocurriendo que algunos de los manuales que abordan esta temática de una forma general no muestran realmente lo que está pasando en las aulas, quizás llevados por ofrecer un análisis ortodoxo que no vaya en disonancia con lo políticamente correcto (Pastor, 2002, p. 52).

Asimismo, parece que este campo de investigación, en lo referente al tratamiento de los alumnos con necesidades educativas especiales en Educación Física, era una asignatura pendiente (Muñoz y Antón, 2006). Como se apreciará en el capítulo correspondiente, existen manuales, ponentes... que insisten en esta idea de la integración (entendida como inclusión) propiciando debates, afloramiento de ideas y, en definitiva, enriqueciendo la formación del profesor y sus actitudes ante estos casos.

En relación a esto, Arráez (2003, p. 19) es tajante al afirmar que todo el proceso de integración del alumnado con necesidades educativas genera en el profesorado, especialmente el de Educación Física, "actitudes que van desde la angustia y la duda al pasotismo, pasando por el temor, la desesperanza y el miedo”.

Respecto del miedo, en parecidos términos se expresa Tierra (2001, p. 144) cuando refleja que el miedo y la desconfianza son dos de las actitudes del profesor ante el proceso de integración del alumnado con necesidades educativas especiales. 
De lo que cada vez hay menos dudas es que el asunto de la integración es bastante complejo y lleno de incertidumbres, sobre todo en lo que se refiere a las sombras que aparecen en el desarrollo de la práctica aun cuando la teoría parece aportar mucha luz (Zabalza, 1997, p. 61).

La realidad, aunque sea en contadas ocasiones, supera con creces los modelos teóricos correctos y formales. La práctica rompe con los principios e ideales que llevamos interiorizados desde tiempo atrás, bien porque así los vivenciamos y sentimos, bien porque de esa forma nos los inculcaron durante las enseñanzas recibidas.

En el curso 2002-2003 estuve inmerso en un grupo de trabajo con los miembros de mi departamento de Educación Física y Deportiva en el IES Santo Tomás de Aquino (Íscar) donde realizamos un estudio de las programaciones sobre nuestra área a través del CFIE $^{9}$ de Medina del Campo (Valladolid). El título de la actividad era: "Una Programación Didáctica realmente útil en Educación Física". El objeto del estudio fue revisar diferentes programaciones de Educación Física, tanto de centros públicos como concertados de la Comunidad de Castilla y León, así como algunas de las que aparecen en Internet, con el fin de comprobar el ajuste a la legalidad en cuanto a sus contenidos, la profundidad al abordar cada uno de los mismos, la aplicabilidad de lo programado, etc. Gracias a este trabajo, pudimos comprobar que las propias programaciones no abordan el tema de la integración o que, en el mejor de los casos, lo hacen de una manera somera y superficial, dando lugar a procesos que recuerdan la exención o dispensa de cursar la materia para un alumno con una imposibilidad física determinada, lo cual me inquieta (y desanima) profesionalmente.

Por todo ello, he sentido la necesidad de romper con esas formas de pensar y actuar con el propósito de obtener nuevas informaciones y pautas de actuación profundas más ajustadas a las necesidades y realidades en las que me muevo (Bores, 2000, p. 26).

\footnotetext{
${ }^{9}$ Centro de Formación e Innovación Educativa.
} 
No creo que todos los alumnos que presenten algún tipo de dificultad de aprendizaje asociada a discapacidad motora, temporal o total, deban estar excluidos de las clases de Educación Física (como veremos más adelante, algunos lo están solo de la parte práctica), pero sí que habría que atender a su tipología o grado de déficit o alteración, intereses, necesidades, esperanza de vida o de rehabilitación, no pudiendo ser nunca iguales una enfermedad degenerativa que avanza irremediablemente en contra de toda voluntad y esfuerzo, y otra con grandes posibilidades de no ir a más e, incluso, con esperanzas de mejora. En definitiva, considero que hay "casos extremos" dentro de la atención a la diversidad en el área de Educación Física. Quizás, la respuesta de la Educación Física hacia estos "casos extremos" ha pasado de la exención generalizada, fácil de pedir y de otorgar, a la integración por integración. Creo que ni todos deban estar fuera, ni todos deban hacer algo. No dudo que la exclusión pueda tener efectos negativos en el alumnado con discapacidad, particularmente a efectos de autoestima (Linares, 2000, p. 14), pero tampoco creo su inclusión en las clases de Educación Física ocasione automáticamente beneficios.

“...La sesión de educación física, por sus propias características, tiene potencialidades contradictorias: puede convertirse en la sesión más socializadora e integradora y, a su vez, puede ser la más segregadora del currículum." (Ríos, 1999, pp. 937-938)

Pero las dudas no surgen solo acerca del cómo actuar ante los "casos extremos". Tengo dudas de no ser excesivamente imparcial en la investigación. A la vista de todo lo expuesto hasta aquí pudiera parecer que estoy excesivamente marcado por un caso singular inolvidable e irrepetible ${ }^{10}$. Esto no lo podría haber negado hace unos años. Ahora, la cuestión es bien distinta.

Mi experiencia profesional durante casi dos décadas compartida con compañeros de departamento que han contribuido a mi enriquecimiento profesional de muchas y muy diversas maneras, la formación continuada recibida, la posibilidad de desarrollarme

\footnotetext{
${ }^{10}$ En el capítulo dedicado a las cuestiones metodológicas aclararé cómo he intentado aminorar la implicación subjetiva de este investigador.
} 
profesionalmente en otros ámbitos educativos ${ }^{11}$, así como conocer otras vivencias y experiencias que conllevan diferentes posibilidades de atender a este tipo de alumnos con necesidades "extremas"12, me han servido para aclarar las lentes con las que percibo e interpreto el asunto.

No cierro las puertas a diferentes posibilidades y actuaciones. La exención para estos "casos extremos", tras analizar y contemplar todas las posibilidades educativas factibles a sus demandas y características personales, no la considero desacertada si con ello se mejora o facilita el bienestar del alumno (y su familia).

${ }^{11}$ He trabajado como Profesor Asociado del "Departamento de Didáctica de la Expresión Musical, Plástica y Corporal" de la Facultad de Educación y Trabajo Social de la Universidad de Valladolid durante los cursos 2010-2011 (Asignatura cuatrimestral: Educación Física Escolar), 2011-2012 (Asignaturas cuatrimestrales: Educación Física Escolar y Potencial Educativo de lo Corporal) y 20142015 (como tutor de Practicum y tutor de TFGs).

${ }^{12}$ Durante el curso 2010-2011 tuve la oportunidad de trabajar con una alumna ciega que me ilustró acerca de sus experiencias en las clases de Educación Física durante la Secundaria. Fue sumamente enriquecedor conocer de primera mano un relato como el suyo. 


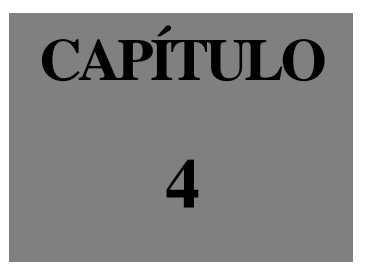

OBJETIVOS Y LÍMITES DE LA TESIS 
Si no sabemos qué buscar, difícilmente sabremos qué encontrar (Ander-Egg, 2000, p. 89). Por ello, el propósito de este capítulo es formular las metas a alcanzar con esta tesis a fin de que nos sirvan en todo momento como guía del estudio, evitándonos las divagaciones por aquello que sea ajeno al objeto de la investigación y que no nos lleva a ningún resultado provechoso.

A partir del planteamiento general del asunto a investigar, serán formulados los objetivos perseguidos. No obstante, con el fin de ir concretando el tema de estudio, algunos de estos objetivos, tal y como Bernardo y Calderero (2000, p. 98), se han ido redefiniendo y delimitando a medida que avanzaba la investigación.

Además, estimamos conveniente señalar los límites de tipo espacial, temporal y singular en los cuales se ubica esta tesis, de forma que dentro de ellos se pueda otorgar una especial relevancia y significatividad a los datos conseguidos. 


\section{1.- OBJETIVOS}

Tomando como punto de partida lo descrito hasta el momento, el objeto de esta tesis consistirá en la aproximación al concepto y uso de la exención de la Educación Física, tanto en el saber teórico como en la práctica, referida fundamentalmente a los alumnos con dificultades de aprendizaje asociadas a discapacidad motora permanente y/o temporal en los institutos de Educación Secundaria. De manera especial se tendrá en consideración la atención a los "casos extremos" que se encuentren en esta circunstancia.

El progreso en este tema de estudio se llevará a cabo a través del desarrollo y esclarecimiento de los siguientes objetivos:

1.- Conocer cuáles son las normas legislativas que desarrollan la atención educativa para los alumnos con dificultades de aprendizaje asociadas a discapacidad motora $\mathrm{y}$, de forma especial, las que contemplan cualquier posibilidad de exención.

Acercarnos al contexto legislativo en el que se mueve la exención supone un punto de partida relevante. Por tanto, se trata de revisar las normas y leyes, nacionales y algunas autonómicas, que contemplan y/o consideran la exención (en cualquiera de las formas que se apreciarán en su momento) como una respuesta posible dentro del ámbito educativo de la Educación Secundaria Obligatoria y el Bachillerato.

Todo ello será desarrollado en el Capítulo 6, apartado 1. 
2.- Comprobar cómo aparece la exención en el marco del saber disciplinar de la Educación Física, y qué puede estar favoreciendo su aplicación y perdurabilidad.

En este caso se trata de realizar un repaso por las fuentes documentales propias del área para averiguar y analizar cómo aparece y se interpreta la exención. También será necesario revisar las respuestas educativas en esta línea que se ofrecen a los alumnos con dificultades de aprendizaje asociadas a discapacidad motora.

De alguna forma, se pretende dejar constancia del uso de este concepto, con todo lo que conlleva, en la propia teoría disciplinar.

Este objetivo, a pesar de que impregnará a toda la tesis, se encuentra fundamentalmente expuesto en el Capítulo 6, apartado 2.

3.- De igual forma, aproximarnos al uso que el saber popular confiere a dicho término.

Si el saber científico es objeto de revisión, no puede por menos serlo la sociedad. Es necesario acometer un acercamiento, aunque sea somero, a la opinión que la gente, tanto de los que se autodefinen como expertos, como de los "usuarios" de la Educación Física, vierten en foros y páginas Web de dominio público.

Este propósito se aborda en el Capítulo 6, apartado 2.

4.- Comprobar la forma en que se presenta la "exención" en las Programaciones Didácticas de Educación Física de estos IES, previo análisis del ajuste a la norma.

La programación didáctica de área constituye el documento "oficial" que concreta el currículo y su puesta en práctica en los centros.

Mediante un trabajo profundo y exhaustivo se examinará este esencial instrumento diseñado por numerosos departamentos de Educación Física y Deportiva de la provincia de Valladolid, de lo cual se deja constancia en el Capítulo 7. 
5.- Aproximación a la visión y creencias que el profesorado de Educación Física tiene de este asunto.

Si importante es lo que aparece en los documentos, al mismo nivel hemos de situar la opinión y creencias de los profesores respecto de la exención.

La opinión de un gran número de profesores de Educación Física de Secundaria Obligatoria y Bachillerato se pondrá de manifiesto en el Capítulo 8.

\section{6.- Recurrir a mi formación permanente para conocer si en ese contexto la exención} se plantea o emerge de algún modo.

La revisión y exposición autobiográfica de relatos de vida, pertenecientes a la formación del autor de esta tesis, constituirán el grueso del Capítulo 9.

Los foros en los que se imparte formación sobre la atención a la diversidad del alumnado en Educación Física, la responsabilidad del profesorado..., pueden poner de manifiesto no solo prácticas próximas a la exención, sino la exención misma, incluyendo la que puede propiciar la carencia o escasez. formativa institucional.

7.- Indagar sobre los documentos médicos y familiares que los alumnos emplean para justificar la "no práctica" de Educación Física.

Comprobaremos que los escritos, ya sean desde los propios del saber científico como de los de concreción del currículo, otorgan un lugar superior, casi mitificado, al certificado médico como instrumento que pondrá en marcha cualquier medida que se tome respecto del alumno que lo presente.

De forma análoga sucede con los papeles firmados por los padres y madres de esos alumnos.

La cuestión radica en conocer de primera mano lo que acontece en un contexto real, por lo que en el Capítulo 10 se presentará la investigación llevada a cabo en un instituto de Enseñanza Secundaria perteneciente al ámbito de estudio de la tesis. 
8.- Conocer si el factor responsabilidad o el miedo a las consecuencias derivadas de la actuación docente puedes ser incentivos para la aparición de la exención.

En el Capítulo 6 emergerá la cuestión de la responsabilidad de los profesores. El temor o respeto por tan delicado asunto puede ser una de las razones de la puesta en funcionamiento de actuaciones muy próximas, mimetizadas casi, a la exención. Esta responsabilidad será estudiada desde diversos focos (legales, documentales, periodísticos...) en el Capítulo 11.

9.- Conocer cuál es la opinión, vivencias y sentimientos de los principales implicados, es decir, de los propios alumnos con dificultades de aprendizaje asociadas a discapacidad motora y de sus familiares.

A lo largo de la tesis se alude insistentemente a un determinado tipo de alumno, poseedor de unas ciertas dificultades de aprendizaje asociadas a discapacidad motora. De esta forma, dicho alumno es siempre tratado desde un plano general, muy impersonal, que pudiera situarnos, al investigador y al lector, en una panorámica bastante alejada de la realidad.

Por ello, es sumamente necesario poner nombre a ese alumno genérico, dar a conocer un caso real "extremo", para que el tema sea apreciado y entendido en su debida magnitud desde una perspectiva más íntima y, sobre todo, real. Todo ello acontecerá en el Capítulo 12.

Por cierto, el alumno en cuestión, Virginia, no será un instrumento para desarrollar la investigación, sino un valioso colaborador (FernándezBalboa, 1997, p. 103) que aportará, de manera retrospectiva, su contribución para la consecución del objetivo final de esta tesis.

Por último, al margen de la consecución de estos objetivos, no puedo negar cierta ilusión por pretender propiciar la reflexión del profesorado de Educación Física sobre una serie de cuestiones, tales como: si es necesario que no existan exentos en nuestra materia; si se sigue tratando así a determinados alumnos, cómo les beneficia la 
práctica "sin práctica" de la Educación Física; cómo lo debemos hacer, qué objetivos se deben buscar con este tipo de alumnos y a través de qué contenidos, cómo evaluarlos, y si se podría considerar la posibilidad de la optatividad de la Educación Física para algunos de estos alumnos.

Obviamente, como esta aspiración queda totalmente fuera de mis posibilidades, no es redactada en forma de objetivo a alcanzar. Además, su hipotético logro pasa por dar a conocer esta investigación y facilitar su lectura. Aunque ambas cuestiones no dejan de parecerme pretenciosas a estas alturas de la tesis, confío en que el resultado final será lo suficientemente atractivo como para que alguna vez la ilusión se convierta en realidad.

\subsection{1.- PIEZAS DE LA VIDRIERA}

Con la intención de otorgar cierta originalidad visual a la tesis, hemos optado por dar formas simbólicas, a modo de cristales de una vidriera, a las principales ideas que subyacen del desarrollo de cada capítulo en relación a la consecución de los objetivos anteriormente expuestos.

De esta forma, en cada capítulo irán apareciendo piezas, unas nuevas y otras ya conocidas, con las que iremos conformando la vidriera a través de la cual observaremos, en relación a los objetivos planteados, la Educación Física española de finales del siglo XX y principios del XXI.

Conviene matizar que, aunque una misma pieza pueda aparecer en diferentes capítulos, solo será empleada una única vez en la vidriera que será reconstruida al término de la tesis. Será precisamente en ese momento final cuando podremos apreciar claramente lo que el conjunto de la investigación deja al descubierto y que antes, de forma parcelada, no se podía ver. La vidriera resultante se encuentra en la página 513. 


\section{2.- LÍMITES DE LA TESIS}

Por otra parte, es necesario acotar los límites en los que se ubica esta tesis doctoral para poder entender mejor todos los procesos que en ella acontecen, lo cual incluye la concreción de sus contextos espacio-temporales en los que tiene lugar, y definir las características propias que la configuran su singularidad. Así pues, los límites son:

\subsection{1.- LÍMITES ESPACIALES}

Para referirnos a estas limitaciones, estableceremos tres niveles de concreción.

El primero de ellos es el territorio español, ámbito en el que se plantea y sustenta todo el marco general de la investigación.

Las fuentes documentales consultadas, así como las normas legislativas, están referidas en su inmensa mayoría a dicho territorio. De alguna forma interpretamos el uso de todas estas informaciones como una manera de situarnos cerca de las cuestiones investigadas. La referencia a revelaciones provenientes de otros países se reducen a la mínima expresión y su uso suele tener una finalidad comparativa, consolidativa y/o ejemplificadora de una determinada circunstancia, o para situar el estado de la cuestión al respecto del objeto de estudio.

El segundo, en lo referente al marco de las cuestiones legislativas, se ciñe al ámbito de la comunidad de Castilla y León. Además, en algún momento también aparecerán informaciones acerca a la Facultad de Ciencias de la Actividad Física y el Deporte de León en la que yo me formé como Licenciado en Educación Física. 
En tercer y último lugar, máximo nivel de concreción de la investigación, lo situaremos en la ciudad de Valladolid y las localidades de su provincia (solo aquellas en las que exista un Instituto de Enseñanza Secundaria). Incluso, en ocasiones, el límite se acota aún más cuando el proceso investigador solo afecta a uno o dos centros. Concretando, el estudio se circunscribe únicamente a los centros de Enseñanza Secundaria de carácter público existentes en ese territorio. De ellos se obtendrá gran cantidad de información que aparece en esta tesis.

En la Figura 1 queda reflejado de manera más representativa todos los límites espaciales de la tesis.

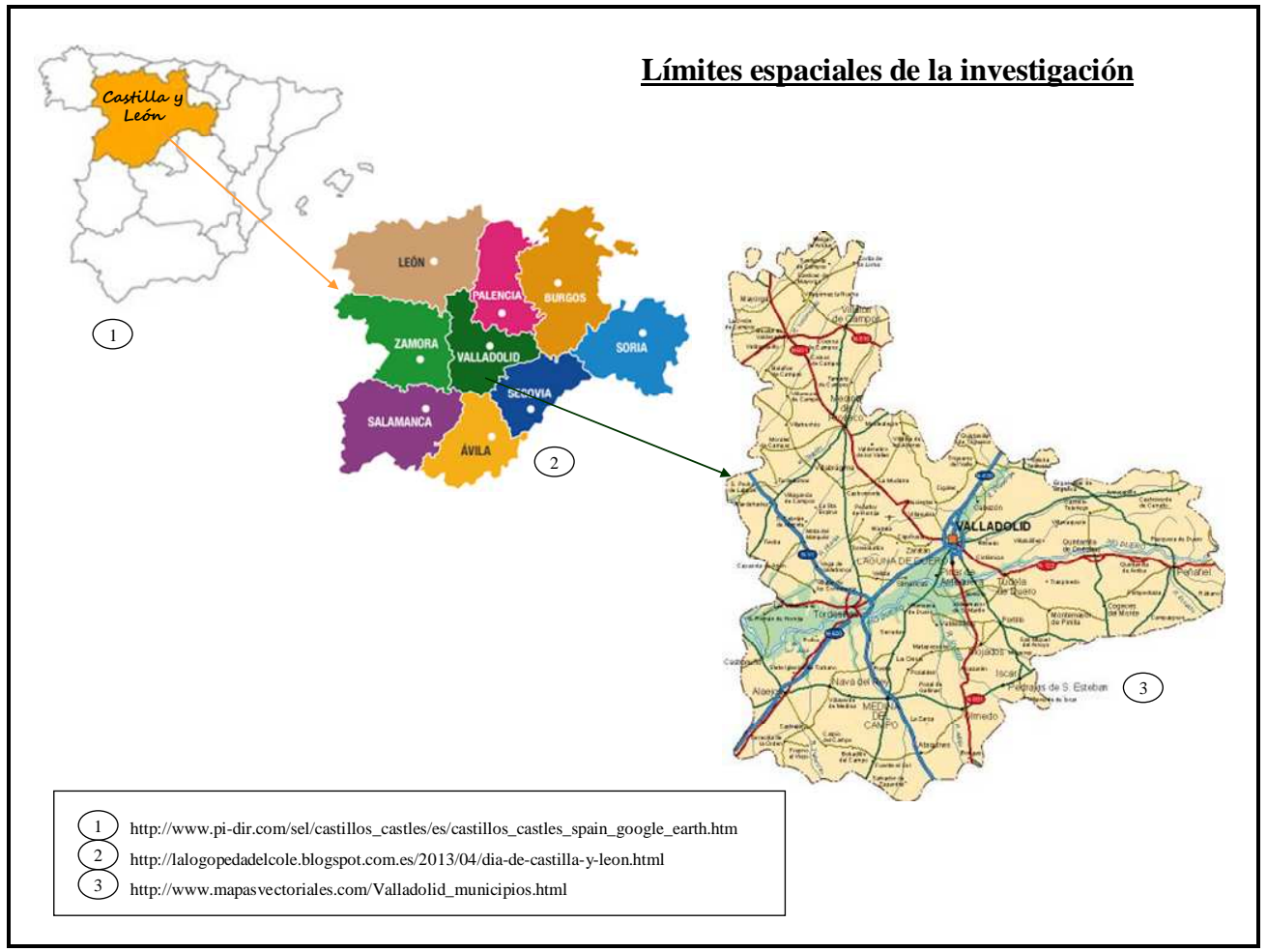

Figura 1. Límites espaciales de la tesis

\subsection{2.- LÍMITES TEMPORALES}

En lo que se refiere a las fuentes documentales y de información que plantean el de alguna forma el asunto de la exención, se ha optado por emplear preferentemente 
aquellas que han sido publicadas con posterioridad a 1995, año que supuso un cambio legislativo radical en relación al tratamiento de los alumnos con necesidades educativas especiales en Educación Física (vid.: Capítulo 6, apartado 1).

Obviamente, el empleo de publicaciones anteriores a esa fecha se considera suficientemente justificado en otros procesos o apartados de la investigación: cuestiones metodológicas y de elaboración, tratamiento genérico de los alumnos con necesidades educativas especiales y atención a la diversidad, revisión de estudios e investigaciones sobre la exención, etc.

El recorrido legislativo abarca el periodo comprendido entre 1961, en el que aparece la orden que regula las dispensas de Educación Física, y el 2015, que es cuando se publica en la comunidad de Castilla y León la última norma que versa sobre la exención en Educación Física (aplicada al Bachillerato).

Por lo que respecta al propio proceso de diseño, elaboración y desarrollo de la tesis, del cual ya he apuntado algo en el Capítulo "ORIGEN Y JUSTIFICACIONES", presento un cronograma ilustrativo de las fases (actividades) realizadas en relación al tiempo en el que han sido desarrolladas (Tamayo, 2001, p. 219).

El cronograma es de lectura fácil e inmediata. El uso de colores proporciona una visión general de todo el proceso. En él se puede apreciar un cierto "vacío" investigador entre finales de 2007 y finales de 2010, que es conveniente matizar. Diferentes motivos de índole profesional y personal me tuvieron algo apartado de la investigación en lo que a grades avances se refiere. Pero, a pesar de este "vacío", como ya apunté anteriormente, nunca he abandonado la idea de seguir manteniendo viva la posibilidad de continuar enriqueciendo la tesis y poder concluirla. 


\section{Cronograma}

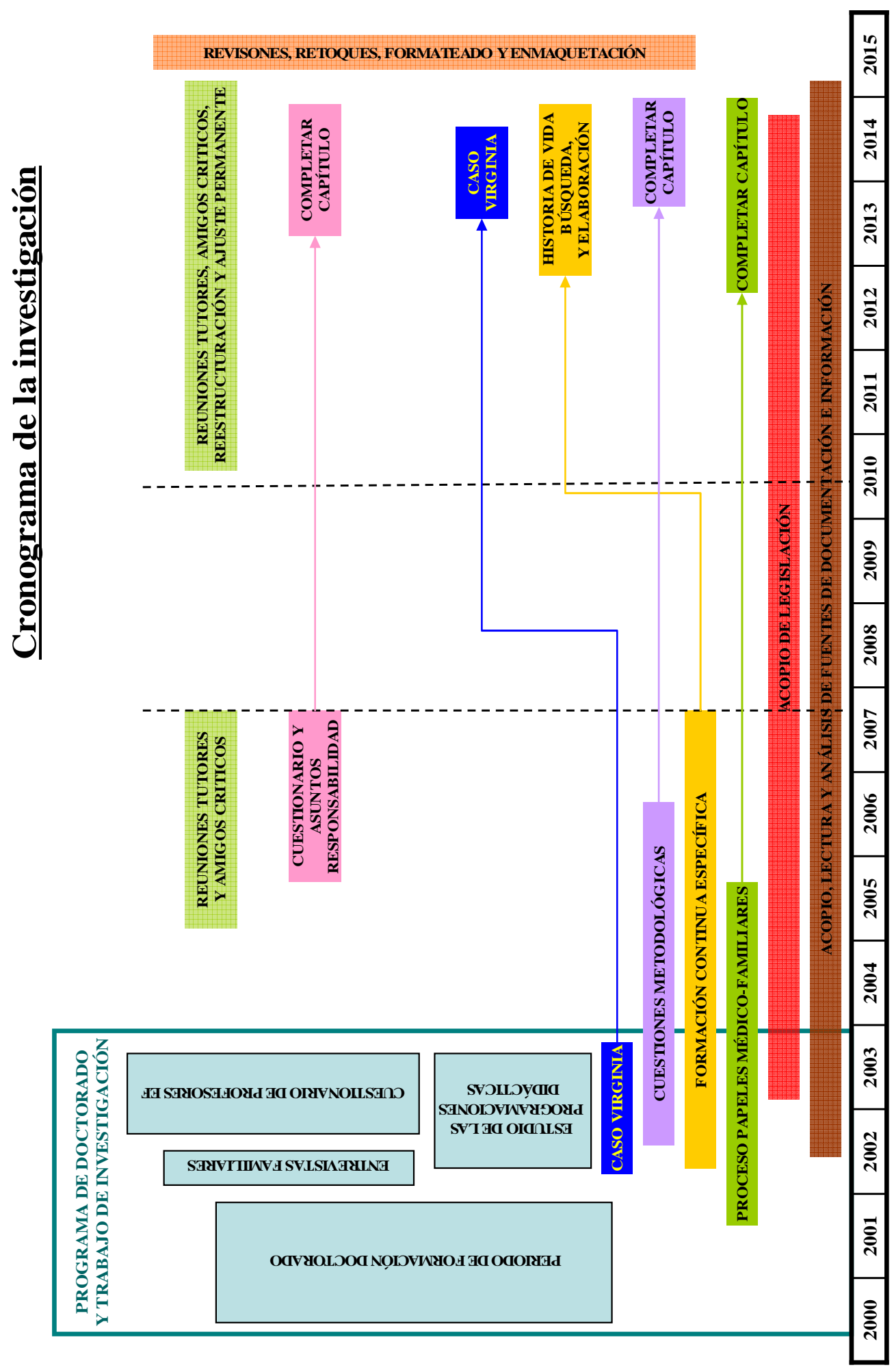




\subsection{3.- CARACTERÍSTICAS SINGULARES}

Quizás la primera de ellas sea precisamente la última aportación realizada en el apartado anterior: mi perseverancia por continuar la investigación merece un lugar destacado. Sin esta actitud, propia de mi personalidad, esta tesis nunca habría visto la luz del final del túnel.

Otra singular característica la encontramos en las dos leyes orgánicas educativas aprobadas que se han implantado en España durante el periodo de elaboración de esta tesis $^{13}$. Desde el inicio del trabajo hasta el curso 2006-2007 todas las normas educativas tenían como marco referencial a la LOGSE. En el curso 2007-2008 comenzó a implantarse la LOE.

En lo que respecta a la ubicación del tratamiento de la atención a la diversidad en estas normas, en la LOGSE nos lo vamos a encontrar en su Título I, Capítulo V, bajo el epígrafe "De la educación especial", abarcando los artículos 36 y 37. Por su parte, en la LOE aparece en el Título II, Capítulo I, "Alumnado con necesidad de apoyo educativo" (artículos 71 y 72).

A pesar de lo que pudiera parecer, esta peculiar situación no afecta para nada a la investigación, ya que el desarrollo normativo referido a la atención a la diversidad no ha sufrido excesiva variación, al menos en lo que afecta al tema de estudio de esta tesis. De hecho, nos encontramos que el asunto de las adaptaciones es recogido de forma análoga en ambas:

“...los centros deberán contar con la debida organización escolar y realizar las adaptaciones y diversificaciones curriculares necesarias para facilitar a los alumnos la consecución de los fines indicados..." (LOGSE, artículo 37, apartado 1)

\footnotetext{
${ }^{13}$ No incluimos la Ley Orgánica 8/2013, de 9 de diciembre, para la mejora de la calidad educativa (BOE 10-12-2013) puesto que en el curso 2014-2015 todavía no se ha implantado ni en la E.S.O. ni en el Bachillerato.
} 
"Los centros contarán con la debida organización escolar y realizarán las adaptaciones y diversificaciones curriculares precisas para facilitar a todo el alumnado la consecución de los fines establecidos." (LOE, artículo 72, apartado 3)

Sin embargo, estas dos leyes orgánicas se desarrollan a través de decretos, órdenes y resoluciones que sí contemplan ciertas peculiaridades. En el Capítulo 6, apartado 1, donde se esboza el marco legal de la exención, se recogerán las más significativas.

Por último, antes de introducirnos de lleno con la investigación, es trascendental explicitar que este autor pretende reflejar una realidad acerca de la exención en Educación Física que ha podido constatar de diversas maneras.

Comienza a partir de este momento la búsqueda de las piezas que irán configurando la exención (in)visible de la Educación Física española de finales del siglo XX y principios del XXI. 


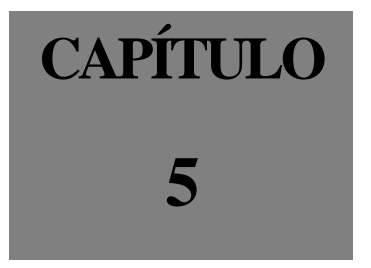

APRECIACIONES METODOLÓGICAS 
Establecidos los objetivos a alcanzar en esta tesis, fijados los límites del mismo y la génesis del interés y preocupación por el tema que aquí se trata, expondré los métodos y técnicas de investigación que he utilizado a lo largo del proyecto de investigación. Para ello, realizaré una breve síntesis de los diferentes paradigmas de investigación existentes y la metodología que surge de ellos, previa aclaración de lo que entendemos por método y técnica.

Además, puesto que a medida que avanzaba en la investigación percibía que tenían lugar multitud de situaciones y acontecimientos que afectaban a todo el proceso, considero oportuno relatar, como muestra de lo sucedido en el transcurso de la investigación, algunos de esos procedimientos y procesos. En todo caso, debe de quedar claro que en este capítulo la reflexión metodológica se realiza desde una perspectiva global, que se verá completada debidamente en cada capítulo correspondiente en donde se describirá con mayor profundidad los métodos y técnicas empleadas según el caso.

Debido a los especiales y delicados momentos acaecidos durante la entrevista mantenida con un familiar de Virginia, alumna que ha sido el principal origen de la realización de esta investigación, hemos optado por incluir todo lo que compete a esta técnica y los detalles que rodearon ese momento en el capítulo correspondiente. 


\section{1.- REFERENTES METODOLÓGICOS}

He comentado en capítulos anteriores las razonas que me han llevado a trabajar sobre este asunto y, más importante aún, he puesto de manifiesto mi sentir y mi manera de pensar y actuar ante el mismo, las cuales, probablemente, condicionan todo el proceso investigativo. En definitiva, he intentado explicar mi forma de comprender e interpretar el tema objeto de estudio, así como el marco en el que lo sitúo.

"Toda persona que realiza un trabajo de investigación percibe e interpreta el mundo a través de unas determinadas lentes paradigmáticas. Un paradigma proporciona una matriz disciplinar (Kuhn, 1970) que contiene una serie de supuestos en los que sus seguidores basan su acuerdo o desacuerdo a la hora de considerar una investigación buena, adecuada o mala, según los términos en que se han definido los objetivos, los puntos de partida, los métodos y las formas de análisis.” (Sparkes, 1992, p. 29)

Sin entrar ahora en los detalles y características que configuran los diferentes tipos de paradigmas que existen en la investigación educativa ${ }^{14}$ (positivista, interpretativo y crítico), de los cuales emanan distintas metodologías de investigación: la científica tradicional, la cualitativa y la crítica respectivamente (Colás, 1992a, p. 55), esta tesis se podría situar en un paradigma más próximo al interpretativo en la medida que considero que existen múltiples realidades y que el objeto estudiado y el sujeto investigador no pueden separarse (Sparkes, op. cit. , p. 31). Este hecho podría venir a significar que no existe una única verdad (Martínez, 2011). De igual forma, considero que toda persona, investigador o no, está en permanente proceso de definición y evolución según las situaciones en las que vive y se desarrolla (ibídem).

\footnotetext{
${ }^{14}$ Vid.: Sparkes (op. cit.), Colás (1992a)
} 
Al objeto de evitar equívocos, es necesario aclarar las nociones de método y técnica pues suele ser habitual que se utilicen de forma inapropiada por trasposición de sus significaciones (Colás, op. cit., p. 62).

En primer lugar, entendemos que el método es una estrategia ordenada con capacidad repetitiva que permite aplicarla en los mismos términos en cualquier circunstancia, y que incluye la propia forma de actuación del investigador. A este respecto, Coller (2000, p. 17) señala que el método son unos pasos lógicos y sistemáticos que permiten comprobar la veracidad de una serie de afirmaciones que se refieren a la parcela de la realidad en la que se está interesado. Este autor diferencia método de metodología, dando al primero el valor de un conjunto de pasos que se siguen en la investigación para llegar a una conclusión, y al segundo se refiere en términos de ciencia del método ${ }^{15}$.

"Por métodos nosotros entendemos toda una variedad de enfoques utilizados en la investigación educativa para recoger datos que se utilizarán como base para la inferencia, interpretación, explicación y predicción." (Colás, op. cit., citando a Cohen y Manion, 1980, p. 26)

De las muchas clasificaciones que existen de los métodos (Ander-Egg, 2000; Colás, op. cit.; Pérez Meléndez et alia, 1998; Goetz y LeCompte, 1988), me sirvo de la recogida por Colás (op. cit.) realizada en base a los criterios de los objetivos y el tipo de conocimiento que se genera con ellos. Establece cinco clases de métodos: experimental, correlacional, descriptivo, cualitativo e investigación-acción. Los tres primeros se encuadran dentro de un paradigma cuantitativo o positivista, el cuarto es propio del enfoque interpretativo o cualitativo, y el último es, en alguno de sus posibles desarrollos, característico del paradigma crítico.

Pues bien, aunque la metodología de investigación que emplearé será eminentemente cualitativa, caracterizada fundamentalmente por considerar que la realidad, en este caso la educativa, es múltiple, construida y dinámica (Soler y

\footnotetext{
${ }^{15}$ Pérez Meléndez (1998, p. 18), señala que en sentido restringido el concepto de metodología puede confundirse con el de método, al entender la primera como la manera o conjunto de pasos que tenemos a la hora de aplicar una determinada programación, proceso o técnica.
} 
Vilanova, 2010, p. 28), intentando examinar las diferentes realidades según como las experimentan los diferentes protagonistas investigados (Martínez, 2011) y considerando todos los escenarios y personas como un todo, es decir, que intentaré comprender y exponer esas realidades desde una perspectiva interna o subjetiva (Pérez, citado por Quintana, 2006, p. 48), esta tesis, como ya viene siendo habitual en los trabajos realizados en las ciencias sociales (Coller, op. cit., p. 21), se caracteriza por un cierto eclecticismo ya que tienen cabida una variedad de métodos, con el uso de las correspondientes técnicas pertenecientes a otros tantos de ellos, "entremezclando" las posiciones cuantitativa y cualitativa con el objeto de hacer más rica, variada y productiva la investigación.

"Las ciencias sociales, cada vez más, se caracterizan por el pluralismo metodológico. Las personas que se dedican a investigar tienden a combinar métodos de naturaleza diferente. Lo relevante es utilizar la imaginación sociológica para encontrar la forma óptima de producir el mejor conocimiento posible sobre una parcela de la realidad que se quiere conocer." (Coller, op. cit.)

Aun así, considero oportuno remarcar los aspectos o características que esta tesis comparte con la investigación cualitativa (Guba y Lincoln citados por Colás, 1992c, pp. 250-252):

- Concepción múltiple de la realidad.

- Investigador y objeto investigado están interrelacionados.

- La cantidad de interacciones y fenómenos que se producen no permiten distinguir con claridad las causas de los efectos.

- Procura desarrollar un conocimiento ideográfico en la medida en que se centra en la descripción y comprensión de lo individual, lo particular de un caso individual.

- Uso de metodología estrechamente relacionada con el paradigma de referencia: se parte de situaciones naturales (no artificiales) en las investigador se convierte en el principal instrumento de recogida de datos; aplicación de técnicas de recogida de datos abiertas; la selección de las muestras no se hace con el propósito de generalizar los resultados 
sino con intencionalidad teórica la cual se genera a partir de datos de una realidad concreta; se describen situaciones y procesos con cierto detalle $\mathrm{y}$, finalmente, plantea criterios de validez para garantizar la credibilidad de los resultados.

En lo que respecta a las técnicas suelen definirse como aquéllas que permitirán la recogida de datos dentro del método de investigación en que se utilicen (Pérez Meléndez et alia, op. cit., p. 25), siendo por tanto, un elemento del mismo.

"Por técnicas entendemos los procedimientos específicos que utiliza una determinada área científica para la obtención de los datos de la investigación. Son procedimientos de actuación concretos y particulares... Mientras las técnicas tienen un carácter práctico y operativo, los métodos se diferencian de ellas por su carácter más global y de coordinación de las operaciones. Las técnicas se engloban dentro de un método y, a la inversa, un método comporta el uso de diferentes técnicas (Ander-Egg, 1995).” (Pérez Meléndez et alia, ibídem)

Así pues, utilizaré técnicas propias de los métodos descriptivos ${ }^{16}$, como serán los cuestionarios de autocumplimentación que tendrán que realizar, por un lado, los profesores de Educación Física de los Institutos públicos de Educación Secundaria de Valladolid y provincia, y por otro los profesores de todas las asignaturas de algunos centros de este contexto. Pero sobre todo primarán las técnicas de generación y recogida de información de la metodología cualitativa, que deberán responder al momento o situación en que se hagan necesarias y no tanto a una cuestión relacionada con el uso estandarizado de las mismas (Quintana, op. cit., p. 60). Como serán diversos los procesos seguidos en las diferentes realidades investigadas, para la obtención de información se irán variando las técnicas empleadas. Así emplearé diarios, notas de campo y cuadernos (del investigador o/y de los alumnos), el análisis documental (para las pruebas documentales como las programaciones didácticas, normas y documentos de carácter legislativo, etc.), la entrevista (a expertos y familiares), la observación participante (aplicada, entre otros, al capítulo de los justificantes médicos y familiares), los relatos de vida (del alumno y propia del investigador).

\footnotetext{
${ }^{16}$ Para Best (1970), citado por Cohen y Manion (op. cit., p. 101), la "mayoría de los métodos de investigación educativa son descriptivos; esto es, tratan de descubrir e interpretar lo que es.”
} 


\section{2.- TÉCNICAS PARA LA OBTENCIÓN DE INFORMACIÓN}

Se trata ahora de acercarnos a las pautas de uso y características que definen cada una de las técnicas mencionadas, no sin antes matizar que algunos de los procesos metodológicos seguidos a lo largo de la investigación, así como la descripción de las propias técnicas de obtención de información empleadas, se tratarán y desarrollarán con más detalle en los capítulos correspondientes (i. e., revisión de las programaciones didácticas, opinión de los profesores, entrevista...)

\subsection{1.- ANÁlisis DE CONTENIDO (O ANÁLISIS DOCUMENTAL)}

Mientras que para algún autor (Quintana, 2006, p. 65) esta técnica es considerada como el punto de entrada a la investigación cualitativa, otros la consideran como una técnica (método según ellos) híbrida proveniente de la investigación cuantitativa pero que se comienza a utilizar en investigación cualitativa (ÁlvarezGayón, 2003, p. 163). De todas las leídas, entendemos que las que más se aproxima a nuestro uso es la de Berelson (citado en Anguera, 1986, p. 31).

“...técnica de de investigación para la descripción objetiva, sistemática y cuantitativa de contenido de la comunicación." (Berelson, 1952, p. 18)

Esta técnica es emplea para interpretar y valorar la información contenida en cualquier forma de comunicación (Álvarez-Gayón, op. cit. y Soler y Vilanova, 2010). A este respecto, nos servirá para analizar la información que se ha obtenido por medio de cualquier otra forma de investigación (observación, diarios...) o supondrá el principal instrumento de trabajo cuando se emplee con documentos concretos ${ }^{17}$ (Soler y Vilanova, op. cit.).

\footnotetext{
17 En lo que respecta a esta tesis: programaciones didácticas, artículos periodísticos, documentos personales, cuadernos del alumno, normas y documentos legislativos...
} 
Algunos de los pasos seguidos para realizar este análisis de contenido han sido (Álvarez-Gayón, op. cit., p.164):

- Determinar el contenido a estudiar y su relevancia: el asunto en torno al cual giraría el estudio estaba más o menos claro, así como su relevancia (desde el plano de lo personal). No obstante, ha sido necesario enmarcar y entrelazar los temas que se intuían imprescindibles en el propio diseño y planificación de la investigación, como aquellos otros que han ido apareciendo y se han considerado interesantes y apropiados para incluirlos en el resultado final de la tesis.

- Establecer con claridad los elementos objeto de estudio: por la cantidad de categorías y subcategorías existentes, era de crucial importancia definirles con precisión para evitar divagaciones y rodeos inútiles.

- Decidir y elaborar la forma de recabar la información: para ese propósito se han elaborado fichas ad hoc para recogida y sistematización de la información, diseñado un cuaderno debidamente organizados por ejes nucleares, cuadernos para transcripciones...

Además, en todo el proceso de análisis documental, he tenido en consideración las siguientes acciones (Quintana, op. cit., p. 66), todas ellas estrechamente entrelazadas:

- Rastrear, inventariar y clasificar la información: acciones que han tenido lugar desde el minuto cero hasta el final del proceso de elaboración de la tesis. La búsqueda ha sido insistente e interrumpida, agotadora por momentos, al igual que su posterior clasificación.

- Seleccionar: no solo los documentos, registros, informaciones... pertinentes, sino la parte de ellos que me era válida para la investigación.

- Leer en profundidad: Para poder llevar a cabo lo anterior es necesario leer de forma concienzuda, subrayar, identificar, entresacar lo jugoso de los escritos e informaciones de cualquier tipo. 
- Realizar una lectura de forma cruzada y comparativa: todo lo leído, considerado relevante, se comparaba con lo que ya había consultado para, de forma conjunta o individualmente, ubicarlo en el contexto oportuno dentro de la tesis.

Por otro lado, puesto que la exploración de la literatura específica es una parte esencial de cualquier investigación (Quintana, op. cit., p. 55), considero necesario abordar todo el proceso de análisis y revisión de la literatura que he seguido (en cualquiera de las modalidades o formatos empleados), ya que supone un apartado cualitativa y cuantitativamente muy relevante de la tesis.

De entrada, ha supuesto todo un esfuerzo (entendemos que fructífero a la vista del resultado final) la búsqueda y revisión de muchas y variadas fuentes de información. El proceso ha sido permanente y sostenido hasta el final, aunque seguramente inacabado pues la información y el conocimiento no cesan de ser generados en ningún momento. Se ha consultado las cuestiones relacionadas con la exención (en la amplia variedad de asuntos abordados en esta tesis) no solo en los formatos habituales del saber científico, sino que también, para dar cabida a cualquier tipo de información referida al tema de la investigación, se ha dado cabida a variadas fuentes de información: documentos variopintos disponibles en Internet, novelas, leyes y reglamentos...

El tipo de lectura que he efectuado, como expresa Quintana (op. cit.), ha sido de naturaleza crítica y, como no podría ser de otra forma, selectiva. Posteriormente, he extraído las conclusiones que he considerado pertinentes y las he presentado de manera que resultasen apropiadas para la investigación y atrayentes para el lector.

\subsection{2.- CUESTIONARIOS}

Se trata de una técnica mediante la cual se plantea a un conjunto de personas (muestra) una serie de interrogantes relacionados con la cuestión a investigar (Soler y Vilanova, 2010, p. 30). De hecho, "es el instrumento más utilizado para recolectar 
datos" (Hernández citado por Álvarez-Gayón, op. cit., p. 149). Con los resultados obtenidos suele ser habitual realizar un análisis de tipo estadístico.

Dos son los cuestionarios utilizados en esta tesis y ambos han sido elaborados ad hoc para la cuestión a investigar. Uno contiene exclusivamente preguntas cerradas, lo cual lo sitúa en el preferido del paradigma cuantitativo y, a su vez, ha llevado a los investigadores cualitativos a no tenerlo como una opción viable (Álvarez-Gayón, ibídem). Este cuestionario, aunque algo extenso, es sencillo de responder y fácil de codificar y analizar posteriormente. En el segundo se incluyen preguntas abiertas y cerradas, lo que permite que los participantes plasmen lo que piensan al respecto de la cuestión planteada.

\subsection{3. - ENTREVISTAS}

Son varias y de muy diversa índole las entrevistas que aparecen en esta tesis. Algunas se realizan con el propósito de clarificar términos y situaciones, para lo cual se mantienen conversaciones con expertos en asuntos relacionados con el objeto de la investigación. Sin embargo, la más relevante la sitúo en la que efectué a la madre de Virginia. Durante esa entrevista, breve pero muy intensa por las circunstancias que la envolvieron y el contexto en el que se produjo, se estableció un profundo diálogo entre el investigador y el interlocutor, facilitando el contacto directo con el entrevistado y su entorno que permite también obtener información de otras formas de expresión (Soler y Vilanova, op. cit, p. 30).

Decido realizar esta entrevista porque creo necesario e imprescindible para el tema objeto de estudio acercarme a las creencias subjetivas, a la biografía, de una persona relevante para la investigación. No tanto por lo que ella puede opinar al respecto de los asuntos tratados, sino por darme información sobre lo que suponía para la persona ausente. 
Una de las claves del éxito de esta técnica radica en la forma de registrar la información (Martínez, 2011). Por ello, cuando se cuenta con la autorización del entrevistado, las entrevistas se graban. Además, se transcribe lo antes posible todo lo acontecido durante las mismas. De esta forma, el proceso de recogida de información se efectúa de forma exhaustiva y con todo lujo de detalles, recogiendo no solo las palabras de los entrevistados, sino también aspectos relacionados con el escenario, lenguaje no verbal, sentimientos... que la envolvieron.

En el Capítulo 13 se recogen los detalles metodológicos al respecto de esta técnica, así como las cuestiones esenciales pertinentes.

\subsection{4.- HISTORIA DE VIDA}

A estas alturas, a nadie se le escapa que el asunto de esta tesis es fruto de la impactante experiencia profesional del investigador con una alumna y su especial circunstancia. Este episodio singular que tuvo el peor de los finales deseados, único en la medida en que la persona desaparecida es irremplazable, será relatado en el Capítulo 10 de forma biográfica, lo cual supone en cierta manera una historia de vida (Biglia y Bonet-Martí, 2009).

Mientras que los relatos de vidas suponen la "historia de una vida tal y como la persona que la ha vivido la cuenta" (Pujadas citado en Biglia y Bonet-Martí, 2009), configurando así su «life story», las historias de vida estudian a la persona y su propio relato de vida, así como los detalles e informaciones adicionales que permitirán reconstruir dicha autobiografía (ibídem). Para llevar a cabo esta investigación recabé información de las propias palabras de Virginia recogidas en su cuaderno de clase de Educación Física, y otras anotadas en mis diarios de campo al término de conversaciones mantenidas con ella, de mis anotaciones de los cuadernos de clase, de la entrevista realizada a su madre y, finalmente, de un documento escrito por una de sus amigas y compañera de "fatigas" durante años en las clases de Educación Física. 
De igual forma, relato mi historia de vida pues de ella se pueden extraer datos en relación a cómo percibía (percibo) parte del asunto objeto de estudio y toda mi relación y andadura por los mundos de la Educación Física. Utilizaré mi capacidad para evocarla, mis escritos en la etapa de formación inicial y mis primeros documentos curriculares elaborados en el ámbito profesional. La exposición de mi historia de vida pretende ser rica en detalles de mi pasado incluyendo emociones, desilusiones, fracasos y éxitos ya que todos ellos están vivos en mí como si hubieran tenido lugar ayer mismo (Álvarez-Gayou, op. cit., p. 126).

\subsection{5.- OBSERVACIÓN PARTICIPANTE}

Como investigador que indago sobre mi ámbito profesional cercano, irremediablemente me veré dentro del grupo y escenario objetos de estudio (Soler y Vilanova, op. cit., p. 32 y Martínez, 2011), es decir, en el medio natural en el que profesionalmente me muevo, siendo a la vez parte de la situación y participando en la actividad que se estudia.

Entre otros, todo el proceso de la recogida, análisis e interpretación de documentos médicos y familiares, así como algún episodio de la formación permanente, se situó en esta técnica. No obstante, los instrumentos que a continuación enumeraré han sido empleados durante todo el proceso de investigación.

Aunque este tipo de observación depende demasiado de la interpretación del investigador, esto no debe suponer una invalidación de la técnica (Álvarez-Gayou, op. cit., p. 109).

Toda observación realizada se registró mediante la utilización de cuadernos de trabajo, diarios de campo, medios audiovisuales y cuaderno de notas. 


\section{Cuaderno de trabajo}

Esta herramienta viene a ser un "cuaderno de bitácora" en el que se lleva día a día toda la investigación (Blández, 2000, p. 76). Ha servido para organizar y registrar cualquier información observada, leída... (Martínez, op. cit.). Dentro de este instrumento incluyo también las fichas elaboradas ad hoc para la recogida de datos de diferentes documentos o procesos: estudio de las programaciones didácticas y de los documentos médicos y familiares, etc.

\section{Diarios de campo}

También se les conoce como notas de campo. Son escritos que recogen anécdotas, sucesos... acaecidos durante la investigación (Blández, ibídem). Durante su uso no se han incluido comentarios ni valoraciones personales (subjetivas) que pudieran enturbiar el rigor y objetividad que debe existir en este instrumento (Martínez, op. cit.).

Otro asunto bien diferente es el del auténtico diario del investigador. Este diario sí que puede acoger opiniones, sentimientos, preocupaciones, dudas, etc., del propio investigador a lo largo del proceso (Blández, ibídem).

\section{Cuaderno de notas}

No era más que una libreta que siempre me acompañaba en la que iba anotando detalles imprevistos, pensamientos espontáneos e inesperados, hechos... (Martínez, op. cit.). El desarrollo de su contenido se traduce al diario de campo e una forma más elaborada y rica en detalles. 


\section{Medios audiovisuales}

Cuando se contaba con el permiso expreso de los interlocutores (ya sean entrevistados o ponentes) se procedió a grabar sus informaciones y comentarios. Como se comprobará en algún momento de la tesis, suele ocurrir que no todos los entrevistados han querido que sus palabras queden registradas (Martínez, op. cit.).

Con posterioridad a las entrevistas o ponencias, estos documentos sonoros se transcribieron y se devolvieron para confirmar la veracidad de la información recogida. En el caso de ponencias de expertos, al ser tantos y tan difícil su localización una vez concluido el curso correspondiente, se optó por triangular la información con otros asistentes a las ponencias. Para ello, al inicio de cada curso, entablaba conversación con algún participante al que le trasladaba este proceso para poder contar con su colaboración. Este procedimiento lo repetía si encontraba reticencias por parte del sujeto consultado.

\section{3. - RIGOR DE LA INVESTIGACIÓN}

Independientemente de que en algún capítulo se planteen aspectos relacionados con el rigor acerca del uso de determinadas técnicas de obtención de información (como es el caso de la validez de los cuestionarios), utilizo ahora el concepto de rigor, aplicado a toda la tesis, en los términos que lo emplea Álvarez-Gayou (2003, p. 206) para referirse a la seguridad de que la investigación que tenemos entre manos sea "sólida", y por tanto cumpla con los requisitos de una "buena investigación cualitativa".

Antes de seguir, conviene remarcar que el conocimiento de carácter interpretativo que se genera con esta investigación es totalmente fiel al asunto investigado. Asimismo, todas las perspectivas aportadas contribuyen a desarrollar un grado máximo de verdad entre lo que se narra y la realidad de investigada de sus participantes (González Monteagudo, 2000, p. 239), es decir, estamos en condiciones de 
asegurar el grado máximo de verdad existente entre lo que se narra y la realidad investigada.

El poder ratificar o apoyar los datos obtenidos en criterios seguros ha sido propio de las corrientes positivistas y eso se ha traducido en críticas a la investigación cualitativa (González Monteagudo, op. cit.), y más en cuanto que los resultados obtenidos mediante su empleo se ven cuestionados con frecuencia (Cortés, 1997). Así pues, se hace necesario "objetivizar" la propia investigación (Anguera, 1986). Esta necesaria objetividad se equipara con calidad del estudio y esta, a su vez, con su rigor científico, fiabilidad, credibilidad, etc. (Sandín, 2000, p. 225). De todos estos conceptos, el más utilizado es el de «validez», de tal suerte que "la investigación no válida, no es verdadera" (ibídem).

Para otros (Anguera, op. cit., p. 34), la objetividad de la investigación tiene dos componentes fundamentales: la fiabilidad y la validez. En definitiva, en todo este asunto de generar conocimiento seriamente considerado por la comunidad académica, los hay que sitúan como crucial que los hallazgos puedan ser catalogados como válidos y confiables (Cortés, 1997, p. 78).

Para que la credibilidad de la investigación cualitativa asociada a este paradigma interpretativo cuente con el máximo de garantías, es necesario tener en consideración una serie de criterios que sostengan dicha credibilidad (González Monteagudo, op. cit., p. 240). Por ello, tomando como referencia los criterios que Guba (1983) y Guba y Lincoln (1985) proponen (citados en González Monteagudo, op. cit., p. 241), justificaré la calidad de esta tesis.

Los conceptos que estos autores emplean son: credibilidad, transferibilidad, dependencia y confirmabilidad. Estos conceptos se identifican con los términos convencionales de validez interna, validez externa, fiabilidad y objetividad respectivamente (ibídem). 
Con el propósito de aclarar estas cuestiones, reproducimos el cuadro (Tabla 1) que presenta Sandín ${ }^{18}$ (op. cit., p. 230) acerca de los términos de los criterios de calidad en la investigación cualitativa.

\begin{tabular}{|c|c|c|}
\hline Aspecto & Término convencional & $\begin{array}{c}\text { Guba y Linclon (1985) } \\
\text { Guba (1989) }\end{array}$ \\
\hline Valor de verdad & Validez interna & Credibilidad \\
\hline Aplicabilidad & Validez externa/Generalización & Transferibilidad \\
\hline Consistencia & Fiabilidad & Dependencia \\
\hline Neutralidad & Objetividad & Confirmabilidad \\
\hline
\end{tabular}

Tabla 1. Términos convencionales y alternativos de criterios de calidad en la investigación cualitativa (extraído de Sandín, 2000, p. 230)

Para Del Villar (1994), la credibilidad de la investigación educativa está ligada a los conceptos de validez interna, validez externa, fiabilidad y neutralidad.

Por cierto, aunque la ética de la tesis será abordada posteriormente, FernándezBalboa (1997, p. 104) plantea el rigor empírico como uno de los valores éticos de cualquier investigación. Para este autor, los criterios que otorgan rigor a una investigación son: Validez interna o credibilidad del estudio, validez externa (generalización) o aplicabilidad de los resultados a otros contextos, replicabilidad del diseño y de los resultados y, por último, objetividad o neutralidad de los puntos de vista y de los resultados.

Es el momento de pasar a abordar con detenimiento el papel de cada uno de ellos en la tesis.

\footnotetext{
${ }^{18}$ En la tabla original Sandín añadía en otra columna la propuesta realizada por Miles y Huberman (1994). La hemos descartado por innecesaria para el propósito con el que utilizamos dicha tabla.
} 


\subsection{1.- CREDIBILIDAD}

Entendida en términos de "isomorfismo entre los datos recogidos por el investigador y la realidad" (Colás, 1992c, p. 275). Empleando la terminología convencional nos situaríamos ante la validez interna de la investigación, la cual se ha aumentado mediante la utilización de los siguientes procedimientos:

a) Observación prolongada: algunas de las fases de la investigación realizadas han sido ejecutadas durante largos periodos de tiempo con el propósito de recabar la mayor cantidad de datos posibles. En otras fases, aunque el proceso se haya ejecutado de manera discontinua (cursos de formación), se ha obtenido mucha información válida para los propósitos de la tesis. A medida que avanzaba el periodo de obtención de datos, las informaciones acaecidas iban siendo ratificadas, en la mayoría de las ocasiones, las unas con las otras.

b) Confrontación de datos con los actores: referido al hecho de contrastar los datos conseguidos con los actores de las investigaciones. Las entrevistas, transcripciones de ponencias y debates posteriores... han sido dadas a conocer a sus protagonistas (principales o secundarios) para que aporten su beneplácito o desavenencias al respecto. Este proceso se percibe como muy cercano al de la triangulación de datos de personas propuesto por Bisquerra (1989, p. 265).

En ese sentido, este momento de la investigación se ha planteado como una especie de auditoría (Cortés, 1997, p. 79). Auditoría interna puesto que parte de los participantes han revisado la recolección de la información con el propósito de ratificarla. Pero también auditoría interna en su forma de amigo crítico (ibídem) ya que "dos cabezas piensan más que una". Esta ayuda ha contribuido a detectar errores, debilidades o carencias, durante parte del proceso constituyéndose como una revisión crítica con el único pretexto de mejorarlo.

Las características que ha tenido el amigo(s) crítico(s) de esta tesis han sido (Sagor citando en Cortés, op. cit., p. 80): 
- No ha sido participante como tal del estudio.

- Ante todo, y por encima de todo, ha sido un colega (entendido en términos de profesión) positivo que ha aportado una visión crítica de lo investigado con el propósito de ayudar y mejorarlo.

- Ha sido un colaborador voluntario, no forzado.

- Su actuación ha sido totalmente honesta.

- Se ha mantenido ocultas todas las identidades de los amigos críticos que han participado en esta tesis.

- Se le ha ofrecido toda la información complementaria que haya solicitado, ya sea de forma oral o en cualquier otro formato.

c) Triangulación: se trata de un procedimiento orientado a contrastar la información desde distintas puntos de vista (Rodríguez et alia, 2006, p. 293), siendo considerada por algunos autores como la técnica de análisis de datos más característica de la investigación cualitativa (Bisquerra, 1989, p. 264).

De la clasificación propuesta por Colás (1992c, p. 275) he empleado los siguientes tipos de triangulación:

- De fuentes: como se comprobará, en esta tesis se han empleado multitud de fuentes documentales (de variopintos formatos y procedencias). Toda la información recogida en ellas ha servido para ir corroborando las aparecidas en otras. Los datos se confirmaban a media que avanzaba el proceso. Cuando una fuente informaba acerca de un suceso, otra se ha empleado para ratificarlo. Es, por tanto, un proceso en el que es difícil delimitar con claridad el principio y el final.

- Interna: dentro de ella se puede situar la triangulación de datos por personas propuesta por Bisquerra (ibídem). Componentes del grupo de trabajo del que formé parte, amigo(s) crítico(s), director de tesis, colegas y compañeros de 
profesión... han contribuido a la elaboración de esta investigación contrastando y revisando en algún momento parte del proceso llevado a cabo ${ }^{19}$.

- Metodológica: basta con echar un vistazo a los múltiples instrumentos utilizados para la obtención de resultados convergentes en un mismo fin.

- Temporal: se da la especial circunstancia de que esta tesis ha estado en proceso de elaboración durante varios años. Esto, como contrapunto positivo, ha permitido comprobar la estabilidad de algunos de los resultados obtenidos inicialmente.

- Espacial: en la medida en que, aunque parte del estudio está circunscrito a Valladolid y su provincia (como parte de la comunidad de Castilla y León), se han conseguido algunos datos similares provenientes de fuera de ese ámbito.

Añado a esta tipología la triangulación con el marco teórico establecida por Cisterna (2005, p. 69) en la medida en que este apartado de la investigación ha supuesto una "fuente esencial para el proceso de construcción del conocimiento".

\subsection{2.- TRANSFERABILIDAD}

La transferabilidad de los resultados, o validez externa, se refiere al grado en que los conocimientos y descubrimientos hallados en la investigación se pueden aplicar a otros sujetos o contextos (Colás, op. cit., p. 274).

En palabras de Lincoln y Guba (citados en Rodríguez Monteagudo, op. cit., p. 241) "la capacidad para juzgar la transferencia del estudio se deja en las manos de los lectores", pero lo que sí se ha hecho para facilitar esta tarea es la de elaborar un extenso

\footnotetext{
${ }^{19}$ Como se habrá podido comprobar, esta triangulación se sitúa muy próxima al concepto de amigo crítico empleado anteriormente.
} 
recorrido teórico, ofrecer numerosos datos y realizar múltiples descripciones minuciosas de los procesos seguidos.

Por tanto, la transferabilidad se produce por la utilidad que esta investigación pudiera tener para otros profesores o investigadores (Del Villar, 1994, p. 31).

\subsection{3.- DEPENDENCIA}

De cara a garantizar la estabilidad de los datos, es decir, su fiabilidad, todo el contexto (global y específico), proceso y técnicas empleadas han sido descritos al detalle, lo cual pudiera permitir que la investigación sea replicada (Cortés, 1997, p. 79). Sin embargo, esta investigación, al igual que ocurre con los estudios de las ciencias sociales (ibídem) y las situaciones educativas (Del Villar, 1994, p. 31), es irrepetible. A lo que se le une la ausencia de uno de sus protagonistas clave: Virginia.

Además, se han ido solapando las técnicas empleadas para la obtención de información de manera que se han ido complementando y supliendo las carencias que alguna de ellas pudiera haber tenido.

\subsection{4. - CONFIRMABILIDAD}

Referida a la neutralidad de los resultados obtenidos, lo que supone dotar de objetividad a la investigación.

Quizás sea este el apartado más difícil de garantizar ya que se comprobará que la forma de interpretar el asunto está sesgada por las vivencias del autor. A estas alturas, afirmar que en la metodología cualitativa lo subjetivo se emplea como forma de generar conocimiento no es algo nuevo. Es más, algún autor plantea la inexistencia de la objetividad al presuponer que cualquier registro está contaminado (Lazarsfel y Barton citados en Anguera. op. cit., p. 34). 
De lo que se trata ahora es de identificar o conocer ese factor subjetivo al objeto de contrarrestarlo. Así se han recogido registros lo más concretos posibles, tales como citas textuales de fuentes documentales o protagonistas, se ha realizado la triangulación en sus diferentes modalidades y, además, ha existido (y existe) un compromiso reflexivo por parte de este investigador (González Monteagudo, op. cit., p. 242).

Asimismo, desde el primer momento se ha intentado dejar patente los puntos de partida y dilemas del investigador. Esta forma de neutralizar la subjetividad pudiera acercarnos aún más a la propia objetividad en la medida que no se pretende engañar a nadie y se permite que el lector la conozca de primera mano para poder interpretar o situarse ante la investigación.

Además, el asunto de la neutralización de la subjetividad se ha procurado resolver a través del desarrollo de los conceptos anteriormente abordados en este subapartado y del que a continuación le sigue acerca de la ética de la investigación.

Por último, destacar que la utilización del análisis de contenido como técnica de investigación, implica la posibilidad de obtener datos con un máximo de grado de objetividad. (Anguera, op. cit., p. 31).

\section{4.- ÉTICA DE LA INVESTIGACIÓN}

Por las características singulares y metodológicas de esta tesis, así como por el tipo de técnicas de obtención de datos que se han empleado, propias de la investigación cualitativa, es necesario, si no indispensable, tratar el asunto de la ética del estudio (Álvarez-Gayou, op. cit., p. 209).

Al igual que este autor, considero harto difícil establecer unas reglas concretas y suficientemente claras, más allá de lo que dicta el sentido común de un investigador, 
que solucionen los problemas éticos que pudieran ir apareciendo a lo largo del proceso (op. cit., p. 201). Por ello, emplearé algunos de los elementos que plantea Kvale (citado en ibídem) en torno a los que discutir este asunto.

\section{a) El consentimiento informado:}

Todas las personas que han sido objeto de estudio directo, ya sea por cuestiones referidas a su ámbito personal o al profesional, han sido convenientemente informadas de los propósitos de los encuentros y conversaciones. Así pues, han participado voluntariamente y han consentido que se emplee sus aportaciones.

Conviene señalar que esta actuación no se ha efectuado cuando los informantes eran ponentes que participaban en cursos o actividades similares de carácter formativo y público. Entendemos que tal circunstancia les sitúa al nivel que lo está cualquier otro tipo de fuente documental. Es más, se puede considerar su actuación como la de un agente experto en su rama de conocimiento que transmite saber a toda la comunidad para que cada uno de sus miembros obtenga de ella un beneficio en términos de mejora del quehacer profesional.

Además, los participantes que han consentido el uso de sus aportaciones han rechazado la idea de tener que firmar un documento autorizando dicho uso por considerarlo totalmente innecesario, mostrando de esta manera un mayor nivel de confianza en el investigador y su trabajo.

\section{b) Confidencialidad de los informantes:}

En primer lugar, cuando cualquier participante que ha sido requerido por el investigador para formar parte en la investigación, desde su ámbito personal o profesional, ha dado su consentimiento para que se la identifique, así se ha realizado. En caso contrario, se ha respetado la decisión y la identidad de la persona no ha sido divulgada. 
En segundo lugar, los ponentes o expertos que fueron identificados en los programas oficiales de las actividades formativas en las que tomaron parte, también lo han sido en esta tesis. No ocurre lo mismo con aquellos otros conferenciantes que no aparecían en programa o documento oficial alguno. Si no se les ha solicitado expresamente su consentimiento para ser identificados (y mostrado su posterior conformidad), permanecerán en el anonimato.

Por lo que respecta a los centros, se han mantenido ocultas las denominaciones de la casi totalidad de los que han participado en esta investigación (entrega de programaciones didácticas, cumplimentación de cuestionarios en sus dos acepciones: de profesorado de Educación Física y de profesorado en general...). Tan solo aparece el centro en el que formé un grupo de trabajo con otros compañeros de departamento y que fue mi destino profesional durante más de una década.

Por último, aunque se recordará en el capítulo correspondiente, todos los cuestionarios empleados han sido totalmente anónimos.

\section{c) Consecuencias:}

La intención de la investigación no es otra que la aportar conocimiento a nuestro saber disciplinar específico. El riesgo al que las personas que aquí son objeto de estudios o participan de alguna forma en la elaboración del mismo, es inexistente. Es más, los familiares de Virginia consideran el uso de su identidad como una forma de reconocimiento y les llena de orgullo y satisfacción saber que forma parte de un estudio de estas características.

\section{d) Papel del investigador:}

Creo haber tenido la suficientemente sensibilidad para intuir o detectar posibles problemas éticos que pudieran acontecer en algún momento del proceso. Esto 
sitúa mi actuación en un plano de responsabilidad hacia lo descubierto o conseguido y el cómo lo he realizado y dado a conocer.

Para finalizar, de lo que no debe haber duda alguna es acerca de mi honestidad. Este valor ético de la investigación (Fernández-Balboa, 1997 op. cit. 104) impregna toda la tesis pues en todo momento he reflejado la verdad de lo investigado.

Así pues, tras la exposición de todos estos matices metodológicos, doy por cumplida mi responsabilidad como investigador hacia los asuntos éticos que se derivan de todo el proceso de elaboración, diseño y exposición de esta tesis. 


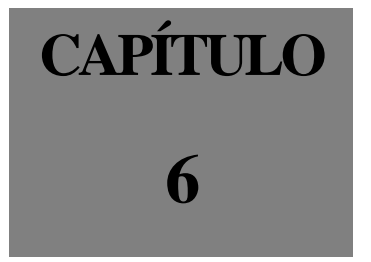

CONFIGURACIÓN DEL MARCO TEÓRICO-LEGAL DE LA EXENCIÓN 
Entendemos que la mejor forma de poder acometer con profundidad un estudio sobre la exención tiene que partir de una aproximación al concepto y usos más frecuentes de dicho término. En definitiva, consideramos que se ha de acotar el contexto legislativo y del saber científico en el que tiene lugar su presencia.

Así pues, lo primero será desgranar las normas que lo regulan ${ }^{20}$. Como veremos, la dispensa de la Educación Física dejó paso a la adaptación curricular en la etapa obligatoria de la E.S.O., pero en el Bachillerato se deja la puerta abierta a la entrada de la exención. Asimismo, comprobaremos que hay otras fórmulas legislativas que, desde nuestro planteamiento, "enmascaran" la exención de las clases de Educación Física. Por todo ello, el esclarecimiento del mapa legislativo que concierne a nuestro objeto de estudio es clave para poder abordarlo posteriormente con absoluto rigor de apreciación.

Al mismo tiempo, es obligado conocer qué nos dice y aporta el saber científico al respecto de esta práctica, lo cual incluye conocer quién o qué puede estar contribuyendo a su mantenimiento, ya sea interpretando la exención en su sentido más conocido y "habitual", o encubierta en cualquier otro tipo de fórmula. Comprobaremos que su presencia (y uso) sigue manteniéndose como una forma de respuesta a un tipo de alumnado muy concreto, a lo cual se suma que el propio saber popular acepta y considera la exención como un término que para nada está en desuso.

\footnotetext{
${ }^{20}$ Durante el desarrollo del apartado legislativo veremos que algunas de las normas que aparecen ya no están en vigor, mientras que otras sí. De ahí que, en determinados momentos de la exposición, aunque la conjugación de algunos verbos se haga en tiempo pasado por la fecha de publicación de la norma, ha de entenderse que también se debe realizar en presente si no ha sido derogada.
} 


\section{1.- MARCO LEGAL: DE LA “DISPENSA" A LA ADAPTACIÓN CURRICULAR (E.S.O.) Y LA “EXENCIÓN”(BACHILLERATO)}

En la normativa que regula la exención o dispensa hay un antes y un después de la entrada en vigor de la LOGSE. Sin embargo, como se verá más adelante, la puesta en marcha de las pertinentes adecuaciones legislativas a dicha ley en materia de alumnos con necesidades educativas especiales asociadas a alguna discapacidad en el área de Educación Física fue tardía en su elaboración y aplicación.

Así, nos encontramos que la principal pauta legislativa en este tema se limitaba a una Orden de 1995, concisa en sus mandatos -termina con la vía de la dispensa en E.S.O. y Bachillerato- y poco explícita en su exposición, por lo que la intervención de los departamentos de los institutos puede ser llevada a la práctica de diversas maneras. Sin embargo, hay otros mandatos legales de aplicación exclusiva en el Bachillerato que contemplan la posibilidad de la exención, lo que pudiera derivar en el trasiego de las normas de una a otra etapa educativa.

En este apartado analizaremos leyes y normas que de alguna forma regulan y/o plantean la dispensa o exención en el área de la Educación Física ${ }^{21}$ (en cualquiera de las formas que interpretamos, incluida la convalidación), y también algunas de las que se centran en las adaptaciones curriculares y/o atención a los alumnos con necesidades educativas especiales en su forma más genérica. También repasamos algunas medidas y

\footnotetext{
${ }^{21}$ A pesar de lo dicho en la nota anterior, en lo que respecta a este apartado, no damos importancia al hecho de que a día de hoy estén o no vigentes, lo realmente significativo es que se hayan dictado con posterioridad a la fecha de publicación de la LOGSE y, sobre todo, de la Orden de 10 de julio de 1995 (hasta su derogación por la Orden EDU/849/2010).
} 
actuaciones relacionadas con este asunto que otras Comunidades Autónomas han elaborado en el ejercicio de sus competencias en materia de educación.

\subsection{1.- ACOPIO DE LA LEGISLACIÓN}

Aunque la legislación que regula el tema que nos ocupa es muy escasa, su consecución no fue una tarea fácil.

El arranque fue a través de Internet, en donde obtuve las primeras pistas sobre las normas que regulan este tema.

Para buscar la norma más antigua, de 1961, me dirigí al Ayuntamiento de la localidad donde trabajo. No obtuve ningún fruto.

Decidí entonces indagar en el Ayuntamiento de Tordesillas, en donde sabía con certeza, por haber trabajado hace años allí, que tenían a disposición del público el ARANZADI o Repertorio Cronológico de Legislación, documento que recoge el contenido de los todos los BOEs desde sus inicios, y que suele estar agrupado en volúmenes por años.

Allí, muy amablemente, un Auxiliar de la alcaldía atendió mis peticiones. Al comentarle lo que estaba buscando, me dijo desconocer su paradero actual, pues hacía tiempo que habían hecho limpieza y modificación de algunas dependencias. A pesar de todo, buscó en el despacho del Secretario sin conseguir resultados. Luego me llevó a una sala para que, por mi cuenta, intentase comprobar si allí estaba lo que buscaba. Como no fue así, me llevó a los sótanos del Ayuntamiento. En el primero de ellos no encontramos nada. En el segundo, tampoco. Me condujo a otra sala superior, y allí, por mi cuenta, busqué entre todos los ejemplares hasta que, ipor fin!, en el último de los rincones apareció el tan preciado y deseado tomo de 1961. 


\subsection{2.- Orden 31 de julio de 1961 (M․ Educ. Nac.). INSTITUTOS} NACIONALES DE ENSEÑANZA MEDIA. Dispensas de educación física. (BOE 15-09-1961) ${ }^{22}$

Como se desprende del título de la propia Orden, la exención, se expresa en términos de dispensa de la Educación Física. La respuesta educativa que se otorgaba a determinados alumnos era en forma de una dispensa por la que se eximía de las lecciones teóricas y prácticas de la asignatura y de las pruebas de ésta, así como de las actividades deportivas.

De acuerdo con esta norma, existían una serie de motivos por lo que se podía obtener la dispensa de la Educación Física. Las causas eran los siguientes:

a) Imposibilidad física.

b) Convalidación de estudios.

c) Pertenencia a un Instituto Religioso con obligación de llevar el hábito del mismo.

d) Haber cumplido 25 años de edad en el año natural en que se desarrollan las pruebas $^{23}$.

La dispensa por imposibilidad física, que es la que tiene que ver con el tema de esta tesis, se concedía a aquellos alumnos que padecían un defecto, lesión o enfermedad que no les permitía practicar la Educación Física o el deporte sin ningún tipo de molestia sensible o sin perjuicio de su salud. La petición correspondía al propio interesado que la formulaba junto con su matrícula.

\footnotetext{
${ }^{22}$ Recomendamos la lectura de Hernández y Martínez (1989), en la que nos ofrecen una serie de consideraciones acerca de los cuatro casos o supuestos para los que esta Orden contempla la exención.

${ }^{23}$ Para Hernández y Martínez (op. cit., p. 51), supone algo insólito que se consagre la ignorancia a partir de los veinticinco años, como si el aprender unas técnicas o adquirir unos conocimientos estuvieran vinculados a la edad cronológica, es decir, que no parece acertado que la edad esté reñida con la adquisición de conocimiento.
} 
La Orden distingue entre dispensa permanente y temporal según sea la naturaleza del motivo que la ocasione. De esta forma se gradúa en el tiempo el efecto del impedimento o imposibilidad física.

Para determinar si verdaderamente existía dicha imposibilidad, se debía pasar un reconocimiento médico competente, pudiendo ser concedida de oficio o a petición de parte. Además, no había lugar a la renuncia de esa declaración de imposibilidad física salvo previo expediente informativo de al menos dos médicos en sentido contrario. Entendemos que, aunque el alumno (o su familia) no desease estar exento de Educación Física, esta circunstancia podía ser inevitable si así lo dictaminaba un médico o, en todo caso, complicada de sortear.

La concesión de la dispensa debía constar en el expediente académico del alumno, así como la aceptación de la renuncia (si la hubiera).

Finalmente, hacemos nuestras las palabras con las que Hernández y Martínez (1989, p. 52) definen lo que supone ser un alumno exento al amparo de esta Orden, la cual se mantuvo en vigor durante más de tres décadas:

“...el desarrollo de la Orden Ministerial..., crea la figura del alumno «exento» como un individuo incapacitado para entender, conocer y practicar sobre todo aquello referido al área de la educación física y deportiva, tanto en sus aspectos positivos como negativos hacia su propia persona, facilitando la perpetuación de esta actitud durante el resto de su vida." 
6.1.3.- ORDEN de 10 de julio de 1995 por la que se regula la adaptación del currículo de la Educación Física para los alumnos con necesidades educativas especiales en el Bachillerato Unificado y Polivalente, en la Formación Profesional de primer y segundo grados y en la educación secundaria, así como la dispensa de la misma para los mayores de veinticinco años (BOE 15-07-1995 ${ }^{24}$ )

Con la aparición de la LOGSE, emergen dos principios claves: la atención a la diversidad (el sistema educativo se debe adaptar al alumno y no al revés, por lo que la figura de la exención no tiene cabida jurídicamente) y la integración (el niño que tenga o no problemas, debe hacer, participar y cursar el área en las mismas condiciones que el resto), ambos contrarios a la exención. Sin embargo, nadie parece caer en la cuenta de que no estaba derogada la O.M. de 1961 que consentía y amparaba la exención en Educación Física, por lo que hasta 1995 hemos convivido con una Ley Orgánica con unos principios contrarios a la exención y con una Orden que la permitía.

Por ello, esta norma legislativa fue, sin lugar a dudas, la piedra angular de nuestra área en el tratamiento a los alumnos con necesidades educativas especiales ${ }^{25}$. Se publica treinta y cuatro años después de la anterior, y en ella sí se utiliza la expresión alumnos exentos para describir lo que hasta esa fecha estaba ocurriendo con un determinado tipo de estudiantes que, dadas sus especiales circunstancias, sí podrían, en el marco de la LOGSE, seguir una parte importante de los contenidos y alcanzar una buena parte de los objetivos del área y, sin embargo, no lo estaban haciendo como consecuencia de la vigencia y aplicación de la Orden de 1961 antes comentada.

En relación con esta cuestión temporal hemos de aclarar que con anterioridad a 1995 algunos profesores de Educación Física ya empezaban a manifestar su rotunda oposición a esta norma dictaminada en 1961. Así pues, las actuaciones, actitudes,

\footnotetext{
${ }^{24}$ En el Anexo 1 se encuentra una copia literal de esta Orden.

${ }^{25}$ Nos resulta insólito comprobar que alguna fuente bibliográfica pase por alto esta norma cuando aborda el tema legislativo en Educación Física para los alumnos con necesidades educativas especiales (vid.: Gallego, 2003a).
} 
perspectivas... y propia formación del profesorado parecían llamar a la puerta del cambio legislativo. Este asunto será convenientemente abordado en el apartado 6.2.1.

Continuando con el análisis de la Orden, nos encontramos que con el argumento de que los currículos de estas etapas educativas contienen objetivos, contenidos, criterios u orientaciones para la evaluación que trascienden la práctica de ejercicio físico de distinto signo se defiende que, con las oportunas adaptaciones curriculares, son hasta cierto punto asequibles para la generalidad de los alumnos con necesidades educativas especiales asociadas a discapacidad motora o sensorial, temporal $\mathrm{o}$ permanente. Intuimos que, sobre todo, se están refiriendo principalmente a los de tipo conceptual y, en menor mediada, a los actitudinales.

Teniendo en cuenta el modelo de desarrollo curricular de las leyes educativas (llámesele LOGSE o LOE), correspondía a los Departamentos de Educación Física elaborar las adaptaciones curriculares oportunas para cada caso. Para ello, se debe tener presente el certificado médico aportado por el alumno, así como el dictamen del Departamento de Orientación o, en su defecto, del equipo de Orientación Educativa y Psicopedagógica que corresponda. En este marco, se han de evaluar los aprendizajes conforme a los objetivos y contenidos para ellos propuestos en la adaptación curricular correspondiente.

El único motivo que aún perdura de la Orden de 31 de julio de 1961 para dispensar de la Educación Física concierne a los mayores de veinticinco años o que cumplan esa edad en el período de formalización de la matrícula ${ }^{26}$, momento en que se debe solicitar ante la Dirección del Centro.

La solicitud de aplicación de la correspondiente adaptación curricular ha de ser presentada por los alumnos (si son menores de edad, por sus padres o responsables

\footnotetext{
${ }^{26}$ Vid.: Nota 23 (referente a lo de la ignorancia a partir de 25 años).
} 
legales) ante la Dirección del Centro, acompañándose de los certificados médicos oportunos $^{27}$.

Como es lógico, esta Orden deroga a la anterior de 1961 (y solo a ella).

Por último, hay que matizar que esta norma ha sido derogada por la Orden EDU/849/2010, de 18 de marzo, por la que se regula la ordenación de la educación del alumnado con necesidad de apoyo educativo y se regulan los servicios de orientación educativa en el ámbito de gestión del Ministerio de Educación, en las ciudades de Ceuta y Melilla (BOE 06-04-2010). Por tanto, la atención a los alumnos con necesidades educativas especiales en la materia de la Educación Física se desarrollará en los términos genéricos previstos para cada etapa previstos en esta orden, es decir, la Educación Física deja de tener un desarrollo normativo estrictamente particular, salvo en lo que respecta a las normas que más adelante trataremos.

Pese a ello, por su contenido, especificidad y vigencia durante casi cinco lustros, será la principal norma tenida en cuenta en el desarrollo de la tesis.

\subsection{4.- CONVALIDACIONES: ¿OTRA FORMA DE EXENCIÓN?}

En este apartado reunimos algunos ejemplos de normas que plantean la convalidación de la materia/área de Educación Física en función de la posesión de determinados estudios o condiciones especiales.

Comenzamos con la Orden de 2 de enero de 2001, del Ministerio de Educación, Cultura y Deporte, por la que se establecen convalidaciones entre las

\footnotetext{
${ }^{27}$ No obstante, tal y como señala en el artículo 37.2 de la propia Ley 1/1990, de 3 de octubre, de Ordenación General del Sistema Educativo (LOGSE), "La atención a los alumnos con necesidades educativas especiales se iniciará desde el momento de su detección...”. Es decir, en caso de no ser solicitada por el interesado la aplicación de una adaptación curricular, se presupone que el centro, bien a través del Departamento de Orientación o del propio de Educación Física y Deportiva, podría poner en marcha los mecanismos que den lugar a la determinación y elaboración de las adaptaciones curriculares más adecuadas.
} 
enseñanzas de régimen especial de Música y de Danza y determinadas áreas de Educación Secundaria Obligatoria (BOE 6-01-2001) nos recuerda que la finalidad de las enseñanzas artísticas de régimen Música y Danza es proporcionar a los alumnos de una formación artística de calidad, garantizando la futura cualificación profesional de quienes las cursen $^{28}$. Como consecuencia de ello, las Administraciones educativas han establecido unos currículos de grado medio cuyos tiempos lectivos suponen, tanto una considerable cantidad de horas de presencia física en el centro por parte de los alumnos, como unos niveles de exigencia que requieren una intensa dedicación al estudio para ser alcanzados.

Por otro lado, se apunta que los objetivos del área de Educación Física de la Educación Secundaria Obligatoria y los de las enseñanzas de régimen especial de Danza, sin ser idénticos, coinciden en parte, por lo que es aconsejable la convalidación entre ambas enseñanzas para los alumnos que las cursen simultáneamente, consiguiendo así aligerar la carga lectiva a la que deben someterse y permitiéndoles compatibilizar ambas enseñanzas con un adecuado nivel de rendimiento.

Obsérvese que esta Orden es equiparable a uno de los supuestos o motivos por el que se concedía la dispensa en Educación Física recogido en la Orden Ministerial de 31 de julio de 1961, "convalidación de estudios". Sobre esta posibilidad, subrayamos que la Orden de 10 de julio de 1995 no decía nada al respecto, de lo que se pudiera deducir que es una decisión que, de alguna forma, nos devuelve al pasado. No obstante, el porqué de su existencia lo podemos localizar en las palabras de Hernández y Martínez (1989, p. 51), los cuales suscriben que este es el único motivo o argumento justificado por el que se puede conceder la exención en Educación Física, ya que consideran que una vez superado el nivel del que se trate, lo supera [el alumno] demostrando unas aptitudes y unos conocimientos que no tiene que volver a repetir y no se trata además de mantener una forma física sino de educar físicamente.

\footnotetext{
${ }^{28}$ Recogido en el artículo 38 de la Ley 1/1990.
} 
De lo que no cabe duda es que se ha recuperado o restaurado la convalidación de estudios para hacer que un alumno esté libre (o lo que es lo mismo, dispensado) de las clases del área de Educación Física de las enseñanzas de régimen general ${ }^{29}$.

Esta Orden quedó derogada con la entrada en vigor de la siguiente norma que pasamos a desglosar a continuación.

Se trata del Real Decreto 242/2009, de 27 de febrero, por el que se establecen convalidaciones entre las enseñanzas profesionales de Música y de Danza y la Educación Secundaria obligatoria y el Bachillerato, así como los efectos que sobre la materia de Educación física deben tener la condición de deportista de alto nivel o alto rendimiento y las enseñanzas profesionales de Danza (BOE 28-02-2009).

Este documento dedica su artículo 4 a la exención de la materia de Educación Física de la Educación Secundaria Obligatoria y del Bachillerato. Así pues, la exención explícita, que no convalidación como se verá en apartados posteriores, se posiciona como una realidad en nuestro marco legislativo actual.

¿Quiénes pueden acogerse a esta norma? Se establece que podrán solicitar la exención de la materia de Educación Física de la Educación Secundaria Obligatoria y del Bachillerato, quienes cursen estos estudios y simultáneamente acrediten tener la condición de deportista de alto nivel o de alto rendimiento, o realizar estudios de las Enseñanzas Profesionales de Danza.

Esta norma emplea el término exención con su significado más habitual ${ }^{30}$, ya que se concreta que el alumnado exento de la materia de Educación Física no será evaluado de esta materia y, por tanto, siguiendo esta misma lógica, la materia de

\footnotetext{
${ }^{29}$ En el apartado siguiente recogemos otras normas de ámbito autonómico que plantean esta línea de las convalidaciones.

${ }^{30}$ Según la Real Academia Española (2001): 1. Libre, desembarazado de algo. Exento de cuidados, de temor. 2. Dicho de una persona o de una cosa: No sometida a la jurisdicción ordinaria. Obispado, lugar exento.
} 
Educación Física no será computada para el cálculo de la nota media del Bachillerato, en el caso del alumnado al que se le haya reconocido la exención en esta materia ${ }^{31}$.

Esta norma responde al desarrollo normativo que se cabía esperar del Real Decreto 971/2007, de 13 de julio, sobre deportistas de alto nivel y alto rendimiento (BOE 25-07-2007). En su artículo 9 se recogen las medidas para promover la formación y educación, y facilitar el acceso a las diferentes ofertas formativas del sistema educativo, para los deportistas de alto nivel y alto rendimiento. Dentro de estas medidas se estipula que en la etapa de Educación Secundaria Obligatoria y en el Bachillerato la materia de Educación Física será objeto de posible exención, previa solicitud del interesado, para aquellos deportistas que acrediten la condición de deportista de alto nivel o alto rendimiento.

Por último, estas dos normas estatales sirven como sustento legislativo para formular la Orden EDU/2739/2009, de 1 de octubre, por la que se determinan las convalidaciones entre las enseñanzas profesionales de Música y de Danza y la Educación secundaria obligatoria y el Bachillerato, y la exención de la Educación Física, en el ámbito de gestión del Ministerio de Educación (BOE 10-10-2009). Su desarrollo, en lo que respecta a la exención de la materia de Educación Física de la Educación Secundaria Obligatoria y del Bachillerato, es exactamente el mismo que el del ya comentado Real Decreto 242/2009.

\footnotetext{
${ }^{31}$ En buena lógica, esta situación es la que cabe esperar de una exención de estas características, es decir, que si por la aplicación de esta norma los deportistas de alto nivel están exentos de la Educación Física, también deberán estar exentos de obtener una nota en esa materia. Al parecer esta práctica no era la habitual tiempo atrás. Tal es el caso de Tania Lamarca, ganadora de una medalla de oro en Gimnasia Rítmica en las Olimpiadas de Atenas de 1996, ya que, como ella misma afirma "nunca íbamos a clases de Educación Física pero siempre nos ponían sobresaliente y eso ellos, los demás, no lo entendían. Supongo que pensaban que, como la profesora era del gremio, nos aprobaban sin más..." [corría por entonces el año 1995, aclaración mía] (Lamarca y Gallo, 2008, p. 34)
} 


\subsection{5.- LA EXENCIÓN IRRUMPE EN EL BACHILLERATO}

En primer lugar, conviene volver a insistir en que la mencionada Orden de 10 de julio de 1995 era de aplicación, entre otros, en los centros de Educación Secundaria. Como todos sabemos, esta enseñanza de régimen general comprende las etapas de Educación Secundaria Obligatoria, el Bachillerato y la Formación Profesional de Grado Medio $^{32}$. Por lo tanto, la fórmula de la dispensa se encontraba cerrada no solo para la E.S.O., sino también para el Bachillerato.

En primer lugar, la Orden de 14 de febrero de 1996, que regula la evaluación del alumnado con necesidades educativas especiales que cursan las enseñanzas de régimen general establecidas en la Ley Orgánica 1/1990, de 3 de octubre, de Ordenación General del Sistema Educativo (BOE 23-02-1996), aunque en la E.S.O. no vislumbre la posibilidad de la exención para los alumnos con necesidades educativas especiales asociadas a discapacidad motora o sensorial, temporal o permanente, y la respuesta educativa para estos alumnos se exprese en términos de adaptación curricular (para lo cual será necesario tener en cuenta los certificados médicos, así como los del Departamento de Orientación), en su apartado quinto, al abordar las exenciones en Bachillerato, establecía que la exención en determinadas materias a que hace referencia la disposición adicional primera del Real Decreto 1179/1992, de 2 de octubre, por el que se establece el currículo del Bachillerato, podrá acordarse, por la Dirección General de Renovación Pedagógica, exclusivamente para los alumnos con problemas graves de audición, visión y motricidad cuando circunstancias excepcionales, debidamente acreditadas, así lo aconsejen. Esta Orden fue derogada por la Orden EDU/849/2010 y en ella lo que se recoge es que se podrán realizar adaptaciones del currículo en la materia de Educación física al alumnado que así lo requiera, por presentar necesidades educativas especiales derivadas de discapacidad o por condiciones personales de salud.

Con posterioridad, el Real Decreto 938/2001, de 3 de agosto, por el que se modifica el R.D. 1179/1992, de 2 de octubre, por el que se establece el currículo del

\footnotetext{
${ }^{32}$ Artículo 3.2 de la Ley 1/1990 (LOGSE).
} 
Bachillerato $^{33}$ (BOE 07-09-2001), se expresaba en los mismos términos que la norma a la que sustituye ya que, en su disposición adicional primera afirma que el $M E C$ establecerá, para aquellos alumnos con problemas graves de audición, visión y motricidad, el marco que regule las posibles adaptaciones curriculares y podrá autorizar, en su caso, la exención total o parcial en determinadas materias de Bachillerato.

Por la tanto, la exención, ya sea total o parcial, se contemplaba como una posibilidad en la Educación Física pues es una de las materias comunes del currículo de $1^{\circ}$ de Bachillerato, como se recoge en el desarrollo de dicho Real Decreto de 1992, y su posterior modificación de 2001.

Sin embargo, todo este panorama legislativo se renovará con la entrada en vigor del Real Decreto 117/2004, de 23 de enero, por el que se desarrolla la ordenación y se establece el currículo del Bachillerato (BOE 18-02-2004), pues deja sin efecto los anteriores Reales Decretos (1179/1992 y 983/2001) y todas las normas de igual o menor rango que se opongan a lo establecido en él ${ }^{34}$.

En su Disposición adicional segunda aborda las medidas de atención educativa y exenciones. Las diferencias con respecto a los anteriores radican en que ahora ya no se distingue entre exención total y parcial para los alumnos con problemas graves de audición, visión o motricidad, y que serán la Dirección General de Cooperación Territorial y la Alta Inspección quienes acordarán las exenciones que estimen oportunas en determinadas asignaturas en los términos que estén establecidos, cuando las circunstancias excepcionales, debidamente acreditadas, así lo aconsejen. Al igual que sucedía antes, las exención se hará figurar en el expediente académico del alumno y se adjuntará una copia de la resolución de la concesión de dicha exención.

\footnotetext{
${ }^{33}$ (BOE 21-10-1992).

${ }^{34}$ Por el Real Decreto 1318/2004, de 28 de mayo, por el que se modifica el Real Decreto 827/2003, de 27 de junio, por el que se establece el calendario de aplicación de la nueva ordenación del sistema educativo establecida por la Ley Orgánica 10/2002, de 23 de diciembre, de Calidad de la Educación, queda diferida al año académico 2006-2007 la aplicación de esta medida (BOE 29-05-2004). Este Real Decreto $117 / 2004$ será derogado en parte por el Real Decreto 1467/2007, de 2 de noviembre, por el que se establece la estructura del bachillerato y se fijan sus enseñanzas mínimas (BOE 06-11-2007).
} 


\subsection{6.- POCAS VARIACIONES EN LAS NORMAS AUTONÓMICAS}

En este apartado queremos exponer que algunas comunidades autónomas, a través de los desarrollos normativos que realizan en el ejercicio de sus competencias en materia educativa, se favorece explícitamente algún tipo de exención en Educación Física. Junto a ellas, como hemos hecho ya en el anterior apartado 6.1.4, también analizaremos la concesión de convalidaciones en nuestra área cuando un alumno ha cursado o cursa simultáneamente estudios de enseñanzas de régimen especial de Danza con enseñanzas de Educación Secundaria Obligatoria y Bachillerato. Como no podía ser de otra manera, todas las normas y resoluciones que examinaremos han sido publicadas con posterioridad a la Orden de 10 de julio de 1995.

\section{Exención de la Educación Física en el Bachillerato}

En primer lugar nos detendremos en la Orden Foral 266/2003, de 11 de junio, por la que se aprueban las instrucciones que van a regular, durante el curso 2003-2004, la organización y el funcionamiento de los centros docentes públicos que imparten las enseñanzas de segundo ciclo de Educación Infantil, Educación Primaria, Educación Secundaria Obligatoria, Bachillerato, Formación profesional y Programas de Iniciación Profesional (BONavarra 30-06-2003) que emite el Departamento de Educación y Cultura del Gobierno de Navarra. En su ANEXO III, referido, entre otros, a los Institutos de Educación Secundaria, articula un apartado dirigido a la exención y adaptaciones en la Educación Física.

Se establece que la exención solo está permitida por causas de edad (mayores de 25 años). Además, como viene siendo habitual, las solicitudes de las adaptaciones deberán formularse a la dirección del centro acompañadas de los pertinentes certificados médicos.

Sin embargo, en línea con lo establecido en el anteriormente comentado R.D. 1179/92 (derogado por el R.D. 117/2004), se contempla la exención en la etapa de 
Bachillerato para aquellos alumnos con problemas graves de motricidad cuando circunstancias excepcionales y debidamente acreditadas así lo aconsejen (resulta del todo evidente que el certificado médico es el documento imprescindible para la concesión de la exención).

En parecidas condiciones se expresa la Orden de 17 de mayo de 2002, por la que se dictan instrucciones para la aplicación del Decreto 41/2002, de 28 de marzo, por el establece el currículo del Bachillerato, en el ámbito de gestión directa de la Consejería de Educación y Juventud de la Comunidad Autónoma de Cantabria (BOCantabria 23-05-2002) ${ }^{35}$. En los casos de graves problemas de audición, visión y motricidad, debidamente acreditados, en los que no haya sido posible realizar una adaptación curricular $^{36}$ se plantea la posibilidad de conceder una exención en determinadas materias. Los directores de los centros tramitarán la propuesta al Servicio de Inspección de Educación, y este elevará las solicitudes a la Consejería de Educación y Juventud para que resuelva.

En esta línea de exenciones en la etapa postobligatoria nos podemos encontrar con más ejemplos tremendamente ilustrativos.

Así, el Decreto 138/2002, de 08-10-2002, por el que se ordena la respuesta educativa a la diversidad del alumnado en la Comunidad Autónoma de Castilla-La Mancha (BOCMancha 11-10-2002), nos encontramos que mientras en la Educación Obligatoria no podrá existir la exención en ninguna de las áreas en razón de necesidades educativas especiales, en el Bachillerato sí podrán tener lugar en determinadas materias para el alumnado con graves problemas de audición, visión y motricidad.

\footnotetext{
${ }^{35}$ En este mismo Boletín aparece la Orden de 17 de mayo de 2002, por la que se dictan instrucciones para la implantación del Decreto 40/2002, de 28 de marzo, por el que se establece el currículo de la Educación Secundaria Obligatoria en el ámbito de la gestión de la Consejería. En el su artículo 7, apartado 5, se recogen las condiciones para que se realicen las convalidaciones de las áreas de Música y Educación Física para los alumnos que cursen simultáneamente las enseñanzas de régimen especial de Música y Danza.

${ }^{36}$ En su favor hemos de decir que al menos bosqueja la posibilidad de adoptar este tipo de medidas.
} 


\section{Graduación de la exención: parcial y total}

La Viceconsejería de Educación del Gobierno de Canarias promulga la Resolución de 16 de julio de 1996 (BOC $\mathrm{n}^{\circ}$ 100, 16-08-1996) por la que se completan determinados extremos contenidos en la Resolución de la Dirección General de Centros de 20 de julio de 1995, que aprueba las instrucciones que regulan la organización y funcionamiento de los Centros de Enseñanzas Medias, dependientes de dicha Consejería.

Esta Resolución se hace eco de la Orden de 10 de julio de 1995 y corrobora que la exención total (o dispensa) solo está permitida a los alumnos mayores de 25 años o que cumplan esa edad en el periodo en que se formaliza la matrícula. De hecho, determina que cuando un alumno con seria disminución física o sensorial no pueda ejecutar algunos ejercicios o actividades será el Departamento de Educación Física el que elaborará la necesaria adaptación curricular significativa.

Sin embargo, previamente aclara que la exención en Educación Física tendrá exclusivamente la modalidad de exención parcial, la cual supone la dispensa a determinados ejercicios o actividades, pero el alumno deberá cursar los contenidos de la materia y aquellos otros ejercicios que con carácter general se encuentren programados, compatibles con la limitación documentalmente acreditada.

Por lo que se refiere al procedimiento para la concesión de la exención, cabe destacar que los padres o tutores presentarán en la Secretaria del centro, en el periodo de la matrícula o en el momento que sobrevenga la discapacidad, solicitud razonada, certificado médico y toda la documentación que se estime oportuna y que avale la petición. Posteriormente, será el Departamento de Educación Física, en un plazo de 10 días, el que emitirá un informe en el que se acepte o no la exención parcial solicitada, y que incluirá la propuesta de adaptaciones curriculares.

En 1999 nos encontramos con la Resolución no 194 de 4 de agosto, de la Dirección General de Centros, por la que se aprueban las Instrucciones de organización 
y funcionamiento de los Centros de Educación Obligatoria dependientes de la Comunidad Autónoma de Canarias ${ }^{37}$. El punto 13.3 está dedicado por entero a las exenciones o dispensas en determinados bloques de contenidos para alumnado con minusvalías. Entre las áreas que pudieran estar en esta situación se menciona a la Educación Física. A pesar de que propone la elaboración de una adaptación curricular significativa para los casos de importante disminución física o sensorial ${ }^{38}$,

Entre otros asuntos nos informa sobre el procedimiento a seguir cuando se trate de dispensa para realizar determinadas actividades físicas por presentar el/la alumno/a una discapacidad de carácter temporal o permanente (lo que más adelante aparecerá como dispensa parcial). Esta forma de dispensa, como viene siendo ya habitual, debe ser obligatoriamente certificada por informe médico.

Además, anuncia que será la Dirección del centro quien resolverá la solicitud de dispensa visto el informe favorable o no del tutor y del especialista, para lo cual se contará con la participación del Orientador del centro.

No obstante, también se nos advierte que siempre que la casuística específica de un determinado alumnado, avalada por el correspondiente informe de los expertos así lo aconsejase, podrá solicitarse dispensa total [énfasis mío] de una determinada materia a través del EOEP [Equipos de Orientación Educativa y Psicopedagógica] específico...

Otro ejemplo lo podemos encontrar, aunque no sea una norma como tal, en lo establecido en el "Régimen Jurídico del Bachillerato" de la Consejería de Educación de la Comunidad de Madrid, Subdirección General de Inspección Educativa ${ }^{39}$. En el

\footnotetext{
${ }^{37}$ No hemos podido confirmar la publicación de esta Resolución en el Boletín Oficial de Canarias. La fuente de la que nos hemos nutrido ha sido la siguiente dirección de Internet: http://www.educa.rcanaria.es/udg/cen/TextosRefundidos/TextoRefundidoCEO2003.pdf

${ }^{38}$ A tal respecto de la adaptación curricular esta Resolución nos remite a la Orden de 7 de abril de 1997, por la que se regula el procedimiento de realización de las adaptaciones curriculares de centro y las individualizadas, en el marco de la atención a la diversidad del alumnado de las enseñanzas no universitarias en la Comunidad Autónoma de Canarias (BOC 25-04-1997), la cual aconsejamos leer.

${ }^{39}$ COLOM VICH, M. (2003): Régimen jurídico del Bachillerato, en INSPECCIÓN DE EDUCACIÓN, Documentos de Trabajo, 7, Consejería de Educación de la Comunidad de Madrid.
} 
Capítulo 5, de Ordenación Académica, el punto 7 está dedicado a la "EDUCACIÓN ESPECIAL. EXENCIONES Y DISPENSAS". De forma general se nos informa que para los alumnos con graves problemas de audición, visión o motricidad, cuando circunstancias excepcionales, debidamente acreditadas así lo aconsejen, y una vez descartada la posibilidad de realizar adaptaciones curriculares, podrá acordarse la exención total o parcial en determinadas materias. Asimismo, se advierte que en ningún caso las exenciones, totales o parciales, podrán ser determinadas por los propios centros, la cual dependerá de la Dirección General de Ordenación Académica de dicha comunidad.

De manera específica para la Educación Física (apartado 7.5.2) nos encontramos que a pesar de que señala que la dispensa de cursar esta materia ha quedado limitada a los alumnos mayores de 25 años, se apunta la posibilidad de que en los casos de alumnos con necesidades educativas especiales asociadas a discapacidad motora o sensorial, temporal o permanente, se deberá adoptar el currículo de la materia sin que pueda declarársele exento de cursar la materia, pero sin perjuicio de la posibilidad de que el alumno solicite, tal y como se apunta en el anterior párrafo, la exención total o parcial $^{40}$. Como suele ser habitual, la solicitud de la adaptación curricular deberá ir acompañada de los certificados médicos correspondientes.

La Consejería de Educación y Cultura del Gobierno de la Comunidad de Murcia, al igual que ocurriera con el REAL DECRETO 117/2004, articula en el artículo 19, apartado 4, del Decreto 113/2002, de 13 de septiembre, por el que se establece el currículo del Bachillerato en la Comunidad Autónoma de la Región de Murcia (BORM $\mathrm{n}^{\mathrm{o}}$ 214, 14-09-2002) que la Consejería de Educación y Cultura podrá autorizar, para aquellos alumnos con problemas graves de audición, visión o motricidad, la exención total o parcial de determinadas materias de Bachillerato.

\footnotetext{
${ }^{40}$ No se acaba de entender muy bien este documento tan contradictorio ya que primero se nos dice que, de manera general, para un determinado tipo de alumno sí puede haber exenciones o dispensas de determinadas materias. Después viene a ratificar lo dicho en la Orden de 10 de julio de 1995 limitando esta opción para los mayores de 25 años y, por último, vuelve a abrir la puerta a la vía de la solicitud de exención o dispensa a pesar de aclarar que tal alternativa no exista.
} 
En definitiva, se contempla como una realidad educativa la existencia de la dispensa o exención, ya sea parcial o total, para todo aquello que un alumno con necesidades educativas especiales no pudiera hacer o practicar en función de sus limitaciones.

\section{La compatibilidad y convalidación como otra forma de exención}

La Comunidad de Murcia publicó la Orden de 27 de julio de 2004, por la que se establecen medidas para facilitar la compatibilidad de los estudios de Educación Secundaria con la práctica deportiva (BORM n 197, 25-08-2004). El objeto principal de esta Orden es establecer medidas para facilitar la compatibilidad de estudios de ESO y Bachillerato con la práctica de actividades de los deportistas de alto nivel y alto rendimiento de la Región de Murcia.

Entre las medidas establecidas recogemos las dos que más nos interesan. Por un lado se articula la adaptación curricular de la materia de Educación Física en la ESO, y por otro la exención parcial -sin aclarar en qué consiste esta- de la materia de Educación Física de primer curso de Bachillerato ${ }^{41}$. Además, en el primero de los casos se puntualiza que los alumnos estarán dispensados de realizar actividades físicas, y que la adaptación curricular se realizará según establezca la Administración Educativa. En definitiva, que no tendrán práctica.

Para los alumnos que se encuentren en alguna de esas medidas, el artículo 3 de dicha Orden recoge que quedarán liberados de la asistencia a las clases de la citada materia.

Después, con fecha de 27-08-2004 (BORM nº 199), aparece la Resolución de 28 de julio, de la Dirección General de Enseñanzas Escolares, por la que se establece el currículo de Educación Física para los alumnos que simultanean estudios de Educación Secundaria con la práctica deportiva. En ella, se explica que para que las anteriores

\footnotetext{
${ }^{41}$ Nos remite a la exención parcial prevista en el ya comentado artículo 19 del Decreto 113/2002, de 13 de septiembre, (BORM 14-09-2002)
} 
medidas apuntadas en la Orden de 27 de julio se apliquen a todos los alumnos con los mismos criterios es necesario establecer los aspectos fundamentales en los que basarse para poder evaluarles objetivamente. Es más, señala que el profesorado que imparta dicha área o materia deberá recoger en la Programación Didáctica las tareas a desarrollar, los criterios de evaluación y calificación que aplicará a este alumnado y los contenidos mínimos que recojan los aspectos fundamentales.

Esta Resolución, además de recoger el currículo de Educación Física para estos alumnos, señala que entre las tareas citadas anteriormente se encontrará la realización de trabajos relacionados con dicho currículo, y entre los instrumentos de evaluación deberán estar diversas pruebas teóricas que verificarán los conocimientos de los alumnos.

Acentúa, al igual que en la precitada Orden, que estos alumnos quedan liberados de la asistencia a las clases de Educación Física, e insta al profesor a facilitar a los alumnos implicados tanto los contenidos teóricos a desarrollar durante el curso como los criterios de calificación que se seguirán para su evaluación en el área o materia.

Estas dos normas legislativas que propone el Gobierno de la Comunidad de Murcia van más allá de las que hasta el momento nos hemos encontrado, de tal suerte que no solo decretan la adaptación curricular (E.S.O.) y la exención parcial (Bachillerato), sino que las equiparan en su concesión, desarrollo y evaluación, destacando por encima de todo la idea, nueva hasta ahora, de la liberación explícita de la asistencia a clase de Educación Física.

Sin abandonar aún esta Comunidad, en una norma anterior nos encontramos con otra posibilidad de exención parcial cuando en el artículo 3.5 de la Orden de 18 de marzo de 2003, de la Consejería de Educación y Cultura, por la que se establecen medidas para facilitar la compatibilidad de los estudios de Educación Secundaria Obligatoria y Bachillerato con los del grado medio de las enseñanzas de régimen 
especial de Música y Danza ${ }^{42}$ (BORM 02-04-2003), se establece que los alumnos que simultaneen los estudios de Bachillerato y de grado medio de Danza podrán beneficiarse de la exención parcial de la materia de Educación Física de primero de Bachillerato (previa autorización de la citada Consejería). Previamente, en el artículo 2.2, contempla la convalidación del área de Educación Física para los alumnos de E.S.O. Asimismo, en el artículo 5 se advierte que los alumnos que se acojan a esta medida, quedarán liberados de la asistencia a las clases de esa materia.

Para establecer los aspectos fundamentales en los que sustentar la evaluación objetiva de los alumnos a los que se les conceda la citada exención parcial en esta Comunidad se publica la Resolución de 30 de junio de 2003, de la Dirección General de Centros, Ordenación e Inspección Educativa, por la que se establece el currículo de educación física para los alumnos que cursan simultáneamente las enseñanzas de bachillerato y el grado medio de danza (BORM 15-07-2003).

En esta Resolución se señala que entre las tareas que tiene que establecer el profesorado de Educación Física que imparta clase a estos alumnos debe figurar la elaboración de trabajos relacionados con el currículo de dicha materia y la realización de pruebas teóricas. Además, se nos advierte que la adaptación del currículo para el alumnado que se encuentra en las circunstancias expuestas anteriormente, se verá reflejado por la exención de la parte práctica, es decir, nuevamente la exención se limita solo a la parte práctica de la materia.

También, en esta línea de facilitar o compatibilizar estudios entre enseñanzas de Régimen Especial y de Educación Secundaria Obligatoria, nos encontramos en la Comunidad de Madrid con la Orden 4399/2001, de 16 de octubre, por la que se regulan las convalidaciones de determinadas áreas o materias de Educación Secundaria Obligatoria para aquellos alumnos que simultáneamente cursan Enseñanzas de Régimen

\footnotetext{
${ }^{42}$ En parecidos términos está redactada la Orden de 3 de diciembre de 2004, de la Consejería de Educación, Universidades e Investigación, por la que se establecen medidas para facilitar la simultaneidad de los estudios de Educación Secundaria con las Enseñanzas Artísticas de música y danza de grado medio, cuyo ámbito de aplicación es el País Vasco (BOPV 04-01-2005).
} 
Especial de Música o Danza (BOCM 31-10-2001) ${ }^{43}$, por la que se permite o concede para estos casos la dispensa a los alumnos de la asistencia a las clases de Educación Física..., lo que supone un alivio en la carga lectiva que estos alumnos han de soportar $^{44}$.

\subsection{7.- PORMENORES DE LA EXENCIÓN DE LA EDUCACIÓN FÍSICA EN EL BACHILLERATO EN CASTILLA Y LEÓN}

Comenzamos por la Orden de 4 de abril de 2001, de la Consejería de Educación y Cultura, por la que se desarrolla el proceso de convalidación entre las enseñanzas de régimen especial de Música y de Danza y determinadas áreas de Educación Secundaria Obligatoria (BOCyL 11-04-2001) ${ }^{45}$. Aunque no se hace referencia a la dispensa o exención, sí se prevé las condiciones para conceder la convalidación entre el área de Educación Física de Educación Secundaria Obligatoria y las Enseñanzas de Régimen Especial de Danza, de forma que un alumno que reúna los requisitos solicitados podrá obtener la convalidación pertinente de dicho área para el primer ciclo, tercer curso o cuarto curso, según se acredite la superación de las asignaturas de un determinado curso de grado medio de Danza. En el libro de escolaridad se empleará el término "convalidada" en la casilla del área de Educación Física. En definitiva, el alumno, en este caso por haber seguido otros estudios, deja de cursar el área de Educación Física, lo que podía entenderse como una forma de exención total o dispensa.

Esta norma fue derogada por la Orden EDU/2273/2009, de 11 de diciembre, por la que se establecen las convalidaciones entre asignaturas de las enseñanzas profesionales de Música y de Danza y materias de Educación Secundaria Obligatoria y

\footnotetext{
${ }^{43}$ En el Boletín Oficial de la Comunidad de Madrid de 20 de noviembre de 2001 aparece la corrección de erratas de esta Orden.

${ }^{44}$ Las Instrucciones que desarrollan la aplicación de esta Orden se pueden consultar en Internet: http://www.madrid.org/dat_capital/circulares/pdf/Inst_musica_danza.pdf

${ }^{45}$ En esta Orden se nos remite a la Orden de 2 de enero de 2001, del Ministerio de Educación, Cultura y Deporte, comentada en el apartado 6.3.
} 
de Bachillerato, y las condiciones para la exención de la materia de Educación Física en la Comunidad de Castilla y León (BOCyL 21-12-2009).

El Capítulo III está dedicado a las exenciones de la materia de Educación Física de Educación Secundaria Obligatoria o de Bachillerato, la cual la podrán solicitar quienes cursen estos estudios y, simultáneamente, acrediten tener la condición de deportistas de alto nivel o de alto rendimiento o realizar estudios de las enseñanzas profesionales de Danza.

En lo que respecta al apartado de la calificación, el alumnado exento de la materia de Educación Física no será evaluado de esta materia, y se hará constar en los documentos de evaluación con la expresión «EX» (exento), sin especificar calificación numérica alguna...

Así pues, estamos de nuevo ante la exención para deportistas de alto nivel o de alto rendimiento y para quienes cursen estudios de las enseñanzas profesionales de Danza.

En la Orden EDU/2134/2008, de 10 de diciembre ${ }^{46}$, por la que se regula la evaluación en bachillerato en la Comunidad de Castilla y León (BOCyL 15-12-2008) volvemos a encontrarnos que los alumnos con problemas graves de audición, visión o motricidad pueden estar eximidos de calificación en determinadas materias (artículo 9.16)

Además, en la disposición adicional cuarta se hace mención a los alumnos que hayan obtenido una exención de Educación física por tener simultáneamente la condición de deportista de alto nivel o alto rendimiento o por cursar simultáneamente estudios de las enseñanzas profesionales de Danza.

\footnotetext{
46 A pesar de que posteriormente fue modificada por la ORDEN EDU/493/2013, de 20 de junio, (BOCyL 28-06-2013), se mantienen exactamente igual la redacción del artículo y disposición aquí comentados.
} 
La última norma que ha aparecido en relación al Bachillerato (presencial) es la Orden EDU/490/2014, de 10 de junio, relativa a la exención extraordinaria en materias de bachillerato para el alumnado con necesidades educativas especiales (BOCyL 19-062014)

Su objeto es regular el procedimiento para la exención parcial o total de materias en el bachillerato al alumnado con necesidades educativas especiales derivadas de graves problemas de audición, visión o motricidad, o excepcionalmente otros debidamente acreditados que así lo aconsejen.

Por lo tanto, mantiene la "graduación o tipología" de la exención establecida en otras normas revisadas hasta ahora. Veamos lo que dice de una y otra:

En el artículo 3 recoge esta diferenciación entre la exención parcial y total. La exención total supone que el alumno estará exento de evaluación y calificación en la misma. Además, se obliga al centro a que garantice la atención al alumno durante el horario escolar ordinario de la materia objeto de exención y, en todo caso, el alumno podrá participar en las actividades relacionadas con la materia que puedan contribuir a su desarrollo personal. Entendemos que esto último podrá referirse a las actividades extraescolares y complementarias organizadas por el profesor de la materia.

Por su parte, la exención parcial implicará la adaptación de alguno de los siguientes elementos del currículo de la materia correspondiente: objetivos, contenidos, criterios de evaluación y mínimos exigibles para superar la materia. Estamos ante una adaptación que, expresamente, no podrá aminorar la calificación obtenida.

En el artículo 4 se especifica que, con carácter general, pueden ser objeto de exención parcial o total las materias comunes de Educación Física y Lengua Extranjera... Así pues, para la Administración, la Educación Física es claramente una materia de la que se puede estar exento. 
Además, establece que a la correspondiente solicitud de exención (artículo 6) se deberá adjuntar copia del certificado de discapacidad o de la tarjeta acreditativa del Grado de discapacidad del alumno, así como los informes médicos, o de otros servicios, de los que se disponga ${ }^{47}$.

En el Anexo 1 se puede observar el modelo de solicitud de exención de materias en Bachillerato que aparece en esta Orden.

Por último, la Orden EDU/425/2015, de 22 de mayo, por la que se regulan las especificidades propias del bachillerato en régimen a distancia en la Comunidad de castilla y León, establece que su artículo 4, apartado 4, que el alumnado mayor de veinticinco años o que cumpla esa edad en el período para el que formaliza la matrícula podrá formular la solicitud de dispensa de la materia de Educación Física ante la dirección del centro en el momento de formalizar su matrícula. La solicitud quedará archivada en el expediente académico del alumno y en la calificación de esta materia figurará «exento». Como a este respecto ya nos hemos referido anteriormente, solo resaltamos que la adquisición de los saberes está nuevamente limitada a la posesión de una determinada edad. Al parecer, cuando se alcanza esa edad ya no interesa ni su práctica ni su conocimiento.

Para terminar con este subapartado, presentamos la Ilustración 1 para apreciar de forma rápida las normas habidas y en vigor que han regulado la exención en Castilla y León.

\footnotetext{
${ }^{47}$ En el Capítulo 10 podremos comprobar el valor que los papeles médicos desempeñan en la exención en Educación Física (en cualquiera de sus formas).
} 


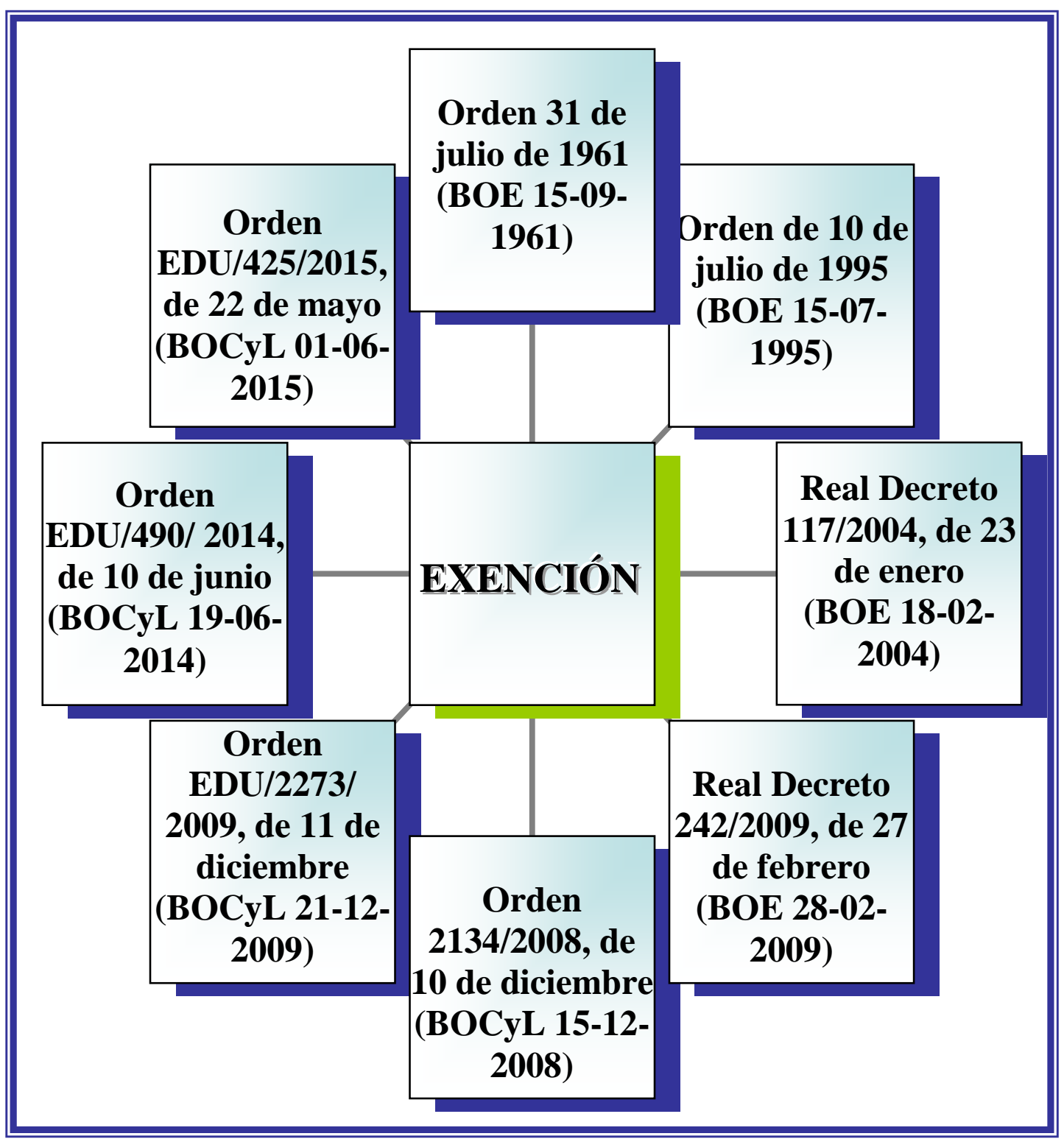

Ilustración 1. La exención en las normas legislativas de Castilla y León desde la aparición de la Orden 31 de julio de 1961

\subsection{8.- SÍNTESIS LEGISLATIVO: CLARIFICANDO CONCEPTOS Y SACANDO A LA LUZ PARADOJAS Y CONTRADICCONES}

Tras la exposición y comentario de las normas legislativas que han regulado o regulan la exención en Educación Física, ya se trate de la Educación Secundaria Obligatoria o del Bachillerato, se puede comprobar que se ha avanzado de la "dispensa" a la que se sometía a los alumnos con necesidades educativas especiales asociadas a una 
imposibilidad física, a la búsqueda de respuestas educativas en términos de adaptaciones curriculares que pretenden, entre otra serie de cosas, su integración y participación en todo el proceso de enseñanza-aprendizaje de una de las áreas comunes del currículo.

No obstante, el concepto de "exención" no ha desaparecido legalmente en el Bachillerato. Esta situación tan particular pudiera estar arrastrando a los profesores al trasvase del concepto, y todas sus connotaciones, de una a otra etapa educativa (independientemente de los motivos que dan lugar a la exención), bien por su propia comodidad, bien por desconocimiento de la norma y todo lo que conlleva su aplicación $^{48}$.

Por otra parte, parece que, con ciertos matices, entre las administraciones hay un patrón que guía los desarrollos normativos que regulan estas situaciones. En este sentido, hemos de decir que nuestra comunidad autónoma ha legislado especialmente la exención en la etapa del Bachillerato.

Con el ánimo de clarificar algunos conceptos que han ido apareciendo hasta ahora relacionados con el tema de estudio, y otros que aparecerán en el siguiente apartado, presentamos el siguiente glosario de términos:

\section{Glosario terminológico}

a) Dispensa por imposibilidad física: Era una respuesta educativa que se otorgaba a determinados alumnos por la que se les eximía de lecciones teóricas y prácticas de la asignatura, incluidas las actividades deportivas, así como de las pruebas que se pudieran realizar. Se concedía a aquellos alumnos que padecían un defecto, lesión o enfermedad que no les permitía practicar la Educación Física o el deporte sin ningún tipo de molestia sensible o sin perjuicio de su salud (Orden de 31 de julio de 1961)

\footnotetext{
${ }^{48}$ En lo que respecta a las adaptaciones curriculares en Educación Física, Arráez (1998, p. 27) afirma que los profesionales de la Educación Física han tenido escasa o nula preparación específica previa en este campo...
} 
b) Adaptación curricular: Se entiende por adaptación curricular la medida de modificación de los elementos del currículo a fin de dar respuesta a las necesidades del alumnado. En todo caso, la adaptación tendrá como referente los objetivos y las competencias básicas del currículo que corresponda (Orden EDU/849/2010). Las hay de dos tipos: no significativas y significativas.

c) Adaptación curricular significativa: Supone la modificación de los elementos del currículo afecten al grado de consecución de los objetivos, los contenidos y los aprendizajes imprescindibles que determinan las competencias básicas en la etapa, ciclo, grado, curso o nivel correspondiente. Se podrán realizar en la educación básica e irán dirigidas al alumnado que presenta necesidades educativas especiales que las necesiten. Requerirán una evaluación psicopedagógica previa realizada por los servicios de orientación educativa, con la colaboración del profesorado que atiende al alumnado. En las etapas postobligatorias se deberán adoptar medidas dirigidas al alumnado que presente necesidades educativas especiales que no impliquen adaptaciones curriculares significativas, con objeto de facilitar su acceso al currículo general (Orden EDU/849/2010).

d) Exención: Actuación o respuesta que se ofrece a una alumno con necesidades educativas especiales consistente en la liberación de cursar Educación Física. Puede ser total o parcial, temporal o permanente.

e) Exención total: Cuando el alumno no cursa ningún contenido de la asignatura, lo cual incluye en muchas ocasiones la inasistencia a las clases. Como veremos en el apartado siguiente, el tratamiento de la calificación para el alumnado que se encuentra en esta situación es dispar. En ocasiones este concepto se mimetiza con el que veremos a continuación.

f) Exención parcial: Cuando el alumno únicamente no cursa determinados tipos de contenidos y/o ejercicios por estar totalmente contraindicados para su salud. 
En otros casos tiene que ver con planteamientos restrictivos referidos únicamente a los contenidos de tipo procedimental, estando posibilitado el alumno para desarrollar y adquirir los de tipo conceptual y actitudinal. En este caso estaríamos ante el concepto de exención de la práctica.

g) Exención permanente o temporal: La primera nos sitúa ante un alumno que durante todo el curso no podrá trabajar los contenidos de toda la materia o solo de algún tipo de contenido. Mientras que la temporal limita el hándicap a un espacio de tiempo que suele ser inferior al de un curso escolar.

\section{Paradojas y contradicciones}

Concluimos planteando una serie de preguntas que reflejan lo contradictorias y paradójicas que pueden llegar a ser las leyes de aplicación en la E.S.O. y el Bachillerato:

× ¿Cabe la posibilidad de que un alumno con graves problemas de audición, visión o motricidad (lo que podíamos decir un alumno con dificultades de aprendizaje asociadas a discapacidad sensorial o motora), que a lo largo de su etapa en la E.S.O. haya recibido una respuesta educativa en forma de adaptación curricular, al pasar al Bachillerato pueda ser considerado exento por esos mismos motivos?

* ¿Acaso la Educación Física carece de valor educativo-social en la etapa postobligatoria? ¿No deberían plantearse y llevarse a cabo adaptaciones curriculares a estos alumnos que cursan el Bachillerato que se encuentran en estas especiales circunstancias?

× ¿Dónde quedan las bonanzas de nuestra materia en cuestiones de educación integral e integradora para esos alumnos de bachillerato?

× ¿El hecho de que un alumno sea deportista de alto nivel, o curse estudios de Danza, o tenga más de veinticinco años, le hace estar en posesión de todo lo que la 
Educación Física aporta al resto de sus compañeros? (que es precisamente por lo que tiene presencia curricular en el sistema educativo).

\section{2.- EL CONCEPTO DE EXENTO: USOS HABITUALES EN LAS FUENTES DE INFORMACIÓN}

Es ahora el momento de sintetizar las ideas dominantes en la literatura de nuestra disciplina en torno al tema de la exención y/o el tratamiento de los alumnos con necesidades educativas especiales extremas. Se considerarán las formas de entender la exención, los documentos que hacen que perdure y la respuesta educativa que desde la Educación Física se suele dar a este tipo de alumnos. Concluimos con una reflexión personal acerca del papel del profesor en el mantenimiento de la exención.

En el apartado anterior hemos visto que a partir de 1995 desaparece en la E.S.O. la posibilidad de la exención por impedimento físico. Por tanto, es lógico pensar que la literatura específica posterior a esa fecha no emplee esta medida con los alumnos con necesidades especiales, pues toda respuesta debe estar en términos de adaptación curricular. Por ello, esta revisión bibliográfica se centrará casi exclusivamente en fuentes informativas cuyas fechas de edición o publicación sean de 1995 en adelante y que, por lo tanto, cuentan con la referencia del cambio educativo planteado en esta norma.

En definitiva, lo que se trata de averiguar es, entre otras cosas, si el uso de la exención se contempla como una "rutina" o práctica habitual en las clases de Educación Física. En caso de ser así, se podría llegar a concluir que si la exención aparece en las fuentes como una praxis que se pueda llevar a efecto, hay notorias contradicciones y discrepancias entre dichas fuentes y la normativa establecida (la Práctica versus la Teoría). 


\subsection{1- ANTECEDENTES: LA EXENCIÓN COMO OBJETO DE ESTUDIO}

Aunque en la búsqueda de documentos y de información realizada en esta tesis se tienen en especial consideración las fuentes publicadas a partir de 1995, momento de inflexión legislativa que supuso la derogación de la norma anterior que amparaba la dispensa de cierto tipo de alumnado, hemos de aclarar que con anterioridad a ese año hay escritos, algunos de ellos en forma de estudios, que versan o tratan el asunto de la exención en Educación Física.

El primero de ellos es el llevado a cabo por Castillo et alia (1964). De entrada, todos los autores de este estudio son médicos, lo cual nos permite hacernos una idea de la perspectiva que orienta la investigación.

Estos autores muestran el sistema que implantaron para peritar el grado de incapacidad física de los alumnos de la segunda enseñanza de aquella época. También ofrecen los datos de los alumnos a los que han visitado por haber solicitado la exención de Educación Física durante el curso 1962-63.

Consideran que el profesional más calificado para realizar dictámenes sobre la incapacidad física de los alumnos es el médico deportivo. De hecho, apuntan cierta disposición complaciente por parte del médico de familia a la hora de extender certificados eximentes, eso sí, quizás presionados por los familiares de los alumnos.

El problema que parecen detectar es que hay alumnos que acuden al final del curso escolar para solicitar "por complacencia" la exención de la asignatura. La recomendación que hacen para subsanarlo es que los alumnos acudan al principio del curso a los Centros Juveniles de Medicina para la correspondiente peritación de sus incapacidades físicas y obtener así el correspondiente certificado médico.

Estos autores establecen cuatro grados de valoración de la incapacidad física: 
"Exención total.- Cuando el individuo no puede realizar la práctica de Educación Física debido a que el proceso patológico padecido se lo impide o también cuando se ha originado una secuela permanente...

Exención temporal.- Para aquellas enfermedades agudas que cursen durante un periodo de evolución hasta tres meses...

Exención de la gimnasia de aparatos.- La gimnasia de aparatos aunque solo sea de saltos de «potro y plinkton» [sic] plantea unos problemas de ejercicios físicos a algunos alumnos que sufren anomalías del aparato locomotor...

Apto gimnasia correctiva.- Es criterio nuestro que muchas exenciones parciales necesitan la práctica de gimnasia aplicada para corregir precisamente su defecto físico... Por lo tanto debe considerarse como muy buena oportunidad para que los alumnos con algún defecto físico que tiene posibilidad de corregirse total o parcialmente a través del ejercicio físico, pueda practicar de una manera correcta la Educación Física..." (op. cit., p. 21)

En lo concerniente a los datos que ofrecen, aunque los presentan con cierto tono de levedad, de los 854 alumnos que asistieron al centro, 357 (41'8\%) fueron declarados exentos totales, siendo los motivos más aludidos las cardiopatías, secuelas de la polio, osteopatías, tuberculosis pulmonar, fracturas y hepatitis (la lista se completa con otras 19 patologías).

Dieciocho años después, González y Sañudo (1982) presentan una revisión de los alumnos que durante 10 años (sin especificar los cursos) han acudido al Centro de Investigación Médico-Deportiva de Pamplona para valorar su incapacidad para la “gimnasia escolar". Nuevamente estamos ante un estudio realizado por médicos.

Apuntan que existen demasiados certificados médicos eximentes de la Educación Física, quizás fruto de la presión de los padres (por diferentes razones).

En este caso, establecen 7 grados de aptitud de cara a la realización de la gimnasia escolar: Apto para la realización de todo tipo de gimnasia; apto para la realización de gimnasia correctiva o especial; apto para la realización de todo tipo de gimnasia excepto por aparatos; exención temporal; exención parcial y, por último, exención total (op. cit., p. 246). 
Para presentar los resultados hacen un recorrido por patologías. De 980 casos estudiados, hubo 357 exenciones totales (36’42\%). De ellas, las relacionadas con las cardiopatías fueron las más extensas (52 de 70 casos), seguidas de las escoliosis (49 de 177) y aparato locomotor (43 de 146).

Finalmente, aunque afirman que no son partidarios de la exención total en Educación Física, reconocen que hay alumnos, aunque pocos, que verdaderamente deben obtener esa consideración.

Martínez de Haro et alia (1987), partiendo del rechazo de un grupo de profesores de Educación Física a aceptar los certificados médicos que declaran a un alumno exento, aportaron dos experiencias reales con las que "rescatan" a alumnos que estaban considerados exentos de la Educación Física, generando así otras formas de trabajar que iban en una dirección totalmente opuesta a la recogida en esa normativa. La primera de ellas se centra en un trabajo teórico-práctico sobre conceptos de nutrición y hábitos alimenticios. En la segunda, pretenden integrar a los alumnos en cuestión en el programa general, para lo cual establecen las siguientes pautas de trabajo:

“- Asistencia a clase obligatoria para todos los alumnos exentos o no.

- Conocimiento de las causas de exención, por parte el profesor.

- Elaboración de una programación teórico-práctica para que los alumnos conozcan, además de realizarla, la educación física.

- Conocimiento por parte de los alumnos exentos de los ejercicios que con la enfermedad que padecen podrían o no realizar.

- En casos extremos, los alumnos realizarán un trabajo teórico sobre su enfermedad y la actividad física.

- En los casos en que no puedan participar en el programa general práctico, realizarán un programa específico práctico para ellos, si lo tienen, y si no, actuarán de auxiliares del profesor en funciones de control, observación o seguridad." (op. cit., p. 28)

Como ejemplos de actividades que estos alumnos pueden llevar a cabo proponen la realización de calentamientos que puedan hacer el resto de compañeros, ejercicios de rehabilitación durante la clase de Educación Física, observaciones, arbitrajes y ayuda al profesor, además de un trabajo teórico sobre su enfermedad (obsérvese la similitud con el concepto de falsa integración que más adelante se planteará en este mismo capítulo). 
Para terminar, nos muestran ejemplos de alumnos a los que han hecho participar en algunas de sus clases, tales como un parapléjico y un ciego, y finalizan con una pequeña crítica a la legislación actual al respecto de los exentos.

Hernández y Martínez (1989), realizan un estudio extenso sobre las exenciones de Educación Física ${ }^{49}$ que se conceden al amparo de la conocida Orden Ministerial de 1961. Esta fuente documental, por su similitud de contenidos con esta tesis, será utilizada en numerosas ocasiones.

Al igual que viene ocurriendo con los tres anteriores escritos, estos autores se sitúan en contra de la exención ya que consideran que a los alumnos que no pueden seguir la asignatura, ya sea de una forma total o parcial, deben proporcionárseles un camino que permita su integración. Y esta, según ellos, se produce mediante tareas de arbitraje, cronometraje y elaboración de trabajos. Es más, plantean la elaboración de estos trabajos como una forma de compensar la falta de práctica.

También realizan un análisis de los aspectos académicos y socioculturales que hacen que el área de Educación Física sea tan peculiar.

Por primera vez encontramos un análisis pormenorizado de la Orden Ministerial de 1961. Como cabía esperar, la revisión de cada uno de los cuatro casos que esta Orden contempla para otorgar la exención de la asignatura de la Educación Física, se hace de forma muy crítica.

A esta crítica le sigue unas propuestas que deberían recoger una nueva legislación para estos asuntos, previa derogación de la citada Orden de 1961. Estas propuestas se resumen de la siguiente manera:

- Solo existirían alumnos exentos total o parcialmente de los contenidos prácticos.

\footnotetext{
${ }^{49}$ Estos son los autores, junto con un tercero (Velázquez Buendía, R.), del anterior escrito al que hemos denominado Martínez de Haro et alia (1987).
} 
- Habría que elaborar unas directrices para que los alumnos adquiriesen el conocimiento de los contenidos teóricos y de los prácticos cuando ello sea posible.

- Que los servicios de inspección educativa tuviesen claras funciones de asesoramiento y orientación.

- Adecuación de los certificados médicos.

Concluyen recabando una serie de experiencias que hasta ese momento se llevaban a efecto con alumnos considerados exentos y que, al parecer, funcionan en la medida en que contribuyen a que disminuya su número. Las experiencias tienen que ver con la elaboración de trabajos teóricos, permanecer en clase (aun sin hacer nada), realizar ejercicios de rehabilitación (incluso toda la clase los haría alguna vez) y, por último, desempeñar labores de organización y control.

En 1990, AA.VV. (Seminario Permanente de Educación Física de Fuerteventura) sitúan a debate el asunto de la exención en nuestra asignatura en el contexto de los centros de Bachillerato. Aunque su marco legislativo referencial es la Circular $\mathrm{n}^{\circ} 1$ de Bachillerato, de 15 de julio de 1988, de la Dirección General de Ordenación Educativa de la Consejería de Educación, Cultura y Deportes del Gobierno de Canarias, es obvio que el tema trasciende ese ámbito autonómico.

Este colectivo se posiciona totalmente en contra de los "exentos por causa médica", argumentando para ello tres razones. La primera porque no ven justificado la supresión de toda actividad física. Segunda, porque suponen que los certificados médicos están manipulados por los alumnos con el consentimiento paterno. La tercera alude a que los objetivos de la Educación Física no son exclusivamente de tipo motriz o físico, habiendo otros aprendizajes y valores igualmente importantes. En este punto apela de alguna forma a lo que luego conoceremos como juegos sensibilizadores.

Para finalizar el artículo, enumeran la siguiente serie de pautas de trabajo para estos alumnos: 
"- Asistencia a clase obligatoria para todos los alumnos exentos o no.

- Conocimiento de los alumnos exentos de los ejercicios que con la enfermedad que padecen podrían o no realizar.

- En aquellos casos en que los alumnos no puedan participar en el programa general práctico, realizarán un programa específico para ellos, o bien tareas de rehabilitación de su lesión o padecimiento.

- Los alumnos exentos pueden prestar un gran servicio a la clase como auxiliares del profesor en tareas como calentamientos, evaluación, cooperación con sus compañeros, etc." (op. cit., p. 8)

Como se habrá podido comprobar, estas propuestas son prácticamente una copia literal de las que se hacen en el documento de Martínez de Haro et alia (1987).

Para finalizar con los escritos anteriores al 1995, Casimiro (1992), autor al que también recurriremos a lo largo de este capítulo, plantea la exención total como una cuestión difícil de encontrar en la Educación Física. Aunque el alumno presente un certificado médico que le catalogue como exento total y permanente, este autor plantea que el alumno en cuestión sí puede trabajar los contenidos teóricos, colaborar con el profesor, ayudar en el cronometraje, pasar lista, realizar fichas, etc. En el caso del exento parcial y permanente, pueden ser evaluados de la teoría y de los contenidos prácticos que sí puedan hacer. Para la exención temporal (esguinces...) no habría problema alguno.

En el escrito se percibe cierto rechazo a lo que él llama el "papelito", refiriéndose al certificado médico que los alumnos presentan. A pesar de que critica la forma en la que se redactan, propone que los médicos deberían explicar con mayor exactitud el diagnóstico, tratamiento, ejercicios que puede o no hacer..., lo cual demuestra que ese "papelito" es indispensable para cualquier decisión.

En lo referente a la existencia en nuestro país de estudios o investigaciones posteriores a 1995 que aporten datos sobre la exención o exclusión de cierto tipo de alumnos en las clases de Educación Física, se puede decir que son escasos y, en general, de no mucha magnitud. 
Quizás el más relevante sobre esta temática sea el presentado por López García (1996). Como propuesta fundamental, este autor trataba de desarrollar material curricular adaptado a las posibilidades y limitaciones de los alumnos con necesidades educativas especiales (alumnos exentos) de la práctica de la Educación Física. Más concretamente, se pretendía elaborar una programación para alumnos de $3^{\circ}$ de E.S.O. con las correspondientes adaptaciones curriculares para todos aquellos que las necesitasen. Entre otras, realiza una revisión de las solicitudes de exención presentadas en 4 centros de secundaria durante el curso 1995-96. De una muestra de 1037 alumnos detectaron que 100 estaban exentos total, parcial o temporalmente de la Educación Física (33 chicos y 67 chicas).

Otro ejemplo se encuentra en el elaborado por Gomendio (2000), quien plasma la realidad de la Comunidad Autónoma Vasca en el curso 1994-95 en relación a los alumnos con necesidades educativas especiales por minusvalías motrices. Tras consultar a las asociaciones de Parálisis Cerebral ASPACE de las tres provincias vascas comprueba que estos alumnos, integrados en las escuelas normalizadas, no participan en las clases de Educación Física escolar, realizando otra actividad en dicha hora (ibídem, p. 116)

Por su parte, Rodríguez-Solano (2003 y 2004) lleva a cabo una investigación para conocer cuál es el perfil que define a este grupo de alumnos, para lo cual parte de lo que él entiende por alumno exento. Se ha de precisar que su estudio se centra en los alumnos exentos por, digamos, carencias de interés, falta de motivación, etc.

"Los alumnos lesionados de un modo real o simulado durante largos períodos de tiempo, los denominados «exentos» [...] En general los resultados nos muestran que los alumnos exentos, son alumnos que no escogerían libremente la clase de Educación Física porque no les gusta la clase, y porque no la consideran tan importante como para ser incluida en el currículo de la Educación.” (Rodríguez-Solano, 2003)

Detallados varios escritos españoles en torno a los alumnos exentos, llega el turno de comprobar si la exención ha sido objeto de estudio o, al menos, ha aparecido recientemente como dato relevante en alguna investigación realizada en otros países. 
De ámbito mundial, nos vamos a encontrar con algunos trabajos que plantean o sacan a la luz la exención de las clases de Educación Física.

Hardman (2008), presenta un estudio basado en la segunda encuesta mundial sobre la situación de la Educación Física, realizada en el 2005 coincidiendo con el año del deporte y la de la Educación Física según la Organización de Naciones Unidas.

En el análisis que esboza sobre la situación en la que se encontraba la Educación Física, alude a la exención como un posible motivo del deterioro del estatus de la propia materia, matizando que dicha exención, concedida en pocos países al presentar un certificado médico, es una práctica reconocible en todo el mundo. Se puede interpretar que los mandatos oficiales o legislativos y la realidad que rodea el ámbito educativo, no siempre van de la misma mano.

La UNESCO (2014) presenta un informe que recoge los resultados de una encuesta realizada a nivel mundial, ofreciendo información sobre la calidad de la Educación Física en las escuelas.

Uno de los hallazgos que expone evidencia que, como consecuencia de las experiencias adquiridas en la Educación Física relacionadas con el deporte competitivo, hay un aumento del número de alumnos exentos, junto con mayores niveles de desinterés y desmotivación. Este resultado aparece recogido en el apartado referido al currículum de la Educación Física.

Al igual que planteó Hardman (op. cit.), este incremento de las exenciones parece minar o deteriorar el estatus de la Educación Física en el sistema escolar. De hecho, este informe de la UNESCO recoge muchas de las aportaciones de este autor, incluidas las que he destacado anteriormente.

Este organismo mundial también se hace eco en esta investigación de algunos estudios realizados por agencias o instituciones norteamericanas, como la Asociación 
Nacional del Deporte y la Educación Física (NASPE), apuntando que en 28 estados están permitidas las exenciones de Educación Física.

Antes de detallar lo que sucede en EE.UU., debemos de tener en cuenta que su sistema educativo no funciona con un currículo centralizado, y que son las agencias de educación estatales y/o las organizaciones nacionales de profesionales de la Educación Física (tales como la ya mencionada NASPE), las que se encargan de desarrollar los estándares de aprendizaje, lo cual provoca que todas las decisiones curriculares se elaboren en las escuelas o distritos escolares, desencadenando una gran diversidad de políticas educativas y en los propios programas de estudio (Cook y Kohl, 2013, p. 200).

Además, en lo que a la exención se refiere, han sido tres las posibilidades o formatos encontrados: la propia exención, concedida por problemas de salud y/o discapacidad (exemption); la renuncia a las clases de Educación Física (waiver), y las sustituciones de las clases por realización de otro tipo de actividades (substitutions), como pertenecer a algún equipo, participar en actividades escolares, formar parte de la banda de música... Obviamente, todas estas opciones, incluida la propia inexistencia de la posibilidad de exención y/o renuncia, dependerá del estado al que hagamos referencia. Por ello, las fuentes consultadas no harán referencia de forma exclusiva a ningún estado en concreto.

Con estos dos hándicaps de inicio, nos vamos a encontrar algunos estudios $\mathrm{y}$ documentos norteamericanos que merece la pena destacar por su conexión con esta tesis.

En primer lugar, la propia NASPE (2012), en colaboración con la Asociación Americana del Corazón (AHA), realiza un informe con el propósito de proporcionar información sobre la situación de la Educación Física en cada uno de los 50 estados y el Distrito de Columbia. El desarrollo del trabajo se desglosa en doce áreas o centros de atención, entre los que se incluye uno dedicado a "Exenciones/Renuncias y Sustituciones" ("Exemptions/Waivers and Substitutions"). En este subapartado, afirma 
que más de la mitad de los estados conceden exenciones, renuncias o sustituciones de las clases de Educación Física (NASPE, op. cit., p. 8).

Entre los motivos más comunes para las exenciones se encuentra la salud, la discapacidad física, las creencias religiosas y las graduaciones tempranas. Además, son las propias escuelas locales o los distritos escolares, los encargados de conceder esa exención. Esta fuente presenta un apartado dedicado a desgranar los perfiles de cada estado en relación a cada una de las áreas de atención fijadas al inicio del informe.

En parecidos términos de formato, la Asociación Nacional de Juntas Estatales de Educación (NASBE), desmenuza en su base de datos uno a uno los estados miembros, ofreciendo datos acerca de cuatro indicadores, entre los que se encuentran las exenciones. Se puede decir que la información que aparece está en la línea de la aportada por la NASPE. Algunos de los estados en los que se concede la exención por motivos de salud, siempre con documento médico acreditativo, son: Arkansas, Connecticut, Delawere, Kansas, Louisiana, Mississippi...

En este desglose de la exención en cada uno de los estados que configuran Norteamérica, nos vamos a encontrar con algunos datos sumamente curiosos. El primero de ellos es que en muchos de estos estados, la exención también es concedida aludiendo a razones de índole religioso. De hecho, en Pennsylvania, solo es concedida por esta razón.

Asimismo, la discapacidad física aparece como otro desencadenante de la exención, tal como sucede en Washington, Texas u Oregon. En Tennessee se establece que estos alumnos deberán seguir un programa modificado con arreglo a las recomendaciones de un médico.

Por último, en Minnesota, la no participación en clases de Educación Física por razones médicas por un periodo menor a seis días, puede ser justificada con un escrito paterno. A partir de la superación de ese tiempo, habrá que presentar un documento médico. 
De otra parte, la Sociedad de la Salud y Educadores Físicos (SHAPE, 2014), tiene elaborada una Guía de Políticas de Educación Física en la que plantea que las renuncias, exenciones o sustituciones de la Educación Física no deberían estar permitidas, y cualquier tipo de excepción al respecto debería concederse únicamente por consideraciones de tipo médico, cultural o religioso.

Por lo que respecta a Europa, la Comisión Europea (2013) publicó el informe "La educación física y el deporte en los centros escolares de Europa", elaborado por Eurydice $^{50}$. Entre otros objetivos, pretendía esbozar el panorama existente de la Educación Física y la actividad deportiva en el ámbito educativo durante el curso 20112012. La recogida de datos se efectuó mediante un breve cuestionario en el que participaron alrededor de 30 países europeos. Los niveles educativos de referencia fueron la educación primaria (CINE 1) y secundaria inferior (CINE 2).

En el Capítulo 2, que versa sobre el "Contenido curricular", hay un apartado muy breve dedicado a las exenciones de Educación Física que incluye el gráfico que aparece a continuación (op. cit., p. 27), y que representa el mapa europeo en lo que respecta al procedimiento de solicitud de la exención de la Educación Física en los niveles educativos anteriormente mencionados.

50 Según reza en una de las páginas Web del Ministerio de Educación, Cultura y Deporte (http://todofp.es/todofp/glosario.html), se trata de la Red de información sobre las estructuras, los sistemas y las mejoras a nivel europeo en el ámbito educativo con el objetivo de mejorar la cooperación educativa entre los Estados miembros, así como a facilitar la preparación de las iniciativas a escala nacional (No aparecerá en la bibliografía). 
Gráfico 2.5: Exenciones de educación fisica en primaria (CINE 1) y secundaria inferior (CINE 2), 2011/12

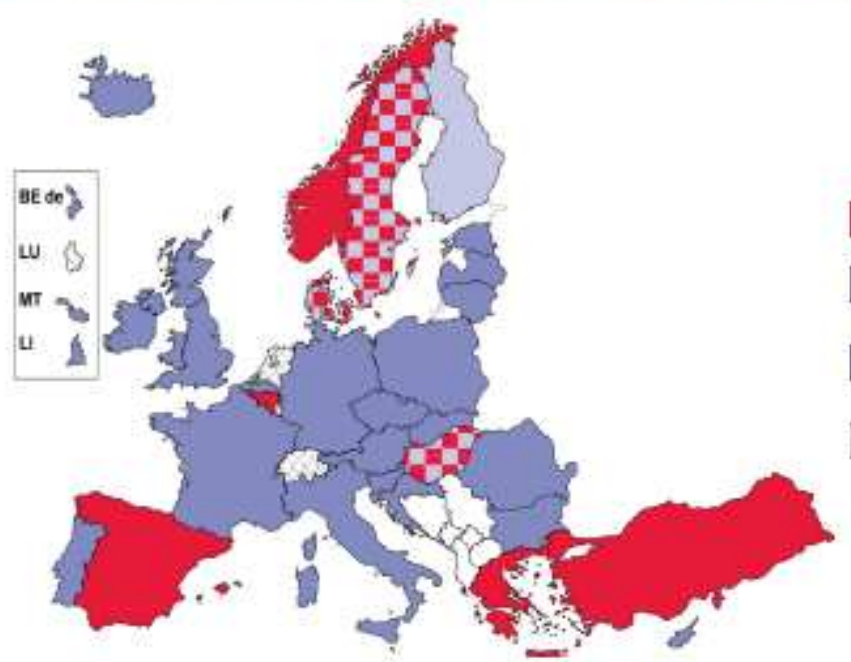

Certificado médico

Justificante de los padres

Justificante de los padres para casos

puntuales y certificado médico para

periodos prolongados

No disponible

Fuente: Eurydice.

Nota explicativa

Las exenciones se refieren a la exención parcial o total, tanto temporal como permanente.

El informe recoge la posibilidad de la existencia de la exención por motivos de salud, tipificándola en total o parcial, temporal o permanente.

A continuación, explica los procedimientos empleados para solicitar las exenciones. Todos ellos pasan por la presentación del certificado médico y/o justificante paterno. Asimismo, señala la validez que estos últimos pueden tener según se trata de uno u otro país.

En último lugar, aparece la respuesta educativa que suele ofrecerse a los alumnos que tengan algún tipo de lesión o enfermedad. El abanico de las propuestas se reduce a dos: hacer actividad física compatible con dicha lesión o enfermedad, o actividades teóricas, labores de arbitraje, ocuparse del marcador... Al parecer, la idea de plantear este tipo de actividades es que así el alumno aprende algo, aunque no participe de manera activa, y se verá obligado a asistir a las clases de Educación Física, no pudiendo dedicar ese tiempo a hacer deberes o tareas de otras asignaturas.

Para terminar con los trabajos realizados fuera de España, recogemos una investigación realizada en Gran Bretaña en torno a este asunto. Se trata del proyecto de participación e integración de gente joven con minusvalías físicas y sensoriales en el 
deporte comunitario y la educación física escolar llevado a cabo por De Potter (1995, p. 46). En él se señala que en estos ámbitos de estudio, entre los que se encuentran las clases de Educación Física, la exclusión de varias actividades alcanza al $96 \%$ de alumnos con minusvalías.

Como conclusión a esta parte dedicada a revisar algunos estudios realizados fuera del ámbito nacional, se aprecia que la exención, a pesar de haber podido constituir un centro de interés con peso propio en alguna investigación, es abordada de una manera más bien superficial, limitándose la mayoría de los autores a constatar su existencia pero sin ofrecer datos pormenorizados al respecto. Por otro lado, el que la legislación que pueda existir en cada país sea diferente a la nuestra, imposibilita cualquier tipo de comparativa o simulación. No obstante, sí que se ha podido constatar que la exención, a día de hoy, sigue apareciendo como un punto de cierta relevancia en nuestra asignatura.

En lo que a los trabajos españoles se refiere, nos encontramos que la exención parece haber sido una práctica habitual en Educación Física (permitida por ley); que la tipología de la lesión o enfermedad influye notablemente en su concesión; que es el médico el que tiene el poder para otorgarla; que, a pesar de que algunos profesores ya se manifiestan contrarios a su existencia, las propuestas realizadas apuntan a la falsa integración y, finalmente, se aprecia una graduación de la exención en términos de total o parcial (casi siempre referida a las cuestiones prácticas de la materia).

\subsection{2.- LA EXENCIÓN EN EDUCACIÓN FÍSICA: UN PROCEDIMIENTO MANTENIDO EN EL MARCO DE LAS ADAPTACIONES CURRICULARES}

Como he señalado en el anterior apartado legislativo, la exención en Educación Física dejó de tener sentido con la entrada en escena del desarrollo normativo de la Ley 1/1990 (LOGSE) y, de forma especial, por medio de la Orden de 10 de julio de 1995 por la que se regula la adaptación del currículo de la Educación Física para los 
alumnos con necesidades educativas especiales en el Bachillerato Unificado y Polivalente, en la Formación Profesional de primer y segundo grados y en la educación secundaria, así como la dispensa de la misma para los mayores de veinticinco años (BOE 15-07-1995).

A pesar de que esta poderosa razón reglamentaria rechazaba el concepto de la exención en un sistema educativo que se define como abierto, flexible e integrador como es el nuestro ${ }^{51}$, y que hay quienes opinan que dicha exención es una práctica lejana y olvidada que se facilitaba en la asignatura de Educación Física al alumnado con discapacidad motora (Puigdellívol en el Prólogo a Ríos, 2003, p. 10), no es difícil comprobar que la realidad ha sido y es muy distinta.

De entrada, la Comisión Europea (2013), a través del informe Eurydice, recoge expresamente la posibilidad de las exenciones en Educación Física en los países que conforman la Unión Europea.

\section{“2.6 Exenciones de educación física}

Por diversos motivos de salud, en ocasiones los alumnos no pueden practicar la educación física. En estos casos, pueden resultar exentos de realizar determinadas actividades de forma temporal o permanente. El que dicha exención sea total o parcial depende de si el alumno puede o no realizar al menos alguna de las actividades en cuestión." (Comisión Europea, informe Eurydice $^{52}, 2013$, p. 27)

Este parecer es compartido por el Equipo Directivo de la revista Tándem ${ }^{53}$ (2003, p. 6), quien afirma que la exención de la práctica de las actividades integradas en las clases de educación física tiene lugar, siendo varias las razones que lo propician.

Se podría pensar que el aumento cualitativo y cuantitativo de publicaciones, artículos o informaciones que están apareciendo en torno al asunto de la atención a los

\footnotetext{
${ }^{51}$ Recordamos que, aunque esta norma fue derogada por la Orden EDU/849/2010, de 18 de marzo, (BOE 06-04-2010), no hay motivo alguno que nos haga creer en la existencia legal de la posibilidad de la exención (en cualquier materia) debido, precisamente a que esta última norma lo que regula es, entre otras cosas, la ordenación de la educación del alumnado con necesidad de apoyo educativo.

${ }^{52}$ Este documento solo está disponible en Internet: http://eacea.ec.europa.eu/education/eurydice

${ }^{53}$ Revista especializada en el área de Educación Física.
} 
alumnos con necesidades educativas especiales contribuyen a una mejora de la situación y atención de dichos alumnos en nuestras clases, dando lugar a procesos de no exclusión. Como se comprobará, hay otra realidad que es bien distinta.

Prueba de esta divergencia entre el saber disciplinar y la práctica diaria se puede encontrar nuevamente en las palabras que el Equipo Directivo de Tándem (2003) publica en un monográfico sobre actividad física y discapacidad.

"De manera paralela, el discurso teórico sobre la educación física y la discapacidad se ha ido elevando a través de publicaciones específicas referidas a este ámbito. Sin embargo, la realidad de la práctica de la enseñanza parece caminar un paso por detrás de la construcción del discurso teórico.” (Ibídem, p. 5)

Por su parte, Mendoza (2003, p. 323) señala que la situación de la Educación Física en relación a la atención del alumnado que presenta necesidades educativas especiales presenta un panorama no demasiado alentador.

Tierra (2001) apuesta fuertemente por la integración de los alumnos con necesidades educativas especiales en Educación Física, pero afirma que los planteamientos que se llevan a cabo son más bien una actuación de maquillaje y reconoce ciertas dudas al respecto de su participación real.

"Los acnee deben estar integrados plenamente en las clases de Educación Física, aunque debemos reconocer que no lo podrán hacer siempre o por lo menos en todas las situaciones." (op. cit., p. 146)

Basta con echar un vistazo a la literatura del saber disciplinario para darse cuenta de que la figura del exento, aplicada a alumnos con necesidades educativas especiales asociadas a discapacidad física, sensorial o psíquica, sigue estando presente en estos niveles de concreción del currículum más próximos a la práctica.

El caso más llamativo, como fuente de información escrita, lo suponen las programaciones didácticas, ya sea de algún centro de enseñanza en particular o de las diseñadas por alguna editorial de las muchas que existen en el mercado. Aunque el 
análisis de las programaciones se realiza en un capítulo posterior, considero inevitable referirme a algunas de las que se encuentran "colgadas" en la red, a disposición de quien lo desee. Además, revisaremos documentos, normas o documentación en general que haga referencia expresa a la exención o dispensa de las clases de Educación Física.

Para comenzar, hay departamentos de Educación Física y Deportiva que se fijan como objetivo a cumplir a principio del curso (Fuente $[30]^{54}$ ) el fijar criterios sobre los alumnos exentos de prácticas, para lo cual propone elaborar una programación paralela para ellos.

En cuanto a las programaciones didácticas, en Internet son muchos los casos en los que se contempla o recoge la exención, sea cual sea su grado de aplicación, tipología, etc. Veamos algunos ejemplos:

"Son aquellos alumnos que por razones médicas, y habiéndolo justificado previa y debidamente, por medio de un certificado médico oficial, no están capacitados para realizar parte o la totalidad de los contenidos prácticos de la asignatura de Educación Física, con lo que los contenidos procedimentales de dicha asignatura se evaluarán por medio de trabajos escritos." (Fuente $[1]^{55}$ )

"Los exentos totales de la parte práctica deben entregar certificación médica oficial acreditando la lesión o enfermedad y posible tiempo de permanencia en dicha situación. Asistirán a clase, colaborarán con la misma en la medida de sus posibilidades. Realizarán actividades de tipo cognitivo. Estas actividades consistirán en la realización de trabajos teóricos por evaluación y su posterior exposición a los demás compañeros...” (Fuente [2] ${ }^{56}$ )

"En la asignatura de Educación Física podemos encontrarnos con alumnos o alumnas que debido a algún problema de salud u otro impedimento físico, no deban o no puedan realizar todos o alguno de los contenidos prácticos que configuran la programación de esta asignatura.

Si tú estas en ese caso debes seguir leyendo con atención ya que en esta página te indicamos los pasos para justificar tu exención... ya que debes entender que se puede estar exento de la práctica pero..." (Fuente $[51]^{57}$ )

\footnotetext{
${ }^{54}$ http://www.juntadeandalucia.es/averroes/iescuencaminera/departamentos/dpto_e_f.htm

${ }^{55} \mathrm{http}: / /$ www.iespana.es/mientrenador/alumnos_exentos.htm

${ }^{56} \mathrm{http}: / /$ pnte.cfnavarra.es/iesmarci/departamentos/educacion_fisica/evaluacion.htm

${ }^{57}$ http://www.ieslasmusas.org/departamentos/index.php?dp=educfisi
} 
"Los alumnos exentos deberán asistir a clase y realizar una serie de trabajos a determinar para cada evaluación. Si no pueden realizar ningún tipo de ejercicio físico realizarán los trabajos teóricos en clase y su evaluación se realizará por medio de conceptos adquiridos." (Fuente $[71]^{58}$ )

Además, alguna programación deja entrever la existencia de la exención referida fundamentalmente a la no realización de los contenidos de carácter procedimental.

"Los procedimientos pueden ser realizados por la totalidad de los alumnos, según su capacidad, excepto por aquellos que por prescripción facultativa estén exentos." (Fuente $[23]^{59}$ )

Otras, como en la Fuente [3] ${ }^{60}$, establecen una "Ficha de trabajos para alumnos exentos".

La Fuente [46] ${ }^{61}$, a la vez que asegura la existencia de los exentos, esboza lo que podría ser una definición y lo que en tales situaciones debería acontecer.

“...En nuestra área se da con más frecuencia de la deseada la exención, que no debería ser sino la constatación -previa certificación, fidedigna y coherente con la Ley, del especialista médico- de dificultades para abordar con éxito determinados contenidos del área. Como es lógico, dichas acomodaciones del currículo no han de suponer en modo alguno la renuncia a los conocimientos e instrumentos que aporta la Educación Física."

Por su parte, la Fuente [22] $]^{62}$ contiene una curiosa carta elaborada por el Departamento de Educación Física dirigida a los padres para los casos de exención total o parcial. En ella se desarrollan las actuaciones a seguir en caso de exención de las

\footnotetext{
${ }^{58} \mathrm{http}: / /$ centros.edu.xunta.es/cpideatios/datos/pdf/programacion/ed_fisica.pdf

59

http://intercentres.cult.gva.es/iessanblas/Educacion\%20Fisica/Programacion\%20Educacion\%20Fisica.ht $\mathrm{m}$

${ }^{60}$ http://centros4.pntic.me.es/ies.galileo.galilei/Edu_fisica/indiceedu_fisica.html

${ }^{61} \mathrm{http} / / /$ www.educa.rcanaria.es/Usr/Apdorta/can-e-ef-htm

${ }^{62}$ http://www.juntadeandalucia.es/averroes/ 41701109/departa/efi/programedfisica03_04.htm
} 
prácticas de Educación Física, aclarando que en cualquier caso la parte teórica no tiene exención posible ${ }^{63}$.

También en la red se puede encontrar otros tipos de escritos oficiales de algún centro educativo que contempla la existencia de la exención. Es el caso del apartado dedicado al del material didáctico necesario para cursar un área y a los documentos que hay que acompañar a la solicitud de matrícula.

Por lo que respecta al listado de los libros de texto que los alumnos deben adquirir para el correcto desarrollo y seguimiento de la materia, hay un centro (Fuente $[72]^{64}$ ) que establece uno para el área de Educación Física en $1^{\circ}, 3^{\circ}$ y $4^{\circ}$ de E.S.O., pero sólo para los alumnos exentos por motivos físicos.

En cuanto a los documentos que deben acompañar la matrícula en el momento de formalizar esta, hay varios ejemplos en Internet:

"Para los alumnos exentos en Educación Física: Certificado oficial del médico especialista, con el motivo de la exención" (Fuente [5] $]^{65}$ )

“e) Certificado médico: Los alumnos que estén exentos para la práctica de Educación Física” (Fuente [6] ${ }^{66}$ )

"Los alumnos que soliciten dispensa o adaptaciones en la asignatura de Educación Física deberán presentar Certificado Médico Oficial." (Fuente $\left.[28]^{67}\right)$

Parece obvio que, en muchas ocasiones, se equipara la dispensa con la adaptación curricular o, al menos, se sitúan al mismo nivel. Si la adaptación curricular, a la que aludiremos en multitud de ocasiones a lo largo de esta tesis, es el conjunto de

\footnotetext{
${ }^{63}$ En el Anexo 3 se encuentra una copia de esta carta.

${ }^{64}$ http://www3.planalfa.es/cmariaferrol/libros.htm

${ }^{65}$ http://centros4.pntic.mec.es/ies.vegas.bajas/secretaria.htm

${ }^{66} \mathrm{http}: / /$ www.colegio.unamuno.com/downloads/reglemento.doc

${ }^{67}$ http://centros4.pntic.mec.es/ies.diego.marin.de.aguilera/info/paginas/P_mat.htm
} 
ajustes o modificaciones que se introducen en la planificación educativa de cada uno de los niveles de concreción curricular (centro, etapa, aula, grupo, individual), para favorecer la adquisición de las capacidades básicas contempladas en la propuesta curricular oficial, a la vez que permite ofrecer una respuesta educativa integral a las necesidades educativas de los alumnos de la diversidad ${ }^{68}$, no es de recibo dicha equiparación (Pérez y Suárez citados en García y Garrido, 2000).

Además, entre las finalidades de la adaptación curricular se encuentra atender a la diversidad del alumnado en un ambiente de normalización educativa; satisfacer las necesidades individuales y colectivas que presentan los alumnos; facilitar que cada alumno pueda conseguir sus objetivos con el mayor grado posible de participación en la dinámica general del aula; prevenir la aparición o intensificación de necesidades educativas especiales a través de un planteamiento educativo adecuado (ibídem), lo cual la sitúa en una órbita totalmente alejada de la propuesta de respuesta en términos de exención.

Hecha esta aclaración terminológica, sirva como ejemplo lo expuesto anteriormente de la Fuente [28]. No es el único caso que se ha encontrado que emplee dichos conceptos con esos usos, concediendo dispensas o exenciones cuando se solicitan adaptaciones curriculares, lo cual hace entrever un desconocimiento de lo que estas son. La Fuente $[31]^{69}$ puede ser otro claro ejemplo al respecto:

"Los alumnos/as que hayan solicitado adaptaciones curriculares y tengan concedida la exención de determinados contenidos procedimentales...” (Fuente [31])

La Fuente [51] también presta una relativa dedicación al asunto de la exención y, en particular, a su solicitud. Plantea al alumno que para justificar esta circunstancia debe rellenar un impreso de solicitud de dispensa o exención de actividades prácticas en la

\footnotetext{
${ }^{68}$ Para esta cuestión de las adaptaciones curriculares recomendamos las lecturas: Contreras (1998, pp. 95 y ss.), Toro y Zarco (1995), Pérez y Suárez (2004, pp. 95 y ss.), González Manjón (1995), González y Sánchez (2003, pp. 575-581) y Gallego y Vicente (2003, pp. 125-128).

${ }^{69}$ http://www.instituto-generalife.com/ef.htm
} 
asignatura de Educación Física ${ }^{70}$, acompañándolo del pertinente certificado médico oficial. En este impreso se pueden solicitar dos medidas: la dispensa de la asignatura por ser mayor de 25 años -cosa totalmente legal-, y la exención total o parcial de la parte práctica de la asignatura, lo cual no entra dentro de las posibilidades que nos brinda la ley. Lo peor de todo es que da a entender que la petición de la exención se encuentra recogida en la Orden de 10 de julio de 1995.

En relación a este asunto de la documentación a presentar para matricularse en la E.S.O. y $1^{\circ}$ Bachillerato, la Fuente $[36]^{71}$ va mucho más lejos:

"Solicitud de dispensa/adaptación de Educación Física, en su caso, facilitado en Secretaría. Después del plazo de matrícula sólo se podrá solicitar cuando los motivos sean por causas sobrevenidas. Los alumnos mayores de 28 años (sic) pueden solicitar la exención de E.F. En los Ciclos Formativos no se cursa esta asignatura."

Lo que hace especial a esta Fuente es que no solo adjunta ese modelo de solicitud de dispensa/adaptación que deberá ser rellenado por los padres, sino que además ofrece otro de informe médico para las dispensas en la asignatura de Educación Física que será cumplimentado por el correspondiente facultativo que reconozca al alumno en cuestión ${ }^{72}$. Por otro lado, desconocemos qué motivos o argumentos emplea para fijar los 28 años como la edad en la que se puede solicitar la exención en las clases de Educación Física, cuando la ley estable que ello es posible a partir de los 25 .

Sánchez (2009) presenta tanto una ficha médica individual del alumno como una FICHA DEEXENT@S DE LA PARTE PRÁCTICA (sic) a la que se debe adjuntar certificado médico ${ }^{73}$.

\footnotetext{
${ }^{70}$ En el Anexo 4 se encuentra una copia de este impreso.

${ }^{71}$ http://www.educarm.es/ies.prado.mayor/D2ESON.doc

${ }^{72}$ Ambos modelos, el paterno y el médico, se encuentran en el Anexo 5.

${ }^{73}$ En el Anexo 6 se encuentra una copia de este impreso.
} 
Por otro lado, algún centro dispone, dentro de las normas escolares que rigen el comportamiento y funcionamiento del mismo, las que regulan la exención de Educación Física (Fuente $[24]^{74}$ ). Por su parte, la Fuente $[4]^{75}$ señala la "Normativa de alumnos exentos o lesionados" y la Fuente [21] ${ }^{76}$ y la [22] recogen la existencia de dos tipos de exentos: totales y temporales de la parte práctica.

Así se muestra la Fuente [47] ${ }^{77}$. Se trata de un Reglamento de Organización y Funcionamiento de un centro educativo que recoge en su artículo 38 el tema de los alumnos exentos de Educación Física. En su apartado 1 señala lo siguiente:

"En determinados casos el padecimiento de determinadas enfermedades o minusvalías, podrán eximir al alumno/a de la impartición de la materia de Educación Física y Deportes (sic), al menos en los aspectos de esfuerzo físico. Esta exención puede ser permanente o transitoria."

Albornoz $\left(2000^{78}\right)$, cuando enumera una serie de elementos que se deben de tener en cuenta para la prevención de accidentes, así como las posibles consecuencias legales que pudieran derivarse de los mismos, señala la exención como uno de ellos.

"El profesor debe ser notificado de los alumnos que sean exentos de la realización de Educación Física..."

En idénticos términos se expresa el "Manual de Seguridad en los Centros Educativos" editado por la Junta de Andalucía (Roldán, 2002 ${ }^{79}$ ):

\footnotetext{
${ }^{74}$ http://www.ccelpilar.com/normas_f.htm

${ }^{75}$ Disponible en dos direcciones de Internet: http://centrosii.pntic.mec.es/ies.miguel.delibes/ef.htm http://www.educa.madrid.org/web/ies.delibes.madrid/ef.htm

76

http://www.juntadeandalucia.es/averroes/iesdonana/departamentos/adufisica/prog\%20educacion\%20fisic a.htm

${ }^{77}$ http://www.elcentroingles.es/espanol/padres/ROF.pdf

${ }^{78}$ http://www.geocities.com/juanmanuellourenco/webteca/albornoz1.htm

79

http://www.juntadeandalucia.es/educacion/www/portal/com/bin/portal/Contenidos/Consejeria/IE/Segurid ad_higiene_en_el_trabajo/Manual_seguridad_centros/manual_de_seguridad.pdf
} 
"La Dirección del Centro notificará al profesor aquellos alumnos que estén exentos de realizar Educación Física."

Antes de pasar a revisar otras fuentes de información podemos detenernos para revisar un documento de carácter interno que todo Departamento de Educación Física y Deportiva debe tener: el Libro de Actas. En él nos podemos encontrar información diversa relacionada con el funcionamiento de la propia programación didáctica, necesidades de material, actividades extraescolares y complementarias, etc. Nosotros hemos revisado algunos de estos libros de actas de los departamentos de los IES objeto de estudio $^{80}$, y hemos podido comprobar como el uso de la exención ha estado plenamente vigente después de varios años de publicarse la Orden de 10 de julio de 1995.

"Acordamos poner para todos aquellos alumnos que en la asignatura de Educación Física, por la razón que fuese: enfermedad, baja prolongada o exentos totales, la realización de los trabajos siguientes...” (24-11-1998)

“...Para los alumnos exentos, se les propone la elaboración de los siguientes trabajos...”(6-10-1999)

En la misma línea, no es extraño encontrar literatura con ideas semejantes que ratifican la persistencia de la exención como práctica diaria habitual en nuestras clases de Educación Física en la E.S.O. y el Bachillerato.

Así por ejemplo, hay editoriales que en las mismas instrucciones de manejo y utilización de sus libros de texto recogen apartados específicos para este tipo de alumnos.

"Investiga: Propone actividades con la finalidad de atender a las diferencias individuales dentro del grupo. Pueden realizarlas los alumnos exentos de la práctica de la Educación Física...” (AA. VV., 2002)

\footnotetext{
${ }^{80}$ Para evitar problemas de carácter ético, solicitamos a los directores de estos centros autorización para hacer uso de esta información y mantenemos en el anonimato de los centros en cuestión.
} 
Por su parte, Lacasa (2002), ofreció en el Seminario de Ejercicio Físico y Salud celebrado en Lleida una comunicación titulada "Alumno «lesionado»... ¿alumno exento?" en la que presentaba un estudio de los justificantes paternos y de los justificantes que elaboran los médicos, en dónde quedó patente la exención como posibilidad real en la Educación Física.

“...una de las cosas que más me llamó la atención en lo que al área de Educación Física se refiere fue la gran cantidad de alumnos que solicitaban la exención de la asignatura por diferentes causas [...] El presente trabajo pretende resaltar cómo gran cantidad de alumnos que presentan justificantes médicos y paternos para resultar exentos en la clase de Educación Física..." (Ibídem)

Entre los asistentes a ese Seminario se encontraba David Ortiz (Fuente [42] ${ }^{81}$ ), estudiante de $4^{\circ}$ curso en el INEFC, quien comentaría lo siguiente sobre dicha comunicación:

\begin{abstract}
“[...]
...he estado durante 1 mes haciendo prácticas didácticas en un centro escolar. En todas las sesiones me he encontrado con alumnos exentos de práctica física. Los motivos explicados eran variados, algunos de ellos eran auténticas historias más propias de un guión de película que de cualquier otra cosa.

...en secundaria y bachillerato el número de alumnos exentos es mucho mayor... ¿Por qué? Tiene fácil explicación. Las edades que comprenden la secundaria y el bachillerato son edades difíciles, aparece la adolescencia y es una época de cambios constantes tanto físicos como mentales. Todo ello origina que los alumnos den gran importancia a las relaciones sociales, a la imagen corporal, a la belleza exterior... y éstos son motivos que explican la ausencia de alumnos en las actividades físicas.” (Énfasis mío)
\end{abstract}

Incluso desde los escritos surgidos al amparo de organismos oficiales el asunto de la exención se reconoce como un hecho presente en la actualidad. Cuando nos encontramos con este tipo de alumnos con necesidades educativas especiales, como apunta López González (1997, p. 13), “...en la mayoría de los casos ante el área de Educación Física el problema era y es solucionado con una privación o exención de la práctica de la actividad motriz en el aula.”. Por su parte, González de Aledo (1995) señala, dentro del apartado de la Atención a la Diversidad, a estos "Alumnos exentos"

\footnotetext{
${ }^{81} \mathrm{http}: / /$ www.deporteyciencia.com/article.pl?sid=02/05/14/1623202
} 
como uno de los grupos a los que hay que dar respuesta en nuestra labor educativa en el aula.

Un claro ejemplo del asentimiento y utilización que la administración pública realiza del término exento lo encontramos en la Junta de Andalucía que, a través de su Consejería de Educación, dicta la Orden de 7 de abril de 2006 por la que convoca proyectos educativos para participar en el programa «El Deporte en la Escuela» para el curso escolar 2006-2007 (BOJA 08-05-2006). En esta Orden se establece que, entre otros documentos, los centros deberán presentar medidas de integración de alumnado de necesidades educativas especiales y de alumnos y de alumnas exentos de Educación Física. Es decir, da por hecho que existe alumnado exento al que trata de forma paradójica, es decir un mismo alumno puede estar exento de Educación Física pero sí puede participar en sus programas de deporte escolar fuera del horario lectivo.

En este sentido, Santoja et alia (2004, p. 15) ratifican esta metáfora cuando plantean la existencia de muchos escolares que están exentos de la Educación Física pero participan por las tardes jugando al fútbol, baloncesto u otros juegos y deportes.

También puede darse la exención si un alumno tiene determinados problemas de tipo motor, llámeseles patologías severas. Bistuer (1996, p. 37) afirma que "Otros casos más graves de cifosis (debidas a osteocondritis, por ejemplo) pueden ser objeto incluso de una exención total de la Educación Física.”. En este supuesto de la cifosis, Arráez (2001, p. 15) corrobora esta opinión al afirmar que “...es cierto que en los casos más graves la actividad físico deportiva puede estar totalmente contraindicada."

Tercedor et alia (2001, p. 202) dan por supuesto que sí existen exentos, pues toman como cuestión fundamental para reflexionar acerca de la coherencia y calidad de la programación de aula del profesorado de Educación Física la siguiente presunta: “; $S e$ busca la integración de los alumnos exentos de práctica de actividad física explicitando para ellos objetivos y contenidos específicos?”. 
Zucchi (2004), cuando esboza los factores que determinan el ingreso, la permanencia y la participación en las prácticas corporales (a lo que él denomina dialéctica de la inclusión-exclusión), señala como cuarto y último el de la discapacidad.

Tierra (2001) plantea la existencia de un tipo de alumno exento que es sometido a cierta marginación ya que ni tan siquiera asisten a clase.

"Por una parte, los alumnos y alumnas son marginados, estando exentos de las clases de Educación Física y la mayoría de ellos/as incluso ni observa a sus compañeros mientras interactúan.” (op. cit., p. 140)

Además, aunque ajenos a la discapacidad motora o cualquier otra, la exención también puede aparecer por otras causas como un hecho plenamente consumado en nuestras clases. Así lo manifiesta Mora y Carranza (1999) al reflexionar en torno a las interculturalidad (asociado a cuestiones de índole religiosas) y la Educación Física ${ }^{82}$.

“QQué hacer con el chador en las clases de educación física, o con la exención de las sesiones con motivo del ayuno propio del mes de Ramadán en los y las adolescentes islámicos?” (op. cit., p. 7)

Este asunto es corroborado por algunas noticias similares aparecidas en prensa.

"En algunos colegios los alumnos musulmanes quedan exentos de la clase de Educación Física durante el Ramadán para evitarles la tentación de beber agua en la ducha posterior.” (Periódico La Vanguardia, 26-10-2003)

"Una niña paquistaní escolarizada este año se niega a hacer gimnasia por motivos religiosos.

Una niña paquistaní de 13 años, que estudia $2^{\circ}$ de E.S.O. en el instituto "Bahía de Almería" de la capital almeriense, se niega a hacer Educación Física por motivos religiosos [...] Según el delegado de Educación, los profesores creen que, además de los impedimentos de la familia para que haga educación física

\footnotetext{
${ }^{82}$ Valle (2002, en la Fuente [52]), experta pedagoga en asuntos de la atención a la diversidad, plantea que han cambiado las poblaciones objeto de estos estudios. Antes solo estaban las relacionadas con discapacitados sensoriales y físicos, y ahora se incorporan, además de los superdotados, las provenientes de otras culturas. Por otro lado, señala que la educación secundaria es la etapa más problemática para que se consiga una integración en un marco normalizador.
} 
por considerar que se trata de una actividad contraria a su religión, influye el hecho de que las clases son mixtas." (Fuente [53] $\left.{ }^{83}, 26-02-2002\right)$

\section{"AL MENOS EN LAS CLASES DE GIMNASIA}

Alumnas árabes de Lérida piden ayuda al colegio para que sus padres no les exijan usar el velo

...niñas y adolescentes árabes que estudian en colegios e institutos de la localidad de Lérida y que tienen edades comprendidas entre los ocho y dieciséis años, han pedido a los profesores de sus respectivos centros educativos que intervengan ante sus padres para que no les obliguen a usar velo, al menos en las clases dedicadas a la gimnasia." (Fuente [63] $\left.{ }^{84}, 26-10-2004\right)$

\section{"El velo y las clases de gimnasia}

[...]

Lo que no refleja este artículo... es lo que está ocurriendo con las clases de educación física. Caso de que en el Instituto San Lorenzo de El Escorial haya clase de gimnasia ¿participa en ella la pequeña Elidrisi? y si en el instituto de San Lorenzo de El Escorial hacen las niñas deporte, ¿Fátima y sus amigas marroquíes también lo hacen?

[...]

Nunca se ha visto a una esquiadora, corredora, nadadora, ni tan siquiera a una jugadora de golf, que practique su deporte con hiyab, así que es de suponer que, o en los colegios no se hace ni deporte ni gimnasia, o todas estas niñas que asisten con velo a clase están siendo eximidas de las normas que rigen, o deberían regir, en su centro escolar." (Alicia Delibes, Fuente [70] ${ }^{85}, 04-03-$ 2002)

De fuera de España llegan noticias que reflejan que este fenómeno también se empieza a producir.

"Un liceo público cercano a París expulsa a dos alumnas por llevar el velo islámico «con ostentación»

\section{[...]}

Además, los responsables del liceo, en el que las hermanas estudian, han motivado su decisión en que "persisten en su negativa a llevar una vestimenta compatible con el buen desarrollo de la educación física y deportiva», puesto que se negaban a desprenderse del velo y de la túnica para la clase de gimnasia." (Fuente [60] ${ }^{86}, 24-09-2003$ )

\footnotetext{
${ }^{83}$ http://www.elmundo.es/elmundo/2002/02/25/sociedad/1014650379.html

También disponible en la Fuente [53-1] (25-02-2002)

${ }^{84}$ http://www.libertaddigital.com/historico/2004/10/23/sociedad.htm

${ }^{85}$ http://www.libertaddigital.com/opinion/alicia-delibes/el-velo-y-las-clases-de-gimnasia-8315/

${ }^{86}$ http://www.elmundo.es/elmundo/2003/09/24/sociedad/1064399820.html
} 
En este sentido, Tajadura (2009, p. 800) recoge dos sentencias del Tribunal Supremo Administrativo Alemán en las que se reconoce el derecho de unas alumnas $a$ obtener una exención de la obligatoriedad de participar en las clases de Educación Física invocando convicciones religiosas islámicas.

En otro orden de asuntos, está comprobado que se producen una gran cantidad de embarazos no deseados en nuestro país en las jóvenes menores de 19 años ${ }^{87}$. Ante este hecho, ¿qué es lo que ocurre en las clases de Educación Física con las posibles alumnas que se encontrasen embarazadas? ¿El hecho de que una alumna esté embarazada la sitúa en una realidad de necesidades educativas especiales en nuestra área? ¿De qué tipo? ¿Se podría llegar a originar, por motivos de salud de la propia madre o del feto, la concesión de una exención (en cualquiera de los tipos que nos encontraremos en los apartados siguientes)? Esta particular situación no está del todo recogida en la Orden de 10 de julio de 1995 ya que esta únicamente se refiere a alumnos con necesidades educativas especiales asociadas a discapacidad motora o sensorial, temporal o permanente, lo cual no tiene por que ser el caso de una alumna en estado.

Como dato, en Chile existe un Reglamento para alumnas Embarazadas y Madres $^{88}$ que surge de la necesidad de ofrecer una respuesta a esta posible -realsituación. Con respecto a la Educación Física, se establece lo siguiente:

"Artículo 9": En lo relativo a la asistencia a clases de Educación Física, las alumnas embarazadas, deberán asistir en forma regular, siguiendo las

\footnotetext{
${ }^{87}$ Para el año 2007 se hablaba de una cifra en torno a 10.700 adolescentes menores de 18 años según el Ministerio de Sanidad (Fuente [39]). En el 2000 más 18.000 españolas menores de 19 años se quedaban embarazadas al año. De ellas, cerca de 800 eran casi unas niñas de entre 11 y 15 años (Fuente [40] y [41]). Por su parte, Salamanca (2007) señala que los embarazos en niñas menores de 15 años aumentó un $76 \%$ entre el 2001 y el 2005. En este año, 153 madres de esa edad tuvieron su primer hijo. En Valladolid, en el 2007 hubo 40 nacimientos de niños cuyas madres no superaban los 18 años. Incluso en 19 ocasiones el niño fue concebido por madres menores de 16 años (Periódico El Día de Valladolid, 12-04-2008) Por otro lado, la Consejería de Educación de la Junta de Castilla y León parece que es sensible a este fenómeno social cada vez más habitual y

88

http://www.mineduc.cl/usuarios/convivencia_escolar/doc/201103050209570.Reglamento_de_las_alumna s_en_situacion_de_embarazo_y_maternidad.pdf
} 
orientaciones del médico tratante, sin perjuicio de ser evaluadas en forma diferencial o ser eximidas en los casos en que por razones de salud así procediera.

Las alumnas que hayan sido madres estarán eximidas del Subsector de Educación Física hasta el término del puerperio..."

Con el género como fondo de la cuestión, se observa que la exención de las clases de Educación Física puede tener mayor cabida entre las alumnas que los alumnos, aunque sea adoptada unilateralmente de forma voluntaria.

"Muchas de las alumnas en general desertan de la clase de educación física por diferentes motivos tal como: 1. Flojera 2. Problemas médicos 3. Menstruación” (López, en Fuente [43] ${ }^{89}$ ).

En una investigación llevada a cabo por López Pastor et alia (2003, p. 24), en la que se acercan al mundo de las experiencias vividas en la Educación Física escolar por alumnos en fase de formación para ser profesores, constatan que en Secundaria, durante la década de los noventa, empezaron a surgir experiencias negativas respecto al deporte y la Educación Física. Incluso insinúan que algunos alumnos fueron aprendiendo estrategias de evitación durante sus clases de Educación Física. Finalmente, se afirma que este tipo de experiencias negativas son mucho mayores en las alumnas que entre los alumnos, lo cual nos induce a pensar que también ocurriría así con la elaboración y puesta en práctica de estrategias de evitación.

Finalmente, como curiosidad y para mostrar el valor o sentido que aún hoy día tiene el concepto de exento, se reproducen algunas de las definiciones que se han encontrado de dicha palabra en diccionarios de uso actual. Lo llamativo no es la definición en sí, que es como cualquier otra, sino el ejemplo que emplean para aclarar su significado.

"Exento, ta: libre de tener que hacer una cosa, de una obligación o una culpa. Se utiliza seguido de la preposición de: Tiene la espalda mal y por eso está exenta de hacer gimnasia." (Diccionario ESPASA de la lengua española, 2004. Énfasis mío)

\footnotetext{
${ }^{89}$ http://www.saludactual.cl/spm/educacion-fisica.php
} 
"exento, - a:.. Estoy exento de gimnasia. I'm excused from PE." (Diccionario Oxford Pocket, 2005. Énfasis mío)

"exento, ta adj. exempt: estar exento de una obligación...; Hoy estoy exenta de hacer gimnasia - I'm excused from gym today." (Diccionario Cambridge Compact, 2009, p. 929)

Es curioso cómo estos manuales de tipo ortográfico tienden a ejemplificar el concepto de exento aplicándolo a nuestras clases.

"Decimos que Juan está exento de hacer gimnasia cuando no está obligado a hacerla.” (Álamo, 2010, p. 111)

\subsection{3.- EXENCIÓN EXCLUSIVAMENTE DE LA PRÁCTICA PARA ATENDER A LA DIVERSIDAD}

En el apartado anterior, la Fuente [1] ofrecía una visión global de lo que se puede entender por exento. Conviene recordar lo que afirma:

"Son aquellos alumnos [refiriéndose a los alumnos exentos] que por razones médicas, y habiéndolo justificado previa y debidamente, por medio de un certificado médico oficial, no están capacitados para realizar parte o la totalidad de los contenidos prácticos de la asignatura de Educación Física, con lo que los contenidos procedimentales de dicha asignatura se evaluarán por medio de trabajos escritos." (Aclaración mía)

Esta es la concepción de la exención que predomina en la literatura de nuestra disciplina. Es decir, lo de estar exento en Educación Física no deja de ser, como poco, imposible, pues es tanta la diversidad de sus contenidos curriculares que se pueden ofrecer posibilidades para todos ${ }^{90}$. En el caso de que verdaderamente exista un alumno

\footnotetext{
${ }^{90}$ En el anterior desarrollo curricular se distinguían tres tipos de contenidos: conceptos, procedimientos y actitudes. Ahora, con la entrada en vigor del DECRETO 7/2002 de 10 de enero por el que se establece el Currículo de la Educación Secundaria Obligatoria de la Comunidad de Castilla y León (BOCyL 16-012007), a pesar de que desaparece este tipo de nomenclatura, se sigue apreciando la distinción en función del verbo con el que se redactan los objetivos, contenidos y criterios de evaluación.
} 
que reúna las características que le permitan acreditar dicha condición, la Educación Física estará presente en su formación pero aplicándole una exención de la práctica.

“...Hemos de recordar que no existen los alumnos exentos totales, ya que la Educación Física es una materia obligatoria, pero sí los exentos de unos determinados contenidos.

[...]

Son aquellos casos (refiriéndose a los alumnos con discapacidad física grave y permanente) en los que existe una patología crónica grave que impide la práctica de cualquier tipo de actividad física." (Fuente $[7]^{91}$ Fuente [2Bis $]^{92}$. Aclaración mía)

"Con la entrada en vigor de la nueva reforma educativa, se elimina la exención total del área de Educación Física. Todos los alumnos de $3^{\circ}$ y $4^{o}$ de ESO que demuestren, previo informe médico, algún impedimento físico recibirán un tratamiento individualizado o quedarán exentos de la parte práctica, debiendo realizar solamente los contenidos de los diferentes objetivos programados a nivel teórico (pruebas escritas, entrega de trabajos y cuestionarios de las unidades del libro de texto)." (Fuente $[8]^{93}$ )

"Alumnos lesionados o incapacitados.... Si lo están para toda la Unidad didáctica, quedan exentos de los contenidos y objetivos motrices..." (Fuente $[9]^{94}$ )

\section{"IV. Alumnos con problemas motrices}

Pueden estar exentos de la Educación Física Práctica [a pesar de que anteriormente, en el apartado de Metodología y Programación, se haya afirmado que en la enseñanza no se debe hablar de clases teóricas y clases prácticas...]" (Fuente $[37]^{95}$. Aclaración mía)

\footnotetext{
${ }^{91} \mathrm{http} / / \mathrm{www}$. institutonervion.es/programaciones_didacticas/DEPEDF__programaciones.html 92

http://iesmarcilla.educacion.navarra.es/menu/codigo//departamentos/educacion_fisica/atencion_diversida d.htm

${ }^{93}$ http://www.iespadrepoveda.com/documentos/cat_view/75-educacion-fisica.html

${ }^{94}$ http://www.e-ducalia.net/temarios/S.E-Tema_37_\%20U.D.pdf

${ }^{95}$ http://centros5.pntic.mec.es/ies.ezequiel.gonzalez/PCBACH.htm
} 


\section{“EXENCIÓN DE EDUCACIÓN FÍSICA \\ $[\ldots]$}

SOLICITA: Que le sea concedida la Exención de las Prácticas de la asignatura de Educación Física durante el periodo expresado en el Informe Médico que adjunto, quedando sujeto a la calificación de la parte teórica." (Fuente [83])

Por lo tanto, nadie debe quedar excluido de sus conocimientos y saberes (aunque parece ser que sí de su práctica), pues son tantas y tan importantes las teorías, reglas, normas y principios en los que dicha práctica se sustenta, que todos los alumnos deben conocerlos.

"A nuestro entender la exención total no debiera existir. Nos apoyamos para mantener la anterior aseveración en un hecho evidente: La Educación Física es en la actualidad algo más que una colección clasificada de ejercicios; es una ciencia aplicada que tiene unas bases teóricas bien establecidas y cuyo conocimiento es de interés para cualquier persona que ingrese en el sistema educativo [...] Sería en esta segunda parte de la asignatura (refiriéndose a la práctica de ejercicios adecuados) donde podrían teóricamente darse las exenciones por razón de enfermedad o minusvalía..." (Mantas, 1995, p. 404. Aclaración mía)

“Ahora bien, estos mismos alumnos, que por sus características particulares no puedan seguir el desarrollo normal de la asignatura total o parcialmente no deben ser apartados de la misma, sino que al contrario debe establecerse un cauce de participación que permita una integración del alumno, tanto en su propio grupo mediante tareas de apoyo (arbitraje, cronometradores, etc.), como en los contenidos de la asignatura (elaboración de trabajos con apoyo bibliográfico). En este último caso se intentaría dar a estos alumnos una base teórica y cultural que compense su falta de base práctica de la que disponen sus compañeros, para que al igual que ellos, puedan obtener una aptitud favorable hacia la práctica de actividades físico-deportivas cuando desaparezca la causa que impida esa práctica o bien busque fuera del ámbito escolar aquellas instituciones y organismos que puedan facilitarle el acceso a dicha práctica físico-deportiva.” (Hernández y Martínez, 1989, p. 50)

“...la exención de los contenidos teóricos de la asignatura por motivos de imposibilidad física acaba con toda posibilidad de que los alumnos implicados adquieran unos conocimientos teórico-culturales que:

a) Formen parte de su propio bagaje cultural.

b) Facilite la comunicación y comprensión con el grupo en que vive respecto a la actividad físico-deportiva, incluso como fenómeno de relación social, nacional e internacional. 
c) Facilitar..., una mentalización positiva hacia la práctica de actividades deportivas-recreativas de lo que podrían beneficiarse sin riesgo para su salud.” (op. cit., pp. 51-52)

"Los alumnos y alumnas que tengan algún tipo de exención de la práctica, total o parcial,... en ningún caso estarán exentos de la asistencia y de la parte teórica." (Fuente $[76]^{96}$ )

"Aquellos alumnos que están exentos de la realización de actividades de educación física a causa de lesiones o enfermedades normalmente tienen que realizar algún tipo de actividad que sea compatible con dichas dolencias. En las exenciones parciales, puede tratarse de actividades físicas que el alumno pueda realizar a pesar de su enfermedad o lesión. En otros casos, se pide a los alumnos que realicen actividades teóricas o de naturaleza no física relacionadas con la materia, como, por ejemplo, trabajos escritos, como sucede en Bélgica (Comunidad francesa), labores de arbitraje, ofrecer feedback u ocuparse del marcador, como sucede en Irlanda o Italia. Esto permite garantizar que el alumno aprenda algo en las clases, aunque no participe activamente en las mismas. También contribuye a disuadir a los alumnos de no asistir a las clases de educación física para hacer deberes o trabajos de otras asignaturas.” Comisión Europea, informe Eurydice, 2013, p.28. Énfasis mío)

Puede que sea el propio Currículum Oficial el que "promueva" este tipo de Educación Física "sin práctica" pues, a pesar de que advierte de la necesidad de trabajar conjuntamente los tres tipos de contenidos (conceptos, procedimientos y actitudes), se insinúa que puede haber situaciones o circunstancias especiales que aconsejen el que se opte de forma específica por uno de ellos (MEC, 1989, p. 204). Quizás todo el bagaje, experiencias y formas de actuar desde 1961, cuando sí se permitía la dispensa, hasta la aparición de la Orden de 10 de julio de 1995, hayan marcado las praxis posteriores a esa última fecha que contemplan la posibilidad de que la exención no puede existir sobre la totalidad de la materia ya que la Educación Física no tiene solo carácter procedimental.

“...A partir de estas premisas no hay justificación alguna para que un alumno se encuentre exento de la disciplina de Educación Física, sobre todo teniendo en cuenta que no sólo es un área procedimental, sino que también tiene contenidos conceptuales y actitudinales." (Editorial revista Apunts ${ }^{97}, 1995$, p. 4)

\footnotetext{
${ }^{96} \mathrm{http} / /$ www.iesgaherrera.com/ef/Archivos/Comunicaciones/GSOb\%20Con\%20CE.doc

${ }^{97}$ Revista especializada en Educación Física y Deportes.
} 
Incluso, a pesar de reconocer la importancia (por otro lado, indiscutible) que la práctica tiene sobre la Educación Física, se transmite la sensación de que el alumno que no pueda hacer dicha práctica tiene que conocer sus principios teóricos aunque solo sea para, entre otras cosas, poder evaluarle y justificar así la emisión de un juicio de valor que sirva para su calificación, "asegurando", de alguna forma, la presencia de la Educación Física en los currículos ${ }^{98}$.

“...no hay que perder de vista que lo más importante en esta asignatura no es la mera asimilación de sus bases teóricas, sino la aplicación de las mismas, no pudiendo decirse que alguien posee una buena y completa formación en este campo sino cuando además de estos conocimientos, su desarrollo físico, habilidades e inteligencia motoras han sido educados de la única forma en que esto es posible: con la práctica de los ejercicios adecuados [...] No a la exención total (se mantendría la obligación de asistencia a clases y examen teórico en todos los casos)." (Mantas, 1995)

"Nuestra asignatura es eminentemente práctica, y es muy raro encontrar a alguna persona -sea de la edad que sea-, que no pueda ni deba realizar ningún tipo de ejercicio físico [...] Este certificado de exención total debería presentarse a principio de cada curso académico y este tipo de alumno debería ser evaluado por sus conocimientos teóricos...”. (Casimiro, 1992, p. 85)

Se comprueba que la explicación que predomina se apoya en el concepto de "exención total", el cual permite imaginar la "exención parcial".

Para acercarnos más de esta clasificación se puede utilizar la establecida en 1993 por la Dirección General de Centros de la Consejería de Educación, Cultura y Deportes del Gobierno de Canarias ${ }^{99}$ a través de la Resolución de 15 de julio que regulaba la organización y funcionamiento de los Centros de Enseñanzas Medias dependientes de dicha consejería. En ella se detalla lo siguiente:

“10.2. La exención en Educación Física tendrá dos modalidades: exención total y exención parcial.

\footnotetext{
98 Comparto con Melgar (1992, pp. 210-211) que "No son válidas las fórmulas exportadas de concepciones tradicionales de una enseñanza academicista que tratan la evaluación en términos de éxito o fracaso y que algunos adoptan con el fin de 'prestigiar' la asignatura”.

${ }^{99}$ Fuente [38]
} 
La exención total consistirá en la dispensa absoluta de cursar estudios y realizar los ejercicios previstos en la Programación del Seminario. Se concederá únicamente en aquellos casos en que las condiciones de minusvalía, enfermedad u otras causas así lo aconsejen. El alumno/a será calificado y en las actas figurará con la leyenda de EXENTO. En todo caso, esta circunstancia no puede suponer la marginación del alumno/a por lo que el profesorado propiciará su integración con las medidas que estime oportunas.

La exención parcial supondrá una dispensa a determinados ejercicios. Deberá, por tanto, el alumnola cursar la parte teórica de la materia y realizar los restantes ejercicios que con carácter general se encuentren programados por el Seminario. Tendrá carácter de "adaptación curricular" y la evaluación se llevará a cabo teniendo presente esta circunstancia. [A continuación dispone el procedimiento para la concesión de exenciones.]” (Aclaración mía)

Estos dos conceptos -que actualmente no tienen fundamento legal algunopermiten acomodar las prácticas antiguas a la nueva filosofía educativa sin que nada cambie, sirven para articular con cierta coherencia pasado y presente, para compaginar la exención de siempre con las nuevas exigencias de "adaptaciones curriculares".

El argumento general que subyace es muy simple. Desde la aparición del diseño curricular de la LOGSE, se diversifica la gama de contenidos (conceptos, procedimientos y actitudes). Por otro lado, se prohíbe la exención y obliga a adaptar el currículo a las necesidades individuales. En esta tesitura, se inventa la "exención parcial", es decir, se exime solo de la práctica que, en un pequeño salto, se identifica con los contenidos procedimentales motrices.

Otro ejemplo más de esta realidad se encuentra en el artículo elaborado por Tejero et alia (2003) en el que establecen unas directrices para evaluar al alumnado de secundaria en Educación Física basado en su propia experiencia educativa y en el convencimiento de que no toda la práctica de la Educación Física es necesariamente motriz. En él señalan a los alumnos exentos de realizar la parte práctica como un colectivo más dentro de la diversidad del alumnado que se han encontrado en sus clases. De hecho, a pesar de reconocer previamente que no existen alumnos exentos en 
Educación Física, plantean algunas pautas para realizar la evaluación de los alumnos/as exentos de realizar la parte práctica ${ }^{100}$.

"De acuerdo con la normativa vigente no existen alumnos/as exentos de cursar el área de Educación Física...; por tanto, todos los alumnos/as menores de esta edad [se refiere a los menores de 25 años] deben estar evaluados en EF; la pregunta entonces es la siguiente ¿cómo se puede evaluar a los alumnos que por razones de impedimento físico no puedan realizar la práctica motriz de la asignatura?” (Tejero et alia, 2003, p. 44. Aclaración mía)

Por cierto, a pesar de que la Orden de 10 de julio de 1995 no establecía en ningún momento la distinción o separación explícita entre lo práctico y lo no práctico, hay quienes sustentan su actuación en una interpretación de la citada Orden en esos términos, lo cual, como se ha podido observar anteriormente, suele ser lo habitual aunque no de manera explícita.

\section{“EXENTOS}

Los alumnos que legalmente acrediten estar dispensados de la práctica de la asignatura (O.M. 10 de julio de 1995)...” (Fuente [10] ${ }^{101}$ )

"Las exenciones aquí citadas no han de ser necesariamente por el total de la asignatura, pueden afectar tan sólo a la parte práctica, pero no así a la teoría.” (Fuente [18] ${ }^{102}$ )

"De acuerdo con la normativa vigente, aquellos alumnos con alguna necesidad educativa especial..., podrán solicitar la exención de la parte práctica de la asignatura... (R.D. 800/1995)” (Fuente [77] ${ }^{103}$ )

\footnotetext{
${ }^{100}$ Para acercarnos más a este asunto de la evaluación del exento en Educación Física, recomendamos la lectura de Pérez Cortés et alia (1997).

${ }^{101}$ http://www.educastur.princast.es/ies/perezaya/EducaciFisic/EXENTOS.htm

102 http://intercentres.cult.gva.es/intercentres/03001908/ibad/general/Guia_Estudiante.doc

103 http://iesreypelayo.com/oficial/docinsti/
}

Por otro lado, es destacable que el Real Decreto que aparece en esta fuente nada tiene que ver con los alumnos con necesidades educativas especiales ni con la educación, sino que se trata del documento que regula el acceso a determinados sectores de la función pública de los nacionales de los demás estados miembros de la Unión Europea (BOE 7-6-95). 
Emerge así una nueva Educación Física "sin práctica", una curiosa forma de adaptarse a los nuevos tiempos haciendo lo mismo de siempre, una imitación camaleónica que impide ver que las cosas continúan como estaban.

"Los alumnos oficiales de Enseñanza Secundaria Obligatoria y Bachillerato que tengan alguna imposibilidad física que no les permita la práctica de la materia... En todo caso, la exención se aplicará, exclusivamente, a las clases prácticas." (Fuente $[11]^{104}$ )

Estrechamente relacionados con estos conceptos (a veces se utilizan con el mismo valor) aparecen los de "exento permanente" y "exento temporal". No son más que una forma de categorizar o graduar la exención que presentan -que se concede a- los alumnos. Aunque ya se han recogido algunos ejemplos en los que se emplean estos términos ${ }^{105}$, aún se pueden encontrar alguno más.

Así, Viciana (2002), cuando explica el proceso de construcción de un cuadro de temporalización en Educación Física, señala que el apartado de Observaciones puede servir para prever la participación de los exentos de práctica física [de nuevo Educación Física "sin práctica"] tanto para los permanentes (enfermedades $o$ impedimentos médicos justificados) como para los temporales (esguinces, resfriados, etc.). Como se ha dicho anteriormente, la Fuente [21], en el capítulo de su programación didáctica dedicado a las exenciones, señala dos posibles formas de producirse estas: para todo el curso o durante un periodo de tiempo. En ambos casos, la exención se limita exclusivamente a la parte práctica. En similares términos se pronuncia la Fuente [22], denominando a los alumnos que se encuentran en esas situaciones exentos totales y exentos temporales, respectivamente. Véanse algunos casos más.

“...EXENCIONES PARCIALES O TOTALES en la práctica de la actividad física. En las primeras, siempre que el tiempo y el espacio lo permitan, se

\footnotetext{
${ }^{104} \mathrm{http}: / / \mathrm{www}$. iesconcepcionarenal.com/taboleiro/dispensas.htm

${ }^{105}$ Especialmente relevante es el apuntado por la Comisión Europea: "Por diversos motivos de salud, en ocasiones los alumnos no pueden practicar la educación física. En estos casos, pueden resultar exentos de realizar determinadas actividades de forma temporal o permanente. El que dicha exención sea total o parcial depende de si el alumno puede o no realizar al menos alguna de las actividades en cuestión." (Comisión Europea, informe Eurydice, 2013, p. 27. Énfasis mío)
} 
elaborarán sesiones específicas o incluso Unidades Didácticas personalizadas. En el caso de las segundas (muy poco frecuentes), se evaluará al alumnado sin tener en cuenta la parte práctica pero ampliando en su lugar la evaluación de tipo teórico." (Fuente [33] ${ }^{106}$ )

"Las solicitudes de exención de Educación Física... se indicará si la exención será total o sólo limitada a determinados ejercicios o actividades..." (Fuente $[34]^{107}$ )

En algunos escritos se produce el encuentro o presencia de ambos tipos de exención (total-parcial y permanente-temporal).

"Las solicitudes de dispensa de Educación Física deberán acompañarse del respectivo informe médico, en el que se indicará si la exención deberá ser para toda la actividad física o sólo limitada a determinados ejercicios y actividades, especificando cuáles. Igualmente, se indicará si la exención debe ser permanente o temporal, según la naturaleza del motivo que la aconseje." (Fuente [29] ${ }^{108}$ )

La Fuente [36], en el informe médico que propone, establece tres clases de dispensas que el médico podrá recomendar:

"Parcial: Sólo puede realizar alguna actividad...

Temporal: Indicar el tiempo estimado...

Definitiva: No puede realizar ninguna actividad física durante todo el año."

Igualmente, Pérez Cortés et alia (1997) establecen tres tipos de alumnos exentos de actividad física según sean las afecciones detectadas en ellos.

“- Totales: no pueden realizar actividad física.

- Parciales: están impedidos para algunas actividades.

- Temporales: no realizan actividad durante el tiempo de su recuperación."

Sin pretender ahondar en las posibles clasificaciones que se encuentran de los alumnos exentos, resulta muy curiosa la propuesta que Rodríguez-Solano (2003) realiza

\footnotetext{
${ }^{106} \mathrm{http}: / / \mathrm{www}$. ieslascumbres.com/programacion.pdf

${ }^{107}$ http://anitaconrad.com/es/info/norm/

${ }^{108}$ http://www.institutovegabaja.com/infogeneral/secretaria.htm
} 
al respecto, diferenciado entre dos tipos de orígenes o causas de la exención: la física o corporal y la actitudinal.

"Podemos encontrar dentro del grupo de los exentos, alumnos realmente lesionados y alumnos vagos o desinteresados que no realizan la clase por todo tipo de excusas." (Ibídem)

Por otra parte, bajo esta Educación Física "sin práctica" subyace la visión hegemónica tradicional de los contenidos de nuestra materia que, como explica Astráin (2002), son las cualidades físicas y las destrezas deportivas. Esta visión reduccionista de los contenidos procedimentales recrea una visión del cuerpo-máquina en la que los sujetos con problemas no tienen cabida, son "parcialmente eximidos", son evaluados por sus conocimientos teóricos.

En dicho planteamiento, para los alumnos con necesidades educativas especiales, los pilares de la lógica interna del área ${ }^{109}$, el cuerpo como instrumento del que nos servimos para realizar las acciones motrices y el movimiento como medio de mejora, logro de metas, etc. (Cuevas, 2002, p. 19), desaparecen y dejan de tener sentido pues se concibe que cuando ese cuerpo está, digamos, "anulado" o, al menos, inhibido por diversas causas físicas, del tipo que sean, no puede haber mejora alguna y se obvia que el objetivo que pretende la Educación Física en términos de integración desde el punto de vista de la singularidad personal es, como señalan Martínez y Martínez (2001), hacer al sujeto consciente de su propia realidad corporal, de sus posibilidades de actuación en el entorno físico y humano, y de sus propias limitaciones (...)de acuerdo con sus capacidades físicas, sus intereses, su ritmo individual (cinético y de aprendizaje), su grado de madurez motriz y sus circunstancias personales".

En fin, esta concepción da lugar a que se aplique una exención total o se ratifique en sus argumentos de una "Educación Física sin práctica", ya que al

109 “El cuerpo y el movimiento son los ejes básicos en los que se debe centrar la acción educativa del Área. En este sentido ha de resaltarse la importancia del conocimiento corporal y sus posibilidades de movimiento [...], da el verdadero sentido de educar de manera integral a través del cuerpo, sirviéndose de él y de sus posibilidades de movimiento, para lograr unos objetivos educativos de carácter más amplio.” (DECRETO 7/2002) 
desaparecer el cuerpo y el movimiento no hay práctica alguna o es suplida por otro tipo de tareas que favorecen una "falsa integración", tal y como señala Ríos (1998b, 2001a, $2001 b)^{110}$.

Si, como asegura Boné y Contreras (1985, p. 60), no es posible un desarrollo integral de la persona si se separa lo corporal de lo afectivo-intelectual, me pregunto qué desarrollo integral ofrece esta "nueva área" sin práctica, y si sigue siendo la misma Educación Física que para el resto de alumnos. ¿Acaso esta "sin práctica" no es una forma de exención?

Llama la atención un hecho contradictorio que aparece con cierta frecuencia: hay escritos que, a pesar de demostrar el conocimiento de la existencia de la Orden de 10 de julio de 1995, postulan supuestos en términos de exención o dispensa ${ }^{111}$, aun a sabiendas de que en dicha Orden se establecía que la exención de cursar esta disciplina se presenta en la actualidad, para alguna de las situaciones previstas en la Orden de 31 de julio de 1961, como una medida improcedente y contraria al principio de adaptación del currículo y de integración que establecen los artículos 36 y 37 de la Ley Orgánica de Ordenación General del Sistema Educativo y el Real Decreto696/1995, de 28 de abril, en su desarrollo.

"Para la dispensa de la asignatura de Educación Física se estará a lo establecido en la O.M. de 10 de julio de 1995.

Las solicitudes de dispensa de Educación Física deberán acompañarse del respectivo informe médico [...] La petición de dispensa tendrá que ser formulada..." (Fuente [29])

"Las solicitudes de exención en Educación Física se regirán por lo dispuesto en la Orden del MEC de 10 de junio (sic) de 1995..." (Fuente [73] ${ }^{112}$ )

\footnotetext{
${ }^{110}$ Huguet (2010, p. 99) recoge un amplio listado de estrategias que no propician una práctica inclusiva de la Educación Física, lo que está en línea con las actividades propias de la falsa integración.

${ }^{111}$ Hecho que se reproducirá en algunas de las programaciones didácticas de los IESs de carácter público de Valladolid analizadas en el Capítulo 8.

${ }^{112}$ http://www.juntadeandalucia.es/averroes/ieslosalamos/doc/DEPYBI.doc
} 
"Los alumnos y alumnas que tengan algún tipo de exención de la práctica, total o parcial, tendrán que justificarlo mediante certificado médico (tal como establece la Orden de 10 de julio de 1995)...” (Fuente [76])

"Partiendo de la Orden de 10 de julio de 1995...

[...]

Las distintas afecciones detectadas en el alumnado nos proporciona tres tipos de alumnos Exentos de actividad física." (Pérez Cortés et alia, 1997)

Se supone que, más que por desinterés en la aplicación de la legislación, lo que se está produciendo en muchos centros sea simplemente una continuidad en el uso de una terminología que no es acorde a las leyes actuales pero que, hasta cierto punto, es entendible por todos. Como ejemplo, la Fuente [74] ${ }^{113}$ articula un apartado para los exentos en Educación Física en el que queda claro que lo que corresponde en los casos de limitación temporal o permanente es una adaptación curricular, estando limitada la dispensa a los mayores de 25 años.

En todo caso, a pesar de ser conscientes de que la normativa es contraria a este planteamiento de la dispensa, pudiera haber momentos en los que "no queda más remedio" que aplicar la exención. Así, Calverol (2000, p. 40), en un estudio sobre la "Atención a las necesidades educativas especiales de los alumnos con discapacidad física en los institutos de enseñanza secundaria de la ciudad de Barcelona", recoge el caso de un alumno que está exento de Educación Física... ya que está afectado de dos discapacidades a la vez, física y sensorial.

No obstante, puede que sí que haya cierto desconocimiento legislativo. Es el caso de un documento (Fuente [35] ${ }^{114}$ ) que, a pesar de estar actualizado a fecha de 2904-1996, sigue haciendo alusión a la Orden Ministerial de 1961 en ese supuesto de que la adaptación curricular no sea posible, motivo por el cual se podrá conceder la exención.

\footnotetext{
${ }^{113} \mathrm{http}$ ://www.educa.madrid.org/web/ies.larra.madrid/alumnos/enferacc/enfacc.htm

${ }^{114}$ http://www.upv.es/ jhueso/lvives/adapta.htm
} 


\subsection{4.- EL PODER DE LOS "PAPELES" MÉdiCOS Y PATERNOS EN LA APLICACIÓN DE LA EXENCIÓN}

Cada vez son más los que defienden que el ejercicio físico es el mejor medio para tratar y prevenir muchas de las enfermedades o alteraciones en las que, hasta ahora, se desaconsejaba realizar el más mínimo movimiento, incluso con fines educativos ${ }^{115}$.

"Numerosos estudios epidemiológicos realizados en los últimos años han constatado los efectos negativos del sedentarismo sobre la salud y, por el contrario, la beneficiosa influencia de la práctica programada y regular del ejercicio físico para el bienestar físico, mental y social de la población.

Pocos dudan ya de que la práctica de ejercicio físico sea uno de los pilares que sustentan las estrategias para la consecución de objetivos de promoción y protección de la salud" (Martín, 1995, p. 19)

De entrada, se puede afirmar que no todo ejercicio físico es saludable. Hay unos ejercicios que están totalmente contraindicados por la peligrosidad que entraña su ejecución y el alto riesgo de desencadenar lesiones en quienes los realizan. Además, hay otros en función de las características de los sujetos que habrían de realizarlos. Como señala Devís y Peiró (1992, p. 65), "Hay dos tipos de ejercicios contraindicados... En segundo lugar, están los específicamente contraindicados. Estos son ejercicios que resultan peligrosos para ciertos grupos de personas que tienen debilidades particulares o están afectados por algún problema o lesión". Guillén (1998a, pp. 106-109) recoge las patologías más frecuentes relacionadas con la actividad físico-deportiva en edad escolar y sus respectivas contraindicaciones $(e . g$., en la osteocondritis deformante juvenil de la cadera, o enfermedad de Legg-Calvé-Perthes, está contraindicada cualquier actividad que involucre a esa zona). Este hecho implica que mientras unos ejercicios sí pueden realizarse, otros no deben, ni por asomo, intentarse.

Pero también hay una serie de patologías (de la Cruz, 1989) o enfermedades agudas (Guillén, 1998b, p. 150), en las que la actividad físico-deportiva está totalmente contraindicada. Autores como Tercedor et alia (2001, p. 201) y Martín Escudero

\footnotetext{
${ }^{115}$ Para este tema del ejercicio físico como estrategia y fuente de salud, vid.: de la Cruz $(1989,1992)$; Martín (1995); Mestre (1995, p. 326); Guillén (1998b, pp. 156-162); Latorre y Herrador (2003). Estos últimos establecen unos interesantes criterios o pautas de actuación para la prescripción del ejercicio físico en los alumnos con necesidades educativas especiales (op. cit., pp. 143-151).
} 
(2000), presentan una serie de contraindicaciones absolutas a la práctica de la actividad física (e. g., las alteraciones neuro-musculares graves, inflamaciones del sistema músculo-esquelético, etc.). Barrios (2000, p. 146) presenta una tabla en la que se muestran veinticuatro factores y/o enfermedades en las que el deporte está totalmente contraindicado o de modo relativo.

Desde esta perspectiva de la salud, los médicos, voluntaria o involuntariamente, desempeñan un cometido decisivo en la Educación Física, tanto cuando prescriben el ejercicio físico para favorecer o ampliar la salud, como cuando lo prohíben -total o parcial- en cualquier situación, es decir, que pueden incluso justificar la exención en cualquiera de las formas vistas hasta ahora.

Los siguientes casos, a los que podríamos añadir otros que han ido apareciendo a lo largo de lo que llevo de exposición, son solo algunos ejemplos de los muchos que hay en los que el dictamen emitido por el facultativo es la pieza clave para considerar a un alumno exento.

"Si algún alumno-a debiera ser considerado exento para la asistencia a las clases de E.F. debería presentar COMUNICADO MÉDICO que justifique tal exención." (Fernández et alia, 1993, p. 187)

"Aquel médico que le indica a un niño con alguna patología funcional leve (actitud escoliótica o cifótica, asma...) que no realice ejercicios bruscos o violentos, o mejor, que esté exento y no haga nada." (Casimiro et alia, 1998 y Fuente $[13]^{116}$ )

"Aquellos otros alumnos y alumnas que durante el transcurrir del curso presenten algún tipo de impedimento que les dificulte el seguimiento normal de las clases prácticas, con el certificado médico pertinente, podrán quedar dispensados total o parcialmente, de modo definitivo o temporal." (Fuente [10])

"La exención de participación en la signatura de Educación Física por un tiempo prolongado se concederá si en un informe escrito de un médico se considera necesaria esta medida." (Fuente $[14]^{117}$ )

\footnotetext{
${ }^{116} \mathrm{http} / / / 146.83 .210 .163 /$ pagalum/fisico/web/RodrigoRamirez_MarceloMena/educación_fisica.html

${ }^{117} \mathrm{http}: / /$ www.dsbarcelona.com/service/schulord_esp.htm
} 
"La Educación Física... Las exenciones deberán justificarse a efectos académicos con el correspondiente justificante médico.” (Fuente [19] ${ }^{118}$ )

"Sólo podrán ser declarados exentos aquellos alumnos que aporten un certificado médico en el que se incluirá se la exención es total o parcial." (Fuente [24])

Los hay que remarcan que no vale cualquier tipo de documento o papel médico $^{119}$.

“...CERTIFICADO MÉDICO OFICIAL donde tu médico de cabecera o el médico especialista que te esté tratando señale el problema que tienes... ;OJO! Tiene que ser un certificado médico oficial. Los venden en los estancos. No valen los volantes o justificantes normales que a veces dan los médicos ni los impresos de recetas de los Centros Médicos Privados.” (Fuente [51])

Algunos llegan más lejos al pretender encajar en un marco legal la concesión de la exención a través del correspondiente certificado médico, como si este verdaderamente existiera.

“...la exención, que no debería ser sino la constatación -previa certificación, fidedigna y coherente con la Ley, del especialista médico- de dificultades para abordar con éxito determinados contenidos del área."(Fuente [46])

Por otra parte, Gallego Antonio (2003b), cuando aborda el asunto de la valoración de la salud corporal de niños con discapacidad física deja muy claro que todas las pruebas que deberían llevarse a cabo (antropométricas, respiratorias, cardiológico y de análisis clínico) tendrían que ser realizadas por especialistas en medicina del deporte y rehabilitación.

La propia Comisión Europea (2013, pp. 27-28), analiza los procedimientos para solicitar las exenciones, siendo mayoritario el número de países (entre los que se sitúa España) que exigen un certificado médico acreditativo de la incapacidad para la

\footnotetext{
${ }^{118} \mathrm{http}: / /$ www.nsrecuerdo.com/general/page12.html

${ }^{119}$ Como se apreciará en el Capítulo 11, en el que se realiza un estudio dedicado a la revisión de los documentos médicos que los alumnos presentan para "justificar" sus lesiones y malestares, existe una variopinta gama de escritos que, en muchas de las ocasiones, se alejan considerablemente de lo que se entiende por "oficial".
} 
práctica. En muy pocos casos se admite como válidos los justificantes familiares o paternos pero, como el caso de Dinamarca, Hungría y Suecia, se concede libertad a los propios centros para que acepten o rechacen este último tipo de documento o justificante.

Es conveniente recordar que la propia Orden de 10 de julio de 1995 establece que la solicitud de aplicación de la correspondiente adaptación curricular ha de ser presentada por los alumnos (si éstos son menores de edad, por sus padres o responsables legales) ante la Dirección del Centro, acompañándose de los certificados médicos oportunos.

Por lo tanto, parece acertado pensar que en los mismos centros debería de existir un documento oficial (llámesele PEC, RRI u otro ${ }^{120}$ ) que recogiese el mecanismo que ha de regir la aplicación de cualquier tipo de adaptación curricular para casos de este tipo en función de los informes médicos pertinentes. Así por ejemplo:

"Los alumnos deberán presentar al principio del curso, informe o justificante médico cuando se tenga motivo para que se le aplique una adaptación curricular total o parcial de la práctica deportiva y/o de la Educación Física." (RRI de uno de los IES sujetos al estudio)

Hay casos en los que la posibilidad de elaborar una programación paralela para un determinado tipo de alumnos se recoge a principio de curso en un documento con cierto carácter oficial interno, como lo puede ser un Plan de Centro por Departamentos.

"Elaborar una programación paralela para ellos [refiriéndose a los alumnos exentos de prácticas], de acuerdo con las directrices marcadas por el médico." (Plan de Centro del Departamento de Educación Física, Fuente [30]. Aclaración mía)

Algunos centros tienen por norma solicitar a los alumnos de nuevo ingreso, de $1^{\circ}$ E.S.O. y de $1^{\circ}$ Bachillerato, un Informe de Salud que debe ser entregado junto con la documentación de la matrícula, y que puede ser recogido en dicho centro o en cualquier

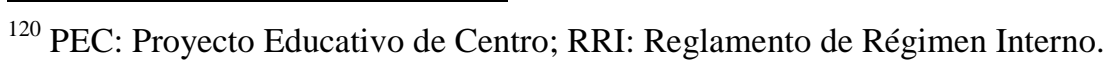


centro de salud para que lo rellene el facultativo (Fuente [25] ${ }^{121}$ ). Otros, en el momento del ingreso en el Centro, obligan a los padres a ofrecer todo tipo de datos médicos en los que pudiese tener incidencia las actividades físicas (Fuente [47]). Digamos que es una forma de conocer por adelantado la forma física y estado de salud del sujeto, así como para prevenir y evitar accidentes y responsabilidades ${ }^{122}$.

Durante el mismo proceso de detección y determinación de las necesidades educativas especiales de un alumno necesario para la posterior toma de decisiones en torno a la aplicación de una adaptación curricular, suele ser habitual, o al menos recomendable, realizar una evaluación del mismo y recabar información de muy diversas fuentes. Entre ellas, se encuentran los detalles relacionados con los aspectos biológicos. Qué duda cabe que dentro de éstos, los antecedentes y referencias de tipo médico serán de utilidad para la planificación de la posterior respuesta educativa (Blanco, 1992, pp. 118-119).

Así pues, el certificado o informe del médico puede determinar si procede o no aplicar una adaptación curricular (significativa o no), pero también, dependiendo del facultativo en particular, puede originar o dar lugar a una exclusión. De hecho, la exención de la parte práctica podría ser determinada por un servicio médico (Mantas, 1995, p. 405), pues no debemos olvidar que es competencia del médico determinar qué enfermedad tiene un paciente, qué tratamiento debe seguir y de qué debe abstenerse (op. cit., p. 441). En definitiva, en la gestión de los casos de alumnos con necesidades educativas especiales, y más concretamente de la aplicación o concesión de la exención de la Educación Física, el certificado o informe médico se suele presentar como inevitable.

121

http://intercentres.edu.gva.es/intercentres/03005719/ADMISION\%20DE\%20ALUMNOS.htm\#DOCUM ENTACION

${ }^{122}$ Albornoz (2000) apunta la conveniencia de solicitar a los padres la realización de un examen médico a sus hijos para descartar problemas y dolencias, y poder adecuar las propuestas pedagógicas a sus posibilidades. Asimismo, en los centros en los que la actividad deportiva sea muy importante es aconsejable tener una ficha médica y de aptitud física. Parecida opinión muestran Latorre y Herrador (2003, p. 284). 
A este respecto, Barbero (1996, p. 24) ya apuntaba la tradicional autoridad que ejercen las disciplinas y saberes biomédicos en el campo de la Educación Física. De hecho, la figura de la existencia del exento en nuestras clases pone de manifiesto que nuestra disciplina solo era para gente más bien sana, dejando fuera de su práctica y participación a las más necesitadas.

Los médicos, lo cual no deja de ser comprensible, suelen aconsejar reposo absoluto y el cese de todo tipo de práctica de ejercicio físico cuando el alumno presenta una lesión -temporal o permanente- que pueda verse agravada por dicho ejercicio.

"La mayoría de los médicos hasta ahora, como el resto de la población en general, suelen identificar Educación Física con gimnasia, por lo que en caso de cualquier enfermedad creen que lo mejor es suprimir la Educación Física y recomendar la rehabilitación como terapéutica y además sustitutivo, incluso ventajoso, de aquélla." (Mantas, 1995, p. 403)

Esta concepción de "recetar" el reposo, del tipo que sea -absoluto o relativochoca en muchas ocasiones con el sentir o forma de entender la Educación Física por los profesionales que se dedican a su enseñanza.

"Es un sentir anacrónico la idea de que personas con problemas físicos dejen de realizar todo tipo de ejercicio físico en la suposición de que éste pudiera perjudicarle. La fuerza de la razón y de la experiencia han llevado a aconsejar, en la medida de las posibilidades de cada uno, la actividad física adecuada a cada enfermedad o dolencia. Se está en el camino de desterrar la idea de absoluto reposo...” (Hernández y Martínez, 1989, p. 50)

Además, suele ocurrir que los profesores de Educación Física aprecian en los médicos una cierta costumbre a autorizar la exclusión de ciertos alumnos de la práctica sistemática de nuestra área por motivos no muy acertados (digamos que por un posible desconocimiento de la enfermedad o dolencia y de la influencia que el ejercicio físico regular tiene en su proceso de evolución y mejoría). La opinión, la forma de ver y tratar el asunto por unos, difiere con el diagnóstico y tratamiento de los otros.

"El presente trabajo pretende resaltar cómo gran cantidad de alumnos que presentan justificantes médicos y paternos para resultar exentos en la clase de educación física, son precisamente sobre enfermedades y lesiones para las 
cuales el ejercicio físico puede ser un método de tratamiento complementario muy efectivo" (Lacasa, 2002)

“...un grupo de profesionales de la educación física nos venimos resistiendo a aceptar estos certificados [refiriéndose a los certificados médicos en los que se constata que un alumno no puede realizar ejercicio físico] y esta automarginación sin más [plantea anteriormente la automarginación de los exentos por causa médica], puesto que, a veces, la causa no parece suficiente (y cada vez son menos desde el punto de vista médico) y, otras, porque es manipulada por parte del alumno para liberase de una asignatura." (Martínez et alia, 1987, p. 28. Aclaraciones mías)

"Por otra parte, estas «exenciones», vienen siendo extendidas por el colectivo médico de una forma un tanto heterogénea, por falta de un criterio unificador entre los mismos, así, mientras un determinado trastorno funcional es causa de exención total para un colegiado, para otro sólo lo es de exención parcial." (Hernández y Martínez, 1989, p. 49)

En esta línea, aunque fuera de España, los certificados médicos son presentados para eximir temporalmente a las alumnas durante el período de la menstruación ${ }^{123}$. Por el asunto al que concierne, suponemos que esta práctica se repetirá a lo largo de cada mes.

“...los certificados médicos por menstruaciones son cada vez más numerosos.” (Saavedra, 2004)

"Los certificados médicos por menstruación para evadir las clases de educación física están a la orden del día...” (Antúnez, 2003)

Lo que parece frecuente es que, independiente de la opinión o directrices de los médicos y profesores, el alumnado se escuda en este tipo de justificantes para no realizar las prácticas (Morales, 2010, p. 97).

\footnotetext{
${ }^{123}$ Se coincide con Latorre y Herrador (2003, p. 166) en que algunas alumnas suelen manifestar nulas disposiciones a la práctica de ejercicios físicos por encontrarse en esa situación a pesar de que son conocidos los efectos beneficiosos que dichos ejercicios pueden producir sobre los problemas derivados de la menstruación -dismenorrea- (Bohórquez et alia, 1992, p. 61), por lo que la esta, por norma, no debería suponer una limitación a la actividad física o deportiva (Latorre y Herrador, op. cit.). En esta misma línea se sitúa Pendenza (2009), López (Fuente [43]) y la Fuente [48]. González (Fuente [44]) incide sobre todo en la importancia del ejercicio físico sobre el Síndrome Pre Menstrual (SPM).
} 
Por lo tanto, se puede afirmar que, en ocasiones, la distancia entre los que propugnan la exención de ejercicio físico con el fin de salvaguardar la salud de su paciente y los que pretenden no excluir a ningún alumno, independientemente de su afección y/o déficit, por estar amparados por un precepto o derecho universal como es la educación, es tan grande que se llega, incluso, a los reproches profesionales, tanto por la concesión de la exención como por la carencia de datos.

“..., es sumamente condenable la actitud médica de "dispensar de realizar ejercicio físico" ya que se priva al niño del derecho a recibir una formación global, física e intelectual.” (de la Cruz, 1989, p. 76; 1992, p. 105)

"El problema, como docentes, se nos plantea año tras año cuando el alumno nos trae el «papelito» del médico informando que no puede hacer ejercicios bruscos, que no es aconsejable la práctica de ejercicios violentos, etc.

Pensamos que va siendo hora que el médico... se conciencie de que su paciente -es decir, nuestro alumno- sí puede realizar algún ejercicio..." (Casimiro, 1992, p. 85)

“...en los casos de exención parcial, raras veces se explica de forma clara qué aspectos de la práctica física son perjudiciales realmente y cuáles no, encontrándonos con adjetivos tales como «ejercicios violentos», «determinadas actividades físicas», etc., que dificulta la comprensión exacta de las actividades nocivas para el alumno en cuestión impidiendo si ello fuera posible, una elaboración adecuada de un programa de actividades para dicho alumno."

[...]

Dentro del colectivo de profesores de Educación Física, se viene detectando últimamente una gran preocupación por el conjunto de alumnos denominados «exentos» que saldan su relación con la asignatura mediante la entrega de un certificado médico, en el que de forma más o menos precisa se indica la inconveniencia de la práctica física (raras veces se explicita si esta inconveniencia es total o parcial, por tiempo indefinido o transitoria)." (Hernández y Martínez, 1989, p. 49 y 52)

Se llega a dar el caso de que hay profesores de Educación Física que crean algún tipo de vía para asegurarse la posibilidad de poder comprobar los diagnósticos médicos cuando éstos sean poco precisos.

"El Departamento se reservará el derecho de reclamar a la Inspección Médica de la Delegación Provincial de Educación y Ciencia, la validez y fiabilidad de las prescripciones y diagnósticos médicos, en aquellos casos de imprecisión manifiesta o escasa temporalización de los mismos." (Fuente [73]) 
Es obvio que el encuentro de posturas e intereses que se produce entre ambos no es lo más recomendable. Ambos profesionales deberían encaminar y aunar sus respectivos esfuerzos para mejorar, entre otras, la salud de los alumnos/pacientes, elaborando vías de comunicación fluidas, pautas de actuación consensuadas y, en definitiva, generando mecanismos de estrecha colaboración (de la Cruz, 1989, p. 63; 1992, pp. 93 y 106). Es más, cada vez alcanza mayor peso la idea de integrar al profesor de Educación Física en los equipos de salud -multidisciplinares- de cualquier localidad (Mestre, 1995, p. 334; Alonso López, 2000).

A pesar de estas "luchas" y disparidad de opiniones, la figura del médico sigue siendo clara y concluyente en el desarrollo de la intervención del profesor de Educación Física, pues los referentes de su trabajo en el aula con este tipo de alumnos no pueden ser ni sus creencias e ideales educativos, ni sus conocimientos médicos (por muy versados que sean), ni su sentido común y buen hacer, sino que toda actuación que determine deberá de pasar en primer lugar por tener en cuenta la opinión del experto clínico que es quien posee un mayor grado de sabiduría en materia terapéutica, y habrá de seguir al pie de la letra las indicaciones que este le señale (Lacasa, 2002). Ruiz y García (2003, p. 268) plantean que el hecho de ignorar o no hacer caso alguno a los informes médicos, permitiendo la incorporación a nuestras clases de alumnos que aún no están totalmente recuperados puede suponer un factor que desencadene lesiones y/o accidentes. Es más, aunque pueda ser muy recomendable poseer nociones de tipo médico, anatómico, aplicación y tratamiento de primeros auxilios, etc., no se debe olvidar que los profesores no tienen la obligación de poseer conocimientos médicos y por tanto no pueden decidir la pauta a seguir en base al nombre de una enfermedad o lesión (López García, 1996).

"Coordinarse con el especialista correspondiente es imprescindible para saber qué suprimir y qué otra propuesta se puede introducir que potencie su desarrollo.” (López González, 1997, p. 28)

"Con la información anterior proporcionada por el médico puede el profesor de educación física llevar a cabo, de forma segura y adecuada, su propia competencia..." (Mantas, 1995, p. 441) 
En contraposición a esta forma de pensar, Latorre y Herrador (2003, pp. 151152) realizaron un estudio sobre la incidencia de lesiones y patologías sobre la práctica deportiva escolar, las cuales condicionan también la aplicación del currículo de Educación Física. Concluyeron que por la variedad y gran frecuencia de algunas patologías, el educador físico necesita conocer los aspectos más relevantes de la etiología, sintomatología, prevención y actuación de emergencia en ellas, así como las estrategias metodológicas oportunas para garantizar el acceso al currículo. Además, en la Fuente $[45]^{124}$ se señala que para evitar riesgos en nuestras clases el profesor debe preocuparse por detectar obesidad o problemas nutricionales o defectos físicos (desviaciones de miembros, columna vertebral, etc. o deformidades). Lo cual pudiera traducirse en una mejor formación del profesorado y en una mayor comunicación de los médicos con los docentes (y sus propios pacientes, los alumnos).

A pesar de todo, los profesores tienen tendencia a demandar de los médicos, incluso exigir, que les faciliten la mayor cantidad de información posible en torno a los impedimentos, lesiones, etc., que presenta el alumno ${ }^{125}$, de forma que su posterior actuación en las clases se fundamente en esa valiosísima información.

También pudiera ser que, como señala Barbero (1996, p. 24), el profesorado haya podido ser cómplice, de una forma más o menos voluntaria, de la exención facilitada por los médicos, de tal suerte que, al no tener que atender a este tipo de alumnos, se ha visto liberado de una serie de problemas derivados de dichos alumnos.

Una de las propuestas que Hernández y Martínez (1989, p. 52) realizaban al respecto de la elaboración de un nuevo articulado legislativo que regule el tema de este tipo de alumnos, se refería a que los certificados médicos fuesen claros y precisos en el sentido de ofrecer más información sobre la lesión o enfermedad (duración, contraindicaciones, etc.). También, como ya se apuntó anteriormente, la Fuente [36] ofrece un modelo de informe médico para las dispensas (Anexo 5), en el que se solicitan los siguientes datos: enfermedad o lesión, tratamiento seguido, tiempo que debe estar

\footnotetext{
${ }^{124} \mathrm{http}: / / \mathrm{www}$.accidentadosnet.org.ar/anet/base.asp?nota=187

${ }^{125}$ Este hecho será corroborado en los capítulos en el que se analizan las programaciones didácticas y los documentos médico-familiares (Capítulo 8 y 11, respectivamente)
} 
sin actividad, actividad física no recomendada, actividad física recomendada y la clase de dispensa recomendada (parcial, temporal o definitiva). En esta misma línea se muestra el "Modelo de carta que envía el instituto al médico" (Anexo 7) empleado por López García (1996) en su investigación. La idea de esta hoja era obtener datos relevantes para el profesor de Educación Física y que, como confiesa el autor, frecuentemente son omitidos en los informes médicos.

Incluso en los mismos libros de texto con los que trabajan los alumnos (Fernández et alia, 1997, 1998; Fernández y Vera, 2000) aparecen fichas médicas para ser rellenadas por ellos mismos, es decir, se le plantean una serie de cuestiones relativas a la posibilidad de que tenga o no impedimentos para realizar Educación Física. En caso afirmativo, deberá aportar un certificado médico. Pero aún más, para esos casos afirmativos se articula un apartado en el que reflejarán qué actividad física es la que les conviene y cuál no, para lo que deberán consultar al médico y al profesor.

Igualmente, es muy demostrativo el ejemplo de carta dirigida al médico que nos propone Perelló $\left(2005^{126}\right)$. Se trata de un documento que obligatoriamente debe presentar todo alumno que no pueda realizar actividad física. La peculiaridad de esta carta reside en que al médico se le informa del programa de Educación Física del centro para que señale las actividades contraindicadas y las favorables ${ }^{127}$ para un alumno en particular. Pero hay muchas más muestras de este tipo ${ }^{128}$.

"Los alumnos... que tengan alguna imposibilidad física que no les permita la práctica de la materia, presentarán un Certificado Médico Oficial en el que necesariamente se tendrá que especificar los ejercicios que no puede hacer el alumno así como el tiempo de la dispensa de los mismos." (Fuente [11])

\footnotetext{
126 Esta fuente bibliográfica tiene de especial que se trata de un temario para la preparación de oposiciones al Cuerpo de Profesores de Enseñanza Secundaria en la especialidad de Educación Física, por lo que podrá marcar las actuaciones de los futuros profesores que se hayan guiado por sus propuestas.

${ }^{127}$ En el Anexo 8 transcribimos una copia de esta carta.

${ }^{128}$ En el capítulo dedicado a los documentos médicos y familiares hacemos constar la existencia de otros modelos de hojas o informes para ser rellenados, en este caso, por los padres o tutores (alguno recogido del estudio realizado sobre las programaciones didácticas en el Capítulo 8).
} 
"Cualquier exención de la práctica, sea parcial o total, temporal o permanente, debe estar debidamente justificada mediante informe médico que especifique el diagnóstico, el tipo de actividades que no debe realizar, si existe algún trabajo específico de recuperación de la lesión, enfermedad, etc., y en su caso el tiempo previsible de exención." (Fuente [20] ${ }^{129}$ )

"El alumno con exención [previamente se nos informa que para ser exento hay que presentar un certificado médico] presentará un informe médico sobre el tratamiento de las dolencias y el proceso de recuperación del alumno." (Fuente [24]. Aclaración mía)

"A la anterior solicitud [referida a la que se efectúa para ser declarado exento total o parcial de las prácticas de Educación Física] le adjuntará un informe certificado médico con los siguientes apartados: diagnóstico de la dolencia, tratamiento propuesto, tiempo estimado de convalecencia, ejercicios que no debe realizar el alumno y cualquier otra observación que considere oportuna." (Fuente $[32]^{130}$. Aclaración mía)

"Las solicitudes de exención de Educación Física deberán acompañarse de certificado médico oficial en el que se indicará si la exención será total o sólo limitada a determinados ejercicios o actividades, especificando cuáles." (Fuente [34])

"De acuerdo con la normativa vigente..., podrán solicitar la exención de la parte práctica de la asignatura mediante instancia a la Dirección del Centro a la que acompañarán el respectivo Certificado Médico Oficial... En este certificado se indicará, además de las causas, si la exención es total o parcial. En el caso de ser parcial deberá quedar reflejado si la exención está limitada a determinadas actividades y/o ejercicios, especificándose cuales y el tiempo de duración de la exención." (Fuente [77])

“...En el caso de que soliciten [refiriéndose a los alumnos con limitaciones temporales o permanentes] una adaptación curricular, se realizará en base a un certificado médico oficial en el que se debe constar especificando con claridad, las limitaciones, deficiencias, discapacidades que tenga esa persona, así como formas de actuación recomendadas y actividades perjudiciales o prohibidas." (Fernández y Pernas, 2006)

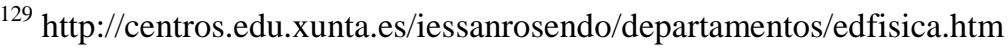

${ }^{130}$ http://www.juntadeandalucia.es/averroes/alhadra/pag6042.htm
} 
Como se viene diciendo, el problema que suele aparecer es que esa información que se ofrece en los informes médicos es considerada insuficiente ${ }^{131}$, lo que agudiza el camino hacia esa "Educación Física sin práctica" para evitar males mayores (el tópico de "ante la duda, mejor que se quede sentado").

“...La información (al hablar sobre los informes médicos y la colaboración de los fisioterapeutas) suele ser tan escueta que la intervención se hace difícil por el miedo ya descrito a provocar lesiones.” (Ríos, 1998b, p. 31. Aclaración mía)

“...deberíamos exigir que en ese " papelito», el médico explicara exactamente la patología que presenta (diagnóstico), los ejercicios que no puede realizar y aquellos que debería utilizar para la rehabilitación o mantenimiento de su estado físico." (Casimiro, 1992, p. 85)

“...Los problemas observados suelen centrarse en la poca precisión del diagnóstico médico y sobre todo en la ausencia de recomendaciones específicas respecto a la posibilidad de realizar actividad física." (López García, 1996)

“...esto obliga a emitir informes [médicos] justificados y entendibles por padres y profesores, donde se contemplen las incapacidades que puede presentar un niño y los ejercicios más recomendables." (de la Cruz, 1992, p. 95. Aclaración mía)

Dejando de lado los informes médicos y la presunción de que constituyen el principal documento que puede originar o desencadenar la "exención" a un alumno, se aprecia que también hay otro tipo de documento, digamos "oficioso", al que se le otorga un valor y poder similar, y no es otro que los justificantes familiares.

"Si un alumno-a presentara una exención por un periodo de tiempo igual a una semana los padres deberán comunicar este hecho al profesor de E.F." (Fernández et alia, 1993, p. 187)

"Las situaciones leves de duración menor de dos días será suficiente con justificación paterna.” (Fuente [20])

"Aquel padre superproteccionista que favorece algunas «exenciones» de nuestras prácticas en su hijo, por algún motivo dudosamente justificado." (Casimiro et alia, 1998 y Fuente [13])

\footnotetext{
${ }^{131}$ Puede que el verdadero problema resida en que el propio sistema educativo tiene carencias obvias relacionadas con el control médico del alumnado (González Halcones, 1995)
} 
Este tipo de escrito suele tener una efectividad absoluta cuando se trata de "exenciones" temporales (sobre todo para pequeñas enfermedades o lesiones, ya sean o no asociadas a discapacidades). ¿Qué profesor de Educación Física "obliga" a un alumno a realizar una actividad física, aun a sabiendas de los grandes beneficios que esta le puede reportar, cuando ese alumno ha traído un "papelito" firmado por su padre / madre en el que se dice que no debe hacer actividad alguna por causa de su lesión o enfermedad ${ }^{132}$ ? Además, suele darse el caso de padres que presionan a los médicos para que, ante cualquier enfermedad o dificultad de sus hijos, extiendan el correspondiente certificado que les exima de la Educación Física (Mantas, 1995, p. 403).

Esto último podría venir a corroborar lo que Rodríguez-Solano (2003) comentaba al respecto de que hay alumnos que son exentos por vagos o mostrar un desinterés total hacia la asignatura y que no realizan la clase alegando todo tipo de excusas.

En general los resultados [de la investigación que realiza para conocer el perfil de los alumnos exentos] nos muestran que los alumnos exentos, son alumnos que no escogerían libremente la clase de Educación Física porque no les gusta la clase, y porque no la consideran tan importante como para ser incluida en el currículo de Educación." (Rodríguez-Solano, 2003. Aclaración mía)

No es objeto de esta tesis reprochar todas las conductas de los padres hacia sus hijos en relación a este tema, pues es evidente que suelen desear lo mejor para ellos, lo cual, a veces, les lleva a solicitar la exención (o la no práctica) de las clases de Educación Física. En este sentido, recogemos las palabras que Palmer (Fuente [15] ${ }^{133}$ ) escribe sobre una serie de estrategias que funcionaron en la integración en la secundaria de su hijo autista:

"Una de las situaciones sociales más duras para mi hijo en la secundaria fueron las clases de Educación Física. Él odiaba los deportes y tenía problemas motrices que le creaban dificultades, por consiguiente se volvió el blanco de los

\footnotetext{
${ }^{132}$ Igualmente puede suceder si la comunicación es verbal por parte del propio alumno (e. g., alumnas con menstruación, pequeñas dolencias o lesiones -visibles o invisibles-, etc.)

133

http://www.asperger.es/articulos_detalle.php?id=131Estrategias\%20para\%20sobrevivir\%20a\%201a\%20in tegraci\%F3n\%20de\%20un\%20ni\%F10\%20autista\%20en\%20la\%20escuela\%20secundaria
} 
demás alumnos. La situación en los vestuarios era especialmente difícil y había un joven supervisor para protegerlo. Después de un par de incidente, conseguimos que él no entrara más en los vestuarios... En $8^{\circ}$ grado quedó exento de asistir a las clases. Escribí una carta al director adjuntándole la nota de un pediatra especialista en desarrollo, que conocía a mi hijo y sabía mucho acerca del autismo. No tuvimos problema en eximirlo de las clases. Sugiero esta posibilidad sólo si su hijo no saca nada positivo de las horas de Educación Física..."

Retomando el tema, ya se trate de uno u otro documento, el profesor puede reaccionar de diversas maneras, pero lo habitual es aceptar la información que en ellos se ofrece, dispensando al alumno de la práctica de la Educación Física por el período que se indique. ¿Cuál es la razón? Probablemente haya que buscarla en el desconocimiento y falta de formación (y de medios) para afrontar estos casos, y en el miedo asociado a provocar más daño del que ya hubiera como consecuencia de una inadecuada actuación o de un mero accidente (factor responsabilidad) (Ríos, 1999, p. 940, 2001b, p. 101 y 2009, p. 91). De todas formas, conviene recordar que el sentido común y la experiencia aconsejan que no es muy recomendable realizar actividades físico-deportivas con las aptitudes físicas o mentales mermadas, o justo después de haber tenido una lesión no completamente recuperada (Guillén, 1998a, p. 111).

En capítulos posteriores retomaremos los temas de la responsabilidad jurídica del profesor, el de los certificados médicos y justificantes paternos, si bien estos últimos desde una perspectiva más real, en base a un estudio de campo sobre la práctica diaria.

Sin embargo, también es curioso comprobar alguna propuesta en la que el profesor hace o desempeña un papel de médico al poner o imponer algún tipo de programa rehabilitador. Así, en Rueda et alia (2001, p. 58) se establece: “Alumnos con un diagnóstico claro del médico sobre la lesión específica que padecen, pero a los que no se les ha indicado ningún tratamiento rehabilitador. En este caso se les facilitarán unas fichas con ejercicios específicos para la rehabilitación de su lesión.”. Bistuer (1996, p. 36), llega a afirmar que “...lo mismo que un profesor de una asignatura cognitiva puede aconsejar unas lecturas o ejercicios para paliar el déficit de un alumno en su materia, el profesor de Educación Física puede y debe recomendar una serie de actividades que a parte de las terapias correctivas o ejercicios determinados por el 
facultativo correspondiente, ayuden a una evolución favorable de la afección del sujeto." Por tanto, no es extraño que Alonso López (2000) afirme que el profesor de Educación Física, por los conocimientos y formación que posee, es el idóneo para instrumentar, previa autorización médica, un sistema de clases de Educación Física adaptada a la enfermedad del alumno, participando con su programa de ejercicios físicos en la rehabilitación de dichos sujetos.

En el siguiente apartado se podrá comprobar que la utilización de las clases de Educación Física para la rehabilitación de lesiones es una situación que se da con cierta frecuencia.

\subsection{5.- RESPUESTAS EDUCATIVAS QUE LA EDUCACIÓN FÍSICA OFRECE A ESTOS ALUMNOS}

Hasta ahora se ha acreditado que la respuesta más habitual a estos alumnos acostumbra a traducirse en participar sin práctica ${ }^{134}$. Esto quiere decir que el profesor de Educación Física les encomienda multitud de tareas no motrices diferentes a las realizadas por sus compañeros, que se suelen explicar en términos de adaptación curricular.

Esta variada gama de tareas pudiera provocar en el profesor, entre otras cosas, la sensación de que un alumno con dificultades de aprendizaje asociadas a cualquier discapacidad está trabajando y "participando activamente" en sus sesiones, pasando de una situación en la que estaba exento de la práctica a otra en la que ha de hacer o "funcionar" durante dicha práctica, independientemente del tipo de tarea o trabajo encomendado.

"En definitiva, nosotros debemos dar en la medida que los alumnos puedan recibir; de esta forma haremos de la Educación Física una actividad integradora (no con alumnos pasivos y vestidos «de calle») y hacer nuestra aula un lugar donde todos puedan participar...” (Casimiro, 1992, p. 91)

\footnotetext{
${ }^{134}$ No obstante, hay variadas muestras en sentido contrario: vid. Pérez Brunicardi et alia (Coords., 2004)
} 
Pero es que a veces, incluso para quienes defienden a ultranza la integración de estos alumnos en términos de participación en las prácticas físico-deportivas (lo cual es aplicable a las clases de Educación Física), resulta imposible no caer en la habitual falsa integración (Ríos, 1998b, 2001a, 2001b).

"Cuando se trata de juegos colectivos o actividades jugadas en grupo se pueden asignar tareas o funciones específicas a los alumnos con discapacidad. Por ejemplo, un alumno que utiliza prótesis en las piernas y tiene menores posibilidades de movilidad puede desempeñar el papel de pívot en un partido de baloncesto; otro que utiliza silla de ruedas puede arbitrar un partido de futbito, o ser el portero, o sujetar el pañuelo en el juego que lleva el mismo nombre." (Olayo et alia, 1996, p. 71)

Por si esto fuera poco, encima el resto de los alumnos demandan que este alumnado acuda a clase y presente trabajos, como queda presente en un estudio realizado por el ICE de Zaragoza en el que según los propios compañeros, "los alumnos exentos deben asistir a las clases de Educación Física y realizar trabajos especiales y complementarios.” (Macazaga et al., 1985, p. 41).

Esta Educación Física "sin práctica”, recibe en ocasiones otras denominaciones. Por ejemplo, Rueda et alia (2001, p. 58) se refieren a ella como "pausa activa", entendiendo por tal la colaboración en los apoyos y ayudas, del tipo que sea, a la práctica de sus compañeros.

En los casos en los que el diagnóstico de la lesión y el tratamiento a seguir no da lugar a equívocos, algunos autores son partidarios de que las clases de Educación Física sirvan como lugar de trabajo rehabilitador ${ }^{135}$.

“Alumnos con un diagnóstico claro del médico sobre la lesión específica que padece... y que tienen indicado un trabajo de rehabilitación con unos ejercicios

\footnotetext{
${ }^{135}$ Para Guillén (1998a, p. 113), el profesor especialista en Educación Física debe colaborar con el médico y el fisioterapeuta en acciones como la reeducación funcional y la gimnasia correctiva una vez producida la lesión. Suponemos que, al referirse en estos términos al profesor de Educación Física, dichas actuaciones pudieran desarrollarse durante las propias clases de Educación Física. Es más, cuando con posterioridad plantea la cuestión de a quién corresponde el trabajo de prevención de lesiones (1998b, p. 156), incluye al profesor especialista en un equipo multidisciplinar formado, entre otros, por el médico. Obsérvese que estas ideas ratifican la comentada en el apartado anterior sobre la participación del profesor de Educación Física en los equipos de salud.
} 
determinados. En este caso utilizarían la clase de Educación Física para realizar dicho trabajo de rehabilitación.” (Rueda et alia, 2001, p. 58)

"Si un alumno, por ejemplo, tuviera alguna alteración de la columna, realizaría sus correspondientes ejercicios de rehabilitación durante la sesión, en el momento en que no pueda realizar los ejercicios del programa general con el resto del grupo." (Martínez et alia, 1987, p. 28)

"Todos estos alumnos [exentos de la práctica, total o parcialmente] durante las clases tendrán las correspondientes adaptaciones curriculares y realizarán actividades alternativas o correctoras de su lesión..." (Fuente [76]. Aclaración mía)

“Algún otro [profesor] hace que sus alumnos exentos realicen sus programas de rehabilitación si lo tienen en horas de clase e incluso alguna vez todo el grupo realiza esos mismos ejercicios.” (Hernández y Martínez, 1989, p. 52. Aclaración mía)

En el libro-cuaderno del alumno de Educación Física elaborado por Fernández et alia (1997), sale a la luz esta idea de realizar durante la clase de Educación Física algunos ejercicios de rehabilitación.

"Si tienes algún tipo de escoliosis..., debes saber los ejercicios que debes evitar; cuando tu «profe» te diga algunos ejercicios que no te conviene, aprovecha para mejorar tu escoliosis; [a continuación proponen unas tablas de ejercicios en función del tipo de escoliosis]” (op. cit., p. 208. Aclaración mía)

Para Latorre y Herrador (2003, p. 150) la participación de todos los alumnos, sobre todo de los alumnos con necesidades educativas especiales, va a depender, entre otros factores, de la propia disposición del alumno. Es decir, se aprecia que los intereses, necesidades y motivaciones del sujeto son prioritarios a la hora de elaborar propuestas de integración.

Junto a ellos, también se pueden situar los sentimientos que tienen, y a veces padecen $^{136}$, algunos de estos alumnos a los que se les plantean propuestas en la línea de

\footnotetext{
${ }^{136}$ Para López García (1996), un alumno que tiene alguna exención de actividad física o deportiva puede considerarse marginado por el grupo y con ello el perjuicio consiguiente para su calidad de vida y su rendimiento académico.
} 
la falsa integración. Sirvan como ejemplo las palabras de Schroeder (Fuente [16] ${ }^{137}$ ), en las que lo verdaderamente importante no es corroborar la práctica real de la exención en Educación Física (aunque sea fuera de España), sino demostrar la respuesta que se le dio en nuestras clases por tener problemas de visión (posteriormente se quedó ciego) y lo que supuestamente él debía de sentir con dichas actuaciones.

“...Estaba exento de todas las exigencias de lectura y escritura... También estaba exento de gimnasia (educación física). Si se crece con una discapacidad y al mismo tiempo se está automáticamente exento de educación física, probablemente se está sin moverse en un montón de lugares. No estaba absolutamente exento, porque recuerdo que en la educación física de la escuela primaria, cuando el entrenador nos enseñaba baloncesto, me dejaban como árbitro. Podía ver lo suficiente para saber lo que estaba pasando, pero me paraba en los lados y eso me debía haber hecho estar «totalmente incluido»."

En esta línea de tener en cuenta lo que piensan y sienten nuestros alumnos, no s encontramos que cuando el origen de la exención no se halla en causas físicas o corporales, sino en factores de tipo actitudinal (falta de interés, desmotivación...), Rodríguez-Solano (2003) propone indagar sobre la percepción de diversión del alumno hacia la actividad pues una práctica divertida disminuye la posibilidad de abandono de dicha actividad. En definitiva, conocer los motivos por los que el alumno exento practicaría actividad físico deportiva, podría ayudarnos a dar un primer paso para que participe de nuevo en nuestras clases. Este autor finaliza su investigación concluyendo que:

\begin{abstract}
"Siempre encontraremos alumnos «exentos» en nuestras clases, pero tratando a estos alumnos de un modo más individualizado, adaptando las clases a sus posibilidades físicas, proponiendo actividades variadas cercanas en la medida de lo posible a sus gustos, y potenciando la socialización e incidiendo sobre el beneficio para la salud, quizá podremos acercarnos al $100 \%$ de alumnos activos, consiguiendo clases más cómodas de dirigir y más beneficiosas para todos los alumnos." (Ibídem)
\end{abstract}

Como ya se hiciera en el anterior apartado de este capítulo (vid.: Nota 126), por la posible huella que pudiera dejar en los fututos profesores de Educación Secundaria en

\footnotetext{
${ }^{137}$ http://www.proyectovision.net/spanish/news/06/schroeder.html
} 
Educación Física, se realiza una breve revisión de algún texto-temario que las editoriales ponen a su disposición para la preparación de la fase de oposición.

Así, Perelló et alia (2003) plantean un manual de planteamientos didácticos (P.D.) y/o unidades didácticas (U.D.) en el que nos encontramos con una amplísima y variada gama de propuestas de actuación para atender a las necesidades educativas especiales del alumnado. A continuación se transcriben las más significativas en la línea del tema que nos ocupa ${ }^{138}$.

"En aquellos casos en los que haya una indisposición temporal, el alumno realizará un control del material y ejecución del trabajo realizado por cada uno de los grupos.” (U.D.: Condición física y autonomía personal, p. 20)

"Cuando algún alumnos presente indisposición temporal para participar en las sesiones prácticas, colaborará en el desarrollo y organización de las mismas.” (U.D.: El balonmano y los deportes colectivos: aspectos básicos, p. 92)

"La existencia de alumnos con dificultades de tipo motórico severo dificultará, que duda cabe, la realización y experiencias de las actividades, para los cuales habrán de realizarse adaptaciones curriculares significativas, pasando a ser colaboradores externos de los procesos y teniendo un papel de ayuda y colaboración constante con el docente." (P.D.: Iniciación al rugby-imagen, p. 376)

"La atención a las diferentes discapacidades en este tratamiento didáctico dependerá en gran manera del tipo de deficiencia que presente el alumno y el grado de la misma. Así por ejemplo, un alumno con una discapacidad psíquica ligera precisará, por su propia seguridad, una atención particular a la hora de realizar las prácticas en rocódromo; asimismo, quedará exento de practicar las actividades de la sesión 9 [rápel libre], por el nivel de riesgo que conllevan y que, tal vez, este alumno no pudiera asumir.” (P.D.: Iniciación a la escalada y rápel, p. 416. Énfasis y aclaración mía)

Por otra parte, se ha constatado que hay una propuesta de adaptación al ámbito escolar del aeróbic en silla de ruedas en la que el alumno exento es nuevamente requerido para realizar funciones de apoyo "a la persona discapacitada en algún movimiento que no pueda realizar" (Mendoza et alia, 2001).

\footnotetext{
138 Como temario de "Aplicaciones didácticas", ofrece otras muchas actuaciones y adaptaciones en la línea de favorecer o propiciar la participación del alumno con necesidades educativas especiales.
} 
En la Tabla 2a, 2b, 2c, 2d, 2e y $2 \mathbf{f}$ se sintetizan algunas fuentes y documentos que recogen la exención, en cualquiera de sus formas, como una respuesta educativa que se ofrece en Educación Física a los alumnos con dificultades de aprendizaje asociadas a cualquier discapacidad, así como los fundamentos en los que se basa su evaluación. 


\begin{tabular}{|c|c|c|c|c|c|c|}
\hline 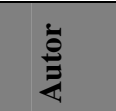 & $\begin{array}{l}\text { Ríos (1998b, } \\
\text { 2001a, 2001b) }\end{array}$ & $\begin{array}{c}\text { Casimiro } \\
\text { (1992) }\end{array}$ & $\begin{array}{l}\text { Rueda } \text { et alia } \\
\qquad(2001)\end{array}$ & $\begin{array}{l}\text { González de } \\
\text { Aledo (1995) }\end{array}$ & $\begin{array}{c}\text { Fernández et } \\
\text { alia (1993) }\end{array}$ & Mantas (1995) \\
\hline \multirow{2}{*}{ 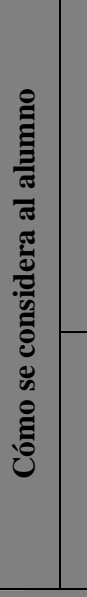 } & $\begin{array}{l}\text { Critica la falsa } \\
\text { integración en las } \\
\text { sesiones de } \\
\text { Educación Física }\end{array}$ & & $\begin{array}{l}\text { Plantea la } \\
\text { posibilidad de } \\
\text { que haya alumnos } \\
\text { que por su lesión } \\
\text { estén totalmente } \\
\text { imposibilitados } \\
\text { para realizar todo } \\
\text { tipo de } \\
\text { actividades } \\
\text { físicas. }\end{array}$ & & & \\
\hline & & $\begin{array}{l}\text { - Exento total y } \\
\text { permanente. } \\
\text { - Exento parcial y } \\
\text { permanente. }\end{array}$ & & $\begin{array}{l}\text { - Exentos totales } \\
\text { - Exentos } \\
\text { parciales. }\end{array}$ & $\begin{array}{l}\text { - Exentos de } \\
\text { asistir a clase. }\end{array}$ & $\begin{array}{l}\text { - Exentos } \\
\text { temporales y } \\
\text { totales de la parte } \\
\text { práctica. } \\
\text { - No a la } \\
\text { exención total. }\end{array}$ \\
\hline 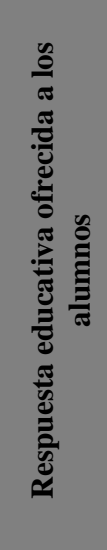 & $\begin{array}{l}\text { Hacer acto de } \\
\text { presencia, asumir } \\
\text { roles pasivos, } \\
\text { trabajos teóricos, } \\
\text { sesiones de } \\
\text { fisioterapia, } \\
\text { laisser faire. }\end{array}$ & $\begin{array}{l}\text { En la exención } \\
\text { total, el alumno } \\
\text { debe ser un } \\
\text { colaborador del } \\
\text { profesor } \\
\text { ayudando en } \\
\text { cronometrajes, } \\
\text { contar, pasar } \\
\text { lista, tomar nota } \\
\text { de las } \\
\text { actividades, } \\
\text { realizar fichas, } \\
\text { dibujos, etc. } \\
\text { El aula puede ser } \\
\text { utilizada como } \\
\text { gimnasio de } \\
\text { rehabilitación. }\end{array}$ & $\begin{array}{l}\text { Una pausa activa, } \\
\text { entendiendo por } \\
\text { ello realizar } \\
\text { tareas tales como } \\
\text { toma de } \\
\text { pulsaciones, } \\
\text { control de } \\
\text { tiempos, } \\
\text { anotación de } \\
\text { ejercicios. } \\
\text { Pueden utilizar la } \\
\text { clase para realizar } \\
\text { trabajos de } \\
\text { rehabilitación. }\end{array}$ & $\begin{array}{l}\text { Acudir a clase, } \\
\text { tomar nota de los } \\
\text { contenidos } \\
\text { teóricos, ficha } \\
\text { diaria de las } \\
\text { actividades } \\
\text { realizadas, } \\
\text { colocar material, } \\
\text { arbitrar, anotar, } \\
\text { encargarse de la } \\
\text { música, etc. } \\
\text { Pueden realizar } \\
\text { los ejercicios } \\
\text { prescritos por el } \\
\text { médico durante } \\
\text { las clases. }\end{array}$ & $\begin{array}{l}\text { Trabajos escritos } \\
\text { sobre temas } \\
\text { deportivos. }\end{array}$ & $\begin{array}{l}\text { Obligatoriedad de } \\
\text { asistir a las } \\
\text { clases. } \\
\text { Recoge una rica y } \\
\text { variada gama de } \\
\text { ejercicios } \\
\text { contraindicados y } \\
\text { beneficiosos por } \\
\text { enfermedades o } \\
\text { lesiones. }\end{array}$ \\
\hline 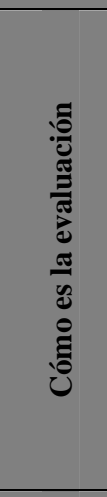 & $\begin{array}{l}\text { No dice nada al } \\
\text { respecto }\end{array}$ & $\begin{array}{l}\text { Debe ser } \\
\text { evaluado por sus } \\
\text { conocimientos } \\
\text { teóricos, además } \\
\text { de por colaborar } \\
\text { en esas tareas. } \\
\text { Si es exención } \\
\text { parcial, se les } \\
\text { examinará de la } \\
\text { parte práctica que } \\
\text { pudieran realizar. }\end{array}$ & $\begin{array}{l}\text { No dice nada al } \\
\text { respecto. }\end{array}$ & $\begin{array}{l}\text { Trabajos de los } \\
\text { encargados en } \\
\text { clase, y otros } \\
\text { específicos para } \\
\text { ellos. Harán el } \\
\text { examen teórico } \\
\text { obligatoriamente } \\
\text { siendo opcional } \\
\text { para el resto de } \\
\text { compañeros. } \\
\text { Si es exención } \\
\text { parcial, examen } \\
\text { de la parte } \\
\text { práctica que } \\
\text { pudieran realizar. }\end{array}$ & $\begin{array}{l}\text { Calificación de } \\
\text { estos trabajos. }\end{array}$ & Examen teórico \\
\hline 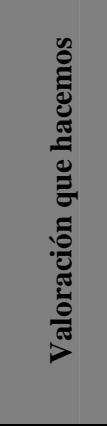 & $\begin{array}{l}\text { - Se aproxima } \\
\text { fidedignamente a } \\
\text { la realidad. }\end{array}$ & $\begin{array}{l}\text { - Contradicción: } \\
\text { exento total no } \\
\text { debería poder } \\
\text { hacer nada. } \\
\text { - Predominio } \\
\text { trabajo teórico. } \\
\text { - Falsa } \\
\text { integración. } \\
\text { - Rehabilitación } \\
=\text { ¿participación? }\end{array}$ & $\begin{array}{l}\text { - Existe el exento } \\
\text { parcial. } \\
\text { - Falsa } \\
\text { integración. } \\
\text { - Rehabilitación } \\
=\text { ¿participación? }\end{array}$ & $\begin{array}{l}\text { - Existe el exento } \\
\text { total. } \\
\text { - Contradicción: } \\
\text { no debería poder } \\
\text { hacer nada. } \\
\text { - Falsa } \\
\text { integración } \\
\text { - Rehabilitación } \\
\text { = ¿participación? }\end{array}$ & $\begin{array}{l}\text { - Exento total, } \\
\text { incluso de la } \\
\text { asistencia. }\end{array}$ & $\begin{array}{l}\text { - Contradicción: } \\
\text { no hay exentos } \\
\text { totales, pero sí } \\
\text { durante un } \\
\text { período de } \\
\text { tiempo concreto. } \\
\text { - Muy útil la } \\
\text { información que } \\
\text { ofrece. }\end{array}$ \\
\hline
\end{tabular}

Tabla 2a. Las respuestas en Educación Física a los alumnos con necesidades educativas especiales 


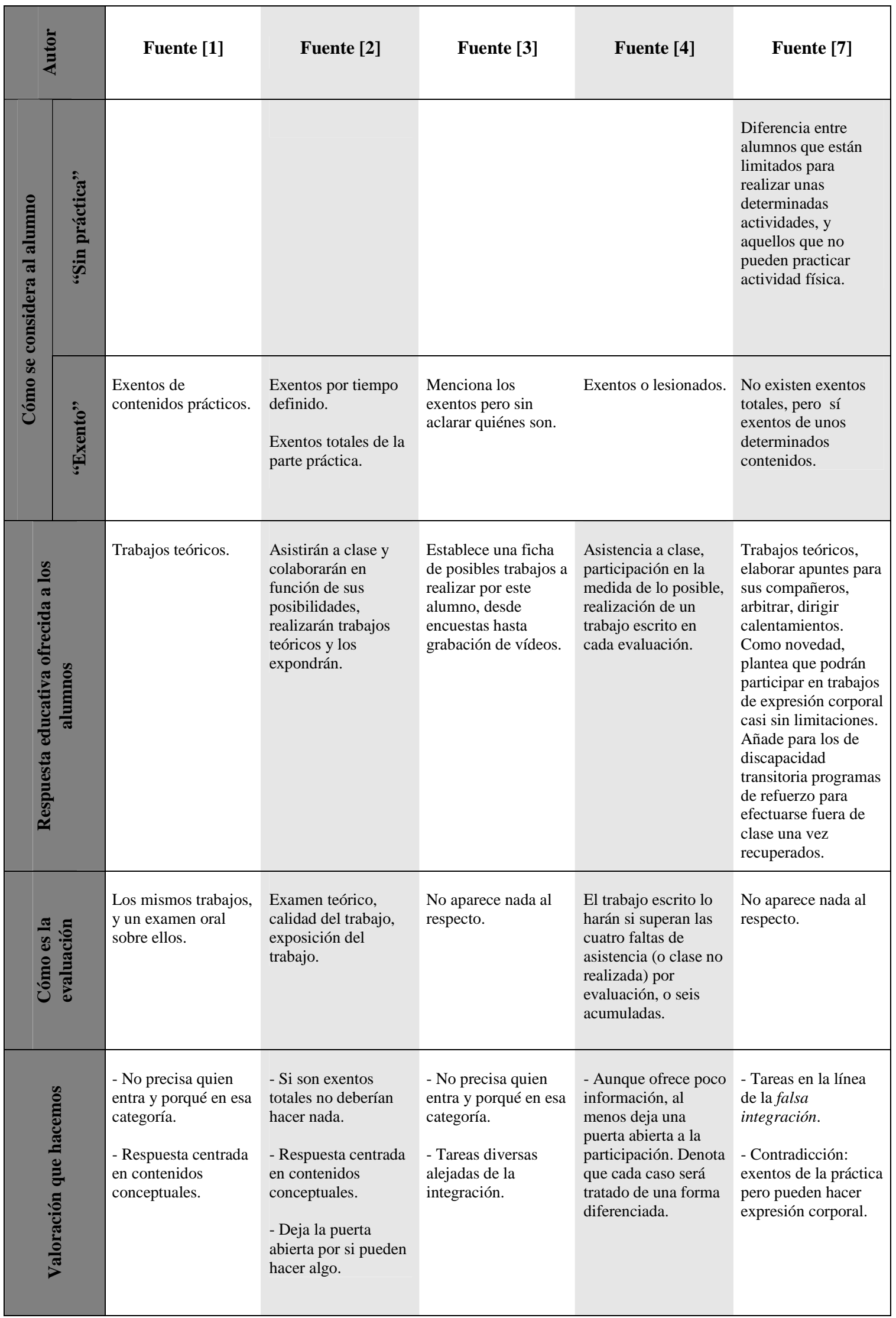

Tabla 2b. Las respuestas en Educación Física a los alumnos con necesidades educativas especiales 


\begin{tabular}{|c|c|c|c|c|c|}
\hline$\stackrel{\Xi}{E}$ & Fuente [8] & Fuente [9] & Fuente [10] & Fuente [20] & Fuente [21] \\
\hline 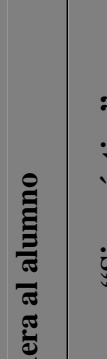 & 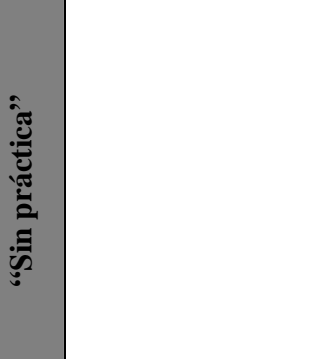 & & $\begin{array}{l}\text { - Dispensados de la } \\
\text { parte práctica. } \\
\text { - Existe la } \\
\text { posibilidad de estar } \\
\text { dispensado total y } \\
\text { parcialmente, de } \\
\text { modo definitivo o } \\
\text { temporal (de la } \\
\text { práctica). Necesario } \\
\text { certificado médico. }\end{array}$ & & \\
\hline 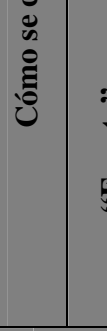 & $\begin{array}{l}\text { Exentos de la parte } \\
\text { práctica. }\end{array}$ & $\begin{array}{l}\text { Exentos de los } \\
\text { contenidos y } \\
\text { objetivos motrices. }\end{array}$ & & $\begin{array}{l}\text { Exento de la práctica, } \\
\text { total o parcial, } \\
\text { temporal o } \\
\text { permanente } \\
\text { (necesario certificado } \\
\text { médico) }\end{array}$ & $\begin{array}{l}\text { - Exentos de la parte } \\
\text { práctica para todo el } \\
\text { curso. Necesario } \\
\text { certificado médico. } \\
\text { - Exentos de la parte } \\
\text { práctica durante un } \\
\text { periodo de tiempo. } \\
\text { Necesario certificado } \\
\text { médico. }\end{array}$ \\
\hline 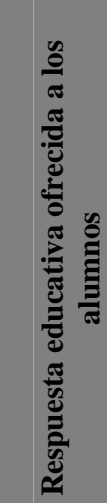 & $\begin{array}{l}\text { Realizarán solamente } \\
\text { los contenidos de los } \\
\text { diferentes objetivos } \\
\text { programados a nivel } \\
\text { teórico. }\end{array}$ & $\begin{array}{l}\text { Colaboran en tareas } \\
\text { de organización, } \\
\text { evaluación... }\end{array}$ & $\begin{array}{l}\text { Se les asignarán } \\
\text { tareas como: } \\
\text { delegados de equipo, } \\
\text { jueces, } \\
\text { cronometradores..., } \\
\text { confeccionarán temas } \\
\text { sobre deportes o } \\
\text { salud, ayudarán al } \\
\text { profesor en el } \\
\text { seguimiento de la } \\
\text { tarea. Serán uno más } \\
\text { en todas las sesiones } \\
\text { de carácter teórico. }\end{array}$ & $\begin{array}{l}\text { Asistir a clase, tomar } \\
\text { nota en su cuaderno } \\
\text { de los expuesto y } \\
\text { realizado en clase y } \\
\text { colaborar en lo que } \\
\text { fuese necesario } \\
\text { (material, } \\
\text { anotaciones, } \\
\text { arbitrajes, etc.), } \\
\text { trabajos específicos } \\
\text { de rehabilitación. }\end{array}$ & $\begin{array}{l}\text { Suponemos, por la } \\
\text { evaluación que } \\
\text { propone, asistencia a } \\
\text { clase, actitud y } \\
\text { colaboración. } \\
\text { Contempla varios } \\
\text { casos de exención: a } \\
\text { principio de curso, de } \\
\text { la evaluación y a } \\
\text { mediados de ella. } \\
\text { A los alumnos con } \\
\text { necesidades } \\
\text { educativas especiales } \\
\text { se les adaptará la } \\
\text { programación. }\end{array}$ \\
\hline 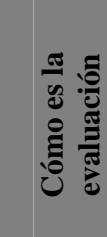 & $\begin{array}{l}\text { Pruebas escritas, } \\
\text { trabajos y } \\
\text { cuestionarios de las } \\
\text { unidades del libro de } \\
\text { texto. }\end{array}$ & $\begin{array}{l}\text { Trabajos y tareas por } \\
\text { escrito } \\
\text { complementarios } \\
\text { (Adaptación } \\
\text { Curricular) }\end{array}$ & $\begin{array}{l}\text { Pruebas teórico- } \\
\text { conceptuales }(60 \%) \text { y } \\
\text { colaboración con la } \\
\text { clase }(40 \%)\end{array}$ & $\begin{array}{l}\text { Examen teórico, } \\
\text { realización de } \\
\text { trabajos escritos y } \\
\text { cuaderno del alumno. }\end{array}$ & $\begin{array}{l}\text { Asistencia a clase, } \\
\text { actitud y } \\
\text { colaboración con el } \\
\text { profesor (5 puntos). } \\
\text { Examen teórico, } \\
\text { trabajos y cuaderno } \\
\text { (5puntos). }\end{array}$ \\
\hline 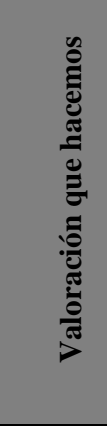 & $\begin{array}{l}\text { - Respuesta centrada } \\
\text { en contenidos } \\
\text { conceptuales. }\end{array}$ & $\begin{array}{l}\text { - Falsa integración. } \\
\text { - La Adaptación } \\
\text { Curricular se basa en } \\
\text { que realice } \\
\text { actividades por } \\
\text { escrito. }\end{array}$ & $\begin{array}{l}\text { - Falsa integración. } \\
\text { - Respuesta centrada } \\
\text { en contenidos } \\
\text { conceptuales. } \\
\text { - El certificado } \\
\text { médico determina el } \\
\text { carácter de la } \\
\text { dispensa. }\end{array}$ & $\begin{array}{l}\text { - Falsa integración. } \\
\text { - Certificado médico } \\
\text { imprescindible. } \\
\\
\text { - Respuesta centrada } \\
\text { en contenidos y } \\
\text { tareas conceptuales. }\end{array}$ & $\begin{array}{l}\text { - Falsa integración. } \\
\text { - Certificado médico } \\
\text { imprescindible. } \\
\text { - Respuesta centrada } \\
\text { en contenidos } \\
\text { actitudinales y } \\
\text { conceptuales. } \\
\text { - ¿Diferencia entre } \\
\text { exentos y alumnos } \\
\text { con NEE? }\end{array}$ \\
\hline
\end{tabular}

Tabla 2c. Las respuestas en Educación Física a los alumnos con necesidades educativas especiales 


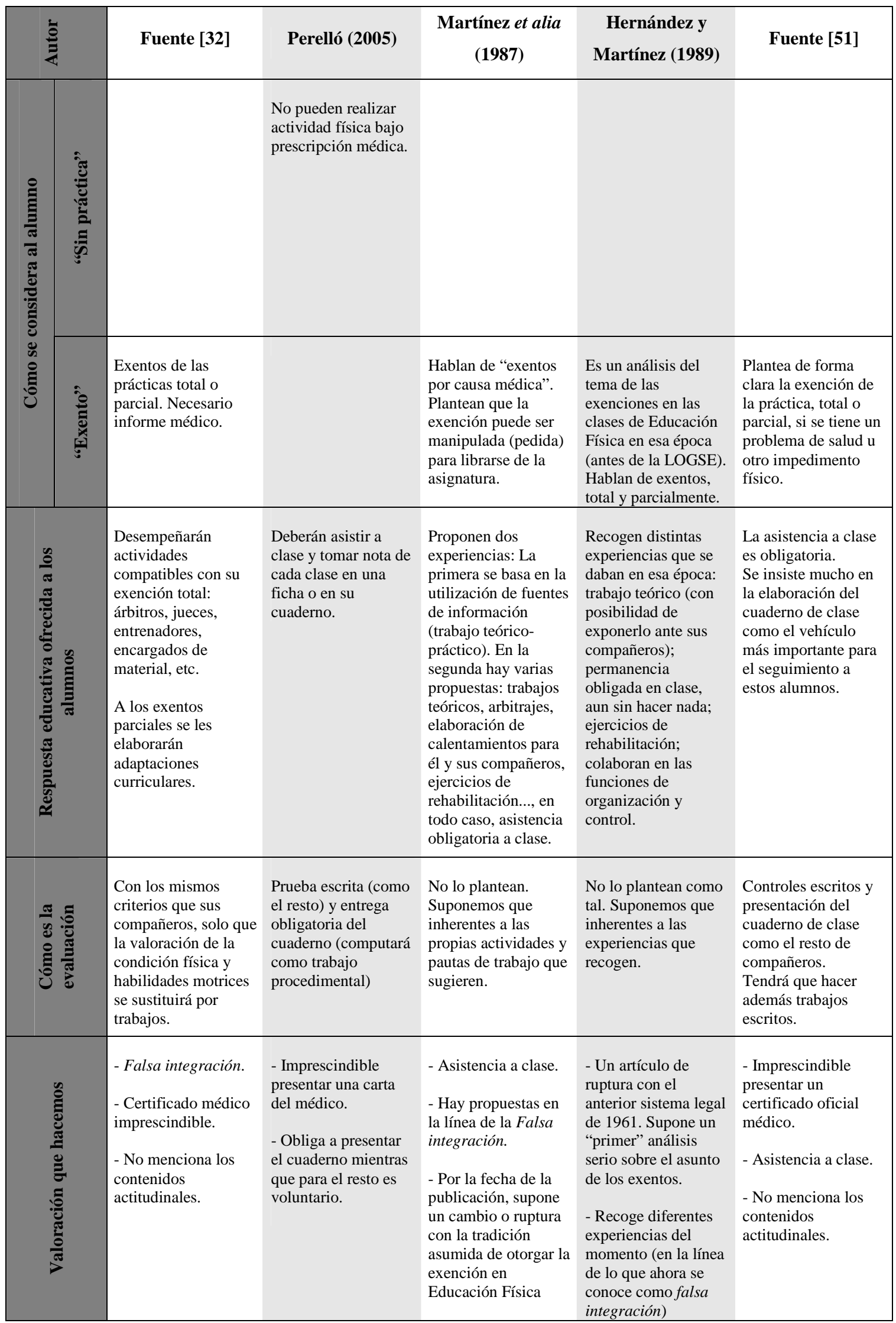

Tabla 2d. Las respuestas en Educación Física a los alumnos con necesidades educativas especiales 


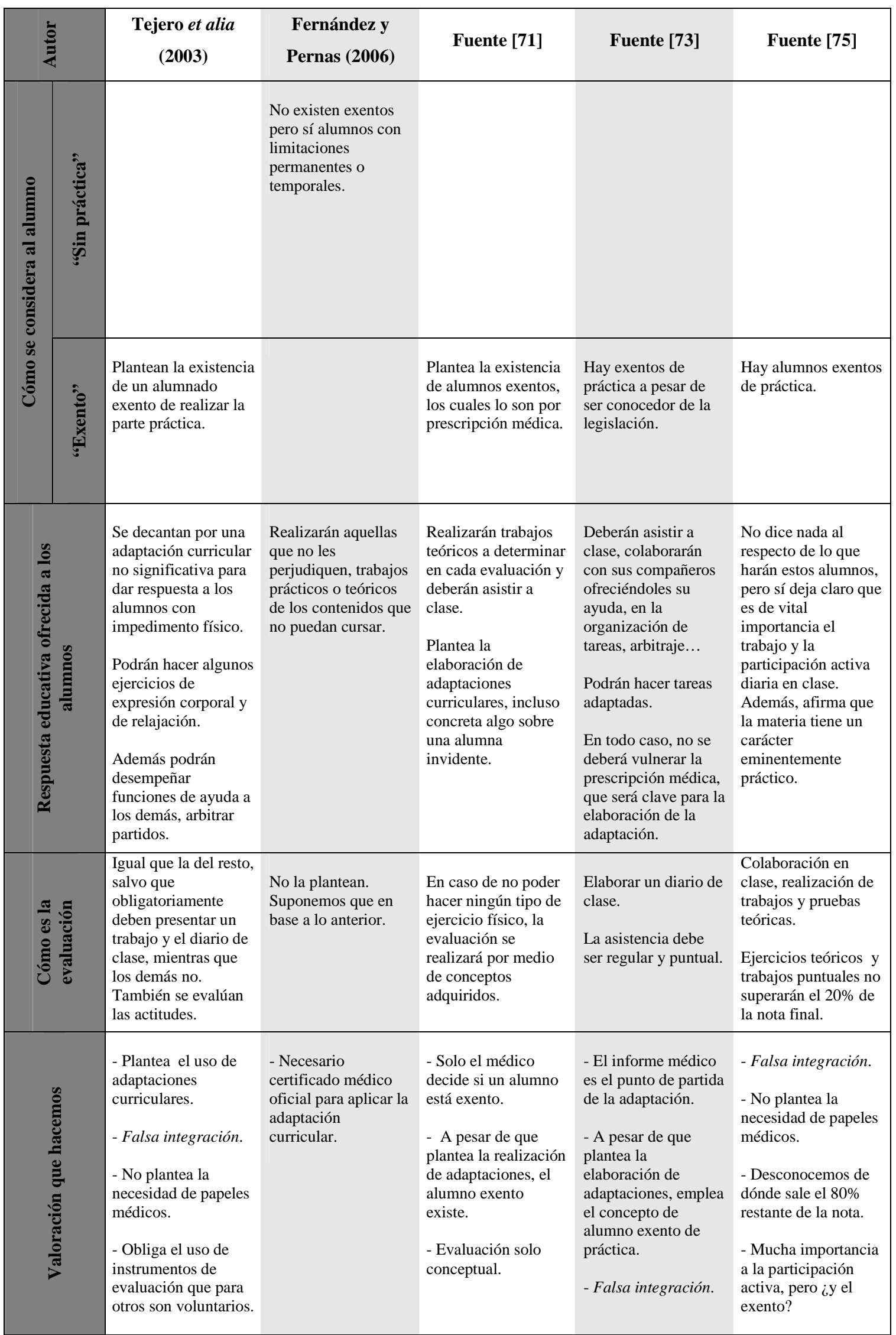

Tabla 2e. Las respuestas en Educación Física a los alumnos con necesidades educativas especiales 


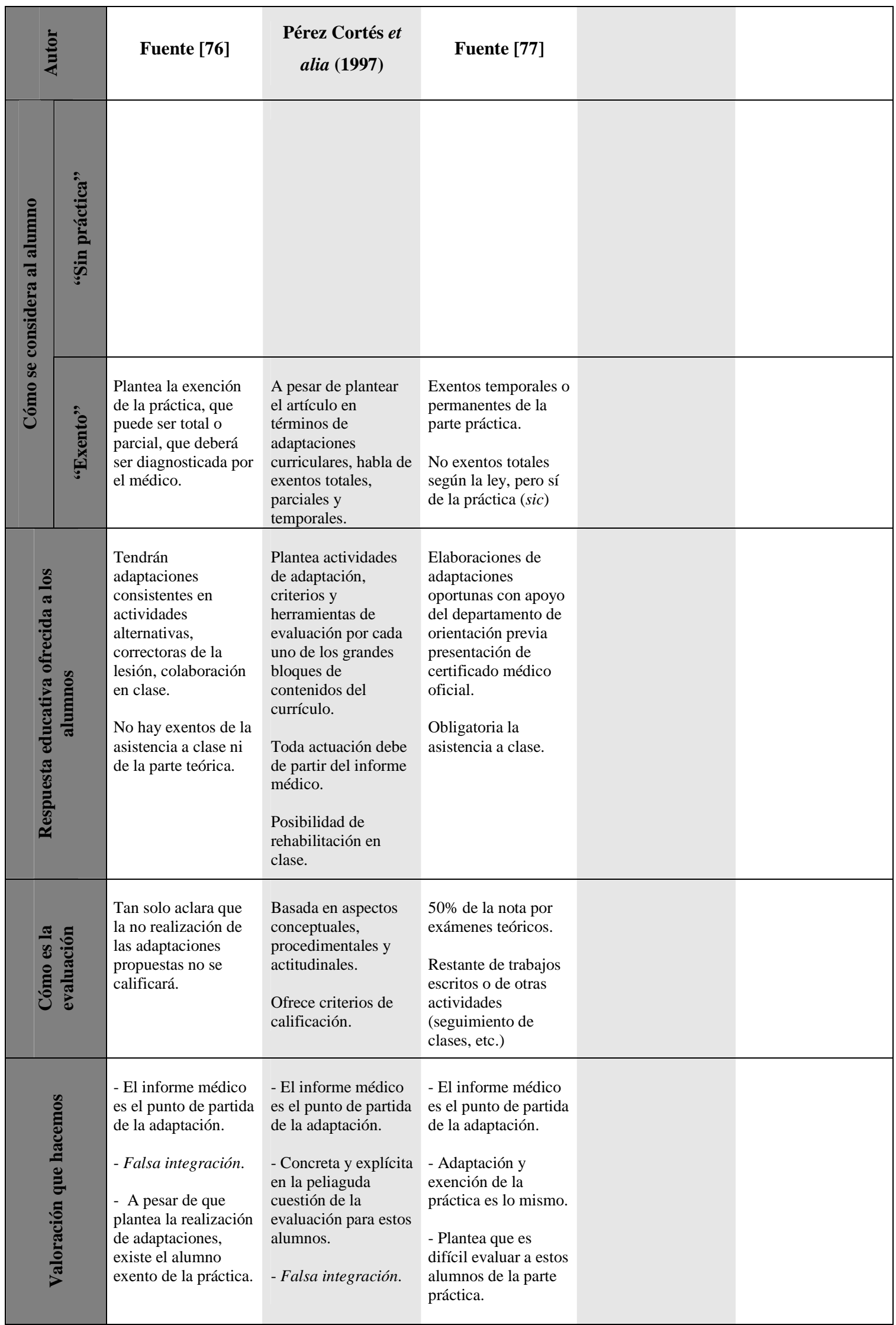

Tabla 2f. Las respuestas en Educación Física a los alumnos con necesidades educativas especiales 
Si se observa con detenimiento el apartado de la respuesta educativa ofrecida a estos alumnos, se percibirá que son varias las veces que aparece la anotación de ejercicios o elaboración de fichas sobre las actividades realizadas diariamente por el resto de compañeros. Un ejemplo más se encuentra en la Fuente [50] ${ }^{139}$ que presenta una ficha para lesionados. Se trata de una ficha que se propone como el trabajo práctico que deben hacer los alumnos que tengan algún problema (no aclara de qué tipo) y que no puedan realizar la práctica correspondiente durante el tiempo que ese problema perdura. En concreto, se dice que el trabajo de estos alumnos consistirá en tomar nota por escrito de todos los ejercicios que el grupo realiza en clase (inclusive el calentamiento). Según la ficha propuesta, la descripción de los ejercicios tiene que ser escrita y gráfica.

En otra línea, los hay que lo que proponen o realizan en sus clases son adaptaciones (en formas de cambios de rol) del resto del grupo a los déficits que presenta el alumno con algún tipo de discapacidad, bien porque se eliminan objetivos que ellos no alcanzarían, o bien por "situarles" en un plano motriz al mismo nivel "deficitario" o restringido que presenta el alumno con discapacidad. En la Tabla 3 se recogen algunos ejemplos:

\footnotetext{
${ }^{139}$ http://es.geocities.com/rafaperezp/fichalesionados.html
} 
AUTOR

PROPUESTA DE CAMBIO DE ROL

Olayo et alia $^{140}$

(1996)

Plantea crear situaciones en las que los compañeros perciban las limitaciones de los que tengan alguna discapacidad: con los ojos tapados, oídos taponados, que todos se desplacen a la pata coja cuando haya un compañero que utiliza una prótesis en su pierna.

Soriano (1998)

Sus alumnos han experimentado en diversas ocasiones la situación de un compañero con deficiencia visual.

Cumellas

(2000)
En la línea de los juegos sensibilizadores, propone actividades en dónde se simulará la discapacidad del alumno con limitaciones: todos "ciegos" o "mudos", en silla de ruedas...

Ríos (2001b y Plantea incluir en las primeras sesiones juegos motrices sensibilizadores ${ }^{141}$ para que otros) tomen conciencia de la realidad que vive una persona con discapacidad.

Fernández-Río Plantea diferentes propuestas prácticas inclusivas para el área de Educación Física. et alia (2000) Entre ellas, la del voleibol con todos los alumnos sentados ${ }^{142}$.

Perelló et alia (2003)
Se trata de un manual de preparación de oposiciones al cuerpo de Profesores de Educación Secundaria en Educación Física. En una Unidad Didáctica propone la adopción del cambio de rol para equilibrar las herramientas de lucha (p. 435).

Tabla 3. Cambios de rol en la Educación Física

A modo de ejemplo, se reproduce un pasaje de Ríos (2004) cuando hace referencia al deporte adaptado a las personas con discapacidad en el ámbito de la Educación Física, si bien esta autora es defensora de que no todos los alumnos deben hacer la clase a oscuras por tener un compañero con una deficiente o nula visión ni se debe de dejar a este último excluido de la práctica porque no ve.

\footnotetext{
${ }^{140}$ Aunque las propuestas que hace van encaminadas sobre todo a la participación del alumnado con discapacidad en las actividades extraescolares de tipo físico-deportivas, tiene una clara aplicabilidad en el área de Educación Física. Como se podrá apreciar, es una idea similar a la de los juegos motrices sensibilizadores vistos en la propuesta que le precede.

${ }^{141}$ Para tener una noción más clara de este concepto, vid.: Ríos et alia (1998a, 2001c, 2004). En todo caso, esta autora los define como aquellos que, con la presencia de personas con discapacidad o no, hacen que los participantes vivan de manera lúdica las limitaciones de las personas con dificultades (físicas o sensoriales) y valoren sus capacidades (2001c, p. 153).

142 Acerca de la sensibilización dice lo siguiente: "La sensibilización de los participantes hacia estas personas y sus necesidades precisaba de una aproximación vivencial a través de actividades que les permitiera tomar conciencia de sus dificultades y limitaciones de una forma lúdica, valorando así sus capacidades.” (Fernández-Río et alia, op. cit. , p. 327)
} 
“...Sus compañeros simularán la discapacidad (si ello es posible y/o necesario) y podrán conocer otras modalidades deportivas. Por ejemplo, si tenemos un alumno con discapacidad visual y se está trabajando el bádminton, podemos proponer que un pequeño grupo, con los ojos vendados y de forma rotatoria, practique con él el goalball... También si tenemos un alumno con amputación del tren inferior, puede practicarse el voleibol sentado." (op. cit., p. 165)

En este sentido, se comparte con Zucchi (2001) que si el disminuido participa exclusivamente en un ambiente de disminuidos, en poco se favorece la integración ${ }^{143}$. Aun así, los hay que de nuevo plantean la integración de estos alumnos separándoles del resto de la clase ${ }^{144}$.

"Los alumnos que utilizan silla de ruedas pueden participar, pero en otra canasta distinta a la de sus compañeros para evitar choques o accidentes. En caso de que haya más alumnos que utilizan silla se puede proponer que realicen el mismo juego, pero ente ellos, para evitar choques con quienes pueden correr normalmente." (Olayo et alia, 1996, p. 136)

Sáenz-López et alia (2001, p. 177), en un estudio sobre la opinión del alumnado de Magisterio de la Educación Física Especial, destacan que este alumnado es favorable a adaptar la clase a la discapacidad del alumno en cuestión, y está en contra de que sea el discapacitado el que se adapte a las tareas propuestas en clase.

\subsection{6.- LA DISPENSA POR APOYO EDUCATIVO}

En primer lugar, podemos entender que se produce una peculiar forma de exención, que viene a significar la dispensa del $50 \%$ de la práctica, para todos aquellos alumnos con algún tipo de necesidad de aprendizaje que suelen salir de nuestras clases

\footnotetext{
${ }^{143}$ Puigdellívol (2001, pp. 14-15) dice al respeto que “...lo que entendemos como aprendizaje humano sólo puede llevarse a cabo en situaciones de grupo... Todo grupo humano se nutre, básicamente, de las aportaciones de sus compañeros. Lógicamente aportaciones diferentes, pues si fueran idénticas no enriquecerían para nada el conocimiento del grupo."

${ }^{144}$ Ríos (2004, p. 152) llega a decir que en algunas circunstancias, y de forma excepcional, pudiera estar indicada la actividad individual al margen del seno del grupo. Lo que nunca debe producirse es que se convierta en una práctica o procedimiento habitual.
} 
de Educación Física para recibir apoyos o refuerzos educativos. Veamos en qué sustento esta afirmación $^{145}$.

La Dirección General de Formación Profesional e Innovación Educativa de la Consejería de Educación de Castilla y León habitúa a enviar a los centros docentes instrucciones para llevar a cabo actuaciones con el alumnado en el ámbito de compensación educativa y de necesidades educativas especiales.

Así por ejemplo, la Instrucción 21/2003 de dicha Dirección General de Formación Profesional e Innovación Educativa relativa a la planificación de las actuaciones de compensación educativa e interculturalidad para el curso 2003-2004 concreta, entre otros asuntos, algunas aclaraciones sobre el alumno destinatario de dichas instrucciones.

Primero destaca al alumnado de necesidades educativas especiales, refiriéndose a él como aquellos alumnos de necesidades educativas especiales asociadas a condiciones personales de discapacidad y suelen mostrar estas necesidades de modo permanente a lo largo de su paso por el sistema educativo.

Seguidamente hace referencia al alumnado de necesidades de compensación educativa como aquel alumnado con necesidades educativas específicas en razón de sus circunstancias de desventaja, sin que exista discapacidad personal asociada.

Previamente a estas aclaraciones conceptuales recoge la normativa específica de carácter educativo que es aplicable en estos casos. En concreto señala, entre otras, la Orden de 22 de julio de 1999, por la que se regulan las actuaciones de compensación educativa en centros docentes sostenidos con fondos públicos (BOE 28-07-99).

\footnotetext{
${ }^{145}$ No se incluye este apartado en el capítulo legislativo porque las normas y leyes que se emplearán para justificar el razonamiento de este doctorando en ningún momento hacen referencia ni utilizan los términos exención o dispensa.
} 
En esta Orden se hace patente que para desarrollar actividades especiales relacionadas con la adquisición de competencias comunicativas en la lengua vehicular del proceso de enseñanza, así como con la adquisición o refuerzo de aprendizajes instrumentales básicos, en las etapas obligatorias se podrá establecer apoyo educativo en pequeño grupo fuera del aula de referencia, durante un máximo de ocho horas semanales. En todo caso, el horario establecido para estos grupo de apoyo no será nunca coincidente con aquellas actividades complementarias que puedan favorecer la inserción del alumnado con necesidades de compensación educativa ni con las áreas de Educación Física, Educación Artística, religión o actividades alternativas, Educación Plástica y Visual, Música y Tecnología (énfasis mío).

En la Circular que la Dirección General de Centros Educativos del Ministerio de Educación y Cultura remitió en noviembre de 1996 a los Directores Provinciales del MEC, relativa a la organización y seguimiento de las actuaciones de compensación educativa, se señalaba lo siguiente: "El apoyo educativo en pequeño grupo fuera del aula de referencia se establecerá para desarrollar las actividades relacionadas con la adquisición de competencias comunicativas de la lengua de acogida y con la adquisición y refuerzo de aprendizajes instrumentales básicos... En todo caso, el horario establecido para estos grupos no debe ser nunca coincidente con áreas que pueden favorecer la inserción del alumnado con necesidades de compensación educativa: Educación Física... ${ }^{146,}$.

Es decir, que de manera explícita se legislaba para que el alumnado de compensación educativa no pueda salir de las clases de Educación Física para recibir cualquier tipo de apoyo. Sin embargo, ¿qué sucede con el resto de alumnado con otras necesidades educativas?

\footnotetext{
${ }^{146}$ La Orden EDU/849/2010, ya comentada en un apartado anterior, sigue esta misma línea de no permitir que el apoyo educativo en pequeño grupo para adquirir o reforzar las competencias básicas no será coincidente con la materia de Educación Física, entre otras.
} 
Para ver lo que podía ocurrir con el alumnado con necesidades educativas específicas $^{147}$, habría que consultar la Instrucción 22/2003 de la Dirección General de Formación Profesional e Innovación Educativa relativa a la planificación de la orientación en los Departamentos de Orientación para el curso escolar 2003-2004.

Esta instrucción dispone el apoyo educativo como una de las medidas que les serán de aplicación, el cual se dará en pequeños grupos o de forma individual, dentro o fuera del aula ordinaria. En este último caso es conveniente que el tiempo que estén fuera de su grupo de referencia sea el menor posible. Pero en ningún momento se confirma que no puedan salir de ninguna área en general y, ni mucho menos, de la Educación Física en particular.

Por ese motivo, cuando hay que ofrecer a un alumno una medida de este tipo, pudiera darse el caso de emplear una de las dos horas semanales de que dispone la Educación Física en la E.S.O. para ese menester, privando al alumno en cuestión de la mitad del total de las clases presenciales y, por tanto, prácticas.

Con relativa frecuencia este doctorando ha podido comprobar que realmente estas situaciones ocurren en el quehacer diario. Alumnos con disfemia, hipoacúsicos... han salido y siguen saliendo de las clases de Educación Física una vez por semana para recibir apoyo educativo con el profesor de Audición y Lenguaje. Por tanto, podría percibirse a este conjunto de medidas y actuaciones como una particular forma de eximir parcialmente a un alumno en Educación Física. Igualmente, en una de las experiencias que Pérez Brunicardi et alia (2004, p. 94) relatan sobre la atención a la diversidad en Educación Física, constatan que una alumna de $3^{\circ}$ E.S.O. solo asiste en una de las horas porque en la otra tiene apoyo.

\footnotetext{
${ }^{147}$ La Dirección General de Formación Profesional e Innovación Educativa de la Consejería de Educación de Castilla y León tiene elaborada para la recogida de datos relativos a la atención a la diversidad la siguiente clasificación de grupos de alumnado: Alumnado de compensación educativa; Alumnado con necesidades educativas especiales; Alumnado superdotado; Otro alumnado con necesidades educativas específicas. Dentro de este último se encuentran los alumnos con capacidad intelectual límite, con necesidades específicas de lenguaje (NEL) y el absentista.
} 


\subsection{7.- ¿LA FORMACIÓN DEL PROFESOR DE EDUCACIÓN FÍSICA COMO EXCUSA PARA LA EXENCIÓN?}

Hemos visto que la aplicación de una exención, ya sea en la modalidad de Educación Física "sin práctica" o como una exención total o parcial, sigue teniendo plena actualidad en el quehacer diario de nuestra materia. Pero, ¿cuáles son los verdaderos motivos que hacen perdurar esta situación que por ley no debiera existir? Evidentemente, dar respuesta a esta pregunta sería todo un logro para, al menos, intentar solventar el que se siga produciendo. Esta que sigue, y que hace referencia al profesorado, pudiera ser una de ellas.

En primer lugar, se puede afirmar que la carencia de materiales e instalaciones adecuadas, de profesorado o personal de apoyo ${ }^{148}$ y las propias características inherentes al área de Educación Física hacen que de por sí sea ardua y complicada la correcta y completa integración (inclusión) de la totalidad del alumnado, y más si tienen necesidades educativas especiales.

“...Estas mismas limitaciones [escaso número de horas semanales, grupos numerosos de alumnos, niveles muy heterogéneos, instalaciones y material insuficiente, etc.] que nos obliga a soslayar el desarrollo teórico de ciertos temas en beneficio de la parte práctica, dificultaría, por no decir imposibilitaría, una adecuada valoración de las limitaciones y adaptación de las actividades para aquellos alumnos necesitados de una atención especial..." (Hernández y Martínez, 1989, p. 50. Aclaración mía)

Por otra parte, la filosofía de las leyes educativas desde la reforma LOGSE hasta la LOE, sitúan a los docentes en la encrucijada de tener que desarrollar el currículum teniendo en cuenta las peculiaridades específicas del contexto (centro, aulas, alumnado, etc.) en que han de llevarlo a cabo. En esta tarea, el papel que desempeñan los distintos mediadores culturales (específicamente los libros de texto) es decisivo ya que, con mucha frecuencia, funcionan como los verdaderos definidores del tercer nivel de

\footnotetext{
${ }^{148}$ En la Fuente [61-6] se podrá leer una noticia relacionada con esta realidad, tanto en Primaria como en Secundaria: "Padres de alumnos de educación especial de tres colegios de Elche denuncian la falta de profesores. La situación es similar en todos los centros educativos con niños con necesidades educativas especiales: las plazas de personal no docente de apoyo tardan en cubrirse..." (fechada el 01-10-2005).
} 
concreción. Sin embargo, como indicaba el Diseño Curricular Base (MEC, 1989, p. 220) la Educación Física es “...un área que apenas posee materiales curriculares de carácter externo (libro de texto, guías didácticas...) y en la que el profesor elabora casi todas las actividades y situaciones de aprendizaje y enseñanza.”. Aunque esta situación ha variado considerablemente en las dos últimas décadas en las que hemos asistido a una multiplicación considerable de la oferta de mediadores culturales de nuestra materia, sigue siendo bastante cierta la idea de que el docente de Educación Física actúa con una gran "libertad" a la hora de confeccionar y diseñar sus programaciones didácticas y de aula.

En esta línea, López González (1997, p. 9) indica que es el profesorado el creador de toda reforma pues es quien lleva a la práctica las adecuaciones curriculares que considera necesarias. Creemos que en el caso del tratamiento de los alumnos con dificultades de aprendizaje, para que dicha práctica tenga lugar, la formación previa y permanente que los docentes deben poseer tiene que ser lo más abundante y variada posible para garantizar la atención a la diversidad.

Ríos (1998b, p. 30 y 2009, p. 91) bosqueja, entre otros, la falta de formación especializada en Educación Física y necesidades educativas especiales de los profesores como condicionante, relacionado con la práctica docente, de la integración en las sesiones de Educación Física. Hay un miedo a lesionar, por desconocimiento, que puede tener consecuencias legales. Mendoza (2003) apunta que la razón principal del profesorado para no atender a los alumnos con necesidades educativas especiales se encuentra en la carencia de conocimientos para poder tener la seguridad de no cometer errores en su intervención. Martínez y Martínez (2001) recalcan las dificultades que se tienen para llevar a efecto un programa de integración si no hay una preparación específica en el profesorado.

Calverol (2000, pp. 60-61) asegura que la falta de información y de formación de los profesores es un problema a la hora de la toma de soluciones para propiciar las adaptaciones que hagan participar a este tipo de alumnado durante toda la sesión. 
Asimismo, considera necesario el que haya más cursos de formación permanente, no solo teóricos, sino prácticos.

Hay quien apunta que el profesorado en general, y especialmente el de educación física, tiene una reducida preparación en estos asuntos, a lo que hay que añadir unos recursos escasos, como ya se apuntaba al inicio de este apartado, para atender a alumnos de estas características.

“...En el momento presente, cuando nos referimos a escolares con necesidades educativas especiales, se observa que este supuesto de formación está bastante alejado de la realidad, pues el profesorado que se dedica a la enseñanza en general, y a la educación física en particular, tiene una escasa formación básica... y, generalmente, no dispone de una preparación y de unos recursos suficientes para atender a sujetos con estas características especiales. ” (Arráez, 2003, p. 20)

Aún más se sincera Lladonosa (1998, p. 47) al confesar que el profesorado de Educación Física no está suficientemente formado para atender a la diversidad del alumnado, siendo necesarios unos conocimientos teóricos y prácticos para poder dar respuestas adecuadas a cada caso. Cumellas (2002), afirma que, a pesar de la integración en las escuelas convencionales de los alumnos con discapacidades (referido al ámbito de la Educación Física), apenas existe literatura que informe, estudie y profundice en este tema. Opinión que es compartida por otros:

“...se da la paradoja de que si revisamos la literatura especializada dedicada a la Educación Física, y en general al deporte, nos encontramos con una gran sequía: pocas obras que nos hablen de la Educación Física en alumnos con discapacidad, y algunas, pero no muchas, dedicadas al deporte adaptado." (Puigdellívol en el Prólogo a Ríos, 2003, p. 12)

Hernández et alia (1998) ya apuntaban que, a pesar de haber comprobado la existencia de una predisposición positiva en el profesorado hacia la integración de los alumnos con necesidades educativas especiales, las limitaciones pedagógicas para dar respuesta a la diversidad suponen una auténtica dificultad. 
Ríos (2007, p. 87) afirma que el profesorado de Educación Física necesita de información realista sobre sus alumnos con algún tipo de necesidad educativa especial, sin crear falsas expectativas y que hay escasa bibliografía que sirva de apoyo.

Más próximo en el tiempo, la UNESCO (2015) elabora una guía de Educación Física pensada para los responsables políticos en la que ratifica la escasez de preparación de los profesores para enseñar a los niños con discapacidad. De hecho, asegura que los programas teóricos no posibilitan en el profesorado la autoeficacia suficiente como para propiciar la inclusión en la práctica.

A la vista de todos estos datos, pudiera ser que la poca formación del profesorado y la escasa información de que disponen desencadena un miedo a lo desconocido, a cometer errores y provocar daños, etc., haciendo que se consolide la "exención" o la "no práctica" como una alternativa a utilizar por el profesorado en estos supuestos.

"La primera reacción que he detectado en cursos de formación continuada de profesores y profesoras, es, salvo contadas excepciones, la de negar, a priori, la posibilidad de participación de esos alumnos [referido a alumnos con necesidades educativas especiales en nuestra área]. Porque simplemente no se les ocurre ninguna adaptación. El «no» va por delante, sin pararse a pensar qué podrían hacer ante su desconocimiento." (Ríos, 2001b, p. 97. Aclaración mía. En términos parecidos se muestra esta autora en 2009, p. 91)

“...en general, el profesorado no tiene la preparación suficiente para atender a los alumnos con necesidades educativas especiales...El profesorado se escuda en la falta de conocimientos para no cometer errores en su intervención y así no intervenir. Ese miedo a actuar por desconocimiento da lugar a la inactividado deficitaria actividad física desarrollada por el alumno con nee en las clases de Educación Física.” (Mendoza, 2009, pp. 45-46)

“...la exención de la práctica de las actividades integradas en la clase de educación física tiene lugar, en numerosas ocasiones, por el desconocimiento que los docentes tienen para actuar en beneficio de la integración real de las personas con discapacidad.” (Equipo Directivo Tándem, 2003, p. 6)

“...Se ha comprobado que muchas veces la negativa de los docentes a introducir modificaciones en sus prácticas se debe al temor de no tener consolidadas las herramientas y los saberes necesarios." (Villagra, 2003, p. 12) 
También pudiera ser que la administración educativa, a través de cualquier organismo de los que configuran todo su engranaje, esté generando muy poca o nula oferta formativa en asuntos relacionados con la Educación Física y los alumnos con necesidades educativas especiales (Villagra, 2003, p. 12). Otra tema es si el profesorado demanda y busca esa formación específica, ya que, empleando las palabras de Tierra (2001, p. 144), realmente y por desgracia no nos formamos hasta que nos encontramos frente al problema, frente a la realidad del aula, donde se tiene que llevar a la práctica esa realidad. Es a partir de ese momento cuando comenzamos a recabar información y prepararnos para solucionar ese escollo en el día a día.

Junto con esta carencia formativa, las experiencias previas del profesor en este arduo campo de la atención a este alumnado también son un factor que condiciona el adecuado tratamiento integrador (Ríos, 2001b), lo cual se podría considerar como un factor que origina exenciones.

“...La actuación del profesorado de Educación Secundaria [de Educación Física] hacia el alumno que requiere una atención especial ha sido prácticamente inexistente, debido, sobre todo, a la falta de formación y cualificación del profesorado, así como también a la falta de tradición y experiencia." (Hernández, 2000, p. 11. Aclaración mía)

En el estudio realizado por De Potter (1995), alguna de sus conclusiones finales versaba únicamente sobre nuestra área, lo que para el autor tenía estrecha relación con la falta de medios destinados a favorecer la integración en nuestras clases, así como la ausencia de conocimientos y experiencias con estos alumnos.

"Los profesores de educación física reconocieron que, en muchos casos, era problemático aceptar a alumnos en escuelas generales y ofrecerles un programa de Educación Física de igual calidad al que se aplicaba en sus escuelas especiales.” (De Potter, 1995, p. 45)

Íntimamente relacionadas con esa formación específica y las experiencias previas de los docentes, se encuentran las actitudes del profesorado hacia los alumnos con algún tipo de discapacidad, contribuyendo de nuevo a la exención. 
"La actitud de los profesionales de la Educación Física varía con relación a la discapacidad. Así, las actitudes son más favorables hacia la enseñanza de alumnos con problemas de aprendizaje en las clases normales, que hacia los alumnos con discapacidad física.” (Peña y Vázquez ${ }^{149}$, 2001, p. 155)

“...Otro aspecto que dificulta la respuesta educativa hacia los alumnos [que requieren una atención especial] está en las actitudes del profesorado hacia este tipo de alumnos. Muchas veces y debido al desconocimiento del tema, la inseguridad se pone de manifiesto, los docentes no tienen confianza en este proceso, piensan que la atención a estos alumnos dificulta la tarea e influye negativamente en su dedicación.” (Hernández, 2000, p. 11. Aclaración mía)

"Actualmente nos encontramos ante una realidad incuestionable como es la incorporación, cada vez más frecuente, de alumnos y alumnas con necesidades educativas especiales debido al proceso de integración... Este proceso viene generando entre el profesorado en general, y el de educación física en particular, una disparidad de actitudes que van desde la angustia y la duda al pasotismo, pasando por el temor, la desesperanza y el miedo.” (Arráez, 2003, p. 19)

A este respecto, son varios los estudios e investigaciones que hay sobre las actitudes de los docentes hacia la integración y el niño discapacitado (vid.: Susinos, 1997; Pérez y Prieto, 1997; Hernández et alia, 1997).

Zuchhi (2004) señala al profesorado como uno de los desencadenantes de la exclusión de los alumnos con discapacidad. Las raíces de este hecho pueden hallarse en el propio bagaje de experiencias de los docentes, sus carencias formativas y sus actitudes.

“...al momento de incluir un alumno con discapacidad en las mismas, se observa como muchos docentes de Educación Física primero presentan una actitud de indeferencia para luego separarlo en el momento de la participación en las tareas. Esto es debido, en primer término, a representaciones sociales que los mismos construyen en base a la historia compartida dentro del campo de la Educación Física y a una formación de grado disgregada. En segundo término esta actitud del docente puede estar reflejando al mismo tiempo una imagen colectiva de la sociedad en la que se encuentra insertado."

\footnotetext{
149 Estos autores recogen una serie de afirmaciones muy interesantes respecto a las actitudes del profesorado de Educación Física ante la diversidad, y muy especialmente ante los alumnos con necesidades educativas especiales.
} 
Gallardo y Gutiérrez (2007) opinan que el profesorado de Educación Física tiene una gran despreocupación por este tipo de alumnos con necesidades educativas especiales. De hecho, consideran que muchos de nuestros actos los podría realizar cualquier persona con "dos dedos de frente", lo cual demuestra que no "somos educadores en potencia".

“...y aquí viene la parte más dolorosa, «nos lo quitamos de en medio» [refiriéndose a un niño con retraso mental leve]. Parece duro de oír o creer, pero es la absoluta verdad. Los profesores de educación física utilizamos «artimañas» con las que quitamos al alumno del «campo de batalla», tales como asignarle una función menos importante, como por ejemplo que sea nuestro «AYUDANTE», o incluso los eliminamos del juego sin más, achacando mal comportamiento, falta de intensidad en el ejercicio... o cualquier cosa que parezca servirnos para que el niño no nos «estropee» el juego."

Pero pudiera ser que no es solo la actitud hacia este tipo de alumnos, sino también el apego y la concepción global del propio área en términos de deporte / condición física / rendimiento predominantes no solo en la sociedad en general ${ }^{150}$, sino sobre todo en nuestra propia cultura profesional hegemónica. Recuérdese, como ya apuntábamos anteriormente, que Astráin (2002, p. 506), en un estudio sobre la "realidad" de la Educación Física en la Comunidad Floral de Navarra, advertía entre sus conclusiones que “...tanto en las programaciones como en el estudio de caso el 75\%$80 \%$ del tiempo disponible (en la ESO) se ocupa en el desarrollo de los contenidos de «juegos y deportes» y «condición física»”. Asimismo, Contreras (1998, p. 162) señala que el contenido de la condición física es el de mayor tradición en la Educación Física.

${ }^{150}$ Como ejemplo de lo que opinan algunos sectores de la sociedad sobre la Educación Física o lo que debe ser, sirvan dos manifestaciones que han aparecido en prensa escrita de a raíz de los exiguos resultados obtenidos por nuestra selección nacional de atletismo en los mundiales de 2005 celebrados en Helsinki. Por un lado, las declaraciones de José $\mathrm{M}^{\mathrm{a}}$ Odriozola, presidente de la Federación Española de Atletismo:

“...Hay que poner la educación física obligatoria, tres o cuatro veces por semana hasta los 15 ó 16 años... Pero que los jóvenes tengan la capacidad de sufrir físicamente, de esforzarse, de lo que cuestan las cosas, que eso será muy bueno para estudiar, para el posterior trabajo. En España se vive demasiado bien y la gente joven no se esfuerza casi nada..." (Periódico MARCA, 13-08-2005, p. 29)

Por otro lado, un ciudadano cualquiera, Antonio de la Hoz, escribe una carta dirigida al director del periódico El Norte de Castilla (21-08-2005), expresándose en los siguientes términos:

“...Si de verdad queremos potenciar el deporte, hay que empezar por la base, apoyarlo en los colegios, construir instalaciones de barrio y no con disparates como «las clases teóricas de educación física» y los horarios marginales en el calendario escolar." 
No se trata ahora de discutir ni la conveniencia de la presencia de la Educación Física en el currículo ${ }^{151}$ ni el tipo de saberes y contenidos que la configuran, pero comparto con Ríos (2001b, p. 102), que tal vez “...estamos arrastrando el lastre histórico de la «asignatura maría» donde sólo se hace deporte, sin ningún planteamiento pedagógico adicional.”. En otras palabras, parece que ni nosotros mismos somos capaces de asumir el gran reto que supone una Educación Física plenamente integradora con unas sólidas bases pedagógicas de atención a la diversidad, aceptando como normal y válido el papel subsidiario que hemos estado compartiendo con otras áreas formativas (Puigdellívol, 2001, p. 17), desencadenándose la exención.

"En algunos centros docentes, los períodos de exámenes son considerados como eximentes parciales de la clase de educación física, especialmente cuando el estudiante se juega el pasar de curso o el aprobar una asignatura especial. No tenemos nada que oponer a ello.” (de la Cruz, 1992, p. 106)

"No existe una conciencia social de la importancia de la Educación Física, lo que motiva que algunos padres a la menor queja o dificultad física... de su hijo presionen al médico para que extienda un certificado que le exima de tan «inútil»asignatura”. (Mantas, 1995, p. 403)

Por suerte, hay quienes piensan que esta situación está siendo superada con creces por el profesorado, cada vez más interesado y concienciado profesionalmente con este tipo de alumnado (Puigdellívol en el Prólogo a Ríos, 2003, p. 10).

\subsection{8.- LA EXENCIÓN EN LOS MEDIOS SOCIALES DIGITALES}

Estamos inmersos en un mundo digital en donde los medios de comunicación social (las redes sociales) son un escenario en el que, a través de la interactuación online, se facilita el intercambio de información entre un grupo de personas sin la necesidad de coincidencia en la variable temporal (Pantoja, 2011, p. 224).

\footnotetext{
${ }^{151}$ Para este tema de la justificación de la presencia del área en el currículo, así como de su estatus, vid.: Kirk (1990, pp. 57-78), Contreras (1998, pp. 49-52), López Pastor et alia (2003, p. 24).
} 
Conociendo la importancia que actualmente alcanzan este tipo de medios de comunicación (intercomunicación), hemos explorado en foros y páginas Web de consultas para comprobar si la exención de Educación Física, en cualquiera de sus formas, aparece como tema de conversación.

En esta búsqueda nos hemos encontrado con varios ejemplos muy evidentes que expondremos a continuación. Para su presentación hemos optado por emplear un formato basado en colores para resaltar las diferentes entradas o participaciones de cada una de las páginas Web, facilitando así la lectura y comprensión de las conversaciones. Además, agruparemos las diferentes conversaciones en dos grandes núcleos de atención: el exento en Educación Física y la solicitud de convalidación de la asignatura.

Es conveniente aclarar que solo recogemos las preguntas y respuestas (en definitiva, conversaciones) más relevantes para el asunto que aquí nos ocupa. Además, hemos querido mantener el formato original de los escritos, faltas y errores de redacción incluidos.

Las fuentes de información consultadas son plataformas o sitios Web que, o bien recogen consultas con sus respectivas respuestas (del administrador y/o cualquier otro usuario, algunos de los cuales se define como experto en la materia) sobre temas que atañen a las formas de exención vistas hasta ahora, o bien hacen una alusión explícita a dicho concepto. En todo caso, todas ellas evidencian la consideración que la población en general (tanto la especializada como la profana) tiene sobre el asunto, empezando por su propia existencia y/o vigencia.

En concreto, las páginas Web consultadas han sido:

- Plataforma Web todoexpertos.com, que se define como una gran comunidad de expertos de habla hispana que resuelve todas las dudas sobre cualquier tema de forma gratuita.

- Página Web de Carlos González Arévalo, profesor del Departamento de Educación Física del INEFC-centro de Barcelona 
- Otro ejemplo lo encontramos en la página Web de David Argente Checa, creador del Proyecto Web "Compartiendo Educación Física”. Entre sus objetivos está el de unir un poco más al colectivo de maestros de Educación física a través de la red.

- Para terminar, una muestra existente en el Blog de Juan Carlos Muñoz Díaz (El patio de mi cole es particular). Este maestro especialista en Educación Física y Ciencias Sociales es el editor de la revista digital de Educación Física "EmásF".

\section{El exento en Educación Física}

Algunos casos ponen de relevancia, además de la constatación del concepto y uso de la figura del exento, la eliminación de la práctica como forma de responder a un determinado tipo de alumnado.

Por otra parte, los hay que dejan entrever que el peso de la asignatura se atribuye exclusivamente a los contenidos actitudinales y, sobre todo, conceptuales. Es decir, la exigencia teórica es la que decide la nota y justifica la presencia del alumno en la materia.

Además, en alguno de los ejemplos que presentamos queda patente la apreciación sobre la tipología y graduación de la enfermedad para tener en cuenta la exención de la asignatura como una posibilidad. En definitiva, la necesidad de obtener la exención como una solución al padecimiento de determinadas enfermedades, parece estar parejo, entre otras cosas, a la propia gravedad de la misma. Ni todas enfermedades son igualmente graves, ni pueden ser idénticas todas las actuaciones en el contexto educativo. 


\section{No dar Educación física}

http://www.todoexpertos.com/categorias/deportes/educacionfisica/respuestas/1525219/no-dar-educacion-fisica

\section{7-septiembre-2006}

Quisiera que me aclararais una duda/problema que tengo.

En septiembre comienzo $1^{\circ}$ de bachillerato y una de las asignaturas es educación física. Tengo problemas de espalda, por lo que no puedo realizar esfuerzo físico ya que después tengo dolor por toda la parte izquierda de la espalda, cadera y muslo.

Especificamente tengo escoliosis e hiperlordosis lumbar.

A parte de ello también estoy en tratamiento antidepresivo.

¿Qué debo/puedo hacer para librarme de la parte práctica de la educación física?

Respuesta de kunaguero, licenciado y diplomado en educacion...

Hola! Como profesor de educación física no puedo convencerte de que no hagas EF. Si fuera tu, coordinaría a tu medico especialista y a tu profesor para que $t$ diseñaran un paln de EF especifico para ti, que tayude con tu problema. De lo contrario llegara un momento que tendrás muchos problemas de movilidad y pasaras a ser una persona dependiente de otras. Ademas el deporte aporta vitalidad, te ayudara para reanimarte y salir un poco de esa depresión.

\section{4-agosto-2006}

Pero resulta que tengo malos recuerdos en esta asignatura y siempre me ha perjudicado más que ayudado a mejorar mi estado anímico, llegando a no dormir el día anterior a la clase, tener pánico y angustia.

El médico de cabecera no quiere justificarme para exentarme de la parte práctica, se negó a escribirme un justificante. 
18-septiembre-2006

\section{Respuesta de azaher, Director de www}

No te preocupes por eso. Cuando un alumno realmente no puede hacer esta clase por cuestiones físicas no está obligado a ello, aunque el médico te tendrá que firmar un documente conforme no puedes realizar actividad física. Luego habla con la dirección de la escuela y el profesor. Obviamente tendrás que aprobar la asignatura, pero será solo con trabajos teóricos

\section{Exenta de gimnasia}

http://www.todoexpertos.com/categorias/educacion/educacionfisica/respuestas/2292494/exenta-de-gimnasia

\section{9-enero-2010}

Mi hija esta exenta de gimnasia por una enfermedad cardíaca. Es la primera evaluación que sucede esto y cual es mi sorpresa que le han evaluado con un suficiente.

¿De dónde han sacado esa nota si ella no ha hecho ningún tipo de trabajo ni examen?

No se lo que dice la ley en estos casos, ya que esa tampoco es la nota media, se lo han puesto por ponerle algo, pero no me parece una nota correcta... 


\section{Respuesta Raul Gonzalez, Doctor en ciencias de la actividad...}

La ley es muy concreta, dice que no existen alumnos exentos en "educación fisica", es decir, ningún alumno estará exento en la totalidad de los contenidos de educación física, pero si puede ser evaluad@en contenidos conceptuales o actitudinales incluso procedimentales. Yo hablaría con la profesora para saber exactamente en que se ha basado para realizar la evaluación (Puede ser colaboración en la clase, actitud mientras dure la educación física, etv...) y lo más importante como realizará la evaluación de los siguientes trimestres.

Una colaboración dentro del respeto es fundamental entre los profesores y las familias.

\section{9-enero2010}

Ella ni siquiera va a la clase de gimnasia, ya que para que no se sienta apartada del grupo se queda con la tutora haciendo actividades de otras materias.

Hablare con el profesor, pero antes quería saber si había algo claro según la ley, ya que por ejemplo en la universidad, cuando estas exento de alguna asignatura te hacen una media de acuerdo a las demás asignaturas.

\section{0-enero-2010}

La ley no permite que esa alumna no acuda a clase de educación física, me temo que su hija esta sufriendo a una profesora de "gimnasia" y no de educación física.

No se puede hace una media con las demás asignaturas y mucho menos dejarla apartada del grupo, lo que yo haría en su lugar sería pedirle a la profesora que le enseñe la programación general del curso. Allí, usted podrá ver que contenidos puede desarrollar las niñas y cuales no. Es decir, la educación física no es solo correr y jugar, sino que se trabajan muchos aspectos, socialización consumo, lucha contra hábitos de vida no saludables, y sobre todo la integración y el respeto a las diferencias... 
El "experto" se posiciona correctamente en la línea establecida por la ley, sin embargo, parece ser que a la alumna se la considera exenta y, sin embargo, se la califica. Es una paradoja ir en contra de los preceptos legales para luego intentar lo contrario, de ahí que se la califique. Además, más paradójico resulta que se la aparte del grupo para que no se sienta apartada del grupo.

\section{Quería saber como se debe calificar a una alumna exenta de educación física en ESO, que normas hay}

http://www.todoexpertos.com/categorias/deportes/educacion-

fisica/respuestas/ibx4dt6f4c3gw/queria-saber-como-se-debe-calificar-a-una-

alumna-exenta-de-educacion-fisica-en-eso-que-normas-hav

\section{9-octubre-2012}

Mi hija se acaba de hacer exenta en E.F por dermatitis aguda y alergias, quería saber que tipo de normas hay para calificarla es esta materia, ademas del examen teórico, igual que los compañeros, tiene que realizar trabajos extras, con que frecuencia. La nota final en que se basaría y con que porcentajes, muchísimas gracias

\section{2-octubre-2012}

Respuesta de Alejandro García Sánchez, Licenciado en Ciencias de la... Muy buenas. Las características de evaluación para todo el alumnado en general y para los casos particulares como el de tu hija, deben estar contempladas en la programación del profesor, cuyos aspectos específicos reflejados por el profesor en estos aspectos de la evaluación pueden y deben ser explicados y facilitados por el profesor responsable. Como profesor de este área en la que he ejercido durante algunos años, te aconsejo que solicites tutoría con el profesor del área y le comentes que te explique a ti y a tu hija cual es el proceso de evaluación que debe seguir a partir del momento en el que se ha declarado exenta. Lo normal es que te lo facilite sin problemas, puesto que es su obligación. 


\section{3-octubre-2012}

Agradecerte tus palabras, lo hablare con la jefa de estudios ya que la profesora de educación física no es que sea demasiado agradable y ya hizo comentarios muy feos al saber de mi hija era exenta, pues me costa que cuando salio de hablar con la jefa de estudios fue a la sala de profesores y su comentario fue" una lista de $3^{a}$ se ha puesto exenta y me dicen la evalúe por la temario escrito y para optar a nota el ponga trabajos, quiere trabajos pues que se prepare se va ha hartar" y en estas 2 semanas ya van 2 trabajos que ha puesto a la niña, sin embargo la jefa de estudios fue mucho mas comprensiva y razonable. Como ves esperar a esta evaluación a ver cuantos trabajos manda finalmente y la nota que le pone??? No se bien que hacer, mil gracias

\section{¿Cómo hacer para quedar exento de Educación Física si tienes una Minusvalía?}

http://www.todoexpertos.com/preguntas/5dtrjsfbtui8kxet/como-hacer-para-quedar-exento-deeducacion-fisica-si-tienes-una-minusvalia

\section{2-septiembre-2014}

Mi hija tiene 13 años con una Minusvalía de 60\%(Hemiparesia por Infarto Cerebral), comienza el Curso en breve y la Angustia nos invade, el curso anterior tuvo varias lesiones debido a la Gimnasia una de ellas 2 meses con Muletas que casi no podía caminar,tirándome abajo la infinidad de tratamientos y Terapias para mejorar su Calidad de Vida, a cambio le mandaron un Examen que cuando lo vi me dio la Risa y al final terminé llorando, pues me parecía una Tomadura de pelo;Las preguntas no tienian que ver con los Objetivos de dichas Clases...

Por todo esto me planteo que quede exenta de Gimnasia, este curso tendrá el mismo profesor y ya hablé varias veces con el y creo que no tengo nada que hacer, no puedo escribir aquí el adjetivo que me viene a la boca pero ganas no me faltan de ponerlo. 


\section{2-septiembre-2014}

Respuesta de Raul Guerrero, Doctor en ciencias de la actividad...

En primer lugar decirte que los exentos en educación física ya no existen. Es decir, es imposible calificar a un alumno de exento. Por otro lado el profesor debería saber que ejercicios podría realizar su hijo y de que manera y evaluarlo en base a otros criterios que deben de ser contemplados en su programación anual.

Así que yo de usted, hablaría con él y le pediría la programación anual y que le enseñe de que manera piensa atender a su hijo y como lo va a evaluar, pidale a sus médicos y fisioterapeutas que le expliquen que cosas debe hacer y cuales no. En caso de que no funcione siempre esta la opción de ir a la inspección educativa y que se haga el trabajo como debe ser.

Ánimo, la educación física puede serle muy útil a su hijo, claro esta siempre y cuando se realice bien.

\section{4-septiembre-2014}

Muchas Gracias, Como madre y Médico de Profesión se que es lo mejor para mi hija, ella es muy deportista a pesar de su limitación, pero creo que el problema más que mi hija quien lo tiene es el Profesor. Un Saludo 
http://juancamef.blogspot.com.es/2010/04/regulada-la-exencion-en-educacion.html

\section{Anónimo dijo...}

tengo un hijo con cardiopatia congitaltetralogia de falof,de las 4 malfomaciones tiene tabique intreventricular y la orta un poco dañada.Nunca hemos tenido problemas en gimnasia,en la primaria,ni en 1 de la eso,mihijo se limitaba hacer teorica porque creo que el saber no ocupa lugar,peroeste año que cursa no tiene respeto por el certificado medico oficial como exento de gimnasia yme lo esta descrinando delante de todos sus compañeros, hasta tal grado que el jefe de estudios y la dirrectora del centro apollan a mi hijo, y el inspector de zona dice que esto lo tiene que slucionar el centro,como consecuencia mi hijo esta sufriendo,por favor alguien me puede aconsejar ya que esto esta durando mucho tiempo y veo que nadi e ejrce sus responsbidades

\section{8-octubre-2011}

Juan Carlos Muñoz Díaz dijo...

Anónimo de hijo con tetralogia de fallof.

No entiendo muy bien qué es lo que está haciendo su hijo en las sesiones de Educación Física actualmente.

Da la impresión que está realizando actividad física, o bien que por no hacer actividad física se le está suspendiendo.

Indiqueme cual es el motivo concreto de su "sufrimiento". 
EL CLUB DE LA COMEDIA (La Sexta; 9 de octubre de 2011): DOS EN UNO; DAVID GUAPO y los profesores de gimnasia / ERNESTO SEVILLA y el alumnado exento de gimnasia

http://carlesgonzalezarevalo.blogspot.com.es/2011/10/el-club-de-la-comedia-lasexta-9-de.html

\section{0-0ctubre-2011}

Ernesto Sevilla, otro de los monologuistas de la noche nos deja otra perla que no tiene desperdico. Si David ridiculiza a los profesores, ahora Ernesto se ceba con el alumnado que él categoriza como "exento" de la materia. Es decir, con los alumos y alumnas que por una razón u otra no hacen la "clase de gimnasia práctica". De muy mal gusto. Para hacer humor no es necesario superar la barrera del respeto.

La eliminación de la práctica vuelve a aparecer como forma de exención, aunque en este caso parece ser que es utilizada para ridiculizar a los que se encuentran en ella.

https://sites.google.com/site/compartiendoeducacionfisica/

\section{6-febrero-2010}

En nuestro centro, como en muchos, estamos leyendo novelas relacionadas con la EF y el deporte y una de las que más ha gustado es "Lágrimas por una medalla", de la periodista Cristina Gallo. Me parece tan buena que estoy intentando darla a conocer, si no te interesa para grupos enteros es una gozada para los exentos o, simplemente, tenerla en el departamento o biblio... 
En este caso se da a entender la existencia de un tipo de alumnado libre de la Educación Física, aunque no aclara si se está exento de la práctica o de toda la materia. En todo caso, propone la lectura de un libro de temática próxima a nuestra materia como forma de atender a los alumnos exentos. Por cierto, del libro que aparece en esta entrada, "Lágrimas por una medalla", ya hemos hablado anteriormente para poner a su autora, Tania Lamarca, como un ejemplo de la convalidación de la Educación Física que disfrutaban los deportistas de alto rendimiento (vid.: Nota 31).

\section{$\underline{\text { Solicitud de convalidación de la Educación Física }}$}

La convalidación de la Educación Física como otra forma de exención, adquiere también cierto protagonismo. En algún caso se solicita la convalidación en base a la errónea percepción de consideración de deportista de nivel o de alto rendimiento.

\section{Convalidar educacion física}

http://www.todoexpertos.com/categorias/educacion/educacionfisica/respuestas/1729878/convalidar-educacion-fisica

\section{9-noviembre-2007}

Tengo entendido que la asignatura de educación física en el cole ( $3^{\circ}$ Eso $)$ puede ser convalidada en el supuesto que el alumno este en un equipo de 'elite' o que el año anterior halla jugado en categorías autonómicas. No se si me he expresado bien, pero la finalidad que pretendo es saber si mi hijo que juega en el valencia cadete y tiene una preparación física suficiente en los entrenamientos semanales, pueda dedicarle las horas de educación física del cole a repasar o estudiar otras materias.

¿Sabrías algo de esto o decirme donde podría infórmame?

En el instituto no saben nada. 
http://juancamef.blogspot.com.es/2010/04/regulada-la-exencion-en-educacion.html

\section{5-abril-2010}

Navegando por la red he leído un antiguo post de Raúl Guerrero en su Blog "E.F. y salud" que titulaba "sin duda un error garrafal: exentos".

Raúl no quiso meterse de lleno a opinar lo que establece la Orden EDU/2339/2009, de 1 de octubre, sobre convalidación de enseñanzas, yo sí. En el artículo 3 se establece la exención de la materia de Educación Física de la Educación Secundaria Obligatoria y del Bachillerato y se dice lo siguiente:

$[\ldots]$

16-marzo-2011

\section{Anónimo dijo...}

despues de leer atentamente tu comentario, quiero decirte que yo mamá de dos chicas de 15 años que entrenan natación de alto rendimiento estoy pidiendo la eximición, porque todo lo que vos decis tenés mucha razón, pero lamentablemente a educación física del cole van solamente a hacer abdominales, pasitos en fitnes, y tiro de bala, donde por la falta de costumbre la mayoría se quedan sin brazos. Todo lo que vos decis que tienen que enseñar, gracias a Dios las mías lo aprenden entrenando. TODO. Desde el compañerismo hasta los temas relacionados con la salud, y también rinden examen en el cole ah tienen que hacer 100 abdominales para el "10" y contando las cosas importantes que se comparten hoy en el cole: el facebook!!!!!! porque el 80\% de los chicos se pasan el resto del día en la compu. Lamentablemente me gustaría que todo lo que expusiste no fuese todo teoría.

La materia deja de tener importancia por culpa de los profesores que ellos mismos no se la dan.

Yo quiero la eximisión para que no tengan que correr tanto para llegar a nadar y porque considero que es una perdida de tiempo. 


\section{Mi hijo está exento de E.Física}

http://www.todoexpertos.com/categorias/educacion/legislacioneducativa/respuestas/2512672/mi-hijo-esta-exento-de-e-fisica

\section{2-octubre-2010}

Mi hijo está exento de E.Física por ser deportista de élite nivel promoción. ¿Qué nota obtendrá en esa asignatura al final del curso $1^{\circ} E S O$ ?

¿Podrá dejar de asistir a las clases de E. Física durante el curso? ¿Además podrá estar exento de una optativa?

\section{2-octubre-2010}

Respuesta de dufraine, Experto en Educación, colaborador MEC...

[...]

Además te adjunto artículo publicado en la Razón el año pasado..."Desde el próximo curso, los deportistas de "alto nivel y alto rendimiento" o "de élite" que cursen estudio de Secundaria Obligatoria, Bachillerato, FP, enseñanzas de idiomas, deportivas, profesionales de Música o Danza y Ciclos de Artes Plásticas y Diseño en centros públicos y privados autorizados, podrán beneficiarse de toda una serie de medidas que pretenden compatibilizar su actividad deportiva con la formación académica que todo joven debe tener. De este modo, los estudiantes en cuestión podrán elegir el horario o el grupo más idóneo que les permita compatibilizar la asistencia a clase con su actividad deportiva. 


\subsection{9.- EPÍLOGO CONCEPTUAL}

Llegado a este punto, no sería descabellado pensar que todas estas pruebas documentales y bibliográficas expuestas hasta ahora apuntan a la existencia de una Educación Física bien distinta de lo que la retórica oficial y "experta" nos dice que debiera ser, de tal suerte que en el desarrollo docente de la Educación Física aparece encubierta o enmascarada un tipo de práctica o actuación que se puede denominar como "exención (in)visible", la cual entra a formar parte del repertorio cotidiano y habitual de respuestas educativas que solemos dar en nuestras clases al alumnado con necesidades educativas especiales, del tipo que sean, para tenerlo "atendido" primero, y poderlo evaluar después.

Por tanto, se puede concluir, tal y como se comenzaba este apartado, confirmando que la Práctica (entendida en este caso como las pautas de actuación recogidas en el saber disciplinar) y la Teoría (normativa concreta y específica del tema abordada en el capítulo anterior) aún distan de encontrarse en la misma realidad, yendo cada una por caminos totalmente divergentes.

"Integrar e incluir a los alumnos con necesidades educativas especiales es uno de los retos que los educadores tienen en la actualidad. En el plano conceptual parece existir un acuerdo unánime en reconocer que todos los niños y niñas tienen los mismos derechos a recibir una enseñanza de calidad, a no ser discriminados por la naturaleza de sus particulares condiciones, y por lo tanto, a estar incluidos como cualquiera escolar en las aulas y en los gimnasios.

Si esto es así en el plano de las palabras, en el plano de los hechos queda, todavía, mucho por recorrer a tenor de la falta de programas claros, de apoyo e inversiones y de objetivos definidos en cada una de las materias, y de la exclusión de muchas personas de la práctica de actividades físicas y deportivas." (Gomendio, 2000, p. 11)

A continuación, se presenta a modo de síntesis la Figura 2 para distinguir el conjunto de señales y fuerzas (manifiestas y ocultas) encontradas en la literatura específica que originan y/o mantienen la presencia de esa "exención invisible" en las clases de Educación Física en Secundaria. 


\section{REALIDAD PERCEPTIBLE}

- En las Programaciones Didácticas aparece la figura del "exento" o "exento de la práctica".

- Los centros educativos contemplan esa posibilidad en sus documentos de matrícula.

- Hay bibliografía que recoge la exención como una realidad en nuestras aulas. Así, por padecer determinadas enfermedades, aconsejan estar exento.

- La sociedad habla de la exención con relativa

normalidad.
- A pesar de reconocerse la imposibilidad de aplicar una exención en la Educación Física, sí se prevé la "exención de la práctica".

- Aún siendo un área de carácter procedimental, este pasa a un segundo plano en favor de los conceptos y actitudes.

- Se pretende conseguir un desarrollo integral del alumno separando lo corporal (por inexistencia) de lo afectivo-intelectual.

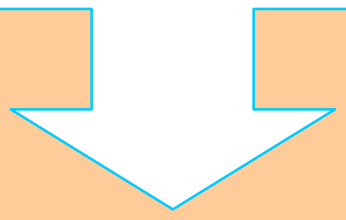

\section{LA "EXENCIÓN INVISIBLE" EN LAS FUENTES DE INFORMACIÓN}

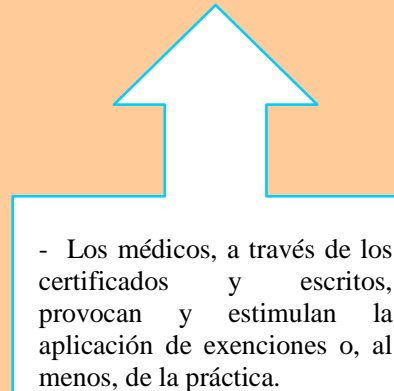

- Los familiares, con sus justificantes, también propician el "brote" de la exención.

\section{EL PODER DE LOS} PAPELES

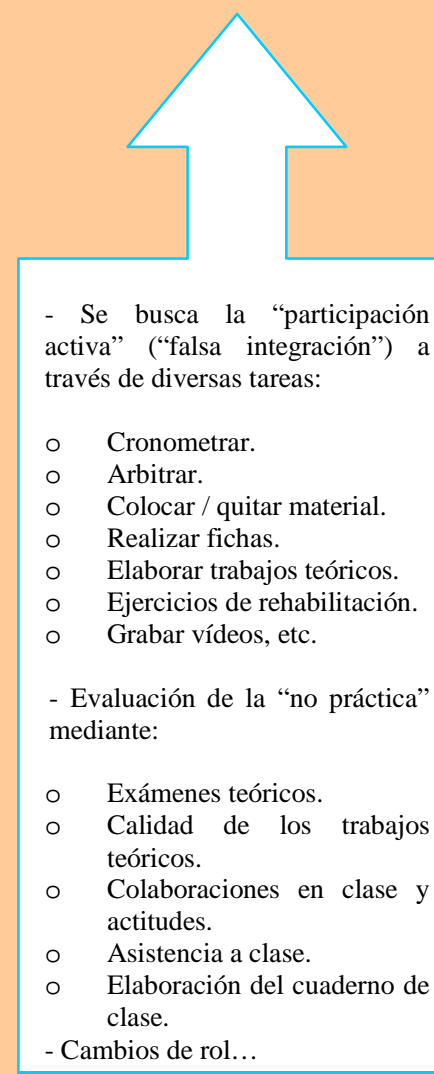

RESPUESTAS HABITUALES

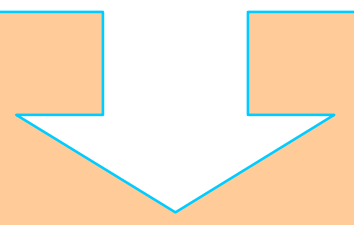

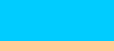


Antes de conocer cuáles han sido las piezas para la vidriera que surgen en este capítulo, presentamos un glosario con los términos más significativos aparecidos hasta el momento, matizando que, como algunos de ellos ya han sido definidos en el glosario terminológico del apartado anterior, no los repetiremos nuevamente (es el caso de la exención total o parcial, temporal o permanente...).

\section{Glosario terminológico}

a) Falsa integración: Concepto que alude a un tipo de situación que se produce cuando a un alumno con necesidades educativas especiales, por el motivo que sea, de forma temporal o permanente, parcial o total, se le ofrece una respuesta educativa que "pretende" su incorporación al desarrollo de la clase a través de propuestas totalmente diferentes a las del resto de sus compañeros, apreciándose una participación más bien pasiva. Los ejemplos más evidentes los encontramos en tareas como arbitrar partidos de los demás, anotar o realizar registros, colocar el material... Muchas de las fuentes bibliográficas que aparecen en esta tesis de Ríos Hernández nos pueden servir para acercarnos aún más a este concepto. No obstante, este concepto, como apunta Ríos (1999, p. 938), fue acuñado por Raufast en 1982.

b) Exención (in)visible: Concepto acuñado por el autor de esta tesis para referirse a una situación en la que, partiendo del término anterior, creemos estar integrando a los alumnos de forma activa al hacerles asumir otro tipo de tareas, apartándoles de otras, y no somos conscientes, o no queremos darnos cuenta, de que estamos generando una forma de eximir al alumno de lo que el resto hace. Suele ser habitual que toda la actuación se "disfrace" en el marco de las adaptaciones curriculares, pero eso no evita la no práctica o la no participación en términos de inclusión. Así pues, la invisibilidad tiene que ver fundamentalmente con dos cuestiones: la primera, es que verdaderamente pasa inadvertida para el profesor, no es consciente de su actuación y consecuencias. La segunda está relacionada con que a veces los profesores no "queremos" verla, 
no asumimos que nuestras respuestas puedan estar en la línea de lo que se supone no debemos realizar (incluida la exención de la práctica, de algunos contenidos... u otras propuestas ofrecidas por el saber disciplinar). En esta segunda fórmula entraría la establecida legalmente a través de las convalidaciones por estudios o cualquier otra razón. El alumno, en cualquier caso, sería un exento (in)visible.

c) Juegos sensibilizadores: Tipo de propuesta lúdica que pretende que los alumnos simulen lesiones, patologías o discapacidades que alguno de sus compañeros posee, con el objetivo, entre otros, de generar mecanismos de empatía. En la Tabla 3 se puede ver un resumen de propuestas en esta línea ${ }^{152}$.

${ }^{152}$ Para conocer más sobre estos juegos vid.: Ríos (1994). 


\section{3.- PIEZAS PARA LA VIDRIERA FINAL}

La revisión de varias normas legislativas de diferente ámbito de aplicación en torno a la atención de alumnos con necesidades educativas especiales, así como la lectura pormenorizada de diversas y múltiples fuentes de información, entre las que se encuentran varias comunicaciones aparecidas en las redes sociales, han hecho visibles una serie de piezas que formarán parte de la vidriera final. No hay duda de que el establecimiento de este marco teórico-legal que rodea la exención ha puesto al descubierto muchas de esas piezas. Aunque es seguro que algunas de ellas volverán a aparecer con diferente intensidad en capítulos posteriores, estas primeras piezas son especialmente valiosas porque, además del lugar que ocupan en la investigación, ofrecen pistas contundentes para seguir buscando otras que encajen a la perfección con ellas.

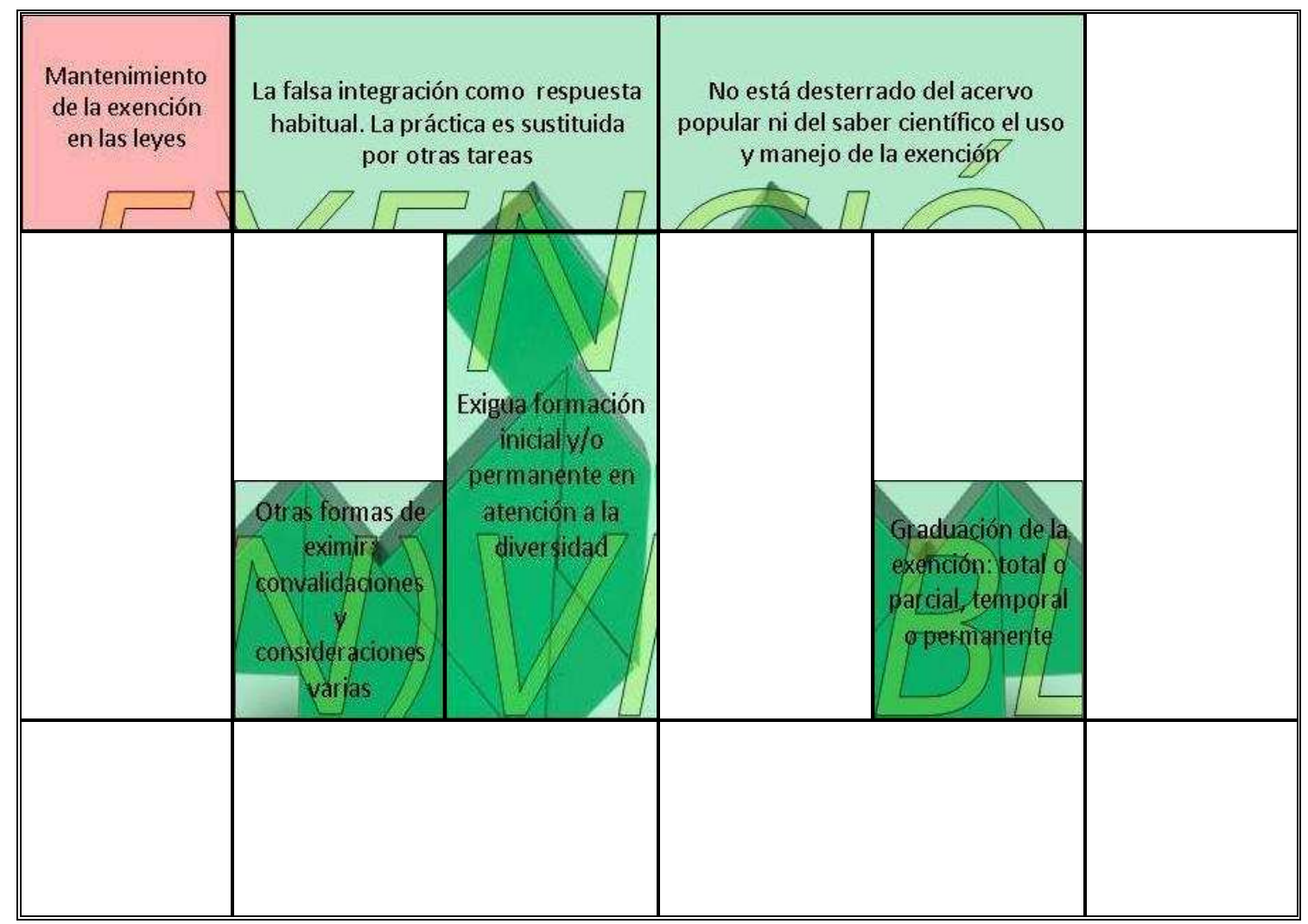




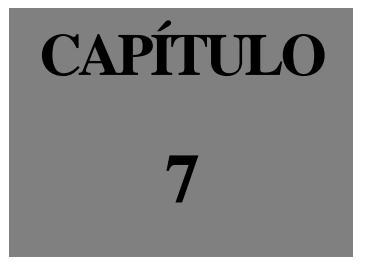

APROXIMACIÓN A LA RESPUESTA QUE DA LA EDUCACIÓN FÍSICA: REVISIÓN DE LAS PROGRAMACIONES DIDÁCTICAS 
Entre las distintas estrategias que nos planteamos para detectar si la exención continúa siendo un hecho habitual en las prácticas docentes de la Educación Física, se encuentra la revisión y el análisis de las programaciones didácticas elaboradas por los Departamentos de Educación Física y Deportiva.

En este sentido, el presente capítulo pone de manifiesto la presencia en este nivel de concreción de una realidad bien distinta de la que promulga la normativa oficial.

Para el análisis de las programaciones nos hemos servido de unos instrumentos o fichas que centran la atención en tres niveles diferentes. Todos los documentos son sometidos a una exploración en escala que va desde lo más global (presentación y cumplimiento de lo establecido a efectos legales), a lo más concreto, incluyendo la respuesta dada a la diversidad del alumnado y la emergencia y justificación de la exención.

A fin de que se perciba y entienda mejor nuestro trabajo, reconstruiremos el proceso seguido. 


\section{1.- CUESTIONES EN TORNO AL PROCESO}

A pesar de que fueron muchos los Jefes de Departamento de Educación Física y Deportiva que se mostraron desde un primer momento dispuestos a colaborar en el estudio, la fase de recopilación de las programaciones no estuvo libre de momentos "anecdóticos" y significativos, que dejan entrever algunas de las peculiaridades y circunstancias que rodean a esta profesión.

El proceso de recopilación comenzó cuando se sentaron las bases del grupo de trabajo del que formé parte durante el curso 2002-2003. Este grupo, bajo el patrocinio del CFIE de Medina del Campo, llevó a cabo un estudio denominado: "Una programación realmente útil en Educación Física". Evidentemente, yo esperaba, y así se lo hice saber a los miembros del grupo y a la asesora de este organismo, nutrirme de las programaciones que pudiésemos ir recogiendo para ir elaborando este capítulo de la tesis.

La asesora, en nuestro nombre, envió una carta a todos los centros de Valladolid y su provincia solicitando la colaboración de los departamentos de Educación Física para que la remitiesen sus programaciones didácticas. En la carta se resumía quién estaba haciendo la actividad y en qué consistía esta. En un principio, nuestra idea era revisar únicamente el apartado de la "Atención a la diversidad" a fin de detectar cómo se estaba trabajando este destacado capítulo que, de acuerdo con la normativa ${ }^{153}$, debe figurar en todas las programaciones.

\footnotetext{
${ }^{153}$ Artículo 68 del Real Decreto 83/1996 de 26 de enero por el que se aprueba el Reglamento Orgánico de los Institutos de Educación Secundaria (BOE 21-2-96).
} 
A partir de ahí, todos los miembros del grupo empezamos a trabajar para conseguir el que se estaba convirtiendo en un "material preciado" (por su escasez). A través de contactos telefónicos con amigos y antiguos compañeros (interinos y con plaza definitiva), nos fuimos haciendo con alguna programación. Incluso, cuando alguno de los componentes del grupo de trabajo participaba en algún curso de formación permanente del profesorado organizado por algún CFIE u otro organismo, aprovechaba la situación para pedir las que nos faltaban y aumentar nuestro repertorio.

En lo que a mí concierne, visité algunos centros para exponer el estudio que pretendía llevar a cabo y solicitar in situ la información que necesitaba.

Finalmente, a través del Inspector de la Dirección Provincial que visita asiduamente mi centro de trabajo, tras comentarle lo que estaba intentando hacer y las dificultades encontradas para ello, también pude conseguir alguna otra programación.

La respuesta obtenida ante la primera petición del CFIE fue absolutamente nula. Ningún departamento nos envió la programación ni el capítulo sobre "Atención a la diversidad". De hecho, algunos profesores llegaron a comentar a la asesora que "como no tengo ningún caso de este tipo, pues no lo incluyo en la programación. Cuando se presente la ocasión ya veré lo que hago con él."

Más de un Jefe del Departamento de Educación Física y Deportiva utilizaba su programación como moneda de cambio, llegándose a producir situaciones del tipo "tú me pasas la tuya y yo te doy la mía para que la revises".

En otros casos, surgían comentarios en los que se apreciaba una palpable situación de "temor" o duda sobre la idoneidad de lo que en ellas se pudiera estar recogiendo: "Te ruego que sea confidencial. Ya sabes que los colegas de nuestra profesión somos muy críticos", o "No saques muchos fallos no sea que luego nos toque a todos revisarlas por no tener lo que deben". 
En un departamento se produjo una especie de discrepancia entre sus dos componentes. Uno de ellos (en ese momento sustituía al Jefe del Departamento por baja laboral), era muy partidario de darme la programación, mientras que el otro se mostraba dudoso y reticente ante el uso que pudiera hacer de ellas y, además, la persona que la había elaborado no se encontraba en el centro y eso, argumentaba, la podría molestar. Al final, fue este último profesor el que me la entregó pues el otro se tenía que ir a clase, pero mi sorpresa fue mayúscula al comprobar que no me ofreció más que un anexo añadido en este curso escolar, faltando el grueso de la programación. Comenté este hecho al "sustituto" y al final me entregó toda la programación.

En otro instituto, tras mantener una conversación telefónica con el Jefe de Estudios, no pude conseguir nada en claro pues, a pesar de que me aseguró su disposición a transmitir todo sobre lo que yo le estaba informando al Jefe del Departamento de Educación Física y Deportiva, se mostraba muy reacio a que este tipo de documento saliese fuera de los recintos del propio centro.

En otro, por dificultades técnicas en el disquete que me habían enviado por correo, tuve que volver a insistir solicitando uno nuevo, encontrando todo tipo de facilidades y buena disposición.

El soporte mayoritariamente utilizado era el papel. En muy pocas ocasiones nos daban un disquete con la programación. En vez de enviarnos una copia, lo que hacían era dejarnos un original para que lo fotocopiásemos por nuestra cuenta.

Casi todas las programaciones estaban actualizadas al curso 2002-2003, pero en dos casos no fue así. Una era del 1999-2000, y otra del 2001-2002, pero, tras contactar con los responsables de su elaboración, me dijeron que eran las que estaban aplicando en la actualidad. 


\section{2.- METODOLOGÍA UTILIZADA}

Tras reflejar algunas de las dificultades y anécdotas que han acontecido en la elaboración de parte de este capítulo, intentaré ahora explicar detalladamente todo lo que atañe a las fichas de análisis empleadas para el estudio de las programaciones.

El proceso seguido se puede resumir en dos etapas. La primera ha tenido por objeto la petición y recopilación de las programaciones didácticas de los Departamentos de Educación Física y Deportiva de los Institutos de Enseñanza Secundaria de carácter público de Valladolid y su provincia. Al concluir esta fase contábamos con 15 programaciones de los 32 centros existentes, lo que equivale a un 47\% (Gráfica $\mathbf{n}^{\mathbf{0}} \mathbf{1}$ ).

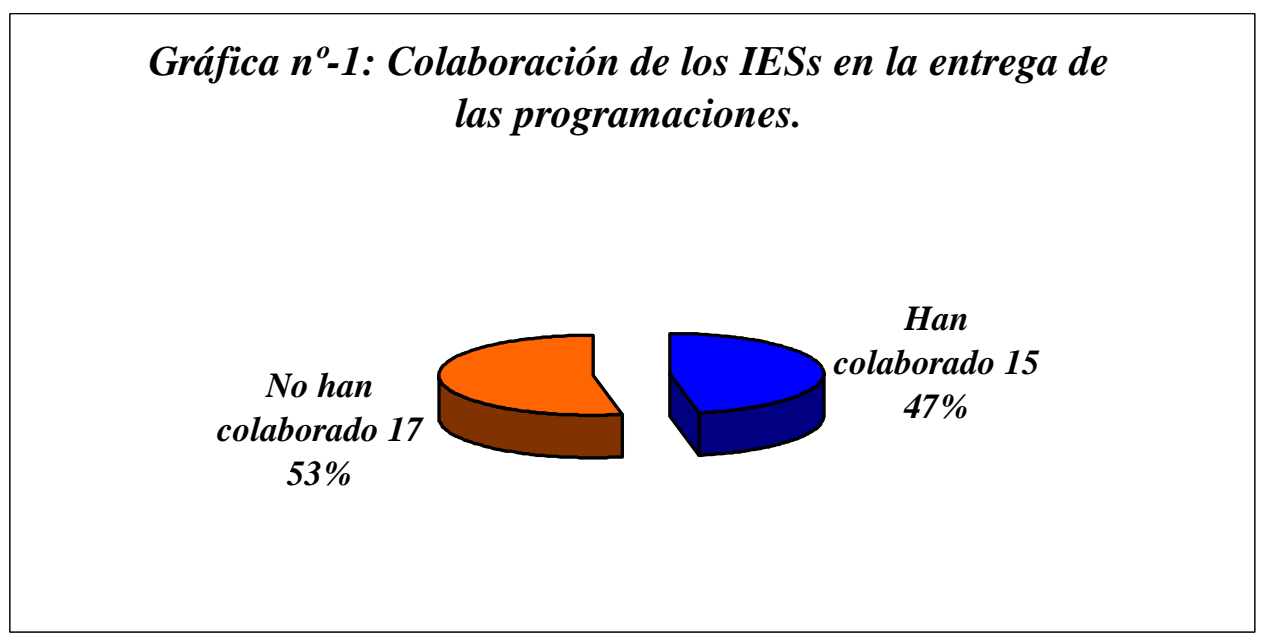

La segunda etapa se centró en la lectura y estudio de las programaciones. Para ello hemos utilizado varios "filtros" consistentes en la aplicación de unas fichas elaboradas para tal fin y que centran la atención en tres vertientes o niveles de análisis: a) información general y ajuste a la norma concreta establecida; b) la respuesta que desde el área se ofrece a la Atención a la Diversidad; y, c) el concepto y uso de la exención (Figura 3). 


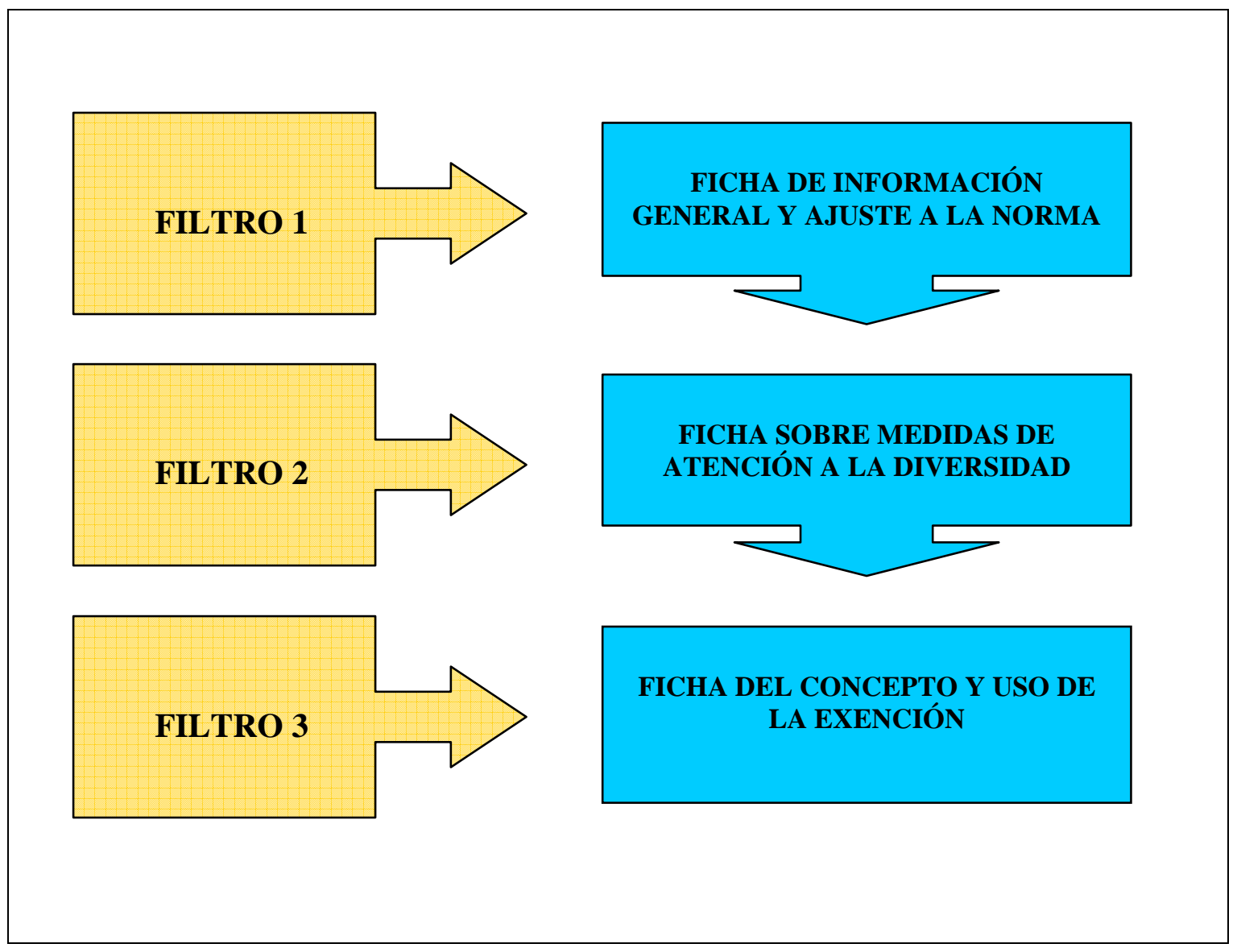

Figura 3. Filtros por los que han pasado las programaciones didácticas

\section{Diseño de las fichas de análisis}

A fin de depurar de algún modo la validez de las fichas de análisis (vid.: Anexos 9-11), su diseño siguió un proceso en el que "triangulamos" las opiniones de distintas personas: el tutor del trabajo de investigación, los componentes de mi departamento y yo mismo. También tuvimos en cuenta análisis similares realizados anteriormente (Astráin, 2002). Por si fuera poco, durante el proceso realizamos algunas pruebas "piloto" para valorar su utilidad.

En un primer momento, elaboré lo que podrían ser los bocetos iniciales de esas fichas. Las preguntas y afirmaciones iban surgiendo como consecuencia de mis ideales, creencias sobre lo que debe o no aparecer en las programaciones, los criterios que 
utilizo al diseñar mi propia programación, lo que dicta la ley, y las pistas que me daban las lecturas relacionadas con este asunto.

Estos bocetos eran presentados al grupo de trabajo de mi departamento para pasar a continuación a revisar y, en caso necesario, reelaborar o eliminar ítems. Como este documento iba a ser utilizado estrictamente de forma interna, pues solo yo iba a manejar y trabajar con las fichas, no reparamos demasiado en la mejor de formulación de cada uno de esos ítems.

Después, esta ficha fue revisada por el tutor de mi trabajo de investigación. De nuevo, los ítems sufrieron una nueva "criba" de redefinición. Tras debatir su contenido, forma y utilización realicé las correcciones que consideré oportunas.

Finalmente, las fichas fueron otra vez presentadas al grupo de trabajo y, de aquí, salieron las que definitivamente entrarían a formar parte de este estudio.

Todos los ítems que orientan la observación tienen un carácter cerrado, entendiendo por tal que su respuesta es SÍ / NO, o cualquier otra siempre que sea muy concreta y susceptible de ser cuantificada (e. g., número de páginas de la programación, nombre del departamento, etc.).

La elaboración de las fichas no se dio por concluida hasta que no se completó el análisis de las programaciones. Se dejó abierta la posibilidad de ir añadiendo nuevos ítems que podían surgir de la lectura de los documentos recibidos pues, como así ocurrió, algunos detalles significativos se nos pasaron por alto en un principio.

Los ítems, a la par que se creaban, eran agrupados en categorías o bloques de interés en torno a los cuales se elaboraría el posterior informe con los resultados obtenidos y las posibles suposiciones que de ellos se pudieran derivar. De esta forma, la atención en los análisis no se desperdiga y se mantiene en todo momento orientada. 
La estructura de las fichas y sus instrucciones de uso son muy sencillas. Se establecieron tres columnas: una para los ítems, otra para los SÍ y la que resta para los NO. Estas dos últimas se dividieron a su vez en celdas. Por otra parte, a las programaciones recibidas de cada instituto se les asignó un número aleatorio y no significativo con el objetivo fundamental de preservar el anonimato de los colaboradores y, también, para facilitar la utilización de las fichas, de forma que la respuesta dada a cada ítem se reflejaba anotando el número de la programación en las celdas de la columna del Sí o NO, según correspondiera. Además, en caso necesario, se complementaba cada respuesta con anotaciones, aclaraciones y comentarios. Para constatar la existencia de dicho comentario, se coloreaba el número de la programación (Figura 4).

\begin{tabular}{|c|c|c|c|c|c|c|c|c|c|c|c|c|c|c|c|c|}
\hline ÍTEMS A TENER EN CUENTA & & $n^{0}$ & ord & gr & ar & 10 & íó & & & & ${ }^{0} \mathrm{p}$ & ro & $\mathbf{N}$ & $\begin{array}{l}0 \\
\text { am }\end{array}$ & aci & ión) \\
\hline \multirow{2}{*}{ Presenta un índice. } & 13 & 11 & 10 & 9 & 8 & 7 & 6 & 2 & & 2 & 15 & 3 & & & & \\
\hline & 5 & 14 & 4 & & & & & & & & & & & & & \\
\hline \multirow{2}{*}{ Tiene las páginas numeradas. } & 13 & 10 & 9 & 2 & 1 & 5 & 3 & 4 & & 2 & 11 & 8 & 7 & 14 & 13 & \\
\hline & & & & & & & & & & & & & & & & \\
\hline \multirow{2}{*}[\ldots]{} & & & & & & & & & & & & & & & & \\
\hline & & & & & & & & & & & & & & & & \\
\hline
\end{tabular}

Figura 4. Ejemplo de cómo se ha trabajado con las fichas

Llegado el momento de materializar los datos obtenidos con las fichas de análisis, junto con sus correspondientes corolarios, creemos que la comprensión de todos ellos se hace más sencilla, aumentando además su utilidad, si son mostrados y desarrollados de forma individual, por lo que los resultados y comentarios que surgen de cada uno de los tres niveles de revisión se presentan de forma segregada. Sin embargo, en el último de ellos retomaremos informaciones anteriores para comprobar su aplicabilidad en los alumnos a los que se refiere el trabajo. 
En esta primera toma de contacto con las programaciones didácticas nos centramos en algunos rasgos de carácter formal (los formatos de letras y párrafos empleados, número de páginas que ocupa, si presentan índice, etc.), así como la adecuación en su elaboración a las pautas establecidas por ley. Además, tomamos en consideración detalles significativos de uno de los momentos de especial relevancia dentro del proceso educativo como es la evaluación.

Para ello, como ya se ha apuntado, hemos agrupado los ítems de la ficha empleada en este nivel inicial de análisis en una serie de categorías o centros de interés que constituyen el guión de este relato con los resultados obtenidos y sus respectivos comentarios. Estos centros de interés son:

a) Aspectos generales y de presentación.

b) Aspectos normativos.

c) Cómo se articula la evaluación.

Para la presentación de los detalles recogidos, hemos optado por organizar los datos cuantitativos en tablas descriptivas que reducen significativamente la gran cantidad de información extraída y ofrecen una rápida visión de conjunto sobre los aspectos objeto de estudio. Tras la exposición de los datos, aparecen las impresiones que emanan de esas informaciones.

\section{a) Aspectos generales y de presentación}

Pretendemos dar una visión de conjunto de las programaciones didácticas en lo que se refiere al formato que emplean, apartados básicos de su contenido y aspectos que creemos elementales, pero no por ello menos necesarios, para su elaboración y 
publicación final. El propósito de este análisis es detectar si este documento es presentado con la adecuada propiedad y profesionalidad, pues no debemos olvidar que estamos tratando con el tercer nivel de concreción del currículo y que, además, en base a este instrumento los profesores de cada área desarrollan su actividad docente ${ }^{154}$.

154 Artículo 68, apartado Tres del Real Decreto 83/1996, de 26 de enero, por el que se aprueba el Reglamento Orgánico de los institutos de Educación Secundaria. 


\begin{tabular}{|c|c|c|}
\hline $\begin{array}{c}\text { ASPECTO } \\
\text { ANALIZADO }\end{array}$ & DATOS OBTENIDOS & PROGRAMACIÓN \\
\hline Número de folios & $\begin{array}{l}\text { ○ La más reducida, de } 14 \text { folios a una cara. } \\
\text { ○ La más extensa, de } 167 \text { folios a una cara. } \\
\text { ○ Tan solo una está a doble cara. }\end{array}$ & $\begin{array}{l}8 \\
2 \\
11\end{array}$ \\
\hline $\begin{array}{l}\text { Formato letra } y \\
\text { presentación }\end{array}$ & ○ En cinco hay formatos diferentes (incluso "fotocopiados"). & $8,10,11,12,15$ \\
\hline $\begin{array}{l}\text { Numeración de las } \\
\text { páginas }\end{array}$ & $\begin{array}{l}\text { Seis sí las numeran. } \\
\text { ○ Nueve carecen de numeración (o aparece incompleta) } \\
\text { - } \quad \text { Una tiene tan solo las quince primeras páginas numeradas. } \\
\text { - } \quad \text { Una tiene numeradas las del } 2^{\circ} \text { Ciclo y Bachillerato. }\end{array}$ & $\begin{array}{c}1,2,3,5,9,13 \\
4,6,7,8,10,11,12,14,15 \\
4 \\
10\end{array}$ \\
\hline Índice & $\begin{array}{ll}\circ & \text { Dos no tienen. } \\
\circ & \text { Una solo lo tiene para el } 2^{\circ} \text { Ciclo. } \\
\circ & \text { Solo tres lo tienen paginado. }\end{array}$ & $\begin{array}{c}3,15 \\
12 \\
1,2,9\end{array}$ \\
\hline $\begin{array}{l}\text { Componentes del } \\
\text { departamento }\end{array}$ & $\begin{array}{l}\text { En nueve casos se nombran los miembros que componen el } \\
\text { departamento para el curso escolar. } \\
\text { ․ En uno solo se refleja el número de profesores, sin nombres. }\end{array}$ & $\begin{array}{c}1,2,3,4,7,9,11,13,14 \\
6\end{array}$ \\
\hline Anexos & $\begin{array}{l}\text { Dos incluyen el Informe para la evaluación de la competencia } \\
\text { curricular. } \\
\text { ○ Una tiene fichas de autoevaluación y de autoinforme. } \\
\text { ○ Una presenta pautas de elaboración de trabajos y del cuaderno de } \\
\text { clase. } \\
\text { ○ Una tiene hojas de observación y ficha de registros. } \\
\circ \quad \text { Una contiene listas de baremación de pruebas físicas. } \\
\text { ○ Una tiene un ejemplo de Adaptación Curricular no significativa. }\end{array}$ & $\begin{array}{l}1,4 \\
1 \\
1 \\
1 \\
7 \\
4\end{array}$ \\
\hline $\begin{array}{l}\text { Normativa explicitada } \\
\text { (vid.: Tabla 7) }\end{array}$ & Cuatro no hacen alusión a ninguna norma. & $5,7,8,14$ \\
\hline Bibliografía & $\begin{array}{l}\text { - Solo una recoge la bibliografía en la que se asienta su desarrollo } \\
\text { teórico / práctico. }\end{array}$ & 1 \\
\hline
\end{tabular}

Tabla 4. Resumen de la información obtenida con la "Ficha de información general y ajuste a la norma" 
Son varias las apreciaciones o comentarios que surgen a raíz de estos datos:

La carencia de un índice y la falta de numeración en las páginas indican que el documento es poco manejable y práctico, ya que para encontrar cualquier apartado hay que rastrear por toda la programación.

El volumen no es sintomático de una mayor o menor calidad. Aun así, se confirma que las que tienen menor número de folios son las que presentan un contenido y desarrollo más escaso. Especialmente llamativo en este sentido es el tamaño de la más reducida, solo 14 páginas.

Las diferencias entre los formatos de las letras y párrafos para los distintos ciclos y etapas, junto con su presentación, hacen pensar que están elaboradas por personas diferentes y, lo más sintomático, que no hay trabajo de puesta en común (elaboración, discusión y presentación). Gran parte del contenido de muchas programaciones son meras fotocopias de otras programaciones.

El hecho de que no se indique quiénes son los responsables de llevar a efecto la programación sugiere una falta de compromiso y de compañerismo profesional. Además de la no inclusión de este dato, se podría deducir una carencia de revisión anual a principio de cada curso escolar.

A pesar de que en muchas (si no en todas) se tratan aspectos desde un punto de vista teórico con sus correspondientes aplicaciones prácticas, no se tiene el hábito de indicar las fuentes bibliográficas. Se adoptan como propios conceptos, términos y teorías que en realidad no lo son.

Presuponemos que ciertos materiales que no forman parte de la programación, se encuentran en algún archivo en el departamento. No obstante, la relevancia de algunos de ellos hace aconsejable que aparezcan junto a ella. Tal es el caso del Informe de 
Evaluación de la Competencia Curricular ${ }^{155}$, las pautas de elaboración del cuaderno de clase del alumno, las que hay que tener en cuenta para los trabajos escritos y las fichas / hojas para ser rellenadas por el médico. A este respecto, los datos sobre los Anexos recogidos en la Tabla 4 indican cierta pobreza.

En definitiva, parece que no se concibe la programación didáctica de área como un documento que dé concreción al currículo y que sirva a todos los componentes del departamento como guía en el proceso de enseñanza-aprendizaje que seguirán con sus alumnos. Se desprende una falta de operatividad consensuada y de trabajo en común y, si como asegura Viciana (2002, p. 167), este documento, entre otros muchos, es un indicador de la calidad de la labor educativa -ya que hay una estrecha relación entre su correcta planificación y los resultados obtenidos-, nos tememos que estos últimos no serán muy buenos.

La impresión global que se extrae es que las programaciones se han convertido en un documento burocrático que debe cumplimentar el profesorado, sin importar gran cosa su contenido.

\section{b) Aspectos normativos}

En este apartado intentaremos comprobar si las programaciones didácticas son fiel reflejo de la normativa que las regula, ajustándose o no a sus preceptos. Para ello, revisaremos distintas cuestiones: la denominación del departamento que aparece en dichas programaciones, el contenido que desarrollan en su interior y la normativa oficial que se tiene en cuenta.

\footnotetext{
${ }^{155}$ Aplicando el artículo $6^{\circ}$, apartado 3, de la ORDEN de 29 de abril de 2002, de la Consejería de Educación y Cultura, por la que se regula la impartición de la Educación Secundaria Obligatoria en Castilla y León, los alumnos/as que no sean evaluados positivamente en el área de Educación Física y, aún así, promocione, el profesor encargado del área realizará un informe de evaluación individualizado, en el que se indicarán las dificultades mostradas por el alumno/a y las medidas educativas complementarias o de adaptación curricular que se proponen al profesor del curso siguiente para favorecer que el alumno/a pueda superarlas.
} 


\section{b.1) Nombre del Departamento Didáctico}

En el artículo 40 del Real Decreto 83/1996, de 26 de enero, por el que se aprueba el Reglamento Orgánico de los Institutos de Educación Secundaria (BOE 2102-96), se recogen los órganos de coordinación docente que existen en los Institutos de Educación Secundaria. Dentro de los Departamentos Didácticos, se señala el de "educación física y deportiva".

Pues bien, como muestra la Tabla 5, en la mayoría de las programaciones didácticas se denomina incorrectamente al departamento.

\begin{tabular}{|c|c|c|}
\hline $\begin{array}{c}\text { NOMBRE DEL DEPARTAMENTO } \\
\text { (Art. } 40 \text { del R.D. 83/1996) }\end{array}$ & \multicolumn{1}{|c|}{ DATOS OBTENIDOS } & PROGRAMACIÓN \\
\hline Educación Física y Deportiva & $\circ \quad \begin{array}{l}\text { Solo dos señalan correctamente el nombre. } \\
\text { El resto, lo nombran únicamente como departamento de } \\
\text { Educación Física. }\end{array}$ & 1,2 \\
\hline
\end{tabular}

Tabla 5. Nombre del departamento

\section{b.2) Cuestiones que deben contener las programaciones didácticas según la normativa}

En el Real Decreto 83/1996, el artículo 68 está dedicado a las programaciones didácticas. En su apartado segundo, se señalan los aspectos que necesariamente han de abordar dichos documentos ${ }^{156}$ y que aparecen reflejados en la Tabla 6.

\footnotetext{
${ }^{156}$ Con posterioridad, con la entrada en vigor de la Ley Orgánica 2/2006, de Educación, el artículo 9 de la Orden EDU/1046/2007, de 12 de junio, por la que se regula la implantación y el desarrollo de la Educación Secundaria Obligatoria en la Comunidad de Castilla y León (BOCyL 13-06-2007), recogía los aspectos que las programaciones didácticas debían incluir en su desarrollo. En lo referente al Bachillerato, estos aspectos aparecen en el artículo 12 de la ORDEN EDU/1061/2008, de 19 de junio, por la que se regula la implantación y el desarrollo del bachillerato en la Comunidad de Castilla y León (BOCyL 2006-2008). Salvando las distancias, se puede afirmar que los aspectos que deben recoger las programaciones didácticas según estas dos normativas son similares a los establecidos en el R.D. 83/1996 (por cierto, aún vigente).
} 


\begin{tabular}{|c|c|c|c|}
\hline $\begin{array}{c}\text { NORMATIVA } \\
\text { (Art. } 68 \text { del R.D. 83/1996) }\end{array}$ & & DATOS OBTENIDOS & PROGRAMACIÓN \\
\hline $\begin{array}{l}\text { a) En el caso de la E.S.O., los objetivos, los } \\
\text { contenidos y los criterios de evaluación } \\
\text { para el primer ciclo y para cada uno de los } \\
\text { cursos del segundo ciclo. }\end{array}$ & $\begin{array}{l}0 \\
0 \\
0\end{array}$ & $\begin{array}{l}\text { Una no señala los objetivos para cada uno de los } \\
\text { ciclos y/o cursos, ni tampoco los criterios de } \\
\text { evaluación. } \\
\text { Dos no tienen objetivos para ningún curso, solo los } \\
\text { generales. } \\
\text { Una no presenta los contenidos para } 2^{\circ} \text { E.S.O., ni } \\
\text { los criterios de evaluación para } 4^{\circ} \text { E.S.O. }\end{array}$ & $\begin{array}{l}5,14 \\
15\end{array}$ \\
\hline $\begin{array}{l}\text { b) En el caso del bachillerato y de los ciclos } \\
\text { formativos, los objetivos, los contenidos y } \\
\text { los criterios de evaluación para cada curso. }\end{array}$ & $\circ$ & $\begin{array}{l}\text { Todas lo presentan. Suele ser una copia del } \\
\text { currículo oficial. }\end{array}$ & \\
\hline $\begin{array}{l}\text { c) En la programación de los distintos } \\
\text { aspectos que se señalan en los apartados a) } \\
\text { y b) deberá aparecer la forma en que se } \\
\text { incorporan los temas transversales. }\end{array}$ & ० & $\begin{array}{l}\text { Dos no presentan. } \\
\text { Una solo lo trata en el primer ciclo. }\end{array}$ & $\begin{array}{c}3,12 \\
10\end{array}$ \\
\hline $\begin{array}{l}\text { d) La distribución temporal de los } \\
\text { contenidos en el ciclo o curso } \\
\text { correspondiente. }\end{array}$ & $\begin{array}{l}\circ \\
\circ \\
\circ\end{array}$ & $\begin{array}{l}\text { Dos no presentan. } \\
\text { En una solo la hay para } 3^{\circ} \text { E.S.O. } \\
\text { Una la recoge para ambos ciclos, pero no distingue } \\
\text { entre cursos. }\end{array}$ & $\begin{array}{c}11,15 \\
12 \\
8\end{array}$ \\
\hline $\begin{array}{l}\text { e) La metodología didáctica que se va a } \\
\text { aplicar. }\end{array}$ & $\circ$ & $\begin{array}{l}\text { Todas presentan algo relacionado con ella. } \\
\text { En una solo para el segundo ciclo. }\end{array}$ & 10 \\
\hline $\begin{array}{l}\text { f) Los procedimientos de evaluación del } \\
\text { aprendizaje de los alumnos. (vid.: Tabla 8) }\end{array}$ & $\begin{array}{l}\circ \\
\circ\end{array}$ & $\begin{array}{l}\text { Dos no lo presentan de forma explícita. } \\
\text { En una solo para } 2^{\circ} \text { ciclo. }\end{array}$ & $\begin{array}{c}8,12 \\
10\end{array}$ \\
\hline $\begin{array}{l}\text { g) Los criterios de calificación que se vayan } \\
\text { a aplicar. (vid.: Tabla 8) }\end{array}$ & ० & Solo una no los presenta. & 12 \\
\hline $\begin{array}{l}\text { h) Las actividades de recuperación para los } \\
\text { alumnos de bachillerato con asignaturas } \\
\text { pendientes y las profundizaciones y } \\
\text { refuerzos para lograr dicha recuperación. }\end{array}$ & o & Siete casos no lo presentan. & $5,3,9,10,11,12,15$ \\
\hline $\begin{array}{l}\text { i) Los materiales y recursos didácticos que } \\
\text { se vayan a utilizar, incluidos los libros para } \\
\text { uso de los alumnos. }\end{array}$ & ० & $\begin{array}{l}\text { En cinco casos no aparece nada. } \\
\text { En seis casos aparece como inventario. }\end{array}$ & $\begin{array}{l}5,8,12,14,15 \\
1,2,4,6,7,13\end{array}$ \\
\hline $\begin{array}{l}\text { j) Las actividades complementarias y } \\
\text { extraescolares que se pretenden realizar } \\
\text { desde el departamento. }\end{array}$ & ० & $\begin{array}{l}\text { En un caso no aparece reflejado. } \\
\text { En un caso se confunde el significado de estas } \\
\text { actividades, dándose el valor de optativas a las } \\
\text { actividades complementarias. }\end{array}$ & $\begin{array}{c}15 \\
3\end{array}$ \\
\hline $\begin{array}{l}\text { k) Las medidas de atención a la diversidad } \\
\text { y las adaptaciones curriculares para los } \\
\text { alumnos que las precisen. }\end{array}$ & ० & En un caso lo aborda solo para el primer ciclo. & 10 \\
\hline
\end{tabular}

Tabla 6. Ajuste a la normativa de las programaciones de Educación Física 
Este análisis, en el que únicamente nos hemos limitado a verificar la existencia de cada uno de los aspectos anteriormente citados sin entrar a valorar la conveniencia o adecuación de su desarrollo, suscita varias interpretaciones:

Hay diez programaciones que no se ajustan a la norma que establece los aspectos que estas deben incluir necesariamente.

Se aprecian desarrollos diferentes entre los dos primeros cursos de la E.S.O. y los dos últimos, de tal manera que aspectos tratados en unos, no se hacen en otros, y viceversa. Por tanto, en unos $\mathrm{u}$ otros cursos hay carencias de alguno de los aspectos obligatorios.

Este punto anterior revela, una vez más, la falta de continuidad, de desarrollo ordenado y de secuencia lógica entre los ciclos, quizás debido a que hayan sido elaborados por personas distintas. El problema no radica tanto en esa individualidad a la hora de realizarlas, sino en la falta de puesta en común y posterior revisión. La recopilación sin más de lo que cada uno haya podido elaborar trae consigo lagunas, incoherencias e, incluso, contradicciones. Como se comprobará más adelante, la labor de coordinación no existe, sustituyéndose por otra meramente sumativa de ideas, conceptos..., folios.

Las programaciones de Bachillerato, etapa no obligatoria de la Educación Secundaria, son considerablemente más pobres. Su desarrollo suele ser una mera copia del currículo oficial, no contextualizándose para nada lo que en él se establece. Llega a ser tal la copia que se hace que, aun siendo un obligado aspecto el recoger las medidas de recuperación para los alumnos con la asignatura pendiente, se omite u olvida este apartado pues no aparece en el desarrollo curricular.

La Educación Física se presta a la utilización de multitud de recursos didácticos y a la aplicación de variados principios metodológicos. Todas las programaciones recogen, en diferente medida, este capítulo. 
Se deja entrever la preocupación por el tema de la diversidad, pues es uno de los asuntos que todas contienen, bien en el propio apartado de "Atención a la diversidad", o bien en los recursos y principios metodológicos.

\section{b.3) Normativas recogidas en las programaciones}

En 2002-2003, eran muchas las normas educativas que desarrollaban el currículo y la organización escolar. Parece lógico pensar que el profesorado dice muestras de su conocimiento cuando concretaba por escrito dicho currículo. Por ello, creímos conveniente reseñar, como se muestra en la Tabla 7, todas las que encontramos reflejadas en las programaciones didácticas. 


\begin{tabular}{|c|c|}
\hline NORMATIVAS QUE APARECEN EN LAS PROGRAMACIONES & $\begin{array}{l}\text { PROGRAMACIONES } \\
\text { QUE LAS RECOGEN }\end{array}$ \\
\hline Ley Orgánica 1/1990, de 3 de octubre, de Ordenación General del Sistema Educativo (BOE 4-10-90) & $1,6,10,12,13,15$ \\
\hline $\begin{array}{l}\text { Real Decreto 1007/91, de } 14 \text { de junio, por el que se establecen las enseñanzas mínimas } \\
\text { correspondientes a la Educación Secundaria Obligatoria (BOE 26-06-91) }\end{array}$ & 1 \\
\hline $\begin{array}{l}\text { Real Decreto 1345/91, de } 6 \text { de septiembre, por el que se establece el currículo de la Enseñanza } \\
\text { Secundaria Obligatoria (BOE 13-09-91) }\end{array}$ & 1 \\
\hline $\begin{array}{l}\text { Real Decreto 1178/92, de } 20 \text { de octubre, por el que se establecen las enseñanzas mínimas de } \\
\text { Bachillerato (BOE 21-10-92) }\end{array}$ & 2 \\
\hline $\begin{array}{l}\text { Real Decreto 1179/92, de } 20 \text { de octubre, por el que se establece el currículo de Bachillerato (BOE 21- } \\
\text { 10-92) }\end{array}$ & 2 \\
\hline $\begin{array}{l}\text { Orden de } 12 \text { de noviembre de } 1992 \text { sobre evaluación en Educación Secundaria Obligatoria (BOE 20- } \\
\text { 11-92) }\end{array}$ & 4,9 \\
\hline $\begin{array}{l}\text { Orden de } 10 \text { de julio de } 1995 \text { por la que se regula la adaptación del currículo de la Educación Física } \\
\text { para los alumnos con necesidades educativas especiales en el Bachillerato Unificado Polivalente, en la } \\
\text { Formación profesional de primer y segundo grados y en la educación secundaria, así como la dispensa } \\
\text { de la misma para los mayores de veinticinco años (BOE 15-07-95) }\end{array}$ & $1,3,10,12$ \\
\hline $\begin{array}{l}\text { Orden de } 28 \text { de agosto de 1995, por el que se regula el procedimiento para garantizar el derecho de los } \\
\text { alumnos de Educación Secundaria Obligatoria y de Bachillerato a que su rendimiento sea evaluado } \\
\text { conforme a criterios objetivos (BOE 20-09-95) }\end{array}$ & 4,9 \\
\hline $\begin{array}{l}\text { Real Decreto 83/1996, de } 26 \text { de enero, por el que se aprueba el Reglamento Orgánico de los Institutos } \\
\text { de Educación Secundaria (BOE 21-02-96) }\end{array}$ & 4,9 \\
\hline $\begin{array}{l}\text { Resolución del } 12 \text { de Abril de 1996, por la que se regulan los Programas de Diversificación Curricular } \\
\text { en la Educación Secundaria Obligatoria (BOE 03-05-96) }\end{array}$ & 4 \\
\hline $\begin{array}{l}\text { Real Decreto 3473/2000, de } 29 \text { de diciembre, por el que se modifica el Real Decreto 1007/1991, de } 14 \\
\text { de junio, por el que se establecen las enseñanzas mínimas correspondientes a la educación secundaria } \\
\text { obligatoria (BOE 16-01-01) }\end{array}$ & 1,15 \\
\hline $\begin{array}{l}\text { ORDEN de } 4 \text { de abril de } 2001 \text {, de la Consejería de Educación y Cultura, por la que se desarrolla el } \\
\text { proceso de convalidación entre las enseñanzas de régimen especial de Música y de Danza y } \\
\text { determinadas áreas de Educación Secundaria Obligatoria. (BOCyL 11-04-01) }\end{array}$ & 1 \\
\hline $\begin{array}{l}\text { DECRETO 7/2002, de } 10 \text { de enero, por el que se establece el currículo de la Educación Secundaria } \\
\text { Obligatoria en la Comunidad de Castilla y León (BOCyL 16-01-02) }\end{array}$ & $1,2,3,9,13$ \\
\hline $\begin{array}{l}\text { ORDEN de } 29 \text { de abril de 2002, de la Consejería de Educación y Cultura, por la que se regula la } \\
\text { impartición de la Educación Secundaria Obligatoria en Castilla y León (BOCyL 10-05-02) }\end{array}$ & 1 \\
\hline $\begin{array}{l}\text { DECRETO 70/2002, de } 23 \text { de mayo, por el que se establece el Currículo de Bachillerato de la } \\
\text { Comunidad de Castilla y León (BOCyL 29-05-02) }\end{array}$ & $1,2,3,13$ \\
\hline $\begin{array}{l}\text { ORDEN de } 3 \text { de junio de 2002, de la Consejería de Educación y Cultura, por la que se regula la } \\
\text { impartición del Bachillerato establecido por la Ley Orgánica 1/1990, de } 3 \text { de octubre, de Ordenación } \\
\text { General del Sistema Educativo (BOCyL 10-06-02) }\end{array}$ & 1 \\
\hline
\end{tabular}

Tabla 7. Normativas aparecidas en las programaciones 
Con estos datos, los cuales evidencian que no son muchas las normativas que se encuentran recogidas en la mayor parte de las programaciones didácticas, podemos apuntar que:

Aun no siendo obligatorio justificar determinadas propuestas que tienen un marco legal que las ampara, es significativo que haya cinco casos en los que no se hace alusión alguna a las normas educativas que afectan al contenido y desarrollo de dichas programaciones.

En el curso escolar 2002-03, entraban en vigor en Castilla y León los nuevos currículos del área de Educación Física en $1^{\circ}$ E.S.O., $3^{\circ}$ E.S.O. y $1^{\circ}$ Bachillerato. Tan solo en cinco casos se hace constar este cambio legislativo.

En dos casos, supuestamente para dar mayor peso a la actuación a realizar y compartir responsabilidades de la misma junto con el Departamento de Orientación, se recurre a una norma que promueve esta toma de decisiones conjunta para la elaboración de adaptaciones curriculares en aquellos casos que así lo requieran.

Casi la totalidad de ellas, excepto una, pasan por alto la posibilidad de convalidación del área para determinados alumnos.

Solo en cuatro programaciones se señala la normativa que regula el proceso de adaptación del currículo de la Educación Física para los alumnos con necesidades educativas especiales, lo cual choca con que en todas se aborda, en mayor o menor medida, el tratamiento a la diversidad y la realización de las oportunas adaptaciones curriculares.

No hay ninguna norma legislativa que aparezca como referente en todas ellas. La más recurrente, la LOGSE, solo se cita en seis documentos.

En definitiva, que no se identifiquen las normativas educativas que amparan y ordenan el quehacer docente puede ser debido a la creencia (a la vista de los resultados 
obtenidos, mayoritaria) de que no es estrictamente necesario para realizar dicha labor. Pero también revela su desconocimiento (ya sea por descuido, negligencia o falta de interés) y, en todo caso, una ausencia de rigor documental / legislativo en la concreción del currículo a través de las programaciones. Ya sea por uno u otro motivo, la manera de proceder de quienes tienen la responsabilidad de coordinar la elaboración y posterior redacción de las programaciones didácticas ${ }^{157}$, debería de dar un giro importante para otorgar mayor rigor y validez a todo su trabajo.

\section{c) Cómo se articula la evaluación}

La inmensa mayoría de las programaciones didácticas recogen una serie de cuestiones que tienen que ver con un relevante momento del proceso de enseñanzaaprendizaje: la evaluación del alumno. En torno a ella, se emplean distintos procedimientos, se establecen unos mínimos a los que todo alumno debe llegar, se crean instrumentos de trabajo para su posterior valoración, y se gradúan y cuantifican los ámbitos de la conducta humana para la calificación.

El hecho de reflejar este apartado (vid.: Tabla 8) se debe a que en el último nivel de análisis comprobaremos cuál es el sentido y aplicación que tienen estos datos en los alumnos con necesidades educativas especiales.

\footnotetext{
${ }^{157}$ Según el artículo 51, en su apartado uno, del Real Decreto 83/1996, de 26 de enero, por el que se aprueba el Reglamento Orgánico de los Institutos de Educación Secundaria (BOE 21-02-96), es el Jefe del Departamento quien coordinará la elaboración de la programación didáctica del área y de la memoria final del curso, y redactará ambas.
} 


\begin{tabular}{|c|c|c|c|}
\hline $\begin{array}{c}\text { PUNTOS } \\
\text { ANALIZADOS }\end{array}$ & & DATOS OBTENIDOS & PROGRAMACIÓN \\
\hline $\begin{array}{l}\text { Procedimientos para la } \\
\text { evaluación del alumno }\end{array}$ & $\begin{array}{l}\circ \\
\circ \\
\circ \\
\circ \\
\circ \\
\circ \\
\circ \\
\circ \\
\circ \\
\circ \\
\circ \\
\circ\end{array}$ & $\begin{array}{l}\text { Observación del profesor. } \\
\text { Pruebas físicas o de habilidades motrices. } \\
\text { Cuaderno del alumno. } \\
\text { Pruebas escritas. } \\
\text { Trabajos escritos teórico / prácticos. } \\
\text { Diseño de actividades. } \\
\text { Pruebas orales. } \\
\text { Autoinformes. } \\
\text { Tienen en cuenta la asistencia a clase. } \\
\text { Valoración de la actitud. }\end{array}$ & $\begin{array}{c}1,2,3,4,5,6,10,14 \\
\text { Todas } \\
1,2,3,4,6,7,8,9,10,14 \\
1,2,3,4,5,6,7,8,10,11,13,14 \\
1,2,4,6,7,8,10,13 \\
4,10,15 \\
1,4,10 \\
1 \\
1,4,7,8,9,10,11,13,15 \\
\text { Todas }\end{array}$ \\
\hline Apartado para "mínimos" & $\circ$ & $\begin{array}{l}\text { Once casos presentan un capítulo de este tipo: } \\
-\quad \text { De ellas, una solo para el } 2^{\circ} \text { ciclo. } \\
\text { - } \quad \text { En dos, son "objetivos mínimos". } \\
\text { - } \quad \text { Dos lo tienen como "contenidos mínimos". } \\
\text { - } \quad \text { Cuatro lo identifican como "mínimos exigibles o } \\
\text { necesarios para superar el área". } \\
\text { - Una los presenta como contenidos, pero algunos } \\
\text { están mal redactados al usar el verbo en infinitivo. } \\
\text { - Una los presenta como "técnicas obligatorias". }\end{array}$ & $\begin{array}{c}1,2,3,4,6,7,8,9,10,11,14 \\
10 \\
4,9 \\
6,14 \\
1,2,3,8 \\
11 \\
7 \\
\end{array}$ \\
\hline $\begin{array}{l}\text { Cuaderno o diario del } \\
\text { alumno }\end{array}$ & $\circ$ & 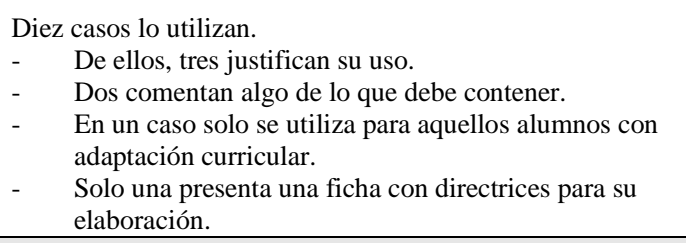 & $\begin{array}{c}1,2,3,4,6,7,8,9,10,14 \\
1,4,9 \\
1,7 \\
3 \\
1\end{array}$ \\
\hline Criterios de calificación & $\circ$ & $\begin{array}{l}\text { Solo una no los presenta. } \\
\text { En un caso, el trabajo diario va unido a la actitud }(60 \%) \text {. } \\
\text { En dos casos, la práctica va unida a lo teórico }(70 \% \text { y } 60 \% \\
\text { respectivamente) } \\
\text { En un caso, da un } 33 \% \text { a cada apartado. } \\
\text { En un caso, varía según el tipo de contenido curricular que } \\
\text { se califique. } \\
\text { En tres casos, los porcentajes varían para cada ciclo. } \\
\text { En un caso no refleja porcentajes, sino que establece que } \\
\text { hay que obtener más de } 3,5 \text { puntos en cada tipo de bloque } \\
\text { de contenido. } \\
\text { Una sobrepasa el } 100 \% \text {. }\end{array}$ & $\begin{array}{l}12 \\
1 \\
3,8 \\
13 \\
9 \\
4,7,10 \\
6 \\
11\end{array}$ \\
\hline
\end{tabular}

\section{Tabla 8. Desarrollo de la evaluación}

El repertorio de procedimientos e instrumentos que el profesorado suele utilizar para la evaluación de sus alumnos es amplio y variado.

Llega a ser tan dispar la gama de valores porcentuales otorgados a los tres tipos de contenidos (procedimentales, conceptuales y actitudinales), que de las quince programaciones analizadas solo dos coinciden en dichos porcentajes $(50 \%, 20 \%$ y $30 \%$ respectivamente). Las diferentes maneras de concebir el área originan desiguales propuestas en torno a lo que se considera más importante (valorable y cuantificable) llegado el momento de poner la nota de los alumnos. Aun así, se sigue primando por 
encima de todos a lo procedimental / motriz. Al mismo tiempo, las actitudes cobran cotas más altas de protagonismo.

La tónica predominante en la evaluación es la de separar y valorar aisladamente estos tres aspectos o ámbitos, tratando a la persona de forma analítica, y no bajo una perspectiva más global.

Los problemas derivados de las faltas de asistencia a clase de los alumnos parecen preocupar al profesorado. De otra manera, no se concibe que en una etapa educativa en que por ley dicha asistencia es obligatoria, se haga tanto hincapié en ella, llegando a ser, incluso, un referente en la propia evaluación.

Como material de trabajo del alumno, y posterior instrumento de su evaluación, debería explicarse mejor el concepto, propósito, contenido y utilización del cuaderno o diario de clase. Además, puesto que suele ser empleado en toda a la etapa, tendría que esbozarse, al menos, la progresión didáctica de su aplicación y, en todo caso, las normas y pautas de elaboración / corrección para ser tenidas en consideración por todos los alumnos / profesores.

El ya conocido Real Decreto 83/1996 no hace alusión alguna a que las programaciones didácticas deban recoger un apartado de "mínimos". En el periodo en que se desarrolla esta investigación, es la Orden de 28 de agosto de $1995^{158}$ la que establece que será el Jefe del Departamento quien elaborará la información relativa a la programación didáctica que será dada a conocer a los alumnos por sus profesores. Entre esta información se mencionan "los mínimos exigibles para obtener una valoración positiva". Resulta curioso comprobar que muchas programaciones didácticas presentan este apartado, pero solo dos mencionan esta norma, aunque no precisamente para este asunto.

\footnotetext{
158 Orden de 28 de agosto de 1995, por la que se regula el procedimiento para garantizar el derecho de los alumnos de ESO y de Bachillerato a que su rendimiento sea evaluado conforme a criterios objetivos (BOE 20-09-1995).
} 


\section{4.- SEGUNDO FILTRO: MEDIDAS DE ATENCIÓN A LA DIVERSIDAD}

En este nivel nos centramos en el modo en que se articula y desarrolla el apartado de las "Medidas de atención a la diversidad y adaptaciones curriculares para los alumnos que las precisen”, que, con carácter prescriptivo, debe formar parte de las programaciones didácticas. No obstante, puesto que será en el siguiente, y último, filtro en donde se detallen minuciosamente las respuestas ofrecidas a los alumnos con dificultades de aprendizaje asociadas a cualquier discapacidad, nos limitaremos ahora a ofrecer la visión general de este asunto que se refleja en dichos documentos.

Este estudio nos ofrecerá, entre otras, una visión global sobre la profundidad con que los departamentos de un área de marcado carácter procedimental (MEC, 1992, pp. 32 y 81) tratan esta temática. El único centro de interés que presentamos para este capítulo es: "Desarrollo de la atención a la diversidad y de las adaptaciones curriculares".

Junto con las tablas de resultados y sus comentarios, recopilaremos pasajes que aparecen en las programaciones con el deseo de constatar aspectos que creemos más significativos y sintomáticos de una realidad que existe en "la teoría de la práctica". 


\section{a) Desarrollo de la atención a la diversidad y de las adaptaciones}

\section{curriculares}

\section{DATOS OBTENIDOS}

- En una solo aparece para el primer Ciclo.

- En dos aparecen solo como "Adaptaciones Curriculares".

- En una solo como "Alumnos con necesidades educativas especiales".

Una lo tiene por duplicado para cada ciclo.

- Nueve casos recogen algo relacionado con este tema en otros apartados, tales como la metodología o la evaluación.

- En seis no ocupa ni una página.

- En cinco casos no llega a ocupar tres páginas.

- Seis casos articulan un apartado para lesionados temporales.

- En dos casos el formato empleado es diferente al del resto de la programación.

- En dos casos este capítulo no tiene identidad propia, y aparece integrado dentro del de la evaluación.

- Cuatro hacen alusión a la Orden de 10 de julio de 1995.

- Dos tienen presente el Real Decreto 83/1996 para la realización de adaptaciones curriculares en colaboración con el Dpto. de Orientación.

- Dos indican los puntos que deben contener los certificados médicos que se presenten.

- En cinco ni se menciona para nada el certificado médico.

- Casi todas mencionan a los alumnos discapacitados o con deficiencias motóricas.
3,14

13

\section{PROGRAMACIÓN}

$1,2,4,5,6,8,10,12,13$

$3,5,6,8,11,14$

$4,7,9,10,12$

$1,2,4,7,12,14$

10,15

11,14

$1,3,10,12$

4,9

4,9

$2,5,6,12,15$

$1,2,3,4,5,6,8,9,10,11$,

$12,13,14$

Tabla 9. La atención a la diversidad y las adaptaciones curriculares

De la revisión de este aspecto que todas las programaciones didácticas deben contener, se derivan los siguientes comentarios:

En lo que a la extensión se refiere, por término medio, la atención a la diversidad no ocupa más de dos o tres páginas. Si verdaderamente este tema despertase un interés apreciable entre el profesorado, estaría ampliamente desarrollado y razonado, presentando, al menos, un abanico de aplicables posibilidades con las que dar respuesta a las necesidades del alumnado. Media página no parece un espacio suficiente para argumentar, explicar o presentar las intervenciones concretas previstas: 
"El Centro en que nos encontramos está incluido en el programa de integración propuesto por el MEC, por lo que las medidas de atención a la diversidad deben encaminarse hacia el tratamiento de alumnos con necesidades educativas especiales temporales o permanentes.

Se realizarán las adaptaciones curriculares oportunas en el caso de alumnos con deficiencias de aprendizaje cognitivo ligeras, previendo secuenciaciones alternativas así como recursos metodológicos diferentes.

A los alumnos con deficiencias motoras se les efectuará también adaptaciones curriculares en función de sus características, proponiéndoles distintas tareas, pero sin olvidar el cumplimiento de los objetivos generales que la LOGSE establece para los alumnos de la Educación Secundaria.” (Reproducción íntegra del capítulo "Atención a la Diversidad” de la Programación Didáctica 6)

En algún caso, la estructura y desarrollo con la que se tratan las deficiencias motoras es muy pobre en relación con lo que presentan para otros tipos de discapacidades, lo que deja entrever una falta de preocupación por la correcta y adecuada exposición (o desconocimiento sobre cómo abordar estos supuestos), así como una escasez de información que da lugar a pocas posibilidades de aplicabilidad.

"Teniendo en cuenta las características de los alumnos, se tomarán las medidas encaminadas a favorecer los procesos de aprendizaje.

En el caso de la invidencia, se tomarán medidas de carácter metodológico:

- desplazamientos con compañeros

- explicaciones complementarias concisas

- modelaje con el propio cuerpo

- a lo largo del curso se valorará la posibilidad de variar algunos contenidos procedimentales: equilibrio, coordinación óculo-manual y óculo-pie.

En el caso de la deficiencia auditiva: se tomarán medidas de carácter metodológico:

- apoyo con información visual y escrita

- buena vocalización

- ayuda de los compañeros

- modelo imitativo

En el caso de las deficiencias motoras: a partir de la evaluación inicial se detectarán las dificultades y se pondrán en marcha las medidas de apoyo correspondientes." (Reproducción íntegra del capítulo "Atención a la Diversidad" de la Programación Didáctica 10)

Que en Educación Física haya alumnos lesionados, ya sean permanente o temporalmente, parcial o totalmente, es una situación que se produce con bastante frecuencia, siendo habitual que durante todo un curso, o incluso un trimestre, tengamos en clase algún alumno en esta circunstancia, afectando indudablemente al trabajo a 
realizar. Por ello, resulta, cuando menos, extraño comprobar que este hecho no sea tratado en todas las programaciones didácticas (véanse las dos citadas anteriormente), reflejándose de antemano las medidas educativas que a estos alumnos se les debieran de aplicar. Sin embargo, en otras aparece tanto la tipología de los lesionados o imposibilitados como las respuestas que se les darán.

"Siguiendo las diferentes informaciones que a través del BOE nos han llegado, que no hacían sino coincidir casi en su totalidad con los planteamientos que ya estábamos desarrollando en el Departamento, los alumnos con problemas físicos o sensoriales serán valorados de acuerdo con los siguientes criterios:

- Alumnos con imposibilidad total de realizar ejercicio físico alguno. Asistirán a clase y serán colaboradores del profesor y de los compañeros durante la misma...

- Alumnos con imposibilidad parcial, realizarán los ejercicios que puedan hacer y con la intensidad pertinente, siendo evaluados de los mismos.

- Alumnos con imposibilidad temporal. Regirán los mismos principios que para las anteriores categorías hasta la resolución de su problema o el paso a otra categoría." (Recopilación de parte del capítulo "Adaptaciones Curriculares" de la Programación Didáctica 7)

La escasa calidad y cantidad de información que ofrecen los certificados médicos presentados por los alumnos para justificar una lesión o impedimento físico (que en algunos casos conlleva la solicitud de una exención), desencadena que haya profesores que establezcan minuciosamente qué puntos deben contener estos documentos para que tengan algún valor, lo que en cierta medida puede considerarse como un acto de "intromisión profesional". Por el contrario, otros no otorgan ningún protagonismo al certificado médico ya que, o lo mencionan por encima o ni tan siquiera lo nombran.

"Este documento [refiriéndose a una Hoja de Detección de Problemas Médicos] nunca será informe suficiente, al mismo deberán acompañar Certificado Médico Oficial firmado por personal competente (especialista de la patología en todo caso) en el que se incluyan:

a.- Patología y/o defecto físico.

b.- Contraindicaciones en la práctica para dicha patología.

c.- Ejercicios y naturaleza de las actividades que sí puede realizar.

d.- Otros ejercicios o actividades que además de poder realizar resulten convenientes al pacientelalumno." (Recopilación de parte del capítulo “Atención a la Diversidad” de la Programación Didáctica 4. Aclaración mía) 
En cualquier caso, es innegable el crédito que se le otorga a este documento para la toma de decisiones y la aplicación de medidas educativas ante un alumno con cualquier tipo de problema físico o motor.

"Los alumnos con problemas físicos... Se pedirá un informe médico donde aparezca el tipo de lesión y los ejercicios que no puede realizar." (Recopilación de parte del capítulo de "Mínimos exigibles" de la Programación Didáctica 8)

"Todo aquel alumno/a que, por cualquier circunstancia, se halle incapacitado para realizar actividad física..., habrá de acreditarlo mediante el correspondiente Certificado Médico Oficial o informe médico... En él deberá constar claramente los motivos excluyentes y aquellas actividades que el alumno pueda o no realizar..." (Recopilación de parte del capítulo "Alumnos con necesidades educativas especiales" de la Programación Didáctica 13)

Desde un punto de vista normativo, como ya se ha dicho, son escasos los que reseñan las leyes que desarrollan y tratan estos temas. Dentro de estos casos, los hay que no mencionan qué norma lo regula pero sí insinúan que existe, otros se ajustan férreamente a sus dictados, y los hay que utilizan la ley para no "estar solos" en la aplicación de una medida educativa como es la adaptación curricular.

"Cumpliendo la normativa establecida, en aquellos alumnos/as que bajo prescripción médica tengan alguna limitación para llevar a cabo todo o parte del proyecto curricular, se realizarán las correspondientes adaptaciones curriculares tomando como referente el informe facultativo." (Recopilación de parte del subcapítulo "Atención a la Diversidad" de la Programación Didáctica 11)

"Con fecha 10 de Julio de 1995 sale publicada en el BOE la Orden por la que se regula la adaptación del currículo de la Educación Física para los alumnos con necesidades educativas especiales en el B.U.P y E.S.O.

La presente Orden nos dice en el apartado $1^{\circ}$ de su artículo 2, "... se adaptará a aquellos alumnos con necesidades educativas especiales asociadas a discapacidad motora o sensorial, temporal o permanente.

En el artículo 3 apartado 1 dice: " Las solicitudes de las adaptaciones a que se refiere el apartado $1^{\circ}$ del artículo 2, serán formuladas ante la Dirección del Centro por los alumnos o, si éstos son menores de edad, por sus padres o representantes legales e irán acompañadas de los certificados médicos correspondientes.

Apartado 2, " EL Departamento de Educación Física acordará las adaptaciones oportunas a la vista de los certificados médicos..."

Apartado 3," La evaluación de los aprendizajes de los alumnos con necesidades especiales a los que se refiere esta Orden se hará conforme a los objetivos y 
contenidos para ellos propuestos."” (Recopilación de la mayor parte del capítulo "Adaptaciones Curriculares" de la Programación Didáctica 3)

“...existe el caso de darse alumnos que necesiten de una readaptación curricular a las muchas que hacemos en las sesiones de E.F.; alumnos con deficiencias psíquicas, físicas, alumnos hiperactivos, alumnos con grandes deficiencias sensoriales, etc.

En estas situaciones y de forma conjunta con el Departamento de Orientación, conforme se establece en el R.D. 83/96, se realizarán las actividades de adaptación curricular de esta área para los alumnos con necesidades educativas especiales." (Recopilación de parte del capítulo "Atención a la Diversidad" de la Programación Didáctica 9. Énfasis mío)

Por todo lo expuesto hasta aquí, la idea concebida en el capítulo anterior de que este tema preocupaba e inquietaba entre el profesorado no parece confirmarse. La falta de rigor normativo, la pobre y escasa redacción con la que este asunto se afronta, la omisión de las adaptaciones curriculares a aplicar, el que el apartado sea una mera fotocopia o recorte de otras programaciones, el que pase desapercibido al incluirlo dentro de otros capítulos "más importantes", etc., evidencian una realidad, al parecer "invisible", dentro de nuestra área.

No obstante, también es justo afirmar que por varios motivos hay programaciones didácticas (las menos) que dan a este apartado una especial relevancia: el tamaño que ocupa, su desarrollo y estructura posee una lógica más o menos coherente, tienen una argumentación teórica para justificar las propuestas, presentan actividades para estos alumnos (aunque sean en la línea de la "falsa integración”), gradúan las lesiones y/o discapacidades, etc.

\section{5.- TERCER FILTRO: CONCEPTO Y USO DE LA EXENCIÓN}

Comentada la información general desprendida de la lectura de las programaciones didácticas, junto con la del apartado específico de atención a la diversidad, llega el momento de exponer cómo aparece la exención, en cualquiera de las formas que puede adoptar según lo recogido en el Capítulo 6. 
Para ello hemos recurrido a la última de las fichas de análisis, "Concepto y uso de la exención”. Además de comprobar cómo está recogida la exención en estos documentos, también retomaremos algunos de los datos expuestos hasta ahora en los anteriores niveles de análisis con el propósito de ver cuál es su utilidad o aplicabilidad en los alumnos con dificultades de aprendizaje asociadas a discapacidad física en los casos extremos.

Los centros de interés en los que fijamos nuestra atención en este capítulo son: a) la exención: práctica mantenida; b) gestión de los casos extremos; c) respuestas ofrecidas; d) evaluación; y, e) contradicciones que aparecen.

Por último, el carácter de la información que manejamos en este apartado no sigue el formato empleado hasta ahora en el que las variables eran relativamente fáciles de identificar y cuantificar. Ahora, el relato adopta un sesgo más descriptivo, de presentación y comentario de los aspectos que consideramos más significativos en relación con el tema que nos ocupa y que ratificamos con citas de las propias programaciones.

\section{a) La exención: práctica mantenida}

Son varias las programaciones que recogen el concepto "exento", "exento de la práctica" o "exento parcial" para referirse a un tipo muy concreto de alumno, aunque no siempre aclaren las características que lo definen. Según los datos obtenidos, podemos afirmar que las programaciones didácticas del área de Educación Física en el curso 2002-2003 albergan el concepto de "exento", en alguna de las modalidades ya comentadas.

Lo más común suele ser encontrar la expresión "exento de la práctica" o "exento parcial", que, como dijimos en capítulos anteriores, no es más que una forma invisible de declarar a un alumno exento. Con el pretexto de aplicar una adaptación curricular se le dispensa de la práctica (procedimientos motrices) para dar únicamente cabida a lo 
conceptual•actitudinal, alimentando la falsa integración (Ríos, 1998b) con la que se enmascara su participación.

"Todos los/las alumnos/as exentos, tanto los que están de forma parcial como total, al igual que los que, por cualquier circunstancia no puedan hacer la práctica que corresponda en un momento determinado..." (Recopilación del capítulo "Alumnos/as exentos" de las Programaciones Didácticas 5 y 12.)

"Nos referimos a la exención de la práctica en general y de algunas actividades muy concretas, también prácticas, realizadas a lo largo del curso en particular [...] todos los alumnos exentos de algún tipo de práctica...” (Recopilación de parte del subcapítulo "Alumnos «exentos» y detección de problemas físicos y de salud” de las Programaciones Didácticas 9 y 4)

"Distinguiremos aquellos alumnos/as que están limitados para realizar unas determinadas actividades, de aquellos que no pueden practicar actividad física. Hemos de recordar que no existen los alumnos/as exentos totales, ya que la Educación Física es una materia obligatoria, pero sí los exentos de unos determinados contenidos." (Recopilación de parte de las Programaciones Didácticas 1, 2 y 15. Énfasis mío)

En algún caso, a pesar de no recoger textualmente el concepto "exento de la práctica", deducimos su utilización a partir de la redacción del apartado dedicado a los alumnos con necesidades educativas especiales.

"Todo aquel alumnola que, por cualquier circunstancia, se halle incapacitado para realizar actividad física de forma genérica, o alguna en particular, [...] En ningún caso se hallarán exentos del apartado teórico, ni de la valoración de su actitud..." (Recopilación de parte del capítulo "Alumnos con necesidades educativas especiales" de la Programación Didáctica 13. Énfasis mío para resaltar que si emplea esta expresión está dando a entender que también concibe la del exento de la práctica)

Hay un documento en el que no se emplea ninguno de estos conceptos, pero sí se señala la posibilidad de que puede haber alumnos que tengan dificultades para realizar el proyecto curricular elaborado por el departamento. Subyace la visión reduccionista de los contenidos procedimentales motrices como los imperantes en nuestra área.

“...en aquellos alumnos/as que bajo prescripción médica tengan alguna limitación para llevar a cabo todo o parte del proyecto curricular, se realizarán 
las correspondientes adaptaciones curriculares...” (Recopilación de parte del capítulo "Atención a la diversidad" de la Programación Didáctica 11. Énfasis mío)

\section{b) Gestión de los casos extremos}

Lo lógico es pensar que ante estas situaciones especiales que conllevan la puesta en práctica de medidas excepcionales se tenga siempre en cuenta lo que establece la ley. En nuestro caso se atenderá a lo señalado por la ya mencionada Orden de 10 de julio de 1995.

"Las solicitudes de las adaptaciones..., serán formuladas ante la Dirección del Centro por los alumnos o, si éstos son menores de edad, por sus padres o representantes legales...

El Departamento de Educación Física acordará las adaptaciones oportunas..." (Artículo 3, apartados uno y dos de la Orden 10-07-95)

Pues bien, aun existiendo esta norma específica para nuestra área, solo cuatro programaciones la señalan, como quedó patente en la Tabla 9.

“Con fecha 10 de Julio de 1995 sale publicada en el BOE la Orden por la que se regula la adaptación del currículo de la Educación Física para los alumnos con necesidades educativas especiales en el B.U.P y E.S.O. [...]" (Recopilación de parte del capítulo "adaptaciones curriculares" de la Programación Didáctica 3)

"La referencia de alumnos/as «exentos» ha desaparecido de la legalidad vigente... Se tendrá presente en todo momento la ORDEN de 10 de julio de 1995 por la que se regula la adaptación del currículo de la Educación Física para los alumnos con necesidades educativas especiales... en la educación secundaria, así como la dispensa de la misma para los mayores de veinticinco años." (Recopilación de parte del subcapítulo "Algunas consideraciones sobre la clase de Educación Física” de la Programación Didáctica 1)

En la misma Tabla 9, pudimos comprobar que diez programaciones didácticas señalaban en su exposición algo relacionado con el certificado médico. Además, en el Capítulo 6 quedó patente la autoridad que se atribuye a los "papeles" oficiales (certificados médicos) para aplicar cualquier medida en el plano de las adaptaciones curriculares. De hecho, en los apartados uno y dos del artículo 3 de la Orden de 10 de 
julio de 1995, se establece que las solicitudes de las adaptaciones irán acompañadas de los certificados médicos correspondientes, y que le compete al propio Departamento de Educación Física el acuerdo de estas a la vista de los certificados médicos (énfasis mío).

Ahora constatamos que poseen dicha autoridad:

"Todo aquel alumno/a que, por cualquier circunstancia, se halle incapacitado para realizar actividad física de forma genérica, o alguna en particular, habrá de acreditarlo mediante el correspondiente Certificado Médico Oficial o informe médico... En él deberá constar claramente los motivos excluyentes y aquellas actividades que el alumno pueda o no realizar." (Recopilación de parte del capítulo "Alumnos con necesidades educativas especiales" de la Programación Didáctica 13)

"Para aquellos alumnos-as que tengan un impedimento planamente justificado, parcial o total, después de revisar el informe médico, se les confeccionará un plan de trabajo adaptado a su incapacidad." (Recopilación de parte del subcapítulo "Adaptaciones curriculares" de la Programación Didáctica 14)

“...en aquellos alumnos/as que bajo prescripción médica tengan alguna limitación para llevar a cabo todo o parte del proyecto curricular, se realizarán las correspondientes adaptaciones curriculares..." (Recopilación de parte del capítulo "Atención a la diversidad" de la Programación Didáctica 11)

"Cualquier resolución sobre el estado físico y, por lo tanto, sobre las adaptaciones curriculares se tomará en presencia de informe médico completo o certificado médico oficial, en caso de afectación importante, o de justificación médica normal si la afectación es de presentación periódica o de escasa duración." (Recopilación de parte del capítulo "Adaptaciones curriculares" de la Programación Didáctica 7)

En ocasiones, se recurre a lo que el centro educativo establece para estos casos. De hecho, debería ser siempre pues, como ya hemos comprobado, así lo regula la Orden de 10 de julio.

«Tal y como se encuentra recogido en el artículo 204 del Reglamento de Régimen Interno del centro, «los alumnos deberán presentar al principio del curso, informe o justificante médico cuando se tenga motivo para que se le aplique una adaptación curricular total o parcial de la práctica deportiva y/o de la Educación Física.»" (Recopilación de parte del subcapítulo "Algunas 
consideraciones sobre la clase de Educación Física" de la Programación Didáctica 1)

Anteriormente hemos dejado constancia de que algunas programaciones señalan los puntos que necesariamente deben contener los certificados médicos oficiales. Pues bien, en algún documento hemos apreciado que no se acepta con facilidad el que los médicos sean quienes concedan a los alumnos la exención de cursar nuestra área.

"En absoluto servirán aquellas en las que se indica que el alumno ESTÁ EXENTO DE LAS CLASES DE EDUCACIÓN FÍSICA, (que suelen ser las más), o de Educación Física o de otra práctica cualesquiera que sea." (Recopilación del parte del subcapítulo "Alumnos «exentos» y detección de problemas físicos y de salud" de la Programación Didáctica 9. En la misma línea se encuentra la 4)

Es curioso comprobar que a pesar de la importancia que se concede a los justificantes paternos (vid:: el Capítulo 11), ninguna programación refleja nada al respecto.

\section{c) Respuestas ofrecidas a estos alumnos}

Nuestro primer referente, como viene siendo habitual, es la normativa específica, la cual señala en su artículo 2 que nuestro currículo de Educación Física..., se adaptará para aquellos alumnos con necesidades educativas especiales asociadas a discapacidad motora o sensorial, temporal o permanente.

Las orientaciones que encontramos en estos documentos para dar una respuesta educativa a este alumnado son variadas, numerosas y, en muchas de las ocasiones, coincidentes. Casi todas las posibilidades ofrecidas están en la línea de la ya comentada "falsa integración". Con el pretexto de integrar a los alumnos en las clases de Educación Física se recurre a los contenidos conceptuales-actitudinales y a la realización de tareas totalmente diferentes a las de sus compañeros. 
“...estos alumnos tienen la obligación de asistir a las sesiones diarias, pudiendo realizar en momentos determinados labores de observadores externos." (Recopilación de parte del subcapítulo "Adaptaciones curriculares" de la Programación Didáctica 14)

"El establecimiento de los programas específicos para estos alumnos/as debe centrarse tanto en los contenidos adaptados (especialmente orientados hacia los conceptos y actitudes) como en los recursos didácticos que se van a emplear para integrar a los alumnos en la marcha de la clase. Proponemos a continuación algunas posibilidades para llevarlos a cabo:

- Realización de trabajos teóricos relacionados con los contenidos que se están trabajando para exponer a sus compañeros.

- Elaboración de apuntes para sus compañeros.

- Participación en las actividades deportivas realizando el arbitraje de los partidos que jueguen sus compañeros.

- Dirección de actividades a sus compañeros: juegos, estiramientos, ejercicios de relajación." (Recopilación de parte de las Programaciones Didácticas 2 y 15. En la misma línea la 1)

“...dichos alumnos habrán de acudir, de forma obligatoria, a cada una de las sesiones, ..., habiendo de satisfacer el apartado teórico de la asignatura con la elaboración de trabajos de investigación, o cualquier otra actividad pedagógica..., como la recopilación de ejercicios, objetivos, metodología, etc., de cada una de las sesiones..." (Recopilación de parte del capítulo "Alumnos con necesidades educativas especiales” de la Programación Didáctica 13)

“...todos los alumnos exentos de la práctica deberán acudir a clase de forma obligatoria, tomar nota de los contenidos teóricos que se expongan y hacer una ficha diaria mediante observación de las actividades que se realicen en clase, así como alguna tarea de profundización sobre las mismas; ficha que quedará registrada en su cuaderno y que tendrá que supervisar el profesor [...]

Los alumnos exentos dentro de lo posible colaborarán en la sesión en los momentos que se precisen ayudas: filmación en video, arbitraje, anotaciones, organización, observación de aspectos a destacar, etc." (Recopilación de parte del subcapítulo "Alumnos «exentos» y detección de problemas físicos y de salud” de las Programaciones Didácticas 9 y 4 )

“...los/as alumnos/as exentos..., tienen que acudir a clase, tomar notas de los contenidos teóricos que se expongan y hacer una ficha diaria de las actividades que se realicen... Además, deben colaborar con la clase en los momentos que se precisen ayudas para la utilización del material, arbitraje, anotaciones..." (Recopilación del capítulo "Alumnos/as exentos" de las Programaciones Didácticas 5 y 12)

"Alumnos con imposibilidad total de realizar ejercicio físico alguno. Asistirán a clase y serán colaboradores del profesor y del resto de los compañeros..." 
(Recopilación de parte del capítulo "Adaptaciones curriculares" de la Programación Didáctica 7)

"Los alumnos con alguna discapacidad que les impida realizar ejercicios físicos, deberán llevar un seguimiento de las clases que quedará reflejado en un cuaderno. Realizarán trabajos teóricos sobre los contenidos de la asignatura. Estos trabajos podrán ser también sobre libros o artículos de revistas que el profesor considere interesante para la formación del alumno." (Recopilación de parte del capítulo "Adaptaciones curriculares" de la Programación Didáctica 3)

En la línea de alumno-colaborador del profesor, encontramos un caso en el que se utiliza al alumnado exento y/o lesionado temporal para la observación del trabajo diario, actitudes, etc., del resto de sus compañeros.

"Observación directa de la actividad diaria: Tanto por parte del profesor como por parte de los alumnos, que se designarán prioritariamente entre los exentos y/o discapacitados temporalmente..." (Recopilación de parte del capítulo "Procedimientos y sistemas de evaluar el aprendizaje de los alumnos" de la Programación Didáctica 10)

Hemos observado en tres programaciones didácticas la posibilidad de realizar tareas propias del bloque de contenidos "Expresión corporal" o "Ritmo y expresión". Esta propuesta difiere totalmente de las opciones mayoritarias y además, como se verá en apartados posteriores de este capítulo, choca con el desarrollo de las programaciones didácticas que lo proponen.

"En los trabajos de expresión corporal pueden participar casi sin limitaciones." (Recopilación de las Programaciones Didácticas 1, 2, y 15)

Otra de las tareas que puede llevar a cabo estos alumnos es la ejecución de sus propios programas de rehabilitación motriz.

"Existe la posibilidad de que los/as alumnos/as con desviación de columna, o con otro tipo de trastorno funcional, realicen los ejercicios prescritos por el médico durante las clases de Educación Física." (Recopilación del capítulo "Alumnos/as exentos" de la Programación Didáctica 12. En los mismos términos se encuentra la $\mathbf{1}$ )

Aunque también hay detractores de dicha práctica. 
"No consideramos oportuno que los alumnos con problemas de columna o de otra región anatómica y sometidos a ejercicios de rehabilitación realicen los mismos durante las sesiones de E.F., ya que debemos evitar el aislamiento respecto al grupo." (Recopilación de parte del subcapítulo "Alumnos «exentos» y detección de problemas físicos y de salud" de las Programaciones Didácticas 9 y 4$)$

Para terminar, creemos necesario apuntar que son escasas las programaciones que establecen para el grupo de compañeros la realización de prácticas adaptadas a las características de este tipo de alumnado o, lo que es lo mismo, no se proponen juegos motrices sensibilizadores, como señalamos en el Capítulo 6.

"Consideramos necesario en los centros de integración establecer contenidos referidos a las actividades físico-deportivas que practican los alumnos/as discapacitados. Tan importante es que éstos se integren en la marcha del centro como que sus compañeros vivencien las circunstancias y limitaciones de su actividad y aprendan a valorar el esfuerzo que supone la adaptación. A este respecto hay experiencias llevadas a cabo con éxito en algunos centros de programación de unidades didácticas dedicadas a deportes adaptados: baloncesto en sillas de ruedas, fútbol-sala o prácticas con supresión de la vista, etc." (Recopilación de parte del capítulo "Atención a la diversidad" de la Programación Didáctica 1)

Como ya apreciamos en el anterior nivel de análisis, se suele recurrir al

Departamento de Orientación para la realización de adaptaciones curriculares.

"Adaptaciones curriculares: Ya hemos hecho mención a las mismas al hablar de la atención a la diversidad y al problema de los exentos.

No obstante, existe el caso de darse alumnos que necesiten una readaptación curricular a las muchas que hacemos en las sesiones de E.F.: alumnos con deficiencias psíquicas, físicas, ...

En estas situaciones, y de forma conjunta con el Departamento de Orientación, conforme se establece en el R.D. 83/96, se realizarán las actividades de adaptación curricular de esta área para los laumnos con necesidades educativas especiales." (Recopilación de parte del subcapítulo "Adaptaciones curriculares" de la Programación Didáctica 9) 


\section{d) Evaluación}

La citada Orden de 10 de julio de 1995 establecía en el artículo 3, apartado tres, las pautas para la evaluación del alumnado con necesidades educativas especiales, lo cual no quiere decir que se especifique clara y concretamente en qué debe consistir esta, pues está en función de la adaptación curricular que se elabore (y que pasa a formar parte del expediente de cada uno de los alumnos).

"La evaluación de los aprendizajes de los alumnos con necesidades especiales a los que se refiere esta Orden se hará conforme a los objetivos y contenidos para ellos propuestos." (Artículo 3, apartado tres, de la Orden de 10 de julio de 1995)

Junto con el tipo de tareas que deben realizar estos alumnos, es frecuente encontrarnos en las programaciones didácticas los instrumentos y procedimientos con los que evaluarlos, los cuales suelen ser, casi siempre, los mismos. Suponemos que, en aquellos documentos en los que no se mencionan explícitamente dichos procedimientos, la evaluación se centra en las propias tareas que se les encomiendan. Evidentemente, los conceptos y las actitudes aparecen como el referente principal, lo que, por otra parte resulta obvio en una "Educación Física sin práctica".

"Alumnos con imposibilidad total de realizar ejercicio físico alguno... Realizarán examen teórico y aquellos trabajos que se le soliciten..." (Recopilación de parte del capítulo "Adaptaciones curriculares" de la Programación Didáctica 7)

"Estos alumnos/as serán calificados mediante la entrega y valoración correspondiente de todos los trabajos que se encarguen a la clase y de algunos más que les serán encargados de forma especial a ellos, así como a través de las fichas diarias de clase que deberán haber realizado durante el curso. Si la exención es parcial o temporal, se les examinará de la parte práctica que pueden realizar." (Recopilación de parte del capítulo "Alumnos/as exentos" de la Programación Didáctica 12)

"Estos alumnos serán calificados mediante la entrega y valoración correspondiente de los trabajos que se les encarguen, así como a través de las fichas diarias de clase que deberán haber realizado. Si la exención es parcial o temporal se les examinará de la parte práctica que puedan realizar." (Recopilación de parte del capítulo "Alumnos/as exentos" de la Programación Didáctica 5) 
"En las recuperaciones estos alumnos tendrán que entregar un trabajo teórico distinto del realizado en las evaluaciones, en el supuesto de no haber entregado el trabajo teórico en la evaluación en la recuperación tendrán que entregar dos trabajos teóricos." (Recopilación de parte del capítulo "Adaptaciones curriculares" de la Programación Didáctica 3)

El último de los puntos analizados en la Tabla 8 trataba sobre los criterios de calificación que se aplican a estos alumnos. Comprobamos que la casi totalidad de los documentos presentaban este apartado, ¿pero qué señalan para las situaciones en las que nos estamos moviendo? Lo lógico sería pensar que, independientemente de la adaptación curricular realizada, estableciesen los porcentajes de las notas para cada apartado de la conducta humana, tal y como se hizo para el resto de los alumnos. Pues bien, son escasos los que concretan este asunto.

"La nota de los alumnos con adaptaciones curriculares será $70 \%$ la nota del trabajo teórico, 30\% de la actitud, (Presentación del cuaderno de clase, sin éste no se puede superar la Evaluación)." (Recopilación de parte del capítulo "Adaptaciones curriculares" de la Programación Didáctica 3)

"Contenidos teóricos, evaluados a través de pruebas escritas, del cuaderno, de trabajos y de pruebas orales; representará un 10\% salvo, claro está, en el caso de los exentos en los que se realizará una adaptación curricular personalizada..." (Recopilación de parte del capítulo "Procedimientos y sistemas de evaluar el aprendizaje de los alumnos" de la Programación Didáctica 10)

En algunos que no abordan en absoluto el asunto de la evaluación de este colectivo minoritario, se entrevé, por la forma en que conciben el área, que difícilmente habrá un lugar para las necesidades educativas de estos alumnos.

"Al ser un área fundamentalmente práctica, la asistencia y participación activa en las clases es de suma importancia, considerándola como un requisito muy importante para superar las distintas evaluaciones... Nuestra propuesta de calificación para el conjunto de la materia implica evaluar tanto la destreza físico / motriz, los conocimientos teórico-prácticos adquiridos como la participación y actitud del alumnola...” (Recopilación de parte del capítulo "Evaluación" de la Programación Didáctica 11) 
Asunto similar ocurre con el apartado de "mínimos". En solo un documento se indica cuáles son los aplicables a este tipo de alumnos, estando en la línea de las tareas que les suelen encomendar para dar respuesta a sus necesidades.

"Los alumnos con problemas físicos, deberán asistir obligatoriamente, llevar al día el cuaderno del alumno, aprobar los controles teóricos y realizar los ejercicios que no estén contraindicados...” (Recopilación de parte del capítulo "Mínimos exigibles" de la Programación Didáctica 8)

En todo caso, algunos de los "mínimos" prácticos que se mencionan en las programaciones didácticas se eliminan para estos alumnos.

"Llegar a los baremos de 4 sobre 10 de los tests de condición física..., a no ser que exista impedimento justificado que de origen a una adaptación curricular individualizada." (Recopilación de parte del capítulo "Criterios mínimos para $3^{\circ}$ de E.S.O.” de la Programación Didáctica 10)

Hay una ausencia generalizada de ejemplos de adaptaciones curriculares o de fichas para la valoración de la competencia curricular, tratando todo este asunto de una forma muy general, abierta e imprecisa.

\section{e) Contradicciones que aparecen}

La contradicción que con más frecuencia hemos encontrado está relacionada con el hecho de que hay documentos que reflejan normativa específica que se aplica en estos casos (Orden de 10 de julio de 1995) y, al mismo tiempo, determinan y reconocen la práctica de la exención. Recordemos que la norma, en su apartado introductorio, dice que la exención de cursar esta disciplina se presenta en la actualidad... como una medida improcedente...

“...que se designarán prioritariamente entre los exentos [...] salvo claro está en el caso de los exentos en los que se realizará una adaptación curricular personalizada, ateniéndose a lo dispuesto en la Orden 17.207 del M.E.C. de 10 de julio de 1995 (BOE de 15 de julio." (Recopilación de parte del capítulo "Procedimientos y sistemas de evaluar el aprendizaje de los alumnos" de la Programación Didáctica 10) 
Las hay que, previa cita de la norma que rechaza explícitamente la exención, no solo reconocen la existencia de alumnos de este tipo, sino que además gradúan dicha condición como total y/o parcial.

“Orden 10 de julio de 1995. B.O.E. 15 de julio de 1995.

- Artículo 2 y 3.

Todos los/as alumnos/as exentos, tanto los que lo están de forma parcial como total..." (Recopilación de parte del capítulo "Alumnos/as exentos" de la Programación Didáctica 12)

"La referencia de alumnos/as "exentos" ha desaparecido de la legalidad vigente... Se tendrá presente en todo momento la ORDEN de 10 de julio de 1995 por la que se regula la adaptación del currículo de la Educación Física [...] Hemos de recordar que no existen los alumnos exentos totales, ya que la Educación Física es una materia obligatoria, pero sí los exentos de unos determinados contenidos..." (Recopilación de parte de la Programación Didáctica 1)

En otras ocasiones, se detecta una cierta incoherencia en algunas de las argumentaciones que aparecen en el desarrollo del capítulo o apartado en el que se aborda esta problemática.

Algunas de ellas tienen que ver con eso que hemos denominamos anteriormente “intrusismo profesional”, ya sea en una u otra dirección. Los profesores de Educación Física no aceptan que los médicos sean quienes otorguen o concedan la exención, aunque solo sea de la práctica, pues esta es competencia exclusiva del profesor / departamento.

"Nos referimos a la exención de la práctica en general y de algunas actividades muy concretas, también prácticas [...] En absoluto servirán aquellos [refiriéndose a los certificados médicos] en los que se indica que el alumno ESTÁ EXENTO DE LAS CLASES DE GIMNASIA, (que suelen ser las más), o de Educación Física o de otra práctica cualesquiera que sea." (Recopilación de parte del subcapítulo "Alumnos «exentos» y detección de problemas físicos y de salud” de la Programación Didáctica 9. Aclaración mía)

Otras veces, el propio departamento señala los puntos que todo certificado médico debe contener, para luego no respetarlos o utilizarlos en caso de no ajustarse a sus intereses. 
"Los alumnos deberán entregar Certificado Médico oficial... en el que se incluyan:

[...]

d.- Otros ejercicios o actividades que además de poder realizar resulten convenientes al pacientelalumno [...]

No consideramos oportuno que los alumnos con problemas de columna o de otra región anatómica y sometidos a ejercicios de rehabilitación realicen los mismos durante las sesiones de Educación Física..." (Recopilación de parte del subcapítulo "Alumnos «exentos» y detección de problemas físicos y de salud" de las Programaciones Didácticas 4 y 9)

No acabamos de concebir por qué quieren saber qué ejercicios les son beneficiosos a estos alumnos (entendemos por ellos ejercicios propios de rehabilitación), si luego no permiten que los ejecuten, aun a sabiendas de que no pueden realizar otra cosa. Todo lo hacen argumentando que debemos evitar el aislamiento respecto al grupo, cuando previamente han asignado a estos alumnos, supuestamente para favorecer la integración, actividades tales como la filmación en vídeo, arbitraje, anotaciones, organización, observación de aspectos a destacar, etc. (Programaciones Didácticas 4 y 9 ).

Por último, hay documentos que presentan incoherencias entre las concepciones que tienen sobre el tema y las posteriores respuestas que ofertan, de tal suerte que primero afirman que hay alumnos que no pueden realizar ningún tipo de actividad física $\mathrm{y}$, después, señalan que sí pueden participar en aquellas que tienen que ver con unos contenidos, los cuales suelen ser considerados habitualmente como carentes de movimiento o actividad, siendo bien distinta la realidad.

"Alumnos con discapacidad física grave y permanente: Son aquellos casos en los que existe una patología crónica grave que impide la práctica de cualquier tipo de actividad física [...] En los trabajos de expresión corporal pueden participar casi sin limitaciones." (Recopilación de parte de las Programaciones Didácticas 1, 2 y 15. Aclaración mía) 


\section{6.- OTRAS PROGRAMACIONES DIDÁCTICAS}

Disponemos de otras programaciones didácticas de Institutos de Educación Secundaria de carácter público que no hemos utilizado como muestra de este trabajo por no pertenecer a centros de Valladolid o provincia. En concreto, son de otras provincias de la comunidad de Castilla y León o de otras comunidades autónomas (Madrid).

\section{a) Más de lo mismo}

Sin embargo, con el objeto de verificar que no solo en el contexto en el que se circunscribe este estudio se mantiene la exención como práctica habitual en las clases de Educación Física, creemos conveniente reflejar algunos aspectos de su contenido.

Así, las concepciones acerca de lo que es un alumno exento siguen siendo similares a las encontradas hasta ahora, al igual que la tipología que para ellos se establece. Además, en muchos casos sigue habiendo una clara alusión a la parte práctica.

"Se contemplan alumnos exentos de la parte práctica..." Recopilación de una programación didáctica de la Comunidad de Madrid)

"Esa exención será tan sólo y exclusivamente para parte o la totalidad de las clases prácticas...” Recopilación de una programación didáctica de la provincia de Salamanca)

"Alumnos con discapacidad física grave y permanente: No existen exentos totales ya que la Educación Física es una materia obligatoria, pero sí los exentos de unos determinados contenidos." (Recopilación de una programación didáctica de la provincia de Ávila)

“EXENTOS: Los alumnos que se lesionen a lo largo del curso, así como los que tengan alguna lesión o limitación permanente, estarán exentos de la parte práctica de la asignatura que no puedan realizar..." (Recopilación de una programación didáctica de la Comunidad de Madrid) 
Es más, en un caso se llega a argumentar en términos de adaptación curricular la eliminación de la parte práctica del área.

“...el alumnado tendrá que entregar al matricularse la documentación necesaria para que el profesorado realice las oportunas adaptaciones curriculares, pudiendo llegar éstas a la exención total de la parte práctica del área." (Recopilación de una programación didáctica de la provincia de Salamanca)

La gestión de estos casos sigue pasando inexorablemente por la presentación del correspondiente certificado médico. Este documento sirve para declarar a un alumno exento de un tipo de contenido o parte del área y además, como pudimos comprobar anteriormente, suele ser "habitual" que se establezcan qué puntos o informaciones debe contener.

"Estos alumnos [refiriéndose a los alumnos exentos de la parte práctica] presentarán informe médico que alegue su condición física.” Recopilación de una programación didáctica de la Comunidad de Madrid. Aclaración mía)

"A los alumnos exentos que presenten Certificado Médico Oficial que acredite que no pueden realizar ningún tipo de ejercicio físico durante todo el curso escolar, se le concederá la exención de la parte procedimental de la asignatura... Cada evaluación presentarán al profesor el tratamiento médico que siguen para su rehabilitación." (Recopilación de una programación didáctica de la provincia de Burgos)

“...es obligatorio presentar u informe médico cuando sea por poco tiempo, y un certificado médico oficial cuando sea para todo el curso o un tiempo muy prolongado. En el informe o certificado deberá constar, la lesión o enfermedad que padece, el tiempo aproximado de curación y el tipo de ejercicio que no puede realizar." (Recopilación de una programación didáctica de la Comunidad de Madrid)

En lo que respecta a las respuestas que la Educación Física formula para estos alumnos, continúa manteniéndose la tónica de proponer actividades muy en la línea de la conocida "falsa integración".

"Aquellos alumnos que no puedan realizar la clase práctica, por el motivo que fuere, realizarán una actividad que le asigne el profesor, ya sea un comentario sobre un artículo de prensa, tomar nota de las actividades realizadas en clase 
por sus compañeros, etc." (Recopilación de una programación didáctica de la provincia de Ávila)

“...realizarán todas las actividades relacionadas con los contenidos conceptuales del área, siendo obligatoria su asistencia a clase de igual manera que los alumnos no exentos de práctica [...] deben colaborar con la clase en arbitrajes, anotación de contenidos teóricos y ayudar en el traslado y colocación del material en las clases, cuando sea necesario." (Recopilación de una programación didáctica de la provincia de Burgos)

“...el alumno/a en esta situación [exento parcial o total de las clases prácticas], seguirá como el resto de los compañeros/as el programa de contenidos teóricos desarrollados en el libro de texto asignado en el curso correspondiente, asistiendo a clase y superando los controles que se establezcan [...] estos alumnos, tendrán obligación de asistir a clase donde trabajarán los aspectos conceptuales y actitudes que la asignatura tiene marcados, así como colaborar en la medida que les sea posible en aspectos organizativos y generales de la clase." Recopilación de una programación didáctica de la provincia de Salamanca. Aclaración mía)

"Las tareas que suplirán los ejercicios o actividades que este tipo de alumnos [exentos] no realice, será la realización de fichas, trabajos, preparación y aplicación de sesiones prácticas. " Recopilación de una programación didáctica de la Comunidad de Madrid. Aclaración mía)

En el apartado de la evaluación, los instrumentos y procedimientos manejados para valorar y calificar a los alumnos "exentos" son los mismos que hemos venido apreciando en los documentos de nuestra muestra.

“Cada evaluación... realizarán un trabajo final de su lesión o enfermedad." (Recopilación de una programación didáctica de la provincia de Burgos)

"Los alumnos con lesión o enfermedad permanente que no pueden realizar ejercicio físico, serán evaluados a través de los aspectos teóricos de la materia [...] Los alumnos exentos de la práctica por lesión o enfermedad además de realizar los tests teóricos, deberán realizar un trabajo en cada evaluación y sacar al menos cinco puntos para aprobar..." (Recopilación de una programación didáctica de la Comunidad de Madrid)

Hay una programación que recoge de forma detallada unos criterios de evaluación y de calificación específicos para los alumnos exentos de la parte práctica. 
"Criterios de evaluación.

1. Responder y elaborar las cuestiones teóricas planteadas del libro de texto de educación física que específicamente plantee el profesor además de las que se señalan al resto de compañeros.

2. Desarrollar la capacidad de análisis estadístico sobre las marcas obtenidas por sus compañeros, recoger y estructurar la información necesaria sobre su lesión o enfermedad, y otras cuestiones referidas a su salud.

3. Recopilar la información sobre las sesiones de clase, para que el resto de los alumnos puedan disponer de dicha información.

Criterios de calificación

80\% Parte teórica

- Calificación de trabajo/s teórico/s. Su presentación y elaboración.

- Calificación de examen/es teórico/s.

- Calificación de trabajo/s teórico/s extras. Su presentación y su elaboración.

- Calificación de diario de clase con las sesiones de todo el curso.

20\% Parte actitud

Similar al sistema general haciendo hincapié en su función como alumno ayudante de los demás alumnos." (Recopilación de una programación didáctica de la Comunidad de Madrid)

\section{b) ¿Qué hay de nuevo?: Cortapisas e impedimentos para los alumnos}

Sin embargo, en mismo apartado de la calificación, nos hemos topado con una información totalmente desconocida hasta ahora: la limitación explícita de la nota máxima que puede obtener un alumno de estas características (lo cual es del todo ilegal).

"Los alumnos que por causas médicas no puedan realizar alguna de las pruebas prácticas de evaluación podrán obtener un cinco como máximo en su nota." (Recopilación de una programación didáctica de la provincia de Ávila)

“...la calificación tendrá la limitación en «seis»o «bien» como nota máxima, ya que en esta área los contenidos prácticos son fundamentales [...] Para estos alumnos la calificación será la media resultante de la nota del examen teórico y la nota del trabajo. En ningún caso la nota final será superior a «bien»" (Recopilación de una programación didáctica de la Comunidad de Madrid)

Se llega incluso a coartar la participación de este alumnado en determinadas actividades, lo cual, volviendo al terreno de las contradicciones, no deja de ser paradójico pues por un lado se afirma categóricamente que deben colaborar con la 
clase en arbitrajes, para luego no permitirles la posibilidad de realizar cualquier tipo de práctica físico-deportiva.

“...estos alumnos no podrán participar en las actividades extraescolares físicodeportivas que se realicen a lo largo del curso." (Recopilación de una programación didáctica de la Comunidad de Madrid)

Terminamos afirmando que estas programaciones didácticas, a pesar de que se sitúen fuera del contexto espacial en el que se encuadra este trabajo, sirven como ejemplo contundente que demuestra que la exención, ya sea total o parcial en los términos explicados anteriormente en la investigación, es una realidad presente en nuestras clases y que son varios los procedimientos que se emplean para enmascararla o hacerla "invisible".

\section{7.- EPÍLOGO}

Tras este análisis de las programaciones didácticas, resumimos aquellos aspectos y anotaciones que caracterizan esta fase de la investigación.

En lo que respecta al proceso seguido en este capítulo, recordamos que se ha centrado en la revisión de las programaciones didácticas que nos han sido remitidas por los Departamentos de Educación Física y Deportiva de los IES públicos de Valladolid y su provincia (15 de los 32 existentes, es decir, más de un 46\%). Para ello, elaboramos tres fichas de análisis que hemos ido aplicando en progresión, de forma que primero nos hemos centrado en la extracción de información general para, posteriormente, irnos encaminando hacia el objeto de estudio de la investigación: el tratamiento que da la Educación Física a los alumnos con necesidades educativas especiales asociadas a discapacidad motriz y, sobre todo, comprobar el mantenimiento de una práctica no permitida como es la exención. 
En cada uno de los niveles de análisis, para no perdernos en la búsqueda de información y no olvidar el objeto de estudio, hemos ido centrando nuestra intención en las distintas categorías o centros de interés que ya se han mencionado.

En el siguiente cuadro sinóptico (Figura 5), se refleja la información más significativa que hemos ido obteniendo de cada una de las fichas de análisis, para cada uno de los centros de interés (definidos de antemano con una relativa apertura que nos ha permitido, a lo largo del proceso, incorporar matices inesperados o imprevistos). 

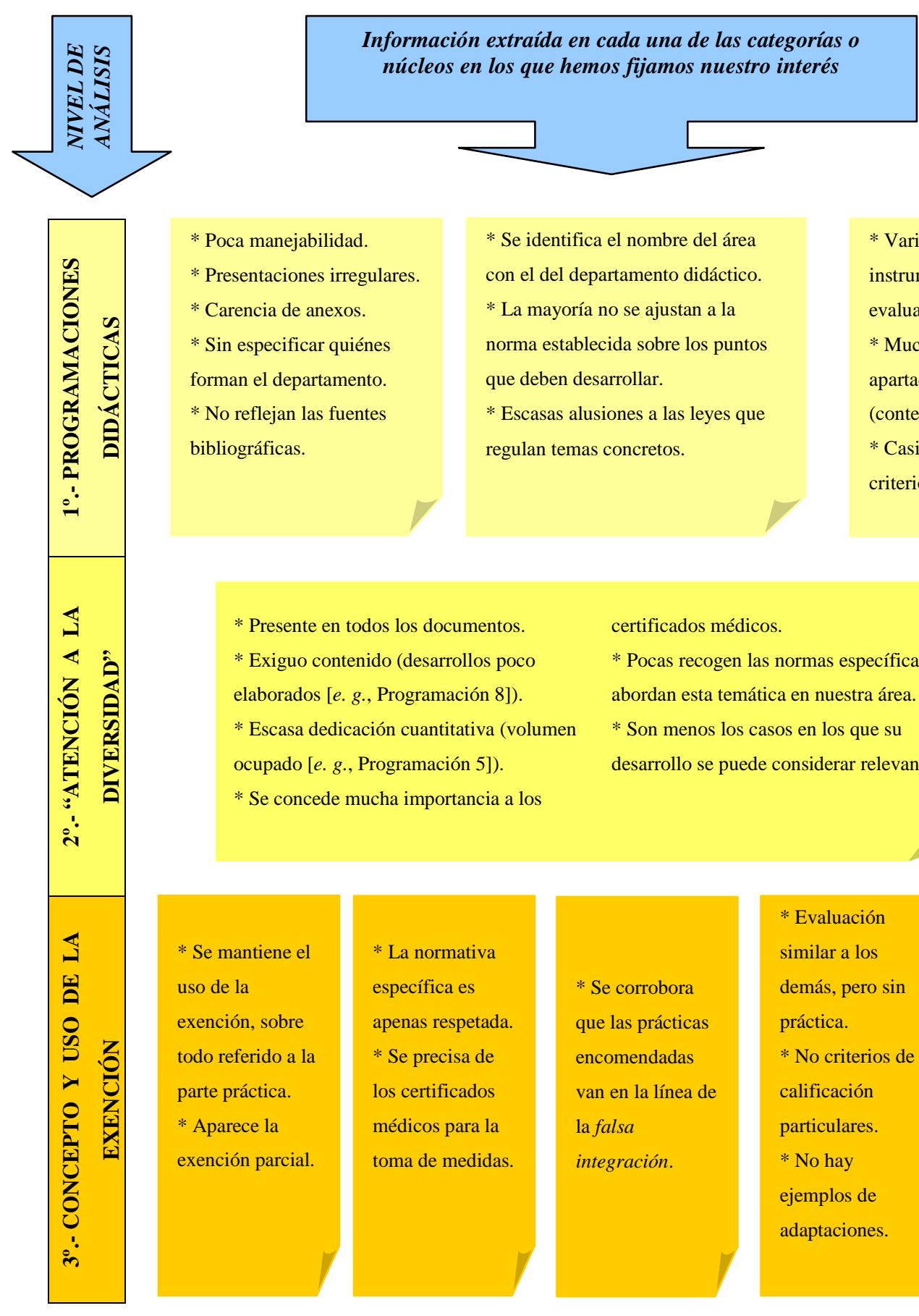

* Poca manejabilidad.

* Presentaciones irregulares.

* Carencia de anexos.

* Sin especificar quiénes

forman el departamento.

* No reflejan las fuentes

bibliográficas.

\section{* Se identifica el nombre del área} con el del departamento didáctico.

* La mayoría no se ajustan a la norma establecida sobre los puntos que deben desarrollar.

* Escasas alusiones a las leyes que regulan temas concretos.

\author{
* Variada gama de \\ instrumentos para la \\ evaluación. \\ * Muchas contienen un \\ apartado para "mínimos" \\ (contenido poco preciso). \\ * Casi todas presentan \\ criterios de calificación.
}

$$
\begin{aligned}
& \text { * Presente en todos los documentos. } \\
& \text { * Exiguo contenido (desarrollos poco } \\
& \text { elaborados [e.g., Programación 8]). } \\
& \text { * Escasa dedicación cuantitativa (volumen } \\
& \text { ocupado [e. g., Programación 5]). } \\
& \text { * Se concede mucha importancia a los }
\end{aligned}
$$

certificados médicos.

* Pocas recogen las normas específicas que abordan esta temática en nuestra área.

* Son menos los casos en los que su desarrollo se puede considerar relevante.
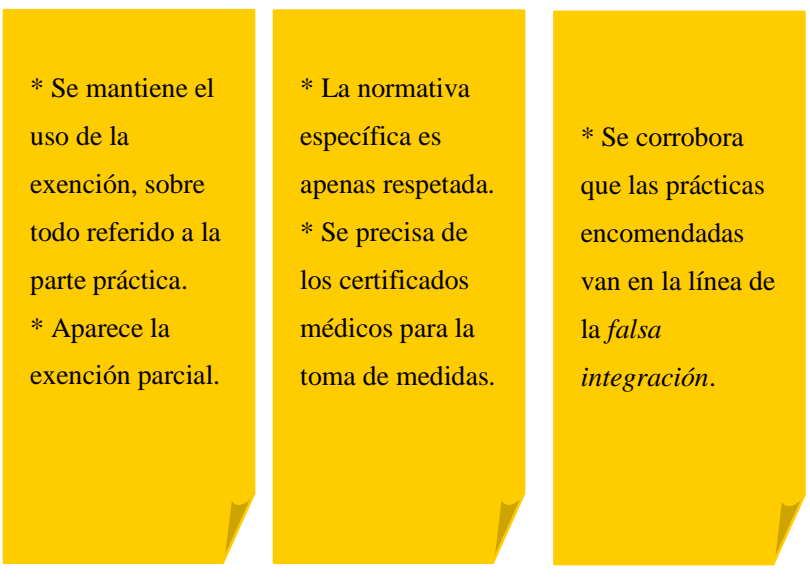

*Evaluación
similar a los
demás, pero sin
práctica.
* No criterios de
calificación
particulares.
* No hay
ejemplos de
adaptaciones.

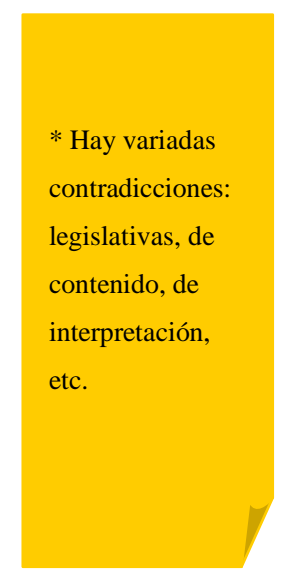

Figura 5. Epílogo a la revisión de las programaciones didácticas 


\section{$\underline{\text { Piezas de la vidriera }}$}

El análisis al que han sido sometidas las programaciones didácticas de varios institutos de Valladolid y provincia participantes en la investigación, nos va a permitir descubrir nuevas piezas para la vidriera final.

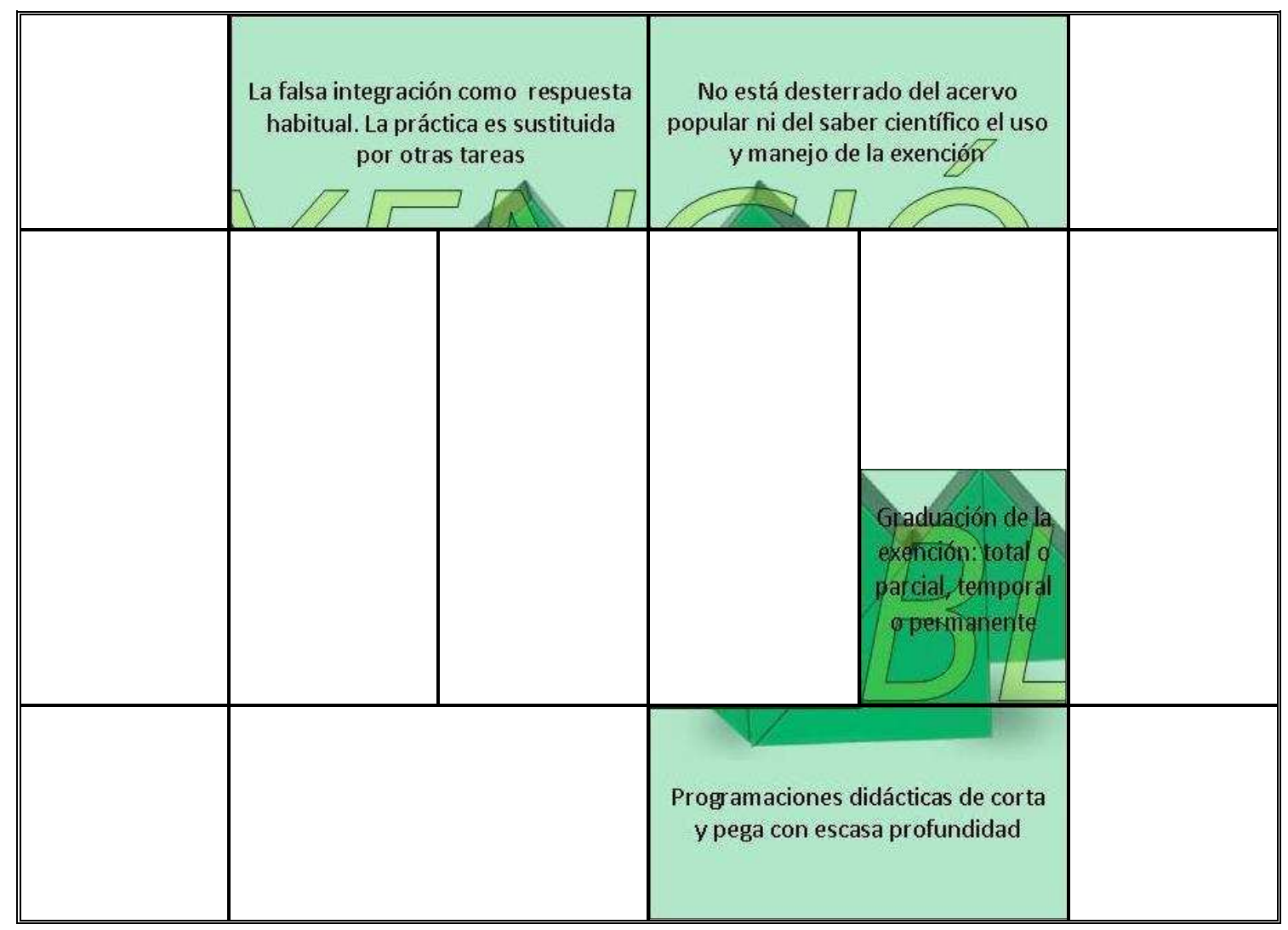




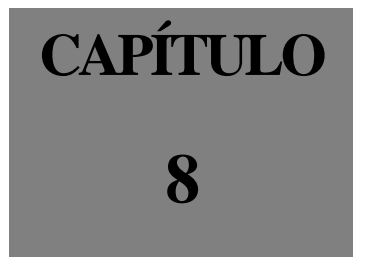

APROXIMACIÓN A LA VISIÓN QUE TIENE EL PROFESORADO 
Para llegar a tener una idea aproximada de cuál es la visión que tiene el profesorado de Educación Física del asunto de la exención y el tratamiento a los alumnos con deficiencias de aprendizaje asociadas a discapacidad motora en un grado severo, hemos optado por la utilización de un cuestionario "ad hoc". El cuestionario, como fuente de obtención de información, suele ser uno de los métodos más utilizados dentro de los proyectos de investigación social (Caplow, 1974, p. 50).

En este capítulo reuniremos todo el proceso que concierne al cuestionario que ha sido utilizado para obtener información entre los profesores de Educación Física en la Educación Secundaria en relación con el objeto de estudio. Realizaremos una breve aproximación teórica a dicho instrumento, comentaremos los objetivos perseguidos y todo el proceso de elaboración y organización adoptado, la presentación de los datos obtenidos y sus oportunas interpretaciones, hasta las conclusiones que de ellos se derivan. 


\section{1.- INTRODUCCIÓN}

De los métodos de investigación existentes, el descriptivo pretende "descubrir sistemáticamente hechos y características de una población dada o área de interés de forma objetiva y comprobable" (Colás, 1992b, p. 177). Dentro de éstos, la encuesta suele ser el método más utilizado en la investigación educativa (Cohen y Manion, 1990) y, a su vez, el cuestionario es la técnica de recogida de datos empleada mayoritariamente para elaborar dicha investigación (Colás, 1992b; Cohen y Manion, 1990; McKernan, 1999).

El cuestionario es un instrumento básico de investigación que pretende conocer lo que unos sujetos hacen, piensan u opinan respecto a un tema mediante la respuesta a una serie de preguntas sin la presencia del investigador (Buendía, 1992, p. 207).

En nuestro caso, utilizaremos el cuestionario postal (Cohen y Manion, 1990; McKernan, 1999), en el que se envía por correo un cuestionario de autocumplimentación, unas instrucciones y un sobre franqueado con la dirección impresa, con el propósito de que el receptor lo responda y devuelva debidamente cumplimentado. En algunos casos, debido a la proximidad con los encuestados, el cuestionario ha sido entregado en mano y recogido unos días después por el investigador. Esta forma de trabajo no se debe confundir con lo que McKernan (op. cit., p.146) denomina cuestionario con contacto personal, pues en este el investigador hace las preguntas directamente al encuestado y anota sus respuestas en su presencia. 
Este tipo de cuestionario presenta una serie de ventajas y de inconvenientes que han sido tenidos en cuenta ${ }^{159}$ y que resumimos en la Tabla 10 (extraídos de McKernan, 1999; Arias y Fernández, 1998; Padilla et alia, 1998).

VENTAJAS

○ Fácil de administrar, y de completar.

○ Proporciona respuestas directas.

○ Hacen falta pocos recursos y personal.

○ Libre disposición de tiempo para los encuestados.

- La información es cuantificable.

- Ahorra tiempo pues se pueden hacer muchos a la vez.

- Facilita la confidencialidad.

- Aporta información estandarizada.

\section{INCONVENIENTES}

- Difícil de elaborar una buena lista de preguntas: mucho tiempo de trabajo.

- Tasa de respuestas bajas.

- Difícil conseguir colaboración.

○ El análisis lleva tiempo.

- Poca sinceridad / honestidad en las respuestas.

- Se intenta producir la "respuesta correcta" o esperada.

- Una respuesta puede estar influenciada por un estado de ánimo o de humor.

Tabla 10. Resumen de las ventajas e inconvenientes de los cuestionarios por correo

Para prevenir la baja tasa de respuestas remitidas al investigador, se han tenido en cuenta una serie de factores que Arias y Fernández (op. cit., pp. 46-47) establecen como recomendaciones para evitar esta situación, como la presentación, claridad, orden, carta de presentación, etc. Caplow (op. cit., p. 58) asegura que un índice de negativas del $30 \%-40 \%$ en un cuestionario por correo es considerado como satisfactorio. Asimismo, Manheim y Rich (1988, p. 166) consideran aceptable un índice de respuestas

\footnotetext{
${ }^{159}$ Para García Ferrando (1996, pp. 158-159), el cuestionario es "el instrumento más utilizado para la obtención de datos en los estudios de sociología empírica. Pese a su rigidez..., presenta otras ventajas que superan claramente a sus inconvenientes."
} 
del 50\%, y muy bueno un índice del 70\%. De todas formas, ya hemos manifestado que varios han sido entregados y recogidos en mano, bien por la proximidad de los centros, bien por la relación de amistad / confianza con algunos de los encuestados.

\section{2.- RECONSTRUCCIÓN DEL PROCESO DE ELABORACIÓN DEL CUESTIONARIO}

\section{$\underline{\text { Objetivos }}$}

En torno al tema genérico de los alumnos con necesidades educativas especiales y, más específicamente, a los casos más extremos asociados a discapacidad física, con la utilización del cuestionario elaborado para la ocasión nos proponemos conseguir los siguientes objetivos (Tabla 11):

\footnotetext{
OBJETIVO $\bigcirc$ Conocer la visión y creencias del profesorado de Educación Física sobre PRINCIPAL este asunto.

- Comprobar si la exención es una práctica que se deba recuperar o, incluso, si ya aparece de una manera encubierta en nuestras clases.

- Conocer lo que, en opinión del profesorado, hacen estos alumnos en

OBJETIVOS SECUNDARIOS nuestras clases.

- Averiguar cuál suele ser, según los docentes, la respuesta de este alumnado.

- Dilucidar cuáles son los problemas o carencias que tiene el profesorado y, por extensión, el sistema educativo.

- Conocer cómo se gestionan o procede ante estos casos.
}

Tabla 11. Objetivos del cuestionario 


\section{Tipo de preguntas}

La totalidad de los ítems (65) están redactados en forma de preguntas o afirmaciones de tipo cerrado (Padilla et alia, 1998; Buendía, 1992; McKernan, 1999), en las que las opciones de la respuesta se reduce a un Sí (equivalente a verdadero) y a un NO (equivalente a falso). En su proceso de elaboración se ha utilizado un lenguaje significativo para el entrevistado, cuidando la sencillez y la claridad con la que están redactadas, de forma que sean fiables y válidas (Padilla et alia, op. cit., p. 126). El cuestionario completo se encuentra recogido, tal y como se envió a los centros, en el Anexo 12.

\section{Organización y administración}

Una vez conocido el número de profesores de Educación Física que hay en los centros educativos objeto de estudio, el siguiente paso fue organizar el cuestionario y su posterior envío a dichos centros.

Junto a cada cuestionario, se adjuntaba grapada una carta explicativa en la que, entre otras cosas, se especificaba que el tema de la investigación gira "en torno al tratamiento que proporcionamos en las clases de Educación Física a los alumnos con necesidades educativas especiales (en sus casos más extremos)", se aseguraba "la confidencialidad de los informantes", y se aclaraba que "el cuestionario no tiene ningún carácter oficial. Forma parte de un estudio más amplio que se realiza para la elaboración de una Tesis Doctoral”.

Para que los encuestados se sintiesen más implicados en su realización, primeramente se les pedía que contestasen a una serie de preguntas relacionadas con sus datos personales y labor docente tales como la edad, sexo, años de experiencia, nivel educativo en el que imparten clase, formación / titulación, y su situación laboral (funcionario o interino). 
A pesar de que el cuestionario era totalmente anónimo, se ofrecía la posibilidad de que indicasen su nombre y teléfono con el propósito de poder charlar sobre el tema en torno al cual giraban todas las preguntas.

Al término de la carta, se especificaba que si querían conocer los resultados del estudio debían de hacer constar la dirección de su centro el sobre en el que nos enviasen sus cuestionarios.

Con el objeto de aclarar la estructura de la encuesta (Cohen y Manion, op. cit., p. 148), se utilizaron páginas en colores. La carta informativa, que servía como una primera toma de contacto, estaba impresa en un folio de distinto color al del resto del cuestionario.

Por mi parte, en la carta de presentación en ningún momento indiqué quien realizaba el estudio. Sin embargo, junto con los cuestionarios remitidos a cada centro educativo dirigidos a la atención del Jefe del Departamento de Educación Física y Deportiva, incluíamos una carta de reducidas dimensiones en la que se pedía a este su colaboración para que repartiese los cuestionarios entre sus compañeros, y luego los recogiese y enviase por correo (vid.: Anexo 10). En dicha carta sí hacía constar mis datos y situación profesional, pues consideré que se sentirían más identificados y próximos al encuestador si este era un compañero del área de Educación Física en sus mismas circunstancias laborales.

Con los cuestionarios y la carta de presentación dirigida al Jefe del Departamento de Educación Física y Deportiva, se adjuntaba un sobre sellado y con la dirección de mi centro de trabajo para que remitiesen los cuestionarios una vez cumplimentados. El motivo de elegir mi centro como destino de los cuestionarios fue para garantizar el hecho comentado anteriormente de que yo también era profesor de un Instituto de Educación Secundaria. 
Una vez organizado el formato de los cuestionarios, lo siguiente fue su distribución entre la población que forma parte del estudio. Para ello, utilizamos dos vías: el correo postal y el contacto directo con los encuestados.

De la "Guía del estudiante 2002-2003. Oferta educativa de Valladolid" (Dirección Provincial de Educación de Valladolid) obtuve la dirección de todos los Institutos de Enseñanza Secundaria de carácter público de Valladolid y provincia.

En aquellos centros en los que teníamos trato personal con alguno de los profesores de Educación Física, la documentación se enviaba a la atención de la persona conocida en vez de dirigirse al Jefe del Departamento. La carta protocolaria en la que se pedía la colaboración de este último era reemplazaba por otra más personal y cercana, asegurándonos así un mayor nivel de compromiso en la entrega y posterior recogida de los cuestionarios.

Además de por correo, hubo cuestionarios que se entregaron en mano, bien por la amistad con alguno de los encuestados o, bien por la proximidad de los centros implicados al mío. El contacto personal aseguraba la colaboración de todos ellos, y aumentaba las probabilidades de respuesta. De hecho, todos los encuestados que recibieron así los formularios respondieron eficazmente a nuestras peticiones.

Transcurridos unos días desde el envío de los cuestionarios a los centros, remitimos un fax dirigido al Jefe del Departamento (vid.: Anexo 13, página 623) recordándole que la elaboración de los mismos por parte de sus compañeros de área suponía una cuestión de vital importancia para que la investigación siguiese su curso y, apelando a la actitud colaborativa que caracteriza a nuestro gremio, le rogamos que los cumplimentaran y remitiesen con la mayor brevedad posible. 


\section{$\underline{\text { Pasos en la confección }}$}

A partir de un borrador inicial de ochenta preguntas, los ítems sufrieron multitud de revisiones tras las cuales se redujeron hasta quedar en los sesenta y cinco definitivos de que consta el cuestionario que forma parte de la investigación.

Como proceso de ratificación de las mismas para aumentar la credibilidad y validez de los resultados obtenidos (Ander-Egg, 2000, p. 81), se utilizó la "triangulación”. Esta impide que aceptemos fácilmente como válidas nuestras primeras impresiones o investigaciones (Goetz y LeCompte, 1988, p. 36). En nuestro caso utilizamos la triangulación de datos de personas (Bisquerra, 1989, p. 265), es decir, utilizamos varios sujetos para confrontar y contrastar las opiniones que cada uno de ellos tenía al respecto del asunto o sobre nuestra manera de percibirlo. Al igual que ocurrió con las fichas de análisis de las programaciones didácticas, los sujetos que participaron en la "triangulación" fueron los de mi Grupo de Trabajo, mi tutor del trabajo de investigación, y yo.

En ese proceso de "triangulación" se iban cotejando las opiniones de los sujetos y/o grupo con el fin de redactar convenientemente las preguntas, colocarlas adecuadamente dentro del marco del propio cuestionario, suprimir aquellas que se considerasen repetitivas o fuera de lugar, etc.

Además, con el pretexto de comprobar la validez y seguridad de nuestro cuestionario (Ander-Egg, op. cit., p. 121), recurrimos a la administración de un "test preliminar" o prueba piloto del mismo entre una población formada por siete profesores de Educación Física en Educación Secundaria. Las características de estos docentes eran similares a las que poseen los que posteriormente formarían parte de la muestra del estudio definitivo (titulación inicial / formación, gama variada de edades y experiencia, nivel educativo en el que dan clase, etc.), pero por el carácter concertado del centro en el que impartían docencia, o por estar destinados en otras provincias, no podían pertenecer a ella. 
"Por mucho cuidado que se haya puesto en el empleo de palabras adecuadas en la formulación de preguntas, en el desarrollo de la secuencia apropiada de las preguntas, y en el diseño del cuestionario, el investigador debe, siempre que ello sea posible, probar el cuestionario antes de proceder a realizar las entrevistas con el conjunto de personas que integran la muestra." (García Ferrando, 1996, pp. 169-170)

Esta prueba previa nos sirvió para revisar alguna pregunta que no estaba claramente redactada, y para añadir alguna información en la carta de presentación inicial.

\section{$\underline{\text { Tratamiento estadístico }}$}

Las tareas propias de la estadística descriptiva son la recogida de datos, su ordenación, su presentación clara y sinóptica (en forma, por ejemplo, de gráficas), así como la elaboración de ciertos cálculos estadísticos.

Nosotros hemos elaborado una tabla de frecuencias absolutas (Anexo 14) para recoger y ordenar los datos. En esta tabla recogemos la totalidad de respuestas emitidas (SÍ / NO) a cada uno de los ítems de que consta el cuestionario. Además, ha sido preciso añadir una columna para las preguntas no contestadas, y otra para aquellas en las que los encuestados nos hacían saber su desconocimiento.

La presentación de los resultados mediante una tabla de distribución de frecuencias es ya una forma de tratamiento estadístico (Ander-Egg, 2000, p. 128). Nosotros nos decantamos mayoritariamente por las representaciones mediante diagramas de distribución de barras. Obviamente, estas representaciones gráficas facilitan la lectura de los datos, sobre todo cuando se trata de hacer comparaciones (Sanchís et alia, 1993, p. 23). La totalidad de las gráficas resultantes, a excepción de aquellas que emplearemos a lo largo de este capítulo, se encuentran recogidas en el Anexo 15. 
En la interpretación de los datos haremos alusión al número total de individuos que han respondido SÍ o NO a cada una de las preguntas /afirmaciones del cuestionario o, lo que es lo mismo, la frecuencia absoluta $(\boldsymbol{F i})$. Además, expresaremos los resultados obtenidos en cada una de ellas en forma de porcentajes, previa división de la frecuencia absoluta entre el tamaño de la muestra utilizada (la frecuencia relativa ó fi).

Por último, en la exposición de algunos datos relacionados con la edad utilizaremos el concepto de media aritmética $(\boldsymbol{M})$, que representa el resultado de la suma de todos los valores de una clase divididos entre el valor de la muestra.

\section{Muestra}

Aunque no hay un número concreto establecido sobre el tamaño más adecuado que debe tener una muestra, sí es conveniente que dicho número no sea menor de 30 casos (Cohen y Manion, op. cit., p. 140).

En este estudio, la población sobre la que se centra la aplicación del cuestionario son los ochenta y ocho profesores de Educación Física, entre profesores de Secundaria propiamente dichos y Maestros Especialistas, o no, que imparten clase en los treinta y dos Institutos de Enseñanza Secundaria que existen en Valladolid y provincia.

En este marco, la muestra obtenida en esta investigación está conformada por los 46 profesores que nos han remitido el cuestionario debidamente cumplimentado, lo que equivale a un índice de respuesta del 52’27\%, pertenecientes a 19 centros (Gráficas $\mathbf{n}^{\mathbf{0}} \mathbf{2}$ y $\mathbf{n}^{\mathbf{0}} \mathbf{3}$, respectivamente). Creemos que la muestra conseguida es representativa, tanto por el tamaño como por la composición (Sanchís et alia, 1993, p. 14). 

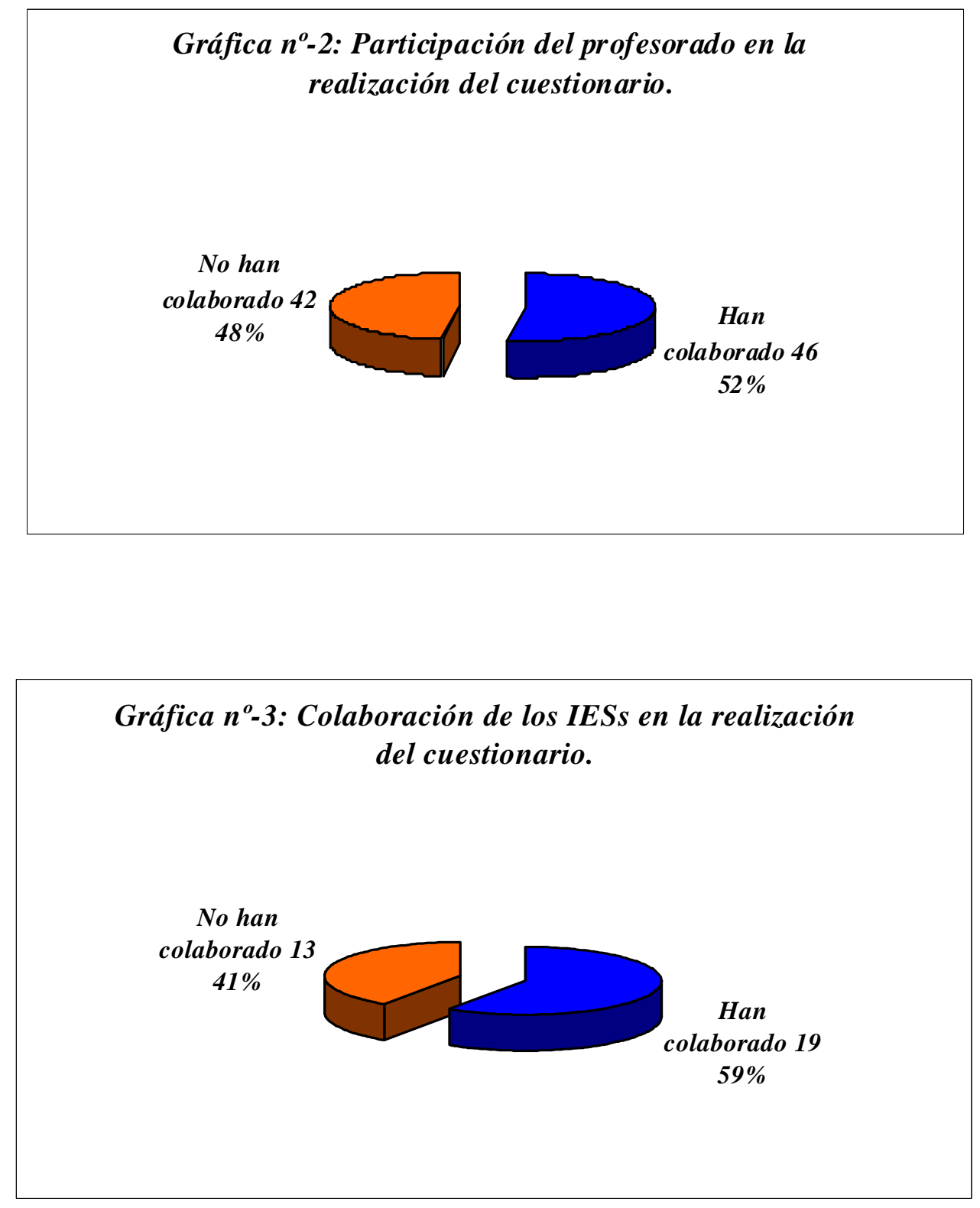

Acerca de los datos personales de los 46 encuestados, 21 son mujeres (45'65\%) y 25 son hombres (54’35\%). La media de edad de todo el profesorado se sitúa en torno a los 42 años, pero mientras que en las mujeres es de 47 años (la más veterana tiene 57 y la más joven 26), en los hombres es de 40 años (el mayor tiene 52 y el menor 27). A pesar de que hay una gran diferencia entre hombres y mujeres, es un colectivo relativamente joven. 
El 80`4\% de ellos (36) son funcionarios, y el resto tienen la plaza en régimen de interinidad.

En lo que respecta a la experiencia docente, la media de años es de 16'2. Las mujeres tienen una experiencia media de $17^{\prime} 4$ y los hombres de $14^{\prime} 4$. Este dato viene a “justificar” la mayor edad de las mujeres.

En cuanto al ciclo y/o etapa en la imparten clase, de los 46 profesores encuestados 7 solo lo hacen en el primer ciclo de Secundaria, 16 en el segundo ciclo, 8 en ambos ciclos, 2 se dedican exclusivamente a $1^{\circ}$ de Bachillerato y 13 en ambos ciclos de Secundaria y en $1^{\circ}$ de Bachillerato.

Por lo que se refiere a los estudios de los profesores, 27 son Licenciados en Educación Física, 2 en Medicina y Cirugía, 4 en Geografía e Historia, 1 es Maestro especialista en Educación Física, y 12 dicen ser licenciados pero no especifican la especialidad. Por lo tanto, un 60'8\% de la muestra de profesores que imparten clase de Educación Física en los centros públicos de secundaria de Valladolid y provincia tienen una formación específica.

\section{Centros de interés}

Para Ander-Egg (1995, p. 333), del establecimiento de unas categorías de análisis dependerá en gran medida la selección y clasificación de la información que se busca. Por tanto, cada una de las preguntas que configuran el cuestionario han sido encuadradas en unos determinados centros de interés o temas ejes.

Estos centros o temas ejes en torno a los cuales fijamos nuestra atención nos permitirán, entre otra serie de cosas, obtener información precisa sobre aquello que hemos considerado más relevante y necesario para la investigación, asegurando a su vez la validez del cuestionario. 
Sobre la información que es analizada en cada uno de ellos realizamos la correspondiente interpretación y, además, con el propósito de facilitar la comparación de los datos obtenidos (Abder-Egg, op. cit., p. 366), representamos gráficamente los mismos mediante diagramas de superficies de barras, los cuales, a su vez, pueden verse complementados con diagramas circulares de sectores para la representación porcentual de las respuestas emitidas.

En definitiva, los centros de interés o categorías de análisis con los que abordaremos el estudio del cuestionario son:

a) Creencias del profesorado sobre el tema.

b) Niveles de concreción del currículo: cómo se contemplan estos supuestos.

c) Cómo se gestionan estos casos.

d) Lo que se pide o espera de estos alumnos.

e) Respuestas de los alumnos implicados.

f) Cómo se manifiesta el resto de alumnos.

g) Implicación o papel desempeñado por los familiares.

h) Formación y conocimiento sobre el tema.

i) Valoración del trabajo y de los medios docentes.

\section{Cuestiones anecdóticas procedimentales}

Durante el proceso de realización del cuestionario el único hecho que puede catalogarse como anecdótico, por no decir inesperado e increíble, tuvo lugar cuando me propuse averiguar el número exacto de profesores de Educación Física que dan clase en los Institutos de Enseñanza Secundaria públicos de Valladolid y provincia.

Ya conocía los que existían en alguno de los centros que en su momento me remitieron las programaciones didácticas, pues en ellas se especificaba el número de profesores o el nombre de los miembros que integraban el del departamento. 
Sin embargo, dado que en algunas de ellas no aparecía este detalle y que no disponía de todas, tuve que idear un método para hacerme con este dato de vital necesidad para el estudio.

Opté por dirigir un escrito vía fax a la Dirección Provincial de Educación y Cultura de Valladolid. Para agilizar todo el "papeleo" y ganar tiempo, pedí se me respondiese por fax.

La petición no tardó más de cuatro días en ser respondida. La información que en ella se me facilitaba estaba presentada en forma de tabla, en la que junto a cada centro de Educación Secundaria se especificaba el número de profesores de Educación Física.

Pero cuando revisé detenidamente su contenido, me percaté de que había algunos datos que no se ajustaban a la realidad, ya que el número de profesores que la Dirección Provincial me había facilitado no concordaba con los que yo tenía por los medios anteriormente señalados.

El caso más ejemplificador lo podemos encontrar en mi propio centro de trabajo: desde la Administración se apunta que hay tan solo dos profesores, cuando en realidad somos tres.

Este suceso suscitó la necesidad de cotejar las cifras recibidas. Para ello, realicé llamadas telefónicas requiriendo ese dato a cada uno de los treinta y dos centros de enseñanza que hay en el contexto en el que se desarrolla el estudio, previa explicación de para qué necesitaba esa información.

Mientras que la Administración me facilitó, para ese número de centros, un total de ochenta y uno profesores, yo conseguí, a través de las llamadas de teléfono, ochenta y ocho. 
A la vista de la no-concordancia en la información obtenida de las dos fuentes, volví a ponerme en contacto con la Dirección Provincial, a través de su Sección de Gestión de Personal, para que me aclarasen lo que ellos me habían facilitado (es obvio que yo daba más crédito a la información que había recibido vía telefónica de cada uno de los centros).

Les comenté lo de mi centro en particular, así como lo de otros que sabía que se encontraban en la misma situación. No supieron explicar por qué se daba esta situación, pero sí me aseguraron que los datos que me habían facilitado eran los únicos que ellos poseían.

Fue entonces cuando les sugerí que si era posible que no hubiesen contabilizado a los maestros que dan clase en este tipo de centros y, ¡eureka!, "Sí, puede que sea eso", me contestaron. Entonces, les pedí el número de maestros en esa situación, pero ellos no me pudieron contestar pues ese dato correspondía a Primaria y no a Secundaria ( $₫$ ?).

Antes de dar por terminada la conversación, rogué me aclarasen qué es lo que ocurría en un IES en el que según ellos había seis profesores, y según el propio centro solo hay cinco, a lo que me contestaron que "puede que haya algún error en los datos". Definitivamente, este comentario dio más credibilidad a la información llegada desde los centros.

Llamé a la Sección de Primaria y allí no me supieron decirme este dato, y lo único que hicieron fue poner pegas y trabas administrativas.

Por todo ello, acepté ochenta y ocho como el número real de profesores de Educación Física que hay en los Institutos de Educación Secundaria, de carácter público, de Valladolid y su provincia (independientemente de si son Licenciados o Maestros). 


\section{3.- INTERPRETACIÓN DE LOS DATOS}

Antes de comenzar a reflejar cuáles han sido los datos obtenidos con el cuestionario utilizado, hemos de aclarar que algunos de los profesores encuestados, sin nosotros pedírselo, han añadido coletillas a algunas de las preguntas realizadas (recordamos que todas ellas eran de tipo cerrado). Por ello, consideramos de utilidad reflejar estas notas cuando así lo requiera la situación.

\section{a) Creencias del profesorado sobre el tema}

Lo primero que queremos poner de manifiesto es que el profesorado tiene una visión del área muy parecida a la de la retórica oficial, pues un 63\% (Fi=29) considera que la Educación Física es eminentemente procedimental, tal y como se pregona desde la Administración (MEC, 1992, pp. 32 y 81) ${ }^{160}$. De hecho, un encuestado nos apostilla al lado de esta pregunta: "Esa es la visión oficial". Sin embargo, es curioso comprobar que casi un $37 \%$ de los docentes $(\mathrm{Fi}=17)$ considera que un alumno sí puede conseguir los objetivos de etapa o ciclo de nuestra área con sólo trabajar contenidos actitudinales y conceptuales (de hecho, en las programaciones didácticas éstos figuraban como el referente principal para la evaluación de los alumnos con necesidades educativas especiales).

\footnotetext{
${ }^{160} \mathrm{Al}$ afirmar que nuestra área es "eminentemente procedimental" se está queriendo decir "procedimental motriz". A este respecto, es asombroso el predominio de esta visión sesgada y restringida de la idea de "procedimiento".
} 


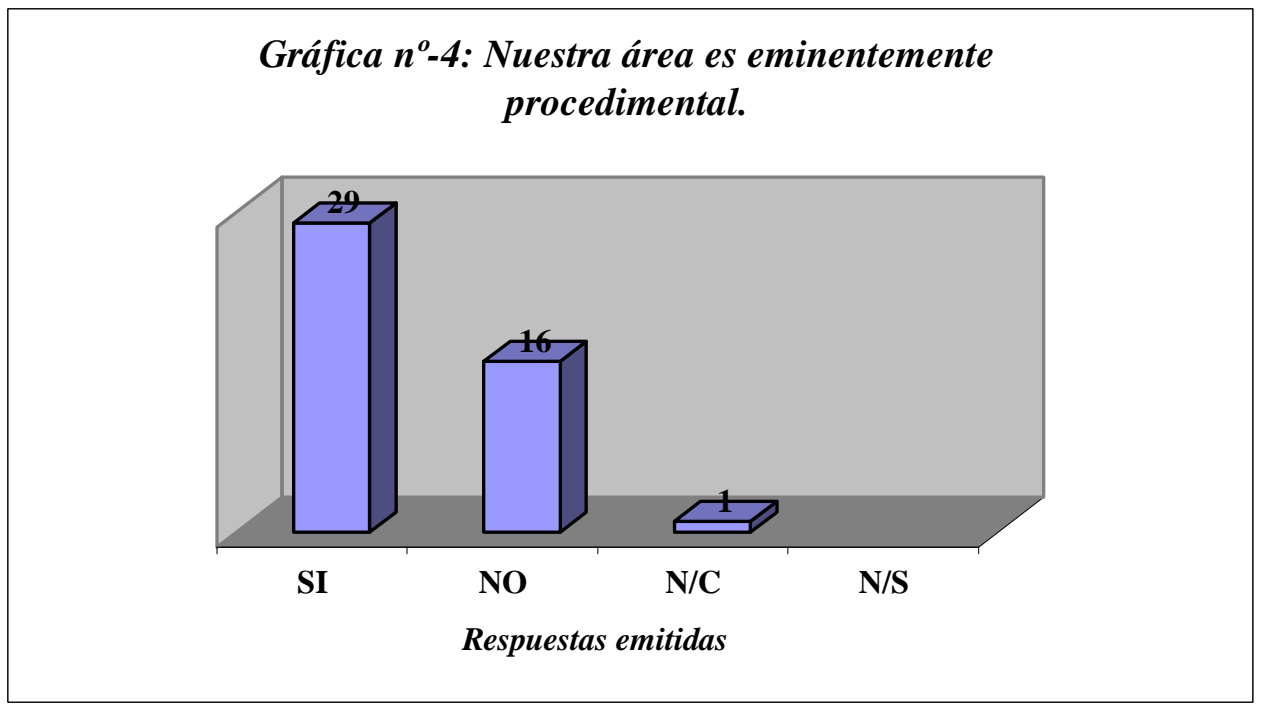

Un 30\% de profesores de Educación Física $(\mathrm{Fi}=14)$ dan clase a alumnos que se encuadran dentro de esta tipología. La casi totalidad de los encuestados, el $91 \%$ $(\mathrm{Fi}=42)$, piensa que debe ser obligada la asistencia a clase de estos alumnos y, además, un $89 \%(\mathrm{Fi}=41)$ considera que sí deben tomar parte activa (de la forma que sea) en las sesiones. Para un $82 \%$, sí pueden por ello alcanzar una nota final de sobresaliente $(\mathrm{Fi}=38)$.

Además, esta temática es considerada por un $47^{\prime} 8 \%$ de los docentes encuestados $(\mathrm{Fi}=22)$ como uno de los campos de batalla de nuestro campo disciplinar. De hecho, casi el $74 \%(\mathrm{Fi}=34)$ cree que la información que aborda este asunto es escasa, al igual que la legislación que lo regula. 


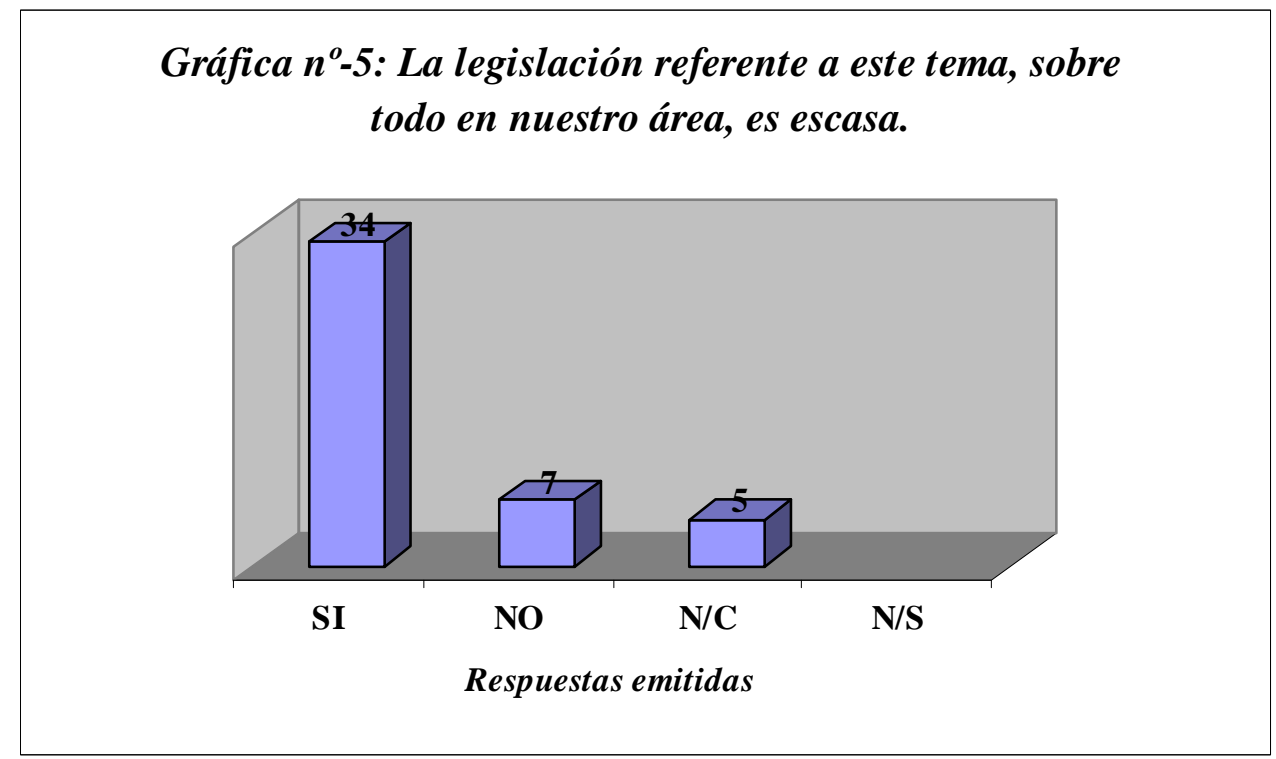

A pesar de que los encuestados en un 74\% ( $\mathrm{Fi}=34)$ afirman que los profesores de apoyo son imprescindibles dentro de nuestras clases para atender mejor a estos alumnos (incluso un profesor nos añade: "Depende del número de alumnos y de la dificultad o discapacidades que tengan”), esto no es óbice para que un 60'8\% ( $\mathrm{Fi}=28$ ) crea posible y realizable la adaptación curricular significativa que se lleve a cabo con ellos (aunque alguno opine que "es una tarea difícil y de mucho trabajo"). Aun así, el 89\% ( $\mathrm{Fi}=41)$ cree que sí se podrían poner en práctica más actividades de las que se hacen para favorecer su participación.

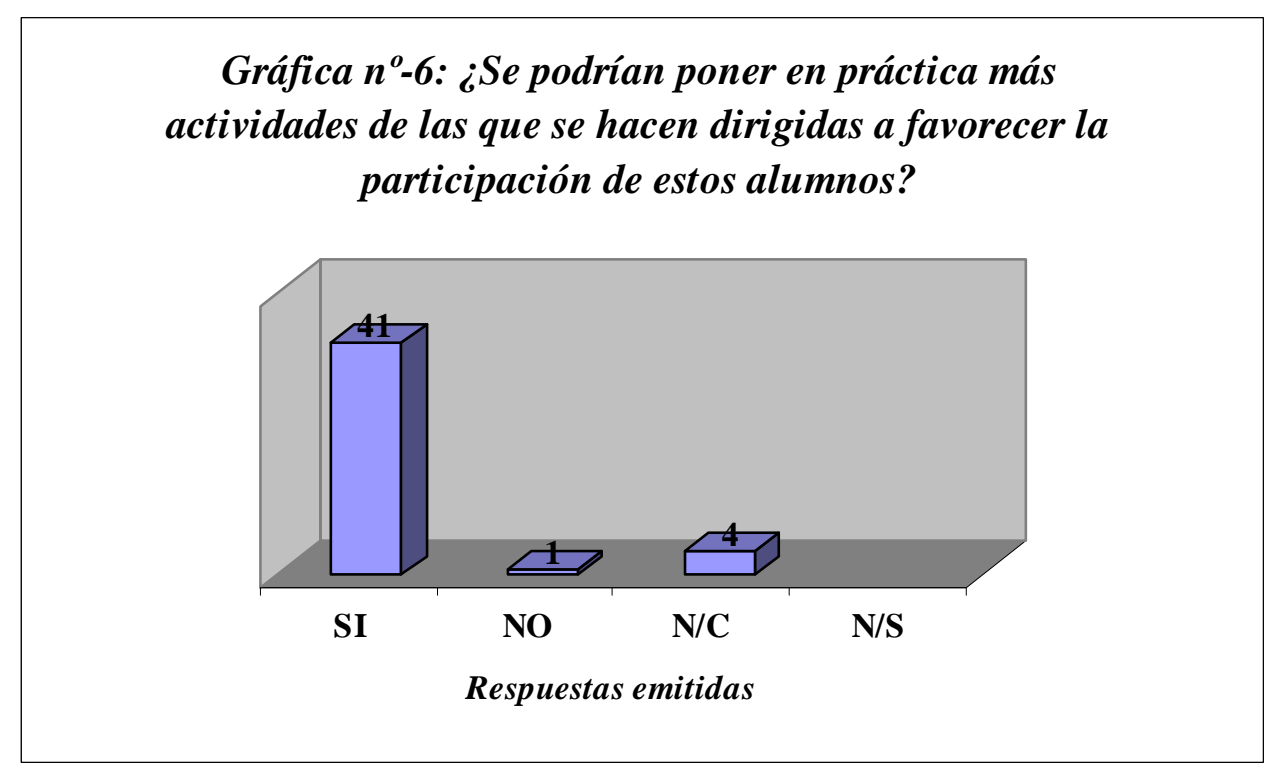


Por lo que respecta a la posibilidad de que se recupere la figura del "exento", el $71^{\prime} 7 \%(\mathrm{Fi}=33)$ considera que no está justificado de ninguna de las maneras, pero es significativo que para un 30'5\% ( $\mathrm{Fi}=14)$ debería haber alumnos exentos si su grado de minusvalía o discapacidad es elevado. Tanto es así, que el 40’74\% del profesorado que dice haber dado clase a alumnos de este tipo $(\mathrm{Fi}=11)$ manifiesta su acuerdo con la recuperación de la figura del exento.

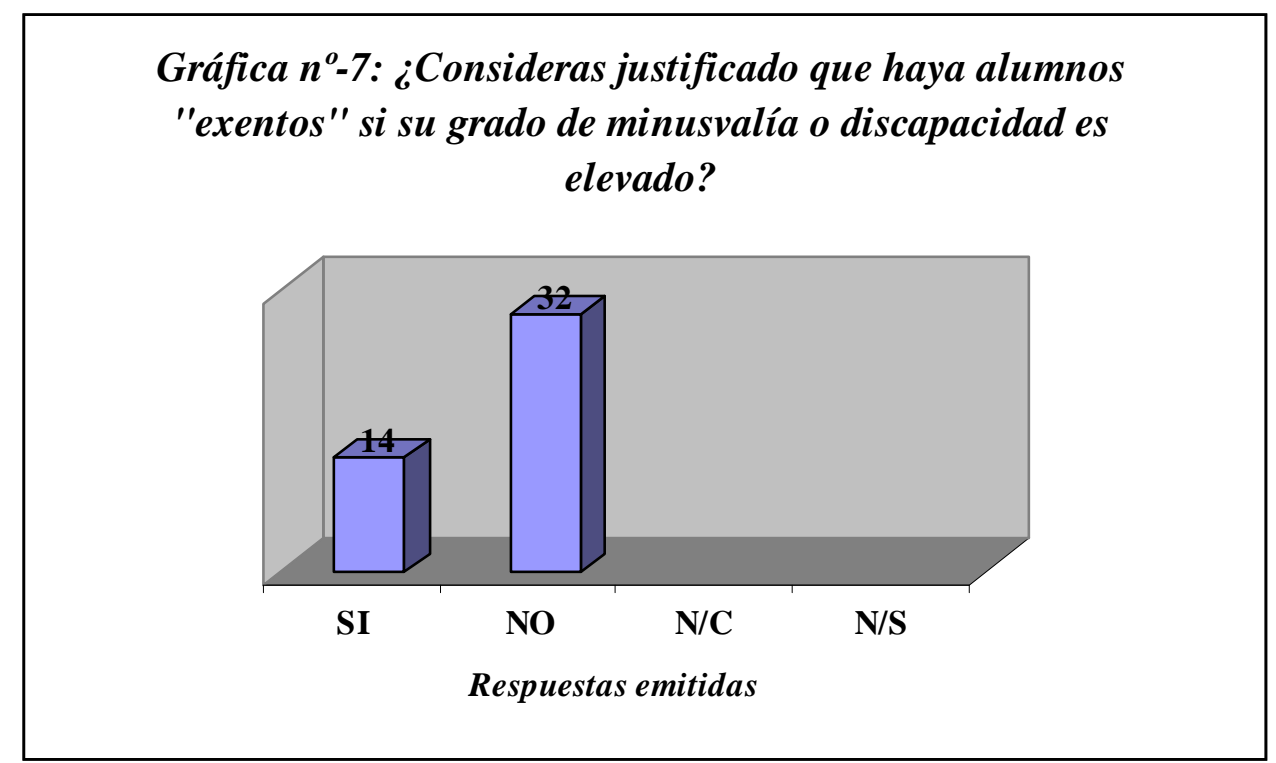

Asimismo, no se considera oportuno que sean los mismos alumnos los que puedan elegir si quieren o no estar exentos de la Educación Física (86'9\%, Fi=40). Es más, un $80 ` 4 \%(F i=37)$ ni tan siquiera cree conveniente que la Educación Física se deba ofrecer como un área optativa para estos alumnos, para que sean ellos mismos los que decidan si la quieren o no tener dentro de sus currículos.

\section{b) Niveles de concreción del currículo: cómo se contemplan estos}

\section{supuestos}

Un 54\% del profesorado $(\mathrm{Fi}=25)$ afirma que el PEC de su centro no recoge algo relacionado con esta temática. Esto puede deberse a dos motivos: que verdaderamente no se trate para nada el tema en este documento de especial relevancia educativa, o que 
hayan preferido elegir esta opción de respuesta por desconocimiento de dicho texto. De hecho, el $21{ }^{\prime} 7 \%$ de ellos $(\mathrm{Fi}=10)$ no contesta a esta pregunta, lo que unido a comentarios del tipo "creo que sí, pero no me acuerdo" o "no lo sé", confirman esta última alternativa.

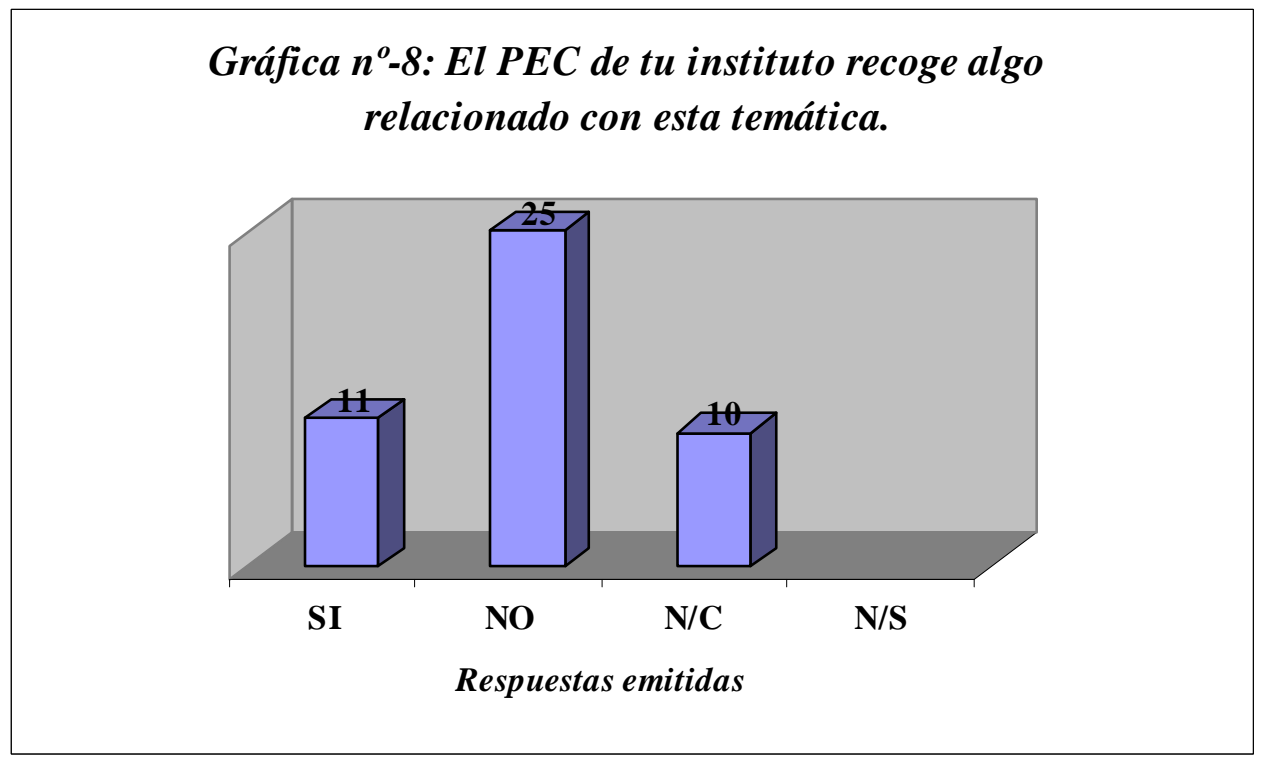

Los mediadores culturales (libros de texto) son poco utilizados en el área, ya que solo un $15{ }^{\prime} \%$ de la muestra los emplea como material didáctico $(\mathrm{Fi}=7)$.

El 82'6\% (Fi=38) afirma que estos alumnos tienen criterios de calificación diferentes a los de los demás, lo cual choca con los datos obtenidos en el anterior análisis de las programaciones didácticas, en donde se evidenció que solo en dos centros aparece recogido este aspecto.

El Documento Individual de Adaptación Curricular (DIAC) o, lo que es lo mismo, el documento en el que se refleja por escrito la adaptación curricular que se le aplica al alumno y que ha de formar parte de su expediente académico, tan solo es elaborado por un 39\% de los profesores de Educación Física $(\mathrm{Fi}=18)$. 


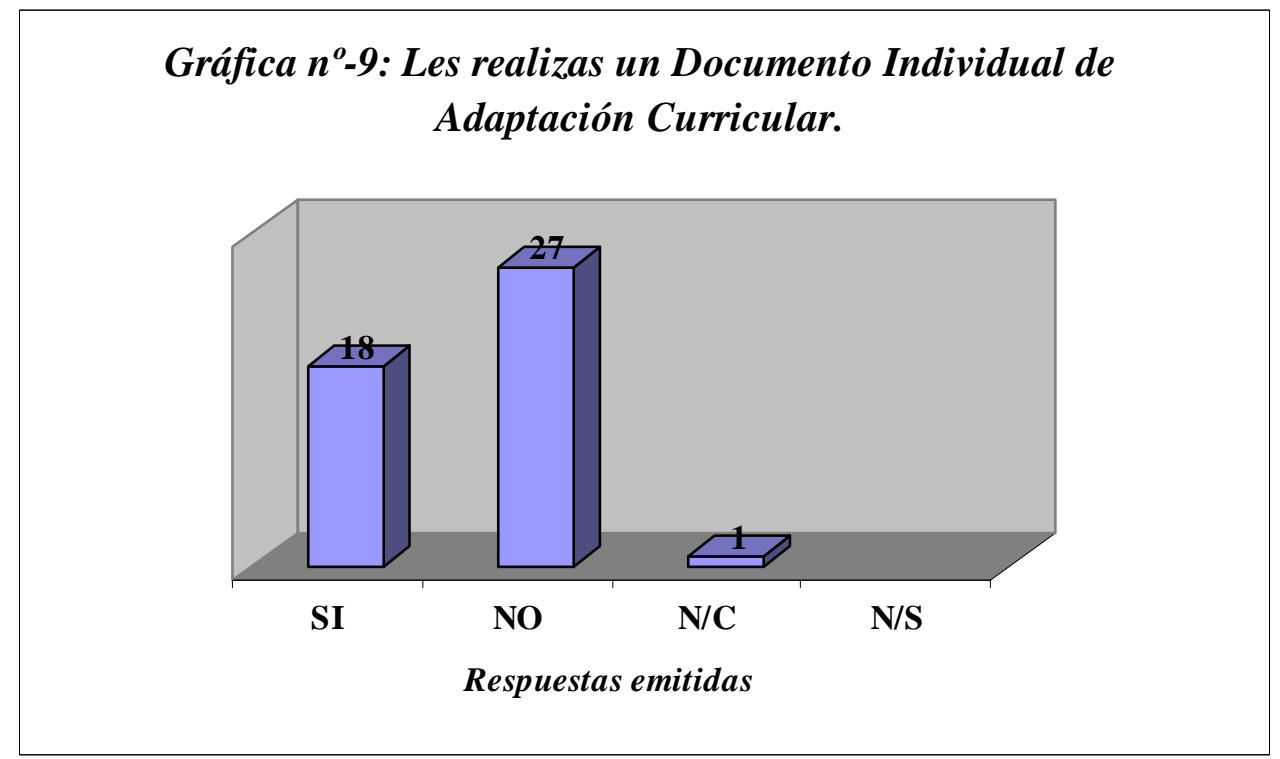

Como volveremos a ver en el apartado d) de este capítulo, un 89\% ( $\mathrm{Fi}=41$ ) propone a estos alumnos diferentes trabajos teórico/prácticos para que los realicen, mientras que solo el 60'8\% ( $\mathrm{Fi}=28)$ utiliza el cuaderno de clase como instrumento de trabajo en el área.

A pesar de que un $50 \%(\mathrm{Fi}=23)$ niega que este tipo de alumno aparezca en la programación como "exento" o como "exento de la práctica", un 39\% ( $\mathrm{Fi}=18$ ) reconoce que esta afirmación es correcta, lo cual deja entrever que esta figura, por otra parte ilegal, aún perdura en la actualidad. Sintomático resulta que casi el $11 \%(\mathrm{Fi}=5)$ no conteste a la pregunta, dando a entender que desconoce ese dato, lo cual demuestra cómo y con qué frecuencia trabajan con la programación. 


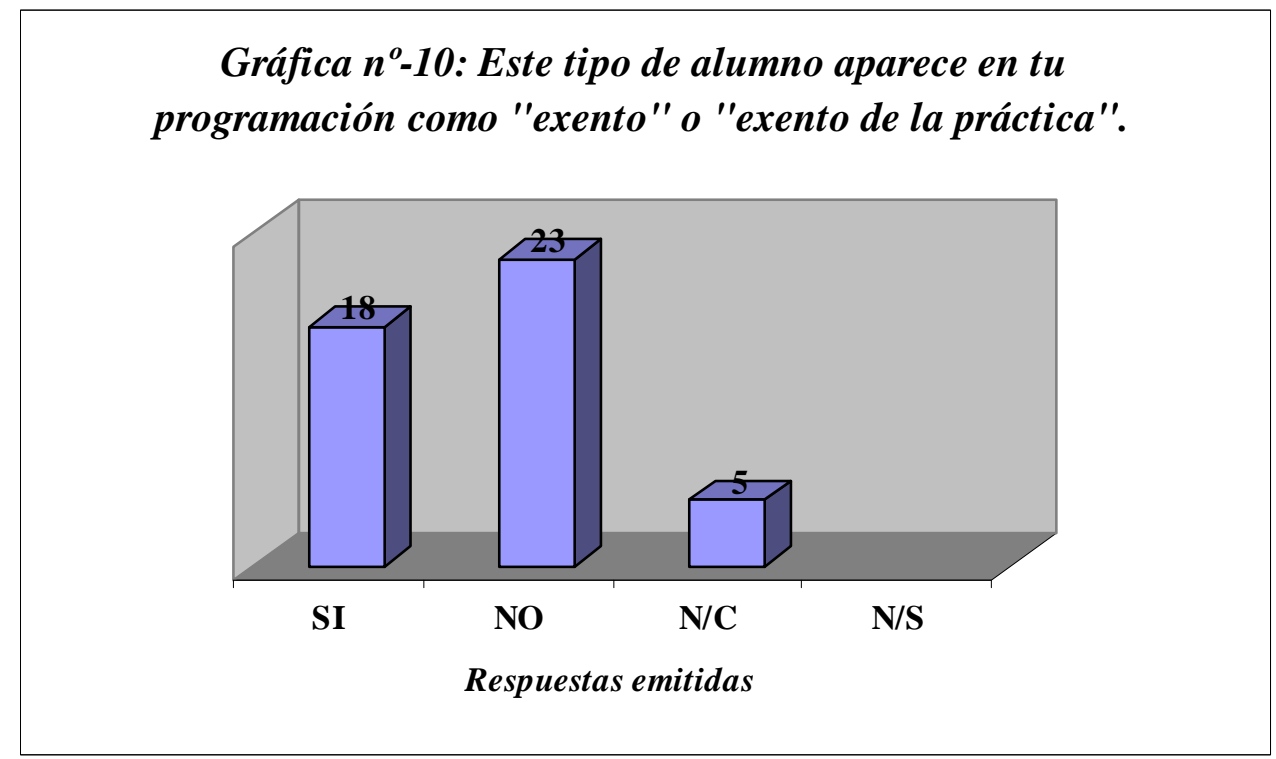

Siguiendo con esta idea de "concepto ilegal”, un 32'6\% (Fi=15) afirma que en su Programación Didáctica se hace alusión al concepto "exento" para aclarar su noexistencia legal. Lo llamativo en este caso es que el $67^{\prime} 4 \%$ restante $(\mathrm{Fi}=31)$ no haga esa mención, ya sea porque no utiliza el término exento o porque lo emplea como si verdaderamente existiera esa posibilidad.

Por último, señalamos que al comparar las respuestas emitidas por los profesores de un mismo centro ante preguntas que no debieran de crear ningún tipo de discrepancia por referirse a aspectos concretos que figuran (deben hacerlo) en las programaciones didácticas, observamos que no hay igualdad en esas respuestas. Mientras algunos profesores de un centro en particular usan el cuaderno de clase con sus alumnos, otros no lo hacen así. También hay disparidad al contestar si en la programación que emplean se hace referencia al alumno "exento" para aclarar su no-existencia legal. Ambas situaciones se producen en tres centros de los analizados. Pero resulta más llamativo que la no concordancia con respecto a si recogen o no el concepto "exento" o "exento de la práctica" en su programación, se produzca en siete institutos.

No sabemos si estos hechos denotan un desconocimiento de las programaciones didácticas y/o un hábito de trabajo independiente al margen del que se dictamina en el 
seno del departamento. Es por tanto el momento de analizar qué datos obtenemos sobre la programación de aula elaborada por cada profesor en particular.

El diseño y la adopción de una medida tan especial como es una adaptación curricular significativa debiera suponer, entre otras cosas, tener en cuenta las opiniones de aquellos a quienes va dirigida, circunstancia que es practicada por el $54 \%$ de los encuestados $(\mathrm{Fi}=25)$.

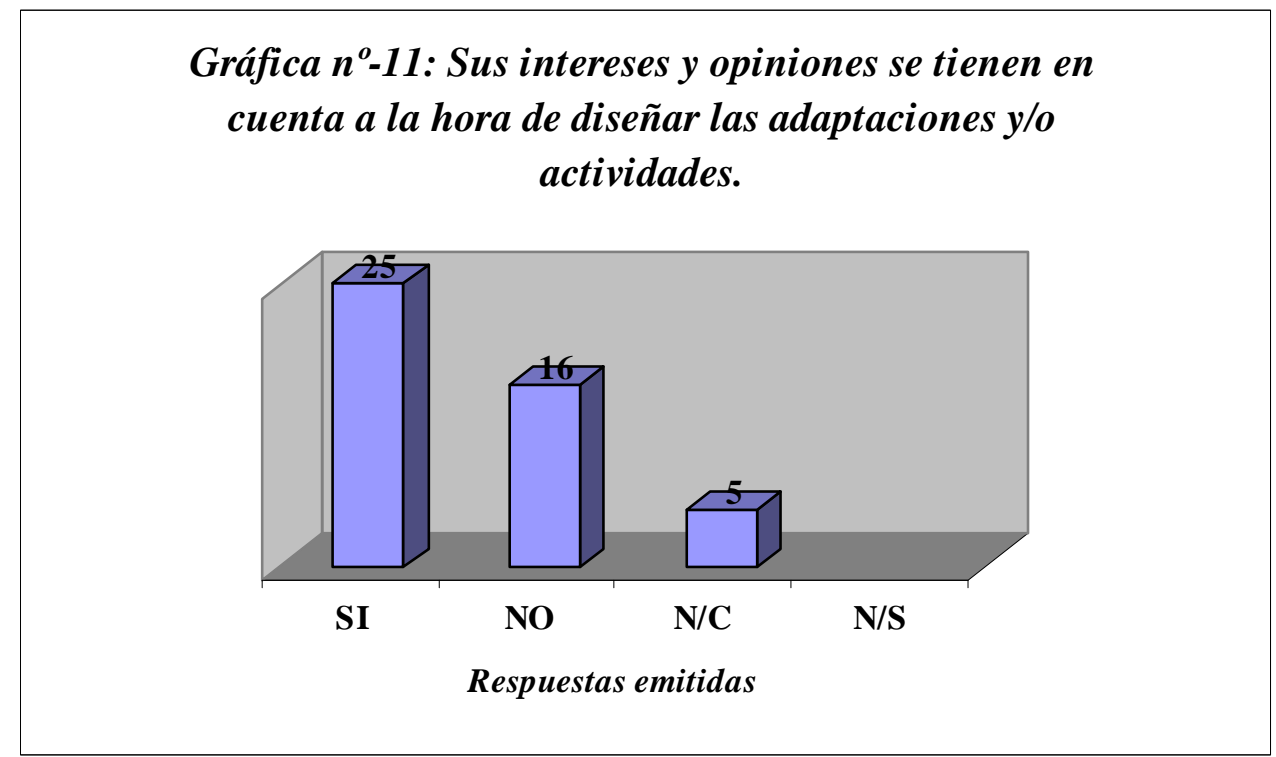

No obstante, esta circunstancia no quiere decir que no se produzcan entrevistas con estos alumnos para conocer sus intereses. En efecto, casi tres de cada cuatro docentes $(71 ' 7 \%, F i=33)$ asegura realizar este tipo de encuentros. Suponemos que estarán encaminadas a las tareas que citamos al principio de este párrafo.

Distinta es la postura, como se verá en el apartado g), que los docentes muestran con relación al mantenimiento de entrevistas con los tutores o padres de estos alumnos, ya que un $63 \%(\mathrm{Fi}=29)$ reconoce que no suele hacerlo.

En un $32 \% 6 \%$ de los casos entrevistados $(\mathrm{Fi}=15)$, las actividades del grupo se adaptan a las características de los alumnos con necesidades educativas especiales. 
Esto podría estar en la línea de los juegos motrices sensibilizadores y/o las prácticas con cambios de rol que mencionamos en capítulos anteriores.

A pesar de que un $15^{\prime} 2 \%$ de los docentes $(\mathrm{Fi}=7)$ asegura utilizar el libro de texto (así estará recogido en la programación didáctica de su departamento), se da el caso que en un mismo centro unos profesores sí los emplean y otros no lo hacen, lo que nos sitúa de nuevo ante una carencia de planificación y de trabajo en común, y más aún cuando todos los profesores implicados dan clase a los mismos ciclos y cursos como hemos observado en dos centros.

De los 12 profesores (26\%) que dicen utilizar a este tipo de alumno como un observador de su práctica docente, tan solo 6 de ellos les prepara para dicha observación. Nos preguntamos qué sentido tiene emplear a nuestros alumnos en una tarea tan ardua, complicada y llena de matices si no les hemos formado mínimamente para ello. ¿Acaso deben de aprenderlo por su propia iniciativa?

Cuando preguntamos si solemos permitir que estos alumnos no participen en una tarea por lo mal que lo puedan pasar, el 52\% de las respuestas emitidas son afirmativas $(\mathrm{Fi}=24)$, mientras que siete profesores $(15 \% 2 \%)$ prefieren no contestar a la pregunta. Es decir, para un porcentaje elevado de encuestados la aplicación de una exención, aun siendo parcial, tiene sitio en sus clases de Educación Física. 


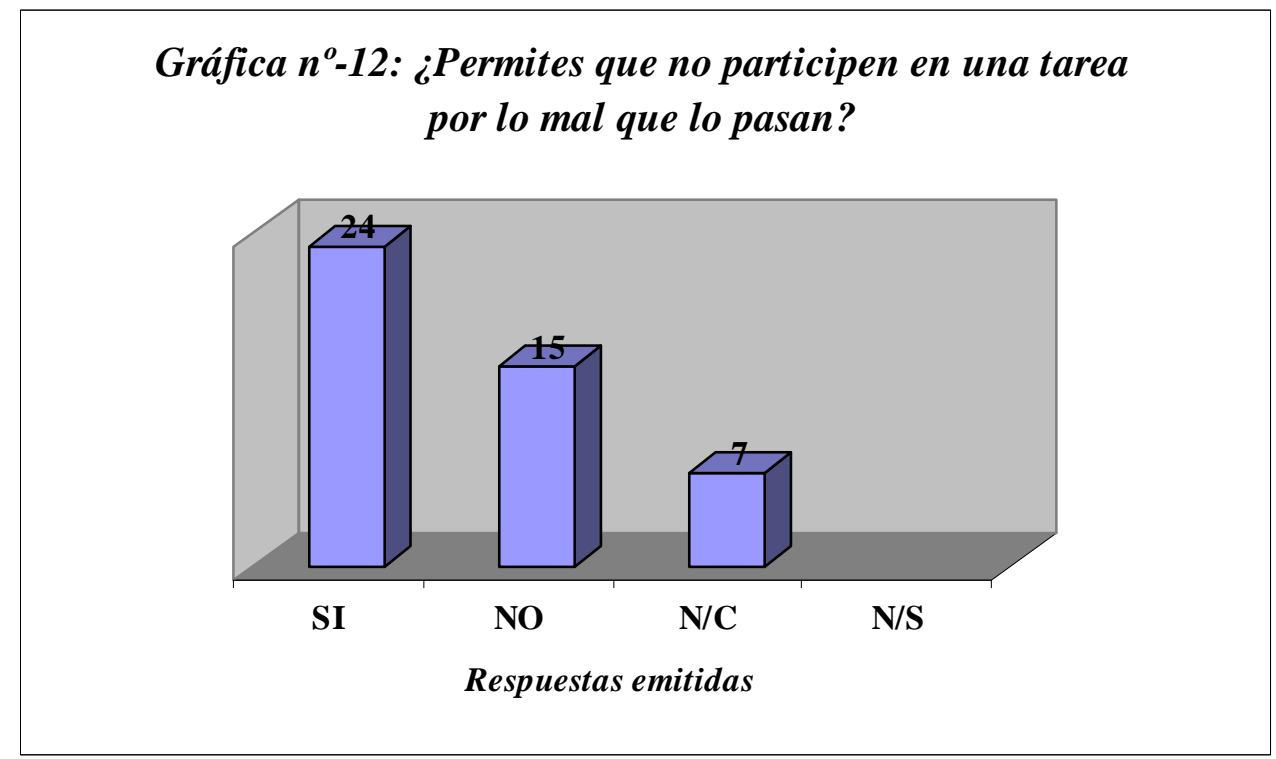

Otra cosa bien distinta es si pueden no asistir a clase debido a los problemas anímicos o de desplazamiento que presentan. A pesar de que un 65 '2\% ( $\mathrm{Fi}=30)$ es rotundo en su respuesta (deben asistir a clase de Educación Física) hay un porcentaje nada despreciable del $26 \%$ ( $\mathrm{Fi}=12$, uno de cada cuatro profesores) que permite que no vayan a sus clases por dichos motivos. Otra vez la exención aparece ante nosotros, y esta vez es más absoluta o contundente en términos de presencia física.

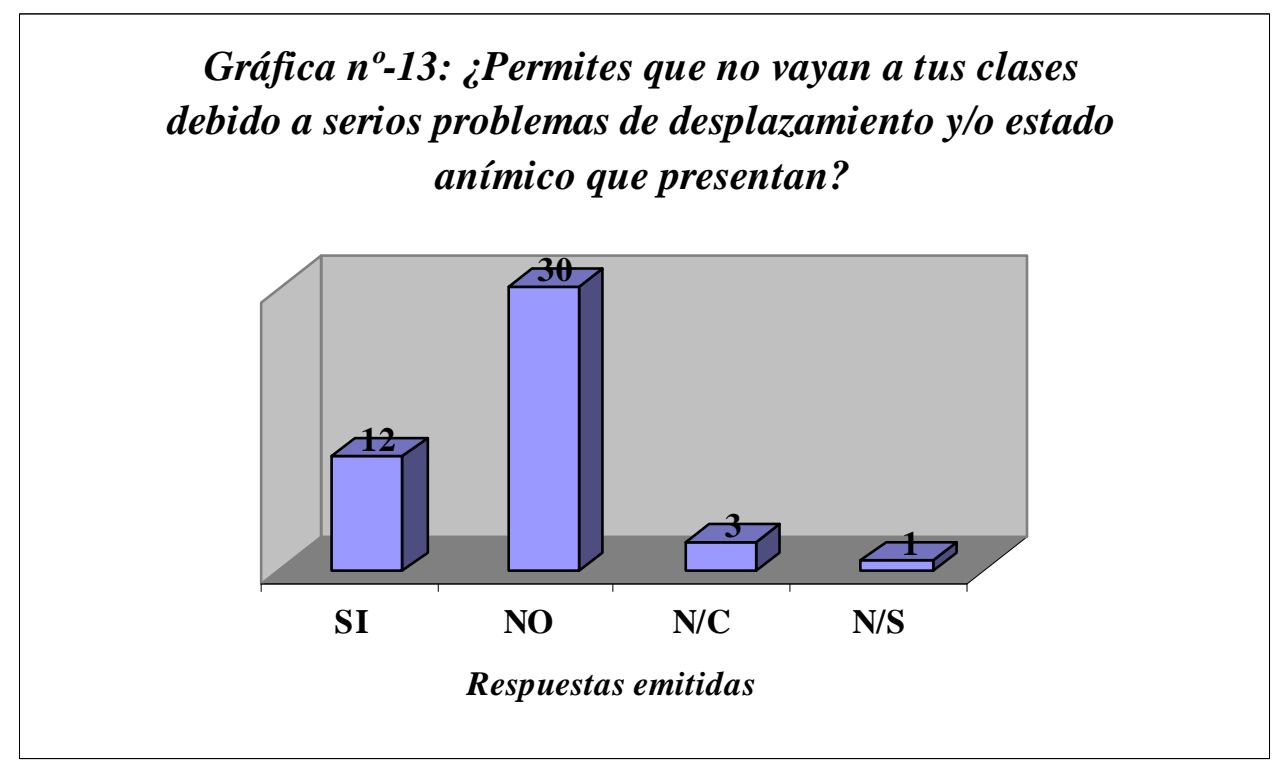




\section{c) Cómo se gestionan estos casos}

Ya hemos comentado en muchas ocasiones el papel desempeñado por los médicos para la aplicación de una medida especial. Los datos que al respecto obtenemos son desconcertantes pues aunque el 56'5\% $(\mathrm{Fi}=26)$ asegura que para aplicar cualquier tipo de medida especial se pide certificado médico oficial, un 43’4\% ( $\mathrm{Fi}=20)$ niega hacerlo así; pero también son contradictorios ya que ahora un $82^{\prime} 6 \%$ de los profesores $(\mathrm{Fi}=38)$ asegura que el Departamento es quien pide ese certificado médico, cuando a la vista de los datos anteriores este porcentaje debería ser menor.

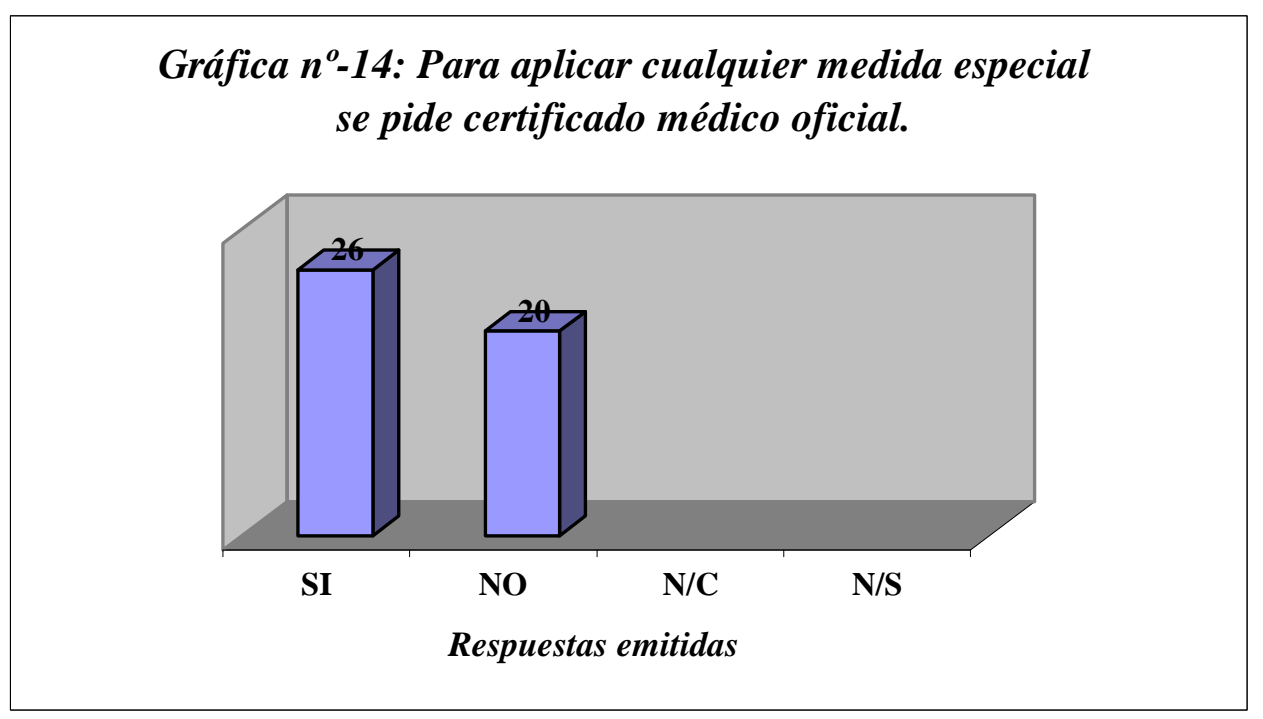

Sobre lo que no hay duda alguna es que sea la Dirección del centro quien pida los certificados médicos, pues un 86'9\% niega esta afirmación ( $\mathrm{Fi}=40)$.

Del DIAC, ya comentado en el anterior centro de interés, poco más se puede añadir. Lo que sí notamos es que un $45^{\prime} 65 \%$ de profesores $(\mathrm{Fi}=21)$ afirma reflejar por escrito la adaptación curricular realizada, y otro porcentaje algo mayor lo niega. Creemos que la falta de concreción en el papel de las adaptaciones y medidas que aplicamos con estos alumnos desvirtúa y desacredita toda nuestra labor, por muy útil y válida que pudiera ser. 


\section{Gráfica $n^{o}$-15: La adaptación que les aplicas, la reflejas} por escrito.

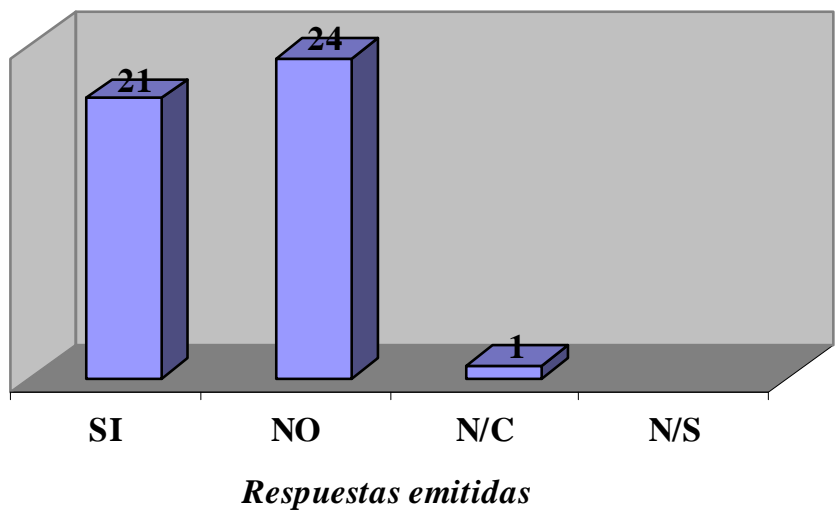

Hay un gran consenso $\left(73^{\prime} 9 \%, \mathrm{Fi}=34\right)$ ) al asegurar que el Departamento de Orientación no colabora con el de Educación Física y Deportiva para realizar las adaptaciones curriculares oportunas. Recordemos que conforme se establece en el R.D. 83/96, las actividades de adaptación curricular de este área para los alumnos con necesidades educativas especiales se han de realizar de forma conjunta con el Departamento de Orientación. De hecho, algunas de las programaciones didácticas analizadas así lo hacían constar en sus desarrollos.

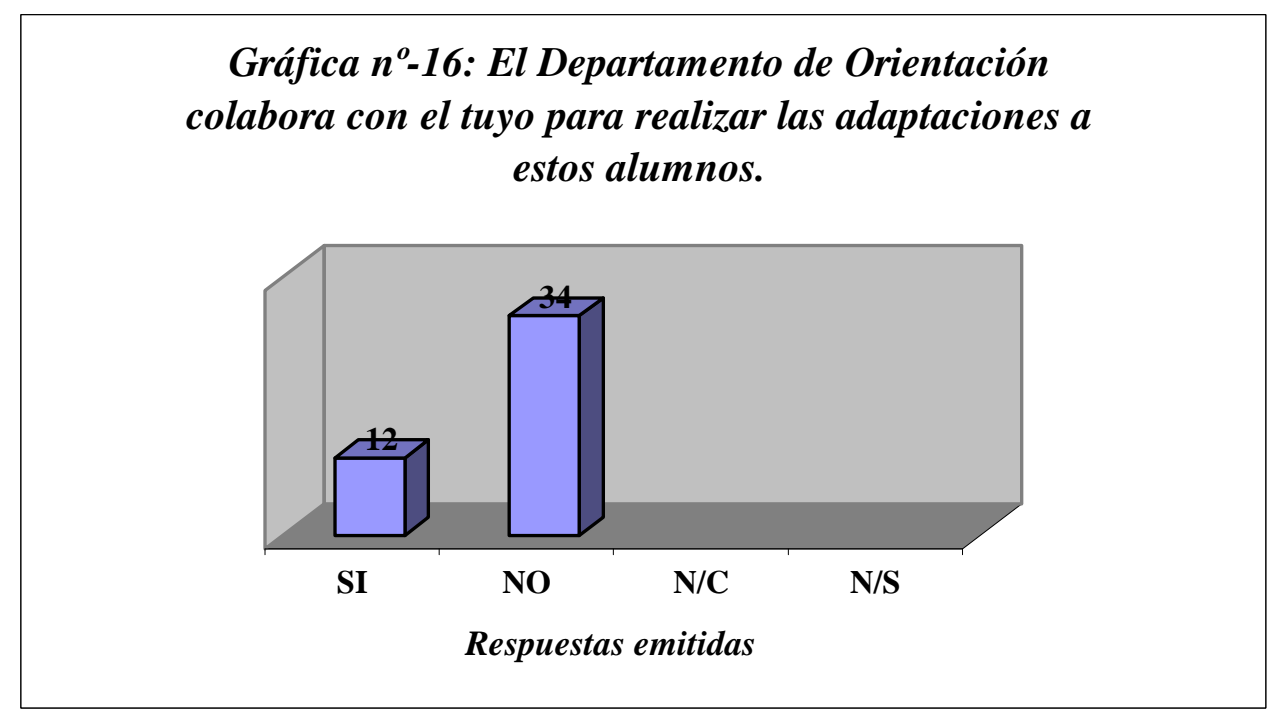


Para concluir, volvemos a repetir que solo un 54'3\% de los profesores de Educación Física $(\mathrm{Fi}=25)$ dice tener en cuenta las opiniones de estos alumnos, quedando en evidencia el lugar que ocupa el alumnado en su proceso de enseñanzaaprendizaje.

\section{d) Lo que se pide o espera de estos alumnos}

Acabamos de ver que sí hay profesores, uno de cada cuatro, que permiten que estos alumnos, si se dan una serie de circunstancias, no acudan a sus clases. Pues bien, ante la afirmación más directa de si la asistencia a clase en estos casos es obligatoria, solo el 8'6\% (Fi=4) sigue manteniendo la postura de permitir la no asistencia. Es más, no solo deben de acudir, sino que para un $89 \%(\mathrm{Fi}=41)$ deben tomar parte activa de la forma que sea. Esta posición es confirmada cuando el $65 \%$ ( $\mathrm{Fi}=30)$ obliga a estos alumnos a ir con ropa deportiva a clase, aunque algún profesor apostille que "sólo siempre que sea necesaria”.

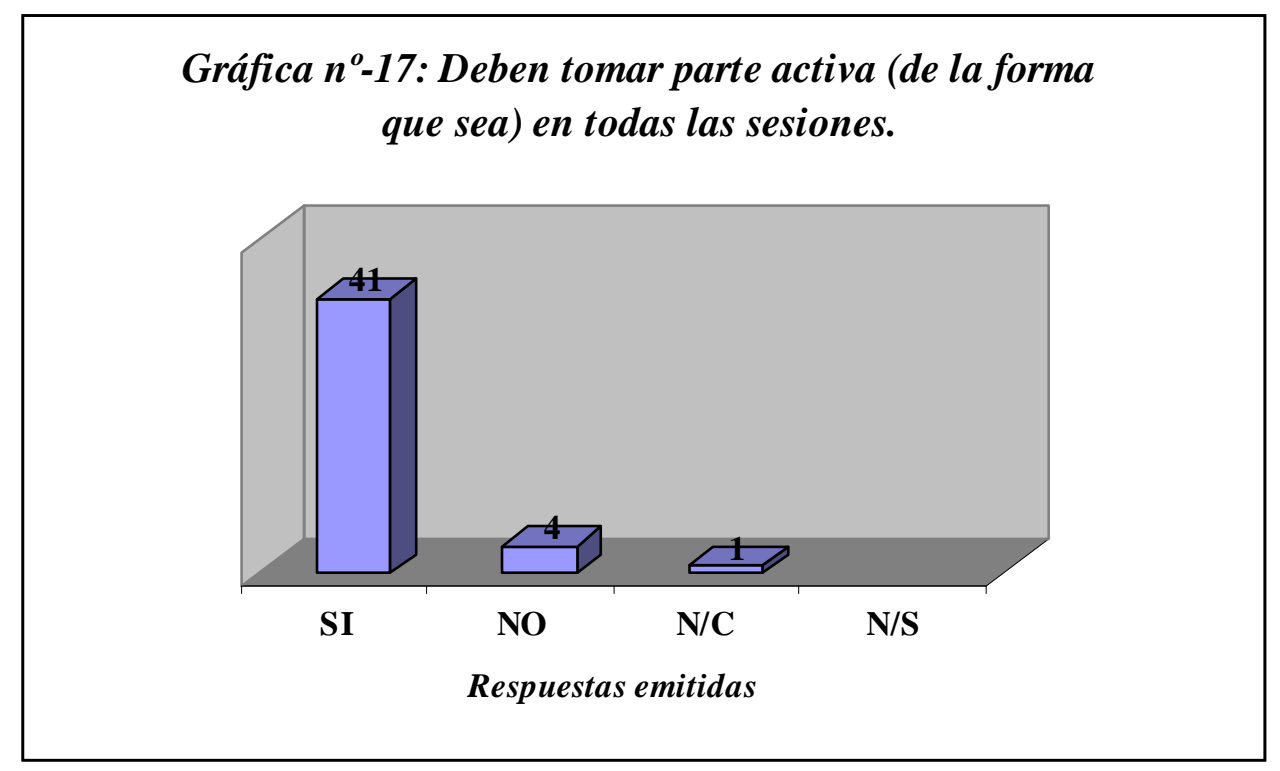

La única pregunta del cuestionario en la que ha habido unanimidad se refiere a si estos alumnos deben elaborar apuntes para sus compañeros, la cual ha obtenido un no 
contundente por parte del $100 \%$ de los encuestados $(\mathrm{Fi}=46)$. Hemos de recordar sin embargo, que esta posibilidad sí era contemplada en las programaciones didácticas.

Como era de esperar, se confirma que lo que se suele pedir a estos alumnos está en consonancia con actividades propias de la falsa integración. La recogida de notas y de observaciones durante el desarrollo de las clases obtiene una Fi de 36, lo que supone el 78’2\% de la muestra.

Muy de cerca les sigue una de las tareas a las que más suele recurrir el profesorado: colaborar en la colocación y retirada del material de las clases, siendo utilizada por 34 docentes (73'9\%). Nos preguntamos de nuevo qué sentido o utilidad tiene esta tarea para el alumno en relación a los objetivos del área y, sobre todo, si un alumno no puede hacer práctica alguna por su discapacidad, ¿cómo es que debe colaborar con estas funciones?

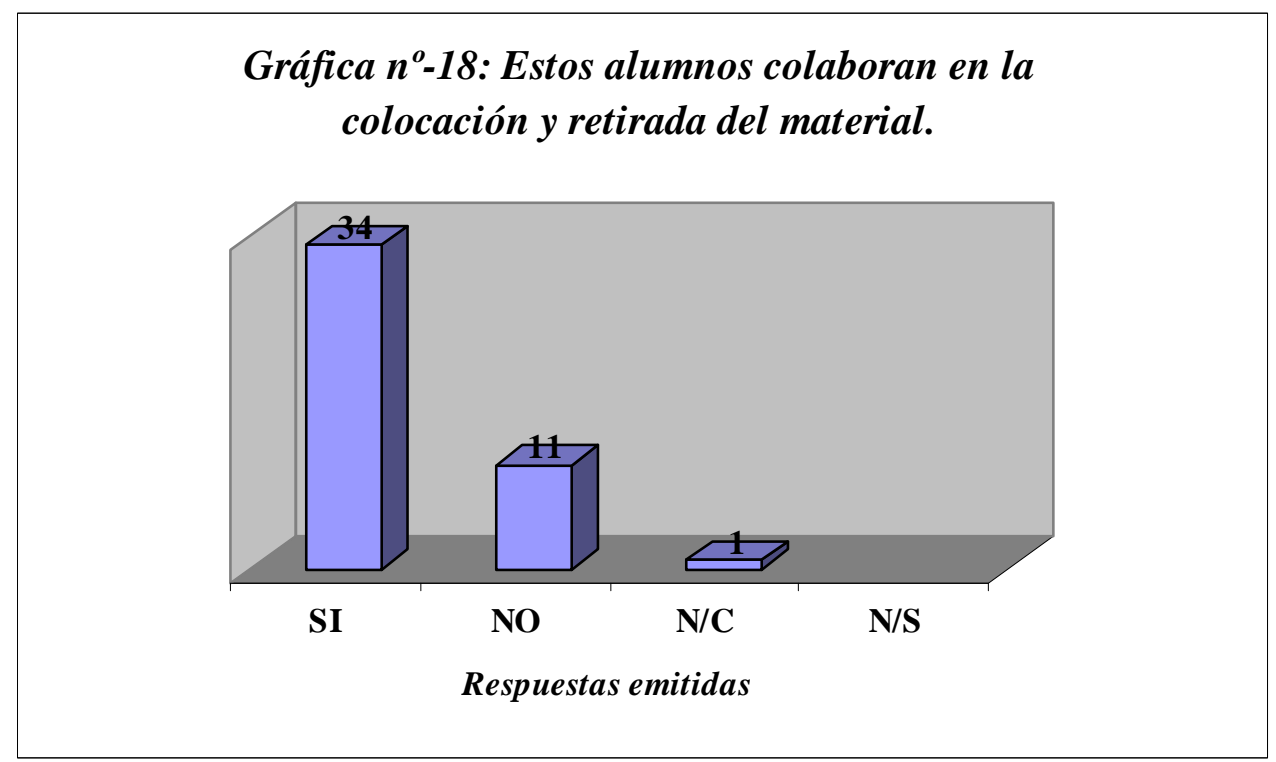

En relación a los trabajos ya vimos que un $89 \%$ de los profesores $(\mathrm{Fi}=41)$ confiesa que les propone diferentes posibilidades de trabajos teórico/prácticos en cada evaluación. De hecho, el 78’2\% $(\mathrm{Fi}=36)$ afirma que estos alumnos realizan los trabajos teóricos para “compensar” la parte práctica. 
Uno de los instrumentos que se utiliza con mayor frecuencia con estos alumnos (Fi=30) es el cuaderno de clase de Educación Física, empleado por el 65’2\%. Como dato anecdótico, señalamos que hay dos profesores que no usan este cuaderno con el resto de los alumnos, pero sí con los que presentan necesidades educativas especiales.

Observamos que el $67^{\prime} 3 \%$ de los encuestados $(\mathrm{Fi}=31)$ permite que durante sus clases de Educación Física estos alumnos realicen sus propios programas de rehabilitación motriz. Solo 9 profesores se niegan a que estas situaciones se produzcan. Como ya pudimos comprobar en el análisis de las programaciones didácticas, este tipo de práctica tiene acérrimos defensores y fuertes detractores.

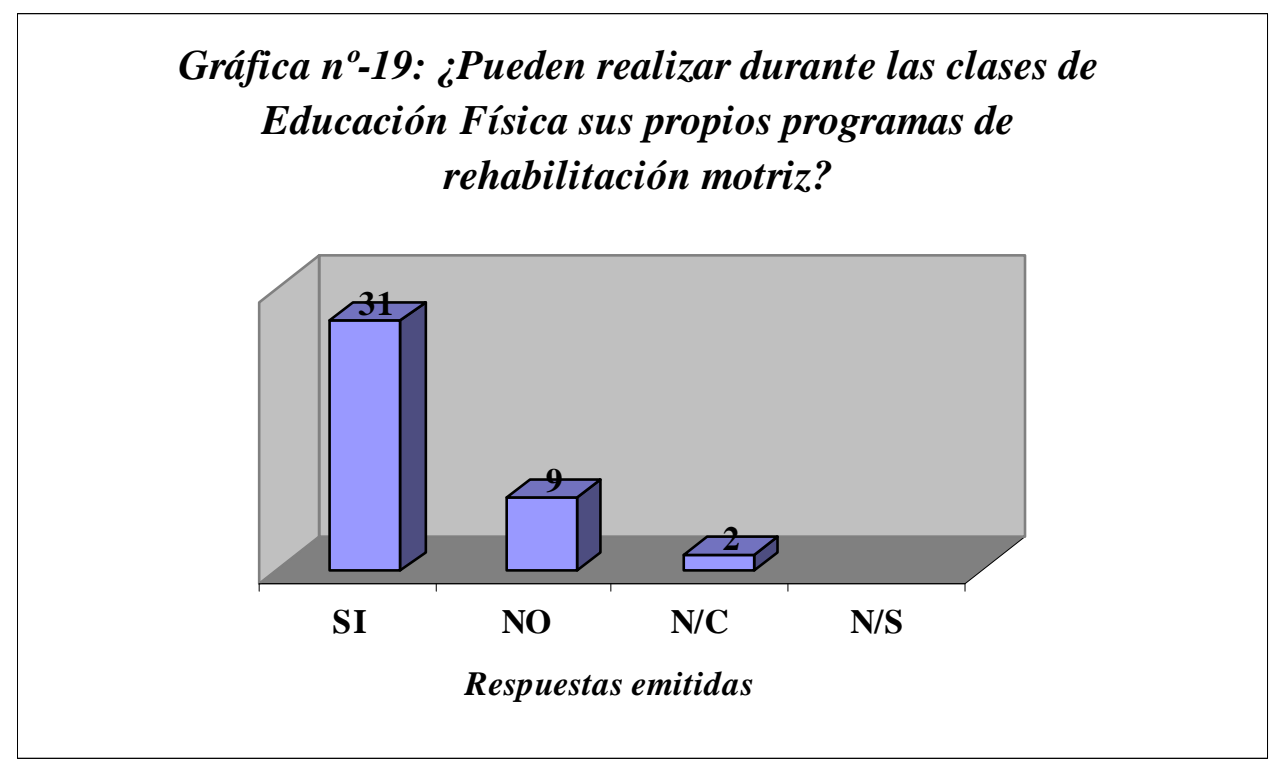

El $63 \%$ de profesores encuestados $(\mathrm{Fi}=29)$ no suele mandar a este alumnado que prepare sesiones o calentamientos para el resto de la clase. Aun así, un 28’2\% ( $\mathrm{Fi}=13)$ sí emplea esta alternativa como actividad que pueden realizar en sus clases. Alguno nos señala al respecto que "depende del caso". 


\section{e) Respuestas de los implicados}

Resulta muy interesante conocer cómo es la adaptación de estos alumnos al resto del grupo. A pesar de que para un 30'4\% del profesorado $(\mathrm{Fi}=14)$ no supone ningún tipo de problema, hay un 54’3\% ( $\mathrm{Fi}=25)$ que sí parece haber observado problemas en este sentido, es decir, uno de cada cuatro profesores de Educación Física aprecia que este alumnado topa con algún tipo de dificultad cuando trabaja con el resto de sus compañeros.

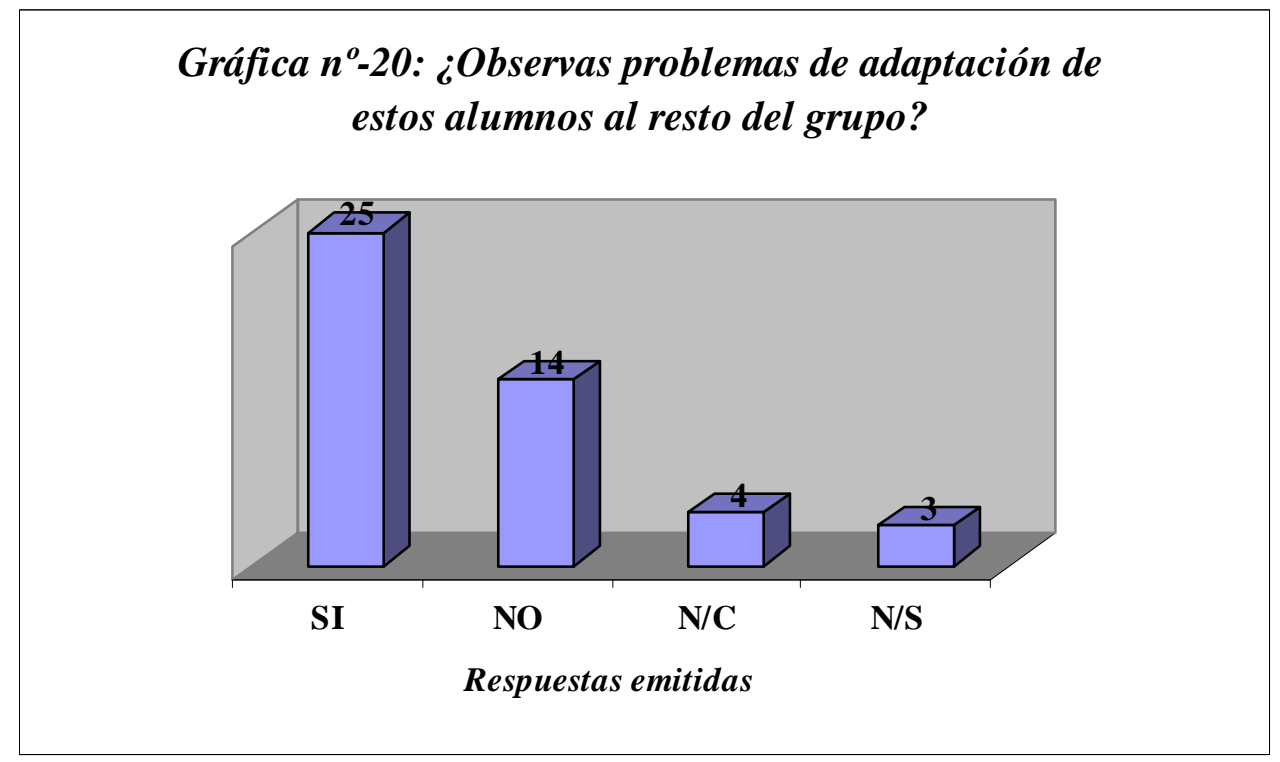

Quizás por ello, 11 profesores han percibido que estos alumnos prefieren no asistir a las clases de Educación Física. Es más, hay un $41 \%$ de docentes $(\mathrm{Fi}=19)$ que en algún momento se ha encontrado con alumnos en estas circunstancias que se han negado a participar en sus sesiones. Estas dos últimas ideas nos sugieren que este alumnado está solicitando, aunque puede ser que sin pretenderlo, la aplicación de una exención como posible respuesta a sus necesidades y sentimientos. 


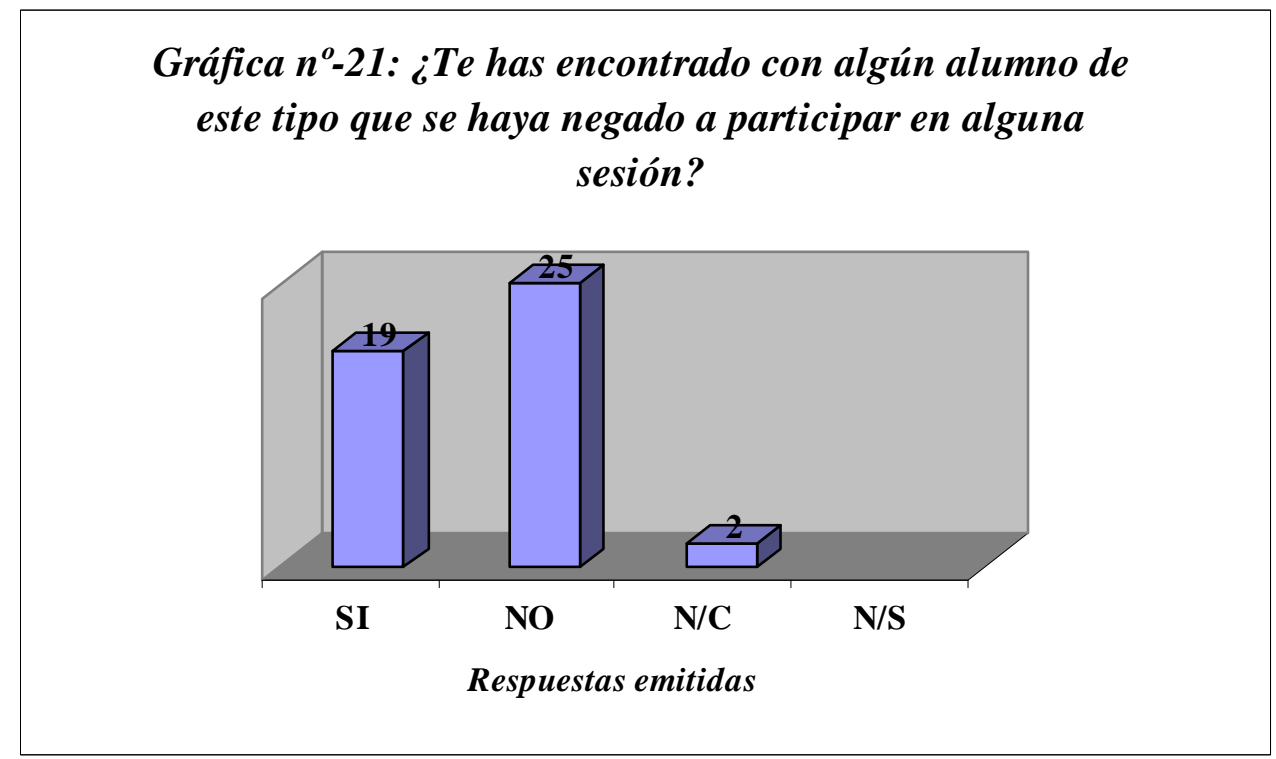

No obstante, un $65 ’ 2 \%(\mathrm{Fi}=30)$ suele coincidir al manifestar que estos alumnos sí muestran un verdadero interés por participar en las sesiones de Educación Física y, lo que es más importante aún, en un mismo porcentaje aprecian en ellos satisfacción tras dichas clases, participen o no, aunque, como reconoce algún encuestado, esto es así "sólo si participan con interés”, “en las clases que más les gusta” y "a veces, pues cada alumno es diferente”.

En definitiva, mientras que hay parte del alumnado con necesidades educativas especiales en su grado más extremo que preferirían no asistir a las clases de Educación Física, hay otra parte del profesorado que aprecia que dichas clases les supone un claro beneficio en la autoestima personal.

\section{f) Cómo se manifiesta el resto de alumnos}

Una alumna a la que di clase recientemente en $1^{\circ}$ de Bachillerato reflejó en un trabajo sobre "El deporte adaptado" lo siguiente:

"A pesar de los avances, creo que casi todos vemos a los discapacitados como «diferentes», y la mayoría sentimos una especie de «lástima» cuando les vemos. Aunque todos nos esforcemos por aceptarles tal y como son, en la mayoría de 
los casos es imposible saltar esa barrera que nos separa (o diferencia) y tratarlos como a cualquier persona, aunque en realidad tendrían que ser para nosotros unos auténticos héroes." (Silvia, alumna de Bachillerato, curso 20022003)

Pudiera ocurrir que en ocasiones nos estemos volcando tanto con el alumnado que por sus características especiales requiere de la aplicación de medidas y atenciones más allá de las "habituales", que olvidemos al resto de los alumnos que configuran el resto del grupo. ¿Acaso nos hemos preguntado alguna vez cómo perciben ellos este tipo de situaciones?, ¿Cómo les afecta?, ¿Cuál es su respuesta en clase hacia estos alumnos "diferentes"?

Cuando preguntamos a los encuestados si se producen situaciones conflictivas entre los intereses del grupo y las adaptaciones realizadas a estos alumnos, esperábamos encontrar un no unánime, propio de una sociedad que presume de moderna, integradora y no segregacionista. Sin embargo, casi un 21'7\% ( Fi=10) nos advierte de lo contrario, es decir, que el grupo "genérico" y estos alumnos han chocado en sus necesidades.

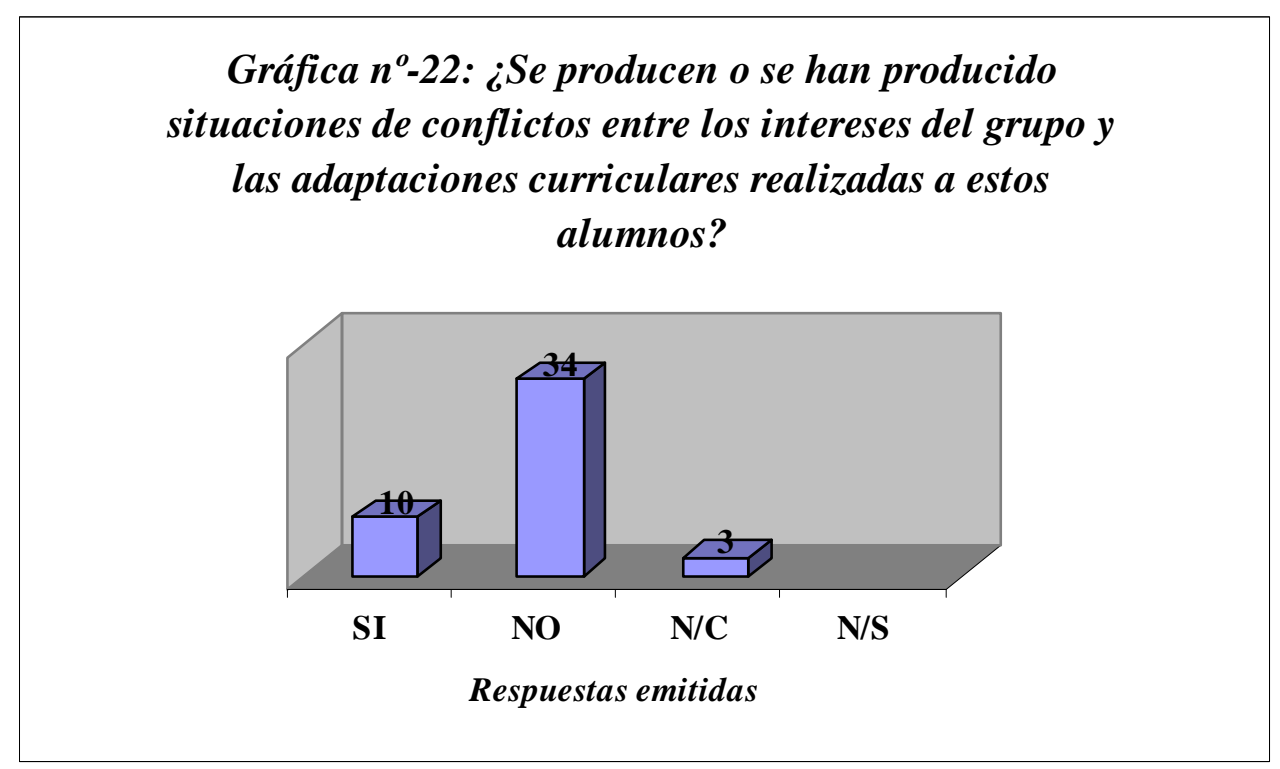

A este respecto, casi uno de cada cuatro profesores (23'9\%) manifiesta que en algún momento ha observado conductas inadecuadas en el resto de los compañeros de clase hacia este tipo de alumno con necesidades especiales, confirmándose así que no 
disponemos del ambiente ideal para llevar a buen puerto las adaptaciones curriculares que pretendamos realizar.

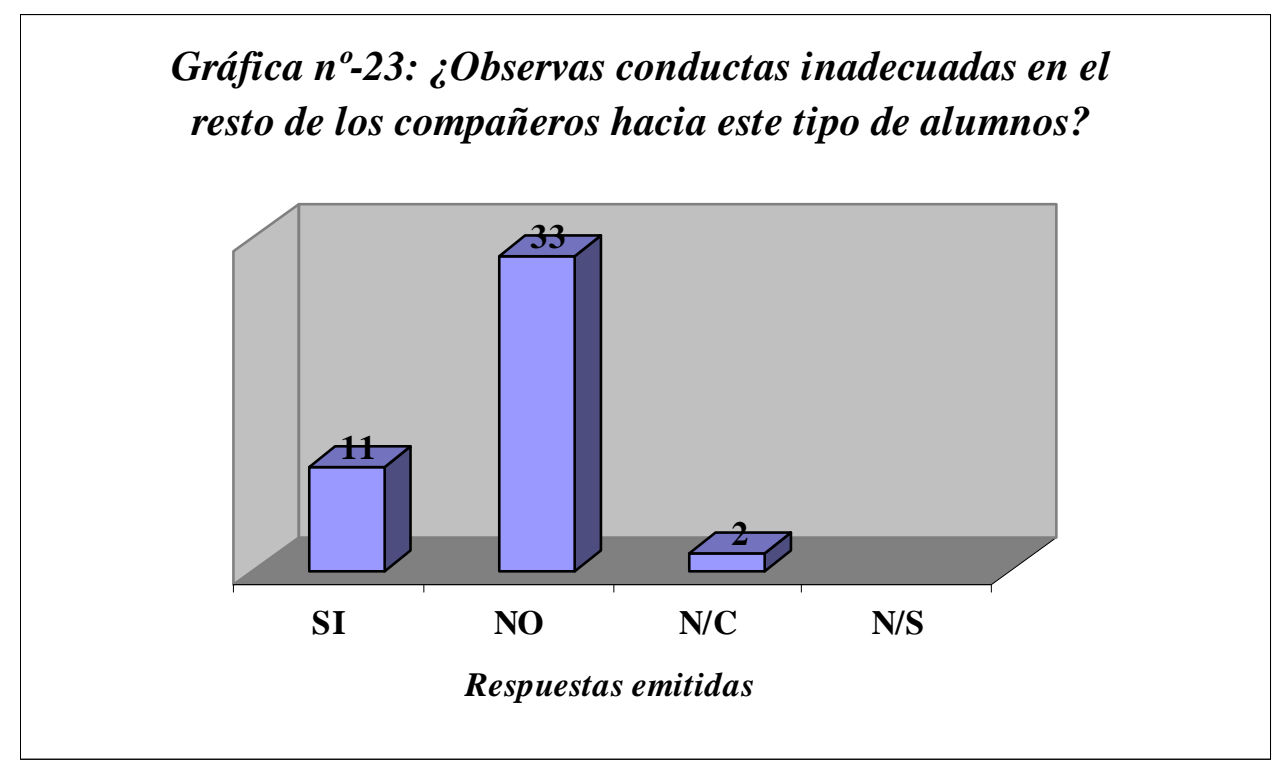

\section{g) Implicación o papel desempeñado por los familiares}

Ya que deben ser los padres o representantes legales de los menores de edad con necesidades educativas especiales asociadas a discapacidad motora o sensorial, temporal o permanente los que han de formular ante la dirección del centro la solicitud de la adaptación del currículo de Educación Física para sus hijos (Orden de 10 de julio de 1995), es lógico pensar que éstos sean informados o notificados de tales adaptaciones.

En la realidad esto no ocurre así. Para empezar, el 63\% de los profesores ( $\mathrm{Fi}=29)$ revela no mantener ninguna entrevista con los familiares o tutores legales de estos alumnos, por lo que difícilmente se les podrá informar sobre la adaptación curricular que se le está realizando a su hijo, lo cual choca con que el $45^{\prime} 6 \%(\mathrm{Fi}=21)$ señale que informa a los familiares sobre esas medidas educativas. De las anotaciones que nos han reflejado los profesores a esta cuestión ("Sólo si los familiares lo desean”, "Bajo su iniciativa", "No, salvo que acudan a informarse", "Sí, si piden información” o "Si 
preguntan, sí”), deducimos que para que un padre o tutor sea informado de las medidas educativas especiales que se le están realizando a su hijo, la iniciativa debe partir de él.

Una adaptación curricular significativa se diseña y se aplica con un claro propósito pedagógico o educativo en favor de los alumnos. Otra cosa muy distinta es que los padres acepten esta medida excepcional de buen grado. De hecho, un 17’3\% de los profesores de Educación Física $(\mathrm{Fi}=8)$ dice haberse encontrado alguna vez con la oposición o negativa de unos padres para que su hijo asista y/o participe en sus clases. Incluso un profesor que nos contestó negativamente a esta pregunta nos advirtió de que “creo que sería fácil”. Es más, un 19’5\% del profesorado ( $\mathrm{Fi}=9)$ afirma que algún familiar le ha mostrado su disconformidad para que sus hijos hagan práctica o asistan a las clases de Educación Física y que por ello sean evaluados.

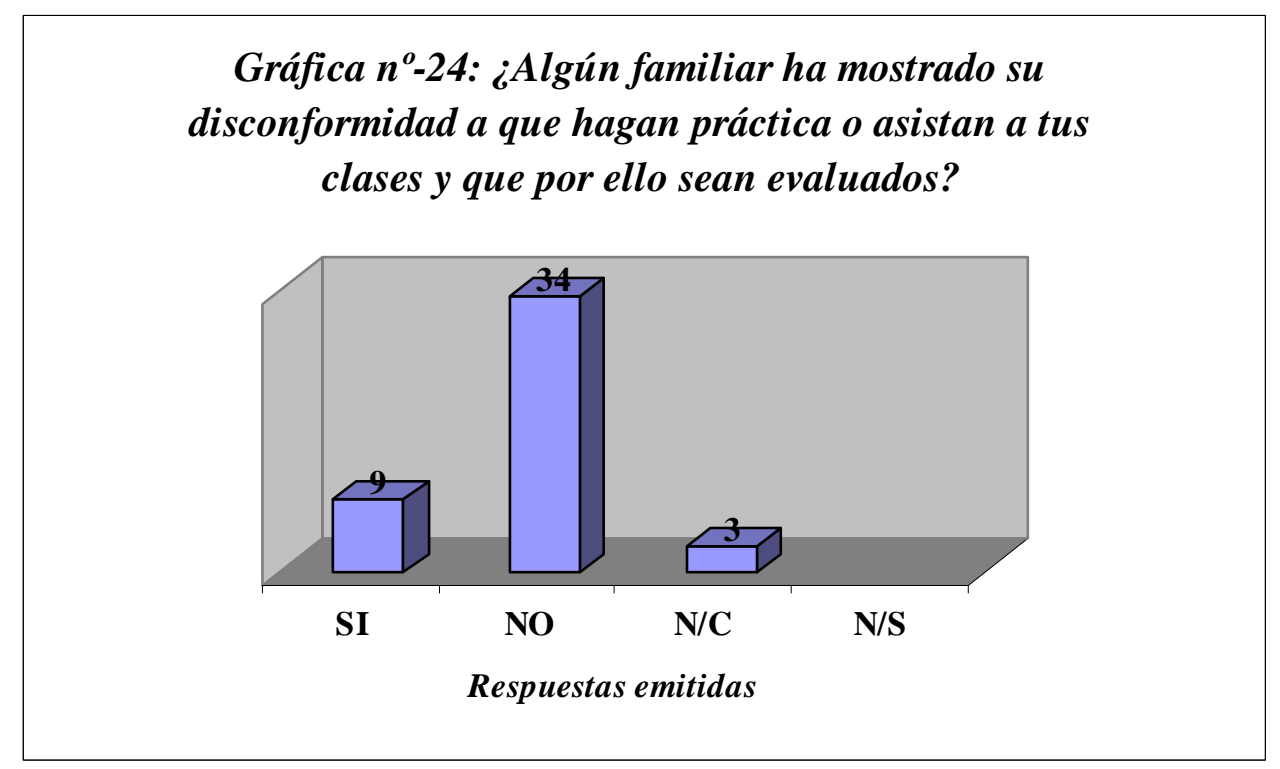

En definitiva, casi uno de cada seis familiares con hijos que presentan alguna necesidad educativa especial asociada a discapacidad motriz, están manifestando su negativa a que vayan a clase de Educación Física y, sin quererlo, solicitan la aplicación (recuperación) de la exención en esta área. 


\section{h) Formación y conocimiento sobre el tema}

Cuando se pregunta al profesorado si ha dado clase a alumnos que puedan entrar en esta categoría de "casos extremos”, 27 contesta que sí (58'6\%), lo cual denota que estos acontecimientos se dan con relativa frecuencia en nuestras clases de Educación Física. Sin embargo, suponemos que desde un punto de vista legal la mitad de los docentes $(\mathrm{Fi}=23)$ no sabrían actuar ya que reconocen que ignoran la normativa que regula este tipo de situaciones, lo cual dificulta enormemente poner en marcha las medidas más adecuadas para cada caso sin riesgo a estar actuando al margen de la ley (un profesor nos comenta: "No la he actualizado desde la carrera").

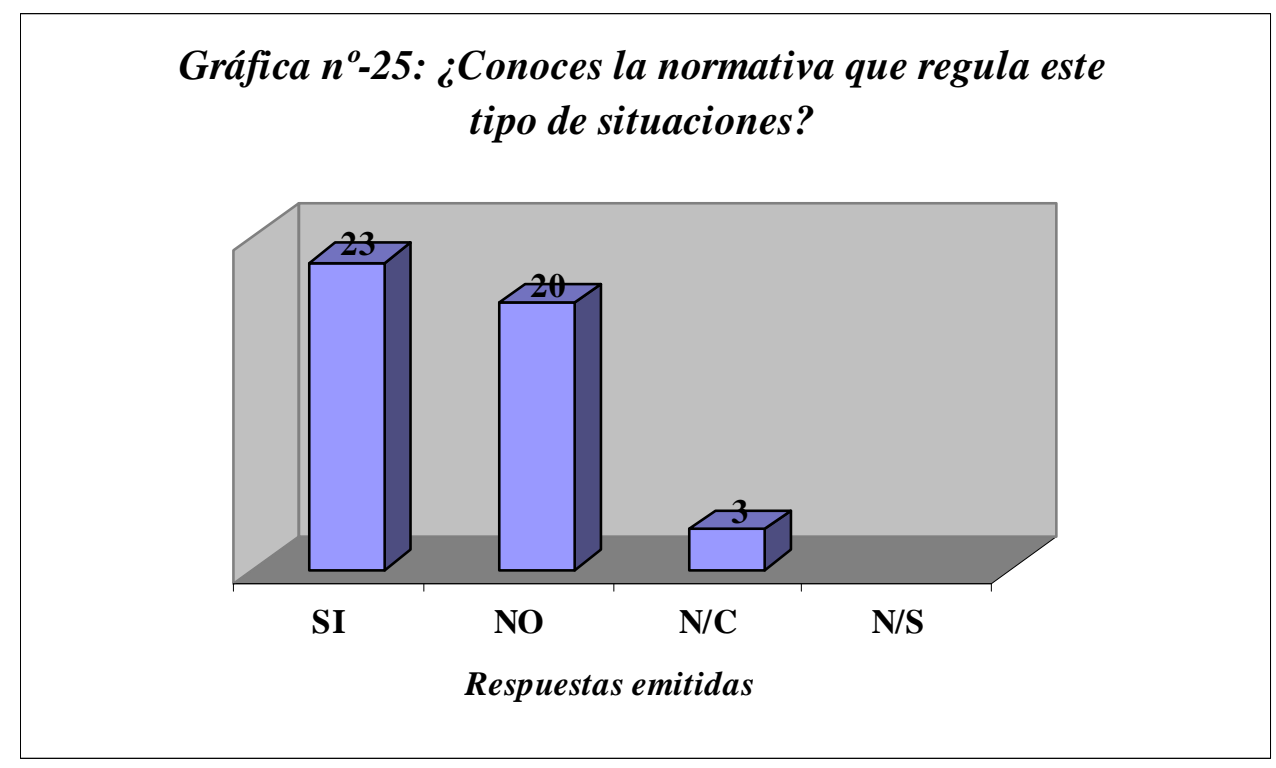

Debido quizás a que el 84’7\% de la muestra $(\mathrm{Fi}=39)$ tiene la sensación de que no recibió suficiente información sobre este tema en su etapa de formación universitaria ( "Todo es poco", señala uno de los encuestados), un porcentaje similar $(89 \%, \mathrm{Fi}=41)$ considera que es necesario una mayor formación en este ámbito, es decir, el docente reconoce las carencias formativas por las que pasó en su etapa universitaria, manifestando una obvia necesidad de mejorar y ampliar unos conocimientos que nunca fueron abordados o, en todo caso, pasaron desapercibidos. Alguno apunta que "No es necesario prioritariamente, pero sí más sensibilización”, dándonos a entender que el verdadero problema no reside precisamente en la formación. 
Sin embargo, es curioso comprobar que a pesar de reconocer esas carencias formativas iniciales tan solo el 32’6\% de los profesores de Educación Física ( $\mathrm{Fi}=15)$ ha asistido a cursos, conferencias, etc. en los que se abordan estos asuntos, es decir, casi el $68 \%$ nunca ha acudido a ningún tipo de actividad de formación permanente que estuviera relacionada con el tratamiento que debemos dar a los alumnos con necesidades educativas especiales.

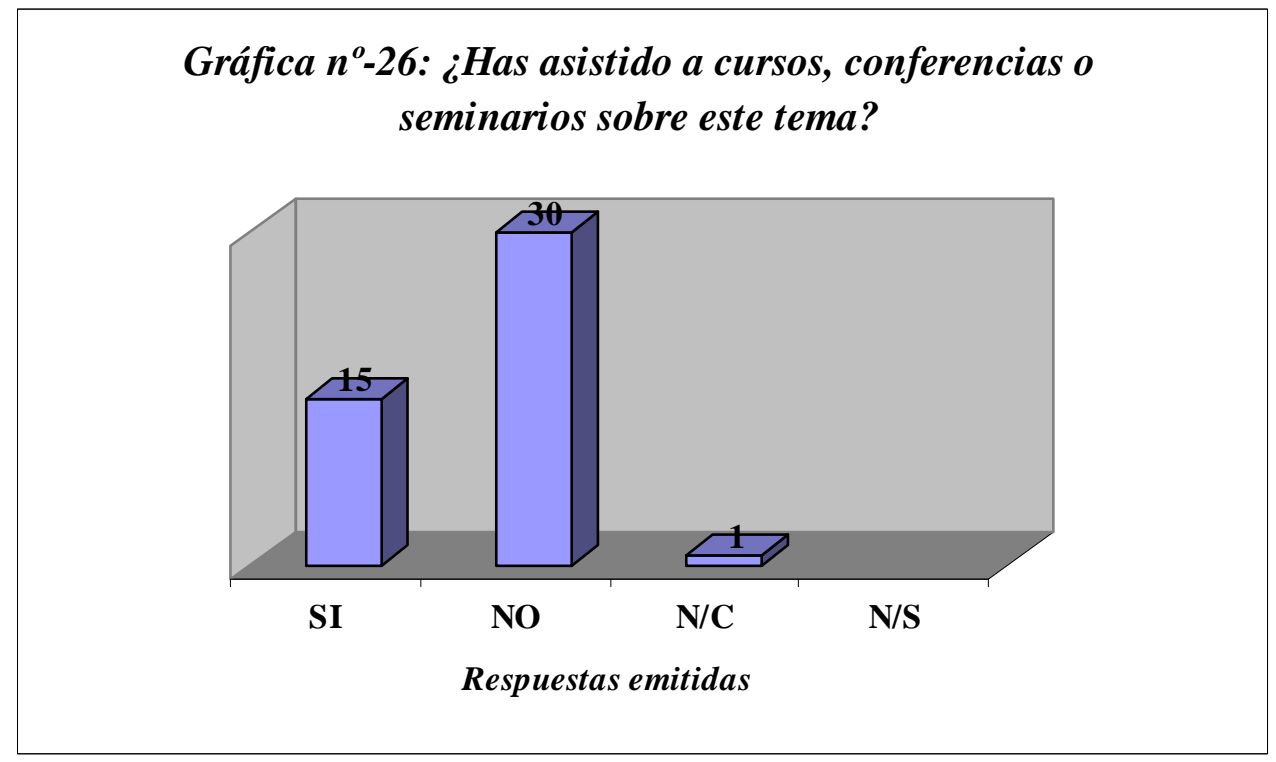

A pesar de estos datos, tres de cada cuatro profesores de Educación Física $(\mathrm{Fi}=35)$ reconoce que alguna vez ha solicitado o buscado información y/o materiales curriculares sobre este asunto, lo cual puede dar a entender que la forma que emplea el profesorado para actualizar sus conocimientos y dar las respuestas oportunas a los problemas que se le aparecen es consultando directamente a las fuentes informativas (libros, asesores, etc.).

\section{i) Valoración del trabajo y de los medios docentes}

El grado de sinceridad que ha mostrado el profesorado con relación a este último centro de interés es sumamente revelador. 
Un 58'6\% (Fi=27) afirma que la atención que presta a estos alumnos no es la suficiente o necesaria, llegándose a decir que “debería ser mayor". Además, tres de cada cuatro $(\mathrm{Fi}=35)$ reconoce no estar satisfecho con la manera de abordar estos asuntos en sus Programaciones Didácticas. Aunque alguno añade que "sí como planteamiento, pero de ejecución muy mejorable”.

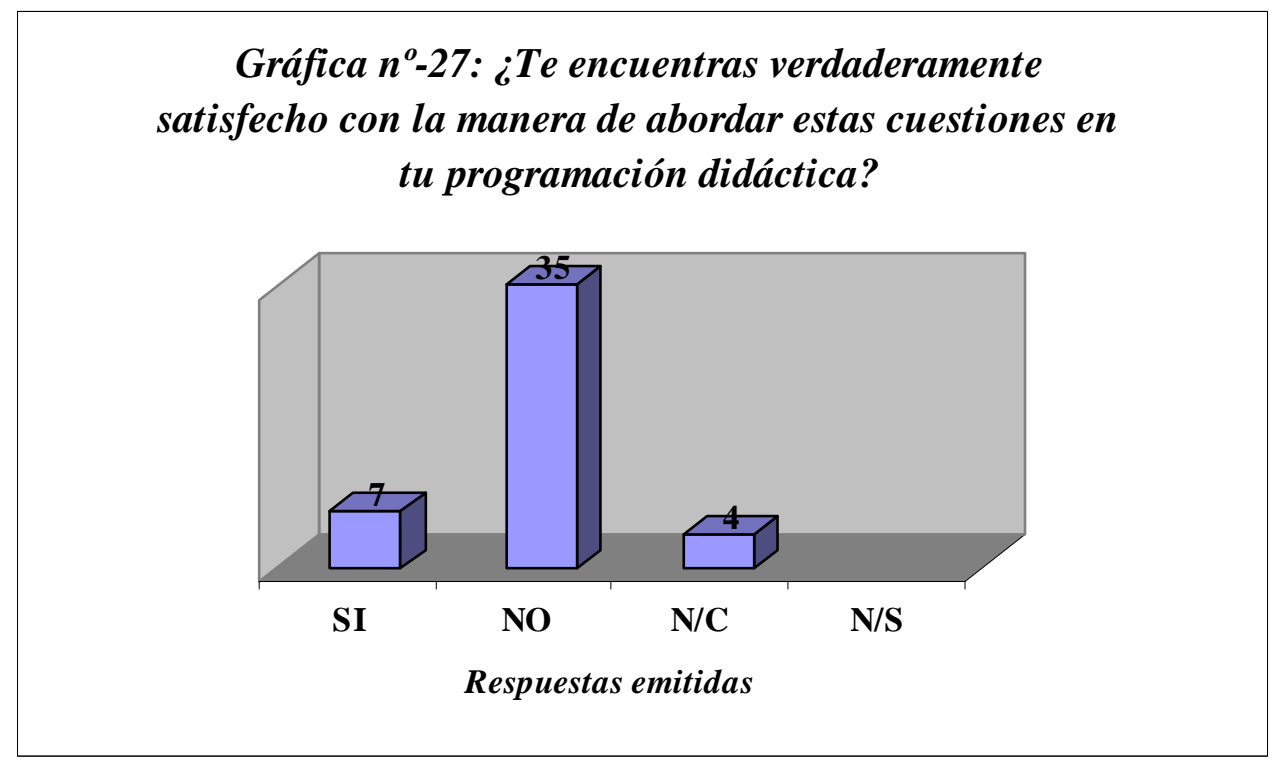

Y más aún, ya hemos comentado anteriormente que el $89^{\prime} 1 \% \quad(\mathrm{Fi}=41)$ es contundente al reconocer que sí se podrían poner en práctica más actividades de las que se hacen para favorecer la participación de estos alumnos.

En definitiva, la valoración que el profesorado hace de su labor docente dista mucho de acercarse a la ideal o necesaria para abordar con mayores garantías de éxito el tratamiento a la diversidad y, más concretamente, a los casos más extremos.

A pesar de que algún profesor afirma que "no me gusta hostigar", hay un pequeño número de docentes $(\mathrm{Fi}=5)$ que ha lamentado en algún momento haber obligado a estos alumnos a participar en las actividades. Parece ser que de nuevo los sentimientos, intereses y opiniones de los alumnos son obviados en pro de la participación por la mera participación 
Ya hemos aludido a la creencia mayoritaria $\left(73^{\prime}, 9 \%, \mathrm{Fi}=34\right)$ de que el profesor de apoyo es imprescindible para atender mejor a estos alumnos. Sin embargo, de los 27 profesores que han dado clase en algún momento a alumnos que pertenecen a esta categoría de "casos extremos", tan solo 7 de ellos han contado con su colaboración en las clases de Educación Física. Por tanto, los medios personales de que disponemos para atender a la diversidad parecen ser escasos e insuficientes.

Por último, a pesar de ser repetitivos, hemos de insistir en que el 73'9\% de los docentes $(\mathrm{Fi}=34)$ tienen la sensación de que la información que existe sobre este asunto es escasa. Supone un tema que interesa, pero que está aún por investigar y descubrir.

Para terminar con este apartado, transcribimos el comentario que nos ha enviado uno de los encuestados que resume fielmente la realidad de nuestras clases, en las que la generalización de las medidas a adoptar no tiene sentido alguno y sí el hecho de partir de la individualidad del sujeto, de sus posibilidades e intereses para la consiguiente propuesta de objetivos y actividades.

"He impartido clase a niños con necesidades especiales de lo más variado. Cada niño es un mundo con sus particularidades. Es difícil establecer criterios generales pues su actitud, su interés así como sus deficiencias son las que marcan el desarrollo de las actividades."

\section{4.- EPÍLOGO}

De la presentación e interpretación de los datos obtenidos con el cuestionario cumplimentado por los profesores de Educación Física de los centros de secundaria públicos de Valladolid y provincia, extraemos las siguientes conclusiones:

Consideramos que el índice de respuesta obtenido del 52’27\% es aceptable y, por tanto, representativo de la población de 88 profesores de Educación Física que imparten dicho área en los 32 IES públicos de Valladolid y provincia. En este sentido, la 
colaboración del profesorado ha sido fundamental para poder llevar a cabo esta investigación.

No deja de ser curioso que ningún centro, a través del Jefe del Departamento de Educación Física y Deportiva, nos haya solicitado que le enviemos los datos, interpretaciones y resultados conseguidos. Este desinterés puede deberse a la plena confianza que tienen en su forma de entender y practicar la docencia de la Educación Física o al poco valor que conceden a este tipo de trabajos que indagan sobre las actuaciones del profesorado, lo que a nuestro parecer evidencia una falta de compromiso consigo mismo, una ausencia de evaluación de la propia labor docente y una desidia por conocer lo que opinan y hacen el resto de los compañeros de profesión.

En síntesis, la visión del profesorado sobre el asunto objeto de estudio es la siguiente:

Sabemos con toda seguridad que actualmente en las clases de Educación Física hay alumnos que presentan necesidades educativas especiales (en sus "casos más extremos") asociadas, sobre todo, a una discapacidad física o motora.

Por lo que se refiere a la legislación e información que hay sobre el tema objeto de estudio, a pesar de ser un asunto importante en nuestra actuación docente diaria, es considerada como reducida y limitada.

Son necesarios más medios personales para atender mejor a las necesidades y posibilidades de nuestros alumnos en esas situaciones.

En lo que respecta a la exención, tres de cada diez profesores son partidarios de recuperar esta figura si las circunstancias o características del individuo así lo aconsejan. De hecho, la mitad de la muestra accede a que no participen si lo pasan mal, y un $25 \%$ permite que ni vayan a sus clases. Asimismo, dos de cada diez profesores creen que se podría ofrecer a estos alumnos la Educación Física como materia optativa 
en vez de obligatoria. Por otra parte, el concepto "exento" o "exento de la práctica" continúa utilizándose en las programaciones didácticas.

Son pocos los profesores de Educación Física que emplean el libro de texto en sus clases, lo cual confirma que es el profesor quien elabora y planifica sus propias actividades diarias, es decir, él es el principal artífice de su práctica docente.

La lectura y seguimiento que hacen del PEC los profesores de Educación Física es, como mucho, somera y superficial, lo que nos hace suponer que a este documento no se le concedía mayor utilidad que la administrativa (idéntico resultado aparece recogido en Astráin, 2002, p. 301). En un menor grado se podría decir lo mismo de las programaciones didácticas.

Las adaptaciones curriculares que se aplican a estos alumnos difícilmente las vamos a encontrar plasmadas en un DIAC (Documento Individual de Adaptación Curricular). Si esto es así, será complicado modificarlas y tenerlas en cuenta para futuras tomas de decisión.

Solo la mitad de los profesores tienen en cuenta las opiniones e intereses de los "principales actores" para elaborar un programa acorde a esas verdaderas necesidades y actuar en consecuencia.

Los juegos motrices sensibilizadores y/o las prácticas con cambios de rol son utilizados con relativa frecuencia en nuestras clases.

Aunque hay datos contradictorios respecto a la necesidad de presentar un certificado para la aplicación de una medida especial, en todos los centros, salvo en uno, se solicita este documento habitualmente.

En opinión de algunos profesores, el Departamento de Orientación no colabora con el de Educación Física y Deportiva en la realización de las adaptaciones curriculares que se llevan a cabo. 
Los alumnos objeto de estudio no solo deben asistir obligatoriamente a clase, sino que además el profesor les suele buscar la manera de que participen "activamente": colocar y retirar el material, recoger notas y observaciones, realizar sus propios programas de rehabilitación motriz, etc. Los trabajos teórico-prácticos y el cuaderno de clase son otras tareas que suelen realizar mayoritariamente.

A pesar de la satisfacción que produce en los alumnos con algún tipo de discapacidad la asistencia a las clases de Educación Física, surgen tantos desajustes, conflictos y problemas de adaptación entre ellos y el resto de los alumnos (o al revés), que algunos no quieren ir a clase ni participar en las actividades propuestas.

A los familiares o representantes legales de estos alumnos se les informa de las medidas que se adoptan con sus hijos cuando ellos así lo solicitan, pero no a iniciativa de los profesores.

Casi uno de cada cinco padres o tutores legales de un alumno de estas características se opone a que su hijo asista o participe en las clases de Educación Física.

Tanto por la actitud del alumno en cuestión, de sus familias, del resto de alumnos y del mismo profesor, como por la falta de preparación formativa de los docentes y la escasez de medios personales, no se están dando las mejores condiciones que anteceden a una acción educativa exitosa.

El profesorado reconoce sus carencias formativas sobre esta temática. A pesar de ello, no suele acudir a cursos específicos, sino que opta por buscar soluciones por su cuenta.

Quizás por la falta de preparación, el profesorado admite que no hace todo lo posible ni presta la suficiente atención necesaria a este colectivo. 


\section{$\underline{\text { Algunas ideas contradictorias }}$}

Las respuestas emitidas por los encuestados han dado lugar a la aparición de contradicciones que, aun habiendo sido expuestas a lo largo del apartado anterior, resumimos en dos.

La primera es que los profesores de Educación Física dicen hacer unas cosas pero en sus programaciones didácticas, documento en el que se contextualiza la intervención que piensan desarrollar en una etapa, ciclo y/o curso, vienen recogidas otras bien distintas (e. g., dicen que sí tienen criterios de calificación específicos para estos alumnos y luego no ha sido así, etc.).

En segundo lugar, no se aprecia que haya un trabajo coordinado en los departamentos, es decir, cada profesor parece trabajar y actuar acorde a sus experiencias, iniciativas, creencias..., independientemente de lo que hagan u opinen el resto de sus compañeros (e. g., en un centro educativo unos sí utilizan el libro de texto y otros no; algunos piden certificado médico y otros no; para algunos el cuaderno de clase sí es un útil de trabajo para el alumno y para otros no...). Se viene a confirmar una idea aparecida en el capítulo anterior: que las programaciones didácticas no son trabajadas ni seguidas por todos los miembros del departamento didáctico y, en algunos casos, las partes de su desarrollo (los ciclos y/o etapas) han sido elaboradas por personas independientes que no han realizado una puesta en común para fusionarse, pero sí sumativa por aquello de añadir folios al documento. 


\section{Piezas de la vidriera}

De los datos obtenidos con los cuestionarios cumplimentados por los profesores de Educación Física que han participado en la investigación desarrollada en este capítulo, conseguimos las siguientes piezas para nuestra vidriera:

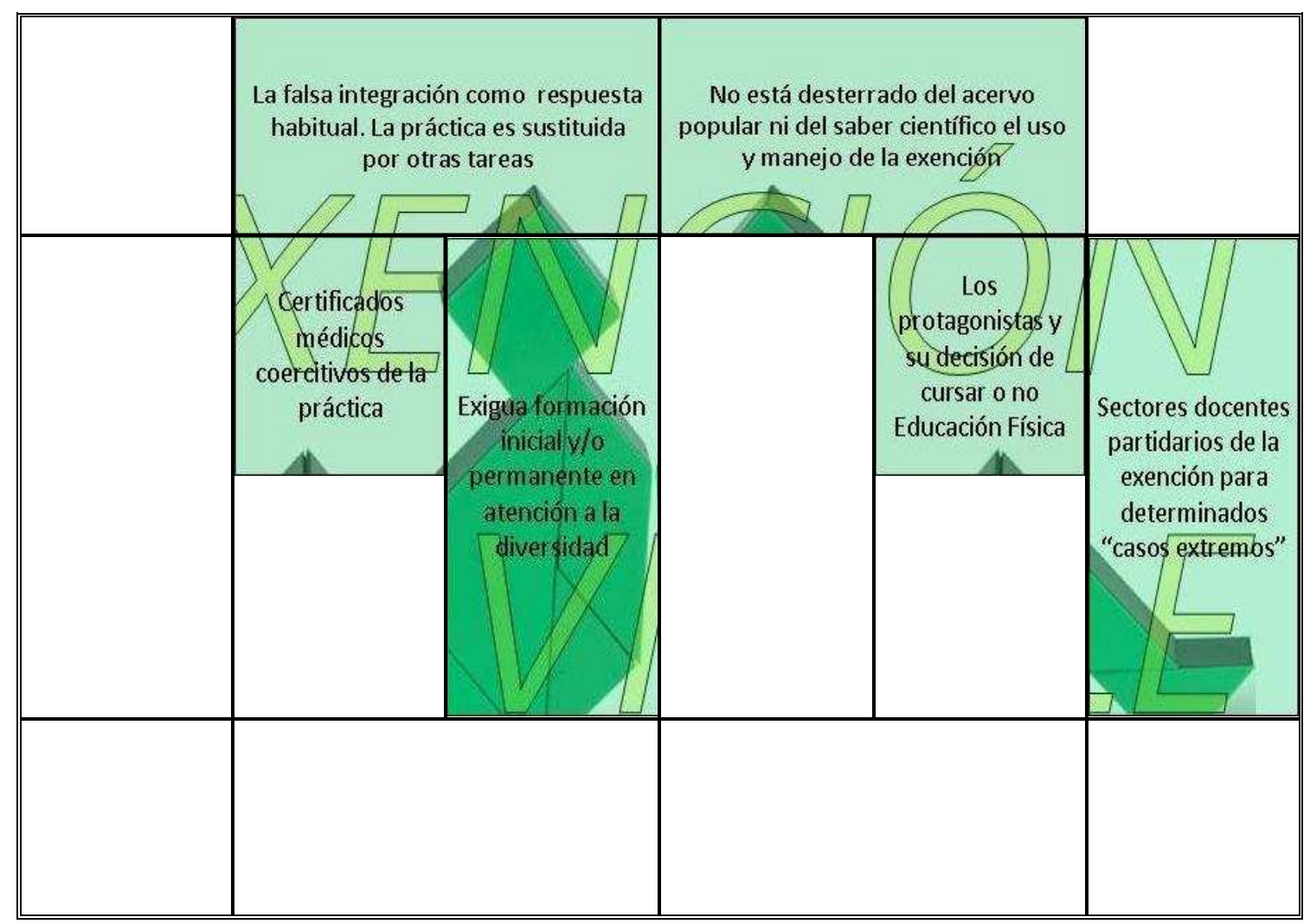




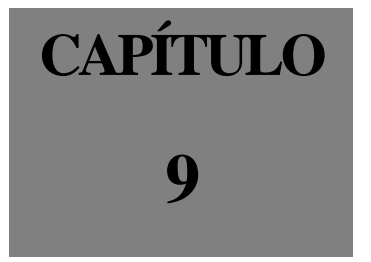

LA EXENCIÓN VISTA A TRAVÉS DE LA FORMACIÓN 
Puesto que en el capítulo “APROXIMACIÓN A LA VISIÓN QUE TIENE

EL PROFESORADO" quedó patente la sensación de no haber recibido suficiente información sobre este tema en la etapa de formación universitaria y la necesidad de una formación permanente en los asuntos de la atención al alumnado con necesidades educativas especiales, consideramos necesario dedicar un capítulo a la revisión de dicha formación.

Para ello emplearé relatos de mi vida relacionados con la Educación Física, tanto en lo concerniente a la etapa de formación inicial en los estudios universitarios realizados, como en lo relativo a la formación permanente que he recibido ya como profesor. Como la narrativa (autobiográfica) constituirá la metodología de investigación de todo este apartado, primero me detendré a exponer sus características más significativas.

En relación a la atención y tratamiento a los alumnos con necesidades educativas especiales, también revisaré los cursos, seminarios y actividades formativas en general que los CFIEs, como máximos organismo públicos implicados en el proceso de la formación continuada del profesorado, han llevado a cabo, como organizadores o como colaboradores, durante un periodo de tiempo que abarca el final del siglo XX y principios del XXI. 


\section{1.- ANTES DE NADA}

Me gusta escribir, no lo voy a negar. Transcribir ideas, pensamientos, situaciones... de mi vida personal y/o familiar es algo consustancial en mí. Agendas, cuadernos y calendarios están repletos de anotaciones, datos y sucesos más o menos relevantes.

En el ámbito profesional me defino (y así me ven los otros) como metódico, organizado y diligente. Suelo recoger por escrito acontecimientos, informaciones... que aparecen en diferentes tipos de reuniones que tienen lugar en mi centro de trabajo: Claustros, Comisión de Coordinación Pedagógica, Consejo Escolar, Departamento, etc.

Tengo por costumbre, adquirida en mi juventud cuando trabajaba como monitor deportivo con niños de 8 a 12 años, anotar siempre al término de cada lección lo más relevante de lo acaecido. Asuntos relacionados con la conducta de los alumnos, su participación, lo explicado, las dudas y dificultades surgidas... pasaban al cuaderno o diario como forma de perpetuar la experiencia y poder hacer el obligado proceso de reflexión y replanteamiento de mi práctica.

Me ha resultado de un valor sumamente extraordinario (incluso así ha sido definido por alguno de mis "amigos críticos") disponer a estas alturas de mi vida profesional de documentos perdidos, no tanto en lo que respecta a la memoria pero sí en los armarios. Poder disponer de cuadernos, trabajos y otro tipo de escritos elaborados hace más de 25 años ha supuesto una ayuda e impulso a la investigación. A este respecto, el uso del refranero popular en boca de un "amigo crítico" es del todo 
acertado: "Quien guarda, halla...". Todo este material ha servido para dar sentido a mi autobiografía.

Por último, no quisiera que el lector confundiese lo que supone este material recopilado (llámesele diarios) de lo que es una autobiografía, para lo cual recojo las palabras de Harré (citado en Sarabia, 1985, p. 178):

“...Este [refiriéndose al diario] sería un conjunto de información recogida en el tiempo que los sucesos registrados ocurrieron mediante las categorías cognitivas, el sistema de creencias y el contexto histórico del momento. La autobiografía trataría de recoger e interpretar los episodios de una vida y la relación el autor con los mimos desde una perspectiva temporal."

\section{2.- LOS ANTECEDENTES}

Han pasado 26 años desde que comencé los estudios para obtener el título de Licenciado en Educación Física en el entonces Instituto Nacional de Educación Física de León. De ellos, veinte los he dedicado a la docencia en centros de B.U.P. y Secundaria ejerciendo como profesor de Educación Física.

En todos esos años, incluyendo el propio periodo de formación inicial, no ha habido año o curso escolar en el que no haya participado, a iniciativa propia, en algún curso, seminario o proyecto de formación. Es más, ya antes de ese periodo comencé a interesarme por cuestiones educativas relacionadas con la enseñanza deportiva pues ese era el ámbito en el que me movía sin cesar.

Comienza ahora la exposición de algunos relatos de mi vida por todo este periplo de formación que, a día de hoy, parece no tener término y, más importante aún, no pretendo dar por concluido ni con la consecución de la ansiada condición de Doctor que espero alcanzar por medio de esta tesis doctoral. Este relato también servirá para ubicar mis percepciones e interpretaciones (y posible evolución) que he tenido sobre los 
asuntos de la Educación Física y la atención al alumnado con necesidades educativas especiales asociadas a cualquier discapacidad.

\section{3.- SITUANDO LOS RELATOS DE VIDA EN MI INVESTIGACIÓN}

Los relatos individuales, en tanto que nacemos y bebemos de una cultura que impregna nuestra interacción social diaria, son también relatos personales y sociales (Sparkes y Devís, 2007, p. 47)

Para estos mismos autores, los relatos de vida, situados dentro de un paradigma cualitativo y pertenecientes a la investigación narrativa, adquieren mayor relevancia en la investigación en las ciencias sociales y humanas. Además, amplían las formas de la propia investigación cualitativa ya que "puede incluir estrategias metodológicas, fuentes de recogida de datos y formas de análisis y representación más convencionales y otras más novedosas" (ibídem, p. 50). Y no conviene pasar por alto que los relatos que las personas hacen de sus vidas son recursos culturales que otorgan cierto sentido a esas vidas, y emplearlos en investigación contribuye, entre otros asuntos, a entender mejor cómo se forman las identidades (ibídem, p. 44).

Incluso antes de ser profesor, desempeñando labores como monitor deportivo o como alumno de algunas asignaturas con carga de tipo práctico, ya empecé a inculcarme la rutina de transcribir los momentos relevantes, circunstancias especiales, sucesos singulares... en un cuaderno para tal efecto. Detalles, conversaciones, relatos... aparecían en esos cuadernos. Por lo tanto, siempre he ejercido como observador de mi trabajo para, posteriormente, reconducir el mismo, es decir, he sido investigador de mi propia práctica, asunto que parece solicitarse del docente de hoy en día (Martín, 2003, p. 45). En la medida de lo posible, intento adoptar una «acción reflexiva» (Romero, 2004) sobre mi mundo laboral para desarrollarme profesional y personalmente. Al igual que plantea este autor, considero que estoy abierto a múltiples cambios si con ello aprecio mejorar en mi quehacer; no creo que nadie esté en posesión de la única verdad, me 
planteo lo que hago y cómo lo hago y considero que soy consecuente con ello y, fundamentalmente, soy sincero.

Así pues, es evidente que en este capítulo, de las posibles formas de realizar la investigación cualitativa, me decantaré por la autobiográfica (Sparkes citado por Barbero, 2007, p. 210). A este respecto, mediante la autobiografía trataré de constatar e interpretar ciertos episodios de mi vida y mi relación con los mismos desde una panorámica temporal (Sarabia, 1985, p. 178).

La investigación cualitativa no suele surgir de una hipótesis, ni de un asunto o problema cuantificable (Martín, 2003). En el caso de esta tesis, el origen principal se asienta en un problema o dilema surgido hace años en una situación profesional y personal delicada (¿acaso se pueden separar estas dos cuestiones cuando trabajamos con personas, con sujetos con nombres y apellidos que se están formando?). No puede evitarse que el autor se involucre emocionalmente con el asunto, evocando relatos y conversaciones, momentos de su vida, intentando acercar su realidad al lector. En cierto sentido, los afectos y las emociones son fundamentales para explicar la actuación docente (Hernández, 2011, p. 15). Sabemos que este tipo de escritos sufren críticas, entre otras, por su subjetivismo, escaso rigor científico, etc., pero, al igual que opinan algunos autores que emplean esta metodología, me "interesa más el viaje que el destino" (Barbero, 2007, p. 212).

Continuando con este lenguaje metafórico, el viaje ha sido largo, lleno de información, documentación y momentos inolvidables. Incluso ha habido hallazgos inesperados de documentos ya olvidados en los archivos y en la memoria, que han servido para despertar de su letargo a esta última.

Todos los relatos de mi vida se irán situando según se narran en un contexto histórico-social concreto, de tal suerte que no se limitarán a ser únicamente una «life story», frente a la «life history» (Pascual, 2003, p. 24). La diferencia entre ambas es difusa ya que desde el mismo momento en que el relato es narrado, pasa de alguna forma a ser parte de la historia de visa del sujeto (Bolívar et alia, 2001, p. 29). Además, 
los relatos de vida se complementarán con fuentes documentales, transcripciones de ponencias y entrevistas...

En los últimos años se ha empezado a originar un auténtico interés por emplear las autobiografías en investigación cualitativa (Hernández, 2011, p. 14), lo cual, entre otras cuestiones, supone empezar a valorarlas como medio de dar a conocer la realidad que nos envuelve frente a otras técnicas más dependientes de modelos estadísticos (Thomas citado por Hernández, op. cit., p. 15).

Por tanto, el proceso autobiográfico que se realizará consistirá en un proceso de recogida de información a través de los propios relatos de vida del autor de esta tesis y los que cuentan otros sujetos sobre sus propias vidas o cuestiones relacionadas con el asunto de la tesis. En la autobiografía coinciden el autor, narrador y personaje en la misma persona (Bolívar, op. cit., p. 31), es decir, el investigador y el sujeto investigado confluyen en una misma persona, al igual que ocurre en otros estudios (e. g., Pascual, 2003).

Los instrumentos de recogida de información serán los diarios del profesorautor, trabajos y memorias de asignaturas, cuadernos de clase del alumno, entrevistas, autoinformes del alumno y los relatos de algunos expertos en cuestiones relevantes para la investigación. Asimismo, el uso de un biograma (Bolívar, op. cit., p. 177) nos va a permitir representar en el tiempo la trayectoria formativa permanente del autor.

Todo este capítulo se podría situar en una perspectiva postmoderna (FernándezBalboa, 2003), ya que lo que se cuenta, lo personal, pretende adquirir cierta potestad y poder, lo que conlleva asumir que el conocimiento no es neutro ni objetivo. De alguna forma, se revindica lo subjetivo como forma de generar conocimiento, a la vez que se otorga de validez a esa subjetividad (ibídem).

No se contempla la posibilidad de que existan problemas éticos derivados de la identificación de las personas que aparecerán a lo largo de este capítulo ya que unas han sido preguntadas al respecto y han autorizado su incorporación al estudio, otras 
aparecían en documentos públicos y, por tanto, no ha lugar a esconder tales identidades $\mathrm{y}$, en el caso de otras con las que no se ha podido contactar, se ha optado por no nombrarlas para preservar su anonimato.

Por último, por lo que se refiere a la forma de plasmar el análisis de los relatos de vida acontecidos, he preferido seguir la trayectoria temporal en la que tuvieron lugar. De esta forma, no solo podré recoger de manera concreta y fidedigna la información relevante, sino que también me permitirá ir descubriendo la evolución que hago de mi experiencia vital, lo cual se sitúa en la línea del análisis holístico de la estructura propuesto por Sparkes (2004 y 2007).

\section{4.- LLAMANDO A LAS PUERTAS DE LA EDUCACIÓN}

Desde que cursaba C.O.U. (Curso de Orientación Universitaria) ya tuve claro que quería estudiar "INEF" (así es como llamábamos, incluso ahora sigue empleándose, a los estudios universitarios de Educación Física). Era una carrera universitaria un tanto nueva ${ }^{162}$ que resultaba muy atractiva para adolescentes como yo, entregados y apasionados del mundo del deporte. El chándal y los playeros eran mi vestimenta habitual. Practicar cualquier deporte (no destacaba en ninguno pero todos los "cogía" rápidamente sin necesidad de entrenar horas y horas) y correr por los caminos eran mi más preciado pasatiempo.

Durante el curso 1986-87 me preparé la prueba de acceso a la universidad (por aquel entonces, la Selectividad) ya que en septiembre del curso anterior la había suspendido. Ese año lo dediqué solo a entrenar y a estudiar (quizás menos esto último). Los entrenamientos eran espartanos: duros e intensos, y los estudios, livianos y timoratos. La decisión que había tomado, junto con algún que otro compañero, era la de

\footnotetext{
${ }^{161}$ Instituto Nacional de Educación Física.

162 En el curso 1987-88 comenzó la primera promoción del INEF de Castilla y León, adscrito a la Universidad de León.
} 
presentarme solo en el INEF de Madrid. Conocía al dedillo las pruebas y todos los trucos para intentar conseguir marcas mayores los había entrenado infinidad de veces. Durante la realización de las pruebas la decepción fue doble: por un lado todos los trucos automatizados para conseguir mejores marcas fueron inútiles y, por otro, el nivel de los "contrincantes" era muy superior al mío. De alguna forma los veía como gigantes, como de otra dimensión. Yo estaba en categorías inferiores y ellos en primera división: sus estilos y técnicas, sus lenguajes, sus indumentarias, sus productos de ingesta para mejorar sus marcas..., todo estaba fuera de mi estilo habitual de vida. El desastre por no entrar no lo fue tanto en cuanto que me lo esperaba por lo allí vivido y sentido.

Como no contemplaba otra alternativa que realizar estos estudios universitarios, no me había preinscrito en ninguna otra facultad, así que se me planteó un nuevo problema: qué hacer durante otro curso hasta la repetición de las pruebas. Decidí dedicarme por entero a preparar las pruebas físicas y me dediqué a entrenar y entrenar pensando que el sacar más y mejor provecho a mi cuerpo era la solución al problema o la llave que me proporcionaría la entrada al INEF. Quería estar a la altura de los de primera división, quería ser uno de ellos y mirar por encima a los demás.

Durante ese periodo se me planteó la posibilidad de hacer un curso a distancia sobre Educación Física ${ }^{163}$ y lo aproveché para empezar a acercarme a ese mundo tan deseado. Se puede decir que fue mi primer contacto académico con cuestiones propias de esta asignatura. Contenidos sobre ejercicios de todo tipo, teoría del entrenamiento, primeros auxilios, metodología... comenzaron a rondar por mi cabeza. Nada sobre atención a alumnos con necesidades educativas especiales; todo estaba relacionado con el acondicionamiento físico, el "cuerpo máquina”.

Pienso que, visto ahora con la madurez de los años, el que yo realizase este curso se podría concebir como un consuelo menor por la desgracia de no haber podido estudiarlo de forma oficial. Al menos podía decir, sin estar contando toda la verdad pero sin llegar a pronunciar ninguna mentira, que estaba estudiando Educación Física. ${ }^{163}$ El título en cuestión era el de "Monitor de Educación Física", de 400 horas de dedicación y expedido
por el centro de estudios a distancia INTESA. 
En el verano de 1988 intento nuevamente acceder a los estudios de INEF, pero esta vez decido presentarme únicamente en León. Aún perduran en mi las sensaciones y emociones tan esperanzadoras que tuve al concluir las pruebas físicas que realizábamos todos los aspirantes como paso previo para dilucidar los 80 "afortunados" que ese año iniciarían estos estudios. Por aquel entonces, no como sucede ahora, las marcas obtenidas en las diferentes pruebas físicas llevaban parejas una nota. Al final de su realización se hacía la media de las notas obtenidas en ellas con la nota que se llevaba de la Selectividad. La resultante era la que se consideraba para graduar el puesto de cada aspirante en relación a los demás. Como he dicho, los ochenta mejores serían los "elegidos para la gloria”. Aquí no había cabida para ninguno que tuviese dificultades motoras; solo la élite motriz, o cercana a ella, podía estudiar Educación Física.

"¡Ya estoy dentro!”. Ese era mi único pensamiento a la vista de las estupendas marcas que había obtenido en la casi totalidad de las pruebas. Tenía evidencias rotundas y objetivas: los resultados eran bastante superiores a los conseguidos en los entrenamientos y también observaba que estaba algo por encima de muchos aspirantes que realizaron las pruebas conmigo. Me había sentido de primera división. La sensación de felicidad y del deber cumplido por los buenos resultados obtenidos no me hacían contemplar otra posibilidad que no fuese la de haber logrado la meta deseada.

¡Qué equivocado estaba! La alegría duró lo que tardaron en darme los resultados definitivos. Días después me confirmaron que había quedado fuera por una puntuación de 0,01 . Todos mis esfuerzos, sufrimientos, horas de entrenamientos... para conseguir ser uno de los mejores había resultado en vano. No había servido para nada machacarme físicamente para demostrar que era de primera división. La cuestión ahora era no perder nuevamente el año desde un planteamiento académico.

Sin embargo, esta vez había tomado la precaución de preinscribirme en la Universidad de Valladolid por si de nuevo la situación no salía como la había soñado. Así que durante el curso 1988-89 me matriculé en $1^{\circ}$ de Magisterio, especialidad de Ciencias, de la Escuela Universitaria del Profesorado de E.G.B. de Valladolid. 
De este primer curso, el único que hice de esta carrera, recuerdo especialmente la asignatura de Educación Física. Supuso una experiencia diferente a toda la acaecida en mi etapa escolar de la E.G.B. y B.U.P. Además de que fue la primera vez que tuve que realizar un cuaderno de clase en el que recoger y comentar lo realizado y experimentado en cada lección, de pronto me encontré que lo físico, el rendimiento, las marcas y el sudor eran sustituidos por un mundo de sonidos, dramatizaciones, movimientos expresivos, relajación...

"Fue una de las mejores clases porque trabajamos cosas nuevas... [era una clase sobre el mimo]" (Cuaderno de clase $1^{\circ}$ Magisterio, 18 de mayo de 1989)

Cambiamos las pelotas, metros, cronómetros y balones medicinales por cuerdas, cintas, sábanas, periódicos, panderetas, globos...

"Al igual que en la sesión anterior, utilizamos un nuevo elemento de trabajo [se trataba de periódicos] al que le sacamos todas las posibilidades. Una clase muy amena y al final muy divertida." (Cuaderno de clase $1^{\circ}$ Magisterio, 16 de marzo de 1989)

Supongo que todo aquello me enganchó $\mathrm{y}$, como poco, rompió con la consideración que tenía de la Educación Física. La tradición hegemónica del cuerpo máquina, que era por la que había sido rechazado para acceder a estudiar en el INEF, se sustituyó por otra más cercana a la del cuerpo expresivo.

“...nuestro cuerpo sirve para algo más que movernos, también nos puede servir como medio de comunicación, podemos representar con él multitud de cosas y objetos, todo es echarle imaginación al asunto." (Cuaderno de clase $1^{\circ}$ Magisterio, 2 de marzo de 1989)

Comprobé otra forma de trabajar y entender la Educación Física en la que no había que correr, saltar, competir... para desempeñar con acierto una asignatura obligatoria. En esta nueva práctica todos teníamos cabida y a todos nos llegaba de una u otra forma. Había despertado en mí una sensación distinta de lo hasta ahora experimentado. 
"Seguro que no exagero si digo que ha sido la clase más positiva de todo el curso...

...creo que has sabido llevarnos poco a poco; al principio (personalmente y creo que a nivel general) éramos reacios a esas ideas de la «nueva» educación física que querías impartirnos...

Nos has hecho perder el respeto a los demás; en mi caso, nunca pensé que llegaría a hacer lo que he hecho (representación de griegos, participación en clase, etc.)" (Cuaderno de clase $1^{\circ}$ Magisterio, Conclusiones finales a la asignatura de Educación Física, mayo de 1989)

Acabé $1^{\circ}$ de Magisterio con todas las asignaturas aprobadas en junio, lo cual me permitiría subir mi nota de selectividad mediante la aplicación de una fórmula elaborada por la Universidad de León para casos como el mío. De pronto me encontré con una nota alta en el apartado académico, lo cual, junto con la nueva Educación Física vivida, pudieran ser las razones por las que ese año empleé menos esfuerzos y tiempo a la cuestión física del entrenamiento. Intuía que no era necesario tanto sufrimiento ni tanto entrenamiento si era mejor en el apartado académico.

Y con estas condiciones me presenté nuevamente a las pruebas de acceso a los estudios de Educación Física en el INEF de León. Y esta vez no fallé: el objetivo, el gran objetivo de estudiar esta carrera de cinco años estaba alcanzado en el verano de 1989. Formaría parte de la que sería la tercera promoción de este INEF.

\section{5.- LA FORMACIÓN INICIAL: PREPARANDO EL CAMINO HACIA LA ENSEÑANZA DE LA EDUCACIÓN FÍSICA}

La formación inicial de los Licenciados en Educación Física puede estar orientada hacia diferentes salidas profesionales, tales como la docencia, el entrenamiento deportivo, la gestión, etc. (Romero, 2004, p. 3). Yo exploré durante los cinco años de formación todos esos caminos, si bien es cierto que desde que inicié los estudios sabía que lo que yo deseaba era ser profesor de Educación Física en un instituto. Recuerdo muchas de las enseñanzas recibidas y las prácticas realizadas. No solo las recuerdo por lo que la memoria me pueda permitir, sino porque consulto con 
cierta asiduidad apuntes de algunas asignaturas, lecturas, documentos y cuadernos con anotaciones que guardo como si tuviera que examinarme de ellos mañana mismo.

A lo largo de esos cinco años cursé diferentes asignaturas más o menos relacionadas con el ámbito de la docencia de la Educación Física. De entre todas ellas destacan las siguientes, todas ellas anuales: Fundamentos de Pedagogía (1 ${ }^{\mathrm{er}}$ curso), Pedagogía de la actividad física (2 $2^{\circ}$ curso), Didáctica I: Métodos y Técnicas de Enseñanza (3 ${ }^{\text {er }}$ curso), Didáctica II: Métodos y Técnicas de Evaluación, Educación Física en las Enseñanzas Medias y Universitarias, Fundamentos Pedagógicos de la Educación Física Especial (todas de $4^{\circ}$ curso), Análisis de la enseñanza en la Educación Física, Educación Física Especial para Minusválidos Sensoriales y Educación Física Especial para Minusválidos Físicos (todas en $5^{\circ}$ curso). Obviamente, estas tres últimas suponen el saber científico más cercano a la atención educativa de los alumnos con algún tipo de dificultad de aprendizaje asociado a discapacidad (motora o sensorial).

Antes de seguir, considero necesario detenerme en este punto para hacer mi propia valoración del papel que este tipo de asignaturas desempeñaban en los currículos de las Facultades de Ciencias de la Actividad Física y el Deporte (o INEFs) durante el momento de mi etapa universitaria, así como la que creo observar ahora.

Para empezar con esa valoración, en el cuadro siguiente recojo la distribución por centros, asignaturas, duración y carácter de la disciplina académica de la Educación Física Especial (Alejandre, 1994, p. 115). 


\begin{tabular}{|c|c|c|c|}
\hline CENTRO & ASIGNATURAS & DURACTÓN & CARÁCTER/CURSO \\
\hline $\begin{array}{l}\text { Instibuto Nacsionel de } \\
\text { Edocación Fixica de Madrid }\end{array}$ & $\begin{array}{l}\text { Fundamentos de ln educación } \\
\text { fisica especial }\end{array}$ & Amual & Optativa $A^{8}$ curso \\
\hline 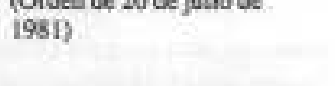 & $\begin{array}{l}\text { Didactica de la educación } \\
\text { fisica especial }\end{array}$ & Cuatrimestral & Optative $5^{2}$ curso \\
\hline $\begin{array}{l}\text { Instinut Nocional d'Educicio } \\
\text { Finica de Catalumya - } \\
\text { Barcelone }\end{array}$ & $\begin{array}{l}\text { Pundamentos de la educación } \\
\text { fisica ergecial }\end{array}$ & Anual & Optativa $4^{2}$ curso \\
\hline $\begin{array}{l}\text { (Ordes de } 20 \text { de jutio de } \\
\text { is:1) }\end{array}$ & $\begin{array}{l}\text { Didacticas de la educselton } \\
\text { fisica especial }\end{array}$ & Cuatrimestral & Optativa $5 \times$ cusso \\
\hline $\begin{array}{l}\text { Institut Nwcional d'Bufucacio } \\
\text { Fivica de Catalurya - Leida } \\
\text { (Ordent de } 20 \text { de julio de }\end{array}$ & $\begin{array}{l}\text { Fundamentos de is educacich } \\
\text { fisica especiat }\end{array}$ & Anual & Optativa 4 Curso \\
\hline issi) & $\begin{array}{l}\text { Didactica de la educación } \\
\text { fisica erpecial }\end{array}$ & Cuatimestral & Optativa $5^{x}$ cuno \\
\hline $\begin{array}{l}\text { Ficulisd de Ciencias de la } \\
\text { Actividad Fisica y el Depone } \\
\text { de Granada }\end{array}$ & $\begin{array}{l}\text { Fundamentos de th educueiofen } \\
\text { fissica especial }\end{array}$ & Anual & Optative 4 exusso \\
\hline $\begin{array}{l}\text { (Onden de } 9 \text { de mayo de } \\
\text { 1983) }\end{array}$ & $\begin{array}{l}\text { Didactica de la colucición } \\
\text { fisice especial }\end{array}$ & Cuatrimestral & Optative $5 \%$ curso \\
\hline $\begin{array}{l}\text { Instituato Nacional de } \\
\text { Educación Firice de Calicia } \\
\text { (Orden de } 15 \text { de julio de } \\
\text { 1987) }\end{array}$ & $\begin{array}{l}\text { Fundamentos de la educación } \\
\text { fisica especial }\end{array}$ & Anual & Opeative, $4^{8}$ curso \\
\hline 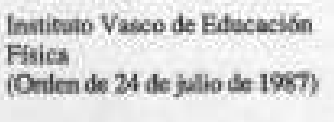 & Pedagogia II & Cuntrimestral & Othligateria $3^{2}$ curso \\
\hline $\begin{array}{l}\text { Instinut Valencià d'Edobeacio } \\
\text { Fisica } \\
\text { (Orden de } 13 \text { de marzo de }\end{array}$ & Bducheibe fisica especial & Anal & $\begin{array}{l}\text { Obligatoria esp, didlictica } \\
\text { espociales, } 4 \text { curso }\end{array}$ \\
\hline [989) & $\begin{array}{l}\text { Discapiciacidec fisice, } \\
\text { pesiquica y sensorial. }\end{array}$ & Anmal & $\begin{array}{l}\text { Obligumaria esp, didactica } \\
\text { especiales } 4^{*} \text { cursw }\end{array}$ \\
\hline $\begin{array}{l}\text { Pacultad de Ciencias de la } \\
\text { Actividad Fisica y el Deporte } \\
\text { de la Uaiversidud Politécnica } \\
\text { de Canarias. } \\
\text { (Resolución de } 2 \text { de junio de } \\
\text { 1989) }\end{array}$ & $\begin{array}{l}\text { Fundamentoe y didsctica de } \\
\text { Is educación físicu especial }\end{array}$ & Anual & Optativa. $2^{\circ}$ ciclo \\
\hline $\begin{array}{l}\text { Instibuto Nacional de } \\
\text { Eduracián Fisics de León } \\
\text { (Orden de is de jalio de }\end{array}$ & $\begin{array}{l}\text { Fundamentos pedagógicos de } \\
\text { la educoción física especial }\end{array}$ & Anual & Obligatoria. 4" curso \\
\hline 1992) & $\begin{array}{l}\text { Ed. fiss especial pars } \\
\text { mirusvilididos fisicos. }\end{array}$ & Anoal & Optativa, $5^{n}$ curso \\
\hline & $\begin{array}{l}\text { Ed. fis. especial para } \\
\text { minusvilidess priquicos. }\end{array}$ & Arual: & Optativa 5" curso \\
\hline & $\begin{array}{l}\text { Ed. fis. especial para } \\
\text { minusvabidos sensorieites. }\end{array}$ & Anual. & -Optativa, $5^{\circ}$ curso. \\
\hline
\end{tabular}

Lo que llama la atención de este cuadro es el reducido número de asignaturas relacionadas con la Educación Física especial que se impartían en los centros de formación de profesores en el momento previo al giro normativo en la atención a la diversidad en Educación Física. 
En muchos de ellos la oferta de asignaturas es de libre elección para el alumnado, lo cual pudiera contribuir a configurar los perfiles de los futuros docentes sin conocimientos específicos al respecto. Tanto si la docencia no era la salida profesional elegida durante la etapa de la formación inicial como si el atractivo de estas asignaturas era minúsculo, no formarían parte del currículo del individuo. Si las circunstancias de la vida llevaron a esos sujetos a incorporarse al ámbito educativo, no cabe duda de las carencias formativas iniciales con las que accedieron.

Centraré ahora el foco de atención en el INEF de León que fue mi centro de formación universitaria, la ahora denominada Facultad de Ciencias de la Actividad Física y el Deporte. En los años que yo cursé $4^{\circ}$ y $5^{\circ}$ de carrera, la profesora que impartía las asignaturas de la índole de la Educación Física Especial era precisamente la autora de ese cuadro.

Resulta curioso que tres años más tarde esta misma autora (Alejandre, 1997, p. 577) constató cierta reducción de este tipo de carga lectiva en los programas del INEF de León, por lo que ya solo existían dos asignaturas, optativas en $5^{\circ}$ y de duración anual: Educación Física para Minusválidos Psíquicos y Educación Física Especial para Minusválidos Sensoriales. Al parecer, al asignatura obligatoria de $4^{\circ}$, Fundamentos Pedagógicos de la Educación Física Especial, desaparece al igual que la de Educación Física Especial para Minusválidos Físicos. Obviamente este tipo de formación estaría perdiendo peso en esta Facultad, cuantitativo por ser menor el número de horas de dedicación, y cualitativo porque se ha pasado a una optatividad en detrimento de una mínima formación obligatoria que antes sí existía.

Pero considero que aún hay más evidencias de la escasez en la formación inicial especializada en el tratamiento de alumnos con dificultades de aprendizaje asociadas a cualquier discapacidad motriz, sensorial o psíquica ya que, consultando los actuales planes de estudio conducentes a la obtención del título de Graduado en Ciencias de la Actividad Física y el Deporte por la Universidad de León ${ }^{164}$, se observa que esas

\footnotetext{
${ }^{164}$ Para ello se ha accedido a la información que aparece en la página Web de la Universidad de León http://www.unileon.es/estudiantes/estudiantes-grado/oferta-de-estudios/planes?titula=1402 (consultado el 24-02-2015)
} 
asignaturas han desaparecido, limitándose ahora la oferta a las siguientes: Actividad Física Adaptada (semestral de 6 créditos y obligatoria en $3^{\circ}$ ), Deporte Adaptado (semestral de 4,5 créditos y optativa en $3^{\circ}$ ) y, nuevamente, Deporte Adaptado (semestral de 4,5 créditos y optativa en $4^{\circ}$ ). Parece como si la oferta se equiparase, en lo concerniente a optatividad y temporalidad, a los planes que existían en 1994 en otras facultades.

En definitiva, si antes me quejaba de la escasa formación inicial recibida al respecto de la Educación Física Especial, me temo que ahora el problema se agudiza de manera alarmante. Lo cual redunda primeramente en la formación del profesorado que se está formando y, en segundo lugar, en los alumnos a los que se dirigirán sus enseñanzas. No tengo ninguna duda al respecto: a menor formación, mayores probabilidades de inseguridad conducentes a no realizar propuestas inclusivas, temores y miedos (in)fundados...

"Los estudios revelan incoherencias en la cantidad de tiempo dedicado durante los programas de FPEF [formación de profesores de Educación Física] a apoyar a los futuros profesores de inclusión, más concretamente, cómo incluir e implicar en la educación física a los niños con necesidades educativas especiales. Una cuestión que se suele abordar de manera teórica y por lo tanto incongruente con el desarrollo de competencias.

...En consecuencia, convendría llevar a cabo una revisión continua de los programas de formación para responder a los retos inherentes a la implementación de la metodología inclusiva..." (UNESCO, 2015, p. 36. Aclaración mía)

Retomando mi narración, por el año en que cursé esas asignaturas señaladas algunos párrafos atrás, posteriores al año de la entrada en vigor de la LOGSE y todo lo que ello conllevaba, era de suponer que las enseñanzas asumían el principio de la integración de cualquier tipo de alumnado en nuestras clases. Así nos lo transmitieron y así cuajó en mí la idea de la integración. No obstante, todo ese ámbito, aplicado a alumnos con dificultades de aprendizaje asociadas a cualquier discapacidad motriz (o sensorial) ya lo intuía como inalcanzable.

"Con todo, las sesiones nos han servido para muchas cosas: situarnos en el lugar de estas personas [referido a alumnos con discapacidades 
motrices o sensoriales], sentir lo que ellos ante determinadas situaciones, ver qué objetivos son adecuados para conseguirlo [la integración y participación], con qué contenidos; en definitiva, acercarnos a un mundo desconocido (y muy difícil de conocer en su totalidad)." (Memoria final de las asignaturas Educación Física Especial para minusválidos sensoriales y Educación Física Especial para minusválidos físicos, mayo de 1994)

De alguna forma, aun estando en un periodo de formación inicial, ya apreciaba la escasa aplicabilidad y profundidad de las enseñanzas recibidas. Asunto que se constata en este mismo capítulo cuando abordo la formación permanente como necesidad imperiosa e imprescindible para lograr ciertos saberes o informaciones.

"Pienso que habría que reducir el número de prácticas y sustituirlas por charlas, discusiones sobre contenidos, objetivos... que se persiguen con estos alumnos [referido a alumnos con discapacidades motrices o sensoriales], preparaciones de DIAC de una manera eficaz [Documento Individual de Adaptación Curricular], etc." (Memoria final de las asignaturas Educación Física Especial para minusválidos sensoriales y Educación Física Especial para minusválidos físicos, mayo de 1994)

Las prácticas servían para aplicar los saberes aprendidos en el aula. Todas las teorías, recomendaciones, pautas... vistas en formato papel tenían que traducirse en propuestas de ámbito motor experimentadas por nosotros mismos, tanto en lo referente al propio diseño de las mismas, como en lo relacionado con su puesta en escena como alumnos actuando en un role-play. Pero esa forma de trabajo, como ya se apuntó en el Capítulo “CONFIGURACIÓN DEL MARCO TEÓRICO-LEGAL DE LA EXENCIÓN", y se corroborará más adelante en el apartado de la formación permanente, es muy reduccionista y repetitiva.

"Es inevitable comenzar por lo que más se ha quedado al final de todo el curso: la monotonía y pocas ganas con las que se hacían las últimas sesiones. Al principio del curso todo era nuevo, pero al incidir tanto sobre los mismo (siempre ciegos o amputados) ha hecho que se hicieran muy pesadas y difíciles de llevar." (Memoria final de las asignaturas Educación Física Especial para minusválidos sensoriales y Educación Física Especial para minusválidos físicos, mayo de 1994) 
Por otro lado, intuía, sentía o percibía que la formación se quedaba corta. La inexperiencia y las ganas de dominar un campo con múltiples aristas me incitaban a demandar un pragmatismo exacerbado en este terreno, como si todo él fuese homogéneo y todas las experiencias certeras en su eficacia independientemente del alumnado.

"Además de preparar una sesión [formaba parte de la asignatura diseñar una sesión que se aplicaba con el resto de los compañeros], deberíamos de realizar un documento en el que se reuniesen todas las características $y$ problemáticas de estas personas [referido a alumnos con discapacidades motrices o sensoriales], así como la elaboración de un DIAC [vid. la cita anterior] para un casos concreto de este tipo." (Memoria final de las asignaturas Educación Física Especial para minusválidos sensoriales y Educación Física Especial para minusválidos físicos, mayo de 1994)

Finalmente, paradojas de la enseñanza, estuve exento de la práctica de forma temporal durante algunas de estas clases. Por el tipo de deporte que yo practicaba por aquel entonces, el judo, no era raro que durante algunas semanas estuviera lesionado. De hecho, tuve dos subluxaciones acromio-clavicular y una esterno-clavicular durante el año 1994. Pues bien, quizás llevado por esa monotonía a la que antes hacía referencia, argumentaba mi imposibilidad para tomar partido en esas sesiones de role playing en base a las lesiones que padecía. De esta forma justificaba y evitaba la práctica. Mi intervención se limitaba a estar sentado en el banco, observar a los demás y ayudar en la toma de notas. Al final de la sesión participaba en la puesta en común con compañeros y profesora. Visto ahora, me percato de que la falsa integración ya hacía acto de presencia en la misma formación inicial. ¿Cómo no reproducir posteriormente lo vivido en las facultades? 


\section{6.- PRIMEROS PASOS EN LA ENSEÑNAA DE LA EDUCACIÓN FÍSICA}

Una vez concluida mi formación en el Instituto Nacional de Educación Física adscrito a la Universidad de León, allá por el año 1994, tenía muy claro que mi futuro profesional se desarrollaría en el ámbito de la educación. Sentía una verdadera vocación e ilusión por enseñar aquello que más me gustaba, para lo cual había estado preparándome los últimos cinco años. De hecho, ya había ejercido como monitor deportivo con equipos de chavales de diferentes edades.

Pero mi andadura laboral seria tuvo sus verdaderos comienzos en el terreno de la gestión deportiva ya que a mediados de 1995 empecé a desempeñar las funciones de Coordinador Deportivo del Ayuntamiento de Tordesillas. Por fortuna para mí, ese mismo año se me abrieron las ansiadas puertas del contexto educativo y pude compaginar ese trabajo con el de profesor de Educación Física a media jornada en un centro de carácter privado de la provincia de Valladolid.

Una de las cosas buenas (o malas, dependiendo de lo que se pretenda buscar) que nos puede deparar el paso del tiempo es que podemos volver atrás y contemplar lo que fuimos, lo que hicimos o lo que pensábamos. Todo eso nos podrá gustar más o menos, estaremos ahora en la misma onda o en una postura antagónica, pero el pasado, lo que dejamos escrito, evidencia nuestro pensamiento y posicionamiento ante situaciones concretas, en este caso de tipo profesional.

Simplemente por dejar constancia de mi forma de pensar y actuar, haré alusión a las dos primeras programaciones didácticas que tuve que elaborar en mis inicios como profesor de Educación Física. De alguna forma, estas primeras actuaciones las enmarco en lo que fue mi rodaje y aprendizaje en ese asunto y, por tanto, forman parte de mi formación. 
La primera programación didáctica que tuve que diseñar lo hice allá por el curso 1995-96. Por las características del tipo de centro en el que desempeñaba mi labor (de carácter priado y con una línea pedagógica establecida desde "altas instancias"), tuve poco margen de actuación en su redacción final.

Por lo que respecta al apartado de la atención a la diversidad, al que denominé "Situaciones especiales", me limité a explicitar el funcionamiento a seguir ante los casos que pudieran aparecer. Y, al igual que lo comprobado en el Capítulo 6, yo también otorgaba un poder relevante al documento médico. Asimismo, ya clasificaba las limitaciones de tipo motor como temporales o permanentes, y totales o parciales.

"Aquellos alumnos que, por cualquier razón, tengan algún problema motor (ya sea temporal o permanente) que les impida el normal seguimiento de las clases como al resto de sus compañeros, deberán entregar un certificado médico oficial en el que se detalle:

- Defecto o lesión

- Tratamiento al que se somete.

- Especificación de si la contraindicación es total o sólo limita a ciertas prácticas físico-deportivas." (Programación didáctica curso 1995-96)

De igual manera, no me libraba de la consideración que habitualmente se hacía de la integración de este tipo de alumnos en términos de la "falsa integración". Pero resulta sumamente curioso ahora que en la redacción del asunto me contraponía a mi mismo, como si por un lado quisiera que verdaderamente estuvieran integrados (en términos de participación) y por otro cayese en las redes del tradicional tratamiento que se les otorgaba como si esa opción fuese verdaderamente la única posible o viable y, además, convencido de que haciendo ese tipo de actividades favorecía la integración del alumno en mis clases.

"Deberán asistir siempre a clase, participando en aquellas tareas que su lesión les permita: arbitrajes, control, ayuda de organización del material, etc.” (Programación didáctica curso 1995-96)

Años después, cuando ya ejercía como Profesor de Secundaria de la Junta de Castilla y León, la situación parecía querer cambiar. Tenía (junto con mis compañeros 
de departamento) la convicción, aunque fuese por prescripción legislativa, que los exentos no existían, pero consideraba(mos) que sí pudiera haberlos de determinados contenidos.

“...Distinguiremos aquellos alumnos/as que están limitados para realizar unas determinadas actividades, de aquellos que no pueden practicar actividad física. Hemos de recordar que no existen los alumnos/as exentos totales, ya que la Educación Física es una materia obligatoria, pero sí los exentos de unos determinados contenidos..." (Programación didáctica curso 2000-01)

La integración era un reto, pero se entendía como una ineludible necesidad a la cual estábamos obligados, si no conseguir, al menos sí intentar.

"Tradicionalmente, los alumnos/as considerados «exentos» suponían una «carga» para el profesor. Se ha tendido a solucionar el problema «aparcándolos» durante las clases y limitando su aprendizaje a contenidos de carácter teórico. Creemos que con un poco de imaginación podemos integrar en mayor o menor medida a dichos alumnos/as dentro de la marcha general del curso, haciéndoles sentirse más útiles y consiguiendo una mayor motivación y nivel de aprendizaje." (Programación didáctica curso 2000-01)

Paro los casos de alumnos con discapacidad grave y/o permanente concebíamos que los programas específicos para ellos tenían que centrarse en contenidos adaptados, primando, como venía siendo habitual, los de tipo conceptual y actitudinal por encima de los de índole motora. Además, aunque caíamos nuevamente en la falsa integración, queríamos fomentar o propiciar su auténtica participación a través del desarrollo de algún contenido de tipo procedimental, como es el caso de la expresión corporal. La cuestión es saber con certeza qué propiciaba todo este planteamiento. No me parece descabellado pensar que los miedos, las inseguridades pedagógicas, el peso de la responsabilidad... favoreciesen todo esas propuestas.

"El establecimiento de los programas específicos para estos alumnos/as debe centrarse tanto en los contenidos adaptados (especialmente orientados hacia los conceptos y actitudes) como en los recursos didácticos que se van a emplear para integrar a los alumnos en la marcha de la clase. Proponemos a continuación algunas posibilidades para llevarlos a cabo: 
- Realización de trabajos teóricos relacionados con los contenidos que se están trabajando, para posteriormente exponerlos ante sus compañeros (lo cual otorga un carácter práctico y de utilidad a la tarea).

- Elaboración de apuntes para sus compañeros.

- Participación en las actividades deportivas realizando el arbitraje de los partidos que jueguen sus compañeros.

- Dirección de actividades a sus compañeros: juegos, estiramientos, ejercicios de relajación...

- Existe la posibilidad de que los alumnos con desviación de columna, o con otro tipo de trastorno funcional, realicen los ejercicios prescritos por el médico durante las clases de Educación Física.

- Recogida de marcas y datos, colocación y recogida de material, etc.

- En los trabajos de expresión corporal pueden participar casi sin limitaciones.” (Programación didáctica curso 2000-01)

En el caso de los alumnos con una discapacidad transitoria o para un determinado tipo de contenidos, la cuestión se plantaba como más certera en lo relativo a su integración, como que no había dudas de que esos alumnos tenían que "hacer algo" en nuestras clases.

"Para los alumnos/as que padezcan una discapacidad transitoria (lesionados temporales), proponemos establecer un programa de trabajo individualizado en el que realicen las actividades que sean compatibles con la lesión durante el tiempo que ésta permanezca, así como la amplia gama de actividades y tareas recogidas en la página anterior." (Programación didáctica curso 2000-01)

Sin embargo, la realidad quedó muy lejos de la teoría y de los planteamientos iniciales. Las "buenas" intenciones plasmadas a principio de curso en la programación didáctica, se quedaron solo en eso pues la práctica del día a día nos demostró que nuevamente el tratamiento pedagógico llevado a cabo con estos alumnos continuó en la línea de la falsa integración. Estábamos atrapados en sus redes y parecía que no había forma de salir de ella. Con todo, el asunto me (nos) preocupaba, se percibía como inacabado, como que aquello no se estaba haciendo del todo correctamente ${ }^{165}$.

\footnotetext{
${ }^{165}$ En parte, fruto de esa preocupación y dilemas pudo surgir la elaboración de esta tesis. Este autor reconoce estar aún inmerso en grandes dudas, miedos, intenciones y divagaciones contradictorias al respecto del asunto. Como dije anteriormente, el replanteamiento de mi labor es constante, llegando incluso a "martirizarme" por las luchas tan duras a las que someto mis intenciones "buenistas e inclusivas" cuando las aplico a una cruda y asfixiante realidad llena de matices y detalles impredecibles e irrepetibles.
} 
"Con respecto al tema de lesionados (con carácter permanente) se ha pretendido integrarles en el desarrollo de las clases a través de diferentes tareas, tales como: anotación y registro de marcas, arbitraje de partidos, colocación de material, ayuda para la ejecución de habilidades gimnásticas, etc. Aun así, este es un tema que nos preocupa y que puede ser objeto de estudio para el año próximo." (Informe final de departamento curso 2000-01)

\section{7.- MI INTERÉS POR SEGUIR FORMÁNDOME}

Casi desde el principio de mi bautizo en el ámbito de la enseñanza de la Educación Física, pude corroborar que las enseñanzas recibidas en la Facultad (INEF) no eran suficiente para afrontar y resolver con garantías de éxito algunas de las situaciones y problemas de diversa índole que se me iban presentando en ambos trabajos, especialmente la docencia (Romero, 2004, p. 3), por lo que tuve que recurrir a la formación continua, paralela a la propia realidad laboral, como forma de paliar las carencias formativas de mi formación universitaria ${ }^{166}$.

Por tanto, mi interés por la realización de cursos, seminarios... creció por las propias demandas profesionales. Pero no fue un crecimiento sin rumbo, sino más bien todo lo contrario. Solo realizaba aquellas actividades que a priori consideraba me eran útiles por los asuntos que en ellas se planteaban, sin importarme tanto la cuestión de los certificados horarios para justificar los complementos de formación en el desempeño de la función docente.

Por poner un primer ejemplo, relacionado directamente con el puesto de Coordinador Deportivo, realicé en 1996 un curso de Administración Deportiva de Castilla y León, organizado por la Consejería de Educación y Cultura, y otro en 1997 de Especialización en Gestión de Organizaciones y Servicios Deportivas, organizado por

\footnotetext{
${ }^{166}$ En parecidos términos se muestran Jové y Miñambres (1997) en un estudio realizado a una muestra de 170 docentes. En sus conclusiones afirman que con la formación inicial recibida en las universidades no se puede hacer frente a los retos que se plantean en el aula cuando hay alumnado con necesidades educativas especiales. Además, el profesorado ha tenido que optar, por iniciativa propia, por la realización de cursos de todo tipo que paliasen los déficits detectados.
} 
la Universidad Politécnica de Madrid, de 14 créditos. A finales de ese año decidí poner punto final a mi paso por la gestión deportiva para dedicarme, además de al trabajo como profesor de Educación Física en el centro privado, a la preparación de las oposiciones al Cuerpo de Profesores de Enseñanza Secundaria de la Junta de Castilla y León. A finales del verano de 1998 conseguí una de las trece plazas convocadas ese año para la especialidad de Educación Física en Secundaria.

Siendo ya profesor de Educación Física, tanto en mi etapa educativa privada como pública, he tomado parte en multitud de actividades formativas con claras repercusiones en el ejercicio de la docencia.

Como muestra de mi interés por este tipo de actividades, en la Tabla 12 aparece mi biograma (Bolívar, op. cit., p. 177) con las más significativas realizadas durante el período comprendido entre el curso 1995-96, momento en el que me inicié como profesor de Educación Física, y el 2005-06 ${ }^{167}$, que es cuando di por decidida toda la temática de la tesis.

\footnotetext{
${ }^{167}$ No incluyo los cursos encaminados a la consecución de los estudios de Tercer Ciclo llevados a cabo durante los cursos académicos 2000-2001 y 2001-2002.
} 


\begin{tabular}{|c|c|c|c|}
\hline CRONOLOGÍA & ACTIVIDAD FORMATIVA & ORGANIZACIÓN & $\begin{array}{l}\text { DURACIÓN / } \\
\text { CRÉDITOS }\end{array}$ \\
\hline \multirow{3}{*}{ 1995-96 } & Elaboración de Unidades Didácticas & $\begin{array}{l}\text { Fundación ECCA / } \\
\text { MEC }\end{array}$ & 5 créditos \\
\hline & Currículo Escolar & $\begin{array}{l}\text { Fundación ECCA / } \\
\text { MEC }\end{array}$ & 5 créditos \\
\hline & $\begin{array}{l}\text { Preparación para la función docente en } \\
\text { el marco de la LOGSE: Aproximación al } \\
\text { área y materia de la Educación Física en } \\
\text { Secundaria }\end{array}$ & $\begin{array}{l}\text { Universidad de León y } \\
\text { COPLEF }^{168}\end{array}$ & 11 créditos \\
\hline \multirow{3}{*}{ 1996-97 } & $\begin{array}{l}\text { Estrategias de intervención en el aula } \\
\text { desde la LOGSE }\end{array}$ & ICEPSS $^{169}$ & 200 horas \\
\hline & Deporte, Salud y Educación & ICEPSS & 200 horas \\
\hline & Animación Sociocultural & $\begin{array}{l}\text { Fundación ECCA / } \\
\text { MEC }\end{array}$ & 4 créditos \\
\hline \multirow{5}{*}{ 1998-99 } & $\begin{array}{l}\text { Actividades extraescolares, ocio y tiempo } \\
\text { libre }\end{array}$ & Aula SIENA / MEC & 5 créditos \\
\hline & Tutoría y Orientación & Aula SIENA / MEC & 10 créditos \\
\hline & La Educación Física en el medio rural. & Universidad Valladolid. & 20 horas \\
\hline & Habilidades Cognitivas & Fundación ECCA/MEC & 6 créditos \\
\hline & Jornadas sobre ejercicio físico y salud. & $\begin{array}{l}\text { Consejería Educación y } \\
\text { Cultura (Junta de } \\
\text { Castilla y León) }\end{array}$ & 20 horas \\
\hline \multirow[b]{2}{*}{ 1999-00 } & $\begin{array}{l}\text { La investigación en salud. Teoría y } \\
\text { práctica }\end{array}$ & Fundación ICEPSS & 120 horas \\
\hline & $\begin{array}{l}\text { Salud y práctica deportiva: Aplicaciones } \\
\text { clínicas del ejercicio físico. Actuaciones } \\
\text { de enfermería }\end{array}$ & $\begin{array}{l}\text { Fundación de estudios y } \\
\text { formación sanitaria }\end{array}$ & 100 horas \\
\hline 2001-02 & $\begin{array}{l}\text { GRUPO DE TRABAJO: Organización } \\
\text { de los alumnos de E.S.O. y atención al } \\
\text { alumnado inmigrante }\end{array}$ & $\begin{array}{l}\text { CFIE Medina del } \\
\text { Campo (Íscar) }\end{array}$ & 10 horas \\
\hline \multirow{3}{*}{$2002-03$} & $\begin{array}{l}\text { GRUPOS DE TRABAJO: Atención a la } \\
\text { diversidad en la E.S.O. }\end{array}$ & $\begin{array}{l}\text { CFIE Medina del } \\
\text { Campo (Íscar) }\end{array}$ & 20 horas \\
\hline & $\begin{array}{l}\text { GRUPO DE TABAJO: Una } \\
\text { Programación Didáctica realmente útil } \\
\text { en Educación Física }(*)\end{array}$ & $\begin{array}{l}\text { CFIE Medina del } \\
\text { Campo (Íscar) }\end{array}$ & 24 horas \\
\hline & $\begin{array}{l}\text { GRUPO DE TRABAJO: Agrupamiento y } \\
\text { atención a inmigrantes }\end{array}$ & $\begin{array}{l}\text { CFIE Medina del } \\
\text { Campo (Íscar) }\end{array}$ & 10 horas \\
\hline
\end{tabular}

Tabla 12a. Biograma de trayectoria formativa 1995-96 y 2005-06

${ }^{168}$ Colegio Oficial de Profesores y Licenciados en Educación Física.

${ }^{169}$ Instituto Canario de Estudios y Promoción Social y Sanitaria. 


\begin{tabular}{|c|c|c|c|}
\hline CRONOLOGÍA & ACTIVIDAD FORMATIVA & ORGANIZACIÓN & $\begin{array}{l}\text { DURACIÓN / } \\
\text { CRÉDITOS }\end{array}$ \\
\hline \multirow{5}{*}{ 2003-04 } & $\begin{array}{l}\text { GRUPO DE TRABAJO: Los juegos en la } \\
\text { época de Isabel I de Castilla }\end{array}$ & $\begin{array}{l}\text { CFIE Medina del } \\
\text { Campo (Íscar) }\end{array}$ & 28 horas \\
\hline & $\begin{array}{l}\text { GRUPO DE TRABAJO: El trabajo } \\
\text { colaborativo: Base de la atención } \\
\text { individualizada en la E.S.O. }\end{array}$ & $\begin{array}{l}\text { CFIE Medina del } \\
\text { Campo (Íscar) }\end{array}$ & 20 horas \\
\hline & $\begin{array}{l}\text { IX Jornadas regionales de intercambio } \\
\text { de experiencias de Educación Física (*) }\end{array}$ & $\begin{array}{l}\text { CFIE Medina del } \\
\text { Campo }\end{array}$ & 30 horas \\
\hline & $\begin{array}{l}\text { Intervención del docente ante pequeños } \\
\text { accidentes escolares y alumnado } \\
\text { enfermo }(*)\end{array}$ & $\begin{array}{l}\text { CFIE Medina del } \\
\text { Campo }\end{array}$ & 20 horas \\
\hline & $\begin{array}{l}\text { Atender a la diversidad a través de los } \\
\left.\text { contenidos de la Educación Física }{ }^{*}\right)\end{array}$ & $\begin{array}{c}\text { CFIE Medina del } \\
\text { Campo Universidad } \\
\text { Valladolid }\end{array}$ & 30 horas \\
\hline \multirow{2}{*}{ 2004-05 } & $\begin{array}{l}\text { Estrategias didácticas en Educación } \\
\text { Física en la escuela rural (*) }\end{array}$ & $\begin{array}{l}\text { CFIE Medina del } \\
\text { Campo }\end{array}$ & 15 horas \\
\hline & $\begin{array}{l}\text { Seminario: Un aula abierta para atender } \\
\text { a la pluralidad de intereses }\end{array}$ & $\begin{array}{l}\text { CFIE Medina del } \\
\text { Campo }\end{array}$ & 2 créditos \\
\hline \multirow{3}{*}{$2005-06$} & $\begin{array}{l}\text { La Educación Física en el proceso } \\
\text { educativo }\end{array}$ & INFORNET & 120 horas \\
\hline & $\begin{array}{l}\text { Riesgos, Accidentes y Responsabilidad } \\
\text { en la Práctica Docente de la Educación } \\
\text { Física (*) }\end{array}$ & $\begin{array}{l}\text { Viceconsejería del } \\
\text { Deporte de la Junta de } \\
\text { Castilla-La Mancha } \\
\end{array}$ & 15 horas \\
\hline & $\begin{array}{l}\text { Control de lesiones y accidentes en la } \\
\text { práctica educativa. Responsabilidad del } \\
\text { docente }(*)\end{array}$ & FEADEF $^{170} / \mathrm{MEC}$ & 3 créditos \\
\hline
\end{tabular}

Tabla 12 (continuación). Biograma de trayectoria formativa 1995-96 y 2005-06

A la vista de las actividades realizadas en este periplo formativo, no puedo por menos que sorprenderme por mi preocupación por la cuestión de la docencia de la Educación Física. Considero que todas ellas me han aportado conocimiento y no tengo ninguna duda de que, junto con mi experiencia profesional diaria, he llegado a ser lo que ahora soy gracias a toda esta formación. Además, interpreto que el número de actividades realizadas es elevado y denota varias cuestiones.

La primera, situada en la etapa anterior a la adquisición de la condición de funcionario en 1998, tiene que ver con mi preocupación por cuestiones de tipo formal, tales como elaboración de unidades didácticas, acceso a la función docente, currículo...

De otra parte, el interés, propio de mi vocación investigadora, por formarme en asuntos propios de la atención a la diversidad y todo lo relacionado con las temáticas que se abordan en esta tesis.

\footnotetext{
${ }^{170}$ Federación Española de Asociaciones de Docentes de la Educación Física.
} 
Finalmente, mi atracción por el trabajo en grupo $\mathrm{y}$, aunque parezca contradictorio, mi gusto por realizar cursos a distancia en formato online.

Pues bien, comienza ahora la exposición de hechos, circunstancias e informaciones destacables a propósito de los objetos de interés para esta tesis acaecidos en las actividades formativas que he realizado en ese periodo de tiempo (señaladas con un * en el biograma).

\section{$\underline{\text { Relatos de mi formación permanente }}$}

Todo mi proceso como investigador arranca con el grupo de trabajo que formé junto con los otros dos profesores que conformábamos el Departamento de Educación Física y Deportiva del "IES Santo Tomás de Aquino" (Íscar), durante el periodo comprendido entre el 15/10/2002 y el 20/05/2003. No me detendré mucho aquí pues ya apunté en los Capítulos 3 y 7 en qué consistía este grupo de trabajo.

Yo fui el coordinador de este unido equipo de personas reunidas en torno al tema de "Una Programación Didáctica realmente útil en Educación Física". En su momento, la investigación desarrollada en él supuso un fuerte impulso a mi trabajo de investigación con el que obtuve la Suficiencia Investigadora por la Universidad de Valladolid. Por aquel entonces yo estaba absorto en estos asuntos pues trabajaba contrarreloj ya que los plazos para realizar esta parte del programa de doctorado estaban acotados y no podía permitirme vacilaciones ni pérdidas de tiempo.

Como se dijo anteriormente, el objeto del estudio era revisar diferentes programaciones didácticas de nuestro área de centros públicos y concertados de Castilla y León (incluso de Internet), con el propósito de averiguar cómo se ajustan a la norma en lo relacionado a los contenidos que obligatoriamente deben aparecer en sus desarrollos, cómo los explican, la aplicabilidad de lo programado, etc. 
Aunque ya se ha visto en el Capítulo 7 todo lo relacionado con el estudio de las programaciones didácticas, sí estoy en condiciones de afirmar que esta experiencia formativa supuso mi bautizo en la coordinación de personas reunidas en torno a un proyecto en común. Fue todo un desafío que cumplió con holgura los objetivos planteados inicialmente. Las reuniones mantenidas para planificar el trabajo, así como las puestas en común de la información y su posterior análisis, me aportaron un enriquecimiento y una madurez como investigador que, al menos ahora, debo reconocer públicamente.

En lo que a las conclusiones del estudio se refiere, quisiera destacar que pudimos comprobar que en este relevante documento de concreción del currículo no se abordaba con verdadera profundidad y seriedad el asunto de la respuesta educativa que nuestro área debe de ofrecer al alumnado con necesidades educativas especiales. En el mejor de los casos, lo hacían de una manera muy insustancial, propiciando mecanismos cercanos a la exención.

Continuaba en el "IES Santo Tomás de Aquino" (Íscar ${ }^{171}$ ) cuando realicé el curso de ámbito provincial "Atender la diversidad a través de los contenidos de la educación física ${ }^{172, " ~ F u e ~ o r g a n i z a d o ~ p o r ~ e l ~ C e n t r o ~ d e ~ F o r m a c i o ́ n ~ e ~ I n n o v a c i o ́ n ~}$ Educativa de Medina del Campo en colaboración con la Facultad de Educación y Trabajo Social de la Universidad de Valladolid, y se desarrolló entre el primer y segundo trimestre del curso 2003-2004. Se podría decir que a partir de aquí es cuando empecé a meterme en la vorágine de la elaboración de esta tesis. Buscaba cursos, información, documentos, noticias... relacionadas con lo "mío".

En un principio, estaba previsto que los ponentes fuesen todos ellos profesores en activo de la Escuela de Magisterio de Segovia, de la Facultad de Educación y Trabajo Social de Valladolid, del INEF de Lleida y de la Facultad de Educación de la

\footnotetext{
${ }^{171}$ En realidad todas las actividades que aquí describiré las realicé estando destinado en este centro de Secundaria de esta acogedora localidad vallisoletana. Son muchos y muy intensos los recuerdos y anécdotas que guardo de esos once años que permanecí destinado allí. Mis compañeros y muchos de los alumnos van siempre conmigo. Incluso las anécdotas, episodios de momentos accidentales o lesivos sufridos por mis alumnos, sirven ahora de ejemplo en mis clases u otros foros de intervención.

${ }^{172}$ En el Anexo 16 se halla una la información con las características del curso.
} 
Universidad Complutense de Madrid. Y digo en principio, porque a lo largo del curso surgieron problemas que hicieron imposible la asistencia de algunos de los profesores previstos, ocupando su lugar otros a los que igualmente se suponía que estaban preparados y capacitados para tratar los contenidos preestablecidos inicialmente, aunque perteneciesen a otros cuerpos no universitarios.

Los destinatarios a los que se dirigía el curso, como no podía ser de otra manera, era el Profesorado de Educación Física de Primaria y Secundaria de la provincia de Valladolid. En concreto, no seríamos más de tres los que pertenecíamos a esta segunda la etapa, lo cual podría dar muestras de una posible despreocupación formativa de este colectivo.

Los contenidos abordados versaban sobre índole diversa, entre las que figuraba la atención a la diversidad del alumnado. De todas las ponencias hubo dos en las que se trataron asuntos directamente relacionados con este tema.

Una de ellas, bajo el título "Poblaciones especiales y condición física", fue ofrecida por un profesor de Secundaria del área de la Educación Física. Tras explicar y comentar las actuaciones y precauciones a tener en cuenta con alumnos diabéticos, asmáticos..., llegó el momento de realizar las preguntas que estimásemos oportunas, que fue donde verdaderamente surgió la información relevante para mi investigación.

Creo que algunas de las preguntas que realicé, a pesar de ser contestadas de forma rápida y concreta (lo cual no ha sido siempre la práctica habitual por parte de los expertos de este y otros cursos), puso contra las cuerdas al profesor-ponente.

Interesado por conocer la importancia que otorgaba a los documentos médicos, el ponente quedó claro el conocimiento de la Orden de 10 de julio de 1995 y ponderó de forma sobresaliente el lugar de esos papeles en la respuesta que debemos dar a los alumnos.

"Doy todo el valor [a los certificados médicos] pues el médico es el que sabe. Todo lo que hagamos de más será responsabilidad nuestra. De todas formas, no 
alcanzo a comprender cómo podemos realizar las adaptaciones que nos exigen con las grandes responsabilidades que a veces asumimos...

Muchas los papeles médicos favorecen la falsa integración, ya que no señalan lo que sí pueden hacer. No queda otro remedio que realizar, entre otras cosas, trabajos teóricos. Lo que sí tengo claro es que si me encuentro con un papel firmado por un médico, sigo al pie de la letra lo que en él se señala. Si hago algo más, es mi problema." (Profesor-ponente. Aclaración mía)

De alguna forma, a pesar de que era la respuesta que yo buscaba ya que estaba en sintonía con mis sospechas, no pude evitar cierta decepción al comprobar cómo esta forma de actuar, tantas veces descubierta en las fuentes y documentos con los que hasta ahora había0 trabajado, se presentaba de nuevo como una realidad. Además, ocurría exactamente lo mismo con los papeles familiares presentados por los alumnos para “exculpar” su no práctica en las clases de Educación Física.

"Desconozco la validez legal de ese documento, pero no me gustaría estar ante un caso en el que un chaval que trae un papel firmado por el padre informando que no puede hacer parte o toda la clase de Educación Física, le pasase algo porque le hemos obligado." (Profesor-ponente. Aclaración mía)

Para terminar el curso, un Grupo de Trabajo de profesores de Educación Física de diferentes ámbitos (Universidad, Secundaria Obligatoria y Ciclos Formativos), presentó una serie de propuestas, en forma de talleres, que llevamos a la práctica entre los asistentes al curso. Podríamos decir que la "filosofía" o idea que este grupo nos quiso trasmitir era la de que cualquier alumno, independientemente de sus circunstancias individuales de movimiento o capacidad (físicas o sensoriales), puede tomar parte de una u otra forma durante nuestras clases de Educación Física. En concreto, la sesión consistió en realizar varias prácticas sobre contenidos propios del área, en las que se propiciaba (simulaba) la inclusión de algunos alumnos con lesiones (piernas "escayoladas") o discapacidades (inmovilidad de ambas piernas, problemas de visión...).

Este grupo de trabajo suele acatar lo que se indica en los documentos médicos, así como en la mayoría de los papeles familiares. No obstante, uno de sus componentes manifiesta que antes de no hacer nada, prefiere que estos alumnos arbitren, colaboren con sus compañeros, realicen trabajos, etc. A pesar de esta afirmación, ponía reparos a 
las prácticas en la línea de la falsa integración. Este hecho me reflejaba mi propia situación, ya que estaba en contra de ese tipo de actuación, pero por otro lado seguía contemplando ese tipo de actuaciones en mis clases. Supongo que este dilema aún perdura en mi quehacer diario, especialmente cuando trato con alumnos de las circunstancias concretas aludidas en el párrafo anterior.

Las propuestas de juegos sensibilizadores que nos propusieron fueron bien recibidas pero, al igual que me pasó a mí en la formación recibida en el INEF, su realización suele cansar física y mentalmente ${ }^{173}$. Por lo tanto, el cambio de rol, la simulación de la lesión o enfermedad por el resto del alumnado, es una respuesta oportuna pero limitada en el tiempo.

Al principio, pude apreciar que casi todos los asistentes tenían una disposición favorable a la integración, en términos de participación activa, de "cualquier" alumno. Pero estas prácticas simuladas destaparon el asunto de la responsabilidad de nuestra actuación y la visión inicial se tornó algo gris. A medida que fluía el debate, sentimientos de temor, riesgo y peligro afloraron en los asistentes. Me percaté de que el colectivo percibía estas cuestiones en el tratamiento a los alumnos con dificultades de aprendizaje. Incluso se dejaron sin resolver inquietudes verdaderamente relevantes para mi estudio, pero el hecho de que surgiera denotó el pensar del profesorado al respecto y constataba el alejamiento de la dura realidad con respecto a los conocimientos e intenciones del profesorado. En definitiva, creo que se puso de manifiesto la cuestión de la teoría "fácil" frente a la "difícil" práctica. La información aparecida estaba en sintonía con mi parecer al respecto.

"En definitiva, se presente o no justificante médico que aconseje la no práctica, no apreciamos que estas actividades deban realizarse en clase, ¿y si pasa algo que agrave la lesión?, ¿no es obvio que con limitaciones parciales (escayolas, lesiones articulares...), es conveniente no propiciar situaciones que pudieran perjudicar al alumno?, ¿es tan importante para la experiencia vital del sujeto la participación en todas las sesiones de Educación Física que no puede estar sin realizarla durante un cierto tiempo?" (Cuaderno de anotaciones personal)

\footnotetext{
${ }^{173}$ Este asunto del cansancio provocado por este tipo de actividades ya ha salido en anteriores ocasiones.
} 
Casi a la par que el anterior, realicé el breve curso "Intervención del docente ante pequeños accidentes escolares y alumnado enfermo ${ }^{174}$,", organizado por el Centro de Formación e Innovación Educativa de Medina del Campo.

Los ponentes eran médicos en activo en Centros de Salud de Castilla y León, en Hospitales de Valladolid o pertenecientes a la Cruz Roja, profesores de la Facultad de Medicina de la Universidad de Valladolid y un abogado del Colegio Oficial de Abogados de Valladolid.

Los asistentes éramos Maestros y Profesores en activo provenientes de diferentes etapas y áreas. En su gran mayoría eran Maestros de Primaria debido, quizás, a la gran preocupación que suscita este asunto como consecuencia de su mayor dedicación tutorial y temporal con alumnos de corta edad (en principio, con más probabilidades de sufrir accidentes y lesiones). De la especialidad de Educación Física seríamos tres los pertenecientes al cuerpo de Profesores de Secundaria y dos al de Maestros. Nuevamente percibí una escasa demanda entre mis compañeros de área y etapa.

En los primeros días hubo una serie de ponencias monográficas dedicadas a enfermedades infantiles, tales como la diabetes, el asma, la epilepsia y las alergias. Posteriormente, se realizaron clases prácticas de aplicación de los primeros auxilios, para concluir con una sobre la responsabilidad civil del profesor.

En la que se trató la diabetes, la ponente dijo en un momento de su intervención que en los centros educativos debe de haber un adulto (profesor) que se responsabilice de la supervisión del ejercicio en estos alumnos. Previamente había dejado claro que en estos niños el ejercicio físico se debe de planificar pues modifica su control metabólico, debiendo ser practicado de forma regular.

La información que pude sacar en claro de toda esta charla fue un tanto decepcionante por la poca concreción de las respuestas o, al menos, en el sentido

${ }^{174}$ En el Anexo 17 se halla la información con las características del curso. 
deseado por mi parte. Es más, preguntada por el asunto de la responsabilidad que asumimos en las actuaciones con los alumnos, la respuesta se limitó a que deberíamos de tener una actitud de buena voluntad.

Más rica en datos relacionados con la exención total o parcial resultó ser la sesión dedicada a la alergia y el asma infantil. En este caso, el ponente utilizó ejemplos en clara alusión a la Educación Física (él se refería a ella como gimnasia). Antes de pasar a mencionar estas alusiones, nos confirmó lo que muchos ya conocíamos respecto al modo y el tipo de ejercicio físico que estos alumnos deben realizar ${ }^{175}$. De hecho, confirmó que "los informes que se redactan en casos de asma inducido por el ejercicio suelen ser siempre los mismos, cambiando únicamente los datos del sujeto.”

Nos comentó que en su consulta se ha encontrado con alumnos torturados psicológicamente por tener que realizar unos determinados tests o pruebas de resistencia, y que por ello no quieren ir a clase de gimnasia. Es más, dijo con rotundidad que es un crimen evaluar en el mes de mayo o junio a un niño con esta patología, debiéndose poner la nota antes (puso mucho énfasis en este dato, insistiendo varias veces en él).

No obstante, se posicionó en contra de la exención por motivos de asma. Pero es curioso que emplease el término total, dando a entender que sí hay una parcial para determinados tipos de contenidos (deduje que de carácter procedimental).

"No me parece acertado. En 30 años sólo he hecho un certificado de exclusión total para un alumno de estas características." (Médico-ponente)

Las tres siguientes sesiones, dadas por una médica de Cruz Roja de Valladolid, tuvieron un carácter eminentemente práctico. En ellas se planteaban, simulaban y resolvían supuesto de accidentes o situaciones que se pueden presentar en nuestras aulas. Como no surgió la oportunidad de preguntar acerca de la viabilidad o no de que

\footnotetext{
${ }^{175}$ Siempre necesario un precalentamiento de 15-20 minutos, no hacer carreras prolongadas en el tiempo, mejor series cortas con pausas de descanso o deportes colectivos que permitan alternar el trabajo intenso con fases de recuperación.
} 
determinados alumnos participaran en clase de Educación Física, el contenido de los informes médicos, etc., opté por entregar a la ponente un pequeño listado de cuestiones para que me las respondiese cuando pudiera. Eso sí, previa explicación del motivo de las mismas. Las respuestas nunca llegaron a mis manos.

Por último, la ponencia que clausuraba el curso, titulada "Actual marco legislativo de los docentes y responsabilidad civil", fue impartida por un abogado del Colegio Oficial de Abogados de Valladolid. Tras una breve y concisa exposición de leyes, artículos y procedimientos que son aplicables a los docentes, nos dio a conocer varios casos reales sobre accidentes y otros sucesos ocurridos en diferentes centros educativos de España, así como sus correspondientes sentencias.

"El seguro de responsabilidad civil, a título particular del profesor, sólo es obligatorio en los centros privados y concertados. En los públicos lo tiene la Administración ${ }^{176}$." (Abogado-ponente)

A la vez que esto sucedía, le íbamos planteando las dudas y preguntas que nos inquietaban. En esta ocasión, las respuestas emitidas fueron del todo propicias para mi investigación. El ponente se explicó de forma clara y rotunda en muchas ocasiones. Y lo hizo no solo como profesional de las leyes, sino también como padre de familia, especialmente cuando le pusimos al corriente de las prácticas inclusivas que se están empezando a promover para alumnos lesionados temporalmente. Este hecho, fuera de toda ortodoxia formativa, supuso una gran revelación.

"Te voy a responder primero como padre y luego como abogado. Como padre te digo que si algo le pasase a mi hijo estando en esa situación, procuraría por todos los medios que asumieses tu responsabilidad pues es tuya la culpa de que haya realizado cualquier actividad física. Como abogado, insisto, te la estás jugando. Yo no lo haría. En todo caso, deberías de implicar a los padres y a los médicos en lo que puede hacer ese chaval. Que en ningún caso sea una decisión sólo tuya, que todos tomen parte en ella y la conozcan." (Abogado-ponente)

No solo confirmó el poder del papel del médico en todas nuestras actuaciones con casos más o menos severos de atención a la diversidad, sino que también ponderó el "papelito" firmado por el padre o madre del alumno.

\footnotetext{
${ }^{176}$ En este mismo sentido se expresa Perona Mata et alia (1998, p. 38).
} 
"Tiene idéntico valor al del médico, pues si algo le pasase al chaval después de que sus padres nos hayan avisado o puesto en alerta por escrito de la enfermedad, afección o problemas que tuviera su hijo, nos la estaríamos jugando. Por vuestra propia seguridad, no es conveniente mandarle hacer nada. Es más, el profesorado está siendo condenado en gran medida por sucesos difícilmente controlables en situaciones normales, como para que nosotros lo compliquemos aún más." (Abogado-ponente)

A la vista de estos dos cursos, percibía que cobraba cada vez más peso en la consideración del alumno exento los documentos médicos y familiares, y el temor y responsabilidad de nuestras actuaciones docentes. Tenía datos muy evidentes al respecto, pero quería seguir corroborando estas ideas con el propósito de validarlas o, en todo caso, proponerlas como lo habitual o "normalizado" entre el colectivo de profesores de Educación Física.

Con estas miras me presenté en las "IX Jornadas Regionales de intercambio de experiencias de Educación Física ${ }^{177,}$, en las que organizador, la Dirección General de Formación Profesional e Innovación Educativa de la Consejería de educación de la Junta de Castilla y León, pretendía difundir y mostrar las experiencias y quehaceres diarios de los docentes del ámbito de la Educación Física para poder aprender, mejorar, avanzar... en su práctica.

En su mayoría, los asistentes éramos profesorado de Educación Física de Educación Primaria y Secundaria de los centros educativos de Castilla y León. No obstante, el CFIE de Medina del Campo también invitó a docentes de Portugal. Ello se debe a que en sus inicios estas jornadas eran de ámbito hispano-luso.

En una de las Mesas-Coloquio propuestas en la primera jornada de trabajo, hubo una sobre "Actividad Física y Deporte para poblaciones especiales" que fue moderada por el Dr. Juan Miguel Fernández-Balboa.

Hubo muchas intervenciones del moderador y de los asistentes que dejaron en el aire información valiosísima que suponía un avance en mi trabajo.

\footnotetext{
${ }^{177}$ En el Anexo 18 se halla una copia del folleto informativo de las mismas.
} 
Parecía asumido que supone un reto de grado superior, incluso llega a ser una tarea imposible de realizar, atender con garantías de éxito a las poblaciones especiales dentro de grupos más o menos numerosos de alumnos. Es muy complejo poner en práctica actividades con alumnos con necesidades educativas especiales, y más si se trata de casos extremos, sin descuidar en algún momento al resto, o al revés.

Por primera vez escuché en un foro de estas características señalar a las familias y a los alumnos como los auténticos protagonistas de su educación. Estas personas tienen intereses y necesidades que van más allá de aprobar una signatura. Se puso de manifiesto la necesidad de consultarles. De hecho, surgió la idea de que, dependiendo del grado de discapacidad, pudieran darse casos que por su propia voluntad no cursasen Educación Física al considerarlo doloroso e inútil a medio-largo plazo.

Como era de suponer, no todos los asistentes estaban de acuerdo con esta propuesta. Pero qué duda cabe que apuntaba en la misma dirección de mis ideales y pretensiones. Fue un logro totalmente sorprendente e inesperado.

Además, quedó patente que la realidad que viven estos alumnos es muy distinta de la teoría que desde las administraciones y fuentes de información se hace llegar al profesorado. No todo es tan sencillo de hacer, tan fácil de escribir y con garantías de éxitos para todos los implicados en los procesos de enseñanza-aprendizaje ${ }^{178}$ (los propios implicados y el resto de compañeros).

En lo que respecta a las Comunicaciones, del total de 24 previstas en el programa, únicamente la que yo presenté bajo el título "De la «dispensa» a la adaptación curricular (E.S.O.) y la «exención» (Bachillerato)" se acercaba a estos temas. Básicamente consistió en exponer una pequeña parte de esta tesis, centrándome exclusivamente en algunas de las leyes que aparecen reflejadas en el Capítulo 6 de esta tesis.

\footnotetext{
${ }^{178}$ No es un tema nuevo los contrastes que existen en la percepción y tratamiento de estos asuntos por los "expertos" y por los que diariamente se enfrentan a ellos. Muñoz Díaz (2005) señala que es fácil teorizar, pero no lo es tanto realizar propuestas prácticas, y cuando se ofrecen alternativas, sobre todo desde los expertos de laboratorio, éstas suelen estar muy lejos de la realidad escolar.
} 
Todavía recuerdo esa exposición pues fue mi primera intervención pública como ponente. Las sensaciones vividas eran una mezcla de nervios y euforia.

Estaba ansioso e ilusionado por dar a conocer los datos de mi investigación. Y quedé ciertamente sorprendido por el desconocimiento mostrado por muchos asistentes respecto de temas como el correcto nombre del departamento didáctico, los apartados que deben contener las programaciones...

Al final, surgió el debate sobre la actuación o respuesta educativa que los departamentos ofrecían a estos alumnos con necesidades educativas especiales, y pude constatar que el sentir general estaba en sintonía con lo averiguado hasta el momento: la dificultad de una respuesta única y válida, así como la aparición de la falsa integración como la forma más habitual de atenderlos.

De los 13 Talleres llevados a cabo en la última jornada de trabajo, solo hubo uno relacionado con la atención a los alumnos con necesidades educativas especiales: " $E l$ goalball como actividad física inclusiva e integradora". Básicamente, supuso una mera aproximación práctica y conceptual a este deporte adaptado, proponiéndonoslo como una posible práctica a realizar en nuestras clases, haya o no alumnos con necesidades educativas especiales asociadas a discapacidad sensorial (a modo de juego sensibilizador). Interpreté la experiencia más como una forma de realizar juegos sensibilizadores que como una auténtica propuesta inclusiva válida para el largo plazo.

Durante el primer y segundo trimestres del curso 2004-05 tuve la oportunidad de embarcarme en otro nuevo curso, "Estrategias didácticas de educación física en la escuela rural $^{179, ", ~ n u e v a m e n t e ~ o r g a n i z a d o ~ p o r ~ e l ~ C F I E ~ d e ~ M e d i n a ~ d e l ~ C a m p o . ~}$

La finalidad del curso residía en facilitar al profesorado especialista en Educación Física un lugar de encuentro y de intercambio de experiencias a través de las cuales poder encontrar soluciones, crear recursos, materiales..., adecuados a la

\footnotetext{
${ }^{179}$ En el Anexo 19 se halla información con las características del curso.
} 
diversidad de problemas que aparecen en nuestras clases, si bien, con especial circunscripción en los núcleos rurales ${ }^{180}$.

Al parecer, según comentarios de la asesora del CFIE, fuimos los propios profesores y maestros especialistas de los centros públicos y concertados del ámbito de actuación de este organismo los que, en encuestas distribuidas y realizadas el curso pasado acerca de las necesidades específicas de formación que creíamos más convenientes que esta entidad organizase, habíamos demandado esta actividad concreta, la cual se estructuraba en torno a unos ejes temáticos. De entre todos los propuestos inicialmente, el grupo de participantes volvimos a seleccionar aquellos que más satisfacían nuestras demandas de formación. Entre ellos elegimos el de Educación Física con alumnos con necesidades educativas especiales y Responsabilidad del profesor de Educación Física.

La metodología que empleamos intentaba propiciar la participación de todos los asistentes. Por tanto, no estaba prevista la presencia de ningún ponente externo al grupo, salvo que así lo decidiéramos, ya que nos interesaba más el poner a disposición de los demás nuestras experiencias y prácticas diarias. Finalmente, para cada uno de los temas acordamos, en sintonía con los organizadores, quiénes de nosotros podíamos iniciar las sesiones contando nuestras vivencias o trabajos.

De esta forma, varios de nosotros nos vimos convertidos en ponentes por un día y, por cómo luego se desarrollaron las reuniones, en "auténticos" expertos en el tema abordado. Es decir, el resto de participantes no solo nos preguntaba acerca de nuestra intervención, sino también sobre las dudas e inquietudes acaecidas en sus situaciones profesionales particulares en relación al tema del que habíamos decidió hablar.

No obstante, a petición de todos los participantes, la organización optó por invitar a un ponente especialista en asuntos de la responsabilidad del profesor de

\footnotetext{
${ }^{180}$ Respecto al planteamiento, metodología y contenido de este curso comparto con Zabala (2004, p. 22) que es necesaria una formación permanente intensa basada en el fomento de una cultura de intercambio y colaboración, en procesos de investigación-acción, de reflexión y análisis de la práctica.
} 
Educación Física. Esta demanda tan concreta me hacía denotar inquietud al respecto entre los asistentes.

Yo fui el "elegido" para iniciar el que trataba sobre Educación Física con alumnos con necesidades educativas especiales. Mi intervención se centró en dos aspectos muy concretos:

Lo primero fue dar a conocer mi interés sobre la exención en las clases de Educación Física, al igual que realicé en el curso anteriormente comentado. De forma somera dejé entrever la realidad de nuestra práctica en esa dirección. En el debate posterior, se aceptó como real el uso de prácticas en la línea de la "exención parcial", la cual parece aplicarse para algunos, o todos, de los contenidos de tipo procedimental, por un periodo de tiempo más o menos extenso, e incluso indefinido, en función de lo que dicte el indispensable documento médico presentado por el alumno en cuestión. No había nada nuevo que no se hubiera dicho antes, pero lo especial de esta ocasión era que las ideas manaban de los máximos responsables de la enseñanza de la Educación Física.

Seguidamente, abordé el desarrollo del segundo de mis propósitos: informar sobre la legislación, entre ellas la conocida Orden de 10 de julio de 1995, que regula y establece las pautas de atención con estos alumnos en lo que respecta a nuestra área, tanto en la educación secundaria obligatoria como postobligatoria.

No faltaron preguntas en torno a la elaboración de las adaptaciones curriculares: quién las debe hacer, con qué ayuda, cómo hacerlas, etc. Al parecer, las actitudes y los conceptos nunca desaparecen, siendo el verdadero objeto de las adaptaciones curriculares (si las hubiese) y, por lo general, no es habitual reflejarlas por escrito.

Además, se efectuaron otras referidas a los informes médicos que deben presentarse como condición previa a la realización de esas adaptaciones. En este punto, la credibilidad y el poder de los papeles o documentos médicos que los chavales nos muestran para justificar sus lesiones o enfermedades fueron motivo de análisis, llegándose a la conclusión de que todos solemos seguir escrupulosamente las 
orientaciones médicas, vengan en el formato que vengan, sin reparar, en muchos de los casos, en la idoneidad o no de dichas recomendaciones.

Pero no se queda ahí el asunto de los escritos, pues al parecer se actúa igual con las notificaciones paternas. El temor a generar una conducta imprudente derivada de una omisión o pasar por alto una comunicación paterna desencadena que la posibilidad de idear y proponer tareas educativas alternativas adaptadas se vea suplantada por otra de consentir la "no práctica" a la que se nos "invita" en dichos papeles. Por tanto, de nuevo el miedo o temor aparece como causante de una forma de exención. Las ideas y palabras confirmaban las informaciones acaecidas en cursos anteriores.

El siguiente eje temático que cabe resaltar es el de la Responsabilidad del profesor de Educación Física. Como dije, en este caso no fuimos ninguno de los asistentes los encargados de aclarar aspectos en torno al mismo, sino que la organización invitó a un Técnico Asesor de la Dirección Provincial de Educación de Valladolid. Su intervención fue catalogada por los asistentes como esclarecedora y reconfortante.

Inicialmente precisó que es más adecuado hablar de responsabilidad patrimonial de la administración que de responsabilidad civil del profesor, lo cual no supone que no pueda solicitarse la responsabilidad penal del profesor en caso de que cometa una imprudencia o actuación grave. Además, también existe la posibilidad de la responsabilidad subsidiaria de la administración. Por cierto, en los inicios de su charla ya nos quedó claro que no hay seguro que cubra la responsabilidad penal de un profesor ya que esta es siempre directa. Lo que se deriva es una responsabilidad civil encaminada a la reparación de los daños causados si los hubiere e indemnizar los perjuicios causados.

Después, continuó desgranando este tipo de responsabilidad patrimonial a la vez que formulaba ejemplos prácticos de posibles situaciones que se nos pudieran dar, y ofrecía pautas y consejos de actuación en nuestra labor de docentes de un área con un 
riesgo cualificado (al menos "mayor que la de matemáticas", según sus propias palabras).

Entre la documentación que nos entregó caben resaltar, además de la puramente legislativa (de la cual hablaremos en el Capítulo 11), unos impresos que la Consejería de Educación y Cultura de la Junta de Castilla y León tiene establecidos para estos asuntos, y que todos centros educativos públicos deben poseer. Son los siguientes ${ }^{181}$ :

- Comunicación de accidente escolar: Debe ser rellenado por el centro educativo cuando se produzca un accidente y enviado a la Dirección Provincial de Educación. Consta de tres ejemplares: Para la Consejería de Educación y Cultura, la Dirección Provincial de Educación y el Centro Escolar.

- Solicitud de indemnización por responsabilidad patrimonial: Podrá ser presentada por el padre/madre o representante legal dl alumno accidentado. En ella figuran datos como la descripción de los hechos, lesiones producidas, justificación por la que se considera que el accidente pudo evitarse y la evaluación económica de la responsabilidad patrimonial. Además de los tres ejemplares del anterior, tiene un cuarto para el interesado.

Obviamente, fue interrumpido por los asistentes en multitud de ocasiones para preguntarle acerca de lo que verdaderamente nos preocupaba y nos sucede a diario. Percibí un ambiente de interés inusual, mezclado con una cierta angustia fruto del tema abordado y sus posibles consecuencias para nosotros.

Como eran tantas las dudas consultadas y tan escaso el tiempo del que disponíamos, al finalizar la sesión decidí plantearle, tras aclararle el motivo de mi especial interés, la posibilidad de que nos reuniéramos para poder realizarle una serie de preguntas en torno a este y otros asuntos. Como era de esperar, aceptó de buen agrado la propuesta.

\footnotetext{
${ }^{181}$ Se encuentra una copia de ambos formularios (del primero de que consta cada ejemplar) en el Anexo
} 20 y Anexo 21, respectivamente. 
Así pues, preparé una entrevista de tipo semiestructurada ${ }^{182}$, que iba a tener lugar días más tarde en un despacho de la Dirección Provincial de Educación de Valladolid $^{183}$.

A pesar de que el ambiente de la misma, salvados los formalismos iniciales, aconteció en un clima distendido y cercano, todas las aportaciones del experto se movieron en el terreno de la no concreción (al menos no en el sentido deseado por mi parte). Continuamente insistía una y otra vez en lo que dice la ley, apuntando la conveniencia de consultar a la inspección u organismo pertinente las dudas que pudiera tener en las actuaciones a llevar a cabo con alumnos de estas características.

Puede que mi limitada y frágil habilidad entrevistadora me impidiese extraer información relevante, pero también creo que la experiencia profesional del entrevistado, habituado a moverse en el ámbito de las leyes, le llevase a no cometer el error de explicitar algo de lo que luego tuviese que arrepentirse.

Aun así, quiso transmitirme la idea, al igual que ya lo hiciera en su día durante el curso en el que nos conocimos, de que los profesores de Educación Física tenemos menos motivos de los que creemos, por la responsabilidad que se pudiera derivar de nuestras actuaciones, para justificar el miedo o temor a poner en práctica determinadas tareas o ejercicios, así como la adopción de medidas educativas (adaptación curricular), siempre y cuando no actuemos de forma negligente ${ }^{184}$, lo cual hemos de suponer que siempre es así ya que nos consideramos profesionales de nuestra disciplina.

Además, aun partiendo de la premisa de que ningún médico puede declarar exento a un alumno, otorgó un lugar primordial al justificante médico. Pero solo en

\footnotetext{
${ }^{182} \mathrm{Al}$ respecto de las cuestiones metodológicas de la entrevista, remito al lector al Capítulo 12.

${ }^{183}$ Una vez trascrito a papel nuestro encuentro, el propio entrevistado tuvo la oportunidad de leerlo y corregir o matizar aquello que consideró oportuno, otorgando credibilidad y fiabilidad a lo que aquí se refleja. Obviamente, también se le solicitó autorización para publicarlo.

${ }^{184}$ Vid.: Capítulo 11.
} 
términos de considerarlo para la elaboración de la correspondiente adaptación curricular.

Lugar muy distinto confirió al papel familiar, que solamente deberíamos de aceptar como válido de forma puntual y esporádica, y según nos dicte nuestro sentido común puesto que desde el punto de vista legal carecen de valor o fundamento. Este dato me generó gran perplejidad ya que había discrepancia con lo apuntado por el abogado de dos cursos atrás. Así se lo hice saber. Pero su respuesta, lejos de solventarme las dudas, me quedó con más dudas, pues argumentó que la opinión del abogado estaba realizada desde un planteamiento estrictamente jurista ¿Y no es precisamente este al que todos tememos en caso de plantearse una situación que requiera de un proceso judicial?

A estas alturas de mi proceso formativo permanente ya disponía de información que servía para corroborar muchas de mis propias indagaciones y sospechas, pero también me daba pie a seguir investigando sobre otras materias con el fin de concretar resultados.

De alguna forma, en este momento daba por concluida esta etapa investigadora. Pero la vida nos depara sorpresas e imprevistos que no podemos sortear ni prever. Y eso fue lo que me ocurrió cuando durante el año siguiente me vi de nuevo participando en dos nuevos cursos de temática similar. Otra vez, casi sin quererlo, tuve que atender a la llamada de la formación permanente, que parece no tener un final determinado.

En concreto, buscando en Internet información sobre la responsabilidad del docente, encontré el curso "Riesgos, accidentes y responsabilidad en la práctica docente de la Educación Física ${ }^{185,}$, organizado por la Viceconsejería del Deporte de la Junta de Comunidades de Castilla-La Mancha.

Se desarrolló en Albacete, entre el 7 y 8 de octubre de 2005, y en él tuvieron lugar un total de diez ponencias y tres coloquios. Todos los asistentes éramos maestros

\footnotetext{
${ }^{185}$ En el Anexo 22 se halla una copia del folleto que desglosa las características y el horario del curso.
} 
y/o profesores de Educación Física (alguno de ellos Catedráticos). Salvo yo, todos los asistentes pertenecían al ámbito de la Comunidad autónoma organizadora del curso (así me lo hizo saber el Coordinador del curso al término del mismo).

Antes de comentar el curso, quisiera exponer que, de todos los cursos que he realizado, este lo recuerdo de una forma especial. Incluso dolorosa, diría yo, pues fue la primera vez que pasé una noche fuera de mi hogar desde el nacimiento dos años antes de mi primera hija. Aún perduran en mí sensaciones de cierta angustia y añoranza. Supongo que me sirvieron para afianzar en mi memoria las informaciones vertidas en las ponencias y posteriores debates y, por tanto, conseguir obtener más provecho de ellas.

Ya en la misma presentación del curso realizada por el Coordinador del mismo, se apuntaron algunas cuestiones de interés: el posible tratamiento que la LOE aplicaría a la Educación Física; se afirmó que en la Educación Física es más fácil que un alumno se lesione que en otras clases, y que el control de riesgos lo tiene el profesor y no los alumnos. La Educación Física ya aparecía como riesgosa.

De lleno en el curso, uno de los ponentes confirmó que "la miocardiopatía hipertrófica por enfermedad es, de por sí, una contraindicación absoluta a la actividad físico-deportiva.” Aunque más tarde rectificó esta postura y aclaró que el alumno que la padezca algo podrá hacer, pero sin concretar el qué. Me preguntaba si se estaría refiriendo a las tareas propias de la falsa integración.

También se abordó el problema de los reconocimientos médicos. Al parecer se hacen muy por encima e, incluso, no se hacen, solo se firman. En estos casos, "la responsabilidad es del que firma y del que lo acepta sin más." Las contraindicaciones médicas deberían estar personalizadas, o lo que es lo mismo, "se debería detallar lo que puede y no puede hacer." Textualmente un ponente señaló que "el médico se debe mojar y decir lo que sí y lo que no puede hacer." Finalmente comentó que "hay muchos 
padres que presionan a los médicos para que firmen la contraindicación absoluta de la Educación Física y del deporte ${ }^{186}$."

En ese momento intuí que la exención empezaba a hacer acto de presencia en el curso. La primera sorpresa o, al menos, información relevante acababa de aparecer puesto que se reconocía que los familiares ejercen precisión a los facultativos para que firmen un certificado médico eximente (al menos de la práctica). Lo cual me lleva a pensar que no todos los informes médicos que nos llegan tienen que ser veraces. Ante las dudas, deberíamos de consultar con los servicios médicos institucionales.

También atestiguó que con suma frecuencia se emiten certificados médicos en los que se excluye de la Educación Física a niños por mero desconocimiento y, en ocasiones, por no complicarse la vida (propio de una medicina defensiva). Y, a la vez, se admitió la actitud pusilánime de muchos profesores que siguen al pie de la letra lo que en esos escritos se les dice, quizás llevados por el temor a caer en responsabilidades. En todo caso, parecía como si al alumnado se le abocase a una respuesta planteada en términos de falsa integración, cercana a la exención.

"Ni la muevas porque se te cae el pelo. Si no hay un buen diagnóstico y prescripción facultativa profesional de la administración no te vas a convertir tú en el redentor del sistema, al revés, puede que por tu buena voluntad te caiga un problema gordo. Si no puede hacer actividad física..., ponla de árbitro. Yo no me arriesgaría, es un tema que cuando hay una responsabilidad civil y penal que te puede caer lo vais a tener claro." (Ponente)

Por si no habían sido claras y contundentes en sus respuestas, volvieron a insistir en esa dirección ante una consulta al respecto de una alumna hemofílica que había presentado un informe médico eximente.

"No la muevas. Haz caso al informe médico." (Ponente)

Se asume que hay pocos niños que tengan una patología de tanta gravedad que tengan que estar exentos de hacer el nivel de actividad física que debería primar en las

\footnotetext{
${ }^{186}$ Obsérvese que sobre este asunto ya hemos apuntado algo en el Capítulo 6.
} 
clases de Educación Física. La exención total no está justificada en ningún caso. Casi siempre son exenciones de tipo parcial por alguna causa muy concreta (rotura de la pierna, etc.). Al parecer, el verdadero problema de la exención, que en su día se planteó para "solucionar" los casos muy graves, era que los niños a los que no les gustaba las clases de Educación Física se la pedían a sus padres para que, a su vez, se la solicitaran al médico de cabecera. Por tanto, sí existían exenciones solicitadas por los propios alumnos. Pero el profesor no debe luchar contra esa exención pedida voluntariamente por el alumno y que le sitúa, al menos, en el plano de la exención de la práctica.

Sin embargo, como cabía esperar, también había voces en contra de cualquier tipo de exención.

"Independientemente de quien haya dicho eso, yo estoy en contra. Hemos de insistir en que existe una normativa que dice que no hay exención, y a partir de ahí no cabe discusión posible. Por otro lado, remarco que debemos contar con el apoyo de los Servicios de Orientación o del Departamento de Orientación. Ellos nos deben asesorar sobre lo que puede o no puede hacer un alumno, lo que necesita, etc." (Ponente)

Las dudas y dilemas retornaron a mi mente. Me preguntaba si, puesto que no debe haber alumnos exentos de hacer Educación Física, pero tampoco es conveniente luchar contra el que no quiere hacer y presenta un informe médico que justifica y ampara esa exención, ¿quiere esto decir que debemos proponer una adaptación curricular basada en contenidos conceptuales (teóricos) y en tareas en la línea de la falsa integración?

El asunto de los peligros y responsabilidades asumidas en nuestras clases también tuvo un lugar importante durante el curso. Hubo planteamientos en los que quedaron patentes los riesgos intrínsecos al propio ejercicio físico, así como el que se deriva del estado de las instalaciones y del material. Todos ellos pueden traer responsabilidades de tipo civil y penal. De hecho, se afirmaron una serie de cuestiones de relevancia para esta tesis. 
“...la práctica de las actividades físicas y ejercicios, en el marco de la Educación Física, aun siendo una actividad beneficiosa para el organismo, puede producir una serie de trastornos lesivos." (Ponente)

"Los propios materiales con los que habitualmente trabajamos también deben ser analizados y revisados para evitar situaciones indeseables. Supone un riesgo muy importante para la integridad de los alumnos el deterioro continuo al que están sometidos. Es responsabilidad nuestra el control continuo de los materiales utilizados ¿Hasta qué punto un accidente por un mal estado del material no es responsabilidad del profesor de Educación Física?...

...no nos pasan más cosas porque no tenemos más horas de clase. Si tuviéramos muchas horas de clase los accidentes serían muchos más frecuentes..." (Ponente)

Me empecé a plantear que parecía incuestionable que los docentes de Educación Física nos movemos en un plano de riesgos implícitos a nuestra profesión. En nuestras clases y actividades extraescolares, el alumnado está sometido a más peligro (corriendo, saltando...) que en otras clases en las que permanece casi todo el tiempo sentado. No obstante, los profesores tenemos la última responsabilidad en la toma de decisiones acerca de los contenidos que vamos a impartir, así como del control de la situación que vamos a ejercer.

Así pues, se constató que el profesor de Educación Física, por la naturaleza del área, es un generador de riesgos, cosa que no ocurre en latín, lengua, etc. En nuestras clases se generan riesgos por doquier. Nos tenemos que dar cuenta de que somos auténticos profesionales de la Educación Física, lo que conlleva asumir riesgos (inherentes) en el ejercicio de nuestra profesión. Es evidente que hay compañeros que han decidido poner en marcha un curriculum oculto en el que suprimen contenidos con mayor índice de riesgos por una mera cuestión de miedo o temor a que pase alguna desgracia. No seamos ignorantes y confiemos en nuestra formación (de hecho, seguimos formándonos con la asistencia a cursos como este).

“...es normal que los profesores de Educación Física tengan miedo, o al menos reserva, a participar en algunas actividades por el factor responsabilidad que conllevan. No obstante, esto no nos debe de ahuyentar, pero sí que es conveniente que tomemos todo tipo de precauciones...

...alguno se estará planteando dar Lengua y Literatura en vez de Educación Física." (Ponente) 
Pero el riesgo o temor también puede venir del lado del alumnado. Esa actitud puede desembocar igualmente en la exención.

“...nos podemos encontrar que en la Educación Secundaria, a pesar de que no debe de existir ningún alumno exento, hay alumnos que provocan esa exención porque tienen miedo, se hicieron daño..." (Ponente)

Lo que sí resultó una novedad fue comprobar cómo la ignorancia era propuesta por algún ponente como forma de evitar responsabilidades (si es que esa cuestión es legalmente posible). El tema surgió a raíz de una pregunta sobre las fichas médicas que muchos profesores o centros docentes piden a los alumnos a principio de curso.

"No obstante pueden ser un arma de doble filo [refiriéndose a las fichas médicas o de salud] ya que si a mí me señalan o informan de que un alumno tiene alguna enfermedad o anomalía, y luego le pasa algo en relación a ello, la culpa será, más que nunca, mía. Por ello, casi es mejor no saber nada. Soy reacio a pasar esas fichas con antelación antes de que aparezca el problema. Te recomiendo que no te pongas trampas pues puedes caer en ellas." (Ponente. Aclaración mía)

Durante el segundo día llegó el turno de la ponencia que había propiciado el que yo estuviese a cientos de kilómetros de mi hogar: "Tratamiento de los "exentos" y grupos especiales de riesgo en las clases de Educación Física”. Pero el fiasco fue mayúsculo ya que no me aportó casi nada que no conociera pues toda la exposición se centró en un análisis de las órdenes de 31 de julio de 1961 y de 10 de julio de 1995. Eso sí, compartí con el ponente que la normativa que lo regulaba era confusa y poco desarrollada.

La verdad es que fue un curso en el que verdaderamente disfruté de las intervenciones de los ponentes y asistentes. Fue prolijo en información y comentarios de calidad, en el que los expertos parecieron abrirse a sus interlocutores, concretando y "aterrizando" en sus respuestas a la realidad en la que trabajamos.

En fechas próximas al término del anterior, recibí un email del responsable de formación de mi centro docente en el que se me informaba sobre el curso online “Control de lesiones y accidentes en la práctica educativa. Responsabilidad 
docente $^{\text {187,", }}$ organizado la Federación Española de Asociaciones de Docentes de Educación Física (FEADEF). Se accedía a él a través de la plataforma que el sindicato ANPE posee en Internet (ANPENET).

Me decanté por realizarlo por uno de los contenidos teóricos que lo configuraban: "Responsabilidad jurídica del docente", intuyendo que podría ratificar algunas de las investigaciones puestas de manifiesto hasta ahora.

Y no me equivoqué, ya que en la misma introducción del curso se nos advertía de que la actividad física, a pesar de ser una indudable fuente de salud física y mental, también puede convertirse, por el propio azar o por un bajo control de la misma, en el peor enemigo de dicha salud.

Además, se insistía en que siempre que demostremos diligencia y preocupación, tanto por nuestro trabajo como por nuestros alumnos, y todas las actividades que propongamos estén debidamente programadas, la posibilidad de ser acusados de negligentes va ser ínfima. No obstante, también se afirmaba que no todas las variables del movimiento se van a poder controlar, por lo que será necesario asumir un cierto nivel de riesgo (pero no solo por parte del profesorado, sino también por los padres, alumnos y administraciones), lo cual puede inducir a algún docente a tomar decisiones drásticas tales como cambiarse de área (yo pensaba que también podría ocurrir que algunas prácticas, contenidos... se coartasen).

“...Muchos docentes viven esta situación [referido al asunto de que en nuestras clases existe un cierto riesgo] como una espada de Damocles sobre sus cabezas, y la presión y el estrés seguramente contribuyen a la aparición de riesgos... Hay docentes que tras malas experiencias han renunciado a impartir la asignatura de Educación Física...” (Apuntes curso. Aclaración mía)

Algunas de las formas de proceder de mis antiguos compañeros en relación al uso de material tradicional de Educación Física eran ratificadas por algunos profesores.

\footnotetext{
${ }^{187}$ En el Anexo 23 se puede consultar la información que detalla los bloques de contenidos y el temario que desarrolla el curso.
} 
Así, Saro ${ }^{188}$, en sus apuntes sobre “Deporte = Salud. ¿Es siempre así?”, señala al minitramp (una pequeña cama elástica) como un material peligroso que debería de estar convenientemente guardado $\mathrm{y}$, por tanto, lejos del alcance los chavales cuando no estemos controlando la actividad.

Se asumía como una realidad indiscutible que en nuestra área hay mayor riesgo de que se produzcan accidentes que en otras.

"El profesor [de Educación Física] o entrenador es un creador de riesgos: por ello está más obligado que cualquier otro docente a cuidar de la integridad de sus alumnos, tanto como a cuidarse él. En esta materia, previsión y prudencia deberían ser nuestro lema." (Ruiz Morales, 2005; Ponencia "Responsabilidad Civil del Profesor de Educación Física. Principio Genérico de las Leyes". Aclaración mía)

Esta idea se vio sancionada con otra escueta ponencia sobre "Cómo evitar ser condenado en un accidente de Educación Física" (de la que nuevamente no aparece el autor/a). En ella se planteaban seis parámetros que se deben de tener presentes para que los profesores de esta área no seamos condenados ante un accidente en nuestra actividad. Independientemente de esas propuestas, se me antojaba pensar que en muy pocas ocasiones, por no decir en ninguna, vamos a poder leer un artículo de esta temática que esté aplicado a cualquier otra área del currículo. Obviamente esto estaba en consonancia con la anterior ponencia.

Así pues, empecé a concebir como acertada la idea de que el profesor de Educación Física debe asumir el factor riesgo como inherente a su práctica cotidiana y, en la medida de lo posible, "sortearlo" con adecuadas programaciones y planificaciones, tareas acordes a la edad y nivel de cada alumno. Y que el miedo al riesgo, como factor que desencadena la asunción de responsabilidades, puede provocar que parte del profesorado lleve a cabo prácticas cercanas a la exención (parcial o total de la práctica).

\footnotetext{
${ }^{188}$ En la Bibliografía de esta tesis aparece como Saro Fernández, F.J. (2005) por ser el año en que se realizó el curso en cuestión. No obstante, conviene aclarar que el tema en sí es el mismo que el autor debió de presentar en otro curso realizado con anterioridad denominado "Las lesiones en la actividad física y su prevención", del cual desconocemos el lugar de celebración y la fecha en que se desarrolló.
} 
Por último, aparecen tres comunicaciones sobre el tema de la responsabilidad del docente de Educación Física (Blanco, 2003; Albornoz, 2002; Angriman, 2002), de las cuales ya tenía conocimiento por otras fuentes ${ }^{189}$. De todas ellas daré debida cuenta cuando acometa el correspondiente Capítulo 11, dedicado a tratar el asunto de la responsabilidad que asume el profesor de Educación Física.

Al ser un curso online, supuso una libertad de horarios y de pautas de realización que no he encontrado en otros de tipo presencial, facilitado así mi participación. Para los profesores de Secundaria (en activo o interinos) muchos de los cursos presenciales que se ofertan suponen excesivos desplazamientos, concentraciones horarias recargadas y metodologías pesadas, lo cual perjudica la sensación última que nos pudieran dejar. En definitiva, las nuevas tecnologías abren grandes posibilidades a la formación permanente del profesorado.

\section{Un punto y seguido en mi formación permanente}

Durante un largo periodo de tiempo me he acercado a distintas posibilidades formativas que nos son ofertadas a los profesores a través de organismos de todo tipo. Cursos, grupo de trabajo, jornadas, curso online..., en todos ellos he participado, escuchado atentamente a los ponentes e interlocutores y, cuando he podido, he preguntado para ahondar más en los asuntos que me interesan.

En este periodo formativo tampoco se puede obviar la riqueza que ha supuesto hablar con otros colegas que compartían inquietudes, dudas y entusiasmo formativo. Durante las rondas de preguntas, en los descansos, en cualquier momento, era habitual entablar conversación con algún asistente sobre los temas abordados en las ponencias, o aún por ser tratados. De hecho, algunos de estos compañeros de auditorio se convirtieron en parte de proceso de triangulación de la información que en este capítulo

\footnotetext{
${ }^{189}$ La primera de ellas se trata de una ponencia ofrecida en el V Congreso Internacional de FEADEF celebrado en Valladolid. Las otras dos las encontramos en Internet en las direcciones correspondientes indicadas en la bibliografía.
} 
aparece. Incluso a alguno le llegué a facilitar información relacionada con el capítulo legislativo de esta tesis.

De cada actividad en la que he participado me llevo sensaciones e impresiones que entiendo que han contribuido de alguna manera a mejorar mi quehacer diario. Pero lo verdaderamente relevante es que muchas de las informaciones que han ido apareciendo en cada una de ellas confluyen en la misma dirección.

En estas actividades he apreciado la presencia de contenidos o temáticas que giran alrededor de la exención en los términos en los que la estoy abordando. Así, la opinión sobre cómo actuar o atender a las demandas solicitadas en los documentos médicos o familiares, la responsabilidad que aparentemente asumimos en nuestra labor diaria, las medidas que adoptamos y planteamos para el alumnado con necesidades educativas especiales asociadas a cualquier tipo de discapacidad, la viabilidad de una exención parcial, incluso para algunos total, son asuntos que aparecen con relativa frecuencia en casi todos ellos. En la Figura 6 se puede apreciar de forma ilustrativa la información más relevante que en cada una de esas siete actividades salió a la luz.

Además, a lo largo del recorrido personal realizado por la etapa de formación inicial también me he topado con evidencias de la exención: una innegable referida a mi propia exención parcial y otra, que debe matizarse, respecto de la que pudiera derivarse de la escasa formación que tuve, y que considero que aún perdura, en atención a la diversidad en Educación Física. En el apartado siguiente profundizaré sobre esta opinión.

Por lo que se refiere a lo que este proceso formativo ha interferido en mi evolución en la forma de pensar y actuar en relación a la atención a "casos extremos" de alumnos con dificultades de aprendizaje, considero que me ha hecho fluctuar por diferentes rumbos que se pueden situar en una trayectoria con inicio en la integración por la integración, lo cual daba entrada a falsas prácticas y procedimientos, y con un final, supongo aún inacabado, en el que me llego a plantear si verdaderamente es imperioso (al margen de preceptos legales) que estos alumnos tengan presencia en 
nuestra área, aun con una adaptación curricular (según las pruebas, por lo general basada exclusivamente en contenidos de carácter conceptual).

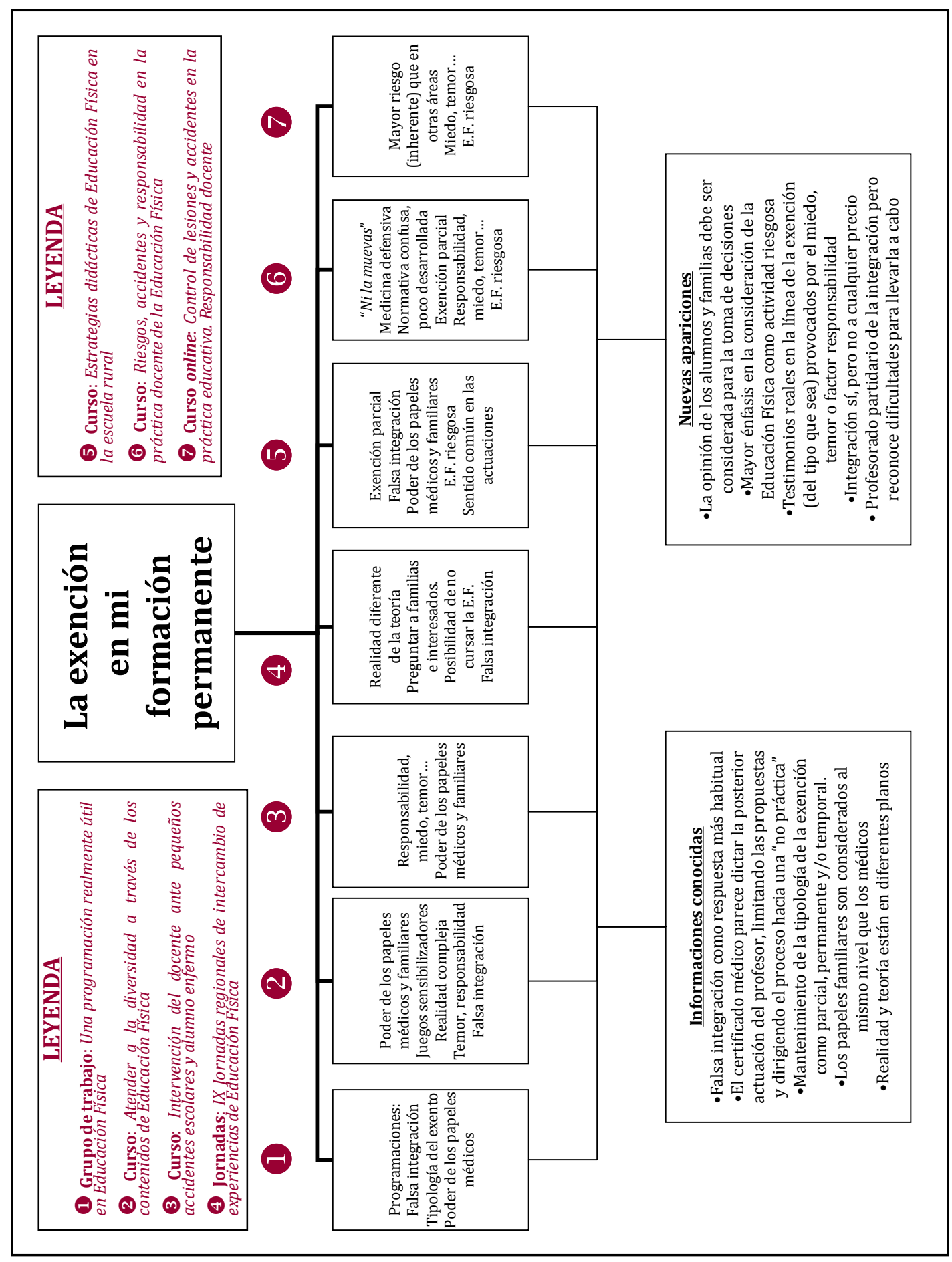

Figura 6: La exención en mi formación permanente 


\section{8.- OFERTA EDUCATIVA DE LOS CENTROS DE FORMACIÓN E INNOVACIÓN EDUCATIVA DE VALLADOLID (CFIES)}

En este apartado realizaré un somero análisis retrospectivo de los cursos, seminarios y actividades formativas en general, ofertados o realizados al amparo de los CFIEs en los que se haya abordado la temática de la atención a los alumnos con necesidades educativas especiales en Educación Física. El análisis no pretende ser profundo en detalles, ya que el objeto del estudio no va más allá de comprobar la existencia o no de actividades formativas encaminadas a perfeccionar un ámbito de estudio e intervención muy concreto: el de la Educación Física en general, y el de la atención a la diversidad en dicha asignatura en particular.

La revisión se acotará al periodo comprendido entre 1995, origen del cambio legislativo que da paso a la imposibilidad de la exención, y los primeros años del segundo milenio, momento en que dicho cambio ya debería ser una auténtica realidad. Dicho periodo casi es coincidente con el manejado en la revisión de mi formación permanente.

De alguna forma, se pretende comprobar si la oferta de formación específica sobre estos asuntos pudo suponer, precisamente por su escasez, una razón que mantuviese las propuestas encaminadas a la no práctica o la exención.

Este estudio se ceñirá al marco de actuación de los cuatro CFIEs que durante ese tiempo mantenían su actividad en Valladolid y provincia: CFIE I y CFIE II en Valladolid capital, el de Medina de Rioseco (CFIE MR) y el de Medina del Campo $\left(\right.$ CFIE MC) ${ }^{190}$.

En la actualidad todos ellos se han integrado en el denominado "CFIE de Valladolid". En su página Web podemos acercarnos a la definición de este organismo:

\footnotetext{
${ }^{190}$ Hasta el curso 2001-2002 funcionaban como Centros de Profesores y Recursos (los denominados CPR). Fue a partir del siguiente curso cuando se crearon el CFIE.
} 
"Los CFIE (Centros de Formación del Profesorado e Innovación Educativa) son instituciones dependientes de la Consejería de Educación de la Junta de Castilla y León encargadas de la formación permanente del profesorado en los niveles no universitarios. Entre sus funciones también se encuentran promover la innovación educativa, apoyar iniciativas de investigación educativa, coadyuvar al desarrollo del currículo en los centros educativos, difundir experiencias didácticas relevantes entre los miembros de la comunidad educativa, promover la aplicación de las nuevas tecnologías en entornos educativos, certificar actividades formativas y asesorar a los docentes respecto a la generación y uso de materiales didácticos y curriculares." (CFIE de Valladolid)

\section{Metodología y proceso de recogida de la información}

El proceso de obtención de la información fue algo más complicado de lo que en principio se esperaba. Parecía sencillo y rápido obtener los datos requeridos de estas instituciones de carácter público, pero el asunto se fue complicando como suele pasar cuando interviene la maquinaria de la administración.

Lo que en un principio se podría haber logrado a través de unas llamadas telefónicas y correos electrónicos, se convirtió en un largo proceso de espera con algunos momentos de relativa incertidumbre.

Lo curioso es que, mientras que unos organismos (todos bajo el mismo nombre y dependientes de la misma Administración) no pusieron ningún tipo de reparo a la búsqueda y posterior entrega de la documentación tras unos contactos más o menos informales vía telefónica, alguno interpretó la cuestión de una forma "inquisitoria” y se negaron a darme la pertinente información por esa vía informal, demandándome que empleara unos mecanismos más oficiales pues debía de cursar la petición a las altas instancias de las que dependían.

Hubo que mantener más conversaciones y explicar más y mejor lo que se pedía y para qué se pedía. Al final, el entendimiento entre las partes llevó a la comprensión de los propósitos de esta investigación y la documentación requerida fue entregada. 
La información que se solicitó a los cuatro CFIEs de Valladolid y su provincia fue el listado de las actividades que, bajo el amparo o supervisión de cada uno de ellos, habían realizado durante el periodo de tiempo citado anteriormente.

\section{$\underline{\text { Análisis e interpretación de los datos }}$}

Por lo que respecta al número total de actividades desarrolladas sobre la Educación Física, han sido 122, repartidas por centros según se puede apreciar en la Gráfica 68.

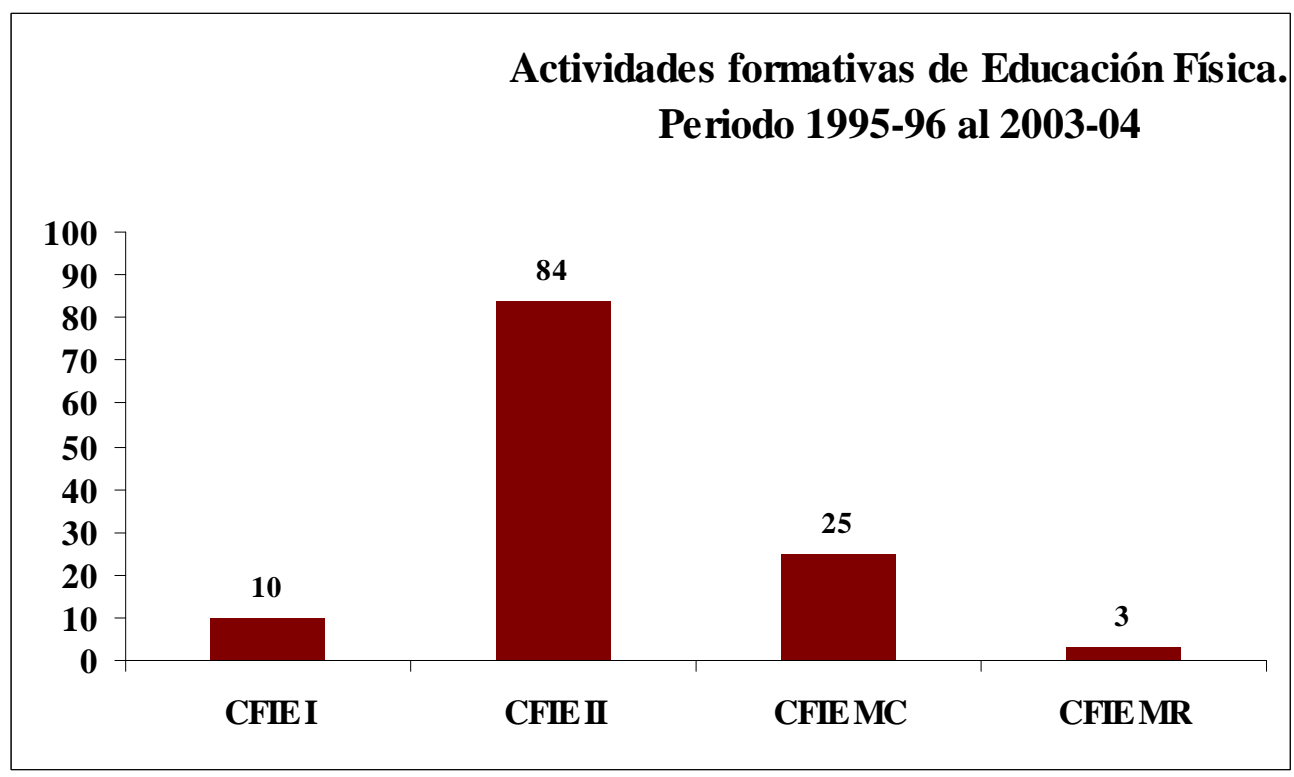

Gráfica 68: Actividades formativas de Educación Física. Periodo 1995-96 al 2003-04

De entrada, se aprecia una clara disparidad de la oferta, siendo el CFIE II el que destaca poderosamente por encima del resto. Al parecer, según nos explicó uno de los directores de estos centros, la causa radica en que tan solo el CFIE II y el de Medina del Campo tenían área de Educación Física y el asesor correspondiente. Aun así, como dato que nos esclarece si estas actividades son muchas o pocas, simplemente constataremos que el CFIE I, uno de los que menos actividades de Educación Física puso en marcha, 
durante ese mismo periodo amparó 1049 actuaciones formativas de otras áreas. El dato habla por sí solo.

La media anual de actividades de Educación Física que se realizaron, dentro del ámbito de actuación de estos entes, en toda la provincia de Valladolid, fue de 13,55. La distribución por años de las mismas fue la que queda de manifiesto en la Gráfica 69.

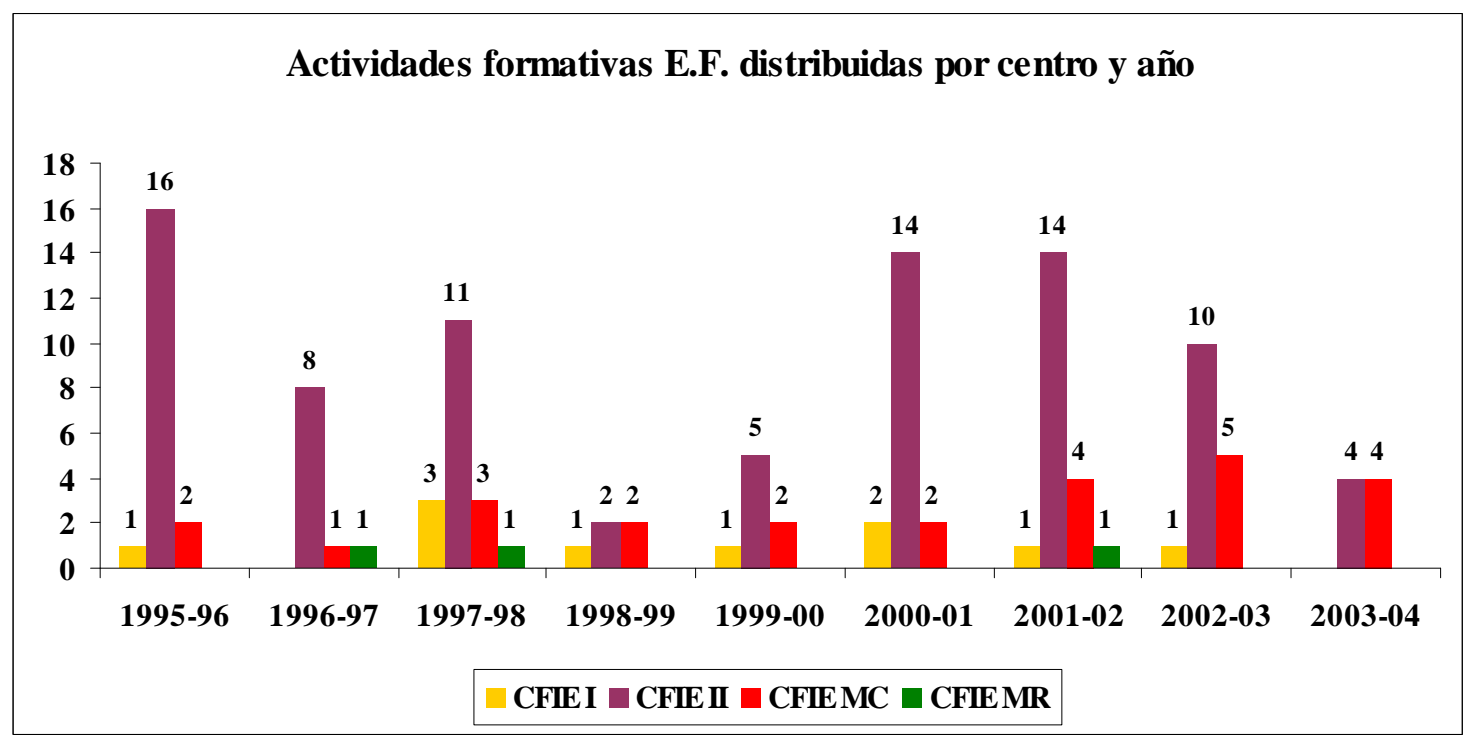

Gráfica 69: Actividades formativas de Educación Física ofertadas por los CFIEs distribuidas por centro y año

Cuando analizamos las actividades de Educación Física que pudieran englobar el asunto de la atención a la diversidad, lo cual lo hemos deducido del título de las mismas, nos encontramos que en ese periodo ha habido solo 7, de las cuales seis eran del ámbito del CFIE II y una del de Medina del Campo en colaboración con la Facultad de Educación y Trabajo Social de la Universidad de Valladolid ${ }^{191}$. Esto nos deja que no hubo ni una actividad por año.

\footnotetext{
${ }^{191}$ Se trataba del curso: "Atender a la diversidad a través de los contenidos de la educación física". De esta actividad formativa ya he recogido lo más relevante en el subapartado anterior. No incluyo en este apartado el curso "Intervención del docente ante pequeños accidentes escolares y alumnado enfermo", organizado por el CFIE de Medina del Campo, ya que era de oferta generales, decir, no solo para el profesorado de Educación Física. De hecho, ente todos los asistentes solo éramos dos los profesores de Educación Física.
} 
En este punto hemos de aclarar que durante el tiempo que abarca el estudio sí que hubo bastantes actividades relacionadas en general con la atención a la diversidad, pero no de forma específica de la Educación Física. Tomando nuevamente el CFIE I como ejemplo comparador, este amparó 59 actividades de esta temática en ese mismo margen temporal. No obstante, ateniéndonos a la nomenclatura de las actividades, la Educación Física pudiera haber tenido un lugar en otras cinco de ellas.

Por la modalidad de actividad de que se trataba, en su casi totalidad Grupos de Trabajo o Seminarios permanentes de profesores, intuimos que la motivación que lleva a realizar la actividad formativa es de carácter intrínseco, es decir, a petición del interesado y procurándose ellos mismos la formación. En la Tabla 13 se recoge la tipología y los títulos de esas seis actividades.

\begin{tabular}{|c|l|c|}
\hline MODALIDAD & \multicolumn{1}{|c|}{ TÍTULO } & CURSO \\
\hline Grupo de trabajo & La diversidad en Educación Física & $1995-96$ \\
\hline Grupo de trabajo & Programación de Educación Física en la E.S.O. & $1996-97$ \\
\hline Grupo de trabajo & $\begin{array}{l}\text { Necesidades educativas especiales de Educación Física: } \\
\text { planteamiento para la integración }\end{array}$ & $1997-98$ \\
\hline Grupo de trabajo & $\begin{array}{l}\text { Materiales didácticos de Educación Física en medio } \\
\text { acuático para alumnos con discapacidad física }\end{array}$ & $1999-00$ \\
\hline Grupo de trabajo & $\begin{array}{l}\text { Cómo atender a la diversidad del alumnado desde la } \\
\text { Educación Física. Una propuesta para la E.S.O. }\end{array}$ & \multirow{2}{*}{$2001-02$} \\
\hline Curso & $\begin{array}{l}\text { Necesidades educativas especiales: estrategias para las } \\
\text { áreas de E. Musical y E. Física }\end{array}$ & \\
\hline Curso & $\begin{array}{l}\text { Atender a la diversidad a través de los contenidos de la } \\
\text { educación física }\end{array}$ & 2003-04 \\
\hline
\end{tabular}

Tabla 13: Cursos realizados relacionados con el asunto

A la vista de estas cifras, verdaderamente reveladoras, se observa que hubo una escasa oferta formativa pública sobre la atención a la diversidad en Educación Física, de la modalidad que fuese, amparada por los principales organismos encargados de ofrecerla. El cambio radical que supuso la aprobación de la Orden de 10 de julio de 1995 y su posterior aplicación, como pauta específica de esta asignatura hacia los 
alumnos con necesidades educativas especiales, no se vio recompensada con un giro en las propuestas formativas.

Algunos autores plantean que el mito de no realizar actividad física por parte de los alumnos con alguna discapacidad, a los que se les consideraba exentos, pudiera estar siendo potenciado, entre otros, por la falta de formación (Muñoz y Antón, 2006). Con los datos obtenidos, no cabe duda que, al menos, durante un periodo relativamente amplio y muy próximo al cambio legislativo, la formación pública específica no fue para nada relevante.

\subsection{0.- TODAVÍA FALTAN PIEZAS}

Como se puede apreciar, las informaciones que van apareciendo en cada uno de los capítulos que configuran esta tesis van siendo sancionadas en alguno de los siguientes, y viceversa. A modo de ejemplo, observamos que la parte de la información sobre la tipología de la exención que aparecía en el Capítulo 6, aflora en estos cursos en boca de los expertos. De hecho, alguno niega con contundencia la remota posibilidad a la existencia de la exención total, pero deja entrever que sí hay lugar para la exención parcial de unos determinados contenidos o actividades. En capítulos anteriores ya se advertía de esta situación.

De esta forma, por cómo se va desarrollando la investigación, parece no acabar de tener un principio claro o un final concreto ya que, a la vista de los descubrimientos, cualquier capítulo o momento podría servir para uno u otro cometido.

No obstante, por aquello de tener en especial consideración la opinión de compañeros de disciplina, si tomamos como punto partida la información extraída en el Capítulo “APROXIMACIÓN A LA VISIÓN QUE TIENE EL PROFESORADO”, comprobamos que parte de esa información se ve corroborada con las declaraciones 
vertidas por expertos y testimonios de los participantes de los cursos formativos realizados a lo largo de un periodo de cuatro cursos escolares.

Pero, para poder emitir unas conclusiones con cierta contundencia, aún falta por investigar y conocer. Así, se hace inevitable indagar sobre algunas cuestiones que han ido apareciendo en algunos de esos cursos.

De un lado, creo necesario indagar sobre el papel que desempeñan los documentos médicos y escritos familiares en la puesta en escena o no de una concreta actuación por el profesor, lo cual, a su vez, implica el desempeño de un determinado rol por parte del alumnado en cuestión.

De otro, es preciso conocer hasta qué punto nuestra labor docente está cargada de esa responsabilidad de la que tanto se habla y, además, si existe una realidad que justifique ese temor o miedo a determinadas actuaciones, lo cual pudiera desencadenar una respuesta en términos de no mandar hacer o no proponer para evitar precisamente el riesgo inherente a nuestra asignatura.

También concibo como relevante e imprescindible acercarme al parecer de los auténticos protagonistas y sus familiares. Sus opiniones, vertidas desde una parcialidad absoluta, también deben ser consideradas pues, en definitiva, ellos son la razón de nuestra labor. 


\section{Piezas de la vidriera}

El relato de mi formación permanente, junto con un breve análisis de la formación específica que ofertan los CFIEs de Valladolid y provincia, evidencian algunas piezas ya conocidas de la vidriera, pero también nos descubren algunas otras de nueva aparición.

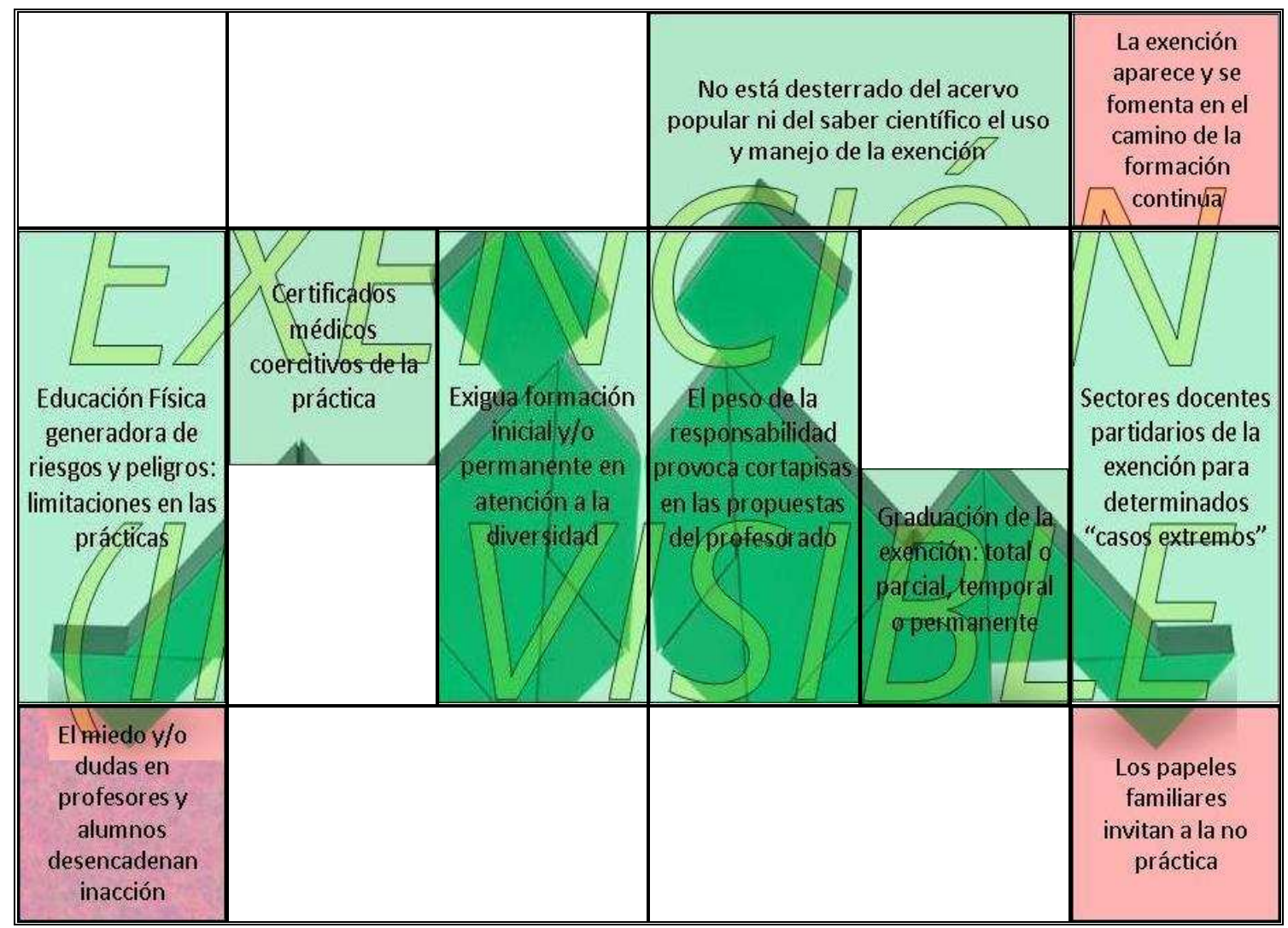




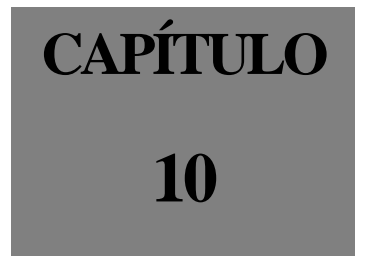

ANÁLISIS DE UNA REALIDAD EN TORNO A LOS DOCUMENTOS MÉDICOS Y JUSTIFICANTES PATERNOS QUE PRESENTAN LOS ALUMNOS PARA ESTAR EXENTOS 
En capítulos anteriores ha quedado en evidencia la importancia y necesidad que llegan a obtener los documentos médicos en la posterior actuación de los profesores ante los alumnos que los presentan.

Ahora bien, estos documentos adquieren mayor relevancia desde el momento en que los alumnos y profesores siguen al pie de la letra las indicaciones y "sugerencias" que los médicos redactan en ellos, reduciéndose su actuación, en muchas de las ocasiones, a no hacer nada por "recomendación médica".

Por ello, consideramos necesario estudiar y analizar estos documentos médicos. Comprobaremos sus habituales formatos de presentación, sus contenidos, omisiones y, obviamente, hasta qué punto pueden propiciar directamente, o inducir indirectamente, la aplicación de la exención en cualquiera de sus formas.

Como se podrá apreciar, los médicos suelen tener cierta visión reduccionista de la Educación Física ya que habitúan a confundirla y equipararla con la condición física y con cualquier disciplina deportiva (incluso algunos siguen llamándola "gimnasia"), lo que provoca que sus diagnósticos y tratamientos sean tan elementales como poco aclaratorios y generales, limitando y coartando (implícita o explícitamente) la participación de estos alumnos.

Asimismo, también revisaremos los justificantes familiares que ofrecen los alumnos para evitar la práctica de la Educación Física. 


\section{1.- CARACTERÍSTICAS DEL ESTUDIO}

El estudio que presentamos ahora se basa en la recopilación, clasificación y análisis de la totalidad de documentos médicos y justificantes familiares presentados por los alumnos en uno de los IES sujeto a estudio para excusar cualquier problema, lesión o impedimento (del tipo que sea), y así "evitar" la práctica en la totalidad o parte de una clase, Unidad Didáctica o curso escolar.

Como profesor de Educación Física del centro en el que se desarrolló la investigación, la principal técnica empleada para la recogida de datos fue la observación participante. En este tipo de técnica el investigador participa en la vida del grupo que estudia y acata sus normas y manifestaciones cotidianas (Bernardo y Calderero, 2000, p. 115). De esta forma, el investigador se convierte en uno más para poder recabar y analizar la información sobre el objeto de estudio. Así entendido, el planteamiento de participación es de tipo coparticipativo (Blández, 2000, p. 76).

"La observación participante representa la investigación que involucra la interacción social entre el investigador y los informantes, y durante la cual se recogen datos de modo sistemático...” (Taylor citado en Fraile, 1995, p. 62)

La observación participante llevada a cabo por el investigador tiene un marcado carácter activo ya que la interacción con todos los sujetos de estudio es máxima, lo que genera un mayor acercamiento a los mismos (Bernardo y Calderero, ibídem).

Por el contrario, uno de los mayores inconvenientes que plantea esta técnica es la dificultad para mantener la objetividad en las apreciaciones. Incluso pudiera llegar a 
suceder que "si la integración es profunda, no se suele ver en el mundo lo que el grupo mismo no ve" (López de Ceballos, 1989, p. 91).

Por ello se ha procurado no caer en el error de analizar los datos sin haberlos reunido en su totalidad, evitando así explicar la realidad observada demasiado pronto. Además, el proceso se ha alargado en el tiempo para dar mayor consistencia a los registros y, por último, se ha contado con el factor experiencia docente como cierta garantía de todo el proceso (ibídem, p. 93).

Asimismo, el investigador que realiza esta observación participante ha desempeñado simultáneamente los roles de investigador y facilitador del equipo de personas que han colaborado en el estudio (Fraile, 1995, p. 71).

Respecto de los aspectos que se han tenido en cuenta para emplear esta técnica, se han considerado los propuestos por Pérez Serrano (citado en Bernardo y Calderero, op. cit., pp. 118-119), tales como: la concreción del plan, determinar el lugar, formas y momentos de los registros, representación de los datos... Algunos de ellos se desarrollan a continuación en los siguientes subapartados.

Por último, esta parte de la investigación también supone un análisis de documentos en la medida que se ha trabajado con datos que han sido recopilados, organizados y clasificados con el fin de descubrir lo importante para la investigación (Bernardo y Calderero, op. cit., p. 122-123)

\section{Contextualización de la investigación}

El IES se ubica en una localidad de aproximadamente 6500 habitantes. A él acuden no solo los alumnos de esa localidad, sino también los alumnos de los municipios cercanos más pequeños. Se imparten estudios de toda la etapa de Educación Secundaria Obligatoria y Bachillerato. Además, cuenta con un módulo de Ciclo Formativo de Grado Medio. 
El municipio en cuestión cuenta con los servicios de un Centro de Salud que atiende a las necesidades sanitarias primarias de los vecinos. A los pueblos colindantes se suele desplazar periódicamente un médico y un ATS. Para cualquier otro tipo de servicio sanitario más complejo y especializado habría que acudir a los hospitales de Valladolid o de Medina del Campo (a unos 44 y 36 kilómetros, respectivamente).

El período durante el que se han recopilado todos estos documentos ha sido el correspondiente a tres cursos escolares, siendo tenidos en cuenta tanto los presentados por alumnos que cursaban Educación Secundaria Obligatoria como de $1^{\circ}$ Bachillerato. Los tres docentes del Departamento de Educación Física y Deportiva de dicho instituto han colaborado y participado en este proceso de acopio de documentación.

A este respecto, la recopilación de estos papeles se convirtió en una auténtica obsesión. El tiempo dedicado a todo este proceso, lo suficientemente prolongado como para que los resultados fueran creíbles, propició que se generara cierta presión entre los profesores que participaron en el estudio, ya que durante esos tres cursos debieron de estar pendientes (en extremo) de que los alumnos aportasen el consiguiente papel médico y/o familiar cuando, por algún motivo relacionado con su salud, no pudieran participar con "normalidad" en las clases.

Aunque la petición del documento médico o familiar estaba recogida en la programación didáctica del área de Educación Física, y perfectamente implantada en el centro escolar objeto de estudio, y que los alumnos conocían y acataban la norma de entregar el "papelito" en caso de enfermedad, indisposición transitoria o lesión, la autoexigencia del seguimiento exhaustivo del proceso derivó en estrés docente. Incluso cuando un alumno no traía el documento el mismo día de clase, se le "invitaba" a traerlo para la siguiente, aun cuando ya pudiese participar. La "no práctica" debía explicitarse en el escrito médico-familiar.

Según los datos que figuran en el Documento de Organización de Centro (D.O.C.) de cada curso escolar en que se ha desarrollado la investigación, tenemos que la media anual de alumnos que cursaron Educación Física durante el período de 
investigación ha sido de 564, de los cuales el $50.15 \%$ eran alumnas y el $49.85 \%$ alumnos (Gráfica 70).

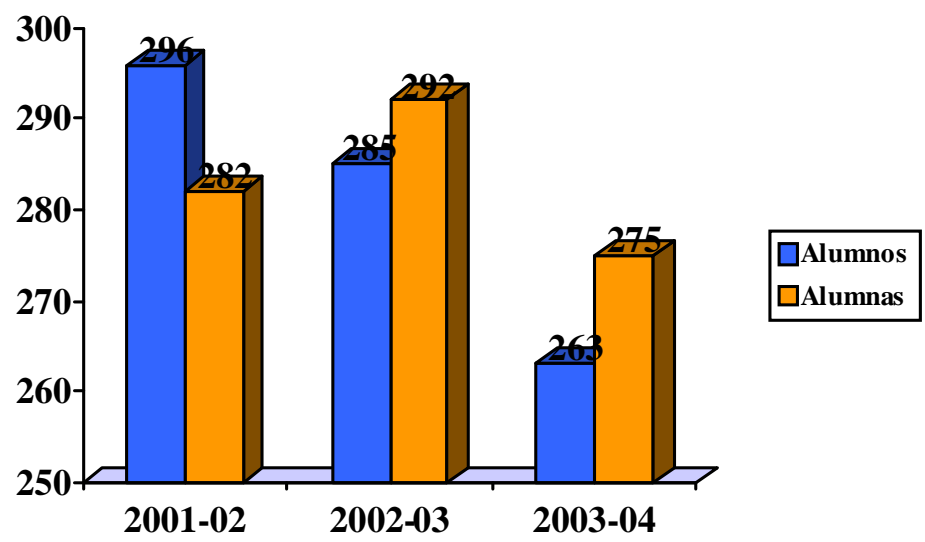

Gráfica 70. Alumnos que han cursado Educación Física durante el período de investigación

En lo que al formato de los papeles se refiere, se ha aceptado como válido cualquier documento médico y justificante familiar que haya sido presentado por los alumnos al profesor de Educación Física, tutor, secretaría del centro..., para los motivos antes citados, independientemente de la calidad y/o ajuste a la legalidad de los mismos (referido a la presencia de aspectos como un sello o distintivo médico oficial, que figure el DNI del padre o madre, papel en el que se realiza, etc.).

Además de los profesores de Educación Física que trabajan en el centro, también han participado todos los que desempeñaron labores de tutoría con grupos de la E.S.O. o el Bachillerato. También el personal administrativo a cargo de la Secretaría del centro estaba informado del asunto y nos alertaba cuando algún documento médico se incluía al inicio de cada curso con el sobre de la matrícula.

Siempre que ha sido posible se han registrado los hechos y situaciones sucedidas lo más rápidamente posible, no dando lugar a que la memoria pudiera empañar lo observado. Los sistemas de registro utilizados han sido cuadernos o diarios de campo y fichas de sistematización de la información. Además, todos los documentos ha sido 
convenientemente archivados y custodiados por si fuese necesario consultarlos nuevamente.

Finalmente, con el objeto de favorecer una mejor exposición de los datos y la posterior obtención de conclusiones, se ha optado por dividir el estudio en dos partes claramente diferenciadas correspondientes a cada uno de los documentos, es decir, nos ocuparemos por separado de los informes médicos y de los justificantes familiares.

\section{2.- DOCUMENTOS MÉDICOS}

En el epílogo del Capítulo 6 afirmábamos que los médicos, a través de sus certificados, provocan la aplicación de exenciones (en cualquiera de sus formas) en la Educación Física, configurando, junto con los justificantes paternos, un vector o línea de acción al que denominábamos "el poder de los papeles".

Pero, ¿realmente los documentos médicos tienen algún poder? Solo con los datos aportados en el apartado 2.4 del mencionado capítulo ya estaríamos en condiciones de asegurar que la respuesta debe ser que sí. No obstante, con el fin de sostener definitivamente esta afirmación, no estará de más validarla con más documentación.

\section{¿Qué valor hay que otorgar a los documentos médicos?}

Para empezar, remito al lector, además de al citado Capítulo 6, al Capítulo 9 que versa sobre mi propia formación permanente. Como se habrá podido comprobar, docentes en activo de Educación Física y expertos en derecho y legislación coincidieron en señalar, entre otros asuntos, que hay que acatar rigurosamente lo que dictan los papeles médicos. 
Más rotundo se muestra Lacasa (2002) ya que cuando se plantea la interpretación de los justificantes paternos y los comunicados oficiales de los médicos, deja del todo claro que en este segundo supuesto hay que "seguir siempre las indicaciones al pie de la letra".

Además, como es sabido, estos documentos son claves en la formulación y elaboración de las Adaptaciones Curriculares Individuales (ACIs a partir de ahora) que se deseen poner en marcha, ya que la propia Orden de 10 de julio de 1995 así lo establecía en su artículo 3, apartados 1 y 2. Entre otras cosas se dictaminaba que el Departamento de Educación Física acordará las adaptaciones oportunas a la vista de los certificados médicos ${ }^{192}$.

Aún más, la propia Dirección Provincial de Valladolid, hasta la aparición de la esa Orden de 1995, tenía a disposición de los profesores que lo requiriesen ${ }^{193}$ una ficha

192 Como quedó aclarado en el Capítulo 6, apartado 1.3, esta norma fue derogada por la Orden EDU/849/2010, de 18 de marzo, por la que se regula la ordenación de la educación del alumnado con necesidad de apoyo educativo y se regulan los servicios de orientación educativa en el ámbito de gestión del Ministerio de Educación, en las ciudades de Ceuta y Melilla (BOE 06-04-2010). En el artículo 18 de esta última norma, apartado 3, se establece, aplicado al Bachillerato, que "De acuerdo con lo previsto en el artículo 21.2 de la Orden ESD/1729/2008, de 11 de junio, por la que se regula la ordenación y se establece el currículo del bachillerato, se podrán realizar adaptaciones del currículo en la materia de Educación física al alumnado que así lo requiera, por presentar necesidades educativas especiales derivadas de discapacidad o por condiciones personales de salud... Las adaptaciones se realizarán en función de las necesidades del alumno, teniendo en cuenta las orientaciones de los servicios de orientación educativa contenidas en el informe psicopedagógico y, en su caso, el certificado médico que aporte el alumno. En el caso de las adaptaciones curriculares de Educación física para el alumnado cuyas condiciones de salud las requiera, se realizarán en base a lo especificado en el certificado médico." (Énfasis mío).

Además, en Castilla y León, RESOLUCIÓN de 17 de agosto de 2009, de la Dirección General de Planificación, Ordenación e Inspección Educativa, por la que se regula el diseño, aplicación, seguimiento y evaluación de las adaptaciones curriculares significativas para el alumnado con necesidades educativas especiales escolarizado en el segundo ciclo de educación infantil, educación primaria y educación secundaria obligatoria en los centros docentes de la Comunidad de Castilla y León (BOCyL 26/08/2009), establece en su artículo 4, apartado 2, que las “...adaptaciones curriculares significativas tomarán como referencia la información contenida en el informe psicopedagógico del alumno afectado...". Si acudimos a la normativa que fija el modelo de la evaluación psicopeddagógica, la Orden EDU/1603/2009, de 20 de julio, por la que se establecen los modelos de documentos a utilizar en el proceso de evaluación psicopedagógica y el del dictamen de escolarización (BOCyL 28/07/2009), observamos que el informe médico puede constituir parte de la información previa de que dispone el Departamento de Orientación.

${ }^{193}$ Los profesores demandamos la mayor cantidad de información acerca de las lesiones, enfermedades o limitaciones que puedan presentar o padecer ciertos alumnos. Sirvan como ejemplo las palabras recogidas en el libro de actas de un departamento de Educación Física y Deportiva sujeto a estudio: "Se acuerda unificar los Certificados Médicos con un impreso facilitado por la Dirección Provincial a fin de que la 
para ser entregada al médico correspondiente en el que se solicitaba asesoramiento adecuado para adaptar la materia a las enfermedades temporales o discapacidades permanentes de un determinado alumno.

Llegado a este punto, haremos un pequeño paréntesis para argumentar con un ejemplo el comentario que hacíamos en la introducción respecto a la visión reduccionista de la Educación Física por parte de los médicos.

Desde las propias instituciones educativas se provocaba una particular forma de entender la Educación Física ya que esta ficha de la que hablábamos antes, en su cara posterior, contemplaba únicamente cuestiones relacionadas con las capacidades físicas (saltos, carreras a diferentes ritmos, flexo-extensiones de tronco, volteretas, equilibrio invertido, lanzamientos y transporte de peso) y con el deporte (fútbol, baloncesto, balonmano, voleibol, bádminton y hockey). Entendemos que solo autorizaban o desautorizaban tomar parte en las actividades físicas y deportivas que únicamente aparecían en la ficha, las cuales representarían el tipo de prácticas con las que se identificaba la Educación Física.

No estaríamos del todo equivocados al afirmar que, entre otras, esta circunstancia ha podido contribuir a crear en los facultativos una idea reducida y confundida de lo que verdaderamente era la Educación Física y lo que en ella se trabajaba y hacía. Por el escaso tiempo que ha pasado, así como por la carencia de información sobre los nuevos derroteros que ha tomado la enseñanza de la Educación Física, probablemente esta situación perdure hoy día ${ }^{194}$.

Volviendo al tema de la importancia y necesidad del informe médico, Pérez Cortés et alia (1997) señalan que para adecuar la respuesta educativa a estos alumnos

información dada por los médicos sea mayor y más específica. (9-11-94)”. Dicho impreso o documento se encuentra recogido en el Anexo 24.

${ }^{194}$ No olvidemos que, tal y como hemos apuntado en el Capítulo 6, los mismos profesores de Educación Física tenemos en los contenidos de la condición física y deportes el grueso de nuestras enseñanzas (vid.: Astráin, 2002). También son sumamente esclarecedores los comentarios recogidos en la Nota 150 de ese mismo capítulo. 
con necesidades educativas especiales es necesario partir de una evaluación inicial objetiva que sirva para detectar el nivel de partida de cada uno de ellos. Dicha evaluación debe de basarse en un informe médico que refleje los datos concretos de la patología y las directrices para su terapia.

Igualmente, Gomendio (2000, p. 126), cuando aborda la elaboración de ACIs, señala a los médicos como una fuente de información que debe ser tenida en cuenta en la evaluación (inicial) interdisciplinar del niño.

Briongos et alia (2000), establecen como condicionante imprescindible para realizar propuestas inclusivas para estos alumnos la exigencia de la correspondiente certificación médica en la que figure lo que padece el alumno y todo lo que puede y no puede hacer.

Aboy Lafuente et alia (Fuente [17] ${ }^{195}$ ), ofrecen un ejemplo de Informe de adaptación curricular cuyo comienzo es muy esclarecedor: "El alumno/a..., a la vista de los informes médicos presentados deberá atenerse a la siguiente conducta en cuanto a la Educación Física se refiere...."

Albornoz (2002), aunque lo emplea para atenuar la responsabilidad civil del docente ante posibles daños que pudieran ocurrir durante el desarrollo de las clases de Educación Física, aconseja la realización de un examen médico de los alumnos al inicio del período escolar de cada curso.

En esta línea de evitar accidentes en los alumnos y depurar algún tipo de responsabilidad, Latorre y Herrador (2003, p. 284) aconsejan exigir a todos los alumnos que acrediten antes del inicio de las clases su perfecto estado de salud mediante el correspondiente informe médico de aptitud física.

De forma parecida se muestra Espartero (1997), quien apunta, entre algunas de las medidas a tomar para amortiguar el peso de la responsabilidad en los docentes de

\footnotetext{
195 http://www.madrid.org/sanidad/salud/educa/asma_y_escuela/ejemplo.htm
} 
Educación Física y técnicos deportivos, la realización de reconocimientos médicos completos y obligatorios previos a la práctica deportiva.

Hasta desde los mismos documentos editados bajo el auspicio de la administración se recomienda solicitar a los padres que sus hijos realicen un examen médico para descartar cualquier tipo de problema (Roldán, 2002), lo cual se debe de complementar con el seguimiento del profesor a través de una ficha médica y de capacidad física de cada alumno.

Por su parte, Guillén (1998b, pp. 149 y 153) recoge la idea de elaborar un reconocimiento médico a los escolares antes de empezar el curso, y de la Cruz (1989, p. $74 ; 1992$, p. 105) aconseja la realización de una revisión médica a los adolescentes -en el plano educativo- de manera anual.

Además, todos reconocemos que cuando se inicia un programa de salud o de actividad física, por muy ligera que esta sea (incluida la que pudiera tener lugar en nuestras clases de Educación Física), es recomendable realizar un chequeo o revisión médica que descarte enfermedades o dolencias que pudieran verse agravadas con la realización de esfuerzos físicos. De hecho, algún centro educativo (Fuente [25]) pide un Informe de Salud como documento a acompañar la solicitud de matrícula.

Resumiendo, los documentos médicos son una importante fuente de información y un poderoso recurso a considerar en nuestras clases, sobre todo cuando se trata de atender y dar respuesta a alumnos con dificultades de aprendizaje asociadas a cualquier discapacidad. De hecho, hay que señalar que hay centros educativos que indican los puntos que deben contener los certificados médicos que presenten sus alumnos (vid.: Capítulo 6).

Que los certificados son presentados para obtener una exención empieza a quedar fuera de toda duda. Pero también pudiera darse el caso de los que plantean que esa posibilidad debiera de existir pero que el problema radica en que la gravedad de la lesión o patología es "menor" y por tanto no cabe la exención (Santoja et alia, 2004). 
Estos mismos autores sitúan el mayor de los problemas en que en ocasiones van a ser los mismos padres los que fuercen o presionen al médico para que firme un documento con este propósito de la exención (ibídem, p. 15)

Además, no es menos cierto que pudiera darse algún caso en el que el documento médico sea del todo obviado por el profesor, bien por la creencia o presunción de la intromisión profesional de los médicos en nuestro terreno comentada en el Capítulo 6, bien por otros motivos personales del profesor hacia los propios alumnos. En este sentido, vamos a reproducir parte de un pasaje sumamente interesante extraído de Pastor (2002, pp. 175-176) que podría servir de ejemplo.

"La primera semana de diciembre, en plena fecha de exámenes viene a visitarme la madre de Luis, alumno de $3^{\circ}$ de la ESO.

Yo soy la tutora de su hijo, y me ha pedido una entrevista para un asunto relacionado con la Educación Física. Quiere que Luis esté presente mientras ella habla conmigo. Durante la entrevista, Luis está cabizbajo. Su madre me cuenta que Luis padece asma, y que no puede realizar determinados ejercicios.

- Si, eso ya lo sé. Tengo el justificante médico que Luis me entregó a principio de curso, y que yo le mostré a la profesora de Educación Física para que sepa que Luis no puede hacer los mismas pruebas que los demás.

- Pues por eso he venido a hablar con usted hoy. Luis me ha dicho que va a suspender la Educación Física porque no hace las pruebas que le manda la profesora. Dice que los chicos se ríen de él cuando la profesora le llama «enclenque»..., y que le hace hacer correr más que a los demás.

- Mire, yo no puedo creer que eso sea cierto. Tendré que hablar con la profesora, y pedirle que me explique lo que ocurre...

Al día siguiente le conté a la profesora la conversación con la madre de Luis.

- iPues claro que le he suspendido! Se cree que trayendo un simple papelito va a dejar de sudar como los demás. ¡Está muy equivocado!

- Escúchame, Ana. Su madre me ha dicho que Luis padece asma, y que por eso el médico no le aconseja hacer ciertos esfuerzos. Ya sabes que está muy delgado y mucho menos desarrollado que los chicos de su edad...

- Pues conmigo no cuela ese papelito del médico. Tendrá que sudar como todos. Ya se puede ir preparando...

La profesora se da media vuelta y se va."

Una vez puesto de manifiesto la relevancia de este tipo de documento, vayamos con la investigación realizada. 


\section{$\underline{\text { Recogida de datos y tabla de documentos }}$}

Como dijimos anteriormente, el período de recopilación de documentos médicos se llevó a cabo durante tres cursos escolares completos. De todos los documentos recogidos, 96 en total, tan solo dos de ellos, a petición de los propios interesados, han "pasado" en primer lugar por la secretaría del centro para darles entrada oficial y así poder figurar en sus correspondientes expedientes. En definitiva, la inmensa mayoría han sido recogidos directamente por los docentes de Educación Física.

Para poder proceder a la “descomposición” y clasificación de los documentos, se procedió a confeccionar una tabla (Tabla 14) que refleja los datos que aparecen en todos ellos, así como información relacionada con algunos de los núcleos de atención empleados para su posterior análisis e interpretación. Por razones de comodidad para el lector, y a fin de facilitar la búsqueda inmediata de la información, hemos decidido incluir esta tabla (descompuesta en 9 partes) en el propio desarrollo del capítulo y no en los Anexos.

Como se podrá comprobar, esta tabla consta de tres columnas.

La primera de ellas es para asignar un número aleatorio a cada uno de los 96 informes o documentos recibidos. Hemos de insistir en que dicho número no tiene ninguna significación especial, tratándose tan solo de una forma rápida y eficaz de dirigirnos a un documento en concreto.

En la segunda, resumimos lo que consideramos más significativo del contenido del documento, siempre salvaguardando (por omisión) los datos que pudieran revelar la identidad de los interesados. Los fragmentos seleccionados reproducen literalmente las palabras que los facultativos plasman en sus escritos.

La tercera columna nos sirve para hacer una escueta alusión sobre aspectos como el formato en que se presenta el escrito, identificación del facultativo, período de 


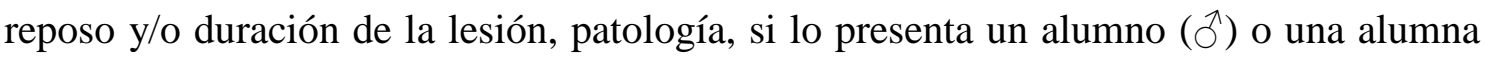
() y, en algún caso, añadir un breve comentario.

Relacionados con esta última columna hemos de aclarar los siguientes aspectos: La terminología empleada obedece a criterios estrictamente personales que nada tienen que ver con las que utilizan los profesionales de la medicina. Así por ejemplo, cuando hablamos del Modelo OTEP y Parte de $\mathrm{CH}$ nos estamos refiriendo a los formularios estandarizados "Orden de tratamiento a enfermeras y practicantes" (conocido en el argot facultativo como P.10) y "Parte de consulta y hospitalización”, respectivamente (Ilustración 2 y 3).

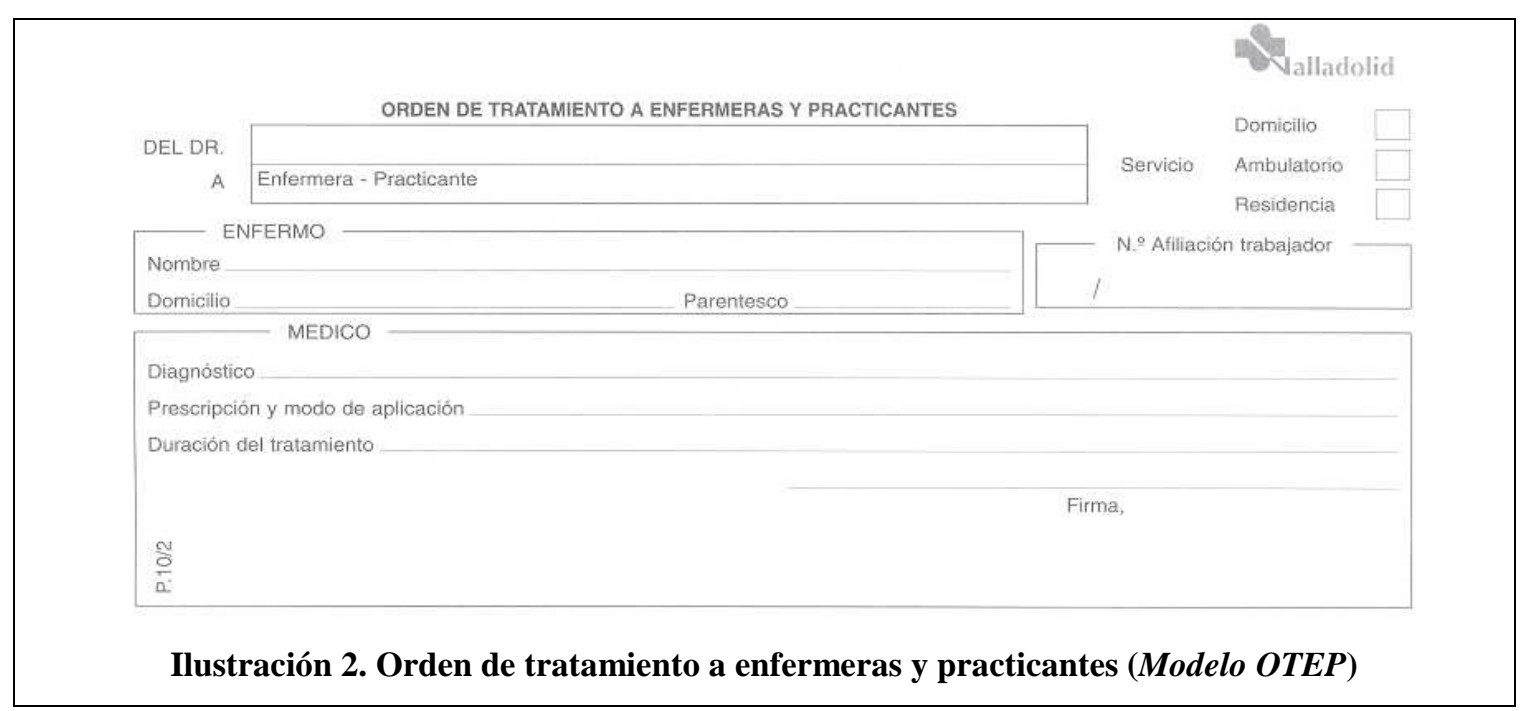




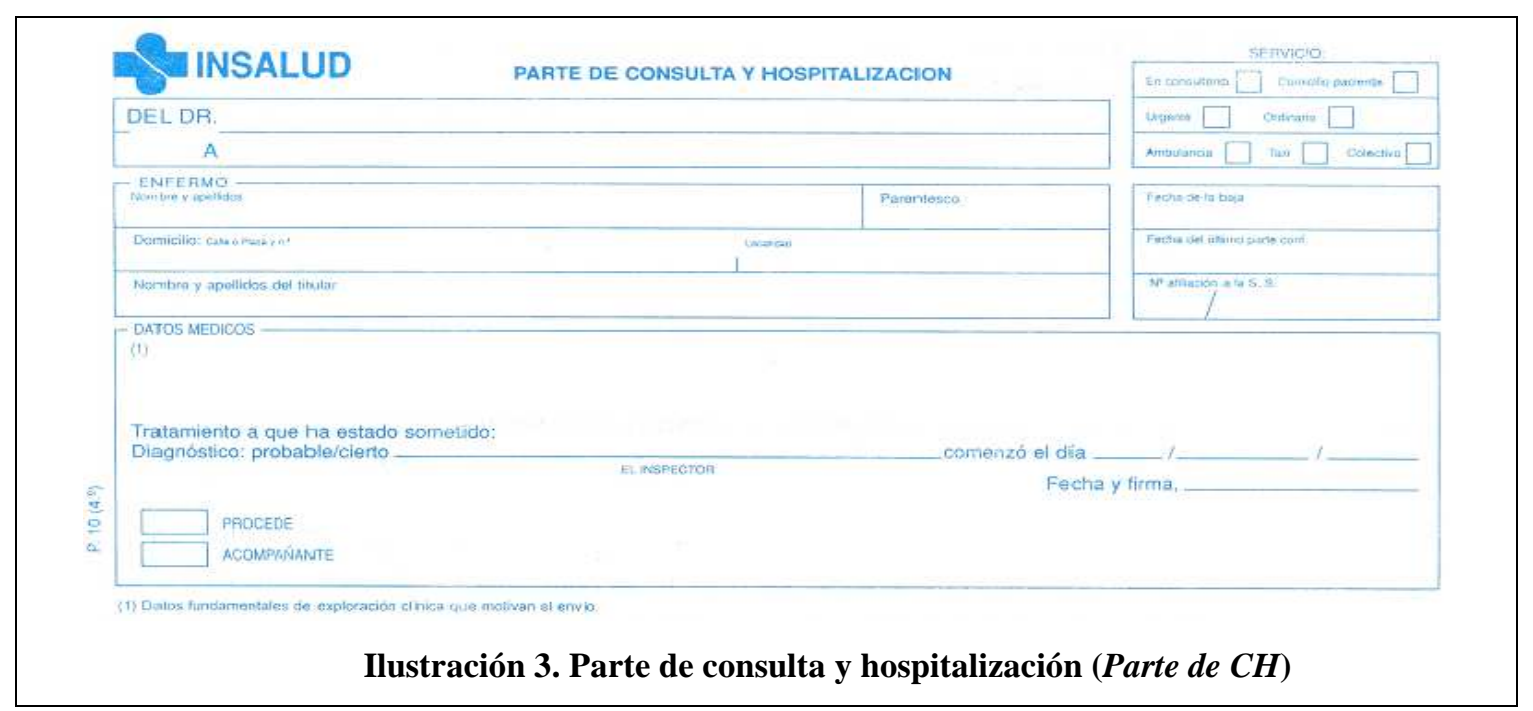

Cuando decimos que se trata de un Informe Clínico Médico es porque así lo refleja el médico o porque hemos decidido incluir en esta categoría a documentos que no tienen una denominación específica.

De igual modo, consideramos relevante destacar si el facultativo se identifica -a pesar de que ello es obligatorio-, pues es un dato que otorga mayor credibilidad y validez al documento. Por ello, también resaltamos aquellos papeles en los que no aparece el sello o la pegatina de identificación "oficial” del médico.

Pues bien, aclaradas todas estas cuestiones, la Tabla 14 queda de la siguiente manera: 


\begin{tabular}{|c|c|c|}
\hline $\mathbf{N}^{\mathbf{o}}$ & CONTENIDO DEL INFORME & OBSERVACIONES \\
\hline 1 & $\begin{array}{l}\text { Esguince de rodilla derecha. Deberá de abstenerse de } \\
\text { realizar Educación Física al menos por dos semanas. }\end{array}$ & $\begin{array}{l}\text { Consulta de urgencias. Modelo } \\
\text { de Orden de Tratamiento a } \\
\text { Enfermeras y Practicantes } \\
\text { (OTEP a partir de ahora). } 0^{n}\end{array}$ \\
\hline 2 & $\begin{array}{l}24-48 \text { horas sin realizar su actividad (se supone que } \\
\text { refiriéndose a mi asignatura. Aclaración mía) }\end{array}$ & $\begin{array}{l}\text { Modelo OTEP. No señala la } \\
\text { enfermedad o lesión. O" }\end{array}$ \\
\hline 3 & $\begin{array}{l}\text { No debe realizar ningún ejercicio físico hasta nueva } \\
\text { orden. }\end{array}$ & $\begin{array}{l}\text { Modelo OTEP. No señala } \\
\text { enfermedad o lesión. } \$\end{array}$ \\
\hline 4 & $\begin{array}{l}\text { Ha estado en consulta con el Especialista en... } \\
\text { problemas de rodilla, hasta que no tengamos resultados } \\
\text { no debe hacer ejercicios. }\end{array}$ & $\begin{array}{l}\text { Modelo OTEP. No tiene ni } \\
\text { sello ni pegatina de } \\
\text { identificación. Sí el nombre } \\
\text { del facultativo. } ᄋ\end{array}$ \\
\hline 5 & No puede realizar ningún tipo de gimnasia en 15 días. & $\begin{array}{llrr}\text { Modelo } & \text { OTEP. } & \text { Subraya } & \text { el } \\
\text { período } & \text { de } & \text { duración } & \text { del } \\
\text { reposo. } & \text { No } & \text { señala } & \text { la } \\
\text { enfermedad o lesión. } . & \end{array}$ \\
\hline 6 & $\begin{array}{l}\text { El paciente ha sido operado de fístula y no puede } \\
\text { realizar gimnasia de ningún tipo en } 2 \text { meses. }\end{array}$ & $\begin{array}{l}\text { Modelo } \\
\text { período } \text { OTEP. } \\
\text { reposo. } \sigma^{n}\end{array}$ \\
\hline 7 & $\begin{array}{l}\text { El traumatólogo ha recomendado reposo absoluto de la } \\
\text { rodilla debido a su alteración rotuliana. No debe hacer } \\
\text { gimnasia. }\end{array}$ & $\begin{array}{l}\text { Modelo OTEP. No especifica } \\
\text { duración del reposo. } \bigcirc\end{array}$ \\
\hline 8 & $\begin{array}{l}\text { Lesión en tobillo pendiente de estudio por traumatólogo. } \\
\text { Se recomienda exención de gimnasia hasta tener } \\
\text { diagnóstico. }\end{array}$ & $\begin{array}{l}\text { Modelo OTEP. No señala la } \\
\text { fecha de emisión o consulta. } \\
\text { Emplea el término exención. } \\
\text { o }\end{array}$ \\
\hline 9 & $\begin{array}{l}\text { Evitar esfuerzos físicos en aproximadamente } 15 \text { días. No } \\
\text { hacer deporte }\end{array}$ & $\begin{array}{l}\text { Parte de Consulta } \mathrm{y} \\
\text { Hospitalización }(\mathrm{CH} \text { a partir } \\
\text { de ahora). } \$\end{array}$ \\
\hline 10 & $\begin{array}{l}\text { Derrame intraarticular en rodilla derecha. Con } \\
\text { impotencia funcional. Recomiendo no realizar ejercicio } \\
\text { físico (Educación Física) al menos hasta mejoría de los } \\
\text { síntomas. }\end{array}$ & Parte $\mathrm{CH} . \mathrm{O}^{+}$ \\
\hline 11 & $\begin{array}{l}\text { Hasta su recuperación física (en torno a 10-15 días) no } \\
\text { es conveniente que haga clases de Educación Física. }\end{array}$ & $\begin{array}{l}\text { Modelo OTEP. No señala la } \\
\text { enfermedad o lesión. } ९\end{array}$ \\
\hline 12 & $\begin{array}{l}\text { Ha acudido en el día de la fecha a Consulta médica no } \\
\text { pudiendo realizar ejercicio físico en los próximos } 15 \\
\text { días. }\end{array}$ & $\begin{array}{l}\text { Parte CH. Parece un modelo } \\
\text { estándar de informe. No señala } \\
\text { la enfermedad o lesión. } ๆ\end{array}$ \\
\hline
\end{tabular}

Tabla 14. Documentos médicos recogidos en la investigación $\left(1^{\text {a }}\right.$ de 9) 


\begin{tabular}{|c|c|c|}
\hline $\mathbf{N}^{\mathbf{o}}$ & CONTENIDO DEL INFORME & OBSERVACIONES \\
\hline 13 & $\begin{array}{l}\text { Ha acudido en el día de la fecha a Consulta médica no } \\
\text { pudiendo realizar ejercicio físico en los próximos } 15 \\
\text { días. }\end{array}$ & $\begin{array}{l}\text { Parte CH. Parece un modelo } \\
\text { estándar de informe. No tiene } \\
\text { ni sello ni pegatina de } \\
\text { identificación. Sí los datos del } \\
\text { facultativo. No señala la } \\
\text { enfermedad o lesión. @ }\end{array}$ \\
\hline 14 & $\begin{array}{l}\text { Este paciente presenta un cuadro de (ilegible) derecha } \\
\text { secundario a cuadro de hiperfunción rotuliana externa. } \\
\text { Pendiente de tratamiento quirúrgico. No debe realizar } \\
\text { ejercicios de salto, carrera rápida ni aquella que le } \\
\text { provoque dolor. }\end{array}$ & $\begin{array}{l}\text { Parte CH. Tiene sello de } \\
\text { consulta traumatología. } \$\end{array}$ \\
\hline 15 & $\begin{array}{l}\text {...por padecer limitación física debido a enfermedad, no } \\
\text { debe realizar ejercicios determinados de Educación } \\
\text { Física, salvo los que practica en el S. de Rehabilitación. }\end{array}$ & $\begin{array}{l}\text { Folio de } \quad \text { "propaganda" } \\
\text { farmacéutica. Presenta sello } \\
\text { oficial. No señala la } \\
\text { enfermedad de forma clara. } \$\end{array}$ \\
\hline 16 & $\begin{array}{l}\text {...presenta un proceso patológico por lo que no podrá } \\
\text { realizar gimnasia. Pendiente de resultado de algunas } \\
\text { pruebas para determinar si será de forma definitiva. }\end{array}$ & $\begin{array}{l}\text { Folio de Historia Actual. No } \\
\text { tiene ni sello ni pegatina de } \\
\text { identificación. Sí los datos del } \\
\text { facultativo. No señala la } \\
\text { patología de forma clara. } \$\end{array}$ \\
\hline 17 & $\begin{array}{l}\text { Rinoconjuntivitis y tos estacional. Sensibilización } \\
\text { moderada a gramíneas... En los meses de mayo y junio } \\
\text { no hará ejercicio al aire libre. }\end{array}$ & $\begin{array}{l}\text { Informe muy completo de } \\
\text { alergias. No tiene ni sello ni } \\
\text { pegatina de identificación. Sí } \\
\text { los datos del facultativo. ㅇ }\end{array}$ \\
\hline 18 & $\begin{array}{l}\text { Lumbalgia inflamatoria en estudio. Absolutamente } \\
\text { contraindicada la actividad física o deportiva en el } \\
\text { momento actual. }\end{array}$ & $\begin{array}{l}\text { Informe Clínico } \text { Médico. No } \\
\text { señala ningún período de } \\
\text { tiempo. } \sigma^{\pi}\end{array}$ \\
\hline 19 & $\begin{array}{l}\text {..ASMA INDUCIDA POR EL EJERCICIO Y } \\
\text { DEPORTE. No realizar carreras de fondo y ejercicio } \\
\text { muy competitivo, y sí deporte de alternancia con } \\
\text { precalentamiento PREVIO. }\end{array}$ & $\begin{array}{l}\text { Informe Clínico Médico. No } \\
\text { tiene ni sello ni pegatina de } \\
\text { identificación. Sí el nombre } \\
\text { del facultativo. } \varnothing^{\star}\end{array}$ \\
\hline 20 & $\begin{array}{l}\text { Paciente de... años, diagnosticado en nuestro servicio } \\
\text { de... Puede hacer vida normal, sin correr, saltar o } \\
\text { ejercicios violentos que afecten las caderas. }\end{array}$ & Informe Clínico Médico. o" \\
\hline
\end{tabular}

Tabla 14. Documentos médicos recogidos en la investigación $\left(2^{\mathrm{a}}\right.$ de 9$)$ 


\begin{tabular}{|c|c|c|}
\hline $\mathbf{N}^{\mathbf{o}}$ & CONTENIDO DEL INFORME & OBSERVACIONES \\
\hline 21 & $\begin{array}{l}\text { El paciente... padece tos o asma inducida por ejercicio. } \\
\text { Esto supone que determinados ejercicios pueden } \\
\text { provocarle tos o asma... Intervienen como factores } \\
\text { favorecedores: realizar el ejercicio al aire libre, en } \\
\text { tiempo de frío... Por tal motivo, en la asignatura de } \\
\text { Educación Física o en cualquier actividad deportiva no } \\
\text { se le exigirán carreras a pie de más de TRES MINUTOS } \\
\text { SEGUIDOS de duración, tanto en pruebas (carreras } \\
\text { cuya distancia se haya de correr en más tiempo) como } \\
\text { en entrenamientos. } \\
\text { Es conveniente, no obstante, que el resto de los } \\
\text { ejercicios que pueda hacer los practique con } \\
\text { regularidad... Practicará cualquier tipo de deporte, } \\
\text { sobre todo aquellos en cuyo desarrollo se incluyan } \\
\text { descansos cortos, deportes de equipo, etc. } \\
\text { La fase de calentamiento es importante para la buena } \\
\text { realización del deporte o prueba que haya de hacer... } \\
\text { En todo momento procurará respirar por la nariz (salvo } \\
\text { en natación), especialmente en tiempo frío... Mantendrá } \\
\text { estas normas al menos hasta que pase cinco años sin } \\
\text { tener episodios agudos de tos... durante todo el tiempo } \\
\text { de primavera NO PARTICIPARÁ en actividad que } \\
\text { supongan acercarse a lugares donde haya hierba o } \\
\text { cereales en floración (excursiones al campo, granjas, } \\
\text { etc.) y en los meses de MAYO Y JUNIO NO HARÁ } \\
\text { EJERCICIO FÍSICO ALAIRE LIBRE. }\end{array}$ & $\begin{array}{l}\text { Es un informe que aparece } \\
\text { como "Normas a tener en } \\
\text { cuenta en la asignatura de } \\
\text { educación física o en actividad } \\
\text { deportiva para pacientes con } \\
\text { tos espasmódica o asma } \\
\text { inducida por ejercicio". } \\
\text { En otro folio están recogidas } \\
\text { las "Normas a tener en cuenta } \\
\text { en pacientes con alergia a } \\
\text { polen de gramineas en } \\
\text { relación con la actividad } \\
\text { escolar". } \\
\text { Muy detallado lo que puede y } \\
\text { no puede hacer. } \sigma^{\pi}\end{array}$ \\
\hline 22 & Idéntico al anterior. & Idéntico al anterior. + \\
\hline 23 & No debe hacer gimnasia hasta nueva orden. & $\begin{array}{l}\text { Modelo OTEP. No señala la } \\
\text { enfermedad o lesión. ơ }\end{array}$ \\
\hline 24 & $\begin{array}{l}\text { Ha acudido en el día de la fecha a Consulta médica no } \\
\text { pudiendo realizar ejercicio físico en los próximos } 9 \\
\text { meses... }\end{array}$ & $\begin{array}{l}\text { Parte CH. Parece un modelo } \\
\text { estándar de informe. No señala } \\
\text { la enfermedad o lesión. } ๆ\end{array}$ \\
\hline 25 & $\begin{array}{l}\text { No debe realizar ningún tipo de gimnasia en } 4-5 \\
\text { semanas. }\end{array}$ & Modelo OTEP. \\
\hline 26 & $\begin{array}{l}\text { Paciente con algo de asma. Sería conveniente no } \\
\text { realizar Educación Física. }\end{array}$ & $\begin{array}{l}\text { Modelo OTEP. No señala } \\
\text { ningún período de tiempo. } 0^{n}\end{array}$ \\
\hline 27 & $\begin{array}{l}\text { Paciente con lumbalgias de repetición. Sería } \\
\text { conveniente no realizar esfuerzos importantes. }\end{array}$ & 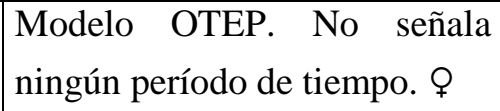 \\
\hline 28 & $\begin{array}{l}\text { Ha acudido en el día de la fecha a Consulta médica y no } \\
\text { podrá realizar ejercicio físico en } 1 \text { mes. }\end{array}$ & $\begin{array}{l}\text { Parte CH. No señala la } \\
\text { enfermedad o lesión. } \$\end{array}$ \\
\hline
\end{tabular}

Tabla 14. Documentos médicos recogidos en la investigación ( $3^{\text {a }}$ de 9) 


\begin{tabular}{|c|c|c|}
\hline $\mathbf{N}^{\mathbf{o}}$ & CONTENIDO DEL INFORME & OBSERVACIONES \\
\hline 29 & $\begin{array}{l}\text { Ha acudido en el día de la fecha a Consulta médica no } \\
\text { pudiendo realizar ejercicio físico en los próximos } 3 \\
\text { meses... }\end{array}$ & $\begin{array}{l}\text { Parte CH. Parece un modelo } \\
\text { estándar de informe. No señala } \\
\text { enfermedad o lesión. No tiene } \\
\text { ni sello ni pegatina de } \\
\text { identificación. Sí el nombre } \\
\text { del facultativo. } \$\end{array}$ \\
\hline 30 & $\begin{array}{l}\text { La paciente no puede realizar actividad física dada su } \\
\text { situación clínica actual, durante todo curso escolar. }\end{array}$ & $\begin{array}{l}\text { Modelo OTEP. No señala la } \\
\text { enfermedad o lesión. } ९\end{array}$ \\
\hline 31 & $\begin{array}{l}\text { Se le recomienda no hacer ejercicios físicos que le } \\
\text { provoquen dolor de espalda, por padecimiento de la } \\
\text { misma. }\end{array}$ & $\begin{array}{l}\text { Parte de CH. No señala la } \\
\text { enfermedad o lesión. } ?\end{array}$ \\
\hline 32 & $\begin{array}{l}\text { Paciente en estudio y tratamiento por posible asma } \\
\text { bronquial. ... no aconsejo ejercicio físico severo. }\end{array}$ & Modelo OTEP. \& \\
\hline 33 & $\begin{array}{l}\text { No puede realizar ciertos ejercicios que requieran la } \\
\text { flexión/extensión y adducción de las dos manos (no } \\
\text { balón medicinal). }\end{array}$ & Modelo OTEP. ㅇ \\
\hline 34 & $\begin{array}{l}\text { No debe realizar ejercicios físicos que comprometan las } \\
\text { articulaciones de ambas rodillas. }\end{array}$ & Modelo OTEP. $९$ \\
\hline 35 & $\begin{array}{l}\text { Ha acudido a consulta hoy y no puede realizar gimnasia } \\
\text { en } 15 \text { días. }\end{array}$ & $\begin{array}{l}\text { Modelo OTEP. No señala la } \\
\text { enfermedad o lesión. } \$\end{array}$ \\
\hline 36 & $\begin{array}{l}\text { La paciente... no puede realizar sus actividades } \\
\text { gimnásticas en } 6 \text { meses. }\end{array}$ & $\begin{array}{l}\text { Modelo OTEP. No señala la } \\
\text { enfermedad o lesión. } \$\end{array}$ \\
\hline 37 & $\begin{array}{l}\text { La paciente no puede realizar ningún tipo de gimnasia } \\
\text { en } 1 \text { mes. }\end{array}$ & $\begin{array}{l}\text { Modelo OTEP. No señala la } \\
\text { enfermedad o lesión. } \$\end{array}$ \\
\hline 38 & $\begin{array}{l}\text { Ha acudido en el día de la fecha a Consulta médica no } \\
\text { pudiendo realizar ejercicio físico en los próximos } 8 \\
\text { meses. }\end{array}$ & $\begin{array}{l}\text { Parte de CH. No señala la } \\
\text { enfermedad o lesión. No tiene } \\
\text { ni sello ni pegatina de } \\
\text { identificación. Sí el nombre } \\
\text { del facultativo. ơ }\end{array}$ \\
\hline 39 & $\begin{array}{l}\text { No puede realizar gimnasia en } 15 \text { días. Fascitis pie } \\
\text { derecho. }\end{array}$ & Modelo OTEP. O" \\
\hline 40 & $\begin{array}{l}\text { La paciente... no puede realizar gimnasia de ningún tipo } \\
\text { en } 3 \text { meses. }\end{array}$ & $\begin{array}{l}\text { Modelo OTEP. No señala la } \\
\text { enfermedad o lesión. o }\end{array}$ \\
\hline 41 & $\begin{array}{l}\text { Ha acudido en el día de la fecha a Consulta médica no } \\
\text { pudiendo realizar ejercicio físico en los próximos } 9 \\
\text { meses. }\end{array}$ & $\begin{array}{l}\text { Parte de CH. No señala la } \\
\text { enfermedad o lesión. No tiene } \\
\text { ni sello ni pegatina de } \\
\text { identificación. Sí el nombre } \\
\text { del facultativo. } \$\end{array}$ \\
\hline 42 & $\begin{array}{l}\text {...presenta dolor de rodillas de tipo continuo... No podrá } \\
\text { hacer determinados movimientos que la sobrecargan } \\
\text { (correr, ejercicios bruscos). }\end{array}$ & Modelo OTEP. ᄋ \\
\hline 43 & $\begin{array}{l}\text { La paciente presenta tendinitis en maleolo tibial pie } \\
\text { derecho. }\end{array}$ & 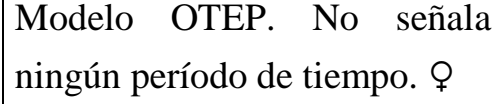 \\
\hline
\end{tabular}

Tabla 14. Documentos médicos recogidos en la investigación $\left(4^{\text {a }}\right.$ de 9$)$ 


\begin{tabular}{|c|c|c|}
\hline $\mathbf{N}^{\mathbf{o}}$ & CONTENIDO DEL INFORME & OBSERVACIONES \\
\hline 44 & $\begin{array}{l}\text { Ha acudido en el día de la fecha a Consulta médica no } \\
\text { pudiendo realizar ejercicio físico en los próximos } 20 \\
\text { días. }\end{array}$ & $\begin{array}{l}\text { Parte de CH. No señala la } \\
\text { enfermedad o lesión. No tiene } \\
\text { ni sello ni pegatina de } \\
\text { identificación. Sí el nombre } \\
\text { del facultativo. } \$\end{array}$ \\
\hline 45 & ...no puede realizar gimnasia en 15 días. & $\begin{array}{l}\text { Modelo OTEP. No señala la } \\
\text { enfermedad o lesión. } q\end{array}$ \\
\hline 46 & $\begin{array}{l}\text { Debe evitar el hacer ejercicio físico o brusco hasta } \\
\text { resolución de problema dermatológico. }\end{array}$ & $\begin{array}{l}\text { Parte } \mathrm{CH} \text {. No señala ningún } \\
\text { período de tiempo. } \$\end{array}$ \\
\hline 47 & Amigdalitis... No ejercicio. & $\begin{array}{l}\text { Modelo OTEP. No tiene ni } \\
\text { sello ni pegatina de } \\
\text { identificación. Sí el nombre } \\
\text { del facultativo. No señala } \\
\text { ningún período de tiempo. on }\end{array}$ \\
\hline 48 & $\begin{array}{l}\text { Laxitud bilateral... del carpo. Evitar ejercicios que } \\
\text { fuercen flexo-extensión muñecas (volley-ball, } \\
\text { baloncesto...), necesiten cargar la articulación de la } \\
\text { muñeca (hacer el pino...), agarrar peso de } \\
\text { aproximadamente } 3 \mathrm{~kg} \text { o más. }\end{array}$ & $\begin{array}{l}\text { Informe Clínico Médico. No } \\
\text { señala ningún período de } \\
\text { tiempo. }+\end{array}$ \\
\hline 49 & $\begin{array}{l}\text { El paciente ha sido intervenido de... en espalda. Para } \\
\text { evitar dehiscencia de rotura se recomienda no hacer } \\
\text { ejercicio físico durante } 1 \text { mes. }\end{array}$ & Informe Clínico Médico. O" \\
\hline 50 & $\begin{array}{l}\text { Paciente que presentaba desde hace } 4 \text { años enfermedad } \\
\text { de Osgood-Schlatter... se detecta una descalcificación } \\
\text { perióstica... Evitar ejercicios que supongan contracción } \\
\text { excesiva del cuadriceps femoral (salto, carrera, etc.). }\end{array}$ & Informe Clínico Médico. ㅇ \\
\hline 51 & $\begin{array}{l}\text { Esguince de muñeca... reposo relativo (evitar deportes) } \\
\text { durante } 10 \text { dias. }\end{array}$ & Informe de Urgencias. $\varnothing^{n}$ \\
\hline 52 & $\begin{array}{l}\text {...padece de..., asma bronquial, anemia ferropénica y } \\
\text { Osgood-Slater en ambas rodillas por lo cual no puede } \\
\text { realizar gimnasia de ningún tipo durante } 1 \text { año. }\end{array}$ & Certificado Médico Oficial. @ \\
\hline 53 & $\begin{array}{l}\text { El paciente... presenta un cuadro clínico de asma } \\
\text { bronquial y/o tos espasmódica... Es lo que denominamos } \\
\text { asma o tos inducidas por ejercicio... } \\
\text {...excepto en momentos de crisis, el esfuerzo físico o la } \\
\text { práctica de un deporte deben seguir recomendándose... } \\
\text { Es muy conveniente que el paciente progrese como los } \\
\text { demás niños en su formación física, lo que se puede } \\
\text { conseguir perfectamente evitando lo que para él es } \\
\text { perjudicial... } \\
\text { Dado que la mayoría de las reacciones se presentan con } \\
\text { las carreras a pie de larga duración..., aconsejamos que } \\
\text { se evite llegar a esta situación limitando la duración de } \\
\text { las carreras a un máximo de tres minutos seguidos... }\end{array}$ & $\begin{array}{l}\text { Es un informe que aparece } \\
\text { como: "Información de interés } \\
\text { para presentar en el colegio y } \\
\text { que será tenida en cuenta en } \\
\text { la asignatura de Educación } \\
\text { Física y en la actividad } \\
\text { deportiva". } \\
\text { Muy detallado en las } \\
\text { recomendaciones. }+\end{array}$ \\
\hline 54 & $\begin{array}{l}\text { No puede realizar gimnasia de ningún tipo en unos } 15 \\
\text { días. }\end{array}$ & 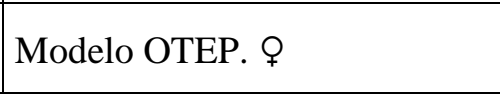 \\
\hline
\end{tabular}

Tabla 14. Documentos médicos recogidos en la investigación ( $5^{\text {a }}$ de 9) 


\begin{tabular}{|c|c|c|}
\hline $\mathbf{N}^{\mathbf{o}}$ & CONTENIDO DEL INFORME & OBSERVACIONES \\
\hline 55 & Exactamente Igual que el 53. & Iguales que la del 53. $0^{\pi}$ \\
\hline 56 & $\begin{array}{l}\text { El paciente... padece tos o asma inducida por ejercicio. } \\
\text { Esto supone que determinados ejercicios pueden } \\
\text { provocarle tos o asma... Intervienen como factores } \\
\text { favorecedores: realizar el ejercicio al aire libre, en } \\
\text { tiempo de frío... Por tal motivo, en la asignatura de } \\
\text { Educación Física o en cualquier actividad deportiva no } \\
\text { se le exigirán carreras a pie de más de TRES MINUTOS } \\
\text { SEGUIDOS de duración, tanto en pruebas (carreras } \\
\text { cuya distancia se haya de correr en más tiempo) como } \\
\text { en entrenamientos. } \\
\text { Es conveniente, no obstante, que el resto de los } \\
\text { ejercicios que pueda hacer los practique con } \\
\text { regularidad... Practicará cualquier tipo de deporte, } \\
\text { sobre todo aquellos en cuyo desarrollo se incluyan } \\
\text { descansos cortos, deportes de equipo, etc. } \\
\text { La fase de calentamiento es importante para la buena } \\
\text { realización del deporte o prueba que haya de hacer... } \\
\text { En todo momento procurará respirar por la nariz (salvo } \\
\text { en natación), especialmente en tiempo frío. } \\
\text { Los pacientes alérgicos al polen de gramíneas evitarán } \\
\text { hacer ejercicio al aire libre en los meses de polinización } \\
\text { (sobre todo en días secos de mayo y junio). }\end{array}$ & $\begin{array}{l}\text { Es un informe que aparece } \\
\text { como "Normas a tener en } \\
\text { cuenta en la asignatura de } \\
\text { educación física o en actividad } \\
\text { deportiva". } \\
\text { Muy detallado lo que puede y } \\
\text { no puede hacer. o" }\end{array}$ \\
\hline 57 & Idéntico al anterior. & Idéntico al anterior. $0^{n}$ \\
\hline 58 & $\begin{array}{l}\text {...diagnosticado de rinoconjuntivitis y asma leve... } \\
\text { Evitará la realización de ejercicio físico intenso y sobre } \\
\text { todo la carrera que no durará más de } 3 \text { minutos. }\end{array}$ & $\begin{array}{l}\text { Informe de Consulta de la } \\
\text { Sección de Alergia que se } \\
\text { acompaña de una lista de } \\
\text { Factores que pueden } \\
\text { desencadenar asma o rinitis } \\
\text { y recomendaciones para el } \\
\text { paciente. o" }\end{array}$ \\
\hline 59 & $\begin{array}{l}\text {...por lo cual no puede realizar gimnasia de ningún tipo } \\
\text { hasta el mes de julio. }\end{array}$ & Certificado Médico Oficial. ๆ \\
\hline 60 & Igual que el 55. & Igual que el 55. 우 \\
\hline 61 & $\begin{array}{l}\text {...no puede realizar ningún tipo de gimnasia en unos } \\
\text { cuatro meses. }\end{array}$ & $\begin{array}{l}\text { Certificado Médico Oficial. } \\
\text { No señala la enfermedad o } \\
\text { lesión. }+\end{array}$ \\
\hline 62 & $\begin{array}{l}\text { Presenta contusión en hombro izquierdo y no podrá } \\
\text { realizar actividad física durante aproximadamente } 15 \\
\text { días. }\end{array}$ & Modelo OTEP. $९$ \\
\hline 63 & $\begin{array}{l}\text { Tiene aplicadas pruebas alérgicas en la espalda por lo } \\
\text { que hasta el viernes (...) que terminan las pruebas no } \\
\text { podrá realizar actividades físico-deportivas. }\end{array}$ & Informe Clínico Médico. @ \\
\hline 64 & $\begin{array}{l}\text { No puede hacer gimnasia hasta recuperación del } \\
\text { esguince de tobillo que padece. }\end{array}$ & $\begin{array}{l}\text { Modelo OTEP. No señala } \\
\text { ningún período de tiempo. } \&\end{array}$ \\
\hline
\end{tabular}

Tabla 14. Documentos médicos recogidos en la investigación ( $6^{\mathrm{a}}$ de 9) 


\begin{tabular}{|c|c|c|}
\hline $\mathbf{N}^{\mathbf{o}}$ & CONTENIDO DEL INFORME & OBSERVACIONES \\
\hline 65 & Ha estado en mi consulta con dolor de hombro. & $\begin{array}{l}\text { Modelo OTEP. No señala } \\
\text { ningún período de tiempo. } \$\end{array}$ \\
\hline 66 & No puede hacer gimnasia en 10-15 días. & $\begin{array}{l}\text { Modelo OTEP. No señala la } \\
\text { enfermedad o lesión. No } \\
\text { señala ningún período de } \\
\text { tiempo. }+\end{array}$ \\
\hline 67 & No puede realizar gimnasia en 15-20 días. & $\begin{array}{l}\text { Modelo OTEP. No señala la } \\
\text { enfermedad o lesión. No } \\
\text { señala ningún } \\
\text { tiemperíodo de }\end{array}$ \\
\hline 68 & $\begin{array}{l}\text { Dolor rodilla izquierda que precisa reposo, no realizar } \\
\text { ejercicios que motiven forzar la misma. }\end{array}$ & $\begin{array}{l}\text { Modelo OTEP. No señala } \\
\text { ningún período de tiempo. } \$\end{array}$ \\
\hline 69 & $\begin{array}{l}\text { Inflamación en rodilla derecha... Ha estado haciendo } \\
\text { deporte. No ha sufrido traumatismo. Reposo. }\end{array}$ & $\begin{array}{l}\text { Informe de Urgencias. } \\
\text { señala ningún } \\
\text { tiemporíodo } \\
\text { ti }\end{array}$ \\
\hline 70 & $\begin{array}{l}\text { Hernia discal L5-S1... se propone tratamiento } \\
\text { conservador... } \\
\text { Evitará esfuerzos físicos violentos y carga de pesos } \\
\text { pesados. Se recomienda se abstenga de gimnasia y } \\
\text { deportes violentos hasta nueva indicación. }\end{array}$ & Informe de Consulta. Ơ $^{n}$ \\
\hline 71 & $\begin{array}{l}\text { Ha acudido en el día de la fecha a Consulta médica no } \\
\text { pudiendo realizar ejercicio físico en los próximos } 20 \\
\text { días. }\end{array}$ & $\begin{array}{l}\text { Parte de CH. No señala la } \\
\text { enfermedad o lesión. } 0^{n}\end{array}$ \\
\hline 72 & No podrá realizar ejercicio físico en 3 semanas. & $\begin{array}{l}\text { Modelo OTEP. No tiene ni } \\
\text { sello ni pegatina de } \\
\text { identificación. Sí el nombre } \\
\text { del facultativo. No señala la } \\
\text { enfermedad o lesión. ơ }\end{array}$ \\
\hline 73 & $\begin{array}{l}\text { Ha acudido en el día de la fecha a Consulta médica no } \\
\text { pudiendo realizar ejercicio físico en los próximos } 20 \\
\text { días. }\end{array}$ & $\begin{array}{l}\text { Parte de CH. No señala la } \\
\text { enfermedad o lesión. O" }\end{array}$ \\
\hline 74 & $\begin{array}{l}\text { Traumatismo lumbar en paciente con antecedente de } \\
\text { Peathes. Reposo } 15 \text { días. }\end{array}$ & Modelo OTEP. $९$ \\
\hline 75 & $\begin{array}{l}\text { Ha acudido en el día de la fecha a Consulta médica no } \\
\text { pudiendo realizar ejercicio físico en los próximos } 3 \\
\text { meses. }\end{array}$ & $\begin{array}{l}\text { Parte de CH. No señala la } \\
\text { enfermedad o lesión. No tiene } \\
\text { ni sello ni pegatina de } \\
\text { identificación. Sí nombre del } \\
\text { facultativo. On }\end{array}$ \\
\hline 76 & $\begin{array}{l}\text { No realizar Educación Física hasta evaluación por el } \\
\text { Servicio de Cardiología. }\end{array}$ & Informe de Urgencias. ㅇ \\
\hline 77 & No debe realizar esfuerzos físicos. & $\begin{array}{l}\text { Modelo OTEP. No señala la } \\
\text { enfermedad o lesión. No } \\
\text { señala ningún período de } \\
\text { tiempo. } \sigma^{n}\end{array}$ \\
\hline
\end{tabular}

Tabla 14. Documentos médicos recogidos en la investigación ( $7^{\mathrm{a}}$ de 9) 


\begin{tabular}{|c|c|c|}
\hline $\mathbf{N}^{\mathbf{o}}$ & CONTENIDO DEL INFORME & OBSERVACIONES \\
\hline 78 & Precisa reposo relativo una semana. & $\begin{array}{l}\text { Justificante de Asistencia. No } \\
\text { señala la enfermedad o lesión. } \\
\text { @ }\end{array}$ \\
\hline 79 & $\begin{array}{l}\text { La paciente ha sufrido un accidente de tráfico y } \\
\text { presenta contusión en hombro derecho, motivo por el } \\
\text { que no debe realizar Educación Física durante una } \\
\text { semana. }\end{array}$ & Parte de CH. Ơ \\
\hline 80 & Presenta contractura muscular. Reposo relativo. & $\begin{array}{l}\text { Justificante de Asistencia de } \\
\text { Consulta de Pediatría. No } \\
\text { tiene ni sello ni pegatina de } \\
\text { identificación. No figura el } \\
\text { nombre del facultativo. No } \\
\text { señala ningún período de } \\
\text { tiempo. }+\end{array}$ \\
\hline 81 & $\begin{array}{l}\text { La paciente ha sufrido un accidente. Está } \\
\text { policontusionada. No debe realizar ejercicios físicos } \\
\text { durante un mes. }\end{array}$ & Modelo OTEP. @ \\
\hline 82 & $\begin{array}{l}\text { Policontusiones. Debe guardar reposo y no hacer } \\
\text { ejercicios físicos en cuatro o cinco días. }\end{array}$ & Informe de Urgencias. ㅇ \\
\hline 83 & $\begin{array}{l}\text { Ha estado en consulta y debe permanecer en reposo dos } \\
\text { o tres días. }\end{array}$ & $\begin{array}{l}\text { Modelo OTEP. No señala la } \\
\text { lesión o enfermedad. } \sigma^{n}\end{array}$ \\
\hline 84 & $\begin{array}{l}\text { Presenta rotura fibrilar a nivel de musculatura } \\
\text { escapular izquierda y no debe realizar actividad física } \\
\text { en aproximadamente } 20 \text { días. }\end{array}$ & Modelo OTEP. ᄋ \\
\hline 85 & $\begin{array}{l}\text { Ha acudido en el día de la fecha a Consulta médica no } \\
\text { pudiendo realizar ejercicio físico en los próximos } 14 \\
\text { días. }\end{array}$ & $\begin{array}{l}\text { Parte de CH. No señala la } \\
\text { enfermedad o lesión. } \$\end{array}$ \\
\hline 86 & $\begin{array}{l}\text { Ha acudido a consulta hoy y no debe realizar gimnasia } \\
\text { en 10-12 días. }\end{array}$ & $\begin{array}{l}\text { Modelo OTEP. No señala la } \\
\text { enfermedad o lesión. } \sigma^{\pi}\end{array}$ \\
\hline 87 & $\begin{array}{l}\text { Paciente con traumatismo en ambas muñecas. Se envía } \\
\text { a hospital... }\end{array}$ & 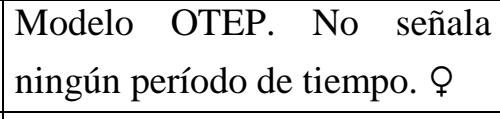 \\
\hline 88 & $\begin{array}{l}\text { Ha acudido en el día de la fecha a Consulta médica no } \\
\text { pudiendo realizar ejercicio físico en los próximos } 20 \\
\text { días. }\end{array}$ & $\begin{array}{l}\text { Parte de CH. No señala la } \\
\text { enfermedad o lesión. } \emptyset^{\pi}\end{array}$ \\
\hline 89 & $\begin{array}{l}\text { Ha sido operada el... bajo anestesia general de... } \\
\text { Recomendamos: evitar ejercicios físicos } 21 \text { dias y de } \\
\text { contacto } 3 \text { meses. }\end{array}$ & $\begin{array}{l}\text { Informe Clínico Médico } \\
\text { Privado. } 0^{n}\end{array}$ \\
\hline 90 & $\begin{array}{l}\text { Dolor e impotencia funcional en tobillo derecho... } \\
\text { Esguince grado I de lig. deltoideo. Debe realizar reposo } \\
\text { deportivo durante tres semanas. }\end{array}$ & $\begin{array}{l}\text { Informe Clínico Médico } \\
\text { Privado. } 0^{n}\end{array}$ \\
\hline 91 & $\begin{array}{l}\text { No debe realizar Educación Física por } 3 \text { semanas. } \\
\text { Esguince tobillo derecho. }\end{array}$ & $\begin{array}{l}\text { Informe Clínico Médico } \\
\text { Privado. @ }\end{array}$ \\
\hline
\end{tabular}

Tabla 14. Documentos médicos recogidos en la investigación $\left(8^{\mathrm{a}}\right.$ de 9) 


\begin{tabular}{|c|c|c|}
\hline $\mathbf{N}^{\mathbf{o}}$ & CONTENIDO DEL INFORME & OBSERVACIONES \\
\hline 92 & $\begin{array}{l}\text { Paciente con amigdalitis y cuadro febril que precisa } \\
\text { reposo y tratamiento. }\end{array}$ & $\begin{array}{l}\text { Modelo OTEP. No señala la } \\
\text { duración del reposo. } \$\end{array}$ \\
\hline 93 & $\begin{array}{l}\text { Rotura fibras musculares. Reposo con brazo en } \\
\text { cabestrillo... }\end{array}$ & $\begin{array}{l}\text { Informe de urgencias. No } \\
\text { señala la duración del reposo. } \\
\text { Q }\end{array}$ \\
\hline 94 & $\begin{array}{l}\text { Paciente que ha padecido un esguince del tobillo } \\
\text { derecho... Debe evitar hacer gimnasia en el colegio } \\
\text { durante } 15 \text { días. }\end{array}$ & $\begin{array}{l}\text { Informe Clínico Médico } \\
\text { Privado. } \sigma^{*}\end{array}$ \\
\hline 95 & $\begin{array}{l}\text {... no puede hacer gimnasia alguna, ni deporte por estar } \\
\text { en Estudio de su problema, etc. } \\
\text { Por lo cual debe ser dispensada de toda ella por las } \\
\text { consecuencias que le puede acarrear. } \\
\text { Por lo cual lo Certifico a expensas de la interesada... }\end{array}$ & $\begin{array}{l}\text { Informe Clínico } \\
\text { Privado. } \$\end{array}$ \\
\hline 96 & $\begin{array}{l}\text {...sufre desgarro L.L.E. de tobillo izquierdo, por lo que } \\
\text { se aconseja la no realización de actividades deportivas } \\
\text { hasta nueva revisión. }\end{array}$ & $\begin{array}{l}\text { Informe Clínico Médico } \\
\text { Privado. } 0^{\pi}\end{array}$ \\
\hline
\end{tabular}

Tabla 14. Documentos médicos recogidos en la investigación (última)

\section{Núcleos de atención: análisis e interpretación}

Para el análisis e interpretación de los datos reflejados en la Tabla 14 centraremos nuestra atención en los siguientes núcleos temáticos:
a) Formato.
b) Información aportada y autoría.
c) Exención: total y parcial.
d) La "no práctica" como tratamiento.
e) Visión (reduccionista y tradicional) de la Educación Física.
f) Recomendaciones y vuelta al trabajo.
g) Actuación del profesorado: descripción de la realidad.

Antes de pasar a desarrollar cada uno de los núcleos de atención, hemos de aclarar que un mismo documento puede ser empleado por sus características y contenido como ejemplo para varios de esos núcleos. 


\section{a) Formato}

En la misma columna de Observaciones de la Tabla 1 ya hemos ido adelantado algunos de los impresos que suelen emplear los facultativos para "comunicarse" con el profesor de Educación Física, pero la gama de "papeles" que nos hemos encontrado es mucho más amplia de lo que se puede imaginar.

El modelo mayoritariamente empleado, en un $44 \%$ de los casos, es la Orden de Tratamiento a Enfermeras y Practicantes (aquel al que hemos llamado Modelo OTEP), seguido del Parte de Consulta y Hospitalización (Parte $\mathrm{CH}$ ) con un 20\%. Los presentados en papel del Estado (Certificados Médicos Oficiales) tan solo representan el $3 \%$ de los documentos recogidos; mientras que el 5\% son informes de consulta médica particular. Podíamos calificar de anecdótico la utilización en un caso de un folio de propaganda farmacéutica. La Gráfica 71 nos demuestra gráficamente la variedad de los formatos recogidos.

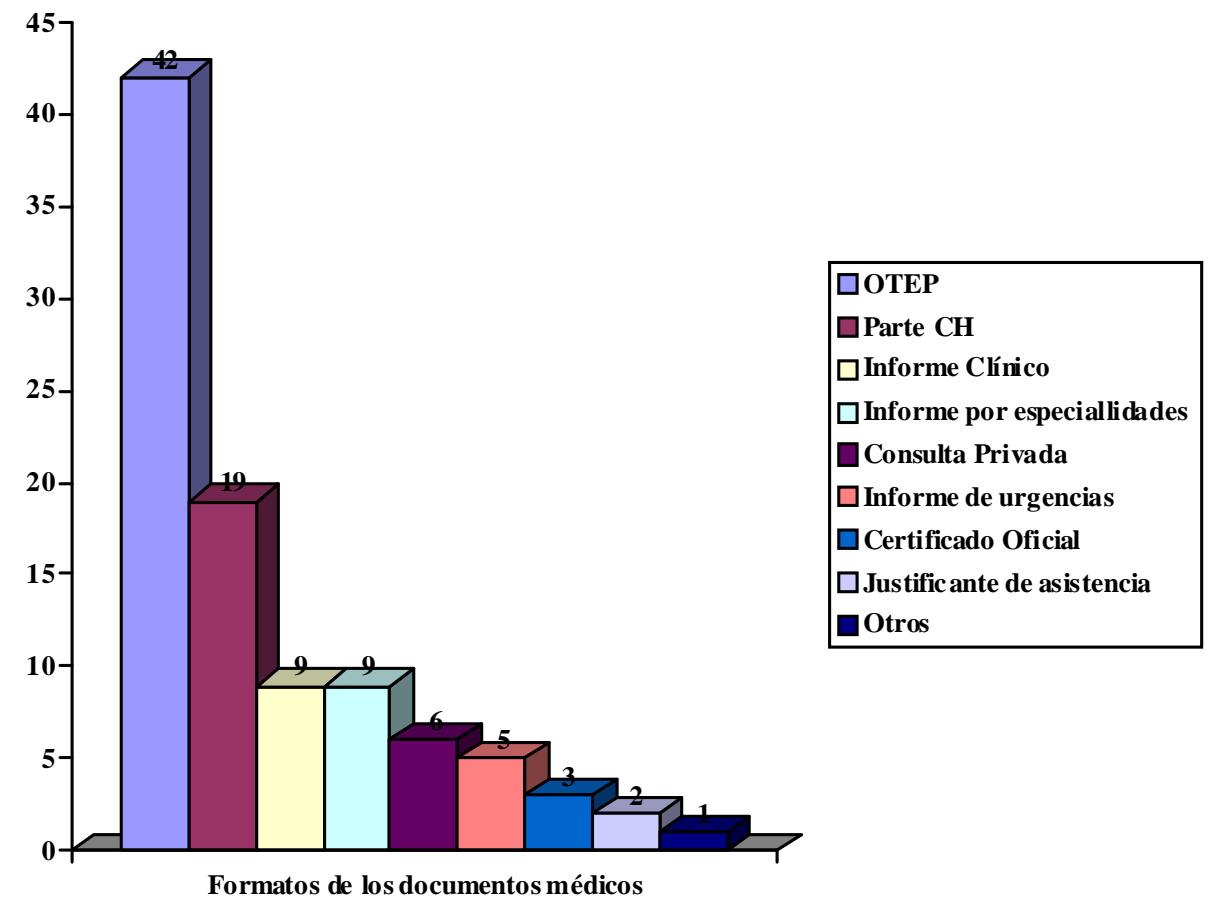

Gráfica 71. Documentos médicos recibidos 
Por otra parte, a pesar de que la gran mayoría de estos documentos se encuentran personalizados para un alumno en concreto, rellenados de puño y letra por el propio facultativo o realizados por ordenador, hay 12 Partes de Consulta y Hospitalización (lo que representa el $12.6 \%$ sobre el total de documentos, y el $63 \%$ sobre este tipo de impreso) que son exactamente idénticos en sus formatos y diagnósticos, diferenciándose tan solo en lo referente al período de duración de lo recomendado, dando así la impresión de ser un modelo de informe estándar válido para muy diversas situaciones y que pudiera venir a simplificar la labor de comunicación con el profesor de Educación Física a requerimiento del propio alumno. El texto dice lo siguiente:

"Ha acudido en el día de la fecha a Consulta médica no pudiendo realizar ejercicio físico en los próximos días/meses" (Doc. 13, 24, 29...)

\section{b) Información aportada y autoría}

Hay 13 documentos (Doc. 4, 13, 16...) en los que no aparece ningún tipo de identificación "oficial" del médico que realiza el escrito (llámesele el sello o la pegatina personalizada que tenga asignada). No obstante, en todos ellos, salvo en un caso en el que no aparece ningún dato al respecto (Doc. 80), sí figura de forma manuscrita el nombre del facultativo.

Por otra parte, resulta muy significativo comprobar que los documentos presentados por las alumnas (64) doblan exactamente al de los alumnos (32), lo que representa el $67 \%$ y $33 \%$ respectivamente ${ }^{196}$. La Gráfica 72 nos realza gráficamente estos datos.

\footnotetext{
${ }^{196}$ En un estudio estadístico de lesiones llevado a cabo en un centro educativo por Antolín (2003), también se aprecia como las alumnas se lesionan más que sus compañeros.
} 


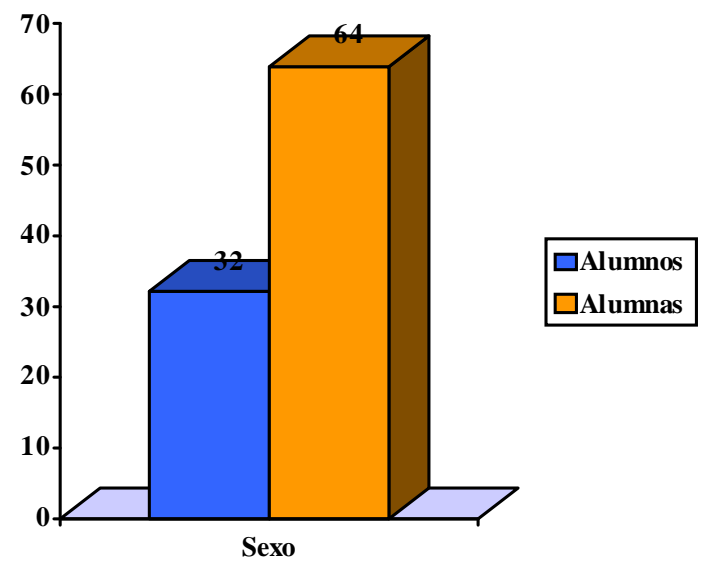

Gráfica 72. Documentos médicos y variable sexo.

Hemos apreciado que la calidad del informe aumenta en la medida en que este es más extenso en sus apreciaciones y comentarios. Es el caso de los emitidos para alumnos que tienen diagnosticado procesos de asma inducida por el ejercicio, en los cuales no solo se dice lo que no deben hacer, sino que además se dan pautas generales de trabajo y recomendaciones específicas ${ }^{197}$ (Doc. 21, 22, 53, 55, 56, 57 y 60).

No obstante, también los hay que con pocas palabras son sumamente aclaratorios y precisos (Doc. 1, 6, 27...).

Sin embargo, lo habitual suele ser que los más breves en explicaciones omitan algunos detalles importantes, tales como la enfermedad o lesión que padece el sujeto (Doc. 2, 3, 5, 11, 23...), el tiempo de duración del reposo o tratamiento (Doc. 7, 26, 27...), o el sello y/o pegatina de identificación del facultativo (Doc. 4, 16, 17...).

En lo concerniente a las lesiones o dolencias que presentaban los alumnos (Tabla 14), podemos observar que, en un $39.5 \%$ de los casos, el médico no daba a conocer mediante sus comunicaciones escritas lo que le sucedía a su paciente (nuestro alumno), limitándose a aconsejar el cese de cualquier actividad u otras recomendaciones

\footnotetext{
${ }^{197}$ Salvo el Documento 26, que no aclara nada al respecto.
} 
similares. De igual modo, como cabía esperar ${ }^{198}$, otro $40.6 \%$ de los volantes o informes están directamente relacionados con el aparato locomotor (traumatismos, esguinces, contusiones...). Tan solo el 14.7\% atañen al aparato respiratorio (incluidos los de asma), y un $5.1 \%$ están referidos a diferentes tipos de dolencias (operaciones, dermatológicas, fístulas, cardiológicas y alérgicas).

\begin{tabular}{|c|c|c|c|c|}
\hline & $\begin{array}{c}\text { APARATO } \\
\text { LOCOMOTOR }\end{array}$ & $\begin{array}{c}\text { APARATO } \\
\text { RESPIRATORIO }\end{array}$ & OTROS & SIN ACLARAR \\
\hline 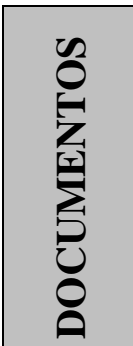 & $\begin{array}{l}1,4,7,8,10,14, \\
15,18,20,27, \\
31,33,34,39, \\
42,43,48-52,62, \\
64,65,68-70,74, \\
79-82,84,87,90, \\
91,93,94,96\end{array}$ & $\begin{array}{l}17,19,21,22,26 \\
32,47, \mathbf{5 2}, 53,55- \\
58,60,92\end{array}$ & $\begin{array}{l}6,46,52,63,76 \\
89\end{array}$ & $\begin{array}{l}2,3,5,9,11-13, \\
16,23-25,28-30, \\
35-38,40,41,44, \\
45,54,59,61, \\
66,67,71-73,75, \\
77,78,83,85, \\
86,88,95\end{array}$ \\
\hline$\underset{1}{0}$ & 39 & 15 & 6 & 38 \\
\hline
\end{tabular}

Tabla 15. Motivos de los informes y volantes médicos

Por lo que se refiere a los médicos que expiden los documentos, tan solo el 21.8\% son médicos especialistas (hay 7 de Traumatología, 3 de Pediatría, 1 de Reumatología, 8 de Alergología, 1 de Neurología y 1 de Medicina Interna). En el restante $78.1 \%$ no figura la especialidad del facultativo, de lo que deducimos que se trata de los médicos de familia.

Finalmente, tan solo hay un documento (Doc. 15) que adjunta una serie de ejercicios de rehabilitación para que sean practicados por el paciente. Hemos de precisar que en ningún momento se dice que deban ser realizados necesariamente en la hora de Educación Física.

\footnotetext{
${ }^{198}$ En el estudio que López García (1996) realiza sobre las adaptaciones curriculares en Educación Física para alumnos exentos (vid.: Capítulo 6, página 109), el escalafón de lesiones o enfermedades más frecuentes que encuentra se sitúa en un orden similar, aunque con diferentes porcentajes: problemas músculo-esqueléticos (78\%), respiratorios y asma (11.7\%), cardiovasculares $(3.9 \%)$ y el resto son variados.
} 


\section{c) Exención: total y parcial}

Son 8 los documentos (8.3\%) que con sus indicaciones no hacen más que situar al profesor de Educación Física en una posición comprometida y acotada en cuanto a las actuaciones a tomar en relación a la participación en sus clases de alumnos con determinadas enfermedades o lesiones. Y lo hacen hasta tal extremo que provocan la inoperancia profesional del docente sobre estos sujetos ya que los médicos redactan sus escritos en términos de abstenerse, no realizar, exención, no hacer..., clases de Educación Física (Doc. 1, 8, 10, 11, 26, 76, 79, 91). Por tanto, e independientemente del tipo o magnitud de la lesión o enfermedad, se propicia la exclusión total más directa de nuestras clases sin reparar en la posibilidad de que el alumno pueda tomar parte en alguno de los diversos tipos de contenidos que pone la Educación Física a su disposición o, incluso, en la realización de tareas que no afecten directamente a la lesión o enfermedad.

Por otro lado, creemos que estas formas de redactar los escritos pudieran dar lugar a que en el alumno se generen o acrecienten actitudes de rotunda negativa a hacer cualquier tarea, y que en el profesor surja un cierto temor a que con sus actuaciones y propuestas se deriven consecuencias nefastas para la salud del alumno y, por tanto, incurra en una falta grave de responsabilidad.

En este sentido, hay un documento en el que el médico únicamente recomienda la práctica de unos determinados ejercicios rehabilitadores, en detrimento de otros que, por la enfermedad del alumno, sí podría realizar en Educación Física y que tampoco empeorarían su estado de salud (Doc. 15). De alguna manera, es una forma encubierta de prohibir parcialmente la realización o práctica de unos determinados contenidos, tareas o ejercicios.

Sin abandonar esta idea, podemos seguir hablando de un caso claro de exención parcial, ya sea por supresión o reducción de algunos ejercicios como por recomendaciones de lo que sí se puede hacer, cuando nos estamos refiriendo a los informes de chavales con asma inducida por ejercicio (Doc. 21, 22, 53, 55-57, 60). 
Como decimos, en ellos se limitan -por el bien del alumno- determinadas prácticas y/o ejercicios y se facilitan otra serie de contenidos que sí es recomendable que realicen (por cierto, referidos sobre todo a deportes).

En otros casos nos encontramos con algunos en los que únicamente se limita la movilidad o utilización de determinadas articulaciones, o se prohíben ciertas prácticas (Doc. 33, 34, 42, 48...).

Para concluir este núcleo de atención, hemos de aclarar que la limitación de no realizar, abstenerse..., de Educación Física puede ser únicamente cuestión de un determinado tiempo (lo cual no deja de ser otra forma de exención parcial), es decir, por la magnitud de la lesión o enfermedad la exención se justifica para un período delimitado de tiempo más o menos largo (Doc. 1, 11, 79, 91) o, lo que viene a ser lo mismo, la recomendación del médico es por un espacio temporal concreto (Doc. 37, 40, $49,54 \ldots)$.

\section{d) La "no práctica" como tratamiento}

Con independencia de los casos tratados en el aparatado anterior, un total de 70 documentos $(73.6 \%)$ recogen en sus tratamientos recomendaciones y propuestas que tienen que ver con la "no práctica". En ellos se emplean redacciones que mayoritariamente contienen verbos o expresiones tales como no puede realizar, evitar, no debe hacer, no realizar, no ejercicio, dispensada... (Doc. 3-9, 12-14, 16-20...).

Hay 10 escritos que tienen como característica en común la indicación del reposo como técnica de tratamiento y recuperación ${ }^{199}$. De ellos, en 3 se nos plantea un reposo relativo (Doc. 51, 78 y 80), lo cual daría a entender que el alumno-paciente sí puede realizar determinadas tareas (lógicamente, a criterio del profesor). En otros 2

\footnotetext{
${ }^{199}$ Sobre este asunto del reposo, ténganse en cuenta las palabras de Hernández y Martínez (1989, p. 50) recogidas en el Capítulo 6: "Es un sentir anacrónico la idea de que personas con problemas físicos dejen de realizar todo tipo de ejercicio físico... Se está en el camino de desterrar la idea de absoluto reposo...”
} 
casos el reposo es deportivo, es decir, el médico equipara la Educación Física con el deporte (Doc. 51 y 90).

\section{e) Visión (reduccionista y tradicional) de la Educación Física}

Como ya apuntábamos al inicio de este capítulo, creemos que la Educación Física suele ser equiparada y situada al mismo nivel que el ejercicio físico y/o los deportes, de tal forma que nuestra área curricular es observada y percibida por los médicos únicamente como sinónimo de dichas prácticas; no se entiende o concibe la Educación Física sin el deporte y el ejercicio físico o los esfuerzos motrices como los ejes nucleares en torno a los cuales gira toda su actuación. Veamos si los papeles médicos confirman o desmienten dichas creencias iniciales.

De todos los documentos presentados para justificar una lesión o enfermedad que motiva la "imposibilidad", total o parcial, de poder participar con absoluta normalidad en las sesiones de Educación Física, en 35 de ellos (36.4\%) se hace la recomendación de evitar, reducir, no realizar, no practicar..., ejercicio o ejercicio físico $^{200}$ (Doc. 3, 4, 12-13...).

En 24 comunicaciones (25.2\%) se refieren a la gimnasia como el objeto o motivo de la privación. Hemos de aclarar que, dependiendo de las redacciones, el significado que parece darse a este término pudiera tener una doble acepción. Por un lado, se puede entender que con su empleo se están refiriendo a cualquier tipo de práctica corporal de tipo gimnástico, es decir, que implique esfuerzo, movimiento, trabajo, etc. (Doc. 5, 6, 25, 36...). Por otro, las composiciones de los escritos dejan entrever que se refieren a la clase de Educación Física, tradicionalmente así considerada y denominada no solo por los médicos sino por otros colectivos de la sociedad (Doc. 7, $8,16,23 \ldots)$. De hecho, hemos de destacar que aunque solo han sido dos los documentos

\footnotetext{
${ }^{200}$ Conviene recordar lo que significa este concepto. Así, Redondo (2003, p. 20) se refiere al ejercicio físico como cualquier actividad física planificada, estructurada y repetitiva que tiene por objeto la mejora o mantenimiento de uno o más componentes de la forma física (resistencia cardiorrespiratoria, resistencia muscular, fuerza muscular y flexibilidad).
} 
en los que aparece escrita la palabra exención o dispensa, en ambos casos se refieren a la gimnasia ${ }^{201}$.

“...Se recomienda exención de gimnasia hasta tener diagnóstico.” (Doc. 8. Énfasis mío)

"Por lo cual debe ser dispensada de toda ella [referida a la gimnasia] por las consecuencias que la pueda acarrear.” (Doc. 95. Énfasis y aclaración mía)

Relacionado con lo que hemos comentado en el apartado c) acerca de la situación comprometida en la que los médicos nos sitúan mediante sus escritos -la puesta en escena de una exención total o parcial-, obsérvese la "seria advertencia" que aparece en el Documento 95. Se hace del todo inevitable seguir sus indicaciones en términos de no hacer nada para eludir males mayores.

El deporte, como cabía esperar, también aparece en estos escritos. En 8 casos las indicaciones son referidas a este término. Expresiones como no hacer deporte, contraindicada la actividad física o deportiva, evitar deportes, se abstenga de deportes violentos..., son empleadas para informar al profesor de Educación Física de la situación, en términos de disponibilidad, en la que se encuentra un alumno respecto a su área (Doc. 9, 18, 51, 63...).

En menor medida, los esfuerzos físicos y la actividad física son los centros de atención en los que los médicos señalan sus restricciones (Doc. 27, 30, 62, 84).

Son 10 los documentos en los que no aparece ningún tipo de referencia o alusión a aquello que se deba evitar o dejar de hacer, limitándose únicamente a señalar lo que le sucede y/o el tiempo de reposo establecido (Doc. 43, 65, 69...).

\footnotetext{
${ }^{201}$ Exención y dispensa son dos términos claramente alusivos a nuestras clases. No olvidemos que hasta 1995, por la Orden de 31 de julio de 1961 por la que se regula la dispensa de la Educación Física en la Enseñanza Media, estaba permitida legalmente su aplicación para dar "solución" a una situación determinada. Por otro lado, el Asesor de la Dirección Provincial de Educación de Valladolid al que entrevisté (página 341), me corroboraba que los médicos aún continúan empleando el término gimnasia para referirse a la Educación Física.
} 
Por último, conviene volver a recordar que, a pesar de que los alumnos (o sus familiares) solicitan al médico este tipo de escritos con la única intención de presentarlo ante el profesor para justificar la lesión o molestia que los imposibilita seguir con absoluta normalidad el desarrollo de las clases de Educación Física, tan solo en 15 de ellos (7 de los cuales son informes para chavales con asma inducida por el ejercicio físico) se menciona explícitamente dicha área. En todos los demás se usan los términos aludidos anteriormente.

\section{f) Recomendaciones y vuelta al trabajo}

Como contrapunto a la sensación "dictatorial" que podamos estar trasmitiendo de las indicaciones de los médicos, hay quienes se limitan exclusivamente a recomendar o aconsejar una determinada práctica o la ausencia de la misma (Doc. 26, 27, 31, 32...), por lo que parecen dejar la decisión final en manos del profesor, atribuyéndole así la posesión de unos conocimientos y criterios que le permitan asegurar un desenlace adecuado a cada situación.

En todo caso, aunque la capacidad de decisión del profesor sea a todas luces inútil por la gravedad o alcance de la lesión, al menos es de agradecer la redacción del informe en esos términos de recomendación más que de abstención o similares (Doc. 49, 96), dejándonos que seamos nosotros los que optemos por la vía más apropiada.

En otro orden de asuntos, vamos a detenernos en la cuestión de la duración del reposo, abstención, no práctica...

Como se puede apreciar en la tabla, hay una gran disparidad de periodos de recuperación, abarcando desde 24-48 horas hasta la totalidad del curso.

Sin embargo, son de resaltar aquellos en los que el médico no establece un tiempo concreto de recuperación o pausa en el trabajo, sino que se limita a disponer un hasta nueva orden (Doc. 3 y 23) o hasta nueva indicación (Doc. 70), por lo que el 
profesor debe esperar la llegada de otro informe en el que se le avise del regreso del alumno a la actividad.

Por último, a pesar de que hemos omitido este dato en la tabla, es necesario precisar que algunos de los informes de los chavales que padecen asma inducida por el ejercicio añaden una nota al final del mismo en la que se advierte que mantendrá estas normas al menos hasta que pase cinco años sin tener episodios agudos de tos espasmódica o asma (Doc. 21 y 22), lo cual debe ser tenido en cuenta por el profesor de un año para otro durante un lustro sin esperar que el médico le avise nuevamente o el alumno deba presentar otro informe.

\section{g) Actuación del profesorado: descripción de la realidad}

No se suele solicitar la expedición de un Certificado Médico Oficial salvo que la situación y circunstancias que rodean al alumno generen desconfianza. En todos los demás casos se acepta como válido cualquier documento que lleve la correspondiente identificación facultativa (datos del médico en particular y/o sello oficial de la Administración), para informar sobre el estado de salud del individuo y justificar así su situación. No obstante, cuando por lesiones o enfermedades más o menos graves y/o prolongadas en el tiempo no traen por su propia voluntad el oportuno informe médico (del tipo que sea), se insiste en la obligatoriedad de presentarlo lo antes posible.

A pesar de que en algunos escritos se dice algo así como "hasta nueva orden" o "hasta nueva indicación", durante el período de investigación nunca llegó a producirse esta nueva comunicación u orden por vía facultativa para avisar de la situación del alumno y, por tanto, dar así el visto bueno para que se reincorpore al desarrollo de las clases. Siempre fue el alumno el que advirtió al profesor de que podía participar sin problemas.

En este sentido, es necesario precisar que el profesor suele fiarse de la palabra de los alumnos (salvo algún caso excepcional), admitiendo como ciertas las informaciones 
que les transmiten en conversaciones con ellos al inicio de las clases, de tal manera que si advierten que todavía tienen los síntomas o dolencias que generaron la emisión de un informe médico, aun cuando este documento haya prescrito en el tiempo, se suele permitir que continúen en las mismas condiciones que tenían hasta ese momento. En todo caso, si esta situación perdura en el tiempo se le vuelve a requerir un nuevo escrito médico actualizado.

También se ha dado en alguna ocasión la situación inversa, es decir, se ha tenido que coartar las ganas de participación a más de un alumno que deseaba tal empresa, aun cuando el documento médico dictaminaba lo contrario o no había transcurrido el tiempo en él estimado para la recuperación total de la lesión o enfermedad. Obviamente se trataba de individuos en los que se percibía que su estado, en términos de salud, no era el más adecuado para tomar parte en las clases con absoluta normalidad, y que sus ganas de participar emanaban únicamente de su interés y atracción por una tarea en particular y/o por la asignatura en general, dejando en un segundo plano el reconocimiento de su actual y, casi siempre, delicado momento de salud. Es más, hemos sido testigos, sin saberlo, de cómo un alumno con asma diagnosticada por el facultativo ha realizado un test continuo y progresivo de resistencia muy exigente (Leger-Lambert ${ }^{202}$ ). Al enterarnos, hemos averiguado que el alumno en cuestión afirmaba encontrarse bien, que en su opinión las medidas preventivas que el médico le determinó en su momento eran muy exageradas e inapropiadas a su situación actual y que, a pesar del dictamen del facultativo, perfectamente podía hacer lo que los demás realizaban.

Dejando este curioso caso aparte, el profesorado también autoriza la participación si intuye que ello no afectará negativamente a su particular situación.

Otras veces no queda más remedio que dar por buenas las explicaciones que facilitan los alumnos ya que algunos informes médicos no indican con claridad algún detalle de relevada importancia (diagnóstico, pronóstico, tratamiento, tiempo de curación, etc.).

\footnotetext{
${ }^{202}$ Se le conoce como "Course Navette". Es una prueba consistente en recorrer durante el mayor tiempo posible, a una velocidad progresiva que aumenta cada minuto, trayectos de ida y vuelta de $20 \mathrm{~m}$. (AA.VV., 1992, p. 330).
} 
Ha habido alumnos con lesiones de carácter traumatológico que realizaban programas de rehabilitación en centros sanitarios específicos fuera del horario escolar, pero que se negaban en rotundo a realizar cualquier tipo de actividad o tarea propia de las clases de Educación Física. Sin embargo, ninguno de los alumnos (ni médicos) nos ha solicitado emplear nuestras clases para practicar los ejercicios de rehabilitación prescritos.

En lo referente a las adaptaciones curriculares individuales (ACIs), solo en los casos de asma inducida por el ejercicio físico, en uno de obesidad patente ( $\sin$ necesidad de mediar en este caso informe médico alguno) y en algunos de carácter muy grave, se han recogido por escrito las correspondientes aplicaciones de esta medida educativa. En cualquier caso, siempre contando con el asesoramiento del Departamento de Orientación.

Por último, han sido puestas en funcionamiento muchas respuestas educativas en una línea muy cercana a la de la "falsa integración", tales como ayudar y colaborar con profesor y compañeros, realización de su cuaderno de clase, elaboración de trabajos escritos (sobre todo con vistas a su calificación), lectura y posterior comentario de libros recomendados, elaboración de calentamientos, propuestas de juegos y tareas para que los realicen sus compañeros, etc. Pero insistimos en que cada caso se ha procurado gestionar atendiendo a la particularidad que representaba, empleando para ello un abanico de opciones con las que ajustarse a las necesidades y posibilidades reales de cada individuo, las cuales, al parecer, no siempre coinciden necesariamente con el dictamen médico. 


\section{Conclusiones}

La media de documentos anuales presentados es de 32, lo que, con independencia de que algún alumno haya podido presentar en más de ocasión un informe médico, equivaldría a que aproximadamente un $5.67 \%$ de los alumnos presentan un documento médico al año ${ }^{203}$.

En lo que respecta al sexo, los resultados nos revelan que las alumnas, aunque no son muchas más en número que los chicos, presentan el doble de informes médicos que sus compañeros. Únicamente con los datos obtenidos sería comprometido dar una explicación lógica y coherente que argumentase el porqué de esta situación, lo cual no es motivo de esta tesis doctoral. No obstante, nos aventuramos a apuntar que podría deberse a una tentativa de evitar realizar actividad física por diferentes motivos (carencias motrices, desinterés y desmotivación, apatía, problemas con el grupo...) ${ }^{204}$. Lo que es evidente es la desproporción tan grande a favor de las alumnas.

Las fuentes bibliográficas y de información coinciden en señalar la relevante necesidad que tiene el profesor de Educación Física de disponer de información acerca del estado de salud, o ausencia de la misma, que poseen sus alumnos al inicio del curso. Información que, obviamente, debe ser proporcionada por los facultativos y/o los familiares. En el caso que nos ocupa, los informes médicos, los cuales son resultantes de reconocimientos más o menos exhaustivos, tienen una eficaz influencia en la toma de decisiones adoptadas por el profesor. De otra forma ¿para qué se piden si no es para obrar en consecuencia a lo que en ellos se dictamina?

203 Con el fin de cotejar estos datos, durante otro curso más (el cuarto) se volvió a archivar los documentos médicos que los alumnos nos entregaban. En esta ocasión, para un total de 508 alumnos (245 chicos y 263 chicas) fueron 28 los documentos médicos obtenidos (20 de chicas y 8 de chicos), correspondientes al 5.51\%. Evidentemente, estos números se asemejan a los alcanzados durante el estudio.

\footnotetext{
${ }^{204}$ Lacasa (2002) ya señaló estas y otras causas, para alumnos y alumnas, como las desencadenantes de muchos de los documentos médicos y, sobre todo, familiares. Por otra parte, recordemos que la Fuente [42] se expresaba en términos similares y que Rodríguez-Solano (2003) apuntaba que había alumnos (en general) que mostraban un desinterés por la Educación Física y buscaban cualquier excusa para no realizarla (vid.: Capítulo 6). Además, tengamos en cuenta que la Fuente [43] afirmaba que hay muchas alumnas que desertan de la clase de educación física por diferentes motivos, tales como flojera o desánimo, problemas médicos y por la menstruación.
} 
Son pocas las ocasiones en las que aparece la figura del médico especializado en alguna rama de la medicina. Además, no se ha dado nunca el caso de que un documento venga avalado por un médico especialista en medicina del deporte.

Por los resultados obtenidos en esta investigación, estamos en condiciones de afirmar que los médicos no acostumbran a ofrecer en primera instancia todos los detalles que nos hacen falta para tomar decisiones sobre lo que debe/puede hacer una alumno. Es decir, salvo que se pida o exija al alumno que requiera de su médico el oportuno Certificado Médico Oficial o similar, en el que se incluyan, además del diagnóstico, una serie de recomendaciones y/o censuras respecto de lo que puede o no puede realizar, no suele ser habitual encontrarnos con escritos médicos muy descriptivos y ricos en detalles al respecto. De hecho, “cualquier" papel puede ser válido para elaborar sus informes. Por ello, no es extraño que en ocasiones los profesores -o los centros- recurran a la confección de sus propias fichas o informes ricos en detalles propios del área de Educación Física para ser debidamente rellenados por el facultativo.

Las expresiones empleadas en las redacciones de algunos de los informes médicos que presentan los alumnos en las clases de Educación Física desencadenan una respuesta educativa en términos de no hacer nada -exención en cualquiera de sus tipos-. No dudamos que esa propuesta pueda ser en algunos casos la más "adecuada", pero las recomendaciones y tratamientos coartan incluso aquello que sí podrían realizar por el limitado alcance de la lesión o enfermedad.

En todo caso, por parte del profesor se ponen en marcha acciones educativas en la línea de la falsa integración que lo único que ponen de relieve es lo que hemos llamado en otras ocasiones "exención invisible", es decir, en numerosas situaciones nos creemos que los chavales están formando parte activa de la clase asumiendo otro tipo de tareas tales como arbitrar, colaborar con el profesor..., y no somos conscientes o no nos damos cuenta de que lo que estamos favoreciendo es una forma de eximir al alumno de lo que el resto hace. Solemos emplear expresiones como "enseñanza individualizada", “adaptación curricular individual”, etc., para referirnos a esas propuestas. Deberíamos plantearnos seriamente si lo único que estamos haciendo es engañarnos a nosotros 
mismos enmascarando con tecnicismos y verborrea una realidad que no deseamos ver, y que no nos permite adoptar para cada alumno en particular la medida de atención incluida la exención- que mejor se ajuste a sus características, intereses y especiales circunstancias que le rodean.

En definitiva, se aprecia una ausencia de colaboración entre médicos y profesores para ahondar en el tratamiento (sanitario y educativo) de estos sujetos, pacientes para unos y alumnos para otros. Entre otros cosas, se tendría que mejorar y renovar el conocimiento y percepción que los facultativos tienen del área de Educación Física, ampliar -crear- vías de comunicación y de trabajo en equipo, y potenciar la toma de decisiones consensuadas, oídos los implicados, en vías de mejorar la calidad de vida de esos alumnos que se encuentren, por cualquier razón, en la amarga realidad de tener reducidas sus facultades de movimiento, temporal o permanentemente, total $\mathrm{o}$ parcialmente.

\section{3. - JUSTIFICANTES FAMILIARES ${ }^{205}$}

A lo largo de cualquier curso académico suele ser habitual encontrarnos con varios papeles manuscritos por los familiares de nuestros alumnos para dar a conocer el estado de salud de sus hijos. Es más, en no pocas ocasiones somos los propios docentes los que requerimos a los padres que nos envíen comunicaciones por escrito para ofrecer las oportunas aclaraciones sobre dicho estado de salud.

La información que nos ofrecen tiene que ver habitualmente con los inconvenientes, dolencias o problemas de cualquier tipo que presenta su hijo en relación a la participación en nuestras clases, "aconsejándonos" permitir la no práctica. Por ello, estos papeles pueden llegar a suponer un poderoso estímulo que propicie en el

\footnotetext{
${ }^{205}$ Consideramos que el término familiar/es engloba al de padre y madre o, en caso de no existir, a los tutores legales del alumno.
} 
profesorado la adopción de un tipo de posturas y actitudes "precavidas" encaminadas a que los chavales implicados no concursen activamente en sus clases.

Pérez Cortés et alia (1997), además de señalar al informe médico como punto de partida para la adecuación de la respuesta educativa -adaptación curricular-, apuntan que dicho informe se complementará con un cuestionario para los padres sobre la evolución de la salud de su hijo.

De la Cruz (1992, p. 99), apunta el deber que tiene el profesor de Educación Física de conocer los antecedentes médicos del alumno, los cuales se pueden conseguir mediante el envío a los padres de una ficha en la que se recojan detalles al respecto.

Algunos centros docentes tienen confeccionada una "Hoja de Detección de Problemas" o ficha "Médica Individual para Educación Física", que recoge aspectos relacionados con cuestiones/problemas médicos, y que debe ser rellenada por los padres del alumno al inicio de cada curso ${ }^{206}$.

Por su parte, la Fuente [22], como quedó patente en el Capítulo 6, tiene establecida una carta que se envía al inicio de curso a los padres para informarles sobre las actuaciones a seguir en caso de que su hijo sea declarado exento de la práctica, así como para que comuniquen cualquier dolencia o enfermedad que, aunque no se encuentre en esa situación, pudiera influir sobre dicha práctica ${ }^{207}$. Hemos de decir que nos llama profundamente la atención que, a pesar de tener fecha del 2003, únicamente haga referencia al Real Decreto de 6 de marzo de 1985 (ENSEÑANZA EN GENERAL. Ordenación de la Educación Espacial. BOE 16-03-1985) para indicar los procedimientos a seguir ante alumnos con enfermedades, deficiencias o minusvalías (lo que hoy conocemos como alumnos con necesidades educativas especiales asociadas a cualquier tipo de discapacidad), obviando la consabida Orden de 10 de julio de 1995 que en aquel momento estaba en vigor.

\footnotetext{
${ }^{206}$ En el Anexo 25 se encuentra una copia de la segunda de ellas.

${ }^{207}$ Vid.: Anexo 3.
} 
En lo que respecta a su interpretación, Lacasa (2002) es partidario de que esta se realice bajo el prisma del sentido común. Lo argumenta de la siguiente manera:

“...si un alumno está tan indispuesto o resfriado como para no hacer gimnasia [sic], también lo debería estar para no acudir al centro escolar.”

Aunque en el Capítulo 6 ofrecíamos unas pequeñas pinceladas al respecto de estos documentos, nos hemos propuesto comprobar cómo es la realidad de nuestro trabajo diario en base a un estudio de idénticas características en lo que respecta al lugar de realización, período de investigación, etc., al que hemos realizado anteriormente con los certificados médicos.

\section{$\underline{\text { Recogida de datos y tabla de documentos }}$}

Como hemos dicho, el período de recopilación de los justificantes familiares ha abarcado tres cursos académicos. Todos ellos han sido recogidos en clase por los profesores de Educación Física.

De igual forma, con todos ellos hemos creado una tabla de estructura similar a la empleada con los documentos médicos (Tabla 16). Para el estudio y análisis de la misma volveremos a emplear núcleos de atención, similares a los manejados en el anterior apartado. Respecto a la tabla de recogida de datos, en la primera columna se asigna un número aleatorio a cada uno de los 49 justificantes reunidos; en la segunda, nos limitamos a transcribir el contenido del documento (omitiendo los datos de los interesados); y en la tercera columna realizamos alguna observación al respecto del escrito: quien lo firma, formato, si lo presenta un alumno $(ð)$ o una alumna $(\varnothing) \ldots$ 


\begin{tabular}{|c|c|c|}
\hline $\mathbf{N}^{\mathbf{o}}$ & CONTENIDO DEL JUSTIFICANTE & OBSERVACIONES \\
\hline 1 & $\begin{array}{l}\text {...no puede hacer ejercicios físicos que tenga que } \\
\text { apoyar su mano izquierda en superficies duras, por } \\
\text { tener hematomas y lesiones en la misma }\end{array}$ & $\begin{array}{l}\text { Formato cuartilla. } \\
\text { Firma del padre. } \varnothing^{n}\end{array}$ \\
\hline 2 & $\begin{array}{l}\text {...no puede hacer física ( } \text { sic), al tener un absceso que se } \\
\text { lo impide. }\end{array}$ & $\begin{array}{l}\text { Formato irregular. } \\
\text { Firma de la madre. } \$\end{array}$ \\
\hline 3 & $\begin{array}{l}\text {...ha sido operado del tabique nasal..., por lo que no } \\
\text { puede realizar ejercicios físicos durante } 2 \text { semanas } \\
\text { aproximadamente. }\end{array}$ & $\begin{array}{l}\text { Formato cuartilla. } \\
\text { Firma de la madre. }{ }^{n}\end{array}$ \\
\hline 4 & $\begin{array}{l}\text {...no puede hacer Educación Física debido a que se } \\
\text { ajigola (sic) y la da la tos y devuelve. }\end{array}$ & $\begin{array}{l}\text { Formato irregular. } \\
\text { Firma de la madre. } \$\end{array}$ \\
\hline 5 & $\begin{array}{l}\text {...no ha podido dar clase de Educación Física los días... } \\
\text { debido a una inflamación de la rodilla. }\end{array}$ & $\begin{array}{l}\text { Formato irregular. } \\
\text { Firma de la madre. } \$\end{array}$ \\
\hline 6 & $\begin{array}{l}\text { Hoy día } 20 \ldots \text { no puede hacer física (sic) por encontrarse } \\
\text { enfermo. }\end{array}$ & $\begin{array}{l}\text { Formato irregular. } \\
\text { Firma de la madre. } \$\end{array}$ \\
\hline 7 & $\begin{array}{l}\text {...no puede hacer de momento Educación Física en } 2 \text { ó } 3 \\
\text { días. }\end{array}$ & $\begin{array}{l}\text { Formato irregular. } \\
\text { Firma de la madre. } \varnothing^{n}\end{array}$ \\
\hline 8 & Mi hijo... no puede hacer gimnasia por dolor de rodilla. & $\begin{array}{l}\text { Formato irregular. } \\
\text { Firma y DNI de la madre. } 0^{n}\end{array}$ \\
\hline 9 & $\begin{array}{l}\text {...no puede realizar ejercicios de Educación Física por } \\
\text { tener una fisura en la muñeca derecha. }\end{array}$ & $\begin{array}{l}\text { Formato irregular. } \\
\text { Firma de la madre. } 0^{n}\end{array}$ \\
\hline 10 & $\begin{array}{l}\text {...no puede hacer Educación Física pues tiene una } \\
\text { torcedura en el pie izquierdo. }\end{array}$ & $\begin{array}{l}\text { Formato irregular. } \\
\text { Firma y DNI de la madre. ㅇ }\end{array}$ \\
\hline 11 & $\begin{array}{l}\text { No puede realizar Educación Física porque la están } \\
\text { haciendo unas pruebas de los bronquios y necesita } \\
\text { reposo. El día... va a consulta y la dirán si puede } \\
\text { hacerlo ya. }\end{array}$ & $\begin{array}{l}\text { Justificante de faltas de } \\
\text { asistencia. } \\
\text { Firma y DNI de la madre. } 0^{n}\end{array}$ \\
\hline 12 & $\begin{array}{l}\text { No puede realizar Educación Física porque lleva unos } \\
\text { días con fiebre y muy cogida de los bronquios. }\end{array}$ & $\begin{array}{l}\text { Justificante de faltas de } \\
\text { asistencia. } \\
\text { Firma y DNI de la madre. } \$\end{array}$ \\
\hline 13 & $\begin{array}{l}\text { No ha podido hacer Educación Física por un problema } \\
\text { de espalda }\end{array}$ & $\begin{array}{l}\text { Justificante de faltas de } \\
\text { asistencia. } \\
\text { Firma y DNI de la madre. } \$\end{array}$ \\
\hline 14 & $\begin{array}{l}\text {...no puede realizar ejercicios físicos por molestias en el } \\
\text { muslo derecho. El lunes va a ir al médico para obtener } \\
\text { así el justificante. }\end{array}$ & $\begin{array}{l}\text { Formato cuartilla. } \\
\text { Firma de la madre. } 0^{n} \\
\end{array}$ \\
\hline 15 & $\begin{array}{l}\text {...no puede hacer Educación Física porque tiene dolor } \\
\text { de garganta y está constipado. }\end{array}$ & $\begin{array}{l}\text { Formato cuartilla. } \\
\text { Firma y DNI del padre. } \varnothing^{*}\end{array}$ \\
\hline 16 & $\begin{array}{l}\text {...no puede hacer Educación Física porque tiene un } \\
\text { poco de daño en los riñones y el médico la ha dicho que } \\
\text { esté varios días sin hacer esfuerzo ni ejercicio. }\end{array}$ & $\begin{array}{l}\text { Formato irregular. } \\
\text { Firma de la madre. } \sigma^{n} \\
\end{array}$ \\
\hline 17 & $\begin{array}{l}\text {...no podrá hacer en unos días gimnasia. El domingo se } \\
\text { la arrancó una uña del pie. }\end{array}$ & $\begin{array}{l}\text { Formato irregular. } \\
\text { Firma y DNI de la madre. } ᄋ\end{array}$ \\
\hline
\end{tabular}

Tabla 16. Justificantes y documentos familiares recogidos en la investigación ( $\left(1^{\mathrm{a}}\right.$ de 3$)$ 


\begin{tabular}{|c|c|c|}
\hline $\mathbf{N}^{\mathbf{o}}$ & CONTENIDO DEL JUSTIFICANTE & OBSERVACIONES \\
\hline 18 & $\begin{array}{l}\text {...no puede hacer Educación Física durante unos días } \\
\text { pues está enferma. }\end{array}$ & $\begin{array}{l}\text { Formato irregular. } \\
\text { Firma de la madre. } \$\end{array}$ \\
\hline 19 & $\begin{array}{l}\text {...ha sido operada de un dedo del pie izquierdo y aunque } \\
\text { el proceso postoperatorio terminó, tendrá que estar sin } \\
\text { realizar algunos ejercicios, en los que sienta dolor. }\end{array}$ & $\begin{array}{l}\text { Formato irregular. } \\
\text { Firma y DNI de la madre. } ?\end{array}$ \\
\hline 20 & ...no puede hacer gimnasia por motivos de la operación. & $\begin{array}{l}\text { Formato irregular. } \\
\text { Firma y DNI de la madre. } ᄋ\end{array}$ \\
\hline 21 & $\begin{array}{l}\text {...no puede hacer Educación Física porque todavía no } \\
\text { está recuperado de la gripe y tiene tos. }\end{array}$ & $\begin{array}{l}\text { Formato irregular. } \\
\text { Firma y DNI de la madre. } \\
\text { Incluye el teléfono. } \$\end{array}$ \\
\hline 22 & $\begin{array}{l}\text {...no se encuentra en condiciones de hacer gimnasia por } \\
\text { estar constipada... le da la tos y se cansa. }\end{array}$ & $\begin{array}{l}\text { Formato irregular. } \\
\text { Firma y DNI de la madre. } 0^{n}\end{array}$ \\
\hline 23 & $\begin{array}{l}\text {...no puede hacer Educación Física por estar } \\
\text { constipada. }\end{array}$ & $\begin{array}{l}\text { Formato irregular. } \\
\text { Firma y DNI de la madre. } \$\end{array}$ \\
\hline 24 & $\begin{array}{l}\text {...no puede hacer Educación Física debido al daño que } \\
\text { tiene en el pie izquierdo...lo ha recomendado el médico. }\end{array}$ & $\begin{array}{l}\text { Formato cuartilla. } \\
\text { Firma de la madre y padre. } ᄋ\end{array}$ \\
\hline 25 & $\begin{array}{l}\text { Justifico a mi hijo de que no puede hacer Educación } \\
\text { Física por motivos del estómago. }\end{array}$ & $\begin{array}{l}\text { Formato cuartilla. } \\
\text { Firma y DNI de la madre. } \$\end{array}$ \\
\hline 26 & $\begin{array}{l}\text {...no puede hacer hoy Educación Física por tener una } \\
\text { pequeña lesión en el hombro. }\end{array}$ & $\begin{array}{l}\text { Formato irregular. } \\
\text { Firma y DNI de la madre. } 0^{n}\end{array}$ \\
\hline 27 & $\begin{array}{l}\text {...padre de..., hace saber que por una lesión jugando al } \\
\text { fútbol tiene daño en el pie. Por ello, ruego al profesor } \\
\text { de gimnasia que le justifique. }\end{array}$ & $\begin{array}{l}\text { Formato irregular. } \\
\text { Firma y DNI del padre. } ๆ\end{array}$ \\
\hline 28 & $\begin{array}{l}\text {...no puede hacer Educación Física pues tiene un dolor } \\
\text { en la espalda. }\end{array}$ & $\begin{array}{l}\text { Formato irregular. } \\
\text { Firma y DNI de la madre. } \varnothing^{n}\end{array}$ \\
\hline 29 & $\begin{array}{l}\text { Ruego disculpe de hacer ejercicios físicos en el día de } \\
\text { hoy por tener un dolor en la pierna derecha. }\end{array}$ & $\begin{array}{l}\text { Formato cuartilla. } \\
\text { Firma del padre. } 0^{n}\end{array}$ \\
\hline 30 & $\begin{array}{l}\text {...por una gripe y una tos persistente lleva varios días } \\
\text { con un dolor en el pecho. Tiene las vías respiratorias } \\
\text { muy irritadas...le pido que no realice esfuerzos físicos } \\
\text { como correr, saltar, etc. En el día de hoy. }\end{array}$ & $\begin{array}{l}\text { Formato cuartilla. } \\
\text { Firma y DNI de la madre. } q\end{array}$ \\
\hline 31 & $\begin{array}{l}\text { Por encontrarse... convaleciente de un proceso gripal } \\
\text { que ha ido acompañado de diarreas, no es conveniente } \\
\text { que en el día de hoy practique ejercicio físico. }\end{array}$ & $\begin{array}{l}\text { Formato cuartilla. } \\
\text { Firma del padre. } \$\end{array}$ \\
\hline 32 & $\begin{array}{l}\text {...no podrá hacer Educación Física durante unos días } \\
\text { ya que tiene molestias en la rodilla derecha, y el médico } \\
\text { le ha recomendado reposo hasta que vea una } \\
\text { radiografía que tiene pendiente. }\end{array}$ & $\begin{array}{l}\text { Formato cuartilla. } \\
\text { Firma de la madre. } \varnothing^{n}\end{array}$ \\
\hline 33 & $\begin{array}{l}\text {...le comunico que no puede realizar ningún tipo de } \\
\text { ejercicio físico, ya que por orden del médico tiene que } \\
\text { tener reposo, andar poco y no coger frío, con lo cual no } \\
\text { puede hacer física (sic). }\end{array}$ & $\begin{array}{l}\text { Formato cuartilla. } \\
\text { Firma de la madre. } \$\end{array}$ \\
\hline
\end{tabular}

Tabla 16. Justificantes y documentos familiares recogidos en la investigación ( $2^{\mathrm{a}}$ de 3$)$ 


\begin{tabular}{|c|c|c|}
\hline $\mathbf{N}^{\mathbf{o}}$ & CONTENIDO DEL JUSTIFICANTE & OBSERVACIONES \\
\hline 34 & $\begin{array}{l}\text {...deberá realizar los ejercicios de Educación Física con } \\
\text { mucho cuidado por una lesión muscular que ha tenido } \\
\text { en la pierna derecha. }\end{array}$ & $\begin{array}{l}\text { Formato cuartilla. } \\
\text { Firma de la madre y el padre. } \\
q\end{array}$ \\
\hline 35 & $\begin{array}{l}\text {...no puede hacer física (sic) porque no puede correr } \\
\text { porque la da la tos. Gracias. }\end{array}$ & $\begin{array}{l}\text { Formato irregular. } \\
\text { Firma de la madre. } \$\end{array}$ \\
\hline 36 & $\begin{array}{l}\text { Ruego por favor no hagan hacer Educación Física a... } \\
\text { Porque tiene catarro y no respira debidamente. }\end{array}$ & $\begin{array}{l}\text { Formato irregular. } \\
\text { Firma y DNI del padre. } \$\end{array}$ \\
\hline 37 & $\begin{array}{l}\text {...como madre de..., le pido que deje a... sin hacer hoy } \\
\text { física (sic) por tener un fuerte resfriado. Gracias. }\end{array}$ & $\begin{array}{l}\text { Formato irregular. } \\
\text { Firma de la madre. } \$\end{array}$ \\
\hline 38 & $\begin{array}{l}\text { Al profesor de Educación Física: somos los padres de... } \\
\text { Le comunico que ayer estuvo todo el día con vómitos y } \\
\text { diarrea. Si usted lo cree conveniente no hacer esfuerzo } \\
\text { se lo agradeceríamos mucho }\end{array}$ & $\begin{array}{l}\text { Formato cuartilla } \\
\text { Firma y DNI de la madre y el } \\
\text { padre. } \sigma^{n}\end{array}$ \\
\hline 39 & $\begin{array}{l}\text { A la atención del profesor de Educación Física: le } \\
\text { comunico que... se hizo un esguince ayer por lo cual no } \\
\text { podrá hacer Educación Física. }\end{array}$ & $\begin{array}{l}\text { Formato irregular. } \\
\text { Firma de la madre. } \varnothing^{n}\end{array}$ \\
\hline 40 & $\begin{array}{l}\text { Como madre de... le pediría que hoy no realizara la } \\
\text { clase de Educación Física ya que el domingo jugando } \\
\text { un partido de baloncesto sufrió un tirón y sigue con la } \\
\text { espalda dolorida teniendo que tomar medicación. }\end{array}$ & $\begin{array}{l}\text { Formato irregular. } \\
\text { Firma de la madre. } \$\end{array}$ \\
\hline 41 & $\begin{array}{l}\text {...no puede coger peso, apoyarse sobre el hombro } \\
\text { derecho ni hacer movimientos bruscos. }\end{array}$ & $\begin{array}{l}\text { Formato irregular. } \\
\text { Firma y DNI del padre. } \$\end{array}$ \\
\hline 42 & No puede hacer gimnasia por dolerla la espalda. & $\begin{array}{l}\text { Formato irregular. } \\
\text { Firma y DNI de la madre. } \$\end{array}$ \\
\hline 43 & $\begin{array}{l}\text {...no podrá hacer ejercicios durante el día de hoy por } \\
\text { tener la rodilla hinchada por un golpe sufrido. }\end{array}$ & $\begin{array}{l}\text { Formato irregular. } \\
\text { Firma del padre. } \sigma^{n}\end{array}$ \\
\hline 44 & $\begin{array}{l}\text {...no puede hacer Educación Física porque tiene un } \\
\text { tirón en la pierna. }\end{array}$ & $\begin{array}{l}\text { Formato irregular. } \\
\text { Firma de la madre. } \sigma^{*}\end{array}$ \\
\hline 45 & $\begin{array}{l}\text { Soy la madre de... No puede hacer Educación Física } \\
\text { porque tiene daño en los ligamentos. }\end{array}$ & $\begin{array}{l}\text { Formato irregular. } \\
\text { Firma de la madre. } 0^{n}\end{array}$ \\
\hline 46 & $\begin{array}{l}\text {...no puede hacer Educación Física durante unos días } \\
\text { debido a su catarro. Según el médico. }\end{array}$ & $\begin{array}{l}\text { Formato irregular. } \\
\text { Firma y DNI del padre. } \$\end{array}$ \\
\hline 47 & $\begin{array}{l}\text {...no debe hacer deporte durante un tiempo a } \\
\text { consecuencia de los dolores que le producen un rebrote } \\
\text { de la artritis juvenil, enfermedad diagnosticada } \\
\text { anteriormente por los médicos. }\end{array}$ & $\begin{array}{l}\text { Formato cuartilla. } \\
\text { Firma del padre. } ९\end{array}$ \\
\hline 48 & $\begin{array}{l}\text { Como madre de... justifico que no puede hacer hoy } \\
\text { Educación Física por tener unas ampollas en la planta } \\
\text { del pie que son bastante dolorosas. Muchas gracias. }\end{array}$ & $\begin{array}{l}\text { Formato cuartilla. } \\
\text { Firma de la madre. }\end{array}$ \\
\hline 49 & $\begin{array}{l}\text { Mi hijo... no puede realizar la actividad de Educación } \\
\text { Física por tener tos y dolor en el pecho. }\end{array}$ & $\begin{array}{l}\text { Formato folio. } \\
\text { Firma de la madre. } \varnothing^{n}\end{array}$ \\
\hline
\end{tabular}

Tabla 16. Justificantes y documentos familiares recogidos en la investigación (última de 3) 


\section{Núcleos de atención: análisis e interpretación}

Hemos centrado nuestra atención en los siguientes ejes argumentales:
a) Formato.
b) Información aportada y autoría.
c) Recomendaciones a seguir.
d) Visión de la Educación Física.
e) Actuación del profesorado: descripción de la realidad.

Insistimos en que un mismo escrito puede ser empleado como ejemplo en varios de estos ejes.

\section{a) Formato}

Para empezar, todos los justificantes se han presentado manuscritos. Además, el formato mayoritariamente utilizado ha sido el de un simple trozo de papel. Sin embargo, ha habido otros modelos que pasamos a desglosar en la Tabla 17. Hemos de aclarar que el centro educativo en el que tuvo lugar la investigación no tenía establecido de forma reglamentaria ningún documento para estos menesteres, lo cual pudiera explicar la disparidad y "calidad" de los justificantes presentados.

\begin{tabular}{|l|c|}
\hline \multicolumn{1}{|c|}{ DESCRIPCIÓN DEL JUSTIFICANTE } & TOTAL \\
\hline Tamaño folio, cuartilla o similar & 16 \\
\hline $\begin{array}{l}\text { Modelo establecido por el centro como } \\
\text { Justificante de faltas de asistencia }\end{array}$ & 3 \\
\hline Otro formatos: trozos de hojas, 1 cuartilla, etc. & 30 \\
\hline
\end{tabular}

Tabla 17. Formatos de justificantes familiares presentados 
En esta línea de la credibilidad de los documentos, el hecho de que se empleen para este tipo de comunicaciones los Justificantes de faltas que se recogen en la conserjería del centro pudiera deberse a la creencia de que utilizándolos, puesto que se trata de un modelo "oficial" o reglamentario diseñado por el propio instituto, aumenta la validez y garantía de la información.

\section{b) Información aportada y autoría}

Por lo que se refiere a la variable sexo, 29 de los justificantes (59.2\%) son de alumnas y 20 de alumnos (40.8\%). La Gráfica 73 muestra visualmente esta proporción.

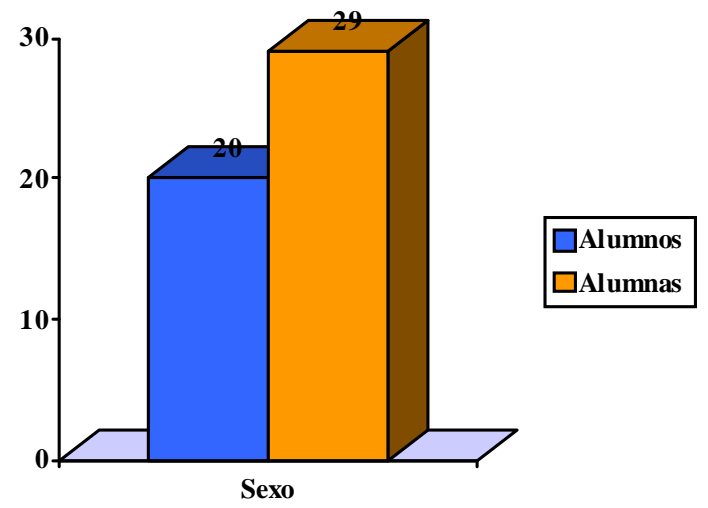

Gráfica 73. Justificantes familiares y variable sexo

Algunos papeles no solo van firmados por el familiar competente para ello ${ }^{208}$, sino que además acompañan su rúbrica del correspondiente número del DNI, como queriendo otorgar mayor rigor al documento (Justificantes 10, 11, 13...).

Solo en un caso (Justificante 21), se indica el número de teléfono familiar por si se quisiera hacer algún tipo de consulta. Parece lógico pensar que con esta opción se

\footnotetext{
${ }^{208}$ En muchos de los escritos sabemos que el que firma es el padre o la madre tan solo por la rúbrica, pues no se identifican en ningún momento como tales, pudiéndose dar el caso que se tratasen de sus tutores.
} 
pretende ofrecer al profesor la posibilidad de ponerse en contacto con ellos para comprobar y obtener la información de forma directa y personal.

En otro orden de asuntos, podemos interpretar el rol desempeñado por el sexo femenino en el seguimiento y control de los estudios de sus hijos ya que en un $73.4 \%$ de los casos es la madre ${ }^{209}$ la que únicamente firma el justificante. Solo un $20.4 \%$ de ellos son firmados exclusivamente por el padre o tutor, y en un $6.1 \%$ por ambos. Sin ánimo de pretender extraer una conclusión absoluta, parece evidente que con estos datos se puede fortalecer la tradicional idea que señala que la madre -figura femenina de la familia- tiene encomendadas las tareas relacionadas con la educación de sus hijos (Uribe, 1994; Arenas, 2000; Fuente [26]).

Finalmente, resulta muy llamativo que no hubo ningún caso en que los familiares de los alumnos en cuestión vinieran al centro a informar directamente al profesor de Educación Física, es decir, no se ha producido ninguna relación/comunicación de forma directa y personal entre familiares y profesores de Educación Física. No obstante, sí han acudido al centro a tratar el asunto con el tutor del centro y este, a su vez, nos ha trasladado a nosotros la información que ha estimado oportuna, bien de forma privada, bien junto con el resto de profesores que imparten clase a dicho alumno.

En lo que respecta al periodo de convalecencia, reposo o justificación de la no actividad, muchos de ellos no concretan el tiempo para el que se expide dicho justificante. Aunque algunos sí que especifican que la justificación se refiere única y exclusivamente para un día de clase en concreto (Justificantes 6, 29, 30...), entendemos que otros muchos también están referidos al día que lo presentan al profesor ya que en caso de que se tratase de una lesión o enfermedad de mayor duración suponemos que así lo harían saber (Justificantes 9, 10, 28...).

Sin embargo, no ocurre lo mismo con los detalles acerca de lo que le pasa al alumno. La inmensa mayoría, aun no siendo en ocasiones muy explícitos, ofrecen datos

\footnotetext{
${ }^{209}$ Vid. la nota anterior. En todo caso, únicamente estamos interesados en resaltar la titularidad femenina del documento.
} 
lo suficientemente esclarecedores. Con todo, nos vamos a encontrar 5 casos que no aclaran nada al respecto, limitándose a decir que "está enfermo" (Justificantes 6, 7, 18...). En la Tabla 18 recogemos las causas que motivas los justificantes.

\begin{tabular}{|c|c|c|c|c|}
\hline & $\begin{array}{c}\text { APARATO } \\
\text { LOCOMOTOR }\end{array}$ & $\begin{array}{c}\text { APARATO } \\
\text { RESPIRATORIO }\end{array}$ & OTROS & SIN ACLARAR \\
\hline 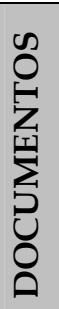 & $\begin{array}{l}1,3,5,8-10,13 \\
14,19,24,26-29 \\
32,34,39-45,47\end{array}$ & $\begin{array}{l}4,11,12,15,21- \\
23,30,31,35-37 \\
46,49\end{array}$ & $2,16,17,25,38,48$ & $6,7,18,20,33$ \\
\hline 岕 & 24 & 14 & 6 & 5 \\
\hline
\end{tabular}

Tabla 18. Motivos de los justificantes familiares

Como vemos, las lesiones o problemas relacionados con el aparato locomotor, con un $48.9 \%$, copan el origen de los justificantes familiares. A continuación, los relacionados con el aparato respiratorio (entre los que incluimos los procesos gripales) que suponen el $28.5 \%$. En menor medida nos encontramos problemas estomacales, uñas doloridas, ampollas, procesos diarreicos...

\section{c) Recomendaciones a seguir}

Casi la totalidad de los justificantes están redactados en términos de "no puede hacer" o "no puede realizar", lo cual deja entrever la postura o respuesta que ofrecerá el profesor. No obstante, algunos familiares, más que manifestar una rotunda negativa a la realización de cualquier tipo de ejercicio físico, parecen confiar la decisión final al profesor de Educación Física, limitándose a explicar lo que le sucede a su hijo y sugiriendo que se procure que no haga grandes esfuerzos o similar (Justificantes 34, 37, $38,40 \ldots)$. Obviamente, esta situación planteará al profesor la búsqueda inmediata de una 
respuesta educativa acorde a la situación descrita en el papel, la cual suele verse ampliada en el inicio de la clase de forma verbal con el alumno en cuestión.

El facultativo se emplea en ocasiones como referente para el comunicado familiar. Varios de ellos aluden al médico para alegar que es él quien aconseja o dictamina una determinada cuestión (Justificantes 16, 24, 32...), mientras que en un caso se matiza que asistirán a consulta para conocer la opinión del profesional de la salud (Justificante 11) y en otro aclaran que irán a pedirle el correspondiente justificante (Justificante 14), dando a entender que es este, y no el suyo propio, el que tiene mayor validez.

Es de destacar que, al contrario de lo que hemos apreciado en los escritos médicos, en ningún justificante aparecen los términos dispensa o exención. Suponemos que por propio desconocimiento de lo que esos términos -tecnicismos- significan o suponen.

\section{d) Visión de la Educación Física}

Al contrario de lo que sucedía en los anteriores documentos médicos, la mayoría de los justificantes (27 de ellos) hacen alusión al área de Educación Física. Entendemos que la comunicación entre las familias y el profesor correspondiente se establece en un contexto educativo muy cercano, es decir, inequívocamente los familiares redactan sus escritos para el profesor de un área en concreto, y para ello no emplean tecnicismos ni denotan intereses de otro tipo que no estén relacionados con justificar a sus hijos en aras de que no se vean afectados o perjudicados académicamente por padecer una enfermedad, indisposición, etc., de cualquier tipo.

Como cabía esperar, el ejercicio físico aparece en varias ocasiones (9 en total) como el objeto a evitar o causa del argumento de la justificación (Justificantes 1, 3, 9...). Sin embargo, tan solo un justificante (Justificante 30) lo plantea en términos de esfuerzos físicos, mientras que otro menciona los deportes (Justificante 47). 
Otro término al que recurren en seis ocasiones es el de gimnasia. Este es empleado claramente en alusión a nuestra área, denotando un cierto tradicionalismo académico (Justificantes 8, 17, 20...).

“...padre de..., hace saber que por una lesión jugando al fútbol tiene daño (sic) en el pie. Por ello, ruego al profesor de gimnasia que le justifique.” (Justificante 27. Énfasis mío)

Curiosamente, en 5 justificantes se produce una situación bastante peculiar. Suele ser una costumbre en este centro que muchos de los chavales denominen "física" a la Educación Física (Justificante 2, 6, 33...). Desconocemos la causa de esta terminología, pero lo que sí parece seguro es que los mismos alumnos se lo han transmitido a sus familiares, y éstos así lo hacen constar en sus escritos dirigidos al profesor de Educación Física o, como dirían ellos, al "profesor de física".

\section{e) Actuación del profesorado: descripción de la realidad}

En primer lugar, hemos de decir que los alumnos traen este tipo de documento porque al inicio de cada curso escolar se les informa acerca de cómo deben proceder ante determinados supuestos de enfermedad, lesión o malestares. Aun así, suele darse con suma frecuencia que muchos de ellos no lo traen en primera instancia, por lo que se les vuelve a insistir en la obligatoriedad de presentarlo en la siguiente clase, aunque el motivo o causa que le de sentido haya desaparecido (esto dependerá de la confianza que genere el alumno en cuestión).

Para lesiones o enfermedades de escasa relevancia, tanto temporales como médicas, se suele dar por válidos estos documentos, es decir, que se toma en seria consideración lo que en ellos se nos explica o advierte, actuando posteriormente en consecuencia y adoptando las oportunas medidas al respecto en términos de participación o reposo (más o menos activo). Solamente cuando la lesión o enfermedad puede ser muy prolongada en el tiempo y/o es de cierta magnitud, se requiere un documento médico más detallado. En este sentido, conviene recalcar que, puesto que el 
departamento no disponía de ninguna ficha o carta para entregársela al médico para que la cumplimente, los escritos médicos suelen ser, como ya se dijo anteriormente, muy escuetos y parcos en datos.

En otras muchas ocasiones, cuando la causa del justificante es de carácter leve, y a pesar del consejo familiar de no hacer nada en nuestras clases, se busca la participación del alumno en unas condiciones adecuadas a dichas lesiones. Esta participación se ve favorecida o dificultada por varios factores. Entre ellos, lógicamente estará el tipo de contenido y tarea que se pretenda llevar a cabo, pero, sobre todo, dependerá de la actitud y predisposición del alumno a participar.

En este sentido, hemos apreciado que cuando los familiares firman un justificante negando cualquier posibilidad de que su hijo haga algún tipo de práctica y/o ejercicio, estos adoptan posturas totalmente reacias a participar en cualquier tarea $\mathrm{o}$ actividad independientemente de que tales tareas no sean contraproducentes para su estado de salud, es decir, los alumnos sí que acatan al pie de la letra lo que sus padres escriben. Por tanto, de algún modo se oponen a que se les realice lo que hemos denominado una adaptación curricular individual "en el momento".

No obstante, también se produce la situación contraria. Ha habido ocasiones en las que se ha obligado a alumnos que no se encuentran en plenas facultades de salud, pero que les entusiasma la Educación Física, a no participar con el resto de sus compañeros solo porque así lo expresan las indicaciones familiares presentadas.

Referente a la adaptación curricular "en el momento", puesto que la justificación se produce, como no podía ser de otra forma, nada más llegar a clase, los profesores parecen estar habituados a articular, para los casos menos graves o de lesión parcial, una respuesta educativa que favorezca la participación del alumnado, es decir, intentan por todos los medios que no se queden sentados viendo como los demás trabajan. Esta respuesta no escrita debe ser considerada como un tipo de adaptación curricular inmediata o urgente que dependerá, además de los factores anteriormente citados, de la capacidad creativa, de improvisación y de conocimientos del profesorado. A ese 
respecto, comprobamos que, dependiendo de cada caso en particular, no siempre son capaces de articular en el momento este tipo de adaptaciones con garantías de éxito (en términos de verdadera integración, no perjudicial para la salud del individuo, acorde a la predisposición del mismo, etc.).

Resumiendo, dependiendo de lo que en estos escritos se informe al profesor, este suele tener muy presentes sus recomendaciones, pero también es verdad que procura, cuando las circunstancias así lo aconsejan (actitud y predisposición del chaval, alcance de la lesión, tipo de contenido trabajado en ese momento, apresto del profesor para la adopción rápida de medidas, etc.), propiciar y crear pautas que estimulen y promuevan el concurso del alumnado.

\section{Conclusiones}

Las alumnas presentan mayor número de justificantes familiares que los alumnos para demostrar sus dolencias, enfermedades... y excusar así su participación en nuestras clases ${ }^{210}$. Comparativamente con el apartado anterior, la desproporción chicaschicos es ahora mucho menor.

La media de justificantes familiares anuales presentados es de 16.3, es decir, aunque algún alumno haya podido presentar en más de ocasión un justificante, aproximadamente un $2.89 \%$ de los alumnos presentan al cabo del curso escolar un escrito de este tipo.

La titularidad de los documentos, en cuanto a quien lo firma, es mayoritariamente femenina. Así pues, suele ser la madre o tutora quien se encarga de estas tareas "administrativas" en relación a la educación de sus hijos.

Los justificantes familiares, aunque suelen ofrecer información clara acerca de lo que le pasa al alumno que lo presenta, se limitan a explicar de manera somera lo que le

\footnotetext{
${ }^{210}$ Vid.: el apartado de Conclusiones de la página 400 y, en particular, la Nota 203.
} 
sucede al alumno, centrando mayoritariamente la atención en aquello que no debe o creen que no puede hacer.

Aun así, no son muchas las ocasiones en que nos vamos a encontrar con categóricas negativas a que sus hijos tomen parte en las clases. Además, en algunos casos, se aprecia que los escritos familiares que presentan los alumnos son más bien solicitudes o ruegos de un especial y cuidadoso trato hacia ellos, que puede ir desde la participación con ciertos reparos hasta la exclusión de determinadas prácticas o momentos, lo cual no deja de ser una exención parcial y/o temporal.

Una vez se ha presentado al profesor un escrito de este tipo son varios los factores que provocan su consiguiente actuación: el propio sentido común, conocimiento de los chavales (referido a cómo son, sus actitudes, motivaciones, intereses, bagaje de experiencias...), dominio de la materia, tipo de contenido...

Como cabía esperar, se aprecia una comunicación directa y fluida entre los familiares y los profesores de sus hijos, bien en forma de entrevistas con los tutores del centro, bien a través de escritos o justificantes muy sencillos dirigidos al profesor de Educación Física. A pesar de algunas excepciones, parecen tener una percepción cercana y real de la Educación Física como área curricular.

En todo caso, ya para terminar, todo lo que se dice en estos justificantes familiares suele ser tenido muy en consideración a la hora de ordenar/articular una tarea y/o respuesta educativa para el alumno implicado. A pesar de que se aspire y propicie la mayor participación posible, el factor -temor- "responsabilidad" podría pesar lo suficiente como para que en no pocas ocasiones se haga un caso escrupuloso de lo que se pide, aconseja o, en ocasiones, ordena en términos de que el alumno "no haga nada". 


\section{4.- EPÍLOGO}

En primer lugar, se considera acertado que el período de recogida de documentos haya abarcado tres cursos escolares completos, dando lugar a una muestra lo suficientemente amplia como para dar por válidos y fiables los resultados obtenidos en ambas investigaciones.

En segundo lugar, a modo de autocrítica ${ }^{211}$, consideramos que, a pesar de haber intentado seguir escrupulosamente con las pautas metodológicas establecidas al inicio de este capítulo, pudiera haberse perdido información de tipo oral en alguna ocasión, es decir, en lo que a las comunicaciones y conversaciones con los alumnos se refiere puede haberse olvidado información en el proceso. La vorágine de los periodos lectivos, reuniones, guardias... sitúan al profesor al final del día en una situación, como poco, de cansancio. Quizás, cuando poníamos en común los datos del día en cuestión, no se recordase todo con la suficiente nitidez y riqueza de datos.

Por último, recogemos a modo de resumen en la Tabla 19 todos los aspectos más relevantes y destacados hallados en el estudio realizado con ambos tipos de escritos -documentos médicos y justificantes familiares-.

\footnotetext{
${ }^{211}$ Esta es una de las cuestiones que según Pérez Serrano (citado en Bernardo y Calderero, 2000, p. 118-
} 119) hay que tener en cuenta a la hora de utilizar la técnica de la observación para la obtención de datos. 


\begin{tabular}{|c|c|c|}
\hline $\begin{array}{l}\text { VARIABLE A } \\
\text { CONSIDERAR }\end{array}$ & DOCUMENTOS MÉDICOS & JUSTIFICANTES FAMILIARES \\
\hline Período de recogida & Tres cursos académicos $(+1)$ & Idénticamente igual. \\
\hline $\begin{array}{l}\text { Número de escritos } \\
\text { reunidos }\end{array}$ & 96 & 49 \\
\hline $\begin{array}{l}\text { Formatos } \\
\text { mayoritariamente } \\
\text { empleados }\end{array}$ & $\begin{array}{l}\text { - Orden de Tratamiento a } \\
\text { Enfermeras y Practicantes P.10) } \\
\text { - Parte de Consulta y } \\
\text { Hospitalización. }\end{array}$ & Trozos de hojas, medias cuartillas... \\
\hline Entrega por sexos & 649 y $32 \sigma^{\lambda}$ & $29+$ y $200^{\lambda}$ \\
\hline $\begin{array}{l}\text { Identificación del firmante } \\
\text { del documento }\end{array}$ & $\begin{array}{l}83 \text { con identificación "oficial" } \\
12 \text { con identificación manuscrita } \\
1 \text { sin identificar }\end{array}$ & $\begin{array}{l}36 \text { firmados por la madre/tutora } \\
10 \text { firmados por el padre/tutor } \\
3 \text { firmados por ambos }\end{array}$ \\
\hline $\begin{array}{l}\text { Claridad del diagnóstico, } \\
\text { tratamiento, período de } \\
\text { convalecencia... }\end{array}$ & $\begin{array}{l}\text { Hay muchos con omisiones de la } \\
\text { lesión o enfermedad; otros del } \\
\text { tiempo de reposo o curación... }\end{array}$ & $\begin{array}{l}5 \text { casos no ofrecen ningún dato } \\
\text { esclarecedor acerca de la } \\
\text { enfermedad o lesión. }\end{array}$ \\
\hline Motivos de los escritos & $\begin{array}{l}39 \text { por aparato locomotor } \\
15 \text { por aparato respiratorio } \\
38 \text { sin aclarar } \\
6 \text { por motivos diversos }\end{array}$ & $\begin{array}{l}24 \text { por aparato locomotor } \\
14 \text { por aparato respiratorio } \\
5 \text { sin aclarar } \\
6 \text { por motivos diversos }\end{array}$ \\
\hline Recomendaciones a seguir & $\begin{array}{l}\text { Mayoritariamente en términos de no } \\
\text { hacer, exención, no realizar, evitar, } \\
\text { abstenerse... }\end{array}$ & $\begin{array}{l}\text { - No se emplea el término exención } \\
\text { - Algunos en términos de no puede } \\
\text { hacer o realizar Educación Física } \\
\text { - Los hay que dejan la decisión final } \\
\text { al profesor, limitándose a informar. }\end{array}$ \\
\hline $\begin{array}{l}\text { Visión de la Educación } \\
\text { Física (expresiones } \\
\text { empleadas) }\end{array}$ & $\begin{array}{l}\text { En } 35 \text { ocasiones aparece el ejercicio } \\
\text { físico. } \\
\text { En } 24 \text { aparece el término gimnasia. } \\
\text { La Educación Física en } 15 . \\
8 \text { veces los deportes. } \\
\text { En } 12 \text { se emplean otras expresiones } \\
\text { relacionadas. }\end{array}$ & $\begin{array}{l}\text { En } 27 \text { ocasiones se nombra la } \\
\text { Educación Física. } \\
\text { En } 9 \text { ocasiones el ejercicio físico. } \\
6 \text { veces la gimnasia. } \\
\text { Una sola vez el deporte. } \\
\text { Y otras expresiones en } 6 .\end{array}$ \\
\hline $\begin{array}{l}\text { Actuación del profesor y } \\
\text { del alumno }\end{array}$ & $\begin{array}{l}\text { Acatan las pautas dadas, incluso la } \\
\text { de la no práctica. } \\
\text { Alientan la participación cuando es } \\
\text { posible. } \\
\text { Aplican medidas en la línea de la } \\
\text { falsa integración. } \\
\text { Se aprecia que el alumnado sí acata } \\
\text { mayoritariamente el saber médico y } \\
\text { acepta sus "órdenes". }\end{array}$ & $\begin{array}{l}\text { Suelen ser tendidos en consideración } \\
\text { en menor medida que los médicos. } \\
\text { Se busca la participación cuando se } \\
\text { interpreta que la lesión o enfermedad } \\
\text { es menor. } \\
\text { Los alumnos se someten al dictamen } \\
\text { del escrito en casi todas las } \\
\text { ocasiones. }\end{array}$ \\
\hline
\end{tabular}

Tabla 19. Resumen comparativo de los resultados obtenidos en el estudio de los documentos médicos y los justificantes paternos 


\section{$\underline{\text { Piezas de la vidriera }}$}

La investigación llevada a cabo en relación a los documentos médicos y familiares presentados por los alumnos a los profesores de Educación Física, sacan a la luz las siguientes piezas de la vidriera final:

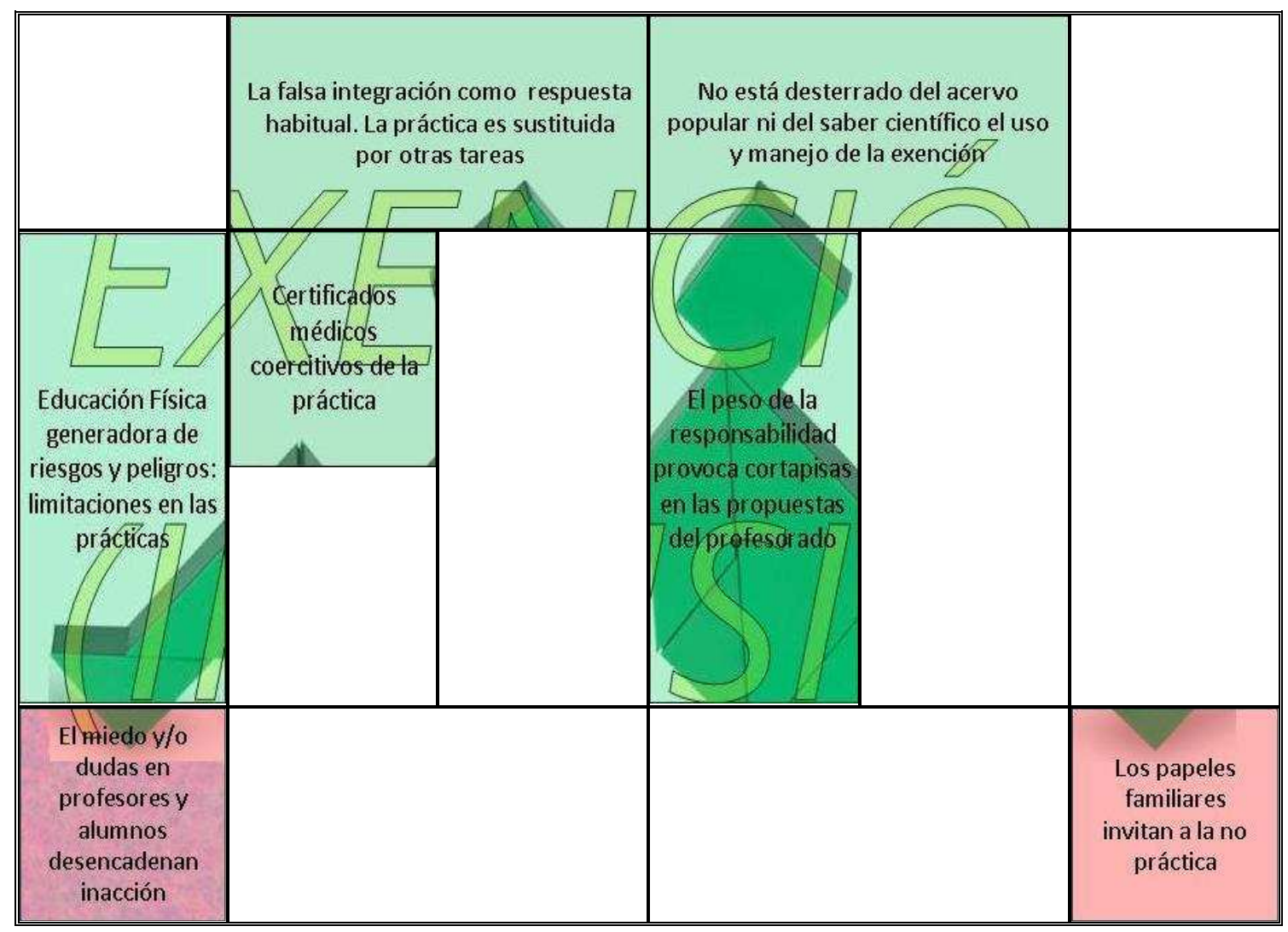




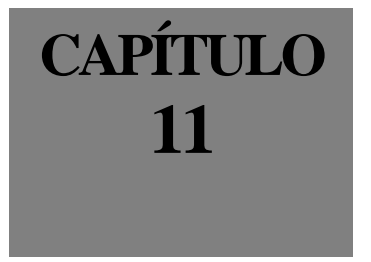

LA RESPONSABILIDAD DEL PROFESOR DE EDUCACIÓN FÍSICA: ¿COARTADA PARA LA EXENCIÓN? 
En este capítulo pretendemos averiguar cuál es la responsabilidad de los profesores hacia sus alumnos durante el tiempo que estos se encuentran bajo su control o vigilancia. Como veremos, esta responsabilidad parece incrementarse durante la realización de actividades propias de la Educación Física. De hecho, la realidad ofrecida por algunos medios de comunicación nos confirmará lo riesgosa que es esta materia.

También mostraremos que en el ámbito de la Educación Física existe una cierta reticencia hacia la propuesta práctica de determinados ejercicios, contenidos y/o modalidades deportivas. No cabe duda que esta situación puede verse agravada según qué condiciones y características presente el alumnado con dificultades de aprendizaje asociadas a cualquier discapacidad. En este sentido, relataré el alcance que ha supuesto este tema y sus consecuencias en mis veinte años de experiencia profesional.

No faltará acercarnos al parecer que tiene el resto del colectivo de profesores de Educación Secundaria al respecto de la responsabilidad y los peligros asumidos durante el ejercicio profesional, incluida la percepción que tienen sobre la Educación Física.

Así pues, trataremos de corroborar que existen elementos, situaciones y circunstancias que pueden propiciar que el profesorado de Educación Física se muestre reticente a proponer determinadas tareas y respuestas educativas como mecanismo de "autodefensa", bien por el peligro que estas suponen y por las consecuencias que de ellas se derivan, bien por las características de movimiento o de cualquier otro tipo que posee el alumno al que van dirigidas. 


\section{1.- LA RESPONSABILIDAD DE LOS DOCENTES}

Sin ánimo de ahondar en las leyes y normas que se aplican a los centros educativos (de cualquier naturaleza) y a los docentes en relación con su responsabilidad (sobre todo civil, aunque también penal) hacia los alumnos, consideramos necesario aclarar cuál es el principal sustento legislativo que regula dicha responsabilidad.

Por su importancia recogemos en primer lugar los artículos del Código Civil (Real decreto de 24 de julio de 1889) y del Código Penal (Ley Orgánica 10/1995) que serían de aplicación a las actuaciones que se pudieran derivar de nuestro ejercicio profesional.

\section{CÓDIGO CIVIL ARTÍCULO 1902}

"El que por acción u omisión causa daño a otro, interviniendo culpa o negligencia, está obligado a reparar el daño causado."

\section{CÓDIGO CIVIL ARTÍCULO 1903}

"La obligación que impone el artículo anterior es exigible no sólo por los actos $u$ omisiones propios, sino por los de aquellas personas de quienes se debe responder.

Los padres son responsables de los daños causados por los hijos que se encuentren bajo su guarda.

Los tutores lo son de los perjuicios causados por los menores o incapacitados que están bajo su autoridad y habitan en su compañía.

Lo son igualmente los dueños o directores de un establecimiento o empresa respecto de los perjuicios causados por sus dependientes en el servicio de los ramos en que los tuvieran empleados, o con ocasión de sus funciones.

Las personas o entidades que sean titulares de un Centro docente de enseñanza no superior responderán por los daños y perjuicios que causen sus alumnos menores de edad durante los períodos de tiempo en que los mismos se hallen 
bajo el control o vigilancia del profesorado del Centro, desarrollando actividades escolares o extraescolares y complementarias.

La responsabilidad de que trata este artículo cesará cuando las personas en él mencionadas prueben que emplearon toda la diligencia de un buen padre de familia para prevenir el daño."

\section{CÓDIGO CIVIL ARTÍCULO 1904}

"El que paga el daño causado por sus dependientes puede repetir de éstos lo que hubiese satisfecho.

Cuando se trate de Centros docentes de enseñanza no superior, sus titulares podrán exigir de los profesores las cantidades satisfechas, si hubiesen incurrido en dolo o culpa grave en el ejercicio de sus funciones que fuesen causa del daño."

\section{CÓDIGO PENAL ARTÍCULO 121}

"El Estado, la Comunidad Autónoma, la provincia, la isla, el municipio y demás entes públicos, según los casos, responden subsidiariamente de los daños causados por los penalmente responsables de los delitos dolosos o culposos, cuando éstos sean autoridad, agentes y contratados de la misma o funcionarios públicos en el ejercicio de sus cargos o funciones siempre que la lesión sea consecuencia directa del funcionamiento de los servicios públicos que les estuvieren confiados, sin perjuicio de la responsabilidad patrimonial derivada del funcionamiento normal o anormal de dichos servicios exigible conforme a las normas de procedimiento administrativo, y sin que, en ningún caso, pueda darse una duplicidad indemnizatoria.

Si se exigiera en el proceso penal la responsabilidad civil de la autoridad, agentes y contratados de la misma o funcionarios públicos, la pretensión deberá dirigirse simultáneamente contra la Administración o ente público presuntamente responsable civil subsidiario."

Antes de continuar, se nos plantea entonces la necesidad de saber lo que significa el término de "responsabilidad". El diccionario de la Real Academia Española (2001) define la responsabilidad como: "2. Deuda, obligación de reparar y satisfacer, por sí o por otra persona, a consecuencia de un delito, de una culpa o de otra causa legal. 3. Cargo u obligación moral que resulta para alguien del posible yerro en cosa o asunto determinado. 4. Capacidad existente en todo sujeto activo de derecho para reconocer y aceptar las consecuencias de un hecho realizado libremente." 
La responsabilidad civil es la obligación que nace para aquel que, como consecuencia de su comportamiento, causa un daño ilegítimo en persona o patrimonio ajeno, y esa obligación consiste en reparar ese daño, es decir, en dar satisfacción a la víctima de esa consecuencia dañosa ((Muñoz, 1999, p. 12). Por tanto, la responsabilidad civil da cumplimiento al citado artículo 1902 del Código Civil. Pero no nos equivoquemos, su finalidad no es sancionar sino reparar un daño causado e indemnizar los perjuicios causados -materiales y morales-. Cualquier otro tipo de sanción corresponde a la responsabilidad penal ${ }^{212}$ (Sánchez, 2003).

Así pues, la responsabilidad civil no tiene finalidad sancionadora, solo compensadora a quien haya sufrido algún tipo de daño, bien de manera económica, bien en especie. Asimismo, en función del objeto indemnizatorio, en responsabilidad civil no afecta o no existe el principio de presunción de inocencia, pero sí el de culpabilidad para que pueda garantizarse la mejor compensación de las víctimas. En caso de insolvencias, la ley permite que las personas puedan delegar su responsabilidad en otras personas físicas o jurídicas.

\section{Cuando en el Capítulo "LA EXENCIÓN VISTA A TRAVÉS DE LA} FORMACIÓN PERMANENTE" relaté lo acontecido en el curso "Estrategias didácticas de educación física en la escuela rural”, mencioné que el Técnico Asesor de la Dirección Provincial de Educación de Valladolid, en su charla sobre la responsabilidad patrimonial del docente, nos entregó abundante documentación legislativa. Pues bien, entre esa documentación se encuentra la Circular (2/2000) de la Dirección General de Recursos Humanos sobre responsabilidad patrimonial de la Administración de Castilla y León, así como la regulación de la asistencia judicial del personal docente no universitario y no docente al servicio de la administración autonómica. Por su importancia y aplicabilidad en nuestra comunidad, pasamos a sintetizar alguno de sus puntos más relevantes en relación co el tema que nos ocupa.

\footnotetext{
${ }^{212}$ Debe saberse que no hay seguro o póliza que cubra la responsabilidad penal de un profesor. La responsabilidad es siempre directa. Para reparar el daño causado lo que se deriva es una responsabilidad civil.
} 
En primer lugar, establece los fundamentos jurídicos relativos a la responsabilidad de la Administración derivados de la actuación de los profesores en el ejercicio de actividades escolares, extraescolares y complementarias. En concreto, la Ley 30/1992 de 26 de noviembre de Régimen Jurídico de las Administraciones Públicas y del procesamiento Administrativo Común, modificada por la Ley 4/1999 de 13 de enero, dedica su Título $\mathrm{X}$ a la regulación de la responsabilidad patrimonial de la Administración Pública, desarrollada por el Real Decreto 429/1993 de 26 de marzo por el que se aprobó el Reglamento de los procedimientos de la Administración Pública en materia de responsabilidad patrimonial.

Asimismo, en lo que respecta a la regulación de la asistencia judicial del personal docente no universitario y no docente al servicio de esta Administración, ambos se encuentran incluidos en el ámbito de aplicación del Decreto 203/1997 de 23 de octubre el cual preceptúa la asunción por parte de los Servicios Jurídicos de la Administración de Castilla y León, de la asistencia judicial del personal al servicio de la misma.

A pesar de toda esta base legislativa, aclara que la ausencia de regulación específica en esta Administración, no obsta, sin embargo, para que, la Consejería de Educación y Cultura asuma directamente la responsabilidad en aquellas contingencias derivadas de la actuación de los profesores en el ejercicio de sus funciones cuando éstas ocasionen daños a terceros.

Finalmente, para atender a las consecuencias derivadas de las actuaciones de los profesores, establece los mecanismos de inicio del correspondiente procedimiento de responsabilidad (bien de oficio, bien previa solicitud de los interesados) y el plazo máximo en el que deberá resolverse dicho procedimiento (no superior a un mes si se trata de un procedimiento abreviado y no superior a seis si, por el contrario, se trata de un procedimiento general). 
Para aquellas cuestiones relacionadas con el contenido de esta Circular, el personal deberá dirigirse a la Dirección Provincial de la que dependa su puesto de destino, la cual les facilitará toda la información que demanden en lo que al procedimiento y a la tramitación se refiere."

En el artículo 3 del citado Decreto 203/1997, de 23 de octubre, por el que se regula la asistencia judicial del personal al servicio de la Administración Autonómica (BOCyL 27-10-97), se exponen los requisitos que han de concurrir para que se produzca la asistencia judicial a este personal cuando exista un proceso civil o penal iniciado por terceros contra ellos.

a) Que el personal afectado estuviera ejerciendo su cargo o en activo.

b) Que existiera una actuación del mismo, por acción o por omisión.

c) Que la actuación se haya producido en el ejercicio d sus funciones, es decir, desarrollando las competencias que tuviera atribuidas normativamente sobre esa materia y en virtud de los cometidos propios del cargo o puesto de trabajo.

d) Que la actuación no haya vulnerado la legalidad vigente o, en cualquier caso, que se haya realizado por una orden de autoridad u órgano competente dictada en forma.

En las CONSIDERACIONES JURÍDICAS expuestas en el Dictamen 58/2003, emitido por el Consejo Consultivo de Castilla y León ${ }^{213}$, se expone, conforme la jurisprudencia del Tribunal Supremo, que la responsabilidad patrimonial de la Administración Pública exige la concurrencia de los siguientes requisitos:

\footnotetext{
${ }^{213}$ Según la Ley 1/2002, de 9 de abril, reguladora del Consejo Consultivo de Castilla y León, este es el superior órgano consultivo de la comunidad, y velará por la observancia de la Constitución, del Estatuto de Autonomía de Castilla y León y de todo el ordenamiento jurídico. Su consulta será preceptiva cuando así lo establezcan las leyes, y facultativa en los demás casos. Sus dictámenes no son vinculantes, salvo en los casos que así se establezca en las respectivas leyes.
} 
“a) La existencia de un daño efectivo, evaluable económicamente e individualizado en relación con una persona o grupo de personas.

b) El carácter antijurídico del daño, en el sentido de que la persona que lo sufre no tenga el deber jurídico de soportarlo, de acuerdo con la Ley.

c) La imputabilidad a la Administración de la actividad dañosa, es decir, la integración del agente en el marco de la organización administrativa a la que pertenece o la titularidad pública del servicio o la actividad en cuyo ámbito se produce el daño.

d) La relación de causa a efecto entre la actividad administrativa y el resultado dañoso, nexo causal que implica la necesidad de que el daño sea consecuencia del funcionamiento normal o anormal de un servicio público o actividad administrativa en relación directa e inmediata.

e) Ausencia de fuerza mayor.

f) Que no haya transcurrido un año desde el momento en que se produjo el hecho causante."

\section{2.- RIESGOS Y RESPONSABILIDAD EN LA EDUCACIÓN FÍSICA}

Basta con echar un rápido vistazo en las fuentes documentales para tropezarnos con claros y contundentes ejemplos que muestran la amarga, y nunca deseada, realidad de los accidentes en nuestras clases, así como la preocupación del profesor por las consecuencias derivadas de ellos (Managua, 2000; Landazuri, 2002; Perona et alia, 1998; Albornoz, 2001 y 2002).

Para empezar, son varios los autores que abordan este delicado tema de la responsabilidad desde una doble perspectiva: práctica, en cuanto que exponen ejemplos de hechos y sentencias relacionadas con Centros educativos y profesores; $y$ 
clarificadora, pues analizan en profundidad asuntos relacionados con esa responsabilidad. En no pocos casos, la Educación Física, la actividad física y deportiva aparece como ejemplo.

Perona et alia (1998, p. 55), cuando plantean el análisis de las diferentes situaciones de responsabilidad del docente, señalan una serie de precauciones a tener en cuenta, entre las que se encuentran las actividades deportivas que, por las propias necesidades de desplazamiento o movilidad que llevan asociadas, implican una estricta vigilancia por parte del profesor, así como la adopción de todas las precauciones necesarias para su práctica y desarrollo. También señalan las actividades peligrosas, entendiendo por ellas que un profesor comete falta cuando no interviene para impedir que un juego, en principio no peligroso, se convierta en tal. Por tanto, deducimos que la cuestión no reside tanto en no autorizar el juego o actividad, sino en no vigilarlo para que se transforme en violento y pueda causar daños a los alumnos. Asimismo, también deben ser consideradas las especiales circunstancias en el alumno. Aunque estos autores las emplean para referirse a alumnos con carácter violento o inestable, nosotros consideramos que se pueden hacer extensibles a todos aquellos alumnos que presentan algún tipo de lesión o enfermedad que dificulte, en parte o en su totalidad, su participación en las actividades que planteemos en nuestras sesiones (p.ej.: un alumno escayolado de un brazo o una pierna, con corsé, esguince de tobillo... u otros casos más extremos con dificultades de aprendizaje asociadas a cualquier discapacidad).

Latorre y Herrador (2003, p. 109) establecen que en la actividad físico-deportiva escolar hay riesgos, en relación a la aparición de lesiones, que tienen que ver con las mismas características y particularidades de cada sujeto, entre las que se hallan las patologías que, en cierta medida, limitarán o comprometerán sus actividades físicas, convirtiéndose en un grupo con necesidades educativas especiales.

Ruiz y García (2003, p. 269) plantean que la actividad físico-deportiva es una actividad cargada de ciertos riesgos y de determinados peligros que pudieran generar situaciones para nada deseables. En parecidos términos se expresan Espartero (1997, p. 685) y Latorre y Herrador (2003). 
Castro (2005) apunta que el hecho de hacer ejercicio físico ya supone un riesgo inherente como consecuencia del movimiento que este implica.

Por su parte, Albornoz (2001 y 2002), a pesar de que recoge textualmente la opinión de algunos Jueces Civiles o Penales que consideran la Educación Física como una actividad riesgosa por las circunstancias de su realización (parecer recogido también en Angriman, 2002 y 2003; Fuente [12] y Fuente [49]), deja muy claro que la ley obliga a los docentes, como no podía ser de otra manera, a tomar durante el desarrollo de sus clases todas las medidas oportunas para su correcto desarrollo y que no se produzcan lesiones a los alumnos, es decir, que nuestra actuación no pueda ser nunca catalogada como negligente.

A este respecto, hemos de aclarar que la negligencia se puede definir como la incompetencia para hacer algo que una persona cuidadosa habría hecho en las mismas circunstancias, o, por el contrario, hacer algo que una persona sensata no habría hecho en las mismas o parecidas circunstancias (Pfeiffer y Mangus, 2000, p. 40). Implica tanto un acto de comisión (actuar de forma inadecuada) como de omisión (inexistencia de la actuación).

Albornoz (2001) realiza un llamamiento a la responsabilidad y el cuidado en las prácticas de los docentes de educación física, y con él, aunque su propósito no sea el de incrementar temores hacia nuestra materia, por la cantidad de ejemplos que ofrece de accidentes producidos en clases de Educación Física, así como por el gran número de medidas preventivas que se deben adoptar para evitar accidentes en las mismas, crea en el lector una sensación de angustia o temor y de elevada responsabilidad por lo que le pudiera suceder derivado de sus acciones u omisiones hacia los alumnos.

Sobre este último asunto destacamos que suele darse una curiosa característica común en algunos de los autores que escriben sobre la responsabilidad del profesorado en general, y en particular de los de Educación Física, consistente en que manifiestan que sus escritos no tienen por objetivo desalentar a los docentes en su práctica diaria, ocasionando el origen de la limitación de su capacidad del trabajo (Sánchez, 2003; 
Notarnícola, 1997; Muñoz, 1999; Albornoz, 2001), lo cual da a entender que saben o intuyen que tras la revisión de sus documentos y trabajos se puede generar en los lectores -profesores de Educación Física- dicha posibilidad.

Landazuri (2002) establece una serie de parámetros que los profesores de Educación Física deberíamos de cumplir para que no seamos condenados en caso de producirse un accidente en nuestras clases.

Morales (2010, p. 98) detalla un nutrido número de situaciones de riesgo en nuestras clases de Educación Física. Es más, en lo que respecta a la temática de esta tesis, señala que uno de los aspectos que debe tenerse en cuenta para prevenir accidentes y lesiones es el de las limitaciones de cualquier tipo que pueda presentar el alumnado, lo cual está relacionado con las prescripciones médicas, la problemática de los justificantes médicos y las adaptaciones de la práctica (ibídem, p. 96).

Álvarez (1986) elabora una escueta lista de causas por las que comúnmente se producen las lesiones en nuestras clases, entre las cuales se encuentran las propias del trabajo con alumnos y las inherentes al mismo ejercicio físico.

Es más, el supuesto riesgo implícito que tienen los ejercicios propios de nuestra disciplina fue el argumento de la defensa empleado por una profesora de Educación Física para eximirse de culpa o responsabilidad en un accidente producido durante una de sus clases (Perona et alia, 1998, p. 49; Muñoz, 1999, p. 113). De hecho, en una sentencia de la Audiencia Nacional (Sala de lo Contencioso) de 19 de Julio de 2000, se afirma que la práctica de una actividad deportiva (planteada durante una clase de Educación Física) en sí conlleva riesgos, y estos riesgos son inherentes a la propia actividad... es inevitable que se produzcan (Perona, 2005, pp. 153-154).

También nos encontramos con el añadido de que hay ciertos contenidos curriculares y ejercicios y/o actividades singulares que suelen ser el origen, en mayores proporciones que otros, de desafortunados accidentes y lesiones durante nuestras clases: el uso del minitramp, cama elástica o trampolín elástico (Fuente [12]; Managua, 2000; 
Morante, 2000; Saro, 2005; Blanco, 2003; Fuente [54 $]^{214}$; Fuente [67] ${ }^{215}$ ); el salto del potro (Perona et alia, 1998; Ruiz y García, 2003); la utilización del plinto (Perona et alia, 1998; Muñoz, 1999; Ruiz y García, 2003; Perona, 2005); acrosport (Ruiz y García, 2003); hockey (Muñoz, 1999; Ruiz y García, 2003; Perona, 2005); ejercicios gimnásticos (Albornoz, 2001 y 2002); rugby (Albornoz, 2001 y 2002; Perona, 2005); actividades en la naturaleza (Castro, 2005) y, en general, todas actividades deportivas (Perona, 2005).

Ni que decir tiene que el mismo uso de determinados materiales convencionales y no convencionales también puede ser un factor de riesgo en nuestras clases (Muñoz, 1999, p. 117; Ruiz y García, 2003; Albornoz, 2002; Fuente [55] ${ }^{216}$ ).

Y si los contenidos y los materiales pueden ser motivos de accidentes, ¿qué podemos decir de las instalaciones en las que solemos desarrollar nuestra práctica diaria?

En un artículo de Hernández $\left(2005^{217}\right)$ sale a la luz un estudio que realizaron Latorre y Herrador ${ }^{218}$ cuyo título era: “Centro escolar: ergosistema saludable. Riesgos en relación con los recursos materiales y didácticos, espacios y equipamiento deportivo en educación física”. Su propósito era el de averiguar el incumplimiento de la normativa en materia de seguridad en el uso de los equipamientos y espacios en las clases de Educación Física. Estos autores constatan que, además de una "dejadez" de la seguridad en las clases de Educación Física, hay una falta de reconocimiento de la misma como materia fundamental para la promoción de la salud y de la educación integral de los sujetos.

\footnotetext{
${ }^{214}$ http://www.elmundo.es/elmundo/2003/11/27/sociedad/1069936782.html

${ }^{215}$ http://www.asociacionabogadosrcs.orgportaljurisrevista8N8-AP-VI.html

${ }^{216}$ http://www.elmundo.es/elmundo/2001/10/30/sociedad/1004429410.html

${ }^{217}$ Fuente [61-7]

${ }^{218}$ Sobre este asunto también recomendamos la lectura de Herrador y Latorre (2004)
} 
Su estudio incluye una encuesta realizada a 400 alumnos universitarios sobre su experiencia como escolares. Entre los resultados destacan los siguientes: La mayoría de las lesiones se deben a accidentes fortuitos. También se aprecia una implicación negligente del profesorado; el nivel de desperfecto de los espacios y equipamientos era otro factor de riesgo; finalmente, la osadía e imprudencia del alumnado también contribuye a la aparición de lesiones.

En otro artículo rubricado por Núñez y otras 42 firmas $\left(2001^{219}\right)$, al respecto de una sentencia del Tribunal Supremo que condena al director de un colegio público y al MEC a indemnizar de forma solidaria a la familia de un alumno fallecido en un accidente ocurrido en el recreo, exponen que cada día lectivo el profesorado corre el riesgo de ser acusado y condenado por las consecuencias derivadas del normal funcionamiento de sus labores de enseñar y educar. Puesto que en la sentencia se argumenta que el daño "no forma parte del servicio público de enseñanza", los firmantes proponen, para evitar los posibles daños que pudieran aparecer en este servicio, eludir actividades como el uso de las pistas deportivas y gimnasios (entendemos que durante el horario escolar, lo cual afecta directamente a las clases de Educación Física).

El profesor Ruiz Morales (2005), en su ponencia Responsabilidad Civil del Profesor de Educación Física. Principio Genérico de las Leyes (a la que hemos aludido en el Capítulo "LA EXENCIÓN VISTA A TRAVÉS DE LA FORMACIÓN PERMANENTE"), advertía que el profesor de Educación Física es un generador de riesgos, estando más obligado que cualquier otro docente a cuidar por la salud e integridad de sus alumnos. De hecho, la responsabilidad que asumimos se incrementa por cuanto que nuestra profesión, avalada por un título universitario, nos sitúa en una posición de garante de la seguridad de nuestros alumnos.

Al respecto, Albornoz (2002) advierte que el deber de prevención del docente de Educación Física está aumentado por el título profesional por el cual ejerce su trabajo. Es decir, se espera de nosotros que seamos diligentes y previsores en nuestro quehacer

${ }^{219}$ Fuente [61-3] 
específico $^{220}$. Así lo confirma de nuevo la Fuente [82] cuando manifiesta que existe un especial deber de cuidado en la clase de Educación Física.

Examinando los dictámenes emitidos por el propio Consejo Consultivo de Castilla y León, nos hemos encontrado con una especie de nota alusiva al ya comentado Dictamen 58/2003, de 22 de enero de 2004, referida a reclamaciones de responsabilidad patrimonial en el ámbito escolar dentro de la clase de Educación Física. Por su relevancia, pasamos a detallar lo más significativo de su contenido.

En su inicio destaca la depuración de responsabilidad que presenta, ya que establece que el hecho de que la responsabilidad patrimonial de la Administración sea objetiva no implica, tal y como ha entendido reiteradamente el Consejo de Estado, que la misma deba responder necesariamente de todos los daños que puedan sufrir los alumnos en centros públicos.

En segundo término, recoge parte de la sentencia del Tribunal Supremo de 5 de junio de 1998, en la que se dicta que la Administración no se puede convertir en la aseguradora universal de todos los riesgos con el fin de prevenir cualquier eventualidad desfavorable o dañosa para los administrados que pueda producirse con independencia del actuar administrativo, porque de lo contrario se transformaría aquél en un sistema providencialista no contemplado en nuestro ordenamiento jurídico.

Es más, para que la Administración sea responsable de resultados lesivos, se hace necesario que esos daños sean consecuencia directa $e$ inmediata del funcionamiento normal o anormal de aquella, como recoge otra sentencia del citado tribunal, de 13 de noviembre de 1997. Por ello, la responsabilidad de la Administración procederá en aquellos casos en los que los daños sean consecuencia del funcionamiento de los servicios públicos, no bastando a estos efectos que los daños aparezcan con motivo u ocasión de la prestación de dichos servicios públicos.

${ }^{220}$ Obsérvese que en los mismos términos se expresa Ruiz Morales (2005) en el Capítulo 9. 
En lo que respecta a la Educación Física, la cual es entendida como un conjunto de ejercicios individuales o colectivos relacionados con el desarrollo corporal y motor de los alumnos, en su sentido más amplio, bajo la dirección, programación y supervisión del profesor encargado de dicha tarea educativa, se aclara que la eventual conexión causal debe ser especialmente analizada.

Esto supone que a efectos de la imputación de responsabilidad, a pesar de que la relación entre el ejercicio físico y el riesgo de que se produzca el daño nos lleva a admitir un principio de presunción favorable a la conexión fáctica entre tal daño y la prestación del servicio educativo (Educación Física), no debe ser causa suficiente o exclusiva de imputación pues ello llevaría a confundir el juicio de ocasionalidad (daño sobrevenido a causa o como consecuencia del desarrollo de tal actividad), que es el requisito exigible para la atribución de responsabilidad.

Es por ello que se hace necesario llevar a cabo un examen más cuidadoso de las circunstancias que pueden implicar casualidad, entre las que se pueden encontrar la adecuación de los ejercicios ordenados con la edad de los alumnos; con las características de las instalaciones en que se desarrollan; con la capacidad objetiva de los participantes; con la naturaleza de los instrumentos, elementos o aparatos utilizados en su ejecución; y con el grado de dificultad que implican), pues es de esas circunstancias, convenientemente valoradas, y no simplemente del hecho de realizar la actividad física, de donde puede derivar un riesgo específico que sirva de título para imputar el daño causado al funcionamiento del servicio público. En definitiva, de la valoración adecuada de las circunstancias en que la Educación Física se desarrolla, pueda deducirse una situación de riesgo específico o cualificado, susceptible de configurar una relación de causalidad con relevancia jurídica suficiente para producir una imputación.

Por último, de nota aclaratoria del dictamen del Consejo Consultivo de Castilla y León se desprende que, por las particulares características, la Educación Física y su desarrollo puede entrañar un riesgo para los alumnos. 
Al efectuar la revisión de algunos de los dictámenes emitidos por los correspondientes órganos consultivos -jurídicos- que tienen instaurados otras comunidades autónomas, caemos en la cuenta de la cantidad de "pequeños" accidentes que ocurren en nuestras clases. Los que siguen son solo algunos ejemplos.

“...La reclamación está motivada como consecuencia de los daños sufridos en una rodilla sufrido mientras realizaba una clase de gimnasia..."

(DICTAMEN 54/00, de 30 de octubre. Consejo Consultivo de La Rioja, Fuente [64])

"Expediente relativo a reclamación de responsabilidad patrimonial de la administración Pública tramitado a instancia de..., por los daños sufridos por su hija... como consecuencia de un accidente escolar acaecido en el C.P. «La Candelaria» de Manzanares (Ciudad Real), el pasado día 4 de febrero de 2000, durante el desarrollo de una clase de Educación Física." (DICTAMEN 60/2000, de 12 de septiembre. Consejo Consultivo de la Junta de Comunidades de Castilla La Mancha, Fuente [65]) 
"Expediente relativo a reclamación de responsabilidad patrimonial de la administración Pública tramitado a instancia de..., a consecuencia las lesiones sufridas por su hijo... en el Colegio Público «Cervantes», de Puertollano (Ciudad Real)

$[\ldots]$

Según relata en su escrito, el 7 de febrero de 2000 el hijo del reclamante se encontraba en la clase de gimnasia..."

(DICTAMEN 104/2001, de 2 de octubre. Consejo Consultivo de la Junta de Comunidades de Castilla-La Mancha, Fuente [66])

"Expediente relativo a reclamación de responsabilidad patrimonial de la Administración Pública tramitado a instancia de..., por los daños sufridos por su hija... como consecuencia de un accidente escolar acaecido en el C.P. «San Isidoro» de Alberche del Caudillo (Toledo), el pasado día 17 de enero de 2000, durante el desarrollo de una clase de Educación Física." (DICTAMEN 61/2000, de 12 de septiembre. Consejo Consultivo de la Junta de Comunidades de Castilla La Mancha, Fuente [68]) 
“Correspondiente a la consulta formulada por el Excmo. Sr. Consejero de Educación..., en relación con el expediente de responsabilidad patrimonial 21/99 instruido por accidente sufrido por el menor I.G.G. en el centro escolar «Las Gaunas» de Logroño durante el desarrollo de la clase de educación física." DICTAMEN 42/00, de 3 de octubre. Consejo Consultivo de La Rioja, Fuente [69])

Volviendo a nuestra Comunidad, el Consejo Consultivo de Castilla y León ha despachado desde el inicio de su actividad en el 2003 hasta el 2009 unas 500 consultas preceptivas de reclamación de responsabilidad patrimonial por accidentes en el contexto escolar $^{221}$ (Fuente [82]). En la mayoría de estos casos se trata de pequeños accidentes, golpes involuntarios o caídas en la clase de gimnasia.

Más preocupante resulta que, aunque el propio colectivo profesional de la Educación Física considere que los docentes llevan a cabo su labor diaria de forma adecuada, algún Juez pueda llegar a calificar sus actuaciones, por muy comunes y habituales que sean, de negligentes e inapropiadas (Fuente [12]).

De hecho, Blanco (2003, p. 309), en sus conclusiones al comentario de una sentencia del Tribunal Supremo ${ }^{222}$, afirma que dicha sentencia no es fruto de un análisis y probaturas de un supuesto de hecho, sino de una reflexión imaginaria seguramente como consecuencia de las huellas de carácter negativo que en el subconsciente le ha dejado su experiencia personal en las clases de "gimnasia” recibidas en su periodo escolar. Tanto es así, que en la propia sentencia se señala que "la apreciación culposa se fundamenta en una estimación subjetiva pura”.

\footnotetext{
${ }^{221}$ Si se desea conocer las consultas efectuadas por este organismo hasta el 2014, remitimos al lector a la dirección Web: http://www.cccyl.es/es/dictamenes/consultas-facultativas

${ }^{222}$ Sentencia de 22 de diciembre de 1999.
} 
La jurisprudencia existente en las que la Educación Física hace acto de presencia también es cuantiosa y bastante ejemplificadora de lo que sucede en los juzgados respecto de nuestra responsabilidad durante nuestro desempeño profesional (Perona et alia, 1998, pp. 39, 48 y 51; Muñoz, 1999, pp. 90, 113, 117 y 143; Perona 2005, pp. 98, $123,129$ y 154$)$

Con el propósito de documentar esta situación de peligrosidad y riesgo en nuestras clases, hemos examinado las hemerotecas online de algunos periódicos para comprobar si había noticias alusivas al asunto de los accidentes durante el periodo lectivo de Educación Física ${ }^{223}$. La sorpresa ha sido mayúscula pues hay un gran número de noticias de accidentes en nuestras clases, muchas de ellas con nefastas consecuencias. Veamos algunos de ejemplos.

\section{Muerte en la escuela}

Supongo que ahora correrán ríos de tinta lamentando e incluso denunciando la muerte tremenda, por innecesaria, de un alumno de 12 años durante la clase de Educación Física...

(Fuente [61-4], 17-11-2003)

\footnotetext{
${ }^{223}$ Aunque alguna de estas noticias se enmarca dentro de la etapa de Primaria, consideramos acertada su exposición pues el propósito de este apartado es únicamente constatar la existencia de accidentes durante las clases de Educación Física.
} 


\section{ESTABA EN CLASE DE EDUCACIÓN FÍSICA}

\section{Muere en una escuela de La Rioja un niño aplastado por una portería}

Un niño de 11 años, alumno de quinto de primaria y vecino de San Asensio (La Rioja), falleció en el centro público donde estudiaba al caerle una portería en la cabeza cuando asistía a clase de educación física...

El niño se colgó de una portería de fútbol, que se volcó y lo arrastró, recibiendo un fuerte golpe en la cabeza que le provocó la muerte de forma instantánea. Tanto el profesor de educación física como el personal médico... nada pudieron hacer por salvarlo.

(Fuente [55], 30-10-2001)

$$
\operatorname{Nota}^{224}
$$

\section{SE DESPLOMÓ EN EL PATIO}

\section{Muere en Málaga un niño de 12 años en una clase de gimnasia}

Un niño de 12 años murió en el colegio público Pablo Neruda, de la localidad malagueña de Cártama, cuando recibía clases de Educación Física en el patio del centro...

Los hechos ocurrieron en este centro educativo... sobre las 11.00 horas del jueves cuando el niño, que cursaba sexto de Educación Primaria, se encontraba en el patio del colegio con sus compañeros y se desplomó repentinamente (sic).

(Fuente [57], 31-10-2003)

${ }^{224}$ Muñoz (1999, p. 117) recoge el caso similar de un niño de once años que muere al caer sobre su
cabeza una portería de balonmano durante la clase de Educación Física (Palma de Mallorca, 18-03-1993). 


\section{SE DESPLOMÓ Y FALLECIÓ EN EL ACTO}

Fallece una niña de 10 años durante la clase de gimnasia en un colegio de Palma de Mallorca

Una niña de 10 años, Andrea C., falleció en la mañana del viernes de muerte repentina durante una clase de gimnasia en el colegio Sagrado Corazón de Palma...

El suceso ocurrió a las 10.30 horas del viernes al comienzo de la clase, cuando la niña estaba realizando una carrera, se desplomó al suelo de forma súbita y falleció en el acto...

El profesor de gimnasia hizo todo lo posible para reanimarla, pero los intentos fueron en vano...

(Fuente [59], 10-01-2004)

\section{Muere un adolescente mientras hacía gimnasia en el instituto}

Un joven de 16 años de Ayamonte (Huelva), identificado como A.M.R., falleció cuando asistía a una clase de Educación Física en el instituto González de Aguilar del municipio onubense...

El suceso se produjo a las 9.40 horas, cuando el joven se desvaneció sobre la pista deportiva, y falleció, al parecer, en el acto por una parada cardiorrespitaroria.

(Fuente [56], 25-02-2002. También disponible en Fuente [62-1]) 


\section{ESTABA EN CLASE DE GIMNASIA}

Condenado un colegio de Jaén a pagar 600.000 euros a los padres de un niño que quedó tetrapléjico

La sección segunda de la Audiencia Provincial de Jaén ha condenado al colegio Sagrada Familia de Villanueva del Arzobispo a pagar 600.000 euros a los padres de un niño de 14 años que quedó tetrapléjico como consecuencia de una caída mientras se encontraba en clase de Educación Física.

[...]

En la sentencia se argumenta que no fue un accidente fortuito y que existió culpa por parte del profesor de Educación Física y del colegio, «que deberían haber extremado las medidas de seguridad tratándose de niños que estaban haciendo ejercicios de gimnasia con aparatos nuevos».

[...]

El ejercicio que estaba practicando consistía en saltar de unas camas elásticas a unas colchonetas, aunque, en la caída, el chaval se dobló el cuello y se produjo una sección en la columna cervical que le provocó un cuadro de tetraplejia.

[...]

Por este motivo, alegó [el abogado de la familia] que «no se extremaron las medidas de precaución» en el gimnasio y se apoyó para ello en la jurisprudencia del Tribunal Supremo, "que exige extremar las diligencias cuando exista cualquier riesgo para los niños». "No vale con la diligencia de un buen padre de familia, como dice el Código Civil, sino que hay que extremarla», aportilló.

(Fuente [54], 28-11-2003. También disponible en Fuente [61-5]. Aclaración mía) 
Fallece un niño de trece años tras desmayarse en una clase de educación física.

Un menor de 13 años, alumno del IES Maruxa Mallo del municipio coruñés de Ordes, ha fallecido mientras participaba en una clase de educación física, supuestamente por un fallo cardíaco.

Según ha explicado a Europa Press el alcalde del municipio, Manuel Regos, el suceso tuvo lugar sobre las 10.00 horas de este jueves, cuando el menor sufrió un desmayo mientras participaba en clase...

(Fuente [80], 07-02-2013)

\section{Un héroe en las aulas}

Se ha convertido en un héroe para sus alumnos pero él mantiene que simplemente hacía su trabajo. Antonio José Mena, profesor de educación física en el IES La Inmaculada de Algeciras, le salvó la vida a una de sus alumnas que sufrió una parada cardiorrespiratoria en el transcurso de una clase...

(Fuente [78], 26-04-2008)

Muere un alumno de un ataque de asma cuando hacía gimnasia en un instituto de Vidreres

Un alumno, de 15 años, del instituto de secundaria Salvador Espriu de Vidreres falleció ayer de un ataque de asma mientras realizaba una clase de gimnasia... El joven, que padecía asma y se medicaba con inhaladores, estaba corriendo por el campo de fútbol del instituto cuando sufrió un desmayo...

(Fuente [61-2], 24-02-2000) 


\section{Un niño de 13 años fallece durante una clase de gimnasia en Getafe}

Un alumno de 13 años del instituto de educación secundaria Ícaro, situado en el barrio de Perales del Río (Getafe), ha muerto después de sufrir un desvanecimiento cuando practicaba gimnasia en el centro...

El adolescente, que cursaba primero de la ESO, estaba en clase de gimnasia y, a los cuatro minutos de iniciar ejercicios de desplazamiento, empezó a tener convulsiones y sufrió un desvanecimiento...

[...]

Tras practicarle maniobras de reanimación, fue evacuado en helicóptero a un hospital de Madrid, donde ingresó cadáver... (Fuente [79], 01-04-2008)

\section{Fallece un estudiante de 16 años en Salamanca en clase de Educación Física}

El joven hacía gimnasia en un instituto de la localidad de Babilafuente cuando sufrió un paro cardíaco

Un joven de 16 años... perdió ayer la vida como consecuencia de un paro cardíaco repentino que sufrió mientras asistía a clases de Educación Física...

...los compañeros del joven señalaron tras lo ocurrido que D. A. comentó durante la clase de gimnasia que comenzaba a sentirse mal y acto seguido cayó desplomado contra el suelo...

(Fuente [81-1], 30-05-2008)

Incluso, en alguna ocasión, no hace falta que el accidente se produzca durante el horario de la clase de Educación Física para que salgamos en los periódicos. Así por ejemplo, en el artículo siguiente se destaca poderosamente en negrita que el suceso ocurrió antes del inicio de la misma. No sabemos si lo hubieran escrito y presentado de esta forma si la clase anterior hubiese sido de cualquier otra área del currículo de Secundaria. 


\section{EL ACCIDENTE FUE ANTES DE LA CLASE DE GIMNASIA}

Muere un niño de 12 años tras una caída en el recinto de gimnasia de un instituto de Sevilla

Un niño de 12 años falleció como consecuencia de las heridas que se produjo tras sufrir una caída justo antes del comienzo de una clase de Educación Física (sic) en el instituto de enseñanza secundaria Mariana Pineda...

Al parecer, el menor, que estaba a punto de cumplir 13 años, intentó efectuar un salto para caer sobre una colchoneta minutos antes del comienzo de su clase de Educación Física...

(Fuente [58], 04-11-2002)

Lo curioso es que otro periódico narra este suceso como si hubiese sucedido durante la propia clase de Educación Física.

\section{Un estudiante de Sevilla muere tras caerse durante la clase de gimnasia}

Un niño de 12 años falleció ayer como consecuencia de las heridas que se produjo tras sufrir una caída durante una clase de Educación Física...

Al parecer, el menor...sufrió una caída mientras hacía ejercicios de saltos en la clase de Educación Física...

(Fuente [61-1], 05-11-2002)

Alguna vez el suceso ocurre al término de la clase de Educación Física, pero la prensa continúa resaltando este hecho de manera especialmente singular, incluso de manera reiterada. Veamos un ejemplo: 
Fallece un alumno de 15 años del instituto Los Sauces después de la clase de gimnasia

...Este alumno... falleció ayer por la mañana después de sentirse indispuesto al terminar la clase de Educación Física.

[...]

(Fuente [81-2], 21-10-2008)

\section{Una multitud despide al alumno que falleció tras la clase de gimnasia}

...el alumno de 15 años... que falleció el pasado lunes después de sentirse indispuesto en la clase de Educación Física.

[...]

(Fuente [81-3], 22-10-2008)

Llegado a este punto, cabe preguntarse cómo se encuentra verdaderamente el profesorado de Educación Física ante toda esta situación.

Blanco (2003, p. 310) opina que el profesor de Educación Física sufre una especial inseguridad jurídica derivada de la carencia de criterios rigurosos a la hora de valorar los accidentes que se producen durante nuestras clases. Considera que es imprescindible que estemos amparados por la Administración con un adecuado asesoramiento jurídico y por medio de seguros de responsabilidad civil. Monroy y Sáez $\left(2008^{225}\right)$ insisten en esta idea de la inseguridad jurídica lamentable que tiene que soportar nuestro colectivo ya que la legislación, la doctrina y la jurisprudencia no siguen una línea pacífica al respecto.

\footnotetext{
${ }^{225}$ http://www.uco.es/IVCongresoInternacionalEducacionFisica/congreso/Documentos/001-164-509-009001.html
} 
Espartero (1997, p. 697) insiste en que sobre los docentes de la Educación Física recae diariamente una gran responsabilidad que hace necesario que se tomen medidas para suavizarla, como por ejemplo los reconocimientos médicos completos y obligatorios, mejorar la formación del profesorado y emplear el material adecuado.

Como era de esperar, el propio colectivo docente también opina sobre su responsabilidad, de los riesgos que asume, y del desamparo administrativo y jurídico al que está sometido.

Núñez y otras 42 firmas más $\left(2001^{226}\right.$ ) solicitan que se lleve a efecto una reflexión sobre las consecuencias colaterales de la labor docente, ya que entienden que si enseñar puede llevarles a una acusación y a una condena, es conveniente poner en marcha una práctica docente más segura, pero que no será ni práctica ni docente, en la que el mayor perjudicado será el alumnado.

Por todo lo expuesto hasta ahora, podemos asegurar que existe una evidente posibilidad de que se produzcan accidentes y/o lesiones durante el desarrollo "normal" de nuestras clases de Educación Física, lo cual, como afirma González (1995), sitúa al docente de Educación Física como el que mayor riesgo profesional sufre en su trabajo, no solo por las lesiones o accidentes que se pueden producir en sus clases, sino también por las anomalías orgánicas que pudieran presentar los alumnos.

En definitiva, el profesor de Educación Física asume un riesgo y una responsabilidad considerable en sus clases ya que está expuesto a una actividad profesional de una naturaleza de cierta peligrosidad, realizada en unas instalaciones y con unos materiales que también pueden conllevar peligro en su uso, y en la que toman parte unas personas con unas características cronológicas y psico-biológicas muy especiales. Si a todo este "cóctel" se le añade la interpretación legislativa que realizan los jueces a la hora de dictar sentencias al respecto de nuestra responsabilidad por las lesiones y accidentes que puedan sufrir los alumnos bajo nuestra tutela, el panorama es desalentador, coercitivo e inquietante.

${ }^{226}$ Fuente [61-3] 


\section{3.- UNA CUESTIÓN QUE DESPIERTA MI INTERÉS PERSONAL}

Durante dos décadas de experiencia profesional en el ámbito de la Educación Física he vivido y padecido, en más ocasiones de las que hubiera querido, las lesiones que alguno de los alumnos sufrió durante "el normal desarrollo" de mis clases o la de mis compañeros de departamento.

Además de los típicos esguinces, torceduras y subluxaciones, golpes y hematomas, epíxtasis, caídas inesperadas (o esperadas), también he vivido casos más impactantes como roturas de brazos, traumatismos craneales, cortes de diversa magnitud y origen, etc.

Cuando se dan estas situaciones traumáticas y sumamente estresantes, en las que un alumno está sufriendo como consecuencia de los daños derivados de un accidente sucedido en tu clase, bajo tu tutela y control, la losa de la responsabilidad y las posibles consecuencias que pudieran devenir, pesan de una manera casi asfixiante.

Rápidamente se ponen en marcha los medios para mejorar, en términos de no agravar, el estado del alumno. La aplicación de los primeros auxilios más elementales y adecuados a cada situación, así como el cumplimiento de las normas básicas de actuación en accidentes, es la opción inmediatamente elegida.

Después viene todo el proceso de aviso a los servicios sanitarios de emergencias (cuando el caso es considerado de gravedad), evacuación del accidentado al centro de salud (si es una opción viable), comunicación a las familias de lo sucedido con especial tacto para no alarmar (posteriormente, cuando estemos ante ellos, les daremos todo tipo de detalles), aviso al equipo directivo para reorganizar el cuadro de guardias del centro $\mathrm{y}$, entre medias, tener controlado y "tranquilo" al resto del grupo de alumnos que han sido testigos directos del accidente y de su posterior desarrollo y actuaciones. 
Mi interés por estar preparado para atender estos casos (aunque nunca se está lo suficiente) me llevó a realizar cursos en los que formarme, o reciclarme, en la aplicación de los primeros auxilios, normas de evacuación y traslado de heridos y protocolos sanitarios en centros públicos.

Pero además, como consecuencia de alguna situación "inquisitoria" a la que me he visto sometido con posterioridad a algún accidente, ya sea por el equipo directivo de turno o por algún padre/madre que no acababa de encajar los sucedido, me llevó a interesarme por el alcance de la responsabilidad asumida en mi trabajo.

Comienza así la búsqueda y realización de otro tipo de cursos y actividades formativas en los que se tratase el tema de la responsabilidad. En el Capítulo de "LA EXENCIÓN VISTA A TRAVÉS DE LA FORMACIÓN PERMANENTE”’ se han descrito algunos de los aprendizajes y experiencias vividas en cada una de estas actividades de formación.

Pues bien, de mis experiencias en primera persona como profesor de Educación Física, de las que he podido vivir junto a un elevado número de compañeros de departamento y de la realización de cursos de la temática expuesta, extraigo una serie de conclusiones:

- Es conveniente realizar cursos de reciclaje (y formación inicial si es que antes no se han hecho) en aplicación de primeros auxilios e intervención ante accidentes escolares. Siempre se dice que una cosa es la teoría y otra la dura realidad; que uno no sabe cómo va a reaccionar cuando llegue el momento de actuar, pero el domino de los conocimientos teóricos es clave para reconducir situaciones como las descritas y concluir todo el episodio de la manera más satisfactoria para todos.

- Es importante, y muy conveniente, dejar constancia de todo lo ocurrido por escrito. Lugares, materiales, hora, contenido trabajado (se expresará que está recogido en la programación didáctica), personas que se han visto involucradas en el infortunio, testigos directos del pasaje, profesores que han 
visto o participado posteriormente, decisiones y actuaciones tomadas en orden cronológico, comunicaciones con el equipo directivo, llamadas realizadas, traslado del alumno... El relato del suceso debe ser prolijo en detalles y todo debe estar escrito con un estilo claro. Si el Jefe del Departamento de Educación Física y Deportiva hubiera sido testigo del suceso, también es conveniente que refleje, en los términos anteriores, todo lo ocurrido en el acta del departamento. No obstante, el escrito que redacta el profesor deberá registrarse en la Secretaría del centro y formar parte de las actas departamentales.

- Siempre debemos actuar con la diligencia y buen hacer de un padre de familia $^{227}$. Es una expresión jurídica hecha pero, como padre de familia que soy, comparto la idea que creo entender subyace a dicho enunciado: la actuación cautelosa y tranquila ante lo que sucede, el sentido común en las intervenciones posteriores, el trato cercano al alumno, el uso de un lenguaje cariñoso y consolador, la no dilatación de las esperas más de lo estrictamente necesario, la empatía y apoyo a las familias..., harán que nuestra intervención se acerque lo más posible a la ideal, por lo menos en lo que respecta a la recuperación de la normalidad y en las mejores condiciones.

- Hay que aprender de las causas desencadenantes de los accidentes y, en la media de lo posible, no volver a caer o encontrarnos con ellas. Esto supondrá un acto de reflexión serena tras lo sucedido. Si es viable, en compañía de otros compañeros que nos ofrecerán un punto de vista menos sesgado por no haber sido ellos sufridores del suceso. De este proceso surgirán nuevas ideas para posibles actuaciones futuras, motivos por los que sucedió el accidente, la forma de evitarlo, etc.

- De este anterior proceso de reflexión es casi seguro que emerja la idea de eliminar determinadas prácticas, contenidos y actividades que son totalmente innecesarias, prescindibles y, sobre todo, sustituibles por otras más seguras y que igualmente contribuyen al logro de los objetivos programados y que cumplen con lo establecido desde el currículo oficial. Pesará más el no

${ }^{227}$ Los Tribunales suelen exigir a los funcionarios una acción diligente en el ejercicio de sus funciones (Arrabal, 1995, p. 19). El nivel de diligencia que se nos exige es el de un buen padre de familia, término indeterminado que sirve como criterio legal a la hora de valorar la culpabilidad o no en nuestras actuaciones. Como ya vimos anteriormente, se recoge en el artículo 1903 del Código Civil español. 
volver a pasar por determinadas situaciones que el enseñar aquello que dominamos y nos gusta transmitir a nuestros alumnos (en el mejor de los casos). Seguro que muchos de nosotros conocemos casos de compañeros, o propios, que han suprimido de sus contenidos habituales de trabajo algunos que consideran peligrosos y, como decíamos antes, los han sustituido por otros con parecido o idéntico propósito ${ }^{228}$. En mi caso, compartí varios años de trabajo con un profesor que había decidido no enseñar las habilidades gimnásticas (volteos, saltos, equilibrios...) por una mala experiencia en una de sus clases ${ }^{229}$. El contenido era sustituido por una unidad didáctica en la que se trabajaban las habilidades y destrezas básicas a través de juegos y deportes modificados que desarrollaban de forma análoga el propósito inicial que pudiera haberse planteado con las habilidades gimnásticas. Revisando mi trayectoria profesional desde mis inicios hasta ahora, me doy cuenta de que las habilidades gimnásticas, con planteamientos pedagógicos centrados más en la ejecución y dominio técnico, han ido dejando paso a un trabajo más abierto y creativo, sin imposiciones ni mínimos estrictos de lo que hay que dominar o ejecutar y realizado en pequeños grupos en los que cada uno trabaja acorde a sus posibilidades y destrezas adquiridas (puede que por su paso en la etapa de Primaria o de forma natural).

- Considero que se forja en el profesor de Educación Física un mecanismo generador de miedos ante el planteamiento de hipotéticas prácticas que pueden desencadenar en situaciones lesivas. Es decir, una vez que ha sucedido un accidente o mala experiencia con un determinado ejercicio, contenido o situación, se puede tomar la decisión de no volver a pasar por ella o, generalizando ese temor, por otras parecidas. Es mejor que no hagan esto, quién me mandaría a mí trabajar esto, para qué complicarme si puedo trabajar otras cosas, que ni lo intenten no vaya a ser que... son expresiones

\footnotetext{
${ }^{228}$ Recuérdese la idea que aparece en las páginas 432 y 433 sobre que ciertos contenidos curriculares, ejercicios y/o actividades suelen ser la causa, en mayores proporciones que otros, de accidentes y lesiones durante nuestras clases.

${ }^{229}$ Morales (2010, p. 98) afirma que el trabajo de las habilidades gimnásticas y acrobacias es el que implica mayor grado de atención respecto de las situaciones de riesgos que se dan en nuestras clases.
} 
que comienzan a circular por nuestras cabezas y que asientan la idea de modificar nuestros planteamientos y forma de trabajar por otras más seguras.

- Me pregunto qué sucede cuando el accidente, golpe, empujón, choque fortuito, ejercicio mal ejecutado o con resultado final lesivo... se produce en un alumno al que, habiendo acudido con documento firmado (médico o familiar, más o menos oficial, más o menos restrictivo en sus exposiciones) hemos intentado incluir en el desarrollo de todas y cada una de nuestras clases. Probablemente hayamos modificado múltiples parámetros y variables para incluir a ese alumno, pero no todo puede estar controlado ya que cada momento o situación son impredecibles. Esto enlaza con la idea de la anterior conclusión: el temor a las consecuencias derivadas de nuestras propuestas nos aconsejan limitar nuestras actuaciones y las de nuestros alumnos.

¿Y qué sucede con todo lo expuesto hasta ahora cuando lo aplicamos a los casos extremos de alumnos con dificultades de aprendizaje asociadas a cualquier tipo de discapacidad?

Ríos (2007, p. 87), cuando presenta los resultados de un grupo de discusión formado por profesores de Educación Física en los que se plantea la inclusión del alumnado con discapacidad y el pensamiento del profesorado, recoge que la asunción del riesgo, entendido en términos de provocar una lesión o por la responsabilidad civil derivada, es entendida por los miembros del grupo como algo consustancial al área. Además, se ha comprobado que el profesor de Educación Física tiene miedo cuando se enfrenta a una clase en la que se incluye algún alumno con discapacidad por la asunción del riesgo que conlleva, el cual se verá acrecentado o disminuido dependiendo de la tipología de la discapacidad que tuviese el alumno (ibídem).

Así pues, ¿intento incluir al alumno en todas las prácticas ${ }^{230}$ ? Creo que se puede pagar un precio por ello: yo asumo una responsabilidad mayor, el alumno está expuesto (sin saberlo siquiera) a un riesgo probable pero real de lesión (recuérdese que la Educación Física es cataloga por los jueces como

\footnotetext{
230 Retomando nuevamente a Tierra (2001, p. 146), reconoce, partiendo de la premisa que todos compartimos que los alumnos con necesidades educativas especiales deben estar integrados en nuestras clases, que no podrán hacerlo siempre ni en todas las situaciones.
} 
riesgosa) o, en ocasiones, el resto de compañeros pueden ver limitada su práctica como consecuencia de algunas de las adaptaciones realizadas.

\section{4.- PERCEPCIÓN DEL RIESGO Y LA RESPONSABILIDAD EN LAS AULAS}

Obviamente mi opinión está sumamente sesgada como consecuencia de mis propias experiencias, tanto por los episodios accidentales como por la pertenencia al Cuerpo de Profesores de Secundaria en la especialidad de Educación Física. Haber vivido acontecimientos como los narrados en el apartado anterior pueden hacerme creer que la realidad de las aulas en Educación Física es tan angustiosa, en términos de existencia de un auténtico riesgo y asunción de responsabilidad, como la he dibujado.

Por ello, hemos decidido realizar un comprobación, un sondeo, a través de un cuestionario, entre el profesorado, independientemente de su especialidad, para conocer cuál es su percepción y parecer acerca de su asunción de responsabilidad como docentes y la que perciben en el resto de sus compañeros de otras materias.

\subsection{1.- INTRODUCCIÓN}

Con objeto de no redundar en los aspectos metodológicos que supone la utilización de esta técnica de recogida de datos en la investigación educativa descriptiva, remitimos al lector al Capítulo 8 en el que reflejábamos todas las cuestiones procedimentales y teóricas al respecto del mismo. No obstante, nos gustaría remarcar algunos de los motivos que nuevamente nos han hecho decantarnos por su uso.

Como expliqué en el capítulo citado anteriormente, es un instrumento básico que permite conocer la opinión de unos sujetos al respecto de un tema concreto mediante la 
respuesta a una batería de preguntas sin la necesidad de que el investigador esté presente (Buendía, 1992, p. 207).

Además, creemos que algunas de las cuestiones que a priori se planteaban como inconvenientes en su utilización han sido resueltas de manera satisfactoria. Por ejemplo, la tasa de respuestas y la colaboración de los encuestados ha sido magnífica ya que los claustros de los centros en los que se ha pasado conocían al investigador, lo cual ha contribuido también a que el grado de honestidad sea mayor. No obstante, siendo totalmente imparciales, se podría argumentar lo contrario ya que pudiera ser que los encuestados hayan intentado producir la "respuesta correcta" o esperada. Esta variable es imposible de conocer y, por consiguiente, de subsanar.

\subsection{2.- RECONSTRUCCIÓN DEL PROCESO DE ELABORACIÓN DEL CUESTIONARIO 2}

\section{Objetivos}

En torno al tema genérico de la responsabilidad civil y los riesgos asumidos durante el desarrollo de las competencias propias de nuestra actividad profesional, con la utilización del cuestionario elaborado para la ocasión nos proponemos conseguir los siguientes objetivos (Tabla 20):

\begin{tabular}{|c|ll|}
\hline $\begin{array}{c}\text { OBJETIVO } \\
\text { PRINCIPAL }\end{array}$ & $\begin{array}{l}\text { Conocer la percepción que el profesorado tiene sobre la responsabilidad } \\
\text { y riesgos asumidos en la profesión. }\end{array}$ \\
\hline & $\circ \begin{array}{l}\text { Conocer qué materias percibe el profesorado como más "riesgosas". } \\
\text { OBJETIVOS }\end{array}$ & $\circ \begin{array}{l}\text { Comprobar la existencia o no de accidentes en los centros escolares. } \\
\text { SECUNDARIOS }\end{array}$ \\
& $\begin{array}{l}\text { Averiguar el grado de inquietud que despierta el asunto de la } \\
\text { responsabilidad entre los docentes. }\end{array}$ \\
\hline
\end{tabular}

Tabla 20: Objetivos del cuestionario 2 


\section{Tipo de preguntas}

El cuestionario consta de 15 ítems. Como ocurriera con el otro cuestionario utilizado en esta tesis, se ha procurado utilizar un lenguaje sencillo y claro. El cuestionario completo se encuentra recogido, tal y como se ofreció a los centros, en el Anexo 26.

De los catorce primeros ítems, 10 están redactados en forma de preguntas o afirmaciones de tipo cerrado (Padilla et alia, 1998; Buendía, 1992; McKernan, 1999), en los que la respuesta se reduce a SÍ (equivalente a verdadero) o NO (equivalente a falso). No obstante, en uno de ellos, al encuestado se le solicita además que responda mencionando las materias que considere oportunas en relación a lo preguntado.

Hay un ítem que está planteado en forma de escala de estimación numérica que va del 1 al 10, con la que se pretende registrar la intensidad del planteamiento realizado en la pregunta en cuestión (García y Morillas, 2012, p. 135).

Otros 2 ítems permiten una respuesta de tipo abierta ya que ofrecen la posibilidad de contestar con el nombre de algunas de las materias que se cursan en la E.S.O. o el Bachillerato, y el último ítem está abierto a cualquier tipo de observación o comentario que quieran añadir los encuestados.

\section{Organización y administración}

Una vez que tuvimos clara la población a la que dirigiríamos nuestra investigación, mantuve reuniones con los Jefes de Departamento de Educación Física y Deportiva de los centros seleccionados. La elección de los centros se hizo por afinidad profesional y personal con dichos Jefes de Departamento. De alguna forma sabía que esa circunstancia aseguraría el reparto y recogida de los cuestionarios como si yo mismo lo efectuase, lo cual garantizaba dos fases esenciales del proceso de investigación y serviría para reducir una hipotética baja tasa de respuestas remitidas. 
Los Jefes de Departamento colaboradores fueron los encargados de distribuir el cuestionario entre el Claustro de profesores de sus respectivos centros y realizar las oportunas aclaraciones sobre su objeto, realización y devolución. Sobre este último aspecto, mis colaboradores me transmitieron que preferían que la entrega del cuestionario no fuese en mano, es decir, no creyeron oportuno ser también ellos los que recogiesen, uno por uno, los documentos. Así pues se eligió un lugar "neutral" para efectuar la entrega: en las Consejerías de cada centro se dispuso una caja al efecto. Previamente contamos con el visto bueno de los Directores y la ayuda desinteresada de los Conserjes.

En la introducción del cuestionario se informaba de que formaba parte de una tesis. A pesar de que el cuestionario era totalmente anónimo, se ofrecía la posibilidad de que los participantes indicasen su dirección y/o teléfono de contacto con el propósito enviarles un informe con los resultados de la investigación.

Acordamos que desde el reparto hasta la recogida transcurriese un periodo no superior a un mes. Además, pasados quince días desde su entrega, los colaboradores tenían la misión de recordar el propósito del cuestionario y la relevancia de su entrega antes de que acabase el plazo.

\section{$\underline{\text { Pasos en la confección }}$}

El cuestionario de partida constaba de veinte preguntas, las cuales sufrieron varias revisiones hasta quedar tal y como consta en la investigación. Con el objetivo de no dar por válidas nuestras primeras impresiones (Goetz y LeCompte, 1988, p. 36) y con vistas a incrementar la credibilidad y validez de los resultados obtenidos (AnderEgg, 2000, p. 81), se utilizó nuevamente la triangulación de datos de personas, es decir, contamos con la colaboración de varios sujetos para confrontar y contrastar las opiniones de cada uno de ellos. Los sujetos que participaron en este proceso fueron mis tutores de tesis, mis dos compañeros del departamento de Educación Física y yo. 
Otra vez, con el pretexto de comprobar la validez y seguridad de nuestro cuestionario (Ander-Egg, op. cit., p. 121), hicimos una prueba piloto entre cuatro de los siete profesores de Educación Física en Educación Secundaria que participaron en la prueba del otro cuestionario de esta tesis. Las características de estos docentes eran similares a las que poseen los que posteriormente formarían parte de la muestra del estudio definitivo (titulación inicial / formación, gama variada de edades y experiencia, nivel educativo en el que dan clase, etc.), pero por el carácter concertado del centro en el que impartían clase, o por estar destinados en otras provincias, no podían pertenecer a ella. Esta prueba definitiva sirvió para terminar de "pulir" el cuestionario y dar por finalizado su proceso de elaboración.

\section{Tratamiento estadístico}

Como ya recogimos en el Capítulo 8, las tareas propias de la estadística descriptiva son la recogida de datos, su ordenación, su presentación clara y sinóptica (en forma, por ejemplo, de gráficas), así como la elaboración de ciertos cálculos (llamados estadísticos).

Hemos confeccionado una tabla para recoger y ordenar los datos (Anexo 27). En esta tabla hemos ido anotando las respuestas emitidas a cada uno de los ítems cerrados de que consta el cuestionario, así como la posibilidad de ir acopiando la información que han ofrecido en las preguntas de carácter más abierto o de elecciones múltiples.

Para la presentación de los resultados hemos optado nuevamente por las representaciones mediante diagramas de distribución de barras. Estas representaciones gráficas facilitan la lectura de los datos.

Nuevamente, en la interpretación de los datos haremos alusión al número total de individuos que han respondido a cada una de las preguntas del cuestionario o, lo que es lo mismo, la frecuencia absoluta (Fi). Además, expresaremos los resultados 
obtenidos en cada una de ellas en forma de porcentajes, previa división de la frecuencia absoluta entre el tamaño de la muestra utilizada (la frecuencia relativa ó fi).

\section{$\underline{\text { Muestra }}$}

Conviene volver a recordar que, aunque no hay un número concreto establecido sobre el tamaño más adecuado que debe tener una muestra, sí es conveniente que dicho número no sea menor de 30 casos (Cohen y Manion, op. cit., p. 140).

Como la entrega de los cuestionarios ha sido realizada de una manera "cercana" por profesores de cada uno de los centros elegidos, hemos asegurado una tasa de respuestas por encima del 50\% de los Claustros. Recordemos que Manheim y Rich (1988, p. 166) consideran aceptable un índice de respuestas del 50\%, y muy bueno un índice del $70 \%$.

La población a la que se le aplica el cuestionario son los ciento cinco profesores de Educación Secundaria y Bachillerato, entre profesores del Cuerpo de Enseñanza Secundaria y Maestros, que imparten clase en los dos Institutos de Enseñanza Secundaria elegidos entre todos los centros de carácter público que hay en Valladolid de estas características en los que se cursa la Educación Física como materia de la E.S.O. o el Bachillerato. Uno de ellos está en Valladolid capital y otro es de su provincia. Entre esos 105 profesores hay 5 compañeros de Educación Física.

Hemos elegido esta población tan reducida (representa un $5.55 \%$ sobre el total de centros de Valladolid y su provincia) porque con este estudio únicamente queremos indagar superficialmente en el parecer de los docentes sobre unas pocas cuestiones relacionadas con el asunto de su responsabilidad. Por tanto, los datos, aunque con valor por sí mismos, serán utilizados e interpretados en clave de ir corroborando o no cuestiones hasta ahora aparecidas en este capítulo. 
Por su parte, la muestra obtenida en esta investigación está conformada por los 70 profesores que han entregado el cuestionario debidamente cumplimentado, lo que equivale a un índice de respuesta del 66.66\% (Gráfica $\mathrm{n}^{\circ}$-74). Entre ellos se encuentran cuatro profesores de Educación Física que han entregado el cuestionario. Creemos que la muestra conseguida es, en general, representativa.

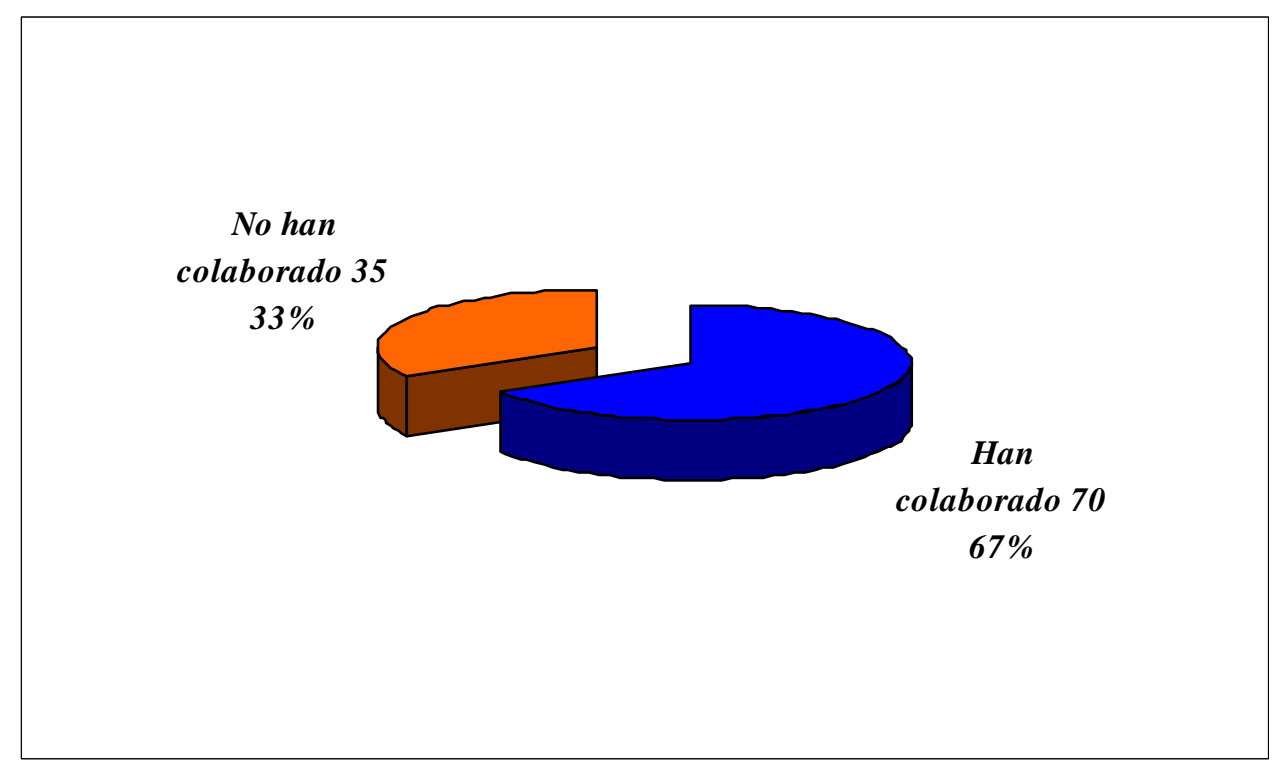

Gráfica 74: Participación del profesorado en la realización del cuestionario 2

De los 70 profesores que han contestado, 34 son mujeres $\left(48^{\prime} 57 \%\right)$ y 33 hombres $\left(47^{\prime} 14 \%\right)$ y 3 no contestan a lo petición de los datos personales (4’28\%). La media de la experiencia docente de todo el profesorado se sitúa por encima de los 19 años y está muy igualada entre hombres y mujeres (19’75 en los hombres y 18’35 en las mujeres).

En el caso de los profesores de Educación Física, hay 3 hombres y una mujer. La media de su experiencia laboral es de 13’25 años; bastante más baja que en el colectivo en general, lo cual nos hace pensar que los profesores de nuestra especialidad son algo más jóvenes que el resto.

No hemos considerado oportuno obtener más datos de tipo profesional como lo hicimos en el cuestionario diseñado en el Capítulo "APROXIMACIÓN A LA 
VISIÓN QUE TIENE EL PROFESORADO” ya que, de cara a la consecución de los objetivos propuestos, no son necesarios. Asimismo, tampoco estableceremos centros de interés ya que cada una de las preguntas será analizada de forma individual o agrupadas en torno a un mismo argumento.

Por último, hemos querido destacar y reflejar la opinión de los cuatro profesores de Educación Física de forma que se aprecie aún más el parecer de nuestro colectivo. Por ello, sus opiniones han sido resaltadas mediante este color en el formato de la escritura. No obstante, en la interpretación general de los datos su opinión formará parte de los mismos.

\subsection{3.- RESULTADOS E INTERPRETACIÓN}

Pregunta $1^{\mathrm{a}}$ : En alguna ocasión, durante el desarrollo de tus clases, ¿algún alumno/a ha sufrido un accidente o lesión?

Han sido 14 los profesores que afirman que algún alumno ha sufrido un accidente o lesión durante sus clases. Este número representa un $20 \%$ de la muestra. Por su parte, los cuatro profesores de Educación Física contestan afirmativamente a la pregunta.

Se podría decir que el profesorado de Educación Física, incluso con menor promedio de experiencia, ya ha pasado por una situación de este tipo en sus clases. Al parecer, la Educación Física puede ser tan riesgosa como en apartados anteriores ha quedado patente. 
Pregunta $2^{\mathrm{a}}$ : Estando de guardia, ¿has tenido que hacerte cargo de un grupo porque su profesor/a tuviera que ausentarse para trasladar a un alumno/a accidentado durante su clase?

El 54.28\% de los docentes ( $\mathrm{Fi}=38$ ), durante su horario de guardia, ha tenido que hacerse cargo de un grupo de alumnos para que el profesor correspondiente se ausentase para trasladar a un alumno/a accidentado.

Son tres los que sí han ejercido esa función. El que dice que no añade en la misma pregunta: "pero al contrario, sî̀. Este profesor parece querer insistir en la idea de haber vivido una situación así en su clase en algún momento.

Pregunta $3^{\mathrm{a}}:$ En caso afirmativo a la anterior, ¿sabrías decir en qué materias se produjo el accidente?

Las materias en las que se produjeron esos accidentes fueron: en 21 ocasiones durante Educación Física (tres de ellos son profesores de Educación Física), 5 en Tecnología, 3 en Lengua y Literatura, 1 en Educación Plástica y Visual y 3 en otras catalogadas como "Varias" (Taller de madera y escaleras).

La realidad vivida en las aulas nos deja apreciar la supremacía de la Educación Física sobre el resto de materias respecto de la aparición de accidentes durante su desarrollo.

Pregunta $4^{\mathrm{a}}$ : Valora, en una escala del 1 (poco) al 10 (mucho), el grado de probabilidad de aparición de lesiones o accidentes en las siguientes áreas/materias.

Las puntuaciones medias obtenidas en cada una de las materias presentadas en el cuestionario han sido: 


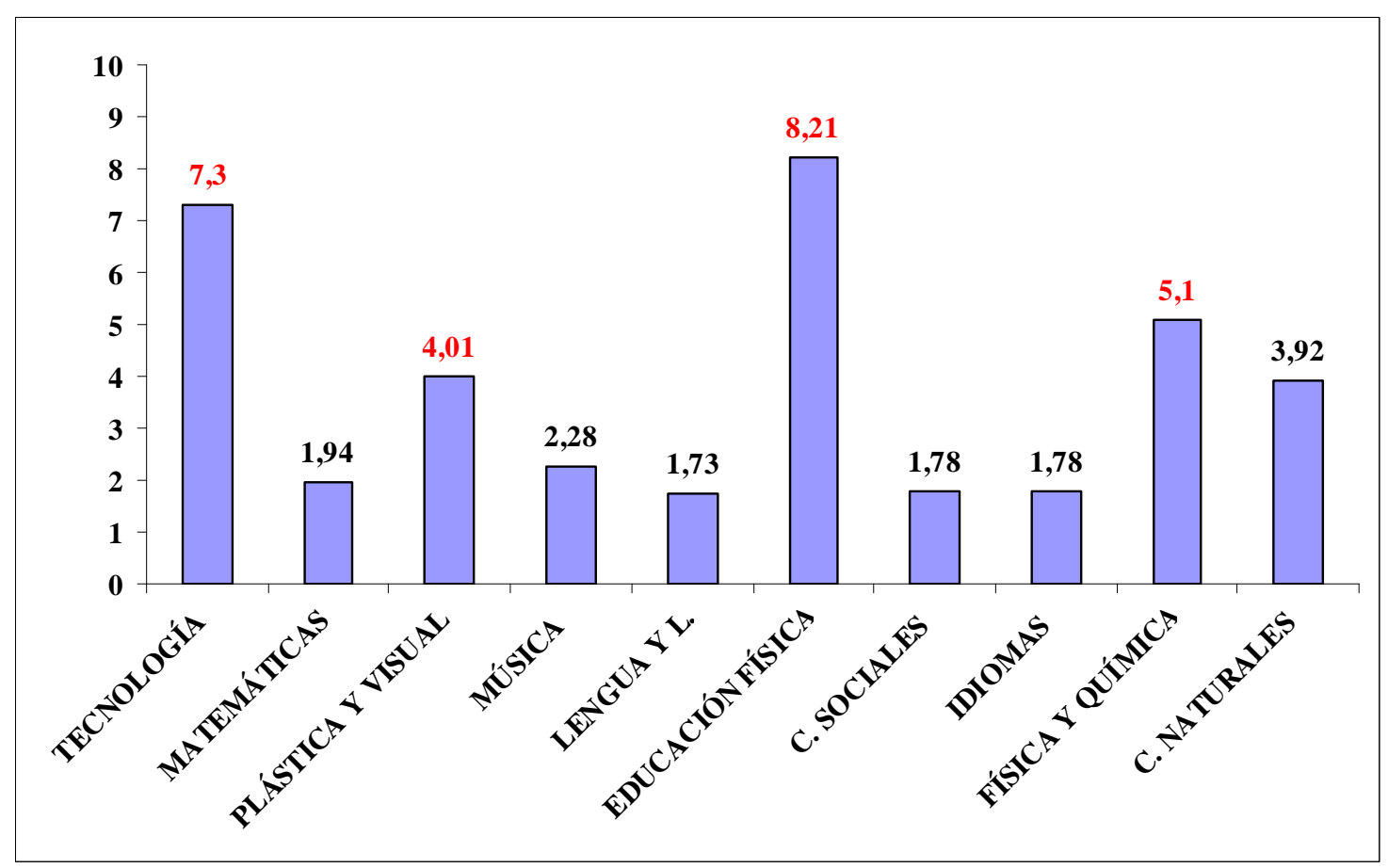

Gráfica 75: Percepción entre los docentes de sufrir un accidente en algunas materias

De forma especial destaca el 8.21 obtenido por la Educación Física, que ha sido votada en veintiuna ocasiones con un 10 y en catorce con un 9. Le sigue la Tecnología, que ha obtenido once votaciones máximas y diez con un 9. La tercera y última materia que está por encima del cinco es Física y Química. El resto de materias tendrían una escasa percepción en la probabilidad de aparición de accidentes durante el desarrollo de las clases.

La opinión de los profesores de Educación Física a este respecto es la siguiente: 


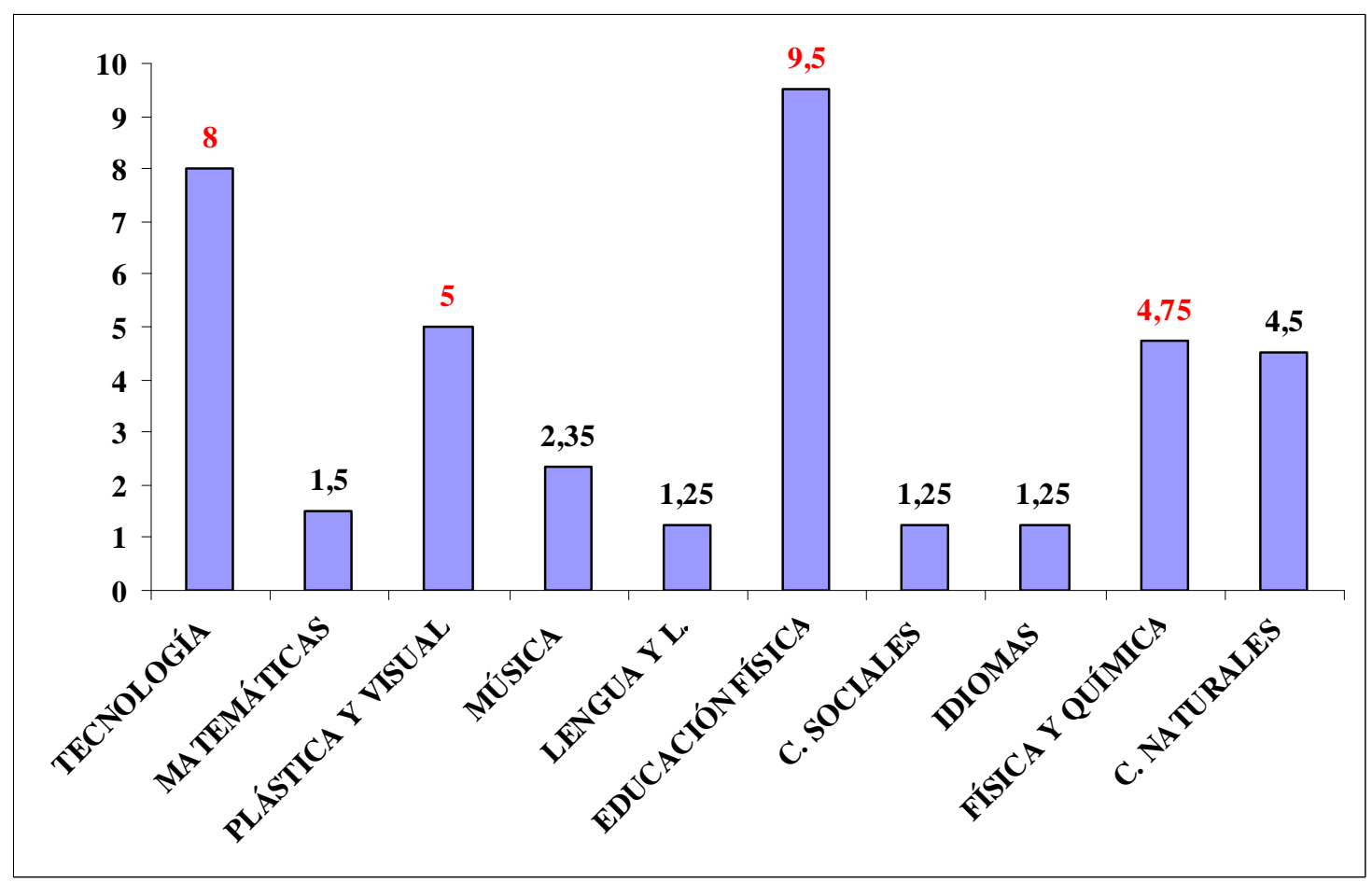

Gráfica 76: Percepción entre los docentes de Educación Física de sufrir un accidente en algunas materias

Las cuatro primeras materias en la consideración de probabilidad de accidentes siguen siendo las mismas que antes. La Educación Física sigue siendo la primera en la percepción de accidentabilidad durante su desarrollo, pero ahora alcanza el 9.5 según nuestro colectivo. Es de suponer que sus experiencias les hayan marcado en este sentido.

Los datos nos demuestran que el profesorado percibe que la Educación Física es la materia en la que se da una mayor probabilidad de aparición de accidentes. Así pues, se confirma la idea transmitida hasta ahora de su peligrosidad, muy por encima de las demás materias.

Por tanto, parece como si durante nuestras clases, realizando las tareas propias del área, los alumnos corren más peligro y tienen más accidentes que en las de otras áreas (Sánchez, 2003; Espartero, 1997, p. 685; Castro, 2005; Fuente [45]; Gutiérrez et alia, 2007, p. 84), lo cual conlleva que los docentes de Educación Física, en el ejercicio 
de su profesión, deben ser conscientes de los riesgos implícitos que asumen y obrar en consecuencia.

Pregunta $5^{\mathrm{a}}$ : ¿Crees necesario que el profesorado cuente con un seguro de Responsabilidad Civil? Pregunta $6^{\mathrm{a}}$ : Por el cauce que sea (colegiación, afiliación sindical...), ¿lo tienes contratado?

Casi la totalidad de los encuestados $(\mathrm{Fi}=66$, lo que representa un $94.28 \%$ de la muestra) creen necesario contar con un seguro de Responsabilidad Civil. Sin embargo, resulta curioso comprobar que tan solo 10 de ellos (14.28\%) lo tienen contratado o concertado por la vía que sea.

En esta línea, los cuatro afirman que es necesario y uno de ellos lo tiene contratado.

Pregunta $7^{\mathrm{a}}$ : ¿A través de cualquier medio de comunicación has tenido conocimiento de algún accidente producido dentro del horario escolar de cualquier otro centro educativo? Pregunta $8^{\mathrm{a}}$ : En caso afirmativo a la anterior, ¿sabrías decir en qué áreas o materias se produjo?

De nuevo, un elevado porcentaje de profesores ha tenido noticias por los medios de comunicación de accidentes producidos dentro del horario escolar. El $91.42 \%$ $(\mathrm{Fi}=64)$ dice ser conocedor de sucesos de este tipo. Sobresale que en 30 casos el accidente tuvo lugar en las clases de Educación Física, 8 en Tecnología, 7 en los recreos, 4 en Física y Química, 7 durante las actividades extraescolares, 2 en Ciclos Formativos y 8 en otras variadas situaciones.

La respuesta es contundente: los cuatro dicen que sí y que ha sido en Educación Física. 
Se percibe la notoriedad mediática de los accidentes en Educación Física. A la vista de los datos obtenidos, el número de casos aparecidos en los medios de comunicación producidos en nuestra materia destacan poderosamente sobre los que se producen en las otras.

Pregunta 9a: ¿En alguna ocasión te has planteado el tema de la responsabilidad civil en tu trabajo con alumnos/as? Pregunta 10a ¿Has asistido a cursos, seminarios... en los que se abordasen cuestiones relacionadas con la responsabilidad civil del profesorado? Pregunta 11'a ¿Crees conveniente que en tu centro se realice alguna charla o ponencia informativa al respecto de la responsabilidad civil?

A pesar de que 51 docentes ( $\mathrm{fi}=72.85 \%$ ) se han planteado en alguna ocasión el asunto de la Responsabilidad Civil en su trabajo con alumnos, tan solo el 10\% (7 casos) ha asistido a cursos de formación en los que se tratase esa temática. No obstante, casi la totalidad de los encuestados (94.28\%, equivalentes a 66 profesores) son partidarios de que en su Centro se desarrolle una charla o ponencia al respecto.

Hay unanimidad también en esta pregunta ya que los cuatro dicen que sí se han planteado estas cuestiones y que sería conveniente realizar charlas en los centros al respecto. Tan solo uno de ellos ha asistido a alguna actividad formativa al respecto.

La cuestión de la responsabilidad ha despertado el interés de tres cuartos de la muestra, lo cual lo interpretamos como una inquietud relevante en el profesorado. Sin embargo, a pesar de que casi el $95 \%$ cree necesario que se ofrezca información en su centro sobre el asunto, tan solo una pequeñísima parte de ellos ha asistido a alguna actividad formativa al respecto (desconocemos la naturaleza de las actividades y las motivaciones que hayan provocado la asistencia). Tan solo cuando se sitúa al profesorado ante el tema de la responsabilidad, parece que surge la inquietud formativa. 
Pregunta12a: En caso de que tengas hijos/as, ¿han sufrido algún accidente o lesión durante el horario escolar? Pregunta $13^{\mathrm{a}}$ : En caso afirmativo a la anterior, ¿sabrías decir en que área o momento se produjo?

Han sido un total de 11 los profesores que han respondido que alguno de sus hijos/as ha sufrido algún accidente o lesión durante el horario escolar. Destaca que 7 de esos 11 accidentes ocurrieran en la clase de Educación Física. El restante 36.37\% se produjo en recreos o actividades extraescolares.

Ninguno de ellos contesta a estas preguntas.

Lo que pretendíamos con esta pregunta era conocer la existencia o no de esa posibilidad accidental durante los horarios lectivos. Como afirman Manzanero y López (2007, p. 7), la emoción juega un papel muy importante en la memoria en general y en la memoria autobiográfica en particular. Es decir, que el recuerdo de una experiencia traumática de un hijo es prácticamente imborrable ya que dicho recuerdo se asocia a un fuerte sentimiento o emoción ${ }^{231}$.

\section{Pregunta 14: ¿Crees que estamos debidamente respaldados o} protegidos por la Administración en cuestiones de responsabilidad civil?

Tan solo un docente afirma que sí estamos debidamente respaldados por la Administración, mientras que un $84.28 \%$ ( $\mathrm{Fi}=59)$ opina todo lo contrario. El restante $14.28 \%(\mathrm{Fi}=10)$ confiesa su desconocimiento al respecto.

\footnotetext{
${ }^{231}$ Papalia y Olds (1992, p. 219) plantean que se recuerda mucho mejor aquellos sucesos que son emocionalmente significativos. Este tipo de recuerdos se denominan memoria vívida y tiene lugar, en lo que respecta al asunto de nuestra pregunta, en un momento de gran significado personal. Barco (2014, p. 18) apunta que los sucesos que se encuentran asociados a momentos de alta carga emocional se recuerdan con especial intensidad. Para este autor algunas recuerdos son más significativos que otros, especialmente los que se originaron tras una experiencia con una elevada carga emocional, como pudiera ser un accidente (ibídem, p. 19)
} 
Uno de los profesores responde afirmativamente a esta cuestión. Es el único de toda la muestra que considera que estamos respaldados por la Administración en asuntos de responsabilidad (lo cual no deja de intrigarnos).

Aunque muchos profesores parecen percibir cierto desamparo administrativo cuando se trata de velar o cubrir su responsabilidad en el desarrollo profesional docente, es significativo el número de docentes que manifiestan desconocer el alcance de sus actos u omisiones hacia sus alumnos.

Pregunta $15^{\mathrm{a}}$ : Si lo deseas, puedes realizar las observaciones que creas convenientes en relación con estos asuntos de la responsabilidad civil del profesorado.

Al final del cuestionario dejábamos la puerta abierta para que, en relación al tema sobre el que se investigaba, los encuestados nos hiciesen los comentarios o puntualizaciones que creyesen oportunas.

De las diecisiete observaciones que nos han realizado otros tantos docentes, agrupamos las más relevantes en dos grupos de atención: uno acerca de la información y formación al respecto, y otro sobre la Educación Física.

\section{Información y formación}

El profesor está poco informado sobre este asunto. En todo caso, parece que solo se interesa por estas cuestiones cuando se produce la situación traumática o accidente. Si se le pregunta (vid.: observaciones 10, 11 y 14) contesta que no se siente protegido o que no sabe hasta qué punto lo está, pero tampoco hace nada por averiguarlo.

"Sinceramente estoy poco informado para opinar sobre el tema (lo digo como autocrítica, aunque me gustaría que alguien nos informase)." 
"El profesorado, en general, concede escasa importancia a un tema tan esencial. Suele tenerse en cuenta cuando ya no hay remedio y se ha producido la denuncia. Existe desidia por parte de la administración en este tema. El número de denuncias ha aumentado de manera exponencial y con ello el precio de los seguros."

"Como no he tenido problemas desconozco si estamos verdaderamente protegidos."

"Es un tema importantísimo al que sólo se le da importancia cuando sucede algo, y entonces es tarde para prevenir."

"Además de en las propias clases, es importante el tema de la Responsabilidad en las actividades extraescolares; como profesor desconozco hasta dónde llega mi responsabilidad en esos casos y sería necesario saberlo."

En definitiva, si no hay necesidad, no hay formación. Choca con la respuesta que ofrecían los docentes de Educación Física a la pregunta $\mathrm{n}^{\mathrm{o}} 11$ del cuestionario ya que, a pesar de que todos se han planteado este asunto y han sufrido accidentes en sus clases, tan solo uno de ellos se ha formado. Nos preguntamos si de nuevo estamos ante una desidia formativa.

\section{Sobre la Educación Física}

Se alude a la existencia de materias con mayor índice de riesgo que otras, pero sin aclarar cuáles son unas y otras. Parece lógico pensar que, por todos los datos obtenidos hasta ahora, la Educación Física bien podría estar en esa primera consideración de materias más riesgosas.

"Las salidas y entradas al centro, junto con los recreos, son tiempos en los que los accidentes son tan probables como en las áreas con mayor índice de riesgo.” 
Aunque también aparece explícitamente la percepción que en la Educación Física, por realizar actividades de tipo deportivo, hay riesgo lesivo.

"No creo que el problema derive de las áreas impartidas, salvo en las que se usan herramientas o productos químicos (como en Tecnología y Física y Química) o se desarrollen actividades deportivas (Educación Física), sino de los accidentes o lesiones que tienen los alumnos como resultado de su propia conducta por ejemplo: en el recreo, cuando se empujan o juegan)."

Por su parte, el único profesor de Educación Física que ha realizado una observación dirige su foco de atención hacia las instalaciones y los materiales empleados.

"En cuanto a las instalaciones y, en general, a las condiciones en las que se imparte clase (material no anclado, no reparado...)."

De alguna forma confirma lo que recoge Hernández (2005) acerca del estudio de Latorre y Herrador. Recordamos que estos autores realizaron una investigación sobre el incumplimiento de la normativa en materia de seguridad en el uso de los equipamientos y espacios en las clases de Educación Física, concluyendo, entre otras, la existencia de una “dejadez" de la seguridad en las clases de Educación Física en estos asuntos.

\section{5.- EPÍLOGO}

Nos hemos acercado a la normativa relacionada con la responsabilidad civil y penal más representativa y directamente aplicable a los docentes en el ejercicio de su profesión; hemos examinado las redacciones de algunas sentencias judiciales y de otro rango (dictámenes de consejos consultivos autonómicos) en los que queda patente el carácter riesgoso de nuestra materia; la jurisprudencia existente recoge ejemplos de accidentes acaecidos en Educación Física; los medios de comunicación digitales nos acercan a una realidad en la que existen casos de accidentes con graves consecuencias 
en nuestras clases ${ }^{232}$; la literatura y fuentes documentales se posicionan claramente en esta línea de riesgo y peligro en la consideración de esta materia; en el colectivo de profesores en general, y en particular el de Educación Física, parece haber unanimidad en la apreciación de esta circunstancia, siendo esta materia en la que más riesgo de accidente se percibe.

Con el propósito de ejemplificar la situación real de peligrosidad y de riesgo existente en nuestras clases se han empleado trece noticias. No obstante, recogemos ahora otras (algunas de ellas de ámbito internacional) con la intención de ratificar la magnitud y alcance de registros existentes a los que hacíamos alusión al principio de este $\operatorname{apartado}^{233}$.

Muere un niño tras desmayarse cuando daba clase de gimnasia (04-10-2013) http://www.telecinco.es/informativos/sociedad/Loja-muere-nieno-desmayoclase-gimnasia_0_1678950442.html (consultado 05-08-2014)

\section{Muerte súbita de un chico en la clase de gimnasia del colegio (24-04-2014)} http://www.lanacion.com.ar/1684608-muerte-subita-de-un-chico-en-la-clase-degimnasia-del-colegio (consultado 05-08-2014)

\section{Murió una adolescente en una clase de gimnasia en Córdoba (05-03-2015)} http://m.diarioveloz.com/notas/34136-murio-una-adolescente-una-clasegimnasia-cordoba (consultado 05-08-2014)

Muerte súbita: tenía 16 años y falleció en la clase de gimnasia (12-08-2011) http://www.clarin.com/sociedad/Muerte-subita-fallecio-clasegimnasia_0_534546653.html (consultado 05-08-2014)

\footnotetext{
${ }^{232}$ En todos los casos que hemos recogido lo único que hemos podido comprobar, por la información ofrecida en los artículos, es que el suceso ocurría antes, durante o después de la clase de Educación Física. No hemos hallado ninguno en el que se relaten sucesos similares acecidos antes, durante o después de cualquier otra materia.

${ }^{233}$ Todas ellas se han agrupado en la Fuente [84].
} 
Chico de 14 años murió de un infarto en una clase de gimnasia (mayo-2006) http://www.sitiosargentina.com.ar/notas/2006/mayo/murio-ifarto.htm (consultado 05-08-2014)

Murió tras descomponerse en una clase de gimnasia (10-05-2007) http://www.diariodecuyo.com.ar/home/new_noticia.php?noticia_id=219611 (consultado 05-08-2014)

Un chico de 15 años fallece al caerle una canasta en el IES de Vilamarxant (24-11-2010)

http://www.levante-emv.com/sucesos/2010/11/24/chico-15-anos-fallece-caerlecanasta-ies-vilamarxant/759869.html (consultado 05-08-2014)

\section{Fallece una niña de 11 años en la clase de Educación Física (25-09-2003)} http://www.elperiodicomediterraneo.com/noticias/sucesos/fallece-nina-11-anosclase-educacion-fisica_69981.html (consultado 05-08-2014)

A la vista de los datos recogidos en este capítulo, podemos concluir que de la actividad de la Educación Física se pueden derivar y se derivan accidentes (sin entrar en los detalles que los provocan), y que los docentes la consideran una materia riesgosa en la que existe una mayor probabilidad de aparición de accidentes que en las demás materias del currículo. Hacemos nuestras las palabras de Morales (2010, p. 96):

"Una de las principales diferencias entre la materia de Educación Física y el resto que completa el currículo de la educación secundaria se refleja de forma muy clara en la naturaleza del cuerpo. La práctica del ejercicio físico y los deportes comporta un riesgo de lesiones y accidentes mucho mayor que el desarrollo de actividades de tipo sedentario."

Es imposible estar libres de cualquier carga o responsabilidad en el ejercicio de nuestra profesión. Por mucho que planifiquemos, programemos, preparemos... siempre puede surgir un accidente ya que los protagonistas que participan en nuestras clases no están bajo nuestro control absoluto: los alumnos (con todas sus características 
individuales), el trabajo de tantas personas juntas, la propia actividad en sí misma, los materiales e instalaciones, climatología...

El profesorado percibe (equivocada o acertadamente) desamparo administrativo en su responsabilidad laboral hacia sus alumnos. Además, el colectivo reconoce la falta de información al respecto, pero se avista cierta desidia por su parte ya que parece como si solo se preocupasen por este asunto cuando hay noticias al respecto por cualquier medio o situación (e.g., cuando se les preguntó a través del cuestionario).

Así pues, con tantas circunstancias y datos que evidencian que la Educación Física es una materia de riesgo (para el docente derivada de su responsabilidad por sus acciones, decisiones y/u omisiones, y para el alumnado porque es el que sufre las consecuencias de los infortunios y/o malas praxis durante su desarrollo), no sería descabellado afirmar que el profesor de Educación Física llegue a generar mecanismos, (más o menos conscientes), que le llevan a adoptar posturas didácticas coercitivas en la planificación y propuesta de determinas actividades y/o contenidos de carácter práctico.

Por el mismo motivo, este mecanismo se verá incrementado cuando se trate de de dar respuesta al alumnado con dificultades de aprendizaje asociadas a cualquier tipo de discapacidad, es decir, lo que hemos denominado como exención (in)visible volverá a presentarse como argumento educativo. 


\section{Piezas de la vidriera}

Tras la exposición de toda la información que configura este capítulo, es el momento de descubrir qué piezas de nuestra vidriera aparecen.

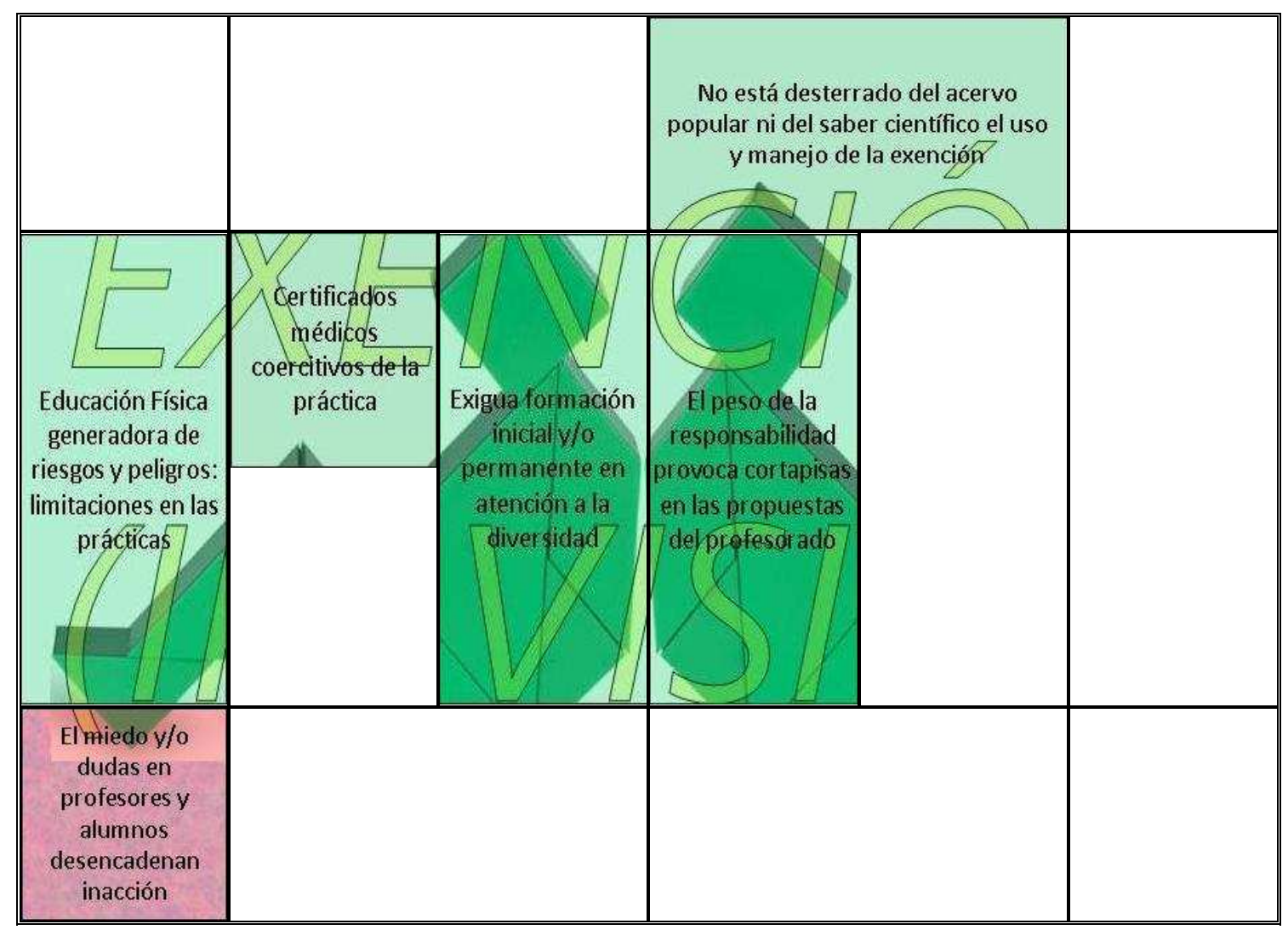




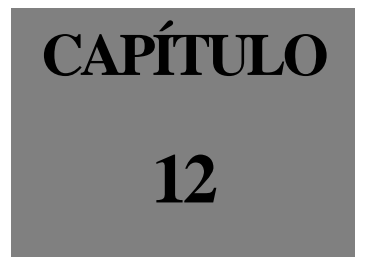

ANÁLISIS RETROSPECTIVO DE UN CASO EXCEPCIONAL: LA EDUCACIÓN FÍSICA A TRAVÉS DE LOS OJOS DE VIRGINIA 
En el Capítulo 2 me he referido a Virginia, una alumna a la que impartí clase durante casi dos cursos consecutivos en el período comprendido entre 2000-01 y 200102 ( $3^{\circ}$ y $4^{\circ}$ E.S.O. $)$, como la causante de que me decidiera a indagar sobre el modo en que, desde la Educación Física, se aborda la problemática de los alumnos con necesidades educativas especiales asociadas a discapacidad motriz y, en particular, el asunto de la exención.

Las opiniones, experiencias y apreciaciones de los alumnos, especialmente la de los afectados, deberían ser consideradas como un referente para nuestra acción a fin de plantear actividades más acordes a sus intereses, posibilidades y perspectivas reales de futuro.

Además de obligado, por mi parte, dedicar un capítulo a Virginia, repasaré su andadura conmigo para conocer cuál era su visión de la Educación Física, realizando así el repaso de un caso, para mí de carácter excepcional, no solo por lo que supuso para mi investigación, sino por el impacto personal que me causó.

Sus anotaciones en los cuadernos de clase de Educación Física que realizaba diariamente y sus comentarios recogidos en el mío, así como los de su familia (su madre) y alguno de sus compañeros serán las fuentes de información que mejor nos acerquen a los sentimientos e interpretación de la Educación Física de Virginia.

Lo primero que realizaremos es una aproximación metodológica al estudio en sí mismo y a las técnicas de recogida de información empleadas: la entrevista, como protagonista de este capítulo, documentos de las alumnas (cuaderno de clases y escritos de clase) y cuaderno del profesor (basado en la observación directa) 


\section{1.- APUNTES METODOLÓGICOS}

Independientemente de que la entrevista sea uno de los procedimientos más utilizados en la investigación social (Ander-Egg, 1995, p. 225), hemos considerado necesario recurrir a ella por varias razones: obtener el consentimiento de los familiares de Virginia acerca de los datos que sobre ella aparecen en este trabajo, y acceder a una información muy íntima de marcado carácter personal.

La entrevista será in situ (Ander-Egg, 2000, p. 72) ya que tendrá lugar en la casa de Virginia. Por el lugar en que se produce, con toda seguridad podremos acercarnos mejor a las experiencias allí vividas.

Nos hemos decantado por una entrevista semiestructurada o no estructurada (Buendía, 1992; Cohen y Manion, 1990), caracterizada por ser flexible y abierta; cualidades idóneas para "irrumpir" en el delicado y doloroso recuerdo que el tema abordado pudiera provocar en el entrevistado.

La entrevista partía de un guión previamente establecido basado en preguntas o temas abiertos que, más que interrogar, origina sugerencias e ideas sobre las que hay que pronunciarse. A pesar de esta preparación anticipada, tenía claro que no sería necesario seguir fielmente el guión previamente diseñado. Si salía a la luz algún tema que pueda ser considerado interesante, lo abordaríamos sin dilación en ese mismo momento o lo dejaríamos para el final de la entrevista planificada. Considerada de esta forma, estamos muy próximos al tipo de entrevista libre o informal propuesta por Ander-Egg (op. cit.). De hecho, la conversación pretendía ser amigable e informal con nuestra interlocutora. 
El sistema de registro utilizado fue, previo consentimiento de las entrevistadas $^{234}$, una grabadora magnetofónica. Al término de la entrevista, antes de que el tiempo pudiese desdibujar lo que había oído y sentido, registré en mi cuaderno de observación el desarrollo de la entrevista con todo lujo de detalles. Posteriormente transcribí lo grabado.

Como era de suponer, la atmósfera que envolvió a la entrevista fue de una tristeza contenida que por momentos no se pudo controlar y, de hecho, nos desbordó. Por ello, teníamos pensados algunos temas o comentarios que sirvieran para aligerar la presión que la emoción y la nostalgia, tales como: hablar de sus amigas, lo bien que lo pasó en alguna sesión muy puntual, cómo se estaba desarrollando la tesis, la opinión de otros profesores, etc.

En cuanto a la fiabilidad y validez de la entrevista, como asegura Kitwood (recogido en Cohen y Manion, op. cit., p. 391) "se convierten en «nociones redundantes», puesto que «se puede decir que es válida cualquier situación interpersonal, como tal, si es conforme o no con lo esperado, si implica o no un alto grado de comunicación y si los participantes aparecen o no alegres o deprimidos»”. En cualquier caso, todo lo que aquí se recoge ha sido dado a conocer a los interlocutores para que confirmasen las informaciones aparecidas, hecho que así ha ocurrido.

Por lo que respecta a la observación, realizo diariamente un registro de anotaciones de aquello que yo he considerado más relevante de cada lección en particular. La observación realizada se encuadra en lo que Fraile (1995, p. 62) denomina observación participante. En ella se recogen notas sobre las personas, situaciones que se dan, comentarios acontecidos y reacciones de los participantes. Además, como soy el profesor no puedo evitar ser uno de los actores de las clases que "estudio" y de todo lo que en ellas tiene lugar, lo cual sirve para catalogar todo el proceso como investigación activa (Caplow, 1974, p. 61), es decir, que soy el observador pero a la vez soy "agente de cambio".

\footnotetext{
${ }^{234}$ Como se verá más adelante, en la entrevista estaba la madre de Virginia y una de sus mejores amigas.
} 
Por su parte, los diarios del alumno (cuadernos de clase de Virginia) que se emplean en este capítulo son de dos cursos académicos. Los utilizo en la medida que nos ayudarán a tener un mejor conocimiento de la realidad en base a varios argumentos, nos transmiten la visión que tiene el alumno de la clase, podremos acceder a la percepción que tienen del papel que desempeñan en cada clase y, más importante aún, conocer sus intereses, necesidades y problemáticas (Fraile, op. cit., p. 65).

A medio camino entre la entrevista (en forma de cuestionario) y el diario del alumno, se puede situar el autoinforme cumplimentado por el alumno que se emplea en este capítulo (Anexo 28). Se trata de un documento semiestructurado que, al término del curso académico, debían realizar todos los alumnos (incluye un apartado dedicado a la autocalificación). Cuenta con preguntas cerradas y otras abiertas, y se contempla la posibilidad del comentario libre.

\section{2.- DOS AÑOS DE CLASE CON VIRGINIA}

Este apartado se basa en la recopilación de pasajes significativos para el tema objeto de estudio reflejados en los cuadernos de clase de Educación Física que Virginia elaboró durante los cursos escolares 2000-01 y 2001-02, período en el que fui su profesor.

Además, con el propósito de ratificar algunas de sus opiniones o sentimientos, emplearé un autoinforme muy extenso elaborado por Verónica, otra alumna que sufrió durante un largo de tiempo una enfermedad que le impedía realizar las clases con normalidad y asiduidad, teniendo que pasar muchas horas junto a Virginia, convirtiéndose en su cómplice de banquillo y comentarios. Fue tanta la unión entre ambas, que en varias ocasiones la menciona en dicho autoinforme.

Virginia, tras las clases de Educación Física, pasaba por unos estados de ánimo de lo más variopinto. Sin embargo, como ya comentamos en el Capítulo 2, se solían 
mover en dos extremos: la desesperación / frustración generada por su estado, y la gran satisfacción que le proporcionaba su "participación” por muy pequeña que fuera.

"Respecto al esfuerzo, como he dicho antes, intento realizar ejercicios que por mi circunstancia me son imposibles, aunque a veces pierda la paciencia y me desmoralice." (Cuaderno de clase de Virginia, $3^{\circ}$ E.S.O., 14 de marzo de 2001)

"Respecto al voleibol, me hizo muchísima ilusión jugar dentro de un equipo (aunque sólo realizaba los saques), pero para mí fue importante porque ya se me había olvidado lo que era participar y «tocar» un balón..." (Cuaderno de clase de Virginia, $3^{\circ}$ E.S.O., 25 de abril de 2001)

Se podría decir que ese último sentimiento era también el mío ya que cada vez que ella participaba en clase yo lo recogía en mi cuaderno de observación con gran satisfacción. "Hoy Virginia ha ayudado y realizado muchas de las actividades propuestas" (11-12-2000), "Virginia participó activamente sacando para un equipo" (25-04-2001), son anotaciones que escribía con escasa frecuencia.

En términos parecidos se situaba Verónica, su habitual compañera de banquillo:

“...Ya en $4^{o}$ E.S.O. me integré un poco más jugando a bádminton con mis compañeros... Y este año ha sido el definitivo. Me siento distinta cuando voy a las clases de educación física..." (Autoinforme final de Verónica, $4^{\circ}$ E.S.O., junio de 2002)

Virginia y yo solíamos mantener habitualmente conversaciones sobre su estado con relación a las clases de Educación Física, y fueron muchas las veces que me mostraba su enfado y rabia contenida por lo que le estaba pasando. Se sentía o percibía diferente a sus amigas de la infancia, esas que saltaban y corrían delante de ella. En una ocasión me dijo que ella nunca haría lo que ellas estaban realizando, que era diferente a sus amigas, el bicho raro del grupo. Verónica expresa muy bien este sentimiento de diferencia e impotencia que ambas sufrían.

“...A mí y a Virginia, cuando no estaba tan grave, nos decían que qué morro teníamos al estar ahí sentaditas, pero no saben lo que duele que te digan eso cuando estás deseando moverte a correr y a jugar con las amigas... Antes Virginia y yo hacíamos trabajos y, sin embargo, ahora los hace toda la clase y 
sientes que no eres la única, la "distinta"." (Autoinforme final de Verónica, $4^{\circ}$ E.S.O., junio de 2002)

A pesar de que nunca utilicé la expresión exenta para referirme a ella en mis clases de Educación Física, Virginia sí entendía su situación en esos términos, lo cual viene a demostrar cómo había sido su paso por la Educación Física en los cursos o etapas educativas anteriores.

"La clase de hoy ha estado bien para los que hacen Educación Física, pero para los exentos yo creo que has dado mucha teoría..." (Cuaderno de clase de Virginia, $4^{\circ}$ E.S.O., 18 de octubre de 2001)

La respuesta habitual que la Educación Física ha dado (¿da?) a este tipo de alumnos suele ir en la línea de no hacer lo que los demás hacen y derivarlos a otras tareas que, precisamente, remarcan las diferencias con los demás.

“...quiero decir que yo he notado una gran diferencia este año respecto a otros... Yo llevo muchos años sin poder hacer ejercicio físico, exactamente desde cuarto de primaria. Al principio mi profesor de educación física me hacía redactar todos los días lo que mis compañeros hacían, mientras los demás no hacían cuaderno...” (Autoinforme final de Verónica, $4^{\circ}$ E.S.O., junio de 2002)

Las actividades o tareas que yo le proponía intentaban favorecer, no tanto su integración en el grupo, pues de hecho era una persona muy querida y admirada por todos sus compañeros, sino su participación para aumentar su nivel de confianza, autoestima y bienestar (en cualquier ámbito de su persona).

"La gente que no podíamos correr (como es el caso mío) realizábamos los 20 minutos andando." (Cuaderno de clase de Virginia, $3^{\circ}$ E.S.O., 18 de octubre de 2000)

Sin embargo, el hecho de que en muchas de las ocasiones no pudiese participar "normalmente" o se negase a ello, hicieron que la propuesta de actividades fuera en la línea de la tantas veces aludida "falsa integración" o "exención invisible". 
"Para terminar se jugó un partidillo en el que la «menda» arbitraba." (Cuaderno de clase de Virginia, $3^{\circ}$ E.S.O., 10 de enero de 2001)

“...si puede ser ayudar a la gente (a traer el material) y si podemos, arbitrar algún partidillo..." (Cuaderno de clase de Virginia, $3^{\circ}$ E.S.O., 9 de mayo de 2001)

"También me has puesto que cuente lo que yo hago en clase de Educación Física, pero como prácticamente no hago nada (salvo recoger material y, si puedo, ayudar a mis compañeros)..." (Cuaderno de clase de Virginia, $4^{\circ}$ E.S.O., 17 de octubre de 2001)

Lo que de verdad le ayudaba a sentirse útil y parte activa durante las clases era la elaboración de su cuaderno de Educación Física. Pero a la vez, reconocía que su aprendizaje no podía ser el mismo que el de aquellos que hacían las prácticas, temiendo por ello que se le calificase en menor medida que al resto.

"Respecto al aprendizaje, sólo de ver a mis compañeros y tomar apuntes en el cuaderno también se aprende, pero no de la misma manera y con los mismos detalles que se aprende a la hora de realizarlo." (Autoinforme de Virginia, $3^{\circ}$ E.S.O., 14 de marzo de 2001)

"Elaborar el cuaderno para mí es un trabajo muy importante... [hace] que me sienta implicada en la clase, ya que si no estoy sentada en un banco ( «muerta de envidia») y sin interés." (Autoinforme de Virginia, $3^{\circ}$ E.S.O., 14 de marzo de 2001)

"La clase ha estado bien para los que hacen Educación Física, pero para los exentos yo creo que has dado mucha teoría, y como no podemos desarrollarla como el resto pues hay cosas que se te olvidan y no las apuntas o las explicas mal en el cuaderno. Espero que lo tengas en cuenta a la hora de corregir." (Cuaderno de clase de Virginia, $4^{\circ}$ E.S.O., 18 de octubre de 2001)

Las palabras de Verónica nos ratifican esta situación de manera contundente:

“...Yo me acuerdo que para Virginia y para mí era casi peor que ir a una clase de matemáticas. Nos aburríamos mucho. Quieras que no cuando estás ahí sentada viendo a todos tus compañeros pasándoselo bien o a veces sufriendo de cansancio, te sientes rara, diferente a los demás..." (Autoinforme final de Verónica, $4^{\circ}$ E.S.O., junio de 2002) 
Para concluir este apartado, deseo reflejar el último día que Virginia anotó en su cuaderno de clase en el que hizo, sin proponérselo, un resumen de su paso por el área, dejando constancia de su habitual "no-participación motriz", de su temor a ser peor calificada que el resto, así como de los momentos eufóricos que la animaban a seguir luchando en su empeño por participar como uno más, aun a pesar de que estaba avocada al fracaso, asumiéndolo estoicamente.

"Mi conclusión de las dos clases de badminton de esta semana es la siguiente: sigo pensando que explicas varios conceptos cada día y para los que luego lo practican pues es fácil de entender pero para los que sólo nos quedamos con la teoría, pues la práctica nos es imposible de realizar, nos resulta más complicado plasmarlo en el cuaderno, por eso espero que tengas en cuenta esto a la hora de corregir y que si he confundido alguno de los conceptos, posiciones u otras cosas es por ello.

También he de decir que la clase de hoy me ha gustado porque por lo menos he hecho algo, he aprendido a levantar el volante del suelo con la raqueta, que ésta hay que situarla al lado del volante un poco curvada y realizas un movimiento rápido para elevar el volante, aunque la mayoría de las veces se me iba lejos y no llegaba a cogerlos. Es que para una vez que se trabaja un deporte que podía realizar pues ahora no puedo y me joroba. ¡Pero la vida es así!” (Último día del Cuaderno de clase de Virginia, $4^{\circ}$ E.S.O., 17 de enero de 2002)

Con todas estas palabras, cargadas de emotividad y de recuerdos vivos e imborrables para este investigador, es harto difícil, por no decir imposible, no efectuar una reflexión crítica y profunda de mi práctica y quehacer diario, y de mi perspectiva pedagógica, y también vital, en lo referente a la manera de afrontar los problemas cotidianos. Virginia y su circunstancia, que fue también la mía, removieron mis estructuras ya configuradas acerca del tratamiento que debía aplicar a estos casos extremos de alumnos con necesidades educativas especiales asociadas a discapacidad.

\section{3.- LA OPINIÓN DE LOS FAMILIARES}

Animado por compañeros de Virginia y algún que otro profesor que compartió momentos con ella, me decido a realizar una entrevista a Mari Cruz, la madre de Virginia (creo que, independientemente de cuestiones metodológicas, y a la vista de lo 
sucedido, considero que fue más bien un encuentro muy íntimo y personal de varias personas alrededor de la figura de la ausente).

Según recojo en mi cuaderno de trabajo, Mari Cruz había accedido a realizar la entrevista tras hablar con varias amigas de Virginia que la habían hablado de mí y de mis propósitos.

En la entrevista estuvo presente Verónica, amiga íntima de Virginia que aparece en el apartado anterior aportando comentarios que corroboran los de la propia Virginia.

El encuentro, de aproximadamente una hora, tuvo lugar en la habitación de Virginia (¡qué sensaciones!), llena de fotos de ella con su familia y, supongo, casi como la dejó. Sin duda un ambiente muy afectivo, cargado de recuerdos y de intensas emociones.

Comienzo explicando a Mari Cruz el motivo que me guía hasta ella y, a continuación, antes de comenzar con la entrevista propiamente dicha, le muestro mi interés por los cuadernos de clases de Educación Física que Virginia había elaborado durante los casi dos cursos que yo la impartí docencia. Le expongo que para mí son muy importantes y que podría sacarles provecho. Ella no duda en dármelos para que yo los emplee como mejor considere y para que los guarde. Cuando le comento que todo quedará en el anonimato ella me responde que para nada le importa que emplee los nombres, en particular el de Virginia. De hecho, me dice que ella lo hará para luchar contra el cáncer en campañas informativas. Obviamente le transmito que para mí es motivo de satisfacción y orgullo poderla nombrar.

Durante esa hora hubo momentos de intensa emoción, muchas veces imposible de controlar pues las lágrimas manaban sin querer. Uno de los más sentidos fue cuando le transmití que Virginia me había marcado personal y profesionalmente.

Lo primero que se pretendía en este encuentro era asegurarnos de que la información que aparece en esta tesis sobre Virginia es correcta y ajustada a la realidad. 
Tras la lectura de los capítulos en los que ella aparece, su madre confirma los datos y consiente en su exposición y/o publicación.

Sobre el paso de Virginia por la Educación Física desde que se le diagnosticó la enfermedad, se confirma que en este caso las respuestas ofrecidas son escasas. Su madre nos asegura que "ha hecho muy poca Educación Física desde que le apareció la enfermedad", lo cual nos da una primera idea sobre la atención prestada a esta clase de alumnos.

Desde entonces, "sí han tenido que presentar certificados o justificantes médicos para la clase de Educación Física”, lo cual corrobora no solo el poder de estos documentos, sino la gestión educativa de estos casos especiales.

Independientemente de que en algún momento, antes o tras las clases de Educación Física, lo pasara mal, “ella quería ir”. Incluso si se la hubiera dado la opción de poder elegir si quería o no asistir a las clases de Educación Física, "elegiría sin dudarlo, asistir”. Cualquier logro o participación solía ser bienvenida. Al principio, cuando la enfermedad no era aún muy limitante, "solamente el correr le hacía ilusión".

Todo esto no quiere decir que no mostrase recelos o suspicacias ante esta clase. Más aún, cuando su estado físico y anímico no estaban en su momento más álgido, surgían comentarios del tipo: “'Qué aburrimiento en Educación Física!”, "No sé para qué voy”, "Hoy toca Educación Física. No sé qué haremos y si podré hacer algo yo". En este punto, Verónica intervino para dejar constancia de que "Virginia a veces se amargaba por ver cosas que ella no podía hacer, pero que le gustaba mi asignatura”.

Cuando su salud fue decayendo, su paso por la Educación Física se reducía casi exclusivamente a la "realización de trabajos que, por momentos, la aburrían".

Sin embargo, en la realización del cuaderno se sentía más implicada, pues como “no le gustaba que la regalasen nada, el cuaderno suponía un mérito más para ser calificada”. El tema de la calificación, vuelve a cobrar protagonismo. 
A pesar del reconocimiento de no haber hecho prácticamente nada en Educación Física a lo largo del primer ciclo de E.S.O. como consecuencia de operaciones, tratamientos, etc., obtuvo una calificación final de sobresaliente, fortaleciéndose la idea aparecida en el capítulo anterior de que solo con contenidos conceptuales y actitudinales (en todo caso no motrices) se pueden conseguir los objetivos de ciclo. Lo significativo es que la nota no figura con adaptación curricular, por lo que no se debió de adoptar tal medida.

El cambio obligatorio de playeros para acceder al pabellón polideportivo "lo llevaba mal, pues luego no iba a hacer nada" o, unido a lo anterior, suponía una carga extra a su pasividad "Encima tengo que llevar playeros.” solía decir.

Una de las cuestiones que más se ha echado de menos, tanto desde las propias familias como desde los alumnos implicados, es la preocupación por conocer cuáles son sus pareceres acerca de su situación: "habría que preguntar a la persona indicada si quiere o no ir a Educación Física. Tengo claro que mi hija iría, pero puede que haya otras personas en distintas circunstancias que no querrían ir”.

De todas formas, la exención, como posible medida a aplicar en una sola dirección (desde el centro sin consultar al interesado) no se contempla como la mejor de las posibilidades: “El quitarles la Educación Física, por mal que lo pasen, tampoco es el remedio".

Sin embargo, las contradicciones aparecieron cuando analizamos lo que decía la ley para estos casos, la Orden de 1995. Yo le planteaba mis inquietudes y mis dudas acerca de si la Educación Física le sirvió para algo, si en algún momento le ayudó. Su respuesta fue un rotundo "que nada de nada".

En definitiva, se me plantea como lo más sensato que la particularidad y la individualidad de cada sujeto deben suponer el punto de inicio para la toma de decisiones y de medidas pertinentes, previo conocimiento de los intereses, necesidades 
y circunstancias que cada individuo quiera alegar, incluida su posibilidad a rechazar la respuesta educativa que se le pudiera dar.

\section{4.- ENTONCES, ¿CÓMO QUEDA EL ASUNTO?}

Este capítulo sin duda tiene un carácter especial debido a la ausencia de la principal protagonista. La imposibilidad de poderla consultar acerca de las cuestiones pertinentes para el objeto de la investigación puede limitar el alcance de la misma. Es más, al encontrarse el origen de la propia investigación en una ubicación temporal posterior a su desaparición, fue imposible siquiera tenerlo en consideración en su momento para así haberla entrevistado con un mayor conocimiento de causa y con unos propósitos bien definidos.

No obstante, conocemos muchas de sus opiniones e impresiones sobre nuestra área. Algunas aparecen en sus escritos; otras están en el recuerdo de las conversaciones o en las anotaciones recogidas en el cuaderno del profesor y, por último, las opiniones de su madre y de su amiga más cercana nos acercan aún más a su visión de la Educación Física.

Con todas esas informaciones podemos afirmar que la posición de este tipo de alumno y de sus familias tiene un carácter contradictorio o, al menos, fluctuante en lo que a su situación en la Educación Física se refiere.

La Educación Física, y todo lo que la rodea, se percibe en ocasiones con entusiasmo y, en cierta medida, gozo. Pero, dependiendo del estado anímico y físico por el que los protagonistas estén pasando en un momento determinado, esa sensación se torna en apatía, desgana y, fundamentalmente, abandono. Las fuerzas que tienen, que no son muchas, no parecen querer gastarse en esta asignatura. 
En definitiva, si se asoman a su pasado en la Educación Física, se ven en banquillos y engullidos en otros menesteres que intentan justificar su presencia en ella. Si miran de frente al futuro, no acaban de ver con claridad el sentido o la razón de su paso por esta asignatura. Cuando miran el presente lo hacen desde el prisma que les transmite su salud y estado anímico, percibiendo la Educación Física como algo verdaderamente positivo o, por el contrario, como una pérdida del tiempo de que disponen.

Para finalizar, puesto que la situación es ciertamente compleja, entiendo que, ante estos "casos extremos", la flexibilidad de los planteamientos y la adecuación de los preceptos legales, pasando por conocer la opinión de los protagonistas, es la opción que quizás más se aproxime a la respuesta que deba ofrecer la Educación Física actual. 


\section{Piezas de la vidriera}

El análisis retrospectivo del caso de Virginia nos aporta las últimas piezas que formarán la vidriera que será reconstruida al final de la tesis.

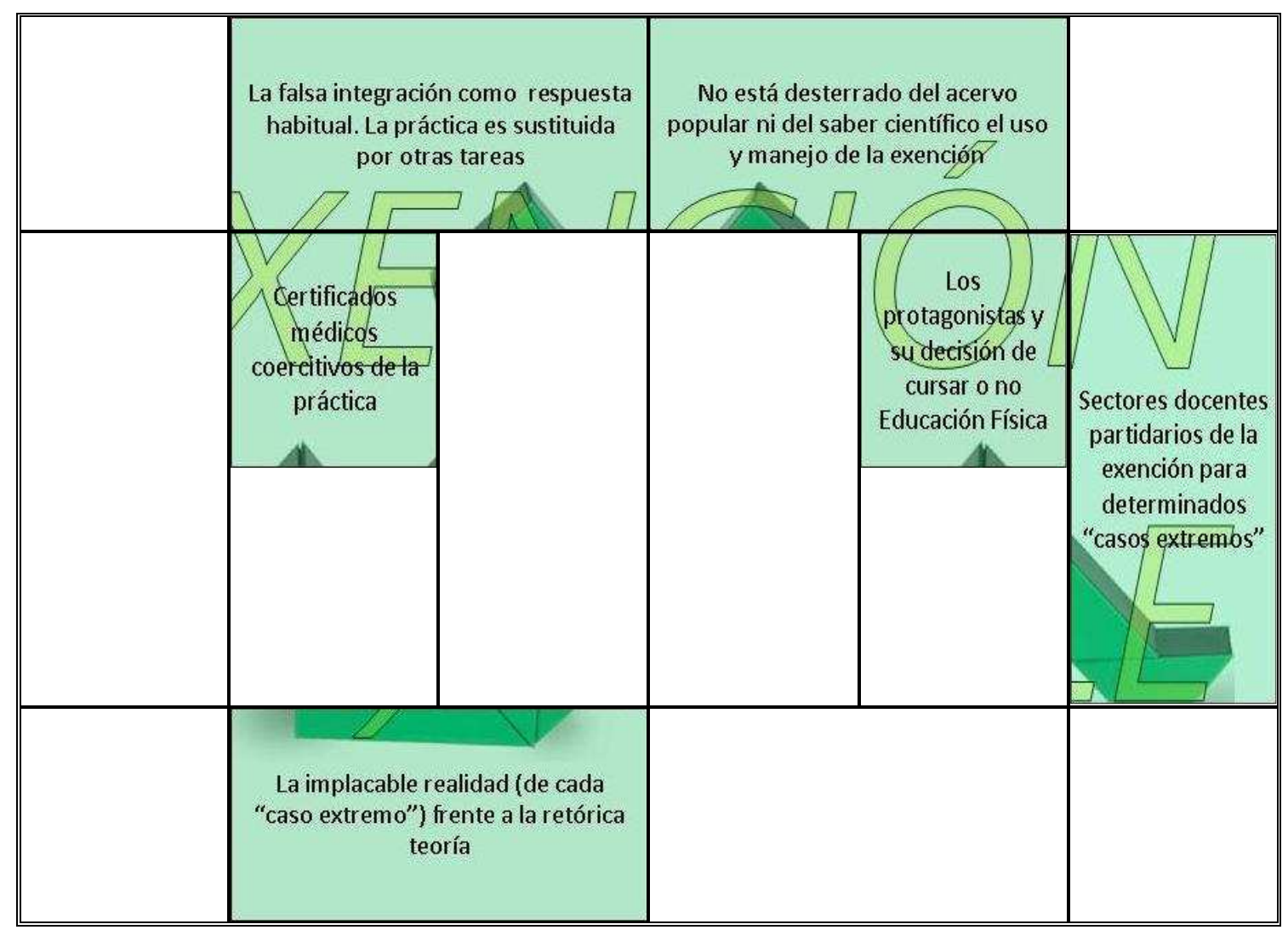




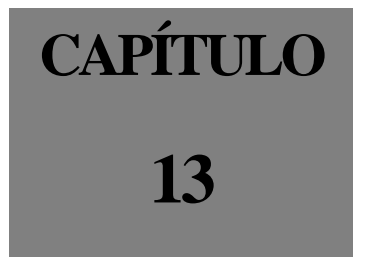


En este capítulo final recogemos las conclusiones que extraemos de los datos que han surgido de la investigación realizada. No obstante, recordamos que, con el propósito de realizar una lectura más inmediata de las mismas, al término de cada capítulo hemos elaborado epílogos en los que se sintetizaban las informaciones más relevantes.

El capítulo se inicia con una revisión global que el autor hace de aspectos tales como el objeto de estudio, duración, los objetivos perseguidos, proceso seguido..., para continuar con lo más destacable que ha aparecido en los capítulos que componen el grueso de la investigación realizada, incluidas las piezas de la vidriera más representativas de cada uno de ellos.

Asimismo, reunimos las contradicciones más significativas halladas en la investigación, dejando así constancia de algunas incongruencias que observamos en nuestra materia al respecto del objeto de estudio.

Para finalizar, nos percatamos que con la conclusión del trabajo son muchas las puertas que hemos abierto en torno al tratamiento que dispensamos desde la Educación Física a los "casos más extremos" de alumnos con dificultades de aprendizaje asociadas a discapacidad motora (incluso sensorial o psíquica), por lo que presentamos algunos de los posibles caminos por los que pueden discurrir futuras investigaciones en relación a este asunto.

Finaliza el capítulo con el descubrimiento de la vidriera a través de la cual hemos observado la Educación Física española de finales del siglo XX y principios del XXI en relación al asunto de la exención. 


\section{1.- ANÁLISIS GLOBAL DE LA TESIS}

Este es un apartado de obligada redacción por mi parte. Si me he presentado como una persona reflexiva, no puedo por menos que realizar una revisión de todo el proceso seguido y del resultado final.

Al respecto del objeto de estudio, ha sido determinante la experiencia personal desarrollada en el marco profesional en el que me muevo diariamente y la relación que he mantenido con varios alumnos que por sus características físicas no podían seguir un “normal” desarrollo de las clases de Educación Física, especialmente Virginia.

Las inusuales y especiales circunstancias que rodearon a esta encantadora persona fueron el detonante de mis replanteamientos profesionales y de mis ansias de conocer qué aporta la Educación Física (y cómo lo hace) a estos alumnos con dificultades de aprendizaje asociadas a discapacidad motora en sus "casos más extremos".

Quiero aclarar que, aunque se pudiera pensar que en la elaboración de esta investigación educativa la implicación personal ha dado origen a una serie de inconvenientes que de alguna forma pudieran desacreditar el estudio (tales como la falta de criterio objetivo, una excesiva dedicación temporal, la delicadeza o "dureza" por las que ha habido que pasar en algunos momentos del trabajo, etc.), lo cierto es que estos aspectos han contribuido notablemente a hacerlo más sólido. De hecho, el sesgo con que se ha realizado la investigación pudo quedar resuelto en el momento en que se señalaron cuáles eran mis puntos de partida, los dilemas que se me plantearon y la evolución que he tenido sobre los mismos. 
Después de concluir la investigación, no puedo más que reafirmarme en mis convicciones de que la enseñanza es un proceso en el que intervienen diferentes actores cuyo protagonismo es dispar en función de determinados momentos y circunstancias. Considero que es de especial relevancia dar el papel que se merece a los alumnos y sus familias. La escuela debe ser más abierta y flexible. Las asignaturas constituyen solo una parte del sistema de formación de un alumno y, en lo que a la nuestra se refiere, no tenemos la solución de todos los problemas, males, o como se quiera llamar, de la educación. La experiencia vital de una persona puede ser completamente plena sin necesidad de haber recibido nuestras enseñanzas. De ahí que insinúe a lo largo de la tesis la posibilidad de preguntar a los alumnos en situación de "casos extremos" y sus familias sobre sus intereses al respecto de la Educación Física.

En lo que a la duración de la investigación se refiere, si se computa el periodo que abarca desde sus inicios (con la elaboración del trabajo de investigación), hasta su finalización y presentación, se antoja algo extenso. No obstante, como ya advertía en el Capítulo 4, ha habido un gran periodo de relativa inactividad (de casi tres años) debido a circunstancias ajenas a la propia investigación. El tiempo efectivo (útil) dedicado a los menesteres propios de un trabajo de este tipo se puede considerar en la línea de lo prudente, en torno a unos tres años (Eco, 2001, p. 33) o unos 5-6 a tiempo parcial (Phillips y Pugh, 2008, p. 103). Además, no se puede pasar por alto que ha habido que compaginar la labor investigadora con las personales, profesionales y formativas del autor.

Una vez delimitado el problema sobre el que deseaba investigar, me propuse la consecución de unos objetivos que, entre otras funciones, han servido para no perderme en la búsqueda de información al margen de la necesaria y no divagar por cuestiones ajenas al estudio. Por tanto, han guiado en todo momento mis decisiones y actuaciones, encauzando y dirigiendo el trabajo hacia lo que considero un éxito personal y profesional.

A lo largo de los capítulos se ha pretendido mostrar la Educación Física de principios del siglo XXI en relación al asunto de la exención. Con toda probabilidad, 
cuanto más cerca nos situemos de 1995 más fácil ha sido encontrar información en esa línea. Pero la situación, como se habrá podido comprobar por la fecha de los documentos empleados, fuentes bibliográficas y de información que se han consultado, etc., no ha variado en demasía y el uso de este término ha perdurado (perdura) aún en nuestra materia.

En el Capítulo 4 se redactaron unos objetivos muy claros y concretos que se han conseguido de manera satisfactoria, como podremos comprobar más adelante cuando presentemos las conclusiones referentes a cada uno de los capítulos o apartados.

Como quedó aclarado en ese Capítulo 4, el proceso de investigación arranca de la revisión y adaptación del trabajo realizado para obtener la Suficiencia Investigadora. Esto supuso no solo retocar, modificar y ampliar aquellos capítulos que lo precisasen (de hecho, fueron todos ellos), sino tener en cuenta las líneas de investigación que en su día surgieron para darlas continuidad o desecharlas. Todo ello ha contribuido a que esta tesis pasase de ser una "obligación" autoimpuesta por el autor, a ser una experiencia personal muy enriquecedora situada en la línea de lo que considero es la formación permanente del profesorado de Secundaria a través de la investigación sobre su propia práctica docente.

Todos los capítulos se encuentran entrelazados los unos con los otros, de manera que es inevitable encontrar en todos ellos revelaciones que van ratificando o modificando la aparecida en otros (ya sean anteriores o posteriores). Además, estas informaciones suelen generar otras líneas de investigación o nuevos pasos a seguir. Así pues, el proceso seguido tiene un carácter cíclico ya que todo el engranaje de obtención y análisis de datos ha estado en continuo movimiento, "rozándose" unos capítulos con los otros y generando piezas de información que servirán para dilucidar el lugar de la “exención invisible" en la Educación Física de la E.S.O. y el Bachillerato de principios del siglo XXI. 


\section{2.- EL LUGAR DE LA EXENCIÓN EN LA NORMATIVA}

El objetivo que se perseguía con el desarrollo del Capítulo 6, apartado 1, era: "Conocer cuáles son las normas legislativas que desarrollan la atención educativa para los alumnos con dificultades de aprendizaje asociadas a discapacidad motora $y$, de forma especial, las que contemplan cualquier posibilidad de exención". A la vista del resultado final, damos por esclarecidas las disposiciones normativas existentes en torno a estos dos asuntos.

Para empezar, la Orden de 10 de julio de 1995, que pone fin a la posibilidad de la dispensa de la Educación Física existente desde 1961, establecía claramente que la respuesta educativa que, en el marco de la LOGSE (y posteriormente de la LOE), había que ofrecer en las clases de Educación Física a los alumnos con necesidades educativas especiales asociadas a discapacidad debía ser en términos de adaptación curricular. Sin embargo, esta norma resultó ser ambigua y muy general, sin apenas aportar respuestas más o menos aplicables.

Con las nuevas apariciones legislativas a partir del 2010 (especialmente la ORDEN EDU/849/2010, de 18 de marzo, por la que se regula la ordenación de la educación del alumnado con necesidad de apoyo educativo), se deja de reglamentar en las etapas obligatorias de enseñanza la forma específica de atender a los alumnos con dificultades de aprendizaje en la Educación Física. La respuesta debe ser la misma que para el resto de las materias: el diseño y elaboración de la correspondiente adaptación curricular más o menos significativa (vid.: página 100).

En la etapa postobligatoria, la exención de la Educación Física es contemplada como una auténtica realidad, especialmente regulada en el ámbito autonómico de Castilla y León (ORDEN EDU/490/2014, de 10 de junio).

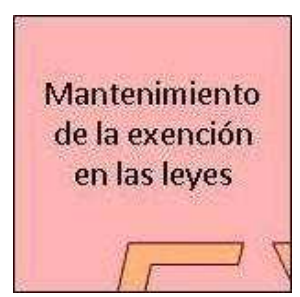


Aunque no se trata de alumnos con dificultades de aprendizaje, existen normas que hacen perpetuar la exención en la E.S.O. y el Bachillerato, pero se "maquilla" este concepto por otro más "correcto". Nos estamos refiriendo a la convalidación de la Educación Física por cursar estudios de las enseñanzas profesionales de danza o por poseer la condición de deportista de alto nivel. Ambos son motivos que generan la exención

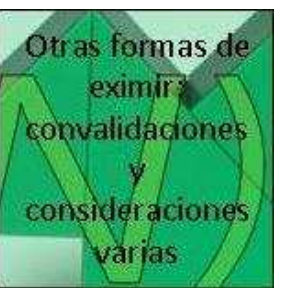
de la materia.

Por otra parte, consideramos que esta madeja legislativa pudiera estar desencadenando un cierto trasvase "camuflado" de las normas del Bachillerato a la E.S.O. ya que, entre otros motivos, suelen coincidir los profesores que dan clase a ambas etapas, siendo relativamente fácil aplicar en una de ellas lo que se hace en la otra.

\section{3.- LA EXENCIÓN EN EL SABER DISCIPLINAR Y POPULAR}

Nos propusimos como objetivo segundo y tercero comprobar cómo aparece la exención en el marco del saber disciplinar de la Educación Física, así como en el popular, lo cual incluía averiguar qué puede estar propiciando su aplicación u perdurabilidad.

Pues bien, con los datos recabados no hemos percatado de que hay autores que, quizás como consecuencia de la consolidada tradición que ha adquirido su uso y significado, continúan empleando dicha terminología para referirse a un alumno muy concreto. De igual manera, se ha constatado que una parte de la sociedad, entendiendo por tal a los que reciben nuestras enseñanzas y sus

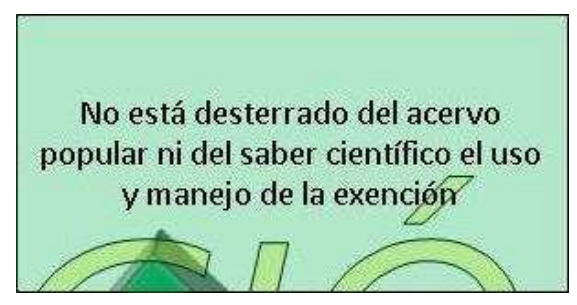
familiares, los médicos, legisladores, periodistas, humoristas, formadores..., no ha desterrado de su lenguaje el concepto de la exención, ni todo lo que lleva asociado su significado. Es un término que la gente usa en el contexto de la Educación Física con 
una acepción muy concreta. No podemos obviar que el concepto ha estado vigente más de 30 años y que la normativa posterior ha sido algo difusa por momentos.

Aunque el término no aparece en las fuentes de información en su sentido más estricto (eliminación de las clases de Educación Física del currículo del alumno), sí adquiere un cierto valor restrictivo y/o privativo referido a la parte físico-práctica de la materia. Cuando los diferentes autores se refieren a un alumno exento, lo suelen hacer con el mismo valor y en los mismos términos que aquellos que lo consideran "exento de la práctica", es decir, eliminan radicalmente de su currículo cualquier actividad o contenido físico-práctico. Este hecho en sí mismo es considerado como una adaptación curricular.

Esto enlaza con los diferentes tipos de exención que van a aparecer constantemente: total o parcial, temporal o permanente (vid.: páginas 100 y 101).

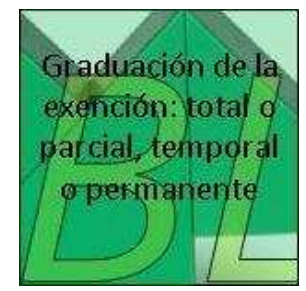

Por lo que se refiere a las respuestas que suele dar la Educación Física a estos alumnos, aparte de las que se sitúan en la línea de la exención parcial, suelen estar muy próximas a las propias de la falsa integración (arbitrar, cronometrar, colocar y retirar

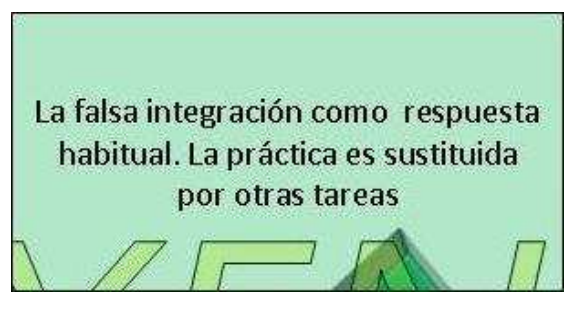
material, anotar, ayudar...). Y lo mismo ocurre con los instrumentos empleados en la evaluación y calificación de estos alumnos. Mayoritariamente se propone, previa asistencia a clase, la realización de pruebas escritas, elaboración de trabajos, exposiciones orales de los mismos, etc. Todo ello responde a la necesidad de tener que justificar una nota que debe figurar en el expediente académico del alumno.

Pero para ofrecer esa respuesta, se establece como requisito indispensable la presentación del preceptivo informe médico en el que se acredite la discapacidad o problemas físicos, sensoriales o psíquicos que tiene el alumno. El poder que se otorga a estos documentos y a quienes los expiden va a ser determinante en la actuación del 
profesor de Educación Física. Idéntico poder parecen tener los justificantes paternos. Por ello, estos dos asuntos fueron objeto de estudio en el Capítulo 10.

Los datos logrados nos llevan a afirmar que el profesor ocupa un lugar privilegiado en el mantenimiento de la exención (en cualquiera de las formas vistas), ya sea por la falta de preparación y de conocimientos sobre el asunto, la escasez de medios con que cuenta para ejercer su labor, los miedos y responsabilidades propias de su profesión, la actitud hacia este tipo de alumnos, así como la concepción y apego que pueda tener de su materia.

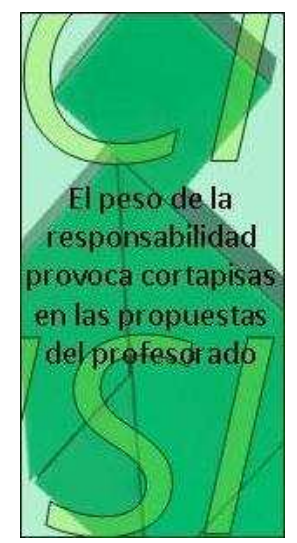

\section{4.- LAS PROGRAMACIONES DIDÁCTICAS: CONCRECIÓN DEL CURRÍCULO Y DE ASUNTOS PROPIOS DE LA EXENCIÓN}

Uno de los primeros pasos dados en el desarrollo de esta tesis fue comprobar la forma en que se presenta la "exención" en las programaciones didácticas de Educación Física de los institutos pertenecientes al ámbito de estudio. Todo el análisis tenía como referencia la norma establecida al efecto que estaba vigente en el momento en que se produjo el estudio.

Hemos comprobado que este documento no se caracteriza precisamente por estar realizado de forma minuciosa, con apoyos documentales y legislativos, con arreglo a lo que dicta la ley y, además, se aprecia que en su elaboración no ha habido un trabajo colaborativo basado en la puesta en común, sino una labor sumativa de información aportada de manera independiente por personas diferentes.

Conectando con esto, también hemos apreciado que son documentos poco operativos, escuetos en información y generales en sus aplicaciones. Quizás se debe a que son instrumentos que más que desempeñar una necesaria labor de concreción del currículo para el adecuado desarrollo del proceso de enseñanza-aprendizaje, comienzan 
a ser considerados como indispensables para el cumplimiento de una función meramente administrativa y burocrática.

De igual manera, se aprecia que los mediadores culturales suelen marcar y definir algunas de las líneas de acción de esta materia, puesto que muchos de los apartados de estos documentos son meras copias de programaciones didácticas elaboradas por las

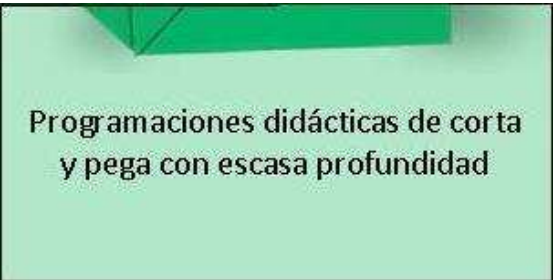
editoriales que aparecen "colgadas" en Internet o están disponibles en formato CDROM.

Unido a lo anterior, se ha comprobado que algunas programaciones presentan un idéntico desarrollo en determinados capítulos, lo cual pudiera ser debido a las copias literales que se realizan de las ya existentes en el mercado o, a que la movilidad a la que está sujeto el profesorado hasta conseguir una plaza definitiva en un centro conlleva el trasiego de sus elucubraciones documentales sin importar en demasía la contextualización de sus proyectos.

En lo que respecta a su contenido, destaca el lugar que ocupa el apartado dedicado a la evaluación. Los instrumentos empleados, los porcentajes establecidos para calificar, los momentos en que se realiza, los mínimos necesarios para superar el área... así lo atestiguan.

Respecto del asunto de estudio de esta tesis, el obligado apartado de la atención a la diversidad, a pesar de ser un tema tratado en numerosos casos, es abordado de manera somera y superficial. Al igual que ocurría con la Orden de 10 de julio de 1995 , las directrices y pautas establecidas por los profesores son muy globales y generales.

Tras el estudio de las programaciones, se confirma el uso de la exención de la práctica, así como la línea de respuestas ofrecidas en la senda de la falsa integración, la evaluación que se les aplica en base a trabajos, pruebas teóricas, etc. y el poder de los certificados médicos para la gestión de estos casos extremos. Asimismo, a pesar de que 
la asistencia a clase es un hecho obligado por la etapa educativa en la que estamos, se insiste en que deben acudir siempre a las sesiones de Educación Física (¿acaso se está aludiendo a una forma de actuar propia del pasado en el que sí se permitía la exención?).

Por último, puesto que el certificado médico adquiere importancia en la propuesta de respuestas educativas para los alumnos que lo requieran, hay profesores que toman la iniciativa y se adelantan a la actuación del facultativo señalando una serie de puntos como necesarios para que el informe tenga algún valor a efectos de provocar una adaptación curricular.

\section{5.- LOS PROFESORES DE EDUCACIÓN FÍSICA SE MANIFIESTAN SOBRE LA EXENCIÓN}

La aproximación a la visión y creencias que el profesorado de Educación Física tiene de este asunto ha sido abordada en el Capítulo 8. A este respecto, de los datos obtenidos del cuestionario cumplimentado por los docentes de Educación Física de los centros públicos de Secundaria de Valladolid y provincia, destacamos las siguientes revelaciones:

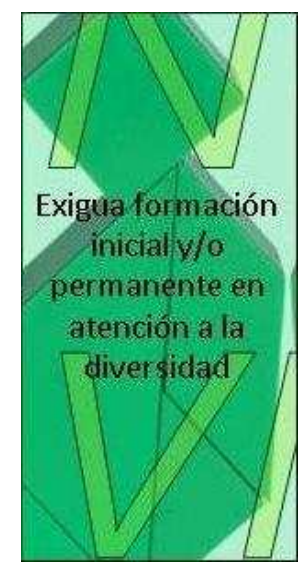

Respecto de la formación, parece ser que esta temática tiene un escaso desarrollo en los planes de estudio de las carreras universitarias que poseen los profesores de Educación Física. Aun así, la formación permanente de los docentes acerca de este asunto se caracteriza por una ausencia generalizada, lo cual se puede transmitir en una falta de conocimientos para tratar a estos alumnos.

A este reducido dominio de técnicas y estrategias se unen los pocos medios materiales y personales con los que cuenta el docente para impulsar la toma de 
decisiones encaminadas a dar una respuesta educativa adecuada al alumnado que posea algún tipo de discapacidad.

Se ha denotado en el profesorado una importante falta de conocimiento legislativo sobre asuntos específicos de la materia, lo cual puede desembocar en la aparición de líneas de actuación erróneas y tomas de decisiones ilícitas e inapropiadas.

Muchos profesores confirman que los conceptos "exento" y/o "exento de la

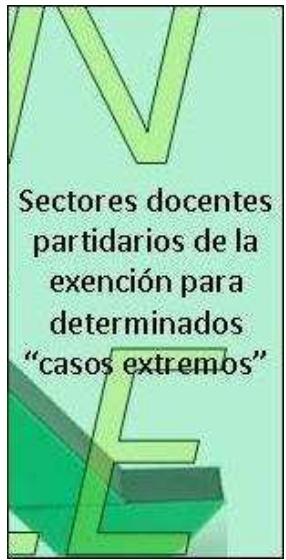
práctica" tienen plena vigencia en nuestra disciplina ya que son empleados en sus programaciones didácticas para referirse a un tipo muy concreto de alumno. Es más, hay encuestados que son partidarios de que se recuperen estos términos con todas sus connotaciones y significados como medida a aplicar a los "casos extremos" de alumno con necesidades educativas especiales asociadas a discapacidad. Otros muchos, no ven como un disparate la posibilidad de que la

Educación Física sea para estos alumnos una materia optativa en vez de obligatoria. De hecho, hay alumnos de estas características que no quieren asistir y/o participar en la clase de Educación Física. su decisión de cursar o no Educación Física

Parece ser que sí se realizan adaptaciones curriculares individualizadas y que el certificado médico suele solicitarse como primera medida en la mayoría de los centros, corroborando así el poder que se concede a dicho documento.

Respecto de las respuestas ofrecidas a estos alumnos, existe una variada gama de tareas para que estos alumnos "participen" en clase. Principalmente se encomiendan las que propician una falsa integración (arbitrar, colocar material, programas de rehabilitación, etc.). También las hay que conllevan una mayor implicación del alumno, como el cuaderno de clase y los trabajos teórico / prácticos.

Un hecho que nos ha sorprendido ha sido la constatación de que aparecen conflictos y problemas de adaptación entre los "casos extremos" de alumnos con 
necesidades educativas especiales asociadas a discapacidad y el resto de sus compañeros.

\section{6.- LA EXENCIÓN IRRUMPE EN EL TRAYECTO DE MI FORMACIÓN PERMANENTE}

Hasta ahora, la formación del profesorado de Educación Física en temas relacionados con la atención a la diversidad, aparece como un desencadenante de la aplicación de medidas en la línea de la exención. Por ello, en el Capítulo 9 recurrí a mi propia formación, inicial y permanente, para conocer de primera mano si en ese contexto la exención se planteaba o fomentaba de algún modo.

Antes de pasar con las revelaciones más importantes halladas en dicho capítulo, quisiera destacar que el tema de la formación permanente, como se dijo al principio de esta tesis, forma parte de mi inquietud personal y profesional. No entiendo el desempeño de mi labor docente sin una constante actualización que conlleve la adquisición de nuevos aprendizajes que me permitan llevar a cabo mi labor diaria con los alumnos y compañeros con mejores sensaciones y, en la medida de lo posible, con más acierto pedagógico.

A lo largo de todo ese camino he podido conocer propuestas novedosas que tomaré prestadas para aplicarlas en mis clases; he compartido momentos y palabras con gente fascinante, llena de inquietudes y, sobre todo, sentimientos maravillosos hacia nuestra apreciada Educación Física; he actualizado y aprendido conocimientos sobre actuaciones ante situaciones lesivas en nuestras clases; he renovado mi formación en lo que a la elaboración de una Adaptación Curricular Individual se refiere; he comprobado que existen otros puntos de vista sobre cómo enfocar este delicado asunto del tratamiento de los alumnos con necesidades educativas especiales asociadas a cualquier tipo de discapacidad motriz; me he familiarizado con las leyes que lo rigen y que 
homogenizan todos los casos como si todos los casos fueran exactamente iguales; dispongo de una extensa fuente bibliográfica y de información que aborda todo el asunto...

En lo que respecta a los datos relevantes para el objeto de estudio, se constata la aparición de opiniones e informaciones que giran en torno a la exención. Es más, en algún momento, la exención, parcial o total, se fomenta desde los propios expertos ("Ni la muevas"). La razón no es otra que evitar males mayores, tanto para la salud del individuo en cuestión, como para el profesorado en lo relativo a las consecuencias derivadas de la

La exención aparece $y$ se fomenta en el camino de la formación continua responsabilidad asumida. Las respuestas educativas que se pudieran adoptar ante los alumnos con necesidades educativas especiales en sus "casos extremos", son sustituidas por la nada o, en todo caso, por "prácticas inclusivas" que no son más que una continuidad de las recogidas en el concepto de la falsa integración.

Finalmente, se ha comprobado que este asunto preocupa entre nuestro colectivo, pudiendo llegar a ocupar un lugar privilegiado en algunos foros de expertos.

\section{7.- EL PODER DE LOS PAPELES MÉDICOS Y FAMILIARES}

Cuando nos propusimos indagar sobre los documentos médicos y familiares que los alumnos emplean para justificar principalmente la "no práctica" de la Educación Física, no nos imaginábamos el auténtico estado de la cuestión.

Lo que llama la atención de los escritos médicos, independientemente de su procedencia, formato, contenido, especificidad..., es su auténtico poder Así, aunque algunos de ellos no tendrían la consideración de documento oficial a tener en cuenta, se acata con "cierta sumisión" lo que en ellos se nos indica. El poder se lo damos nosotros. 
En otros casos el poder ya es más "oficial". El tipo de papel o documento empleado y quien los firma disfrutan de una autoridad que está por encima del saber disciplinar del propio profesor. Aquí el poder es claro, pues el origen de la información se sitúa en otro saber científico con más poder que el nuestro. Los médicos pueden no conocer con certeza lo que en nuestras clases realizamos y cómo lo hacemos, pero se acepta por válida y preponderante su opinión respecto de la que podamos tener nosotros.

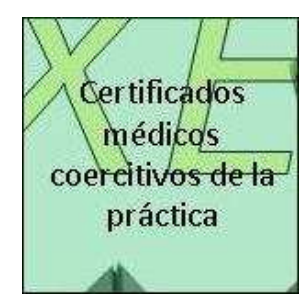

$\mathrm{Su}$ "medicina defensiva" (para evitar males mayores y acelerar la posible recuperación, proceso rehabilitador o lo que fuere, que el alumno no haga nada hasta nuevo aviso) transforma nuestra materia en una "Educación Física defensiva" (mejor que no hagan no vaya a ser que...).

Se echa en falta una norma específica y exclusiva para la Educación Física que, como paso previo a la realización de cualquier tipo de adaptación curricular, detalle los términos en los que se tengan que redactar los certificados médicos aportados. En esta normativa, el profesor de Educación Física debería formar parte del equipo de personas que tienen algo que decir al respecto de las auténticas posibilidades que ofrece la materia a cada caso en particular. Hasta el momento, la decisión de emitir un informe acreditativo del estado de salud de un alumno, en lo relativo a nuestras clases, recae en los médicos, asumiendo un protagonismo mayúsculo en el contexto educativo de la atención a la diversidad.

Por otra parte, los escritos familiares dirigidos a la atención del profesor para comunicar, en forma de advertencias, las limitaciones que tiene un alumno, suelen ser escrupulosamente tenidos en cuenta, desencadenando respuestas en la línea de la falsa

Los papeles familiares invitan a la no práctica integración. 


\section{8.- LA EXENCIÓN MANTENIDA POR LA RESPONSABILIDAD QUE ASUME EL DOCENTE}

En el capítulo dedicado al marco teórico se puso de manifiesto que el factor responsabilidad o el miedo a las consecuencias derivadas de la actuación docente pueden ser incentivos para la aparición de la exención. Por su relevancia, esta idea pasó a ser uno de los objetivos de esta tesis, desarrollándose a lo largo del Capítulo 11.

Con los datos expuestos en este capítulo, se pone de manifiesto que nuestra materia no solo es percibida como riesgosa por todo el colectivo docente, sean o no de Educación Física, sino que verdaderamente existen pruebas que así lo evidencian.

A la vista de las noticias existentes sobre accidentes y sucesos ocurridos en las clases de Educación Física, resulta evidente que esta materia puede ser considerada como de riesgo. $\mathrm{Y}$ esto no pasa desapercibido para los diferentes medios de comunicación, especialmente los de formato digital. De hecho, por aparecer una misma noticia multitud de veces en distintos sitios Web, se la confiere de mayor notabilidad. Es decir, se percibe como un suceso importante desde el momento en que muchos medios ofrecen la noticia en cuestión en sus contenidos.

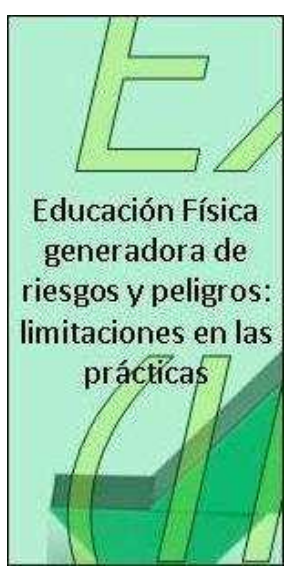

Las normas estudiadas y su aplicabilidad, así como la propia opinión de expertos legislativos y de nuestro saber disciplinar, insisten en la idea de la

Elmiedo $y / 0$ dudas en profesores $y$ alumnos desencadenan inacción enorme carga que asumimos en nuestro quehacer diario. Cuando el trabajo se desarrolla con alumnos que tienen necesidades educativas especiales, la situación se agrava notablemente. Todo ello pudiera estar llevando a los profesores de Educación Física a adoptar una actitud "defensiva" (¿legítima?) en a las respuestas y propuestas que ofrecen a alguno de estos alumnos, los llamados "casos extremos", en favor de una inactividad, total o parcial, o en la línea de la falsa integración. 
Por último, conviene destacar que la ausencia de una correcta formación en el profesorado se presenta nuevamente como uno de los motivos que generan inseguridad y, por ende, aumentan la sensación de responsabilidad asumida que, en última instancia, desembocará en la limitación o ausencia de una auténtica atención educativa de calidad.

\section{9.- LA EXENCIÓN VISTA POR LOS IMPLICADOS Y SUS} FAMILIARES

No cabe duda alguna de que el objetivo que nos habíamos propuesto al respecto de los interesados y sus familias (vid.: página 37, objetivo 9), ha sido logrado con rotundidad durante el desarrollo y exposición del Capítulo 12.

Según la información recogida en dicho capítulo, es evidente que los alumnos que se encuentran con algún tipo de necesidad educativa especial o dificultad de aprendizaje asociada a discapacidad motriz, así como sus familias, desean que su opinión cuente para la toma de decisiones. Quieren expresar sus intereses, motivaciones y necesidades de la Educación Física; que no se les cierre la puerta a la posibilidad de poder escoger libremente si desean que todo el gran esfuerzo y sacrificio, del profesor y

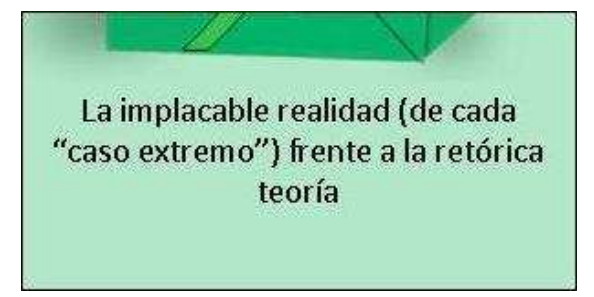

de ellos mismos, tenga lugar. No piden ser declarados exentos de forma automática, pero sí anhelan poder ser escuchados y tener la opción de elegir si esta materia debe formar parte, temporal o

También se ha puesto en evidencia que la Educación Física que se oferta a estos “casos extremos" se sitúa en muchos momentos en la línea de la falsa integración y, 
sobre todo, de la no participación activa, lo cual desencadena sentimientos de marginación más profundos que si se les declarásemos “oficialmente" exentos ${ }^{235}$.

Al respecto de este concepto, los alumnos se sienten y denominan como tal, independientemente de que nunca se les haya aludido en esos términos, lo cual viene a corroborar lo apuntado en la página 185 sobre el uso de la exención que sigue haciendo parte de la sociedad.

Finalmente, a la vista de de las informaciones extraídas en el Capítulo 12, se ha advertido que el ánimo del alumno en cuestión depende directamente del estado de salud en que se encuentre, por lo que es conveniente disponer de instrumentos y momentos para que se puedan expresar y desahogar. En el caso que nos ocupa, el cuaderno de clase surtió este efecto de manera eficaz, contribuyendo notablemente a que Virginia se sintiese atendida. De alguna forma se establece una especial y sincera comunicación entre el autor del cuaderno y el profesor que lo corrige (Rodríguez y Lera, 2006).

\subsection{0.- CONTRADICCIONES RELEVANTES}

En la E.S.O. y el Bachillerato las leyes que regulan la temática de la exclusión o exención en el área de Educación Física son, como poco, contradictorias. No alcanzamos a comprender qué motivos (aparte de la obligatoriedad o no de ambas etapas) originan que en la etapa obligatoria sea imposible aceptar la exención como una práctica que se pueda producir (¿ni plantear?), mientras que en la postobligatoria sí se concibe legalmente esa posibilidad. Si con la inclusión en las clases de Educación Física en la E.S.O. se produce un claro beneficio del individuo con discapacidad, no

\footnotetext{
${ }^{235}$ A este respecto, he vivido alguna que otra situación anecdótica bastante ilustrativa de situaciones similares. La última, pocos meses antes de terminar esta tesis, una profesora con la que trabajé durante un curso escolar, solía enviar a la biblioteca a una alumna con necesidades educativas especiales asociadas a discapacidad intelectual, cuando en su clase se trataban asuntos de cierta "magnitud" teórica. Y lo hacía argumentando que de esa forma la alumna no percibiría que no era igual que el resto y así no se sentiría excluida de la actividad. En definitiva, se la apartaba del grupo para que no se sintiera diferente.
} 
entendemos por qué no se obliga a buscarlo también en el Bachillerato y, sin embargo, el alumno puede optar a la exención si así lo pide y se considera oportuna su concesión.

Los datos obtenidos con esta investigación nos revelan que la forma en que el profesorado lleva a la práctica lo establecido por la ley en el ámbito de la E.S.O. y el Bachillerato, aún dista mucho de ser una misma realidad. Hay casos que siguen utilizando la exención de una forma encubierta, camuflada o "invisible" para dar respuesta a las necesidades educativas especiales que presentan algunos de sus alumnos. Lo mismo se podría decir de muchas de las fuentes bibliográficas.

Es paradójico que en la elaboración de las programaciones didácticas se tenga en cuenta lo que dicta alguna norma en lo referente a la elaboración de forma conjunta con el Departamento de Orientación de las adaptaciones curriculares a los alumnos que así lo precisen (como es el caso del Real Decreto 83/96), y sin embargo no tomen en consideración lo que en esa misma ley aparece recogido para la correcta realización de las propias programaciones. Es decir, parece que se acata la ley en aquello que se quiere.

Hay grandes diferencias entre lo que los profesores establecen en sus programaciones didácticas y lo que dicen llevar a la práctica. La teoría, entendida como el tercer nivel de concreción, aún está lejos de la práctica diaria que tiene lugar en las clases de Educación Física. Se marcan unas pautas de actuación, para luego no ponerlas en acción.

\subsection{1.- FUTURAS LÍNEAS DE INVESTIGACIÓN}

Para completar la aproximación a la actuación del profesorado se podría realizar en un instituto de Secundaria en el que exista algún alumno que reúna las características de un "caso extremo" un estudio de caso centrado en el propio individuo y su convivencia en el centro de forma general, y con la Educación Física de manera 
específica. Del seguimiento pormenorizado de las relaciones entre este alumno y la Educación Física, así como de la revisión de la programación didáctica y de la de Aula, surgirán nuevos datos que nos situarán sobre la auténtica realidad que se vive en nuestras clases.

Además, consideramos fundamental conocer la trayectoria que este alumno ha seguido en la Educación Física a lo largo de los años en que ha estado presente en su formación, para lo cual recurriríamos a su historia de vida. Su paso por la Educación Física desde los comienzos de la escolaridad, sus intereses, sus motivaciones, sus problemas de adaptación, sus logros, etc. Incluso se puede investigar sobre cómo les afecta esta sociedad del culto al cuerpo, donde el rendimiento y la perfección corporal inundan nuestra sociedad. Llegados a este punto, también apelaríamos a la opinión y vivencias de sus familiares más próximos.

Otra línea de investigación podría girar en torno a la creación de un grupo de profesores de Educación Física para tratar y debatir sobre asuntos de esta índole. Así concebido, estaríamos ante la técnica del grupo de discusión, enmarcado como una de las técnicas etnográficas de investigación (Goetz y Lecompte, 1988). Hernández (1994) nos aproxima a la definición de esta técnica con un lenguaje sencillo.

"El grupo de discusión es ante todo un proceso dialéctico en el que un pequeño grupo perteneciente a un colectivo investigado va elaborando un discurso en una situación de comunicación interpersonal. Un discurso en libertad a través del cual es posible poner de manifiesto las concepciones que los participantes tienen de diferentes aspectos de su mundo profesional." (Hernández, op. cit., p. 230)

Para que esta técnica prospere se hace indispensable que el moderador, con sus planteamientos, preguntas y sugerencias de debate, no guíe en exceso a los demás interlocutores hacia la manifestación de unos comentarios poco próximos a su auténtica forma de pensar y proceder (Valles, 2003), evitando también así la "deseabilidad y conformidad social" (ibídem), por la que los participantes responden lo esperado o lo políticamente correcto y no sus opiniones más íntimas y originales. 
Retomando las posibilidades de dar continuidad a esta tesis, el campo de la atención a la diversidad es tan amplio que se podría investigar sobre temas más generales: cómo se contempla la Educación Física por los grupos étnicos inmigrantes con fuertes tradiciones culturales, religiosas y sociales y, más concretamente, cómo les afecta la (in)visible exención por dichas causas.

También se puede investigar sobre alumnos con discapacidad motriz que continúan con estudios relacionados con la Educación Física y luego ejercen esta profesión o similar. En esta línea, se puede revisar el acceso a la función pública docente a lo largo de un periodo de tiempo. De igual manera, resultaría interesante investigar acerca de casos de profesores que continúan ejerciendo su carrera profesional después de haber sufrido algún tipo de lesión, enfermedad, etc. que les haga ser catalogados como discapacitados motrices. 


\subsection{2.- ENCAJANDO TODAS LAS PIEZAS}

Como decíamos al comienzo de la tesis (página 38), hemos ido dando formas de cristales de una vidriera a las principales ideas que subyacen del desarrollo de los capítulos en relación a la consecución de los objetivos establecidos. En este momento final nos encontramos con que todas esas piezas han sido reveladas y expuestas sobre la mesa. Solo falta encajarlas. Cuando lo hacemos, observamos que en la vidriera que se forma, a través de la que hemos estado observando y analizando la Educación Física española entre 1995 y principios del siglo XXI, aparece la exención (in)visible en toda su magnitud. Obviamente, esta panorámica se ve acentuada cuando se trata de la atención a los "casos extremos" de alumnos con necesidades educativas especiales asociadas a discapacidad motriz.

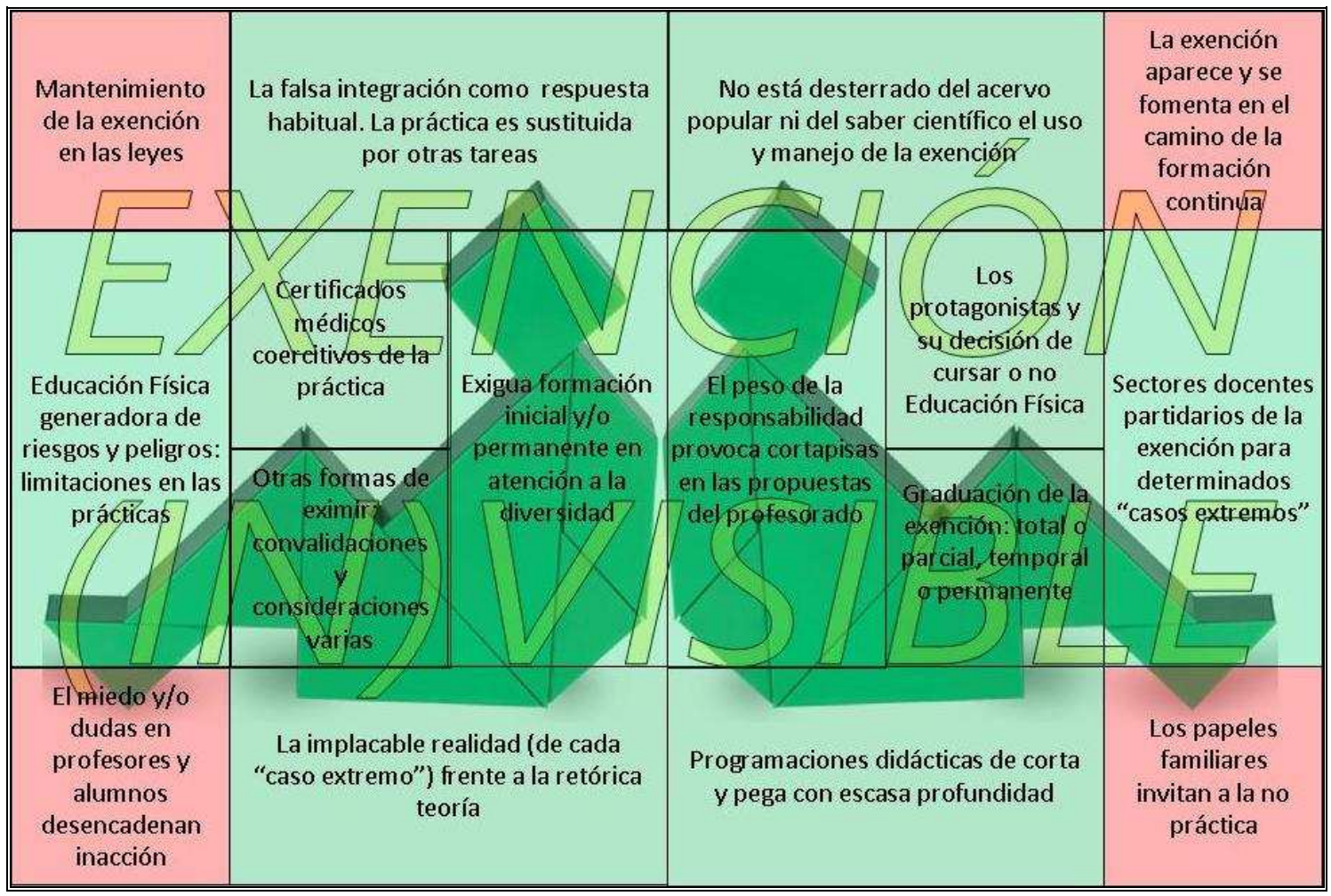

Ilustración 4: La exención (in)visible en la Educación Física española entre 1995 y principios del siglo XXI (elaboración propia ${ }^{236}$ )

\footnotetext{
${ }^{236}$ El dibujo del fondo de la vidriera está extraído de https://www.ludusludi.com/es/producto/tangram-3dverde/
} 
BIBLIOGRAFÍA 
Con la finalidad de identificar clara y rápidamente la procedencia y formato de las fuentes bibliográficas utilizadas en la tesis, hemos empleado símbolos y colores que dan a entender si se trata de un documento escrito $(\mathbb{L} \mathbb{d})$, si la información procede de

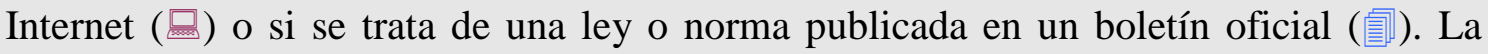
exposición se presenta por orden alfabético según los apellidos del/os autor/es, o por el nombre con el que aparecen en la tesis en caso de tratarse de un documento en formato http (tomado de Internet) sin autor concreto o identificable.

\section{A}

[1] AA. VV. (Seminario permanente de Educación Física de Fuerteventura) (1990). Exenciones en Educación Física. Un tema a debate. Revista de Educación Física Escolar Minitramp, 1, pp. 7-8.

AA. VV. (1992). Programas y contenidos de la educación físico-deportiva en B.U.P. y F.P. Barcelona: Paidotribo.

$\mathbb{E}$ AA. VV. (2002). Educación Física $1^{o}$ de ESO. Barcelona: Santillana.

[D ÁLAMO VAQUERA, P. (2010). Ortografía Cantada y Gramática Española, Madrid: Visión Libros.

ALBORNOZ, O. O. (2001). La práctica de la Educación Física y sus riesgos. 
Revista digital de Educación y Nuevas Tecnologías, 4. Recuperado el 3 de noviembre de 2010, de http://contexto-educativo.com.ar/2001/4/nota-08.htm

ALBORNOZ, O. O. (2002). La práctica de la Educación Física y sus riesgos. Revista Internacional de Medicina y Ciencias de la Actividad Física y el Deporte, 6. Recuperado el 3 de noviembre de 2010, de http://cdeporte.rediris.es/revista/revista6/artriesgo.html

[D ALEJANDRE DE LA TORRE, A. (1994). Formación en Educación Física Especial de los Licenciados en Educación Física. Apunts, 38, pp. 114-119.

C] ALEJANDRE DE LA TORRE, A. (1997). Formación en Actividad Física Especial de los Licenciados en Educación Física. En ARNAIZ SÁNCHEZ, P. y DE HARO RODRÍGUEZ, R. (Eds.), 10 años de integración en España: Análisis de la realidad y perspectivas de futuro (pp. 573-586). Murcia: Universidad de Murcia.

昌 ALONSO LÓPEZ, R. F. (2000). El profesor de Educación Física: especialista del ejercicio físico. Lecturas: Educación y Deportes, 19. Recuperado el 4 de octubre de 2003, de http://www.efdeportes.com/efd19/profef.htm

d] ÁlvareZ BUENO, G. (1986). Materiales de apoyo. Plan de Extensión de la Educación Física y el Deporte. Madrid: MEC.

[D] ÁLVAREZ-GAYOU, J. L. (2003). Cómo hacer investigación cualitativa. Barcelona: Paidós Ecuador.

Q] ANDER-EGG, E. (1995). Técnicas de investigación social. Buenos Aires: Lumen.

[D] ANDER-EGG, E. (2000). Métodos y técnicas de investigación social III. Buenos Aires: Lumen.

ANGRIMAN, M. A. (2002). Algunas recomendaciones sobre la responsabilidad 
legal del docente de educación física. Lecturas: Educación y Deportes, 51. $\begin{array}{llllll}\text { Recuperado el } & 10 \text { de noviembre de }\end{array}$ http://www.efdeportes.com/efd51/legal.htm

D ANGUERA ARGILAGA, M ${ }^{\mathrm{a}}$ T. (1986). La investigación cualitativa. Educar, 10, pp. 23-50.

[D] ANTOLÍN RUIZ, I. (2003). Estudio estadístico de lesiones con atención hospitalaria en centro educativo. En RUIZ JUAN, F. y GONZÁLEZ DEL HOYO, E. P. (Coords.), Educación Física y deporte en edad escolar (pp. 287-294). Actas del V Congreso Internacional de FEADEF. Valladolid: FEADEF.

ANTÚNEZ, S. (2003). Mujeres, actividad física y salud. Recuperado el 11 de mayo de 2004, de http://www.mujeresdeempresa.com/vida_cotidiana/vida03081.htm

[D] ARANZADI. Repertorio Cronológico de Legislación. Pamplona: Editorial Aranzadi.

ARENAS, G. (2000). Las madres en la educación, una voz siempre presente pero, ¿reconocida? En SANTOS GUERRA, M. A. (Coord.), El harén pedagógico. Barcelona: GRAÓ. Recuperado el 21 de marzo de 2005, de http://www.nodo50.org/mujeresred/coeducacion-gloria_arenas-2.html

[D] ARIAS ASTRAY, A. y FERNÁNDEZ RAMÍREZ, B. (1998). La encuesta social como técnica de investigación social. En ROJAS, A. J.; FERNÁNDEZ, J. S. y PÉREZ, C. (Eds.), Investigar mediante encuestas. Fundamentos teóricos y aspectos prácticos (pp. 31-50). Madrid: Síntesis.

[D] ARRABAL DE MATA, P. (1995). Reclamaciones de daños y perjuicios. Madrid: Ed. Paraninfo.

ARRÁEZ, J. M. (2003). Evaluar para integrar en las clases de educación física. 
Tándem, 11, pp. 18-32.

ARRÁEZ MARTÍNEZ, J. M. (1998). Teoría y praxis de las adaptaciones curriculares en la Educación Física: un programa de intervención motriz aplicado en la Educación Primaria. Málaga: Ediciones Aljibe.

[D] ARRÁEZ MARTÍNEZ, J. M. (2001). Dificultades de un maestro especialista de Educación Física ante la diversidad del alumnado. Inadaptados y marginados. En GIMÉNEZ, F. J.; SIERRA, A.; TIERRA, J. y DÍAZ, M. (Coords.), Educación Física y Diversidad (pp. 11-25). Huelva: Universidad de Huelva.

Dd ASTRÁIN GOÑI, C. (2002). LOGSE: Análisis de las divergencias entre teoría y práctica en el área de Educación Física en la Educación Secundaria Obligatoria. Tesis Doctoral no publicada. Universidad de Valladolid.

\section{B}

BARBERO GONZÁLEZ, J. I. (1996). Cultura profesional y curriculum (oculto) en Educación Física. Reflexiones sobre las (im)posibilidades del cambio. Revista de Educación, 311, pp. 13-49.

BARBERO GONZÁLEZ, J. I. (2007). De la «ficción» sobre cultura corporal, vida cotidiana y EF al potencial educativo e investigador de los relatos de vida. En MONERO GÓMEZ, W. y PULIDO QUINTERO, S. M. (Eds.), Educación, cuerpo y ciudad. El cuerpo en las interacciones e instituciones sociales (pp., 195-227). Medellín-Colombia: Ed. Funámbulos.

DDARCO, A. (2014). La materia de los recuerdos: circuitos neuronales y cascadas moleculares. Cuadernos Mente y Cerebro, 9, pp. 18-27.

BARRIOS PITARQUE, C. (2000). Salud y Práctica Deportiva. Aplicaciones 
Clínicas del Ejercicio Físico. Vigo: Fundación de Estudios y Formación Sanitaria.

BERNARDO, J. y CALDERERO, J. F. (2000). Aprendo a investigar en Educación. Madrid: RIALP.

DI BIGLA, B. y BONET-MARTÍ, J. (2009). La construcción de narrativas como método de investigación psico-social. Prácticas de escritura compartida. Forum: Qualitative Social Research, 10 (1), Art. 8.

BISQUERRA, R. (1989). Métodos de investigación educativa. Guía práctica. Barcelona: Ed. CEAC.

BISTUER ICARDO, F. (1996). Actuación del profesor de E. F. ante los alumnos con «problemillas». Revista Española de Educación Física y Deportes, (Vol. 3), 2, pp. 34-38.

[DI BLANCO GUIJARRO, R. (Coord., 1992). Alumnos con Necesidades Educativas Especiales y Adaptaciones Curriculares. Madrid: MEC.

BLANCO PEREIRA, E. (2003). La responsabilidad civil y penal del docente. En GONZÁLEZ DEL HOYO, E. P. y RUIZ JUAN, F. (Coords.), Dimensión europea de la Educación Física y el deporte en edad escolar. Hacia un espacio europea de educación superior (pp. 307-310). Valladolid: AVAPEF.

[D] BLÁNDEZ, J. (2010). La clase de Educación Física: escenario de la investigación. En GONZÁlEZ, C. y LLEIXÁ, T. (Coords.), Educación Física. Investigación, innovación y buenas prácticas (pp. 43-58). 4 (III). Barcelona: GRAÓ.

BLÁNDEZ ÁNGEL, J. (2000). La investigación-acción: Un reto para el profesorado. Barcelona: Inde.

BOHÓRQUEZ SIERRA, J. C.; TORREJÓN CARDOSO, R. y GARZÓN LÓPEZ, 
S. (1992). El ciclo menstrual en la mujer deportista. En MORA VICENTE, J. (Dir.), Estudios Monográficos sobre las Ciencias de la Actividad Física y el Deporte (pp. 59-66). Cádiz: COPLEF Andalucía.

[DI BOLÍVAR, A.; DOMINGO, J. y FERNÁNDEZ, M. (2001). La investigación biográfico-narrativa en educación. Madrid: La Muralla.

[DONÉ PUEYO, A. y CONTRERAS TRIVIÑO, A. (1985). Necesidades e intereses de los alumnos de Bachillerato y COU. En AA.VV., Aspectos didácticos de Educación Física 1: Bachillerato (pp. 45-60). Zaragoza: ICE Universidad de Zaragoza.

BORES CALLE, N. (2000). El cuaderno del alumno en el área de Educación Física en la Enseñanza Secundaria Obligatoria. Tesis doctoral no publicada. Escuela Universitaria de Educación de Palencia, Universidad de Valladolid.

Dd BRIONGOS DE LA FUENTE, F.; FERNÁNDEZ-RÍO, J.; MEDINA, J.; GARRO, J. y PÉREZ, M. (2000). La Educación Física en la LOGSE: Un caso práctico en paralíticos cerebrales. En AA.VV., El valor educativo de la diversidad (pp. 393400). II Congreso Nacional de Educación Especial, CSI-CSIF y Universidad de Valladolid. Valladolid.

BUENDÍA EXIMAN, L. (1992). Técnicas e instrumentos de recogida de datos. En COLÁS BRAVO, Mª P. y BUENDÍA EXIMAN, L., Investigación educativa (pp. 201-248). Sevilla: Alfar.

C

CALDERÓN LUQUIN, A. y MARTÍNEZ DE OJEDA, D. (2014). La formación permanente del profesorado de educación física. Propuesta de enseñanza del modelo de Educación Deportiva. Revista de Educación, 363, pp. 128-153. 
[CALVEROL LLAURADÓ, T. (2000). Atención a las necesidades educativas especiales de los alumnos con discapacidad física en los institutos de enseñanza secundaria de la ciudad de Barcelona. Apunts, 60, pp. 37-44.

Dd CAPLOW, T. (1974). Sociología fundamental. Barcelona: Vicens-Vives. Traducción de VILLA MARTÍN, J.

CASIMIRO ANDÚJAR, A. J. (1992). Exención total. Es difícil en Educación Física. En MORA VICENTE, J. (Dir.), Estudios monográficos sobre las Ciencias de la Actividad Física y del Deporte (pp. 85-92). Cádiz: COPLEF Andalucía.

CASIMIRO ANDUJAR, A. J.; RUIZ, F. y GARCÍA, A. (1998). Reflexiones sobre el pasado, presente y futuro de la Educación Física. En RUIZ, F.; GARCÍA, A. y CASIMIRTO, A. J. (Eds.), Nuevos horizontes en la Educación Física y el Deporte escolar. Almería: Instituto Andaluz del Deporte.

CASTRO BLANCO, F. J. (2005). La enseñanza de los primeros auxilios en el área de Educación Física. Lecturas: Educación y Deportes, 84. Recuperado el 17 de abril de 2008, de http://www.efdeportes.com/efd84/auxi.htm

亘 CFIE de Valladolid

$\begin{array}{llllll}\text { Recuperado el } & 26 \text { de noviembre de }\end{array}$ http://cfievalladolid.centros.educa.jcyl.es/sitio/index.cgi?wid_seccion=25\&wid_ite $\mathrm{m}=14$

CIRCULAR no 1 de Bachillerato, de 15 de julio de 1988, de la Dirección General de Ordenación Educativa, por la que se dan instrucciones para la organización y desarrollo del curso académico 1988-89 en los Centros de Bachillerato dependientes de la Consejería de Educación, Cultura y Deportes del Gobierno de Canarias (BOCanarias 08-08-1988) 
Dd CISTERNA CABREA, F. (2005). Categorización y triangulación como procesos de la validación del conocimiento en investigación cualitativa. Theoria, 14 (1), pp. 6171.

COHEN, L. y MANION, L. (1990). Métodos de investigación educativa. Madrid: La Muralla.

[D] COLÁS BRAVO, Mª P. (1992a). Los métodos de investigación en educación. En COLÁS BRAVO, M P. y BUENDÍA EXIMAN, L., Investigación educativa (pp. 43-68). Sevilla: Alfar.

COLÁS BRAVO, Ma P. (1992b). Los métodos descriptivos. En COLÁS BRAVO, M ${ }^{\mathrm{a}}$ P. y BUENDÍA EXIMAN, L., Investigación educativa (pp. 177-200). Sevilla: Alfar.

COLÁS BRAVO, Mª P. (1992c). La metodología cualitativa. En COLÁS BRAVO, Mª P. y BUENDÍA EXIMAN, L., Investigación educativa (pp. 249-290). Sevilla: Alfar.

COLlER, X. (2000). Estudio de casos. Madrid: Centro de Investigaciones Sociológicas.

COLOM VICH, M. (2003). Régimen jurídico del Bachillerato. En INSPECCIÓN DE EDUCACIÓN, Documentos de Trabajo, 7. Madrid: Consejería de Educación de la Comunidad de Madrid. Recuperado el 15 de septiembre de 2005, de http://www.madrid.org/cs/Satellite?blobcol=urldata\&blobheader=application\%2Fpd f\&blobheadername $1=$ Content-

Disposition\&blobheadervalue1=filename\%3D07_juridico_alta_web.pdf\&blobkey=i d\&blobtable=MungoBlobs\&blobwhere $=1272106437289 \&$ ssbinary $=$ true

Comisión Europea/EACEA/Eurydice (2013). La educación física y el deporte en los centros escolares de Europa. Informe Eurydice, Oficina de Publicaciones de la 
Unión Europea, Luxemburgo. Recuperado el 28 de marzo de 2014, de http://eacea.ec.europa.eu/education/eurydice

Consejo Consultivo de Castilla y León

http://www.cccyl.es/es

http://www.cccyl.es/es/dictamenes/consultas-facultativas

DC CONTRERAS JORDÁN, O. R. (1998). Didáctica de la Educación Física. Un enfoque constructivista. Barcelona: Inde.

COOK, H. D. y KOHL III, H. W. (Eds.) (2013). Educating the Student Body: Taking Physical Activity and Physical Education to School. National Academies Press.

CORRECCIÓN de erratas de la Orden 4399/2001, de 16 de octubre, del Consejero de Educación, por la que se regulan las convalidaciones de determinadas áreas o materias de la Educación Secundaria Obligatoria para aquellos alumnos que simultáneamente cursen enseñanzas de régimen especial de Música o Danza ((BOCMadrid 20-11-2001)

CORTÉS CAMARILLO, G. (1997). Confiabilidad y validez en estudios cualitativos. Nueva época, 1 (15), pp. 77-82.

[DU CUES CAMPOS, R. (2002). Análisis de la nueva organización de los bloques de contenidos de Educación Física en Educación Secundaria. Apunts, 67, pp. 18-26.

CUMELlAS RIERA, M. (2000). Alumnos con discapacidades en las clases de Educación Física convencionales. Lecturas: Educación Física y Deportes, 23. $\begin{array}{llllll}\text { Recuperado el } & 12 \text { de }\end{array}$ http://www.efdeportes.com/efd23/discap.htm

CUMELLAS RIERA, M. (2002). Educación física adaptada e inclusión: alumnado 
con discapacidades físicas. Bibliografía a consultar. Lecturas: Educación Física y

Deportes, 52. Recuperado el 8 de abril de 2004, de http://www.efdeportes.com/efd52/biblio.htm

D

[DU DE LA CRUZ MÁRQUEZ, J. C. (1989). Higiene de la Educación Física en la edad escolar. En RIBAS SERNA, J. (Coord.), Educación para la Salud en la Práctica Deportiva Escolar (pp. 61-79). Málaga: Unisport.

[C] DE LA CRUZ MÁRQUEZ, J. C. (1992). Lesiones deportivas: Prevención en la edad escolar. En MORA VICENTE, J. (Dir.), Estudios Monográficos sobre las Ciencias de la Actividad Física y el Deporte (pp. 93-109.). Cádiz: COPLEF Andalucía.

[D DE POTTER, J. C. (1995). La actividad física adaptada en el movimiento de integración. En GARCÍA LÓPEZ, C. (Coord.), Actas Congreso Científico Olímpico 1992: Actividad Física Adaptada, Psicología y Sociología (pp. 40-48). Volumen I, No 24. Málaga: Instituto Andaluz del Deporte.

DECRETO 160/1975, de 23 de enero, por el que se aprueba el Plan de Estudios de Bachillerato (BOE 13-02-1975).

DECRETO 113/2002, de 13 de septiembre, por el que se establece el currículo del Bachillerato en la Comunidad Autónoma de Murcia (BORMurcia 14-09-2002).

DECRETO 138/2002, de 08-10-2002, por el que se ordena la respuesta educativa a la diversidad del alumnado en la Comunidad Autónoma de Castilla-La Mancha (BOCMancha 11-10-2002)

DEL VILLAR ÁLVAREZ, F. (1994). La credibilidad de la investigación cualitativa 
en la enseñanza de la educación física. Apunts, 37, pp. 26-33.

DEVÍS, J. y PEIRÓ, C. (1992). Nuevas perspectivas curriculares en Educación Física: la salud y los juegos modificados. Barcelona: Inde.

Diccionario Cambridge Compact (2009). Barcelona: Cambridge University Press.

[D] Diccionario ESPASA de la lengua española. Primaria (2004). Barcelona: Espasa Calpe.

$\mathbb{E}$ Diccionario Oxford Pocket para estudiantes de inglés (2005). Oxford University Press.

DIRECCIÓN PROVINCIAL DE EDUCACIÓN DE VALLADOLID. Guía del estudiante 2002-2003. Oferta educativa de Valladolid. Valladolid: Junta de Castilla y León, Consejería de Educación y Cultura.

$\mathbf{E}$

ECO, U. (2001). Cómo se hace una tesis. Barcelona: Gedisa.

EDITORIAL Apunts: Educación Física y Deportes (1995), 42, pp. 3-4.

EQUIPO DIRECTIVO TÁNDEM (2003). Actividad física y discapacidad. Tándem, 11, pp. 5-6.

[d] ESPARTERO CASADO, J. (1997). Responsabilidad penal del profesor de Educación Física en su actividad docente. En AA.VV., Recursos para la gestión, el rendimiento y entrenamiento deportivo, y para la intervención pedagógica en la actividad física y deportiva (pp. 685-697). Volumen II, Curso de verano del INEF de Castilla y León, 1996. Valladolid: Junta de Castilla y León. 


\section{$\mathbf{F}$}

DD FERNÁNDEZ, F. J.; ROS, N. y VERA, A. (1997). Educación Física $1^{o}$ y $2^{o}$ E.S.O. Libro cuaderno de patio. Madrid: Pila Teleña.

[D FERNÁNDEZ, F. J.; ROS, N. y VERA, A. (1998). Educación Física $4^{o}$ E.S.O. Libro cuaderno de patio. Madrid: Pila Teleña.

D FERNÁNDEZ, J. P.; GARCÍA, R. y POSADA, F. (1993). Guía para el DISEÑO CURRICULAR en Educación Física. Lérida: Agonos.

FERNÁNDEZ ABUÍN, J. P. y PERNAS TALLÓN, J. A. (2006). El salvamento acuático, un contenido más dentro del marco curricular de educación física y deporte. Aplicación práctica. Lecturas: Educación y Deportes, 92. Recuperado el 11 de febrero de 2008, de http://www.efdeportes.com/efd92/salvam.htm

FERNÁNDEZ-BALBOA, J. M. (1997). La investigación en la educación física española: un índice para el futuro. Apunts, 50, pp. 100-106.

C] FERNÁNDEZ-BALBOA，J. M. (2003). Postmodernidad e investigación en la Educación Física. Ágora para la EF y el Deporte, 2-3, pp. 5-22.

[D] FERNÁNDEZ LORCA, F. J. y VERA GONZÁLEZ, A. (2000). Educación Física Bachillerato. Libro cuaderno de patio. Madrid: Pila Teleña.

D] FERNÁNDEZ-RÍO, J.; MEDINA, J.; BRIONGOS, F.; GARRO, J. y PÉREZ, M. (2000). El tratamiento de las necesidades educativas especiales en el área de Educación Física. En AA.VV., El valor educativo de la diversidad (pp. 321-327). II Congreso Nacional de Educación Especial, CSI-CSIF y Universidad de Valladolid. 
미 FRAILE ARANDA, A. (1995) El maestro de educación física y su cambio profesional. Salamanca: Amarú.

FUENTE [1]:

http://www.iespana.es/mientrenador/alumnos_exentos.htm (Consultado 21-11-2002)

FUENTE [2]:

http://iesmarcilla.educacion.navarra.es/menu/codigo//departamentos/educacion_fisic a/evaluacion.htm (Consultado 17-05-2004)

葛 FUENTE [2 Bis]:

http://iesmarcilla.educacion.navarra.es/menu/codigo//departamentos/educacion_fisic a/atencion_diversidad.htm (Consultado 24-09-2004)

FUENTE [3]:

http://centros4.pntic.me.es/ies.galileo.galilei/Edu_fisica/indiceedu_fisica.html (Consultado 10-12-2002)

FUENTE [4]:

http://centrosii.pntic.mec.es/ies.miguel.delibes/ef.htm (consultado 15-03-2004)

http://www.educa.madrid.org/web/ies.delibes.madrid/ef.htm

(Consultado 20-06-2006)

FUENTE [5]:

http://centros4.pntic.mec.es/ies.vegas.bajas/secretaria.htm (Consultado 28-05-2003)

FUENTE [6]:

http://www.colegio.unamuno.com/downloads/reglemento.doc (Consultado 2403-2004)

\section{FUENTE [7]:}

http//www.institutonervion.es/programaciones_didacticas/DEPEDF_programacion 
es.html (Consultado 20-01-2015)

FUENTE [8]:

http://www.iespadrepoveda.com/documentos/cat_view/75-educacion-fisica.html (Consultado 13-06-2013)

FUENTE [9]:

http://www.e-ducalia.net/temarios/S.E-Tema_37_\%20U.D.pdf (Consultado 17-052004)

FUENTE [10]:

http://www.educastur.princast.es/ies/perezaya/EducaciFisic/EXENTOS.htm (Consultado 30-05-2004)

PUENTE [11]:

http://www.iesconcepcionarenal.com/taboleiro/dispensas.htm

(Consultado 23-06-2004)

FUENTE [12]:

http://sportsciences.com/colef/230104/sentencia.doc (Consultado 23-05-2004)

FUENTE [13]:

http://146.83.210.163/pagalum/fisico/web/RodrigoRamirez_MarceloMena/educacio n_fisica.html (Consultado 15-03-2004)

FUENTE [14]:

http://www.dsbarcelona.com/service/schulord_esp.htm (Consultado 06-09-2004)

FUENTE [15]: PALMER, A., Estrategias para sobrevivir a la integración de un niño autista en la escuela secundaria.

http://www.asperger.es/articulos_detalle.php?id=131Estrategias\%20para\%20sobrevi vir\%20a\%20la\%20integraci\%F3n\%20de\%20un\%20ni\%F1o\%20autista\%20en\%201 
a\%20escuela\%20secundaria (Consultado 10-03-2004)

FUENTE [16]:

http://www.proyectovision.net/spanish/news/06/schroeder.html

(Consultado 10-03-2004)

SCHROEDER, F., Latino y Ciego: Enfrentado al crisol mítico y a las expectativas bajas.

FUENTE [17]:

http://www.madrid.org/sanidad/salud/educa/asma_y_escuela/ejemplo.htm

(Consultado 28-09-2004)

FUENTE [18]:

http://www.intercentres.cult.gva.es/intercentres/03001908/ibad/general/Guia_Estudi ante.doc (Consultado 17-04-2004)

晹 FUENTE [19]:

http://www.nsrecuerdo.com/general/page12.html (Consultado 05-04-2004)

FUENTE [20]:

http://www.centros.edu.xunta.es/iessanrosendo/departamentos/edfisica.htm

(Consultado 28-09-2004)

FUENTE [21]:

http://www.juntadeandalucia.es/averroes/iesdonana/departamentos/edufisica/prog\% 20educacion\%20fisica.htm (Consultado 05-04-2005)

\section{FUENTE [22]:}

http://www.juntadeandalucia.es/averroes/ 41701109/departa/efi/programedfisica03 _04.htm (Consultado 05-04-2005)

FUENTE [23]: 
http://intercentres.cult.gva.es/iessanblas/Educacion\%20Fisica/Programacion\%20Ed ucacion\%20Fisica.htm (Consultado 05-04-2005)

FUENTE [24]:

http://www.ccelpilar.com/normas_f.htm (Consultado 05-04-2005)

FUENTE [25]:

http://intercentres.edu.gva.es/intercentres/03005719/ADMISION\%20DE\%20ALU MNOS.htm\#DOCUMENTACION (Consultado 05-04-2005)

葛 FUENTE [26]:

http://www.hipnosis.com/noticias/notn/paternidad:--la-paternidad_4369.html (Consultado 21-03-2005)

FUENTE [27]:

http://www.nodo50.org/dona/n.php?n=1025 (Consultado 12-04-2005)

亘 FUENTE [28]:

http://centros4.pntic.mec.es/ies.diego.marin.de.aguilera/info/paginas/P_mat.htm (Consultado 28-11-2005)

F FUENTE [29]:

http://www.institutovegabaja.com/infogeneral/secretaria.htm (Consultado 12-042004)

FUENTE [30]:

http://www.juntadeandalucia.es/averroes/iescuancaminera/departamentos/dpto_e_f. htm (Consultado 12-11-2004)

FUENTE [31]:

http://www.instituto-generalife.com/ef.htm (Consultado 25-04-2004) 
亘 FUENTE [32]:

http://www.juntadeandalucia.es/averroes/alhadra/pag6042.htm (Consultado 15-042004)

FUENTE [33]:

http://www.ieslascumbres.com/programacion.pdf (Consultado 11-05-2005)

P FUENTE [34]:

http://anitaconrad.com/es/info/norm/ (Consultado 12-03-2004)

葛 FUENTE [35]:

http://www.upv.es/ jhueso/lvives/adapta.htm (Consultado 02-03-2004)

FUENTE [36]:

http://www.educarm.es/ies.prado/mayor/D2ESON.doc (Consultado 12-04-2005)

葛 FUENTE [37]:

http://centros5.pntic.mec,es/ies.ezequiel.gonzalez/PCBACH.htm (Consultado 1705-2005)

FUENTE [38]:

http://www.educa.rcanaria.es/General/Legislacion/scripts/Resolucion.asp.?Id=687 (Consultado 06-05-2004)

FUENTE [39]:

Soy madre, voy al 'insti' y no soy un bicho raro

http://www.elnortedecastilla.es/20091127/vida/madre-insti-bicho-raro20091127.html (Consultado 31-10-2010)

\section{FUENTE [40]:}

Más de 18.000 adolescentes españolas se quedan embarazadas cada año http://elpais.com/diario/2000/01/23/sociedad/948582012_850215.html (Consultado 
23-11-2003)

FUENTE [41]:

Adolescencia y embarazo, un binomio en aumento en España

http://www.saludalia.com/docs/Salud/web_saludalia/reportajes/doc/reportajes/doc/d oc_embarazos_adolescencia.htm (Consultado 15-06-2005)

FUENTE [42]:

http://www.deporteyciencia.com/article.pl?sid=02/05/14/1623202 (Consultado 0405-2005)

PUENTE [43]:

\section{LÓPEZ, J.: Educación Física y SPM}

http://www.saludactual.cl/spm/educacion-fisica.php (Consultado 13-08-2012)

\section{FUENTE [44]:}

GONZÁLEZ, J.A.: Ejercicio físico y Síndrome pre menstrual (SPM)

http://www.saludactual.cl/spm/ejercicioyspm.php (Consultado 22-01-2014)

\section{FUENTE [45]:}

http://www.accidentadosnet.org.ar/anet/base.asp?nota=187 (Consultado 06-122005)

FUENTE [46]:

http://www.educa.rcanaria.es/Usr/Apdorta/can-e-ef-htm (Consultado 31-10-2005)

\section{FUENTE [47]:}

http://www.elcentroingles.es/espanol/padres/ROF.pdf (Consultado 13-09-2005)

\section{FUENTE [48]:}

http://www.mailxmail.com/curso/vida/actividadesfisicas/capitulo2.htm

(Consultado 04-12-2005) 
FUENTE [49]:

http://www.rugbyinfantil.org.ar/respcivil.htm (Consultado 07-05-2004)

FUENTE [50]:

http://es.geocities.com/rafaperezp/fichalesionados.html (Consultado 09-01-2006)

皿 FUENTE [51]:

http://www.ieslasmusas.org/departamentos/index.php?dp=educfisi (Consultado 0901-2006)

FUENTE [52]:

Expertos señalan el papel de la comunidad en la integración de los alumnos con necesidades especiales

http://www.elmundo.es/elmundo/universidad/2004/03/30/actualidad/1080676987.ht ml (Consultado 04-05-2005)

FUENTE [53]:

Una niña paquistaní escolarizada este año se niega a hacer gimnasia por motivos religiosos

http://www.elmundo.es/elmundo/2002/02/25/sociedad/1014650379.html

(Consultado 12-08-2004)

FUENTE [53-1]

Una niña paquistaní no acude a clases de gimnasia en Almería por motivos religiosos

http://sociedad.elpais.com/sociedad/2002/02/25/actualidad/1014591602_850215.ht

ml (Consultado 12-08-2004)

\section{FUENTE [54]:}

Condenado un colegio de Jaén a pagar 600.000 euros a los padres de un niño que quedó tetrapléjico 
http://www.elmundo.es/elmundo/2003/11/27/sociedad/1069936782.html (Consultado 08-02-2008)

FUENTE [55]:

Muere en una escuela de La Rioja un niño aplastado por una portería http://www.elmundo.es/elmundo/2001/10/30/sociedad/1004429410.html (Consultado 08-02-2008)

FUENTE [56]:

Muere un adolescente mientras hacía gimnasia en el instituto http://www.elmundo.es/elmundo/2002/02/25/sociedad/1014644331.html (Consultado 08-02-2008)

\section{FUENTE [57]:}

Muere en Málaga un niño de 12 años en una clase de gimnasia http://www. elmundo.es/elmundo/2003/10/30/sociedad/1067519352.html

邑 FUENTE [58]:

Muere un niño de 12 años tras una caída en el recinto de gimnasia de un instituto de Sevilla http://www.elmundo.es/elmundo/2002/11/04/sociedad/1036435388.html (Consultado 08-02-2008)

葛 FUENTE [59]:

Fallece una niña de 10 años durante la clase de gimnasia en un colegio de Palma de Mallorca

http://www.elmundo.es/elmundo/2004/01/09/sociedad/1073669695.html (Consultado 08-02-2008)

\section{FUENTE [60]:}

Un liceo público cercano a París expulsa a dos alumnas por llevar el velo islámico «con ostentación 
http://www.elmundo.es/elmundo/2003/09/24/sociedad/1064399820.html (Consultado 08-02-2008)

FUENTE [61-1]:

Un estudiante de Sevilla muere tras caerse durante la clase de gimnasia http://elpais.com/diario/2002/11/05/andalucia/1036452149_850215.html (Consultado 08-02-2008)

\section{FUENTE [61-2]:}

Muere un alumno de un ataque de asma cuando hacía gimnasia en un instituto de Vidreres

http://elpais.com/diario/2000/02/24/catalunya/951358057_850215.html (Consultado 08-02-2008)

FUENTE [61-3]:

Fallecimiento por accidente en el recreo

http://elpais.com/diario/2001/04/03/madrid/986297063_850215.html (Consultado 08-02-2008)

FUENTE [61-4]:

Muerte en la escuela

http://elpais.com/diario/2003/11/17/madrid/1069071859_850215.html (Consultado 08-02-2008)

FUENTE [61-5]:

Condenado un colegio a pagar $\mathbf{6 0 0 . 0 0 0}$ euros por un accidente http://elpais.com/diario/2003/11/28/andalucia/1069975325_850215.html (Consultado 08-02-2008)

\section{FUENTE [61-6]:}

Padres de alumnos de educación especial de tres colegios de Elche denuncian la falta de profesores 
http://elpais.com/diario/2005/10/01/cvalenciana/1128194299_850215.html

(Consultado 08-02-2008)

FUENTE [61-7]:

HERNÁNDEZ, R.: Un estudio alerta sobre la seguridad en las instalaciones deportivas de los colegios

http://elpais.com/diario/2005/02/01/andalucia/1107213754_850215.html

(Consultado 08-02-2008)

\section{FUENTE [62-1]:}

\section{Muere un chico en su colegio en clase de Educación Física}

http://www.abc.es/hemeroteca/historico-26-02-2002/abc/Sociedad/muere-un-chicoen-su-colegio-en-clase-de-educacion-fisica_81174.html (Consultado 08-02-2008)

\section{FUENTE [62-2]:}

EI TS indemniza con 120 millones, once años después, a un alumno que quedó inválido durante una clase de gimnasia

http://hemeroteca.abc.es/nav/Navigate.exe/hemeroteca/madrid/abc/1999/12/31/046. html (Consultado 14-03-2004)

\section{FUENTE [63]:}

Alumnas árabes de Lérida piden ayuda al colegio para que sus padres no les exijan usar el velo

http://www.libertaddigital.com/historico/2004/10/23/sociedad.htm (Consultado 0808-2006)

\section{FUENTE [64]:}

http://www.ccrioja.es/consejo/indices/pdf/00/d054-00.pdf (Consultado 13-04-2004)

\section{FUENTE [65]:}

http://www.jccm.es/consultivo/d00/06000.pdf (Consultado 13-04-2004)

\section{FUENTE [66]:}


http://www.jccm.es/consultivo/d01/10401.pdf (Consultado 13-04-2004)

FUENTE [67]:

http://www.asociacionabogadosrcs.orgportaljurisrevista8N8-Ap-VI.html

(Consultado 11-03-2006)

FUENTE [68]:

http://www.jccm.es/consultivo/d00/06100.pdf (Consultado 11-03-2006)

FUENTE [69]:

http://www.ccrioja.es/consejo/indices/pdf/00/d042-00.pdf (consultado 11-03-2006)

FUENTE [70]:

El velo y las clases de gimnasia

http://www.libertaddigital.com/opinion/alicia-delibes/el-velo-y-las-clases-degimnasia-8315/ (Consultado 04-03-2002)

虽 FUENTE [71]:

http://centros.edu.xunta.es/cpideatios/datos/pdf/programacion/ed_fisica.pdf (Consultado 13-06-2006)

FUENTE [72]:

http://www3.planalfa.es/cmariaferrol/libros.htm (Consultado 20-06-2006)

葛 FUENTE [73]:

http://www.juntadeandalucia.es/averroes/ieslosalamos/doc/DEPYBI.doc (Consultado 20-06-2006)

FUENTE [74]:

http://www.educa.madrid.org/web/ies.larra.madrid/alumnos/enferacc/enfacc.htm (Consultado 20-06-2006) 


\section{圆 FUENTE [75]:}

http://centros4.pntic.mec.es/candavera/departamentos/ef/html/ef1.htm

(Consultado 20-06-2006)

FUENTE [76]:

http://www.iesgaherrera.com/ef/Archivos/Comunicaciones/GSOb\%20Con\%20CE.d oc (Consultado 27-06-2006)

\section{FUENTE [77]:}

http://iesreypelayo.com/oficial/docinsti/ (Consultado 11-09-2006)

㽞 FUENTE [78]

\section{Un héroe en las aulas}

http://www.laopiniondemalaga.es/malaga/2008/04/26/heroe-aulas/175644.html (Consultado 12-05-2009)

FUENTE [79]:

Un niño de 13 años fallece durante una clase de gimnasia en Getafe http://www.elmundo.es/elmundo/2008/04/01/madrid/1207073231.html (Consultado 12-05-2009)

FUENTE [80]

Fallece un niño de trece años tras desmayarse en una clase de educación física http://www.europapress.es/sociedad/noticia-fallece-nino-trece-anos-desmayarseclase-educacion-fisica-20130207142504.html (Consultado 10-03-2014)

\section{FUENTE [81-1]}

Fallece un estudiante de 16 años en Salamanca en clase de Educación Física http://www.elnortedecastilla.es/20080530/castilla-leon/fallece-estudiante-anossalamanca-20080530.html (Consultado 12-05-2009)

FUENTE [81-2] 
Fallece un alumno de 15 años del instituto Los Sauces después de la clase de gimnasia

http://www.elnortedecastilla.es/20081021/zamora/fallece-alumno-anos-instituto20081021.html (Consultado 12-05-2009)

\section{FUENTE [81-3]}

Una multitud despide al alumno que falleció tras la clase de gimnasia http://www.elnortedecastilla.es/20081022/zamora/multitud-despide-alumnofallecio-20081022.html (Consultado 12-05-2009)

FUENTE [82]

El Consultivo despacha más de 500 consultas de accidentes escolares http://www.jccm.es/consultivo/d00/06100.pdf (Consultado 11-03-2006)

\section{FUENTE [83]}

http://www.ieslascumbres.es/index.php?option=com_search\&searchword=exenci\% C3\%B3n (Consultado 20-01-2014)

\section{FUENTE [84]}

Muere un niño tras desmayarse cuando daba clase de gimnasia (04-10-2013) http://www.telecinco.es/informativos/sociedad/Loja-muere-nieno-desmayo-clasegimnasia_0_1678950442.html (Consultado 05-08-2014)

Muerte súbita de un chico en la clase de gimnasia del colegio (24-04-2014) http://www.lanacion.com.ar/1684608-muerte-subita-de-un-chico-en-la-clase-degimnasia-del-colegio (Consultado 05-08-2014)

Murió una adolescente en una clase de gimnasia en Córdoba (05-03-2015) http://m.diarioveloz.com/notas/34136-murio-una-adolescente-una-clase-gimnasiacordoba (Consultado 05-08-2014)

Muerte súbita: tenía 16 años y falleció en la clase de gimnasia (12-08-2011) 
http://www.clarin.com/sociedad/Muerte-subita-fallecio-clase-

gimnasia_0_534546653.html (Consultado 05-08-2014)

Chico de 14 años murió de un infarto en una clase de gimnasia (mayo-2006)

http://www.sitiosargentina.com.ar/notas/2006/mayo/murio-ifarto.htm (Consultado 05-08-2014)

Murió tras descomponerse en una clase de gimnasia (10-05-2007)

http://www.diariodecuyo.com.ar/home/new_noticia.php?noticia_id=219611

(Consultado 05-08-2014)

Un chico de 15 años fallece al caerle una canasta en el IES de Vilamarxant (2411-2010)

http://www.levante-emv.com/sucesos/2010/11/24/chico-15-anos-fallece-caerlecanasta-ies-vilamarxant/759869.html (Consultado 05-08-2014)

Fallece una niña de 11 años en la clase de Educación Física (25-09-2003) http://www.elperiodicomediterraneo.com/noticias/sucesos/fallece-nina-11-anosclase-educacion-fisica_69981.html (Consultado 05-08-2014)

G

GALlARDO RABADÁN, J. M. y GUTIÉRREZ TORRES, M. C. (2007). Integración de alumnos especiales. ¿Utopía o eterna esperanza? Lecturas: Educación Física y Deportes, 104. Recuperado el 5 de julio de 2008, de http://www.efdeportes.com/efd104/integracion-de-alumnos-especiales.htm

[DALLEGO ANTONIO, J. (2003a). Legislación en educación física para el alumnado con necesidades educativas especiales. Revista Española de Educación Física y Deportes, (Vol. XI), 3, pp. 15-18. 
[D] GALLEGO ANTONIO, J. (2003b). Valoración de la salud corporal de niños con discapacidad física. En RUIZ JUAN, F. y GONZÁLEZ DEL HOYO, E.P. (Coords.), Educación Física y deporte en edad escolar (pp. 653-656). Actas del V Congreso Internacional de FEADEF. Valladolid: FEADEF.

GALLEGO ANTONIO, J. y VICENTE DE HARO, J. J. (2003). Concepto y tipos de adaptaciones en Educación Física. En RUIZ JUAN, F. y GONZÁLEZ DEL HOYO, E. P. (Coords.), Educación Física y deporte en edad escolar (pp. 125-128). Actas del V Congreso Internacional de FEADEF. Valladolid: FEADEF.

[Da GARCÍA-BELLIDO y GARCÍA DE DIEGO, J. (2001). Uso de las referencias bibliográficas: Recomendaciones útiles para saber por qué, cuándo, dónde y cómo citar adecuadamente la bibliografía consultada. Boletín del Ilustre Colegio Oficial de Doctores y Licenciados en Filosofía y Letras y en Ciencias, 127, pp. 24-31.

GARCÍA FERRANDO, M.; IBÁÑEZ, J. y ALVIRA, F. (1996). El análisis de la realidad social. Métodos y técnicas de investigación. Madrid: Alianza Universidad Textos.

GARCÍA SANZ, M. P. y MORILLAS PEDREÑO, L. R. (2012). Técnicas de recogida y análisis de la información. En GARCÍA SANZ, M. P. y MARTÍNEZ CLARES, P. (Coords.), Guía práctica para la realización de trabajos fin de Grado y trabajos fin de Máster (pp. 129-68). Murcia: Universidad de Murcia.

GOETZ, J. P. y LECOMPTE, M. D. (1988). Etnografía y diseño cualitativo en investigación educativa. Madrid: Morata.

GOMENDIO, M. (2000). Educación Física para la integración de niños con necesidades educativas especiales. Programa de actividad física para niños de 6 a 12 años. Madrid: Gymnos.

GONZÁLEZ BALLESTEROS, L. (2003). La aventura de investigar en educación. 
La brújula de papel: Revista de iniciación a la investigación psicoeducativa, 3, pp. 6-15.

GONZÁLEZ DE ALEDO LINOS, R. (1995). Programación Educación Física (1). Secundaria Obligatoria $2^{\circ}$ ciclo. Madrid: MEC.

[C] GONZÁLEZ HALCONES, M. A. (1995). Manual para la evaluación en Educación Física (Primaria y Secundaria). Madrid: Ed. Escuela Española.

GONZÁLEZ ITURRI, J. J. y SAÑUDO MARTÍN, I. (1982). Contraindicaciones a la práctica de la educación física y el deporte. Apunts: Medicina de l'esport, Vol. XIX, N $\mathrm{N}^{\mathrm{T}}$ 76, pp. 245-254. Recuperado el 26 de noviembre de 2010, de http://www.apunts.org/es/contraindicaciones-practica-educacion-fisicael/articulo/13104791/

GONZÁLEZ LORENZO, R. A. y SÁNCHEZ MARTÍN, A. (2003). Propuesta didáctica de Educación Física para un alumno con discapacidad motora. En RUIZ JUAN, F. y GONZÁLEZ DEL HOYO, E. P. (Coords.), Educación Física y deporte en edad escolar (pp. 575-581). Actas del V Congreso Internacional de FEADEF. Valladolid: FEADEF.

GONZALEZ MANJÓN, D. (1995). Adaptaciones curriculares. Guía para su elaboración. Málaga: Ediciones Aljibe.

GONZÁLEZ MONTEAGUDO, J. (2000). El paradigma interpretativo en la investigación social y educativa: nuevas respuestas para viejos interrogantes. Cuestiones pedagógicas: Revista de ciencias de la educación, 15, pp. 227-246.

GUILLÉN DEL CASTILLO, M. (1998a). Anatomía y Fisiología humana implicada en la actividad física. Patologías relacionadas con el Aparato Locomotor. Evaluación y tratamiento en el proceso educativo. En GUILLÉN DEL CASTILLO, M. (Coord.), Curso de Actualización en Didáctica y Educación Física para 
postgraduados universitarios (pp. 77-114). Volumen II. Málaga: Instituto Andaluz del Deporte.

GUILLÉN DEL CASTILLO, M. (1998b). La salud y la calidad de vida. Hábitos y estilos de vida saludable en relación con la actividad física. El cuidado del cuerpo. Anatomía y autoestima. En GUILLÉN DEL CASTILlO, M. (Coord.), Curso de Actualización en Didáctica y Educación Física para postgraduados universitarios (pp. 139-164). Volumen II. Málaga: Instituto Andaluz del Deporte.

GUTIÉRREZ, E.; VALBUENA, C.; ÁLVAREZ, M. J.; CID, L.; MARTÍNEZ, V. y MUÑOA, J. (2007). Causas del absentismo en educación física en ESO. Selección, Revista de Medicina de la Educación Física y el Deporte, 16 (2), pp. 84-90.

$\mathbf{H}$

[DARDMAN, K. (2008). Physical education in schools: A global perspective. Kinesiology, 40 (1), pp. 5-28.

HERNÁNDEZ, F. (2011). Las historias de vida en el marco del giro narrativo en la investigación en Ciencias Sociales: los desafíos de poner biografías en contexto. En HERNÁNDEZ, F.; SANCHO, J. M. y RIVAS, J. I. (Coords.), Historias de vida en educación: biografías en contexto (pp. 13-22). Barcelona: ESBRINA-RECERCA.

HERNÁNDEZ, F. J.; HOSPITAL, V. y LÓPEZ, C. (1997). Educación física, deporte y atención a la diversidad. Málaga: Instituto Andaluz del Deporte.

[ㅁ] HERNÁNDEZ, F. J.; HOSPITAL, V. y LÓPEZ, C. (1998). Educación física especial: actitud y formación de los docentes en primaria. Apunts, 51, pp. 70-78.

@D HERNÁNDEZ, J. L. (1994). Posibilidades en la reestructuración del pensamiento del profesor de E.F.: el grupo de discusión en la investigación educativa. En II 
encuentro Unisport sobre sociología deportiva: investigación alternativa en educación física (pp. 225-247). Málaga: UNISPORT.

Disponible en http://hdl.handle.net/2445/15323 (Consultado 15-01-2015)

[D] HERNÁNDEZ ÁlVAREZ, J. L. y MARTÍNEZ DE HARO, V. (1989). Las exenciones en Educación Física. Selección, Revista de Medicina de la Educación Física y el Deporte, 0, pp. 49-52.

HERNÁNDEZ VÁZQUEZ, F. J. (2000). La educación física, el deporte y la diversidad en Secundaria. Apunts, 60, pp. 6-12.

HERRADOR SÁNCHEZ, J. A. y LATORRE ROMÁN, P. A. (2004). Análisis de los espacios y equipamiento deportivo escolar desde el punto de vista de la seguridad http://www.campus-oei.org/revistadeloslectores/861Herrador.PDF

[D] HUGUET MORA, D. (2010). Estrategias inclusivas en Educación Física. En GONZÁlEZ, C. y LLEIXÁ, T. (Coords.), Didáctica de la Educación Física (pp. 83-103). 4 (II). Barcelona: GRAÓ.

I

INSTRUCCIONES de la Dirección General de Ordenación Académica para la aplicación de la Orden 4399/2001, de 16 de octubre, del Consejero de Educación, por la que se regulan las convalidaciones de determinadas áreas o materias de Educación Secundaria Obligatoria para aquellos alumnos que simultáneamente cursen enseñanzas de régimen especial de Música o Danza (BOCMadrid 31-102001)

http://www.madrid.org/dat_capital/circulares/pdf/Inst_musica_danza.pdf 


\section{$\mathbf{J}$}

JOVÉ MONCLÚS, G. y MIÑAMBRES ABAD, A. (1997). La integración en el aula ordinaria, presente y futuro de una situación: la nueva formación inicial de los futuros maestros/as. Presentación de una experiencia. En ARNAIZ SÁNCHEZ, P. y DE HARO RODRÍGUEZ, R. (Eds.), 10 años de integración en España: Análisis de la realidad y perspectivas de futuro (pp. 549-560). Murcia: Universidad de Murcia.

\section{$\mathbf{K}$}

KIRK, D. (1990). Educación Física y curriculum. Valencia: Universidad de Valencia.

\section{$\mathbf{L}$}

LACASA, A. (2002). Alumno «lesionado»... ¿alumno exento? Seminario Ejercicio Físico y Salud, Lleida.

http://www.deporteyciencia.com/seminario/guia_y_conferencias_2002.pdf

(Consultado 12-03-2004)

[D] LAMARCA, T. y GALLO, C. (2008). Lágrimas por una medalla. Madrid: Eds. Temas de Hoy.

LANDAZURI, M. O. de (2002). Accidentes y responsabilidad civil. LA REVISTILLA de Educación Física y Deporte, Pila Teleña, 12, p. 27.

[ㅁ] LATORRE ROMÁN, P. A. y HERRADOR SÁNCHEZ, J. (2003). Prescripción del ejercicio físico para la salud en la edad escolar. Barcelona: Paidotribo. 
副 LEY ORGÁNICA 1/1990, de 3 de octubre, de Ordenación General del Sistema Educativo (BOE 04-10-1990).

LEY ORGÁNICA 9/1995, de 20 de noviembre, de la Participación, la Evaluación y el Gobierno de los Centros Docentes (BOE 21-11-1995).

LEY ORGÁNICA 10/1995, de 23 de noviembre, del Código Penal (BOE 24-111995)

LEY 1/2002, de 9 de abril, reguladora del Consejo Consultivo de Castilla y León (BOCyL 22-04-02)

LEY ORGÁNICA 10/2002, de 23 de diciembre, de Calidad de la Educación (BOE 24-12-2002).

LEY ORGÁNICA 2/2006, de 3 de mayo, de Educación (BOE 04-05-06).

LEY ORGÁNICA 8/2013, de 9 de diciembre, para la mejora de la calidad educativa (BOE 10-12-2013)

[D LINARES, P. L. (2000). Educación Física y necesidades educativas especiales: posibilidades y limitaciones. Apunts, 60, pp. 13-19.

$\mathbb{E}[$ LLADONOSA USALL, A. (1998). El paso de primaria a secundaria: una propuesta de actuación para alumnado con necesidades educativas especiales en el área de educación física. Aula de Innovación Educativa, 72, pp. 47-48.

[D] LLEIXÁ, T. (2003). Educación física hoy. Realidad y cambio curricular. Barcelona: ICE-HORSORI.

LÓPEZ DE CEBALLOS, P. (1989). Un método para la investigación-acción participativa. Madrid: Ed. Popular. 
[D] LÓPEZ GARCÍA, J. L. (Coord., 1996). Adaptaciones curriculares en el Área de Educación Física para alumnos con exenciones. Proyecto de Investigación Educativa. Aprobado por Resolución de 24-7-95 de la Secretaría de Estado de Educación (B.O.E. de 11-9-95, p. 27312).

[ㅁ] LÓPEZ GONZÁLEZ, P. (1997). El área de Educación Física y el alumnado con discapacidad motora. Madrid: MEC.

LÓPEZ MELERO, M. (1996). La educación física y las personas con necesidades educativas específicas: una cultura cooperativa y solidaria. En SOTO ROSALES, A. (Ed.), Educación Física en niños con necesidades educativas especiales (pp. 13-48). Huelva: Universidad de Huelva.

DU LÓPEZ PASTOR, V. M.; MONJAS, R.; GARCÍA-PEÑUELA, A. y PÉREZ, D. (2003). ¿Qué Educación Física hemos vivido? Analizando nuestro saber profesional a partir de historias de vida. En RUIZ JUAN, F. y GONZÁLEZ DEL HOYO, E. P. (Coords.), Educación Física y deporte en edad escolar (pp. 21-25). Actas del V Congreso Internacional de FEADEF. Valladolid: FEADEF.

[D MACAZAGA, A.; MUÑOZ, E. y PARÍS, F. (1985). Características psicosociales del alumno y su implicación con la Educación Física. En AA.VV., Aspectos didácticos de Educación Física 1: Bachillerato (pp. 27-43). Zaragoza: ICE Universidad de Zaragoza.

[DI MANAGUA, J. A. (2000). La profesora, condenada a pagar 120 millones. LA REVISTILLA de Educación Física y Deporte, Pila Teleña, 5, pp. 15-18.

MANHEIM JAROL, B. y RICH RICHARD, C. (1988). Análisis político empírico. 
Métodos de investigación en ciencia política. Madrid: Alianza Universal Textos.

¿d MANTAS CERVERA, R. (1995). Integración y exención. En LLEIXÁ ARRIBAS, T. (Dir.), La Educación Física en la Educación Secundaria Obligatoria. Guía del profesor (pp. 403-441). Barcelona: Paidotribo.

Q] MANZANERO, A. L. y LÓPEZ, B. (2007). Características de los recuerdos autobiográficos sobre sucesos traumáticos. Boletín de Psicología, 90, pp. 7-17.

[D MARTÍN-CARO SÁNCHEZ, L. (1996). Las Necesidades Educativas Especiales del niño con Deficiencia Motora. Madrid: MEC.

MARTÍN ESCUDERO, P. (2000). Ejercicio físico y pediatría. Madrid: You \& Us.

MARTÍN PASTOR, A. (1995). El ejercicio físico como estrategia de salud. Valladolid: Junta Castilla y León, Consejería de Sanidad y Bienestar Social.

[D MARTÍN PEÑALVER, A. (2003). La Etnografía educativa como alternativa para el profesor investigador de Educación Física. Análisis de una experiencia práctica. Retos, Nuevas tendencias en Educación Física, Deporte y Recreación, 6, pp. 45-49.

DA MARTÍNEZ DE HARO, V.; HERNÁNDEZ, J. L. y VELÁZQUEZ, R. (1987). Salud e integración. Cuadernos de Pedagogía, 149, pp. 27-29.

MARTÍNEZ DUARTE, M. y MARTÍNEZ DUARTE, A. (2001). El profesor de apoyo y la integración en las clases de educación física. Una experiencia con alumnos/as con N.E.E. Lecturas: Educación Física y Deportes, 35. Recuperado el 9 de julio de 2002, de http://www.efdeportes.com/efd35/apoyo.htm

[ㅁ] MARTÍNEZ RODRÍGUEZ, J. (2011). Métodos de investigación cualitativa. Revista de Investigación Silogismo, 8 (1). 
[C] McKERNAN, J. (1999). Investigación-acción y curriculum. Madrid: Morata.

[Dd MEC (1989). Diseño Curricular Base. Educación Secundaria Obligatoria. Área de Educación Física. Madrid.

MEC (1992). Secundaria Obligatoria: Educación Física. Madrid.

MELGAR, A. (1992). Análisis del diseño curricular de Educación Física. En MORA VICENTE, J. (Dir.), Estudios monográficos sobre las Ciencias de la Actividad Física y del Deporte (pp. 207-212). Cádiz: COPLEF Andalucía.

Dl MENDOZA LAIZ, N.; GARCÍA, T. y LEZETA, X. (2001). Aeróbic en silla de ruedas: Propuesta de adaptación al ámbito escolar. Revista de Educación en el Tiempo Libre y Acción Social Monitor Educador, 83, pp. 24-31.

[DENDOZA LAIZ, N. (2003). La Educación Física ante las necesidades educativas especiales. En GONZÁlEZ DEL HOYO, E. P. y RUIZ JUAN, F. (Coords.), Dimensión europea de la Educación Física y el deporte en edad escolar. Hacia un espacio europea de educación superior (pp. 323-328). Valladolid: AVAPEF.

MENDOZA LAIZ, N. (2009). La formación del profesorado en Educación Física con relación a las personas con discapacidad. Ágora, 9, pp. 43-56.

[DESTRE SANCHO, J. A. (1995). Planificación deportiva. Teoría y práctica. Barcelona: INDE.

MONROY ANTÓN, A. J. y SÁEZ RODRÍGUEZ, G. (2008). El profesor de educación física y su responsabilidad por lesiones de los alumnos durante el período de escolarización obligatoria. En IV Congreso Internacional y XXV Nacional de Educación Física. Córdoba: Universidad de Córdoba. Recuperado el 10 de febrero de 2010, de

http://www.uco.es/IVCongresoInternacionalEducacionFisica/congreso/Documentos/ 
001-164-509-009-001.html

MORA, J. M. y CARRANZA, M. (1999). Interculturalidad y educación física. Aula de Innovación Educativa, 82, pp. 6-7.

Q] MORALES, J. (2010). Problemáticas específicas de la sesión de Educación Física. Detección y resolución. En GONZÁLEZ, A. y LLEIXÁ, T. (Coords.), Educación Física. Investigación, innovación y buenas prácticas (pp. 95-107). Barcelona: GRAÓ.

[D] MORANTE DE LA CALLE, M. (2000). Comentario a la Sentencia 1098/1999, de 22 de diciembre, de la Sala de lo Civil del tribunal Supremo. (sin publicar)

MUÑOZ DÍAZ, J. C. (2005). Intentando sacar la viga del ojo propio. EL PATIO de Educación Física, Pila Teleña, 5, pp. 8-12.

MUÑOZ DÍAZ, J. C. y ANTÓN HERRERA, M. A. (2006). Las discapacidades físicas. Integración en Educación Física. Lecturas: Educación Física y Deportes, 98. Buenos Aires. Recuperado el 12 de octubre de 2007, de http://www.efdeportes.com/efd98/discap.htm

MUÑOZ NARANJO, A. (1999). Responsabilidad civil de los docentes. Régimen jurídico y jurisprudencia. Barcelona: CISSPRAXIS.

$\mathbf{N}$

NASBE: State School Health Policy Database. Recuperado el 20 de junio de 2014, de

http://www.nasbe.org/healthy_schools/hs/bytopics.php?topicid=1110\&catExpand=a cdnbtm_catA 
$\mathbb{E}$ NASPE (2012). 2012 Shape of the Nation Report: Status of Physical Education in the USA. Reston, VA: American Alliance for Health, Physical Education, Recreation and Dance.

Disponible en formato en http://www.shapeamerica.org/advocacy/son/2012/upload/2012-Shape-of-Nationfull-report-web.pdf

NOTARNÍCOLA, V. (1997). El profesor de educación física y su responsabilidad civil. Lecturas: Educación Física y Deportes, 4. Recuperado el 19 de diciembre de 2002, de http://www.efdeportes.com/efd4/vn4.htm

NÚÑEZ, J. C. y 42 firmas más (2001). Fallecimiento por accidente en el recreo. Vid.: FUENTE [61-3]

$\mathbf{O}$

[D OLAYO MARTÍNEZ, J. M.; VÁZQUEZ, J. y ALAPONT, A. (1996). El alumnado con discapacidad. Una propuesta de integración (I). Madrid: MEC.

ORDEN 31 de julio de 1961 (M‥ Educ. Nac.). INSTITUTOS NACIONALES DE ENSEÑANZA MEDIA. Dispensas de educación física. (BOE 15-09-1961).

ORDEN de 22 de marzo de 1975, por la que se desarrolla el Decreto 160/1975 (BOE 18-04-1975).

ORDEN de 18 de septiembre de 1987, por la que se modifica parcialmente el anexo I de la de 22 de marzo de 1975, que aprobaba los programas del Bachillerato Unificado Polivalente (BOE 23-09-1987).

ORDEN de 12 de noviembre de 1992, que regula la evaluación y la calificación de los alumnos que cursan el Bachillerato establecido en la Ley Orgánica 1/1990, de 3 
de octubre, de Ordenación General del Sistema Educativo (BOE 20-11-1992).

ORDEN de 10 de julio de 1995 por la que se regula la adaptación del currículo de la Educación Física para los alumnos con necesidades educativas especiales en el Bachillerato Unificado y Polivalente, en la Formación Profesional de primer y segundo grados y en la educación secundaria, así como la dispensa de la misma para los mayores de veinticinco años (BOE 15-07-1995).

ORDEN de 28 de agosto de 1995, por la que se regula el procedimiento para garantizar el derecho de los alumnos de Educación Secundaria Obligatoria y de Bachillerato a que su rendimiento escolar sea evaluado conforme a criterios objetivos (BOE 20-09-1995).

ORDEN de 14 de febrero de 1996, que regula la evaluación del alumnado con necesidades educativas especiales que cursan las enseñanzas de régimen general establecidas en la Ley Orgánica 1/1990, de 3 de octubre, de Ordenación General del Sistema Educativo (BOE 23-02-1996).

ORDEN de 7 de abril de 1997, por la que se regula el procedimiento de realización de las adaptaciones curriculares de centro y las individualizadas, en el marco de la atención a la diversidad del alumnado de las enseñanzas no universitarias en la Comunidad Autónoma de Canarias (BOC 25-04-1997)

ORDEN de 2 de enero de 2001, del Ministerio de Educación, Cultura y Deporte, por la que se establecen convalidaciones entre las enseñanzas de régimen especial de Música y de Danza y determinadas áreas de Educación Secundaria Obligatoria $\left(\mathrm{BOE} \mathrm{n}^{\circ} 6,06-01-2001\right)$

ORDEN de 4 de abril de 2001, de la Consejería de Educación y Cultura, por la que se desarrolla el proceso de convalidación entre las enseñanzas de régimen especial de Música y de Danza y determinadas áreas de Educación Secundaria Obligatoria (BOCyL n $\left.{ }^{\circ} 73,11-04-2001\right)$ 
ORDEN 4399/2001, de 16 de octubre, del Consejero de Educación, por la que se regulan las convalidaciones de determinadas áreas o materias de Educación Secundaria Obligatoria para aquellos alumnos que simultáneamente cursen enseñanzas de régimen especial de Música o Danza (BOCMadrid 31-10-2001)

ORDEN de 29 de abril de 2002, de la Consejería de Educación y Cultura, por la que se regula la impartición de la Educación Secundaria Obligatoria en Castilla y León (BOCyL 10-05-2002).

ORDEN de 17 de mayo de 2002, por la que se dictan instrucciones para la implantación del Decreto 40/2002, de 28 de marzo, por el que se establece el currículo de la Educación Secundaria Obligatoria en el ámbito de la gestión de la Consejería (BOCantabria 23-05-2002)

ORDEN de 17 de mayo de 2002, por la que se dictan instrucciones para la aplicación del Decreto 41/2002, de 28 de marzo, por el establece el currículo del Bachillerato, en el ámbito de gestión directa de la Consejería de Educación y Juventud de la Comunidad Autónoma de Cantabria (BOCantabria 23-05-2002)

ORDEN de 18 de marzo de 2003, de la Consejería de Educación y Cultura, por la que se establecen medidas para facilitar la compatibilidad de los estudios de Educación Secundaria Obligatoria y Bachillerato con los del grado medio de las enseñanzas de régimen especial de Música y Danza (BORMurcia 02-04-2003)

ORDEN FORAL 266/2003, de 11 de junio, del Consejero de Educación y Cultura, por la que se aprueban las instrucciones que van a regular, durante el curso 20032004, la organización y el funcionamiento de los centros docentes públicos que imparten las enseñanzas de segundo ciclo de Educación Infantil, Educación Primaria, Educación Secundaria Obligatoria, Bachillerato, Formación profesional y Programas de Iniciación Profesional (BONavarra 30-06-2003) 
ORDEN ECD/1688/2003, de 19 de junio, por la que se modifica el cuadro de claves indicativas de las materias contenido en la Orden de 12 de noviembre de 1992, por la que se que regula la evaluación y la calificación de los alumnos que cursan el Bachillerato establecido en la Ley Orgánica 1/1990, de 3 de octubre, de Ordenación General del Sistema Educativo, y se asignan nuevas claves indicativas a las materias de Bachillerato (BOE 26-06-2003)

ORDEN de 27 de julio de 2004, de la Consejería de Educación y Cultura, por la que se establecen medidas para facilitar la compatibilidad de los estudios de Educación Secundaria con la práctica deportiva (BORMurcia nº 197, 25-08-2004)

ORDEN de 3 de diciembre de 2004, de la Consejera de Educación, Universidades e Investigación, por la que se establecen medidas para facilitar la simultaneidad de los estudios de Educación Secundaria con las Enseñanzas Artísticas de música y danza de grado medio (BOPVasco 04-01-2005)

ORDEN de 7 de abril de 2006, por la que se convocan proyectos educativos para participar en el programa «El Deporte en la Escuela» para el curso escolar 20062007. (BOJAndalucía 08-05-2006)

ORDEN EDU/1046/2007, de 12 de junio, por la que se regula la implantación de la Educación Secundaria Obligatoria en la Comunidad de Castilla y León (BOCyL 13-06-2007)

ORDEN EDU/1064/2008, de 19 de junio, por la que se regula la implantación y el desarrollo del bachillerato en la Comunidad de Castilla y León (BOCyL 20-062008)

ORDEN EDU/2134/2008, de 10 de diciembre, por la que se regula la evaluación en bachillerato en la Comunidad de Castilla y León (BOCyL 15-12-2008)

ORDEN EDU/1603/2009, de 20 de julio, por la que se establecen los modelos de 
documentos a utilizar en el proceso de evaluación psicopedagógica y el del dictamen de escolarización (BOCyL 28/07/2009).

ORDEN EDU/2739/2009, de 1 de octubre, por la que se determinan las convalidaciones entre las enseñanzas profesionales de Música y de Danza y la Educación secundaria obligatoria y el Bachillerato, y la exención de la Educación Física, en el ámbito de gestión del Ministerio de Educación (BOE 10-10-2009).

ORDEN EDU/2273/2009, de 11 de diciembre, por la que se establecen las convalidaciones entre asignaturas de las enseñanzas profesionales de Música y de Danza y materias de Educación Secundaria Obligatoria y de Bachillerato, y las condiciones para la exención de la materia de Educación Física en la Comunidad de Castilla y León (BOCyL 21-12-2009)

ORDEN EDU/849/2010, de 18 de marzo, por la que se regula la ordenación de la educación del alumnado con necesidad de apoyo educativo y se regulan los servicios de orientación educativa en el ámbito de gestión del Ministerio de Educación, en las ciudades de Ceuta y Melilla (BOE 06-04-2010)

ORDEN EDU/493/2013, de 20 de junio, por la que se modifican las Órdenes EDU/1061/2008, de 19 de junio, por la que se regula la implantación y el desarrollo del bachillerato en la Comunidad de Castilla y León, y EDU/2134/2008, de 10 de diciembre, por la que se regula la evaluación en bachillerato en la Comunidad de Castilla y León (BOCyL 28-06-2013)

ORDEN EDU/490/2014, de 10 de junio, relativa a la exención extraordinaria en materias de bachillerato para el alumnado con necesidades educativas especiales (BOCyL 19-06-2014)

Orden EDU/425/2015, de 22 de mayo, por la que se regulan las especificidades propias del bachillerato en régimen a distancia en la Comunidad de castilla y León (BOCyL 01-06-2015) 
$\mathbf{P}$

PADILLA GARCÍA, J. L.; GONZÁLEZ, A. y PÉREZ, C. (1998). Elaboración del cuestionario. En ROJAS TEJADA, A. J.; FERNÁNDEZ, J. S. y PÉREZ, C. (Eds.), Investigar mediante encuestas. Fundamentos teóricos y aspectos prácticos (pp. 115140). Madrid: Síntesis.

(1] PANTOJA CHAVES, A. (2011). Los medios de comunicación sociales: las redes sociales. Tejuelo, 12, pp. 218-226.

PAPALIA, D. E. y OLDS, S. W. (1992). Psicología. Madrid: McGraw Hill.

[d PASCUAL BAÑOS, C. (2003). La historia de vida de una educadora de profesores de Educación Física: su desarrollo personal y profesional. Ágora para la EF y el Deporte, 2-3, pp. 23-38.

PASTOR, B. (2002). ¿Qué pasa en las aulas? Crónica de un desastre. Barcelona: Planeta.

D] PENDENZA, R. R. (2009). La actividad física y el ciclo menstrual. Argentina: El Cid Editor

PEÑA FERIA, J. y VÁZQUEZ GALIANO, J. F. (2001). Actitudes del profesorado de Educación Física ante la diversidad. En GIMÉNEZ, F. J.; SIERRA, A.; TIERRA, J. y DÍAZ, M. (Coords.), Educación Física y Diversidad (pp. 151-156). Huelva: Universidad de Huelva.

[DI PERELlÓ TALENS, I.; CAUS, N.; RUIZ, A. J. y RUIZ, F. C. (2003). Educación Física. Aplicaciones didácticas. Temario para la preparación de Oposiciones al Cuerpo de Profesores de Enseñanza Secundaria. Sevilla: MAD. 
[De PERLLÓ TALENS, I. (2005). Programación Didáctica de la asignatura de Educación Física para $2^{\circ}$ de ESO. En PERELLÓ TALENS, I.; RUIZ, F. C.; RUIZ, A. J.; CAUS, N. y LÓPEZ, V., Educación Física. Programación Didáctica (pp.65113). Temario para la preparación de Oposiciones al Cuerpo de Profesores de Enseñanza Secundaria. Sevilla: MAD.

[D] PÉREZ BRUNICARDI, D.; LÓPEZ PASTOR, V. M. e IGLESIAS SANZ, P. (Coords., 2004). La atención a la diversidad en Educación Física. Sevilla: Wanceulen.

메 PÉREZ COBACHO, J. y PRIETO SÁNCHEZ, M. D. (1997). La actitud del profesor ante los niños integrados. En ARNAIZ SÁNCHEZ, P. y DE HARO RODRÍGUEZ, R. (Eds.), 10 años de integración en España: Análisis de la realidad y perspectivas de futuro (pp. 587-599). Murcia: Universidad de Murcia.

[D] PÉREZ CORTÉS, A. J.; DE HARO, E., MOLINA, B. y JOVER, J. (1997). La evaluación de los alumnos exentos en Educación Física. En SALMERÓN PÉREZ, H. (Coord.), Evaluación educativa: VII Jornadas LOGSE (pp. 345-350). Granada: Grupo Editorial Universitario.

[D] PÉREZ MELÉNDEZ, C.; ROJAS, A. J. y FERNÁNDEZ, J. S. (1998). Introducción a la investigación social. En ROJAS TEJADA, A. J.; FERNÁNDEZ, J. S. y PÉREZ, C. (Eds.), Investigar mediante encuestas. Fundamentos teóricos y aspectos prácticos (pp. 17-29). Madrid: Síntesis, Madrid.

Dd PÉREZ TURPIN, J. A. y SUÁREZ LLORCA, C. (2004). Educación Física y alumnos con necesidades educativas especiales. Sevilla: Wanceulen.

Periódico El Día de Valladolid, 12-04-2008

Periódico El Norte de Castilla, 21-08-2005 
[D] Periódico La Vanguardia, 26-10-2003

Periódico MARCA, 13-08-2005

PERONA MATA, C.; GARNICA, A. y NAVARRETE, R. (1998). Responsabilidad jurídica de los docentes. Madrid: Federación de Enseñanza de CC.OO.

PETRUS, A. (1998). Esport, educació i diversitat. Congreso de la Educación Física y el Deporte en edad escolar de la ciudad de Barcelona. Ponencia.

D PFEIFFER, R. P. y MANGUS, B. C. (2000). Las lesiones deportivas. Barcelona: Paidotribo.

PHILLIPS, E. M. y PUGH, D. S. (2008). La tesis doctoral: un manual para estudiantes y sus directores. Barcelona: Profit.

[Da PUIGDELlíVOL AGUADÉ, I. (2001). El reto de la diversidad en la escuela de hoy. Tándem, 5, pp. 7-19.

\section{Q}

[D] QUINTANA PEÑA, A. (2006) Metodología de Investigación Científica Cualitativa. En QUINTANA, A. y MONTGOMERY, W. (Eds.), Psicología: Tópicos de actualidad (pp. 47-84). Lima: UNMSM.

$\mathbf{R}$

RATH, T. y CLIFTON, D. O. (2005). Cómo potenciar tus emociones positivas. Barcelona: Ed. Urano. 
[Ld Real Academia Española (2001, 22a ed.). Diccionario de la Lengua Española. Madrid: Espasa.

[D] Real Academia Española (2010). Ortografía de la lengua española. Madrid: Espasa.

REAL DECRETO de 24 de julio de 1889 por el que se publica el Código Civil (BOE 25-07-1889) (Última modificación de 14-11-2012, documento consolidado referencia BOE-A-1889-4763)

REAL DECRETO 1179/1992, de 2 de octubre, por el que se establece el currículo del Bachillerato (BOE 21-10-1992).

REAL DECRETO 696/1995, de 28 de abril, de Ordenación de la Educación de los alumnos con necesidades educativas especiales (BOE 02-06-1995).

REAL DECRETO 83/1996, de 26 de enero, por el que se aprueba el Reglamento Orgánico de los Institutos de Educación Secundaria (BOE 21-02-1996).

REAL DECRETO 938/2001, de 3 de agosto, por el que se modifica el R.D. 1179/1992, de 2 de octubre, por el que se establece el currículo del Bachillerato (BOE 07-09-2001).

REAL DECRETO 117/2004, de 23 de enero, por el que se desarrolla la ordenación y se establece el currículo del Bachillerato (BOE n 42, 18-02-2004)

REAL DECRETO 1318/2004, de 28 de mayo, por el que se modifica el Real Decreto 827/2003, de 27 de junio, por el que se establece el calendario de aplicación de la nueva ordenación del sistema educativo establecida por la Ley Orgánica 10/2002, de 23 de diciembre, de Calidad de la educación (BOE 29-05-2004)

REAL DECRETO 971/2007, de 13 de julio, sobre deportistas de alto nivel y alto 
rendimiento (BOE 25-07-2007)

REAL DECRETO 1467/2007, de 2 de noviembre, por el que se establece la estructura del bachillerato y se fijan sus enseñanzas mínimas (BOE 06-11-2007)

REAL DECRETO 242/2009, de 27 de febrero, por el que se establecen convalidaciones entre las enseñanzas profesionales de Música y de Danza y la Educación Secundaria obligatoria y el Bachillerato, así como los efectos que sobre la materia de Educación física deben tener la condición de deportista de alto nivel o alto rendimiento y las enseñanzas profesionales de Danza (BOE 28-02-2009)

[D REDONDO MARTÍN, S. (2003). La promoción de la salud en los centros educativos. En FRAILE ARANDA, A. (Dir.), Actividad física y salud. Educación Secundaria (pp. 15-21). Valladolid: Junta Castilla y León, Consejería de Sanidad.

Reglamento para alumnas Embarazadas y Madres (Chile) http://www.mineduc.cl/usuarios/convivencia_escolar/doc/201103050209570.Regla mento_de_las_alumnas_en_situacion_de_embarazo_y_maternidad.pdf (Consultado 06-12-2008)

RESOLUCIÓN de 16 de julio de 1996, de la Viceconsejería de Educación, por la que se completan determinados extremos contenidos en la Resolución de la Dirección General de Centros de 20 de julio de 1995, que aprueba las instrucciones que regulan la organización y funcionamiento de los Centros de Enseñanzas Medias, dependientes de la Consejería de Educación, Cultura y Deportes del Gobierno de Canarias (BOC n 100, 16-08-1996)

RESOLUCIÓN no 194 de 4 de agosto de 1999, de la Dirección General de Centros, por la que se aprueban las Instrucciones de organización y funcionamiento de los Centros de Educación Obligatoria dependientes de la Comunidad Autónoma de Canarias.

http://www.educa.rcanaria.es/udg/cen/TextosRefundidos/TextoRefundidoCEO2003. 
pdf (Consultado 23-04-2003)

RESOLUCIÓN de 30 de junio de 2003, de la Dirección General de Centros, Ordenación e inspección Educativa, por la que se establece el currículo de educación física para los alumnos que cursan simultáneamente las enseñanzas de bachillerato y el gado medio de danza (BORMurcia 15-07-2003)

RESOLUCIÓN de 28 de julio de 2004, de la Dirección General de Enseñanzas Escolares, por la que se establece el currículo de Educación Física para los alumnos que simultanean estudios de Educación Secundaria con la práctica deportiva (BORMurcia n $^{\text {199 }}$, 27-08-2004)

RESOLUCIÓN de 17 de agosto de 2009, de la Dirección General de Planificación, Ordenación e Inspección Educativa, por la que se regula el diseño, aplicación, seguimiento y evaluación de las adaptaciones curriculares significativas para el alumnado con necesidades educativas especiales escolarizado en el segundo ciclo de educación infantil, educación primaria y educación secundaria obligatoria en los centros docentes de la Comunidad de Castilla y León (BOCyL 26/08/2009).

RÍOS, M. (2007). La inclusión del alumnado con discapacidad y el pensamiento del profesorado. Resultados de un grupo de discusión. Tándem, 23, pp.86-97.

[D] RÍOS HERNÁNDEZ, M. (1994). Los juegos sensibilizadores: una herramienta de integración socia. Apunts, 38, pp. 93-98.

RÍOS HERNÁNDEZ, M.; BLANCO, A.; BONANY, T. y CAROL, N. (1998a). El juego y los alumnos con discapacidad. Barcelona: Paidotribo.

RÍOS HERNÁNDEZ, M. (1998b). Diversidad: necesidades educativas especiales en el área de educación física. Aula de Innovación Educativa, 72, pp. 29-31.

RÍOS HERNÁNDEZ, M. (1999). Una propuesta para la integración de los alumnos 
con discapacidad en actividades competitivas: la compensación de la desventaja. En SAÉNZ-LÓPEZ, P.; TIERRA, J. y DIAZ, M. (Coords.), Actas del XVII Congreso Nacional de Educación Física (pp. 937-947). Málaga: Instituto Andaluz del Deporte.

DI RÍOS HERNÁNDEZ, M. (2001a) El reto de la participación activa y efectiva del alumnado con necesidades educativas especiales en las sesiones de educación física. Tándem, 5, pp. 20-30.

[Q] RÍOS HERNÁNDEZ, M. (2001b). Integración y participación activa del alumnado con necesidades educativas especiales: un reto en la sesión de Educación Física. En GIMÉNEZ, F. J.; SIERRA, A.; TIERRA, J. y DÍAZ, M. (Coords.), Educación Física y Diversidad (pp. 95-109). Huelva: Universidad de Huelva.

QDI RÍOS HERNÁNDEZ, M.; BLANCO, A.; BONANY, T. y CAROL, N. (2001c). Actividad física adaptada. El juego y los alumnos con discapacidad. Barcelona: Paidotribo.

Q] RÍOS HERNÁNDEZ, M. (2003). Manual de Educación Física adaptada al alumnado con discapacidad. Barcelona: Paidotribo.

RÍOS HERNÁNDEZ, M. (2004). La Educación Física y la inclusión del alumnado con discapacidad. En FRAILE, A. (Coord.), Didáctica de la Educación Física. Una perspectiva crítica y transversal (pp. 147-169). Madrid: Biblioteca Nueva.

RÍOS, M. (2009). La inclusión en el área de Educación Física en España. Análisis de las barreras para la participación y aprendizaje. Ágora, 9, pp.83-114.

DO RODRÍGUEZ, C.; POZO, T. y GUTIÉRREZ, J. (2006). La triangulación analítica como recurso para la validación de estudios de encuesta recurrentes e investigaciones de réplica en educación superior. RELIEVE, 12 (2), pp. 289-305. 
RODRÍGUEZ DE LA CRUZ, J. C. y LERA CORREDERA, J. M. (2006). El cuaderno de clase del alumno/a como instrumento de evaluación y vehículo de comunicación en la Educación Física. Lecturas: Educación Física y Deportes, 100. Recuperado el 8 de marzo de 2008, de http://www.efdeportes.com/efd100/cuad.htm

RODRÍGUEZ-SOLANO RUBIO, A. (2003). El problema de los «exentos» en la clase de educación física: búsqueda del perfil de este colectivo para lograr el 100\% de alumnos activos. Lecturas: Educación Física y Deportes, 64. Recuperado el 25 de abril de 2005, de http://www.efdeportes.com/efd64/exentos.htm

[D] RODRÍGUEZ-SOLANO RUBIO, A. (2004). El problema de los «exentos» en la clase de Educación Física: búsqueda del perfil de este colectivo para lograr el 100\% de alumnos activos. Revista de Educación Física, 96, pp. 15-20.

ROLDÁN VENDRELL, C. (Coord., 2002). Manual de Seguridad en los Centros Educativos. Sevilla: Junta de Andalucía. Recuperado el 22 de abril de 2006, de http://www.juntadeandalucia.es/educacion/www/portal/com/bin/portal/Contenidos/ Consejeria/IE/Seguridad_higiene_en_el_trabajo/Manual_seguridad_centros/manual _de_seguridad.pdf

DI ROMERO CEREZO, C. (2004). Argumentos sobre la formación inicial de los docentes en educación física. Profesorado: Revista de currículum y formación del profesorado, 8 (1), pp. 1-20.

RUEDA, A.; FRÍAS, G.; QUINTANA, R. M. y PORTILLA, J. L. (2001). La condición física en la educación secundaria obligatoria. Barcelona: Inde.

[D] RUIZ JUAN, F. y GARCÍA MONTES, M. E. (2003). Control de contingencias en el centro escolar. Factores a tener en cuenta en el uso de los recursos materiales. En GONZÁLEZ DEL HOYO, E. P. y RUIZ JUAN, F. (Coords.), Dimensión europea de la Educación Física y el deporte en edad escolar. Hacia un espacio europea de educación superior (pp. 265-274). Valladolid: AVAPEF. 
[DU RUIZ MORALES, G. (2005). Responsabilidad Civil del Profesor de Educación Física. Principio Genérico de las Leyes. En Curso: Control de lesiones y accidentes en la práctica educativa. Responsabilidad docente. FEADEF [Online]

\section{$\mathbf{S}$}

SAAVEDRA, C. (2004). ¿Por qué la mujer debe hacer ejercicio? Recuperado el 15 de enero de 2007, de http://www.enplenitud.com/nota.asp?articuloID=1134

@] SÁENZ-LÓPEZ, P.; FRANCO, M. J.; CERA, E. y GIMÉNEZ, F. J. (2001). ¿Qué opina el alumnado de Magisterio de la Educación Física Especial? En GIMÉNEZ, F. J.; SIERRA, A.; TIERRA, J. y DÍAZ, M. (Coords.), Educación Física y Diversidad (pp. 167-181). Huelva: Universidad de Huelva.

SALAMANCA, A. (2007). Los embarazos en menores de 15 años han aumentado el 76\%. Recuperado el 28 de octubre de 2007, de http://www.elnortedecastilla.es/20071028/vida/embarazos-menores-anosaumentado-20071028.html

SÁNCHEZ IGUAL, J. E. (2003). Responsabilidad civil del profesorado de Educación Física en España. Una visión realista y positiva. Lecturas: Educación y Deportes, 67. Recuperado el 8 de septiembre de 2005, de http://www.efdeportes.com/efd67/civil.htm

SÁNCHEZ PALACIOS, P. (2009). Normas básicas para el buen desarrollo de la clase de Educación Física. Revista Digital Innovación y Experiencias Educativas, 14. Recuperado el 6 de abril de 2010, de http://www.csicsif.es/andalucia/modules/mod_ense/revista/pdf/Numero_14/PILAR_SANCHEZ_1. pdf 
SANCHÍS, C.; SALILLAS, J.; RIERA, T. y FONTANET, T. (1993). Hacer estadística. Madrid: Biblioteca de Recursos Didácticos Alambra.

SANDÍN ESTEBAN, M. P. (2000). Criterios de validez en la investigación cualitativa: de la objetividad a la solidaridad. Revista de Investigación Educativa, 18, pp. 223-242.

[D] SANTOJA, F.; RODRÍGUEZ, P. L.; SAINZ DE BARANDA, P. y LÓPEZ, P. A. (2004). Papel del profesor de educación física ante las desalineaciones de la columna vertebral. Selección, 13 (1), pp. 5-17.

SARABIA, B. (1985). Historias de vida. Revista Internacional de Sociología, 29, pp. 165-186.

[D] SARO FERNÁNDEZ, F. J. (2005). Deporte = Salud. ¿Es siempre así? En Curso: Control de lesiones y accidentes en la práctica educativa. Responsabilidad docente. FEADEF [Online]

SHAPE (2014). Guide for Physical Education Policy. Recuperado el 13 de abril de 2015, de http://www.shapeamerica.org/advocacy/upload/Guide-for-PhysicalEducation-Policy-9-23-14.pdf

[Q] SOLER, S. y VILANOVA, A. (2010). La Investigación en Educación Física. En GONZÁLEZ, C. y LLEIXÁ, T. (Coords.), Educación Física. Investigación, innovación y buenas prácticas (pp. 25-41). 4 (III). Barcelona: GRAÓ.

SORIANO, S. (1998). Experiencia de integración de un alumno ciego en la clase de educación física. Aula de Innovación Educativa, 72, pp. 42-43.

SPARKES, A. C. (1992). Breve introducción a los paradigmas de investigación alternativos en Educación Física. Perspectivas, 11, pp. 29-33. 
[D SPARKES, A. C. (2003). Investigación narrativa en la Educación Física y el Deporte. Ágora para la EF y el Deporte, 2-3, pp. 51-60.

SPARKES, A. C. y DEVÍS DEVÍS, J. (2007). Investigación narrativa y sus formas de análisis: una visión desde la Educación Física y el deporte. En MONERO GÓMEZ, W. y PULIDO QUINTERO, S. M. (Eds.), Educación, cuerpo y ciudad. El cuerpo en las interacciones e instituciones sociales (pp. 43-69). Medellín-Colombia: Ed. Funámbulos.

SUSINOS, T. (1997). Ideas y expectativas de los alumnos sobre la educación con integración previas a los programas de formación inicial (Magisterio y CAP). En ARNAIZ SÁNCHEZ, P. y DE HARO RODRÍGUEZ, R. (Eds.), 10 años de integración en España: Análisis de la realidad y perspectivas de futuro (pp. 561571). Murcia: Universidad de Murcia.

T

TAJADURA TEJADA, J. (2009). La libertad religiosa en el ámbito escolar: un estudio comparado de los modelos alemán y francés. Anuario da Facultade de Dereito da Iniversidade da Coruña (pp. 789-818). 13. A Coruña: AFDUDC.

D TAMAYO, M. (2001). El proceso de la investigación científica. México: Limusa.

Dll TEJERO, C. M.; DÍAZ, C.; TEJEDOR, M.; LÓPEZ, M. y CALZADA, R. (2003). Directrices para evaluar al alumnado de enseñanza secundaria en el área de Educación Física: Una propuesta basada en la experiencia educativa. Revista Pedagógica ADAL, 7, pp. 37-46.

[D] TERCEDOR, P.; DELGADO, M y JIMÉNEZ, M. J. (2001). Propuesta para una evaluación de la programación de aula como promotora de salud. En GIMÉNEZ, F. J.; SIERRA, A.; TIERRA, J. y DÍAZ, M. (Coords.), Educación Física y Diversidad 
(pp. 197-212). Huelva: Universidad de Huelva.

TIERNO, B. (2006). Aprendiz de sabio. Barcelona: Grijalbo.

TIERRA ORTA, J. (2001). Educación Física y alumnos con necesidades educativas especiales. XXI. Revista de Educación, 3, pp. 137-147.

TORO BUENO, S. y ZARCO RESA, J. A. (1995). Educación Física para niños y niñas con necesidades educativas especiales. Málaga: Ediciones Aljibe.

$\mathbf{U}$

UNESCO (2014). World-wide Survey of School Physical Education - Final Report 2013. Recuperado el 10 de abril de 2015, de http://unesdoc.unesco.org/images/0022/002293/229335e.pdf

UNESCO (2015). Educación Física de Calidad. Guía para responsables políticos. $\begin{array}{llllll}\text { Recuperado el de } & 10 \text { de }\end{array}$ http://unesdoc.unesco.org/images/0023/002313/231340S.pdf

URIBE, P. (1994). Mujer, maternidad y enfermedades de transmisión sexual. En ELU, M. C. y LANGER, A. (Eds.), Maternidad sin riesgos en México (pp. 91-97). México DF: Comité Promotor por una Maternidad sin Riesgos.

VICIANA RAMÍREZ, J. (2002). Temporalizar la Educación Física: el planning de una programación y consideraciones para la sesión. Lecturas: Educación Física y Deportes, 47. Recuperado el 6 de febrero de 2003, de http://www.efdeportes.com/efd47/tempo.htm 
VICIANA RAMÍREZ, J. (2002). Planificar en Educación Física. Barcelona: Inde.

VILLAGRA ARIEL, A. (2003). La educación física y las necesidades educativas especiales: un análisis crítico en el marco de la innovación educativa. Tándem, 11, pp. 7-17.

$\mathbf{Z}$

[DABALA, A. (2004). La formación del profesorado. Aula de Innovación Educativa, 130, pp. 18-22.

[DI ZABALZA BERAZA， M. A. (1997). Las contradicciones de la integración educativa: una reflexión crítica desde la pedagogía de la inadaptación. En ARNAIZ SÁNCHEZ, P. y DE HARO RODRÍGUEZ, R. (Eds.), 10 años de integración en España: Análisis de la realidad y perspectivas de futuro (pp. 59-73). Murcia: Universidad de Murcia.

ZUCCHI, D. G. (2001). Deporte y discapacidad. Lecturas: Educación y Deportes, 43. Recuperado el 30 de mayo de 2003, de http://www.efdeportes.com/efd43/discap.htm

ZUCCHI, D. G. (2004). La dialéctica de la inclusión / exclusión den las prácticas corporales. Una aproximación crítica al problema. Lecturas: Educación y Deportes, 77. Recuperado el 20 de octubre de 2006, de http://www.efdeportes.com/efd77/inclus.htm 


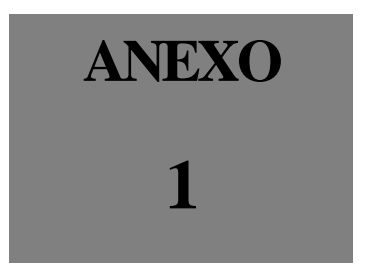


ORDEN de 10 de julio de 1995 por la que se regula la adaptación del currículo de la Educación Física para los alumnos con necesidades educativas especiales en el Bachillerato Unificado y Polivalente, en la Formación Profesional de primer y segundo grados y en la educación secundaria, así como la dispensa de la misma para los mayores de veinticinco años (BOE de 15 de julio de 1995, núm. 168)

La Orden de 31 de julio de 1961 por la que se regula la dispensa de Educación Física en las Enseñanza Media («Boletín Oficial del Estado» de 15 de agosto) preveía una serie de situaciones en las que se eximía a los alumnos de la obligación de cursar esa disciplina. Aunque tanto las condiciones que motivaron aquella norma como los programas de la asignatura objeto de dispensa se han modificado profundamente con el paso de los años, en algunos centros se viene aplicando aquella disposición, al no haber sido expresamente derogada declarando exentos de cursar esa materia a alumnos que, a pesar de sus especiales circunstancias, pueden seguir una parte importante de los contenidos de la misma y alcanzar una buena parte de los objetivos educativos asignados a esta disciplina.

Así lo ha entendido la Comisión de Educación y Cultura del Congreso de los Diputados que en reunión celebrada el 15 de febrero de este año aprobó una proposición no de Ley por la que se insta al Ministerio de Educación y Ciencia para que promulgue una Orden más acorde con los contenidos de la Ley Orgánica 1/1990, de 3 de octubre, de Ordenación General del Sistema Educativo que derogue la de 31 de julio de 1961 antes citada.

En efecto, tanto el currículo de Educación Física establecido para los niveles de Educación Secundaria Obligatoria y Bachillerato regulados por la Ley Orgánica 1/1990, antes citada, como los programas del Bachillerato Unificado y Polivalente modificados por la Orden de 18 de septiembre de 1987 («Boletín Oficial del Estado» del 23) y los correspondientes a esta disciplina en la Formación Profesional de primer y segundo grados incluyen objetivos, contenidos y criterios u orientaciones para la evaluación que trascienden la práctica del ejercicio físico de distinto signo y que son asequibles a la generalidad de los alumnos.

Por tanto, la exención de cursar esta disciplina se presenta en la actualidad, para alguna de las situaciones previstas en la Orden de 31 de julio de 1961, como una medida improcedente y contraria al principio de adaptación del currículo y de integración que establecen los artículos 36 y 37 de la Ley Orgánica de Ordenación General del Sistema Educativo y el Real Decreto696/1995, de 28 de abril, en su desarrollo.

En virtud de los expuesto, y en uso de las atribuciones que confiere al Ministerio de Educación y Ciencia el Decreto 160/1975, de 23 de enero («Boletín Oficial del Estado» de 13 de febrero), en su artículo 11 y disposición final cuarta respecto al Bachillerato Unificado y Polivalente, la disposición final $5^{\text {a }}$ del Decreto 707/1976, de 5 de marzo («Boletín Oficial del Estado» de 12 de abril) para la Formación Profesional, y las disposiciones adicional primera del Real Decreto 1179/1992, de 2 de octubre («Boletín Oficial del Estado» del 21), final primera del Real Decreto 1345/1991, de 6 de septiembre («Boletín Oficial del Estado» del 13) y final primera del Real Decreto 696/1995, de 28 de abril («Boletín Oficial del Estado» de 2 de junio) para el Bachillerato y la Educación Secundaria Obligatoria establecidos por la Ley Orgánica 1/1990, de 3 de octubre, de Ordenación General del Sistema Educativo, respectivamente, previo dictamen del Consejo Escolar del Estado, dispongo:

Artículo 1.

La presente Orden será de aplicación en los Centros de Bachillerato, Formación Profesional y Educación Secundaria del ámbito de gestión del Ministerio de Educación y Ciencia. 
Artículo 2.

1. El currículo de Educación Física de los diferentes cursos de Bachillerato Unificado y Polivalente, de Formación Profesional de primer y segundo grados y de la Educación Secundaria regulada por la Ley Orgánica 1/1990, de 3 de octubre, de Ordenación General del Sistema Educativo, se adaptará para aquellos alumnos con necesidades educativas especiales asociadas a discapacidad motora o sensorial, temporal o permanente.

2. La dispensa de cursar esta materia, que la Orden de 31 de julio de 1961 por la que se regula la dispensa de la Educación Física en la Enseñanza Media preveía para determinados supuestos, se limitará a los alumnos mayores de veinticinco años, o que cumplan esa edad en el período para el que formalizan la matrícula.

Articulo 3

1. Las solicitudes de las adaptaciones a que se refiere el apartado $1^{\circ}$ del artículo 2 serán formuladas ante la Dirección del Centro por los alumnos o, si éstos son menores de edad, por sus padres o representantes legales e irán acompañadas de los certificados médicos correspondientes.

2. El Departamento de Educación Física acordará las adaptaciones oportunas a la vista de los certificados médicos, así como del resultado de la evaluación y el dictamen emitido por el Departamento de Orientación del centro o, en su defecto, por el equipo de Orientación Educativa y Psicopedagógica que corresponda de quienes recabará asesoramiento, si lo estima necesario, para la determinación de dichas adaptaciones.

3. La evaluación de los aprendizajes de los alumnos con necesidades educativas especiales a los que se refiere esta Orden se hará conforme a los objetivos y contenidos para ellos propuestos en la adaptación curricular correspondiente.

Artículo 4.

La solicitud de la dispensa de los alumnos a los que ser refiere el apartado $2^{\circ}$ del artículo 2 será formulada por los interesados ante la Dirección del centro en el que vayan a cursar estudios en el momento de formalizar su matrícula.

Disposición derogatoria única.

Queda derogada la Orden de 31 de julio de 1961 por la que se regula la dispensa de Educación Física en las Enseñanzas Medias

Disposición final primera.

La Dirección General de Renovación Pedagógica podrá dictar las disposiciones oportunas para la ejecución y desarrollo de lo establecidos en la presente Orden.

Disposición final segunda.

La presente Orden será de aplicación a partir del curso académico 1995/96.

Madrid, 10 de julio de 1995.

SAAVEDRA ACEVEDO

Excmo. Sr. Secretario de Estado de Educación. 


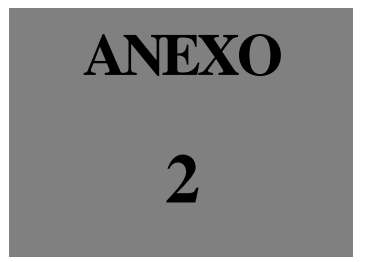

MODELO SOLICITUD DE EXENCIÓN DE MATERIAS DE BACHILLERATO SEGÚN LA ORDEN EDU/490/2014 


\section{Boletín Oficial de Castilla y León B BOGr}

Núm 116

Junta de

Castilla y León

consejetia de Educación

ANEXO I

SOLICITUD DE EXENCIÓN DE MATERIAS DE BACHILLERATO.

Datos del solicitante/s (padre/madre/tutor o alumno/a si es mayor de edad):

\begin{tabular}{|l|l|l|l|l|l|l|l|}
\hline $1^{\circ}$ & Primer apellido: & Segundo apellido: & Nombre: & D.N.I.N.I.E. & \multicolumn{1}{|l|}{ Padre Madre Tutor } \\
\hline $2^{\circ}$ & Primer apellido: & Segundo apellido: & Nombre: & D.N.I.N.I.E. & \multicolumn{2}{|c|}{ Padre Madre Tutor } \\
\hline
\end{tabular}

\begin{tabular}{|l|l|l|l|l|}
\hline Alumno/a: & \multicolumn{3}{|l|}{} \\
\hline Primer apellido: & Segundo apellido: & Nombre: & D.N.I.N.I.E. & Fecha de nacimiento: \\
\hline
\end{tabular}

\begin{tabular}{|l|l|l|}
\hline Teléfono fjo: & Teléfono móvil: & Correo-e \\
\hline
\end{tabular}

Domicilio a efectos de notificación

\begin{tabular}{|l|l|l|l|l|}
\hline Domicilio a efectos de notificación: \\
\hline Dirección: & Portal/Piso/letra: & Localidad: & Provincia: & Código postal \\
\hline
\end{tabular}

\begin{tabular}{|l|l|l|l|l|l}
\hline CENTRO: & \\
\hline
\end{tabular}

\begin{tabular}{|l|l|}
\hline Modalidad de bachillerato en la que está matriculado & \\
\hline
\end{tabular} Curso en el que está matriculado

DECLARA/N que el alumno/a tiene necesidades educativas especiales derivadas de graves problemas de (audición, visión, motricidad u otros) con un Grado de Discapacidad reconocido del __ _ $\%$

SOLICITAIN que se le conceda la exención (parcial o total) en la materia

Documentación que acompaña:
Informe médico
a Certificado del Grado de Discapacidad o Tarjeta de acreditación o
a Autorización para comprobar el Grado de Discapacidad
Otros informes (indicar cuales):

En

a de

de 20

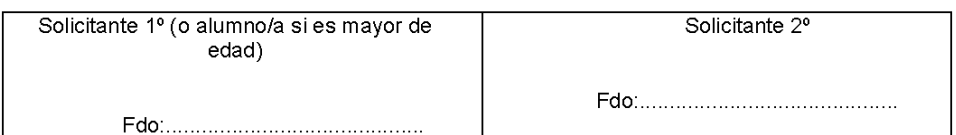

ILMO. DIRECTOR GENERAL DE POLITICA EDUCATIVA ESCOLAR RECIBIDA POR SR/A. DIRECTOR/A del centro 


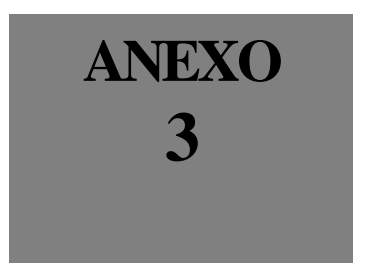

CARTA DEL DEPARTAMENTO DE EDUCACIÓN. FÍSICA A LOS PADRES PARA LOS CASOS DE EXENCIÓN TOTAL O PARCIAL 


\title{
CARTA DEL DEPARTAMENTO DE E. FÍSICA A LOS PADRES PARA LOS CASOS DE EXENCIÓN TOTAL O PARCIAL
}

\author{
IES RAMÓN DEL VALLE-INCLÁN \\ DEPARTAMENTO DE E. FÍSICA
}

Sevilla, septiembre de 2003

Nos dirigimos a ustedes con motivo del comienzo de las clases de Educación Física del nuevo curso escolar para informarles de las actuaciones pertinentes en caso de exención de las prácticas de E. Física (la parte teórica no tiene exención posible).

El Real Decreto 334/1985 de 6 de marzo de Ordenación de la Educación Especial (BOE 16.3.85) nos indica el procedimiento a seguir: si el alumno presenta enfermedad, deficiencia o minusvalía, o la sufriera a lo largo del curso, que le impida el normal desarrollo de actividades físicas, debe presentar en la Secretaría del Instituto un Informe Médico al formalizar la matrícula o una semana después de la aparición de la enfermedad o deficiencia, si ésta se produce a lo largo del curso.

Queremos así transmitirles con esta carta nuestro empeño en que consigamos para sus hijos entre todos (profesores, padres, alumnos) un correcto y sano desarrollo de las actividades físico-deportivas que realizaremos este curso. Por ello también les solicitamos que nos comuniquen cualquier dolencia o deficiencia que, aunque no sea tan grave para la exención, pueda ser lo suficientemente significativa para influir en la práctica físico-deportiva.

Sin más asuntos que tratar, se despiden de ustedes con el debido respeto. 


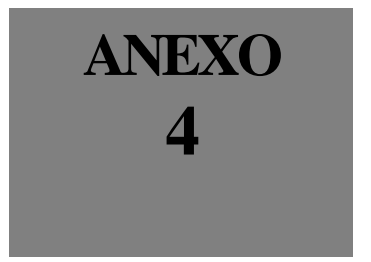

IMPRESO DE SOLICITUD DE DISPENSA O EXENCIÓN DE ACTIVIDADES PRÁCTICAS EN LA ASIGNATURA DE EDUCACIÓN FÍSICA 


\section{IMPRESO DE SOLICITUD DE DISPENSA O EXENCIÓN DE ACTIVIDADES PRÁCTICAS EN LA ASIGNATURA DE EDUCACIÓN FÍSICA}

(Orden $10-7$ - 95, B.O.E.: $15-7$ - 95)

\begin{tabular}{|l|l|}
\hline Alumno/a: \\
\hline Grupo: & Fecha de nacimiento: \\
\hline Domicilio: & Teléfono: \\
\hline Municipio: &
\end{tabular}

SOLICITA: (Coloque una cruz donde proceda).

a Exención de la asignatura por ser mayor de 25 años (Se adjunta fotocopia del D.N.I.)

- Dispensa en la parte práctica de la asignatura (total o parcial), por el siguiente motivo: (Lo cumplimentará el alumno/a si es mayor de 18 años, o los padres, o tutores legales si es menor de 18 años)

A cuyo efecto adjunto a la presente solicitud, CERTIFICADO MÉDICO OFICIAL, más los informes que he considerado oportuno y que justifican los motivos alegados para la exención total o parcial de las prácticas de la asignatura.

Cartagena, a

EL PADRE / MADRE

(Hijo menor de 18 años) de de 200

\author{
EL ALUMNO/A
}

(si tiene más de 18 años)

Fdo.:

Fdo.:

\section{OBSERVACIONES:}

La dispensa para cursar la asignatura de Educación Física se limitará únicamente a los alumnos/as mayores de 25 años. El resto de alumnos/as que, por imposibilidades psicofísicas no puedan realizar ninguna práctica, o solo parte de estas, para aprobar la asignatura deberán cursar y superar las oportunas adaptaciones curriculares que en cada caso proponga el Departamento de Educación Física del Centro. 


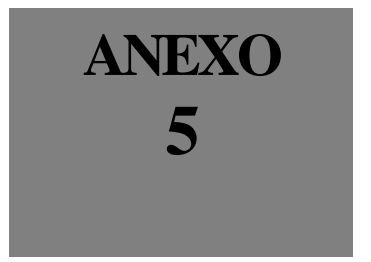

MODELO FAMILIAR E INFORME MÉDICO SEGÚN LA

FUENTE [36] 
Región de Murcia

Consejería de Educación

y Cultura
Instituto de Educación Secundaria "Prado Mayor"
C/Magallanes, 1

30850 Totana

Telf: 968421802

Fax: 968418287

D./D

Padre/madre/tutor del alumno/a:

Matriculado/a durante el presente curso académico en:

BACHILLERATO (indicar curso y modalidad: )

E.S.O. (indicar curso: )

Con domicilio en $\mathrm{c} /$ $\mathrm{n}^{\circ}$ de C.P. hace constar que, atendiendo a las especiales circunstancias que a continuación se especifican:

Solicita la oportuna adecuación de los contenidos de la asignatura de Educación Física, acompañando para ello el correspondiente informe médico.

Totana, a de de 200

(firma del padre, madre o tutor)

Sra. Directora del I.E.S. Prado Mayor 
MODELO DE INFORME MÉDICO PARA LAS DISPENSAS

EN LA ASIGNATURA DE EDUCACIÓN FÍSICA

\section{Nombre del médico:}

$\mathrm{N}^{\circ}$ de colegiado:

Especialidad:

Nombre del alumno:

\begin{tabular}{l|l} 
Curso: & Edad:
\end{tabular}

A

Enfermedad o lesión que padece:

Tratamiento seguido:

Tiempo que debe estar sin actividad:

D

Actividad física no recomendada:

Actividad física recomendada:

(n)

$\mathrm{E}$

Clase de dispensa recomendada por el médico: (marcar la deseada)

\begin{tabular}{l|l|l}
\hline & Parcial: & Sólo puede realizar alguna actividad (mencionarla en el apartado D) \\
\hline & Temporal: & Indicar el tiempo estimado (mencionarla en el apartado C) \\
\hline & Definitiva: & No puede realizar ninguna actividad física durante todo el año
\end{tabular}

Firma del médico:

Fecha: 


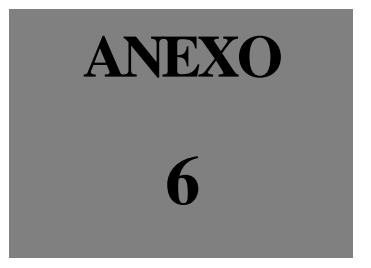

FICHA DE EXENTOS DE LA PARTE PRÁCTICA 
ISSN 1988-eC47 DEP. LEGAL: GR 2822/2007 N0 14 - ENERO 2009

\section{FICHA EXENT@S DE LA PARTE PRÁCTICA}

Yo.

alumna del curso

de ESO / BACHILLERATO (rodea lo que proceda), alego que NO PUEDO REALIZAR LOS CONTENIDOS PRACTICOS DE EDUCACIÓN FISICA durarte el $1^{\circ} / 2^{\circ} / 3^{\circ}$ trimestre del presente curso académico ya que:

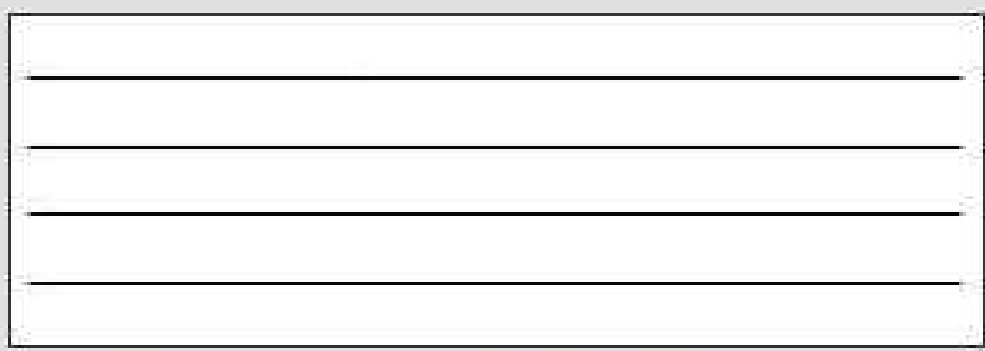

Esta lesión o enfemedad no me pemitrá participar activamente durante:

Especificar dias, semanas, meses:

* Para justificar dicha ajegación, traje en su dia, el certificado médico y lo dejé en la Secretaría del instituto.

* En caso de no haberio hecho asi, adjunto con este documento, el parte médico, que me exime de la parte práctica de Educación Fisica, teniendo que realizar diferentes trabajos altematwos durante las sesiones, además de los comespondientes a cada evaluación.

* Si el médico especialista me ha mandado una serie de ejercicios para mi recuperación o tratamiento, éstos los realizaré en la clase de Educación Fisica.

Para cestificar la alegación, el padre / madre / tutor legal fima su información y confima que:

Don o Dohia:

Firma del padre $f$ madre $/$ tutor

Fima del interesadg 


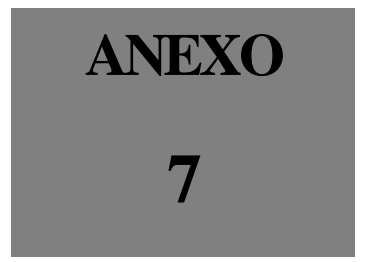

MODELO DE CARTA QUE ENVÍA EL INSTITUTO AL MÉDICO

(LÓPEZ, 1996) 


\section{MODELO CARTA QUE ENVÍA EL INSTITUTO AL MÉDICO}

\section{Estimado Doctor:}

De acuerdo con lo que se establece en la Orden Ministerial de 10 de julio de 1995 (B.O.E. de 1-7-95), todos los alumnos d Enseñanza Secundaria deben cursar en el área de Educación Física.

En la misma Orden Ministerial se especifica que, cuando algún alumno tenga alguna enfermedad o lesión que limite sus capacidades físicas, de tal forma que no pueda realizar los ejercicios previstos para todos los alumnos, se deben realizar las adaptaciones que convengan a su estado físico y para ello necesitamos conocer algunos datos básicos de dicho estado físico.

Por el motivo expuesto, solicito que, respecto del alumno/a:

que está matriculado en este Centro, nos facilite la siguiente información:

DIAGNÓSTICO:

EJERCICIOS FÍSICOS DESACONSEJABLES:

EJERCICIOS ACONSEJABLES:

DURACIÓN PREVISTA DE LA ENFERMEDAD O LESIÓN:

Murcia, a......... de de $19 \ldots . .$.

Doctor

Fdo.:

Colegiado $\mathrm{n}^{\mathrm{o}}$ : 


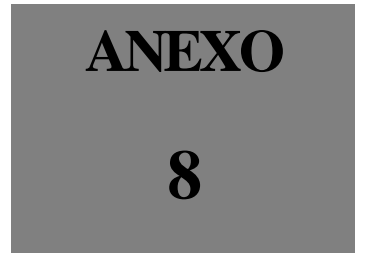

CARTA AL MÉDICO (PERELLÓ, 2004) 


\section{CARTA AL MÉDICO}

\section{I.E.S. MARÍA MOLINER PORT DE SAGUNT}

\section{DEPARTAMENTO DE EDUCACIÓN FÍSICA}

\section{Estimado/a Doctor/a:}

Con la intención de conocer la enfermedad o lesión que el alumno/a:

padece y que le puede impedir la práctica total o parcial del área de Educación Física, estaría muy agradecido si me indicara:

A) Qué tipo de enfermedad o lesión tiene:

B) Por cuánto tiempo deberá evitar la práctica de actividades físicas:

por otra parte, le informo que el programa de Educación Física de este centro se compone básicamente de:
A) Actividades para trabajar la mejora de la condición física, desarrollando la resistencia, fuerza. Flexibilidad y velocidad, y también la coordinación, el equilibrio y la agilidad.
B) Práctica de diversos juegos y deportes tanto colectivos como individuales.
C) Actividades de Expresión Corporal.

Agradecería me indicase qué actividades están contraindicadas y cuáles le serán favorables.

Agradeciendo de antemano su colaboración.

Un cordial saludo.

Fdo.:

Prof. de Educación Física

\section{EDUCACIÓN FÍSICA}




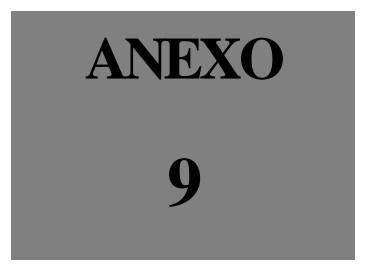

FICHA DE INFORMACIÓN GENERAL Y AJUSTE A LA NORMA (PRIMER FILTRO DEL ANÁLISIS) 


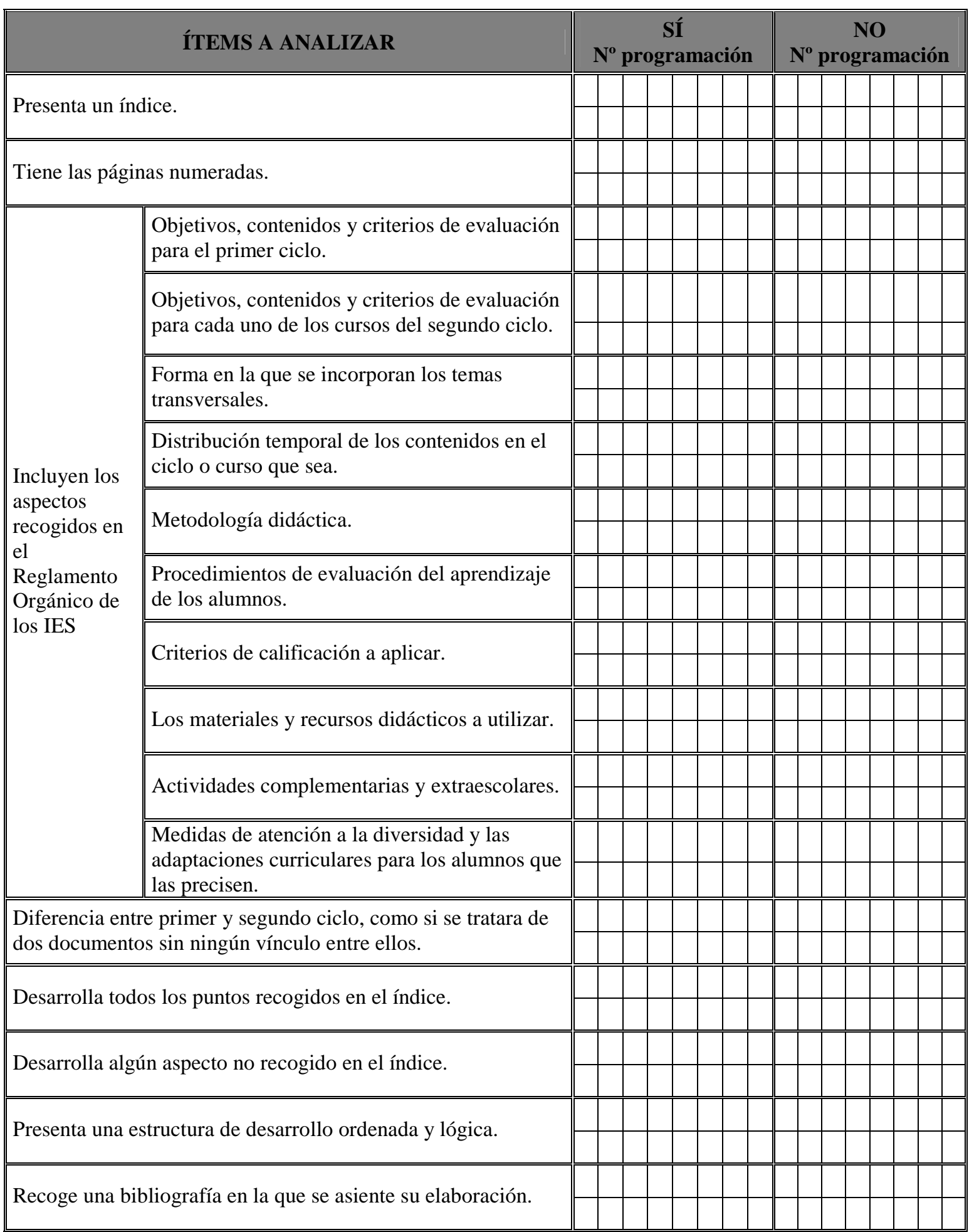




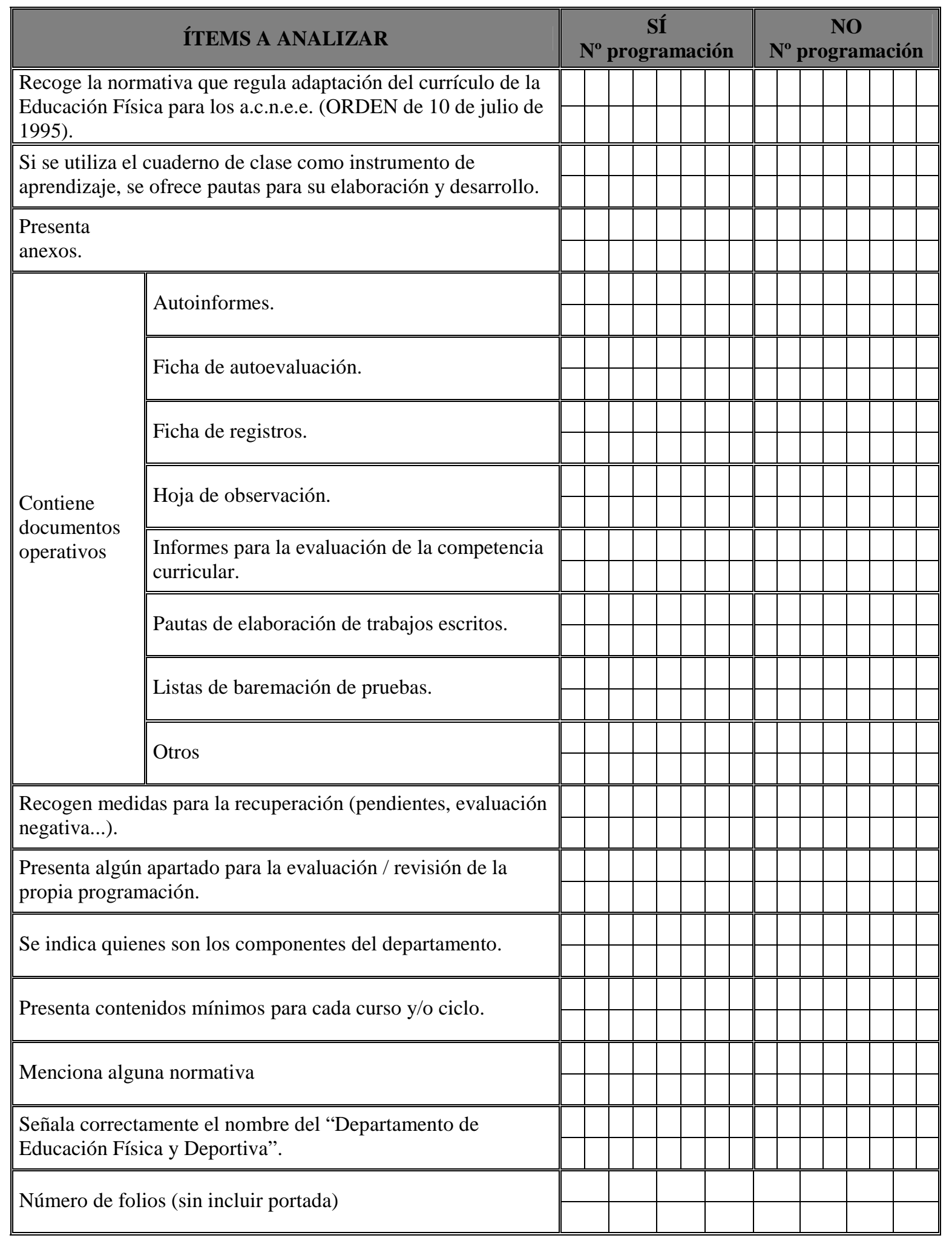




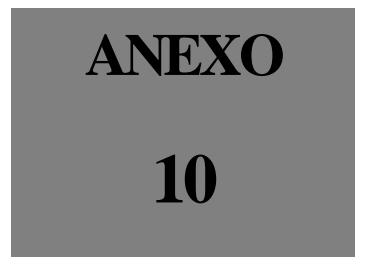

FICHA SOBRE MEDIDAS DE ATENCIÓN A LA DIVERSIDAD (SEGUNDO FILTRO DEL ANÁLISIS) 


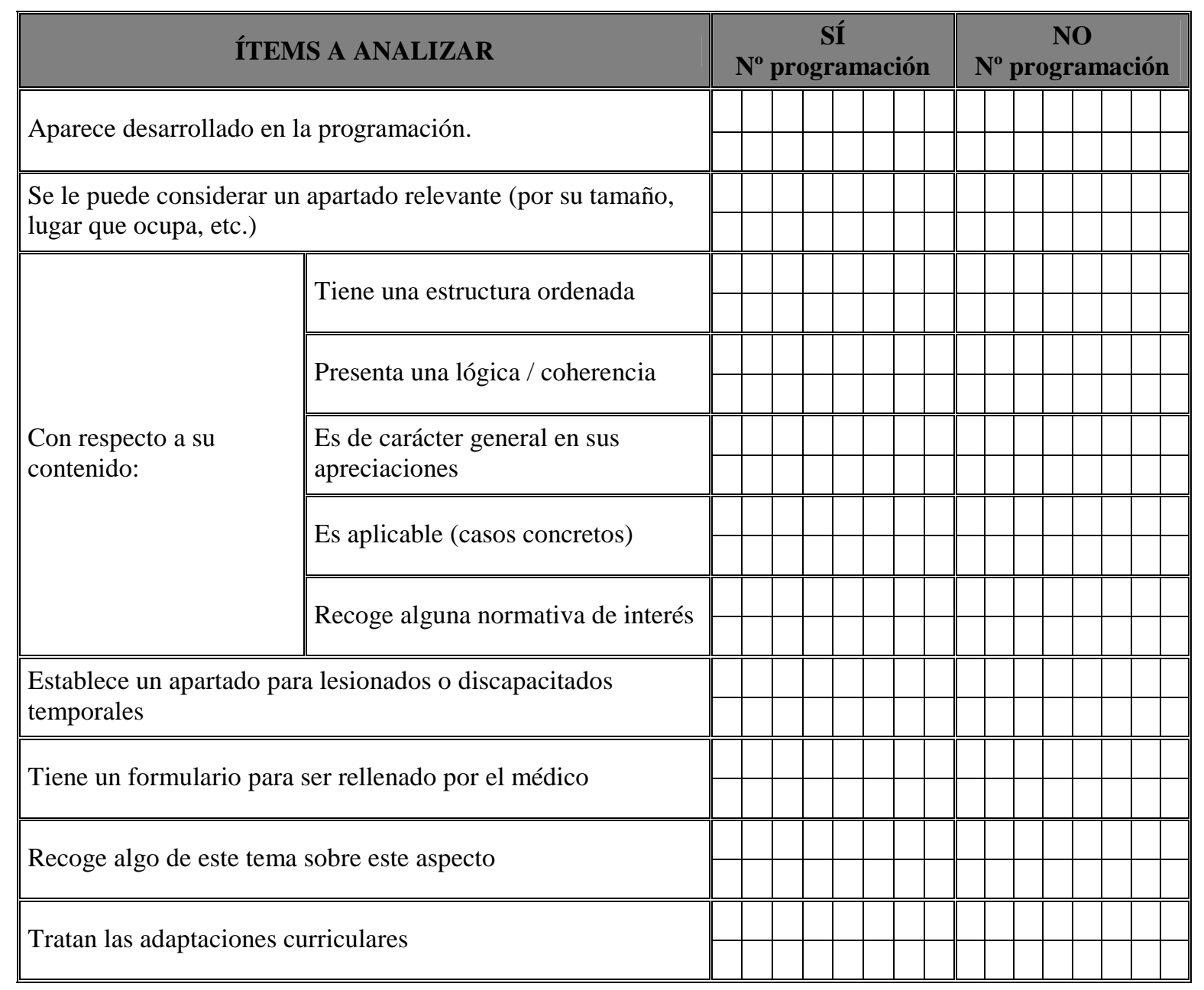




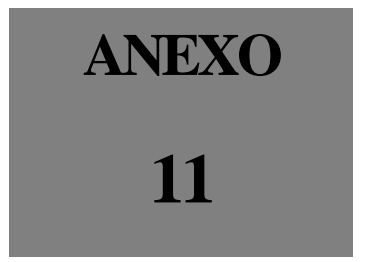

FICHA DEL CONCEPTO Y USO DE LA EXENCIÓN (TERCER FILTRO DEL ANÁLISIS) 


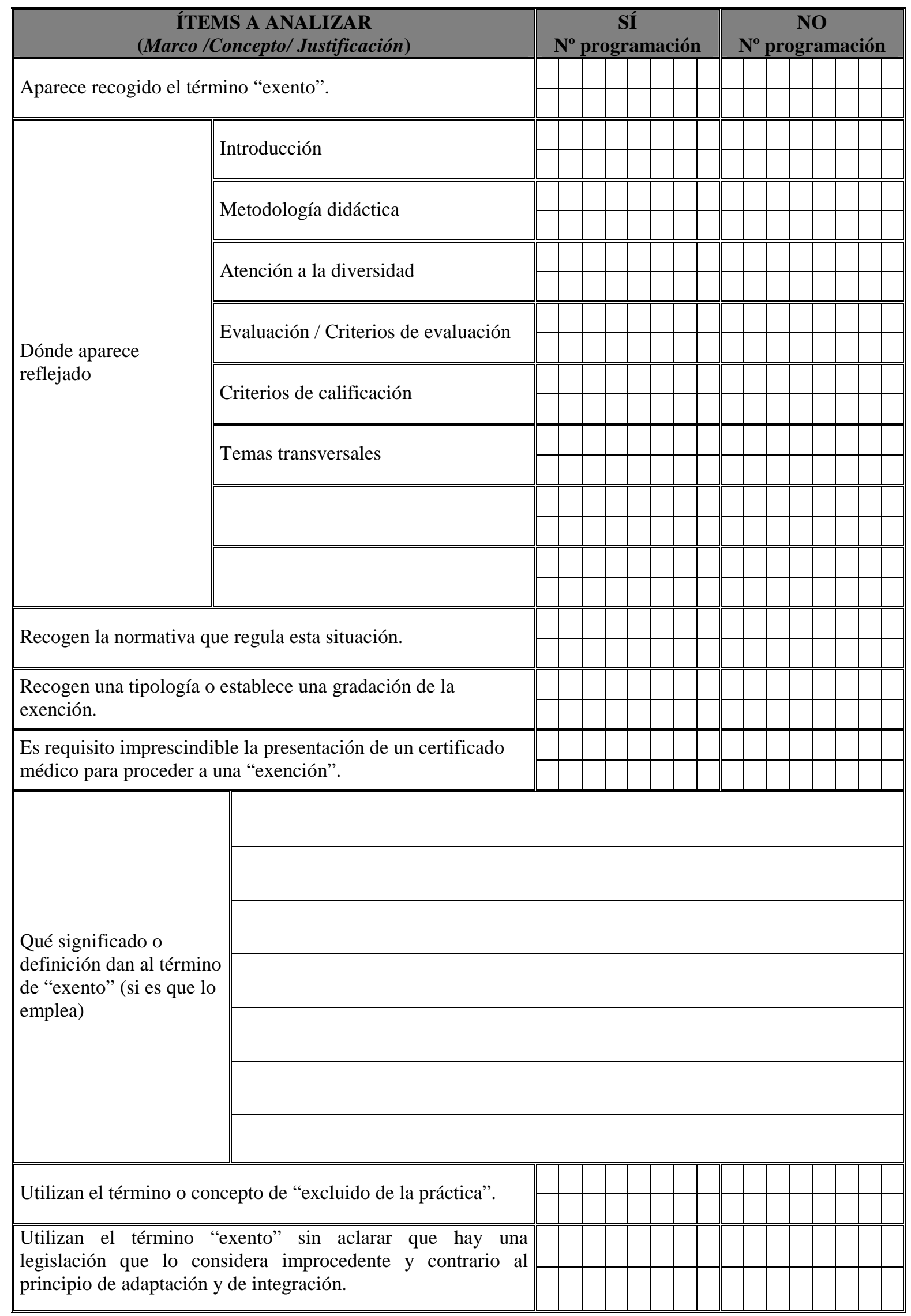




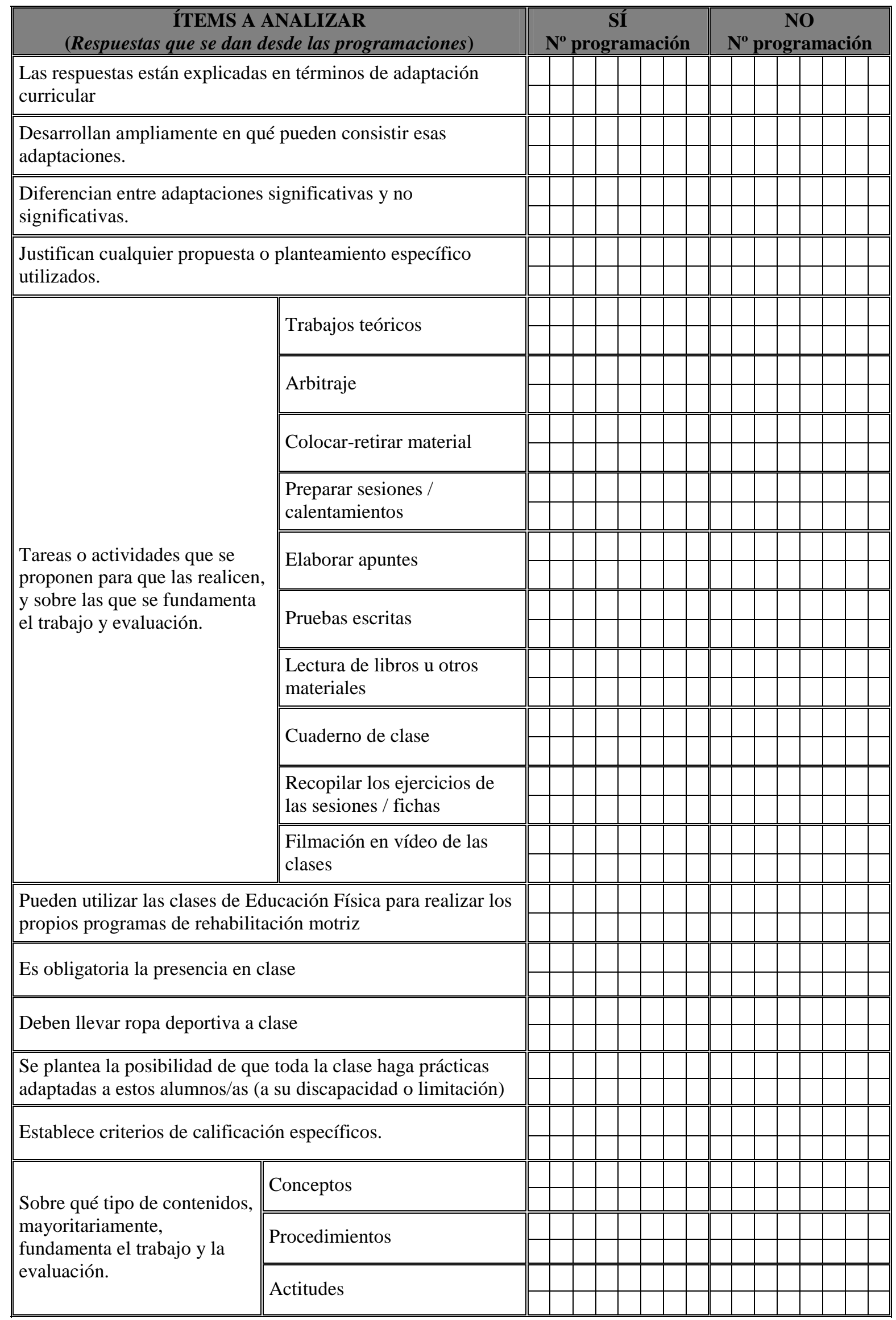




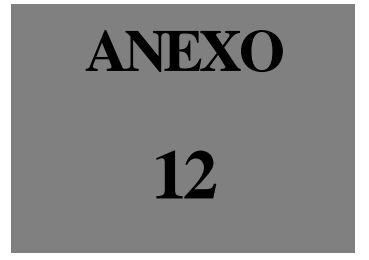




\section{CUESTIONARIO DIRIGIDO A LOS PROFESORES DE \\ EDUCACIÓN FÍSICA DE ENSEÑANZA SECUNDARIA}

Este cuestionario que tienes en tus manos es totalmente anónimo, asegurando la confidencialidad de los informantes. TODAS las preguntas o afirmaciones giran en torno al tratamiento que proporcionamos en las clases de Educación Física a los alumnos con necesidades educativas especiales (en sus casos más extremos), asociadas, sobre todo, a cualquier discapacidad física.

El cuestionario no tiene ningún carácter oficial. Forma parte de un estudio más amplio que se realiza para la elaboración de una Tesis Doctoral.

Todos los ítems están redactados como preguntas o afirmaciones muy sencillas que se contestan marcando una cruz

Sí

VERDADERO ó

NOL
en las columnas.

Hemos utilizado el término genérico "alumno" para referirnos a ambos sexos.

Te agradecemos de antemano tu amable colaboración.

Antes de comenzar a responder a las preguntas, es necesario que rellenes unas cuestiones relacionadas con tu labor como docente.

\begin{tabular}{|lll|}
\hline Hombre $\square$ Mujer $\square$ Edad:__ & \\
Años de experiencia docente: & Funcionario/a: $\square$ Interino/a: \\
Impartes clases en: & $\begin{array}{l}\text { Primer Ciclo de ESO } \\
\text { Segundo Ciclo de ESO } \\
\text { Bachillerato }\end{array}$ \\
Titulación / Formación inicial: & $\square$ \\
\hline
\end{tabular}

Si no tienes inconveniente en mantener una entrevista para charlar de estos temas, indícanos tu nombre y un número de teléfono en el que contactar por las tardes.

Nombre: 临

Utiliza el sobre franqueado que te adjuntamos para enviarnos el cuestionario con la mayor brevedad posible. Si deseas conocer cuáles han sido los resultados obtenidos, remite dicho sobre con la dirección de tu centro. 
CUESTIONARIO: Señala con una "X" para elegir la respuesta deseada. Contesta a todas las preguntas.

\begin{tabular}{|c|c|c|c|}
\hline & PREGUNTAS / AFIRMACIONES & $\begin{array}{c}\text { Sí } \\
\text { (VERDADERO) }\end{array}$ & $\begin{array}{c}\text { NO } \\
\text { (FALSO) }\end{array}$ \\
\hline 1. & ¿Mantienes entrevistas con estos alumnos para conocer sus intereses, opiniones, etc.? & $(\quad)$ & ( \\
\hline 2. & El término "exento" aparece en tu programación para aclarar su "no-existencia" legal. & ( & ( \\
\hline 3. & La asistencia a clase en estos casos es obligatoria. & ( & ( \\
\hline 4. & Deben tomar parte activa (de la forma que sea) en todas las sesiones. & $(\quad)$ & ( \\
\hline 5. & Para aplicar cualquier tipo de medida especial se pide certificado médico oficial. & $(\quad)$ & ( \\
\hline 6. & A los padres de estos alumnos se les informa de las medidas que se les aplican a sus hijos. & ( & ( \\
\hline 7. & ¿Consideras justificado que haya alumnos “exentos” si su grado de minusvalía o discapacidad es elevado? & $(\quad)$ & ( \\
\hline 8. & La dirección del centro es quién pide los certificados médicos. & ( & ( \\
\hline 9. & Estos alumnos realizan trabajos teóricos para "compensar” la parte práctica & $(\quad)$ & ( \\
\hline 10. & ¿Utilizas el cuaderno de clase del alumno en tu área? & $(\quad)$ & ( \\
\hline 11. & En caso afirmativo a la anterior, ¿se lo pides también a estos alumnos? & ( & ( \\
\hline 12. & El departamento de Orientación colabora con el tuyo para realizar las adaptaciones a estos alumnos. & $(\quad)$ & ( \\
\hline 13. & Estos alumnos colaboran en la colocación y retirada de material en las clases. & ( & ( \\
\hline 14. & Les realizas un Documento Individual de Adaptación Curricular. & ( & ( \\
\hline 15. & Su nota final puede ser alta, incluso de sobresaliente. & $(\quad)$ & ( \\
\hline 16. & Recogen notas y observaciones durante la clase. & ( & ( \\
\hline 17. & Deben asistir a clase con ropa deportiva. & ( & ( \\
\hline 18. & El departamento es quién pide el certificado médico. & $(\quad)$ & ( \\
\hline 19. & La adaptación que les aplicas, la reflejas por escrito. & ( & ( \\
\hline 20. & Deben preparar sesiones, calentamientos, etc., para el resto de la clase. & $(\quad)$ & ( \\
\hline 21. & En cada evaluación, les propones diferentes posibilidades de trabajos teóricos / prácticos para realizar. & $(\quad)$ & ( \\
\hline 22. & Elaboran apuntes para sus compañeros. & $(\quad)$ & ( \\
\hline 23. & Sus intereses y opiniones se tienen en cuenta a la hora de diseñar las adaptaciones y / o actividades. & $(\quad)$ & ( \\
\hline 24. & Las actividades del grupo se adaptan a las características de estos alumnos. & $(\quad)$ & ( \\
\hline & ¿Has dado clase a alumnos que puedan entrar en esta categoría de "casos extremos”? & $(\quad)$ & ( \\
\hline 26. & En caso afirmativo, ¿has contado con un profesor de apoyo? & $(\quad)$ & ( \\
\hline & Este tipo de alumno aparece en tu programación como "exento" o "exento de la práctica". & $(\quad)$ & ( \\
\hline 28. & ¿Te has encontrado con algún alumno de este tipo que se haya negado a participar en alguna sesión? & $(\quad)$ & ( \\
\hline 29. & En la actualidad, ¿das clase a algún alumno que pudiera entrar en esta categoría? & $(\quad)$ & ( \\
\hline & ¿Permites que no participen en una tarea por lo mal que lo pasan? & $(\quad)$ & ( \\
\hline 31. & $\begin{array}{l}\text { ¿Se producen o se han producido situaciones de conflictos entre los intereses del grupo y las adaptaciones } \\
\text { curriculares realizadas para estos alumnos? }\end{array}$ & $(\quad)$ & ( \\
\hline 32. & ¿Pueden realizar durante tus clases sus propios programas de rehabilitación motriz? & $(\quad)$ & $(\quad)$ \\
\hline
\end{tabular}




\begin{tabular}{|c|c|c|c|}
\hline & PREGUNTAS / AFIRMACIONES & $\begin{array}{c}\text { Sí } \\
\text { (VERDADERO) }\end{array}$ & $\begin{array}{c}\text { NO } \\
\text { (FALSO) }\end{array}$ \\
\hline 33. & ¿Conoces la normativa que regula este tipo de situaciones? & ( & ( \\
\hline 34. & $\begin{array}{l}\text { ¿Permites que no vayan a tus clases debido a los serios problemas de desplazamiento, estado anímico, etc., que } \\
\text { presentan? }\end{array}$ & $(\quad)$ & ( \\
\hline 35. & Estos alumnos tienen criterios de calificación diferentes a los de los demás. & ( & ( \\
\hline 36. & ¿Observas conductas inadecuadas en el resto de los compañeros hacia este tipo de alumnos? & $(\quad)$ & ( \\
\hline 37. & ¿Entrevistas a los familiares o tutores legales de estos alumnos? & $(\quad)$ & ( \\
\hline 38. & ¿Observas problemas de adaptación de estos alumnos al resto del grupo? & $(\quad)$ & ( \\
\hline 39. & ¿Aprecias satisfacción en estos alumnos tras las clases, participen o no en ellas? & ( & ( \\
\hline 40. & Estos alumnos muestran verdadero interés por participar. & $(\quad)$ & ( \\
\hline 41. & $\begin{array}{l}\text { ¿Alguna vez has llegado a percibir (por el cuaderno, entrevistas, intuición, etc.) que preferirían no asistir a tus } \\
\text { clases? }\end{array}$ & $(\quad)$ & $(\quad)$ \\
\hline 42. & Hay poca información, bibliografía, documentación... sobre el tema. & $(\quad)$ & ( \\
\hline 43. & La legislación referente a este tema, sobre todo en nuestra área, es escasa. & ( & ( \\
\hline 44. & $\begin{array}{l}\text { Dependiendo de las situaciones que se pudieran dar, ¿sería oportuno recuperar la exención en Educación } \\
\text { Física? }\end{array}$ & $(\quad)$ & ( \\
\hline 45. & ¿Utilizas libro de texto? & $(\quad)$ & ( \\
\hline 46. & $\begin{array}{l}\text { ¿Crees que un alumno puede conseguir los objetivos de etapa / ciclo del área con solo trabajar contenidos } \\
\text { conceptuales y actitudinales? }\end{array}$ & $(\quad)$ & ( \\
\hline 47. & ¿Has asistido a cursos, conferencias, seminarios, etc., sobre este tema? & $(\quad)$ & ( \\
\hline 48. & ¿Crees necesaria una mayor formación de los profesionales de la Educación Física en este ámbito? & $(\quad)$ & ( \\
\hline 49. & Nuestra área es eminentemente procedimental. & $(\quad)$ & ( \\
\hline 50. & ¿Se debería dar la opción a estos alumnos de elegir si quieren o no estar "exentos” de nuestra área? & $(\quad)$ & ( \\
\hline 51. & ¿Consideras esta temática como uno de los campos de batalla de nuestra área? & $(\quad)$ & ( \\
\hline 52. & La atención que les prestas es suficiente (la necesaria). & $(\quad)$ & ( \\
\hline 53. & ¿Alguna vez has solicitado o buscado ayuda, información y / o materiales curriculares sobre este asunto? & $(\quad)$ & ( \\
\hline 54. & $\begin{array}{l}\text { ¿Crees posible y realizable una adaptación significativa individual en el seno de un grupo, como puede ser } \\
\text { cualquier aula de Secundaria? }\end{array}$ & $(\quad)$ & ( \\
\hline 55. & $\begin{array}{l}\text { Los profesores de apoyo / refuerzo son imprescindibles dentro de nuestras clases para atender mejor a estos } \\
\text { alumnos. }\end{array}$ & ( & ( \\
\hline 56. & Nuestra área debería ser optativa para estos alumnos. & $(\quad)$ & ( \\
\hline 57. & $\begin{array}{l}\text { ¿Te encuentras verdaderamente satisfecho con la manera de abordar estas cuestiones en tu programación } \\
\text { didáctica? }\end{array}$ & ( & ( \\
\hline 58. & $\begin{array}{l}\text { ¿Te has encontrado alguna vez con la oposición o negativa de unos padres para que su hijo, con estas } \\
\text { características, asista y / o participe en tus clases? }\end{array}$ & $(\quad)$ & ( \\
\hline 59. & ¿Alguna vez has lamentado haber obligado a estos alumnos a participar en alguna de las actividades? & $(\quad)$ & $(\quad)$ \\
\hline 60. & $\begin{array}{l}\text { ¿Se podrían poner en práctica más actividades de las que se hacen dirigidas a favorecer la participación de } \\
\text { estos alumnos? }\end{array}$ & $(\quad)$ & ( \\
\hline 61. & $\begin{array}{l}\text { ¿Algún familiar ha mostrado su disconformidad a que hagan práctica o asistan a tus clases y que por ello sean } \\
\text { evaluados? }\end{array}$ & $(\quad)$ & ( \\
\hline 62. & ¿Recibiste suficiente formación sobre este tema en los planes de estudio de la facultad en la que te titulaste? & $(\quad)$ & ( \\
\hline 63. & El PEC de tu instituto recoge algo relacionado con esta temática. & $(\quad)$ & $(\quad)$ \\
\hline 64. & ¿Utilizas a este tipo de alumno como un observador de tu práctica docente? & $(\quad)$ & $(\quad)$ \\
\hline 65. & Les preparas para esa observación. & $(\quad)$ & $(\quad)$ \\
\hline
\end{tabular}




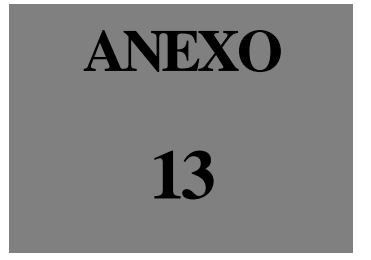




\section{A/A Jefe del Departamento de Educación Física y Deportiva}

IES

Estimado/a compañero/a:

Adjunto te remito unos cuestionarios para que sean realizados por los componentes del Departamento de Educación Física y Deportiva de tu centro.

Forman parte, como verás en las instrucciones de los mismos, de un trabajo de investigación para un Programa de Doctorado que estoy realizando.

Te agradecería que te encargases de su reparto y recogida, y me los envíes con la mayor brevedad en el sobre franqueado que encontrarás en el interior.

Transmite mi gratitud a todos tus compañeros por su colaboración y dedicación en este “pequeño" favor que les pido (incluido tú).

Íscar, 5 de mayo de 2003

Fdo.: César Rodríguez de la Cruz Jefe del Departamento de Educación Física y Deportiva IES Sto. Tomás de Aquino Íscar (Valladolid) 
PORTADA DE FAX

\section{A/A Jefe del Departamento de Educación Física y Deportiva}

Estimado/a compañero/a:

En pasadas fechas te envié unos cuestionarios para que los realizasen todos tus compañeros del Departamento de Educación Física y Deportiva.

Como ya te comenté, dichos cuestionarios son parte de un trabajo de investigación que estoy realizando para la posterior elaboración de una Tesis Doctoral.

Vuestra colaboración es vital e imprescindible para dicho estudio, por lo que te ruego que, en caso de no haberlo hecho ya, cumplimentéis los mismos y me los remitáis lo más rápidamente posible (también os envié un sobre sellado y con la dirección del centro donde trabajo).

Apelo a vuestra colaboración, la que siempre ha caracterizado a nuestro gremio, para que el trabajo siga su curso y pueda concluirse.

Nuevamente, te doy las gracias a ti y a tus compañeros por el tiempo que me habéis dedicado.

Íscar, 23 de mayo de 2003

Fdo.: César Rodríguez de la Cruz Jefe del Departamento de Educación Física y Deportiva

IES Sto. Tomás de Aquino Íscar (Valladolid) 


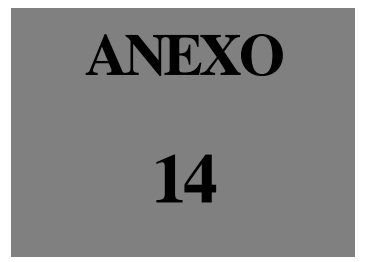

TABLAS DE FRECUENCIAS ABSOLUTAS (Fi) DEL CUESTIONARIO DE PROFESORES DE E.F. 


\section{PREGUNTAS / AFIRMACIONES}

\begin{tabular}{l|lll} 
Sí & NO & N/C & N/S
\end{tabular}

1. ¿Mantienes entrevistas con estos alumnos para conocer sus intereses, opiniones, etc.?

33

2. El término "exento" aparece en tu programación para aclarar su "no-existencia" legal.

33

3. La asistencia a clase en estos casos es obligatoria.

42

4. Deben tomar parte activa (de la forma que sea) en todas las sesiones.

5. Para aplicar cualquier tipo de medida especial se pide certificado médico oficial.

6. A los padres de estos alumnos se les informa de las medidas que se les aplican a sus hijos.

7. ¿Consideras justificado que haya alumnos "exentos" si su grado de minusvalía o discapacidad es elevado?

8. La dirección del centro es quién pide los certificados médicos.

9. Estos alumnos realizan trabajos teóricos para “compensar" la parte práctica

10. ¿Utilizas el cuaderno de clase del alumno en tu área?

11. En caso afirmativo a la anterior, ¿se lo pides también a estos alumnos?

12. El departamento de Orientación colabora con el tuyo para realizar las adaptaciones a estos alumnos.

13. Estos alumnos colaboran en la colocación y retirada de material en las clases.

14. Les realizas un Documento Individual de Adaptación Curricular.

15. Su nota final puede ser alta, incluso de sobresaliente.

16. Recogen notas y observaciones durante la clase.

17. Deben asistir a clase con ropa deportiva.

18. El departamento es quién pide el certificado médico.

19. La adaptación que les aplicas, la reflejas por escrito.

20. Deben preparar sesiones, calentamientos, etc., para el resto de la clase.

21. En cada evaluación, les propones diferentes posibilidades de trabajos teóricos / prácticos para realizar.

22. Elaboran apuntes para sus compañeros.

$\mathrm{N} / \mathrm{C}, \mathrm{N} / \mathrm{S}$

10

31

42

4

\begin{tabular}{|l|l|l|l|}
\hline 41 & 4 & 1 & \\
\hline 26 & 20 & & \\
\hline 21 & 22 & 1 & 2 \\
\hline
\end{tabular}

2

14

\begin{tabular}{l|l|l}
22 & 1 & 2
\end{tabular}

32

5

\begin{tabular}{|l|l|l|l|}
\hline 5 & 40 & 1 & \\
\hline 36 & 9 & 1 & \\
\hline
\end{tabular}




\section{PREGUNTAS / AFIRMACIONES}

Sí $\quad$ NO N/C N/S

23. Sus intereses y opiniones se tienen en cuenta a la hora de diseñar las adaptaciones y / o actividades.

24. Las actividades del grupo se adaptan a las características de estos alumnos.

\section{5

5

$16 \quad 5$

\begin{tabular}{|c|c|c|c|}
\hline 15 & 24 & 5 & 2 \\
\hline 27 & 18 & 1 & \\
\hline 7 & 26 & 13 & \\
\hline
\end{tabular}

24

$24+5 \quad 2$

25. ¿Has dado clase a alumnos que puedan entrar en esta categoría de "casos extremos"?

26. En caso afirmativo, ¿has contado con un profesor de apoyo?

27. Este tipo de alumno aparece en tu programación como "exento" o "exento de la práctica".

28. ¿Te has encontrado con algún alumno de este tipo que se haya negado a participar en alguna sesión?

29. En la actualidad, ¿das clase a algún alumno que pudiera entrar en esta categoría?

30. ¿Permites que no participen en una tarea por lo mal que lo pasan?

31. ¿Se producen o se han producido situaciones de conflictos entre los intereses del grupo y las adaptaciones curriculares realizadas para estos alumnos?

32. ¿Pueden realizar durante tus clases sus propios programas de rehabilitación motriz?

33. ¿Conoces la normativa que regula este tipo de situaciones?

34. ¿Permites que no vayan a tus clases debido a los serios problemas de desplazamiento, estado anímico, etc., que presentan?

35. Estos alumnos tienen criterios de calificación diferentes a los de los demás.

36. ¿Observas conductas impropias en el resto de los compañeros hacia este tipo de alumnos?

37. ¿Entrevistas a los familiares o tutores legales de estos alumnos?

18

$23 \quad 5$

19

25

14

31

24

15

10

10

$34 \quad 3$

\begin{tabular}{|l|l|l|l|}
\hline 31 & 9 & 2 & 4 \\
\hline 23 & 20 & 3 & \\
\hline 12 & 30 & 3 & 1 \\
\hline
\end{tabular}

\begin{tabular}{|l|c|c|c|c|}
\hline 38. iObservas problemas de adaptación de estos alumnos al resto del grupo? & 25 & 14 & 4 & 3 \\
\hline 39. ¿Aprecias satisfacción en estos alumnos tras las clases, participen o no en ellas? & 30 & 8 & 6 & 2 \\
\hline 40. Estos alumnos muestran verdadero interés por participar. & 30 & 9 & 6 & 1 \\
\hline $\begin{array}{l}\text { 41. } \quad \text { Alguna vez has llegado a percibir (por el cuaderno, entrevistas, intuición, etc.) que } \\
\text { preferirían no asistir a tus clases? }\end{array}$ & 11 & 29 & 6 & \\
\hline 42. Hay poca información, bibliografía, documentación... sobre el tema. & 34 & 8 & 3 & 1 \\
\hline 43. La legislación referente a este tema y, sobre todo en nuestra área, es escasa. & 34 & 7 & 5 & \\
\hline $\begin{array}{l}\text { 44. Dependiendo de las situaciones que se pudieran dar, isería oportuno recuperar la exención } \\
\text { en Educación Física? }\end{array}$ & 9 & 33 & 3 & 1 \\
\hline
\end{tabular}

$\mathrm{N} / \mathrm{C}=$ No contesta $\quad \mathrm{N} / \mathrm{S}=$ No sabe (así nos lo comunican al lado de la respuesta) 


\section{PREGUNTAS / AFIRMACIONES}

Sí $\quad$ NO N/C N/S

45. ¿Utilizas libro de texto en el área?

46. ¿Crees que un alumno puede conseguir los objetivos de etapa / ciclo / área con solo trabajar contenidos conceptuales y actitudinales?

47. ¿Has asistido a cursos, conferencias, seminarios, etc., sobre este tema?

48. ¿Crees necesaria una mayor formación de los profesionales de la Educación Física en este ámbito?

49. Nuestra área es eminentemente procedimental.

50. ¿Se debería dar la opción a estos alumnos de elegir si quieren o no estar "exentos” de nuestra área?

51. ¿Consideras esta temática como uno de los campos de batalla de nuestra área?

52. La atención que les prestas es suficiente (la necesaria)

53. ¿Alguna vez has solicitado o buscado ayuda, información y / o materiales curriculares sobre este asunto?

54. ¿Crees posible y realizable una adaptación significativa individual en el seno de un grupo, como puede ser cualquier aula de Secundaria?

55. Los profesores de apoyo / refuerzo son imprescindibles dentro de nuestras clases para atender mejor a estos alumnos.

56. Nuestra área debería ser optativa para estos alumnos.

\begin{tabular}{|c|c|c|c|}
\hline 7 & 38 & 1 & \\
\hline 17 & 23 & 4 & 2 \\
\hline
\end{tabular}

57. ¿Te encuentras verdaderamente satisfecho / a con la manera de abordar estas cuestiones en tu programación didáctica?

58. ¿Te has encontrado alguna vez con la oposición o negativa de unos padres para que su hijo, con estas características, asista y / o participe en tus clases?

59. ¿Alguna vez has lamentado haber obligado a estos alumnos a participar en alguna de las actividades?

60. ¿Se podrían poner en práctica más actividades de las que se hacen dirigidas a favorecer la participación de estos alumnos?

61. ¿Algún familiar ha mostrado su disconformidad a que hagan práctica o asistan a tus clases y que por ello sean evaluados?

62. ¿Recibiste suficiente formación sobre este tema en los planes de estudio de la facultad en la que te titulaste?

63. El PEC de tu instituto recoge algo relacionado con esta temática.

64. ¿Utilizas a este tipo de alumno como un observador de tu práctica docente?

15

30

41

\section{9}

16

1

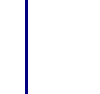

4




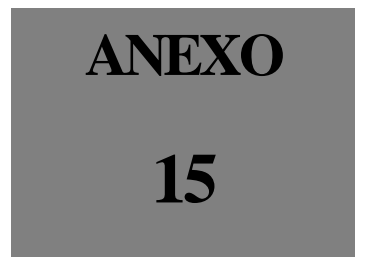

REPRESENTACIONES GRÁFICAS DEL CUESTIONARIO PROFESORES E.F. 
Gráfica $n^{o}$-28: ¿Mantienes entrevistas con estos alumnos para conocer sus intereses y opiniones?

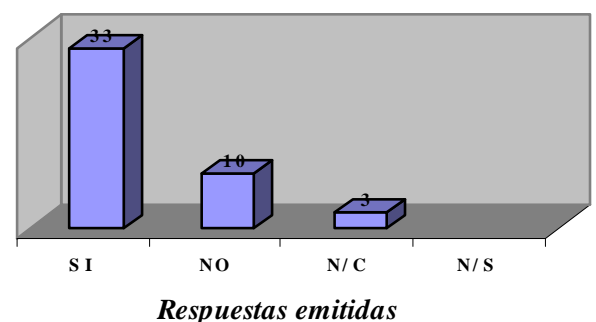

Respuestas emitidas

Gráfica no-29: El término "exento" aparece en tu programación para aclarar su "no existencia" legal.

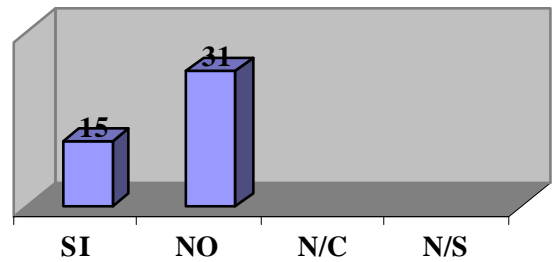

Respuestas emitidas

Gráfica $n^{o}$-30: La asistencia en estos casos es obligatoria.

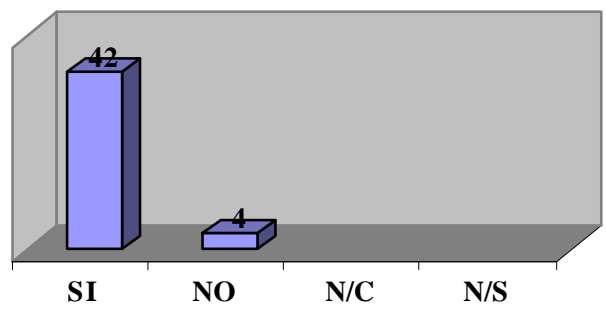

Respuestas emitidas

Gráfica $n^{o}-31:$ A los padres de estos alumnos se les informa de las medidas que se les aplican a sus hijos.

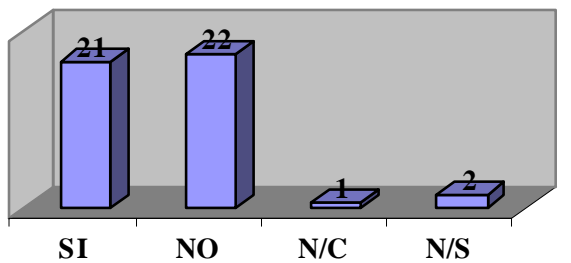

Respuestas emitidas 

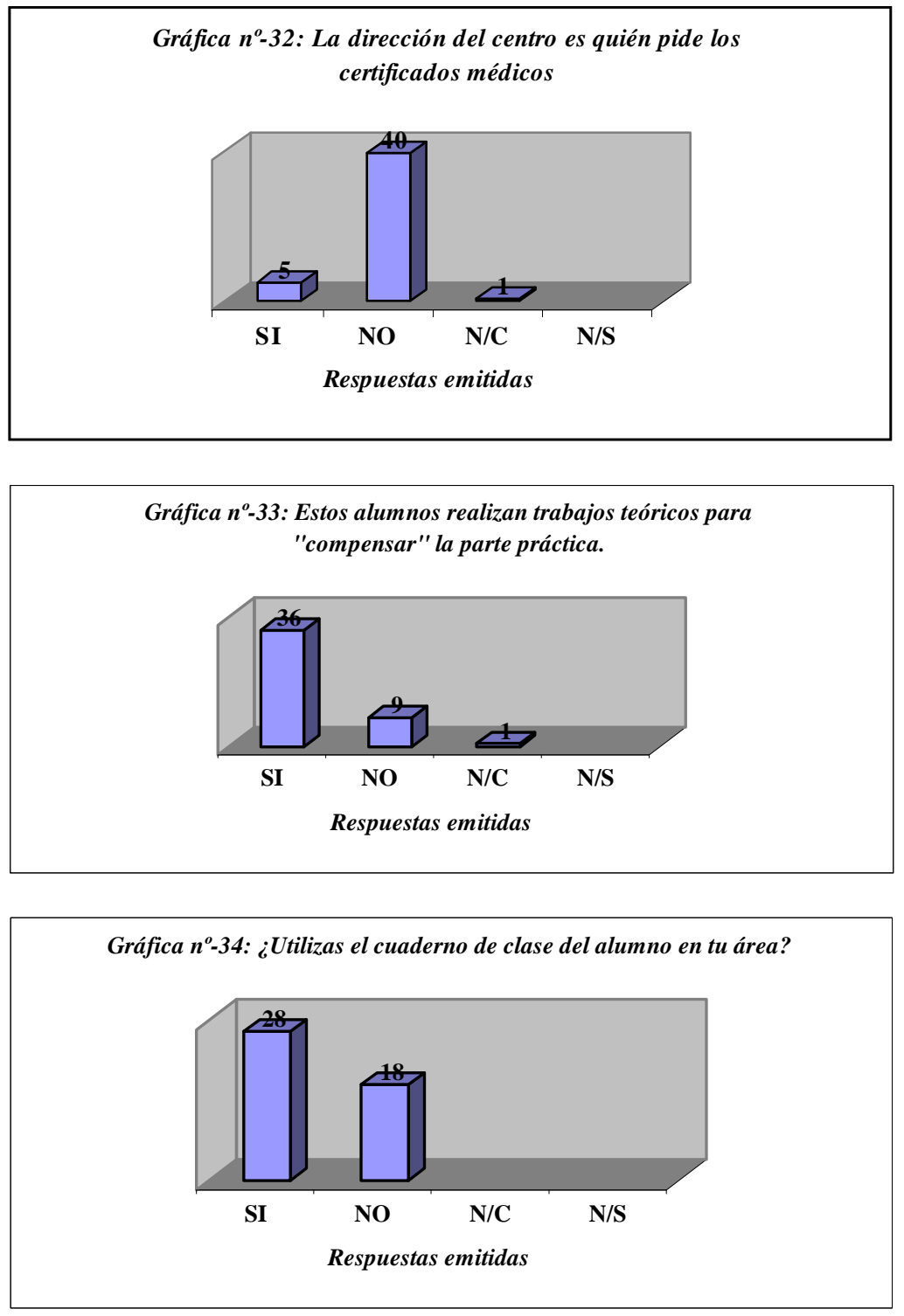

Gráfica $n^{o}-35:$ ¿Se lo pides también a estos alumnos?

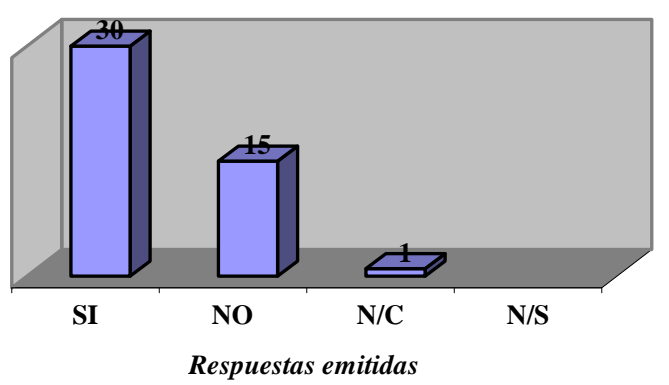




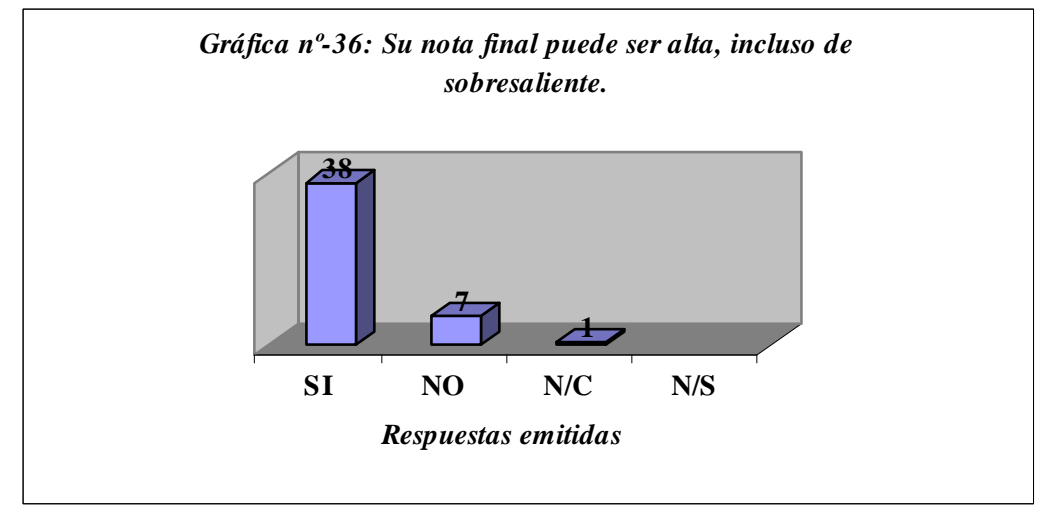

Gráfica $n^{\circ}$-37: Recogen notas y observaciones durante las clases.

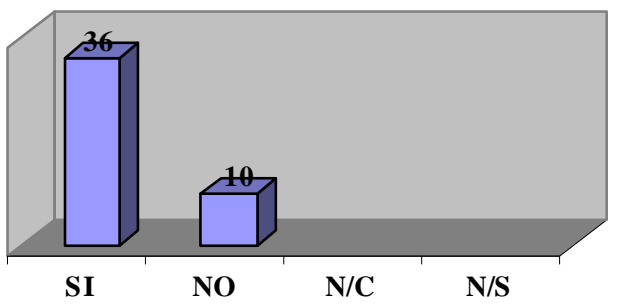

Respuestas emitidas

Gráfica n ${ }^{\circ}-38$ : Deben asistir a clase con ropa deportiva.

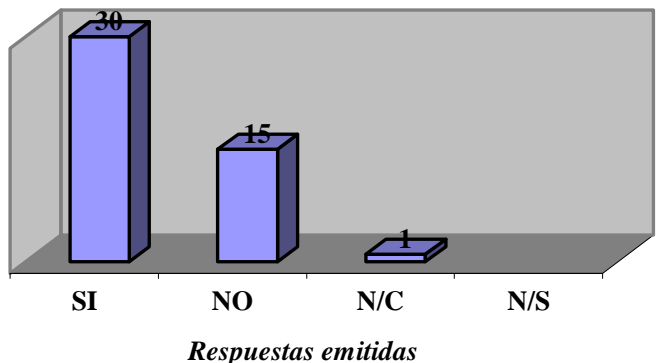

Gráfica no-39: El departamento es quién pide el certificado médico.

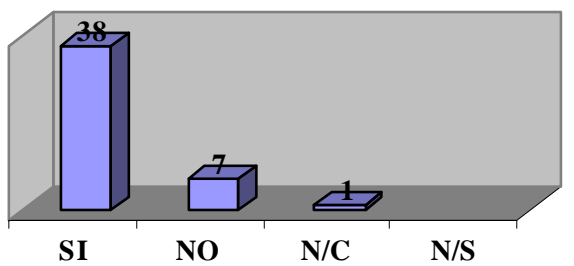

Respuestas emitidas 
Gráfica ${ }^{o}$-40: Deben preparar sesiones y/o calentamientos parar el resto de la clase.

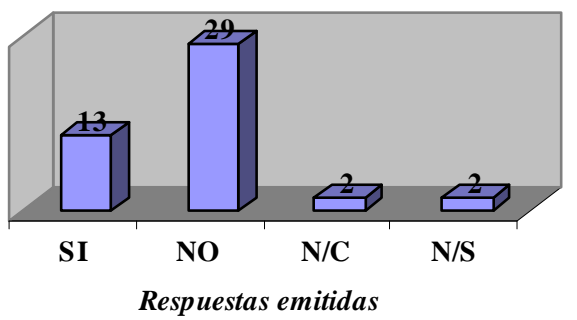

Gráfica ${ }^{o}$-41: En cada evaluación les propones diferentes posibilidades de trabajos teóricos / prácticos para realizar.

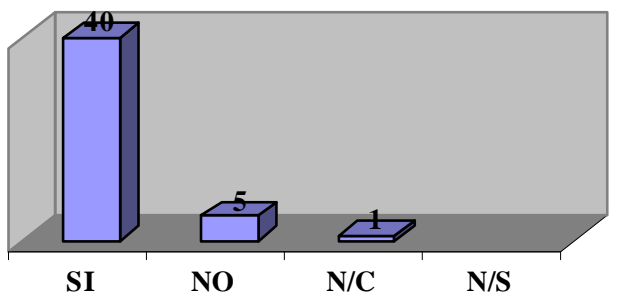

Respuestas emitidas

Gráfica $n^{o}$-42: Elaboran apuntes para sus compañeros.

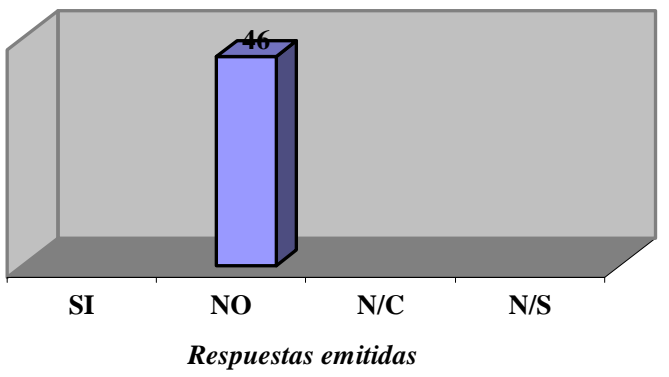

Gráfica $n^{\circ}$-43: Las actividades del grupo se adaptan a las características de estos alumnos.

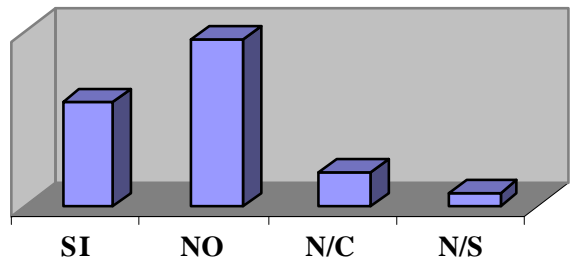

Respuestas emitidas 


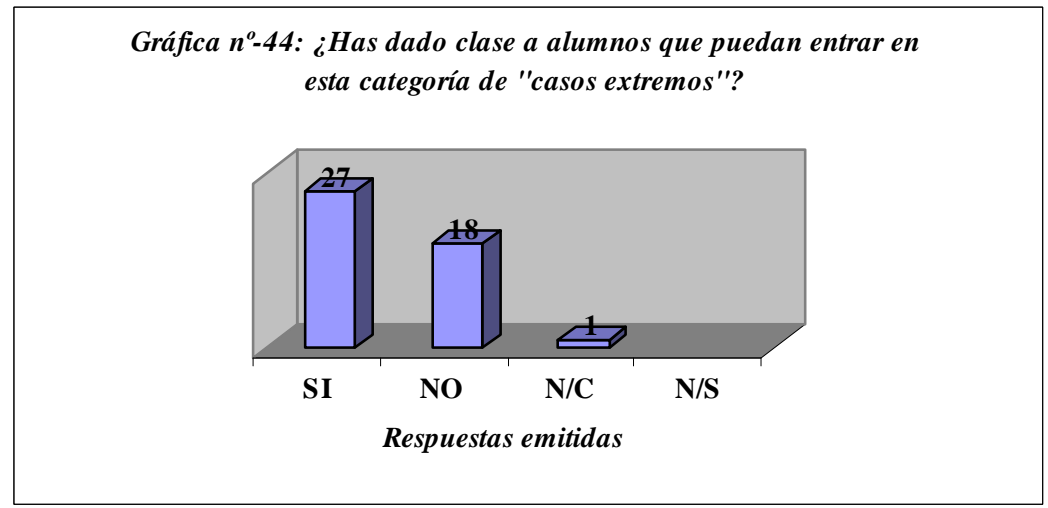

Gráfica $n^{\circ}$-45: ¿Contaste con un profesor de apoyo cuando diste clase a estos alumnos?

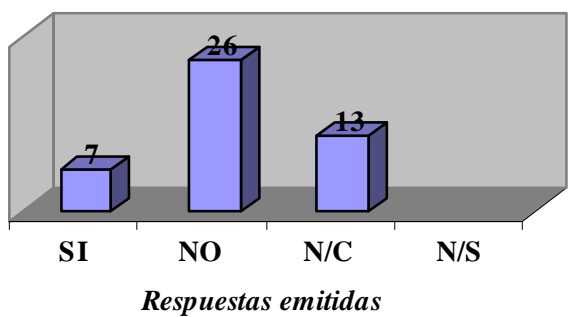

Gráfica $n^{\circ}$-46: En la actualidad, ¿das clase a algún alumno qu epudiera entrar en esta categoría?

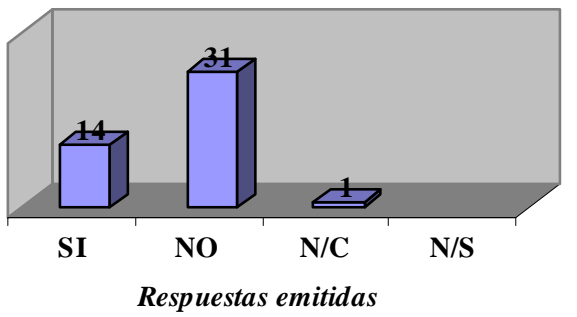

Gráfica $n^{\circ}-47:$ Estos alumnos tienen criterios de calificación diferentes a los de los demás?

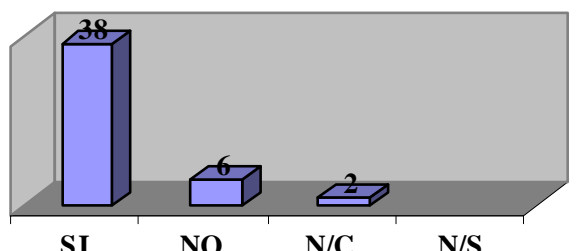

SI NO N/C N/S

Respuestas emitidas 
Gráfica $n^{\circ}-48:$ ¿Entrevistas a los familiares o tutores legales de estos alumnos?

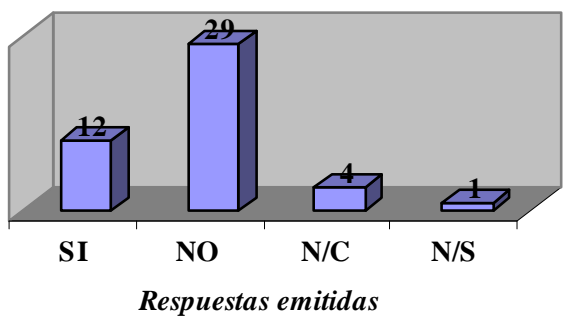

Gráfica ${ }^{o}$-49: ¿Aprecias satisfacción en estos alumnos tras las clases, participen o no en ellas?

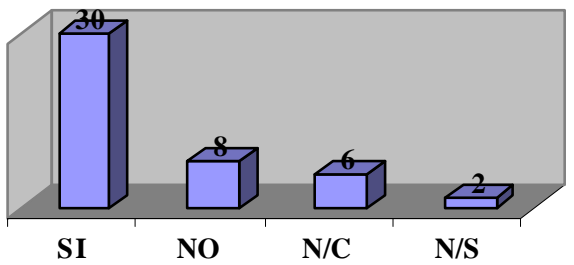

Respuestas emitidas

Gráfica no-50: Estos alumnos muestran verdadero interés por participar.

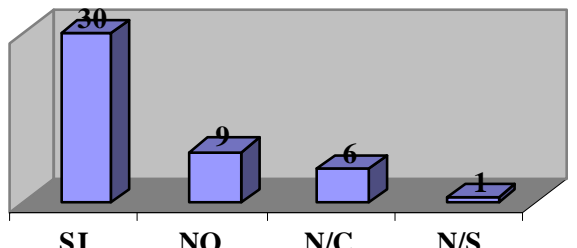

SI NO N/C N/S

Respuestas emitidas

Gráfica n-51: ¿Alguna vez has llegado a percibir que preferirían no asistir a tus clases?

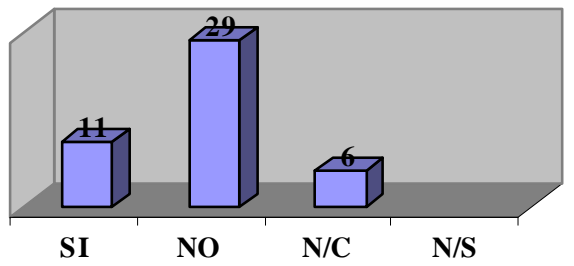

Respuestas emitidas 


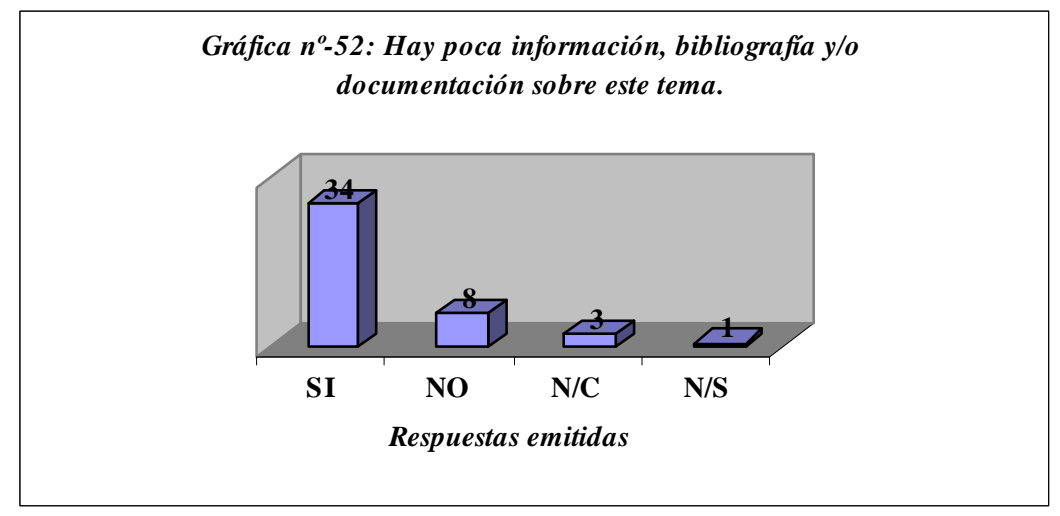

Gráfica $n^{o}$-53: Dependiendo de las situaciones que se pudieran dar, ¿sería oportuno recuperar la exención en Educación Física?

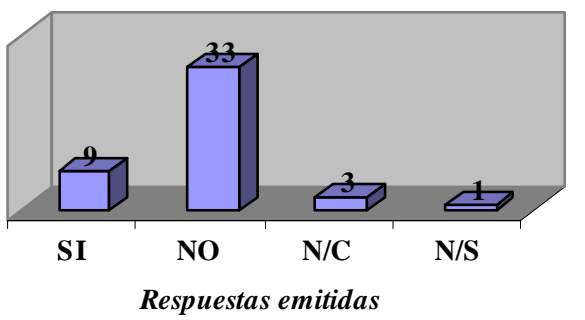

Gráfica ${ }^{o}$-54: ¿Utilizas libro de texto?

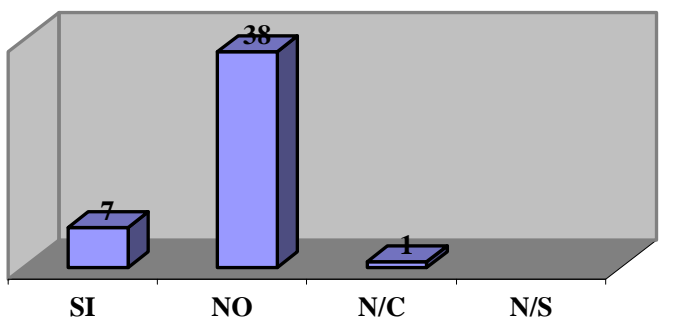

Respuestas emitidas

Gráfica $n^{\circ}$-55: ¿Crees que un alumno puede conseguir los objetivos de etapa/ciclo del área con sólo trabajar contenidos conceptuales y actitudinales?

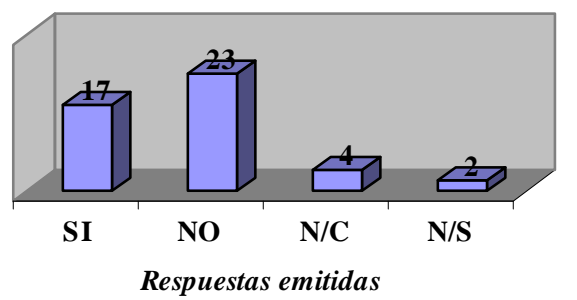


Gráfica $n^{o}$-55: ¿Crees necesaria una mayor formación de los profesionales de la Educación Física en este ámbito?

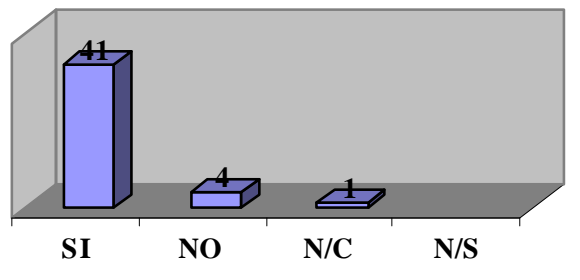

Respuestas emitidas

Gráfica no-56: ¿Se debería dar la opción a estos alumnos de elegir si quieren o no estar "exentos" de nuestra área?

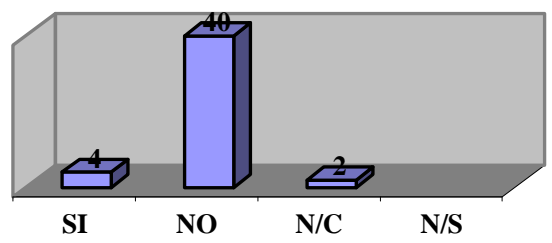

Respuestas emitidas

Gráfica $n^{\circ}$-57: ¿Consideras esta temática como uno de los campos de batalla de nuestra área?

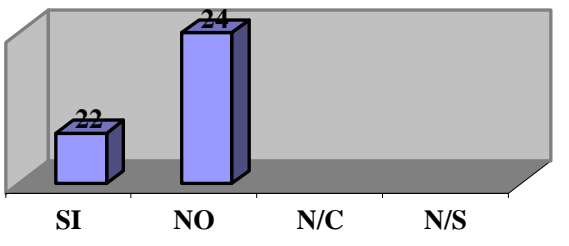

Respuestas emitidas

Gráfica $n^{o}-58$ : La atención que les prestas es suficiente (la necesaria).

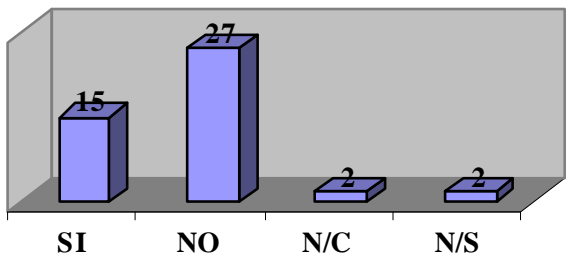

Respuestas emitidas 
Gráfica no-59: ¿Alguna vez has solicitado o buscado ayuda, información y/o materiales curriculares sobre este asunto?

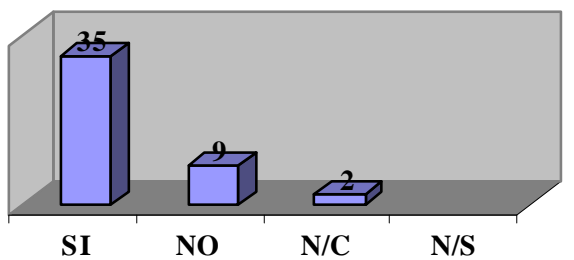

Respuestas emitidas

Gráfica no-60: ¿Crees posible y realizable una adaptación significativa individual en el seno de un grupo de Secundaria?

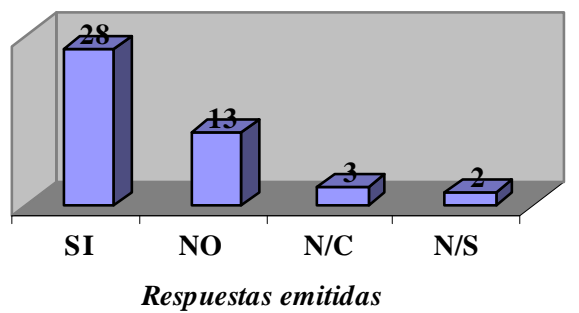

Gráfica n-61: Los profesores de apoyo son imprescindibles dentro de nuestras clases para atender mejor a estos alumnos.

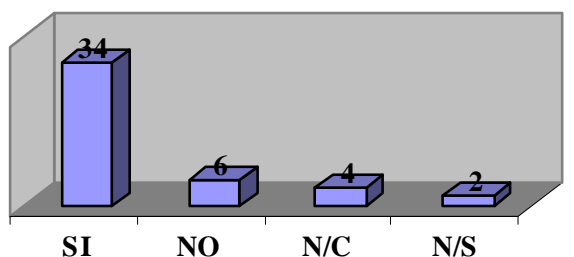

Respuestas emitidas

Gráfica $n^{\circ}$-62: Nuestra área debería ser optativa para estos alumnos.

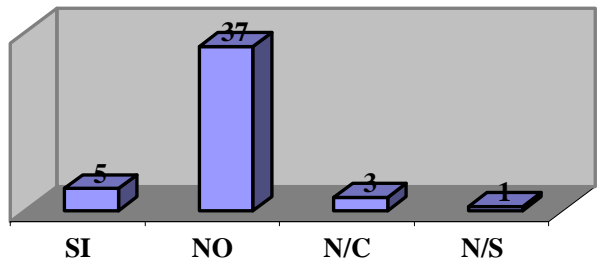

Respuestas emitidas 
Gráfica ${ }^{\circ}$-63: ¿Te has encontrado alguna vez con la oposición de unos padres para que su hijo, con estas características, asista y/o participe en tus clases?

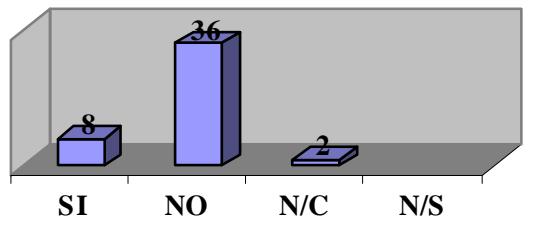

Respuestas emitidas

Gráfica no4: ¿Alguna vez has lamentado haber obligado a estos alumnos a participar en alguna de las actividades?

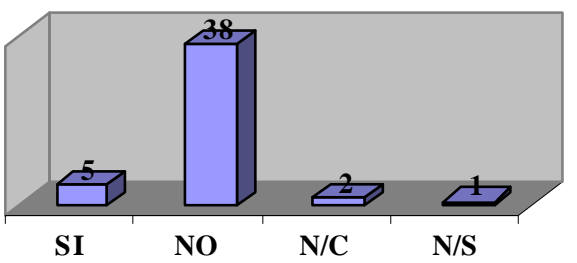

Respuestas emitidas

Gráfica n-65: ¿Recibiste suficiente formación sobre este tema en los planes de estudio de la facultad en la que te titulaste?

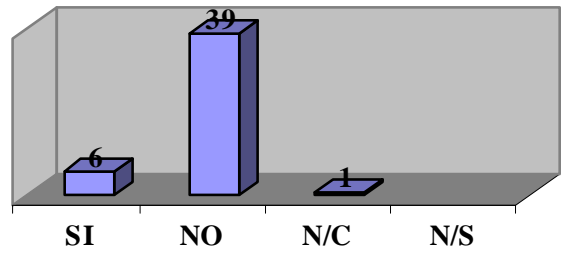

Respuestas emitidas

Gráfica no-66: ¿Utilizas a este tipo de alumno como un observador de tu práctica docente?

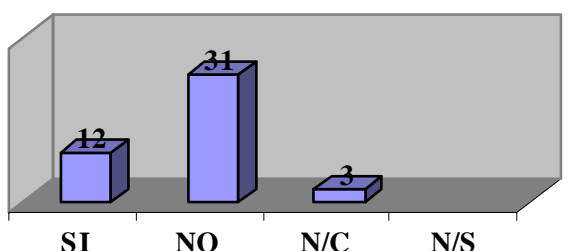

SI NO N/C N/S

Respuestas emitidas 
Gráfica $n^{\circ}-67$ : Les preparas para esa observación.

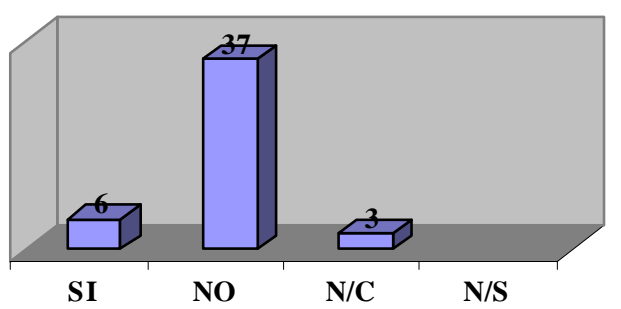

Respuestas emitidas 


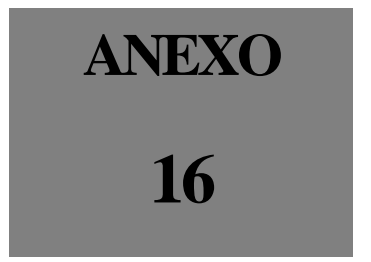

CURSO ATENDER A LA DIVERSIDAD A TRAVÉS DE LOS CONTENIDOS DE EDUCACIÓN FÍSICA 

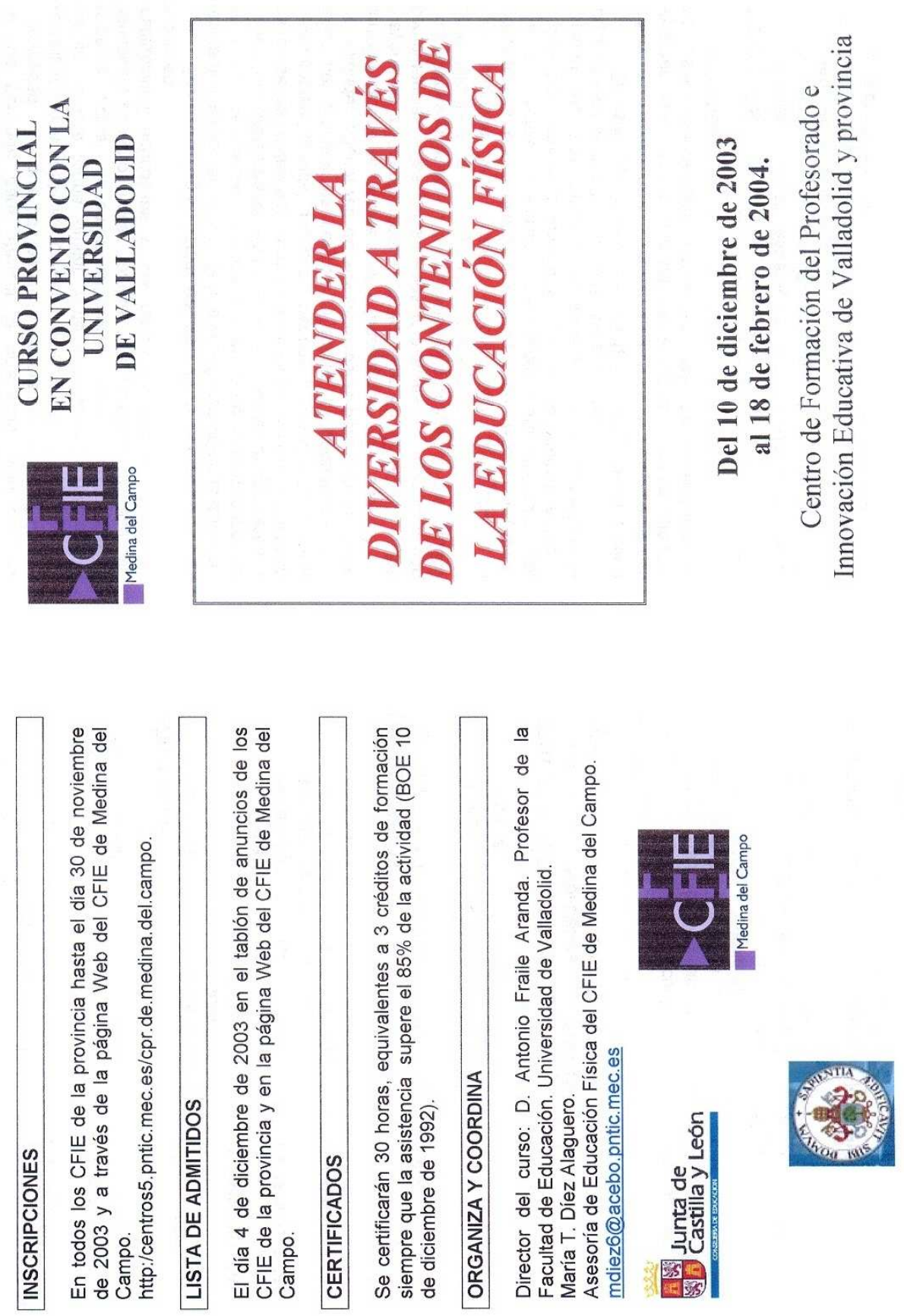

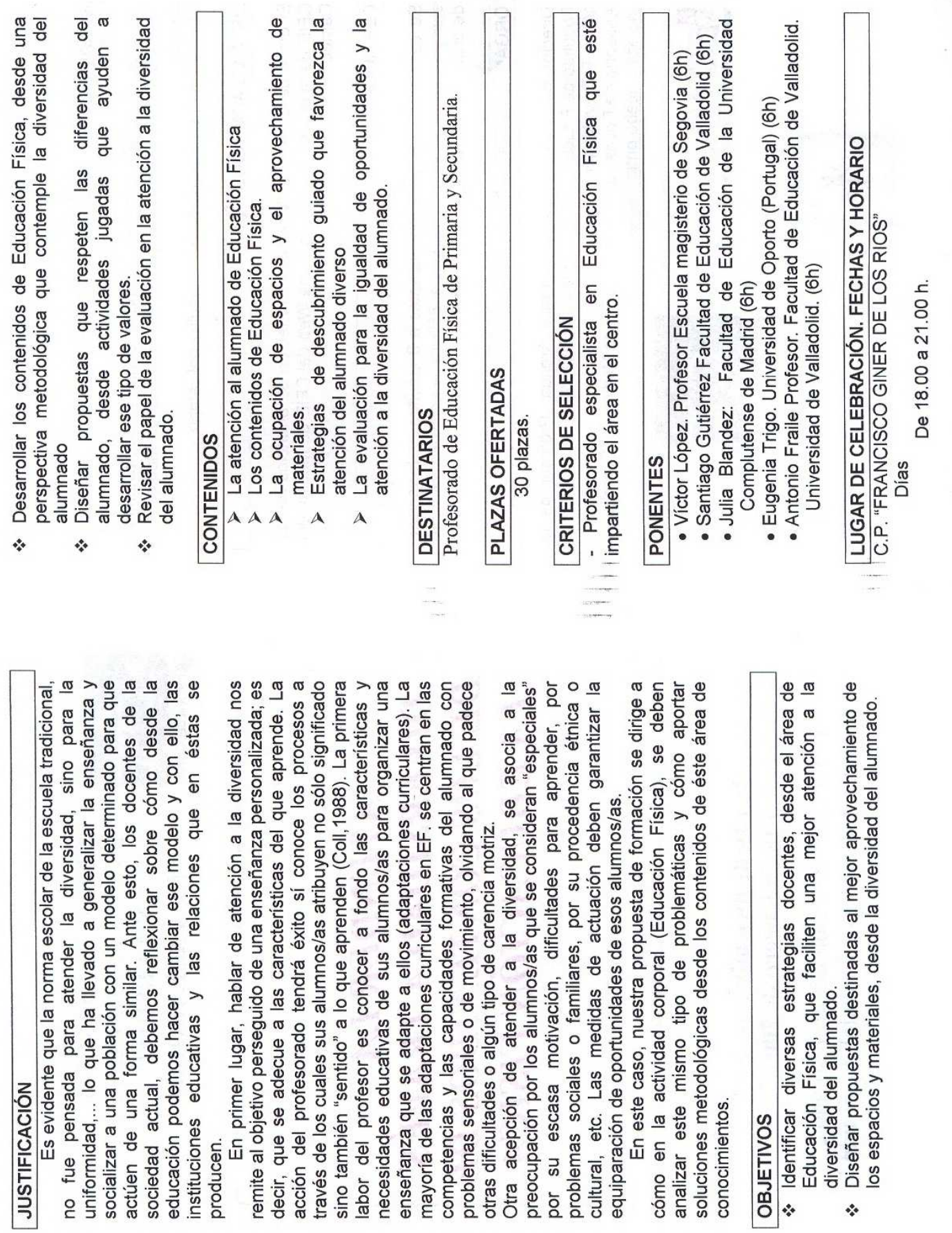


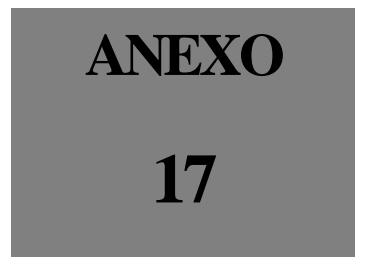

CURSO INTERVENCIÓN DEL DOCENTE ANTE PEQUEÑOS ACCIDENTES ESCOLARES Y ALUMNADO ENFERMO 

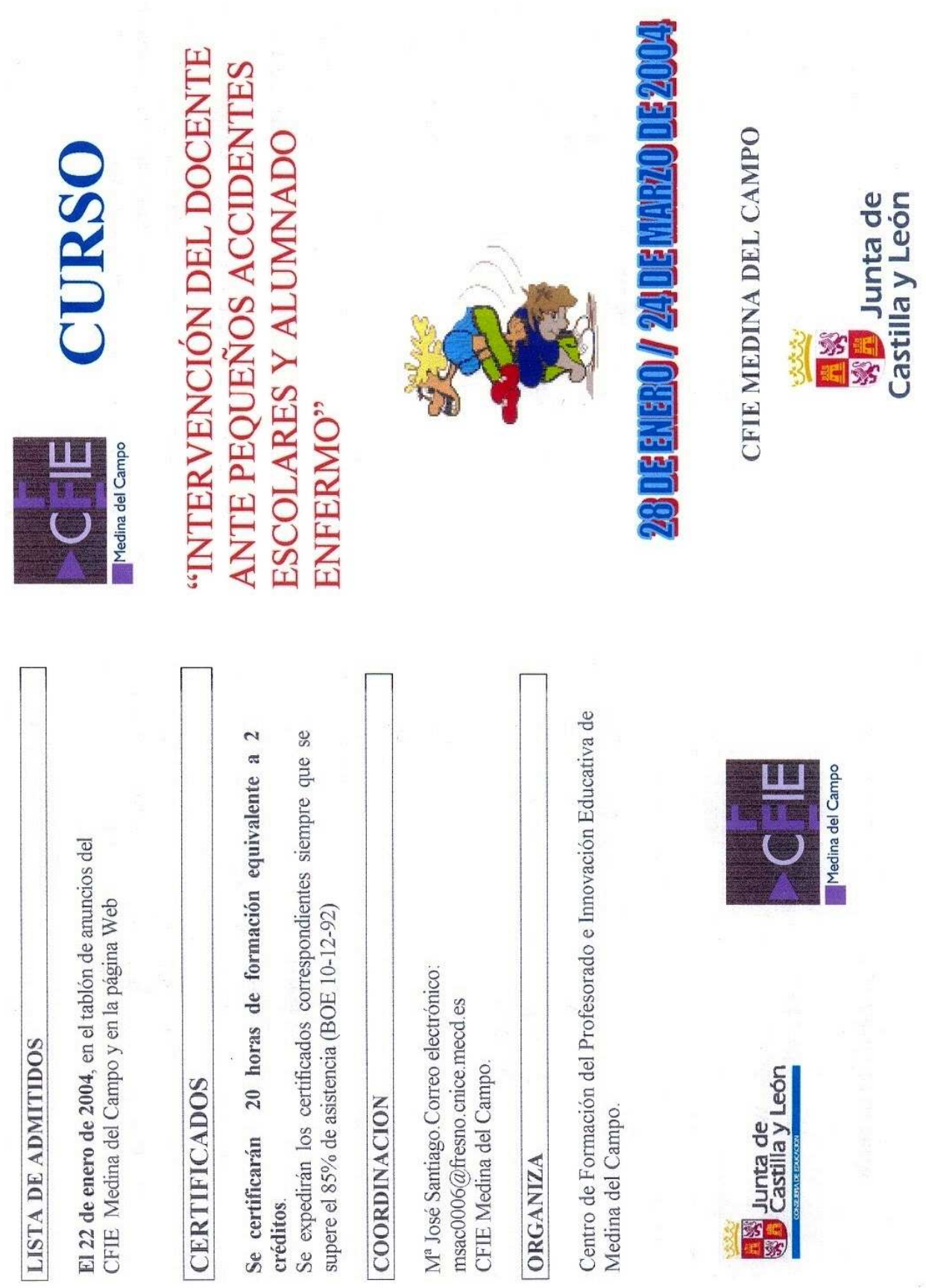

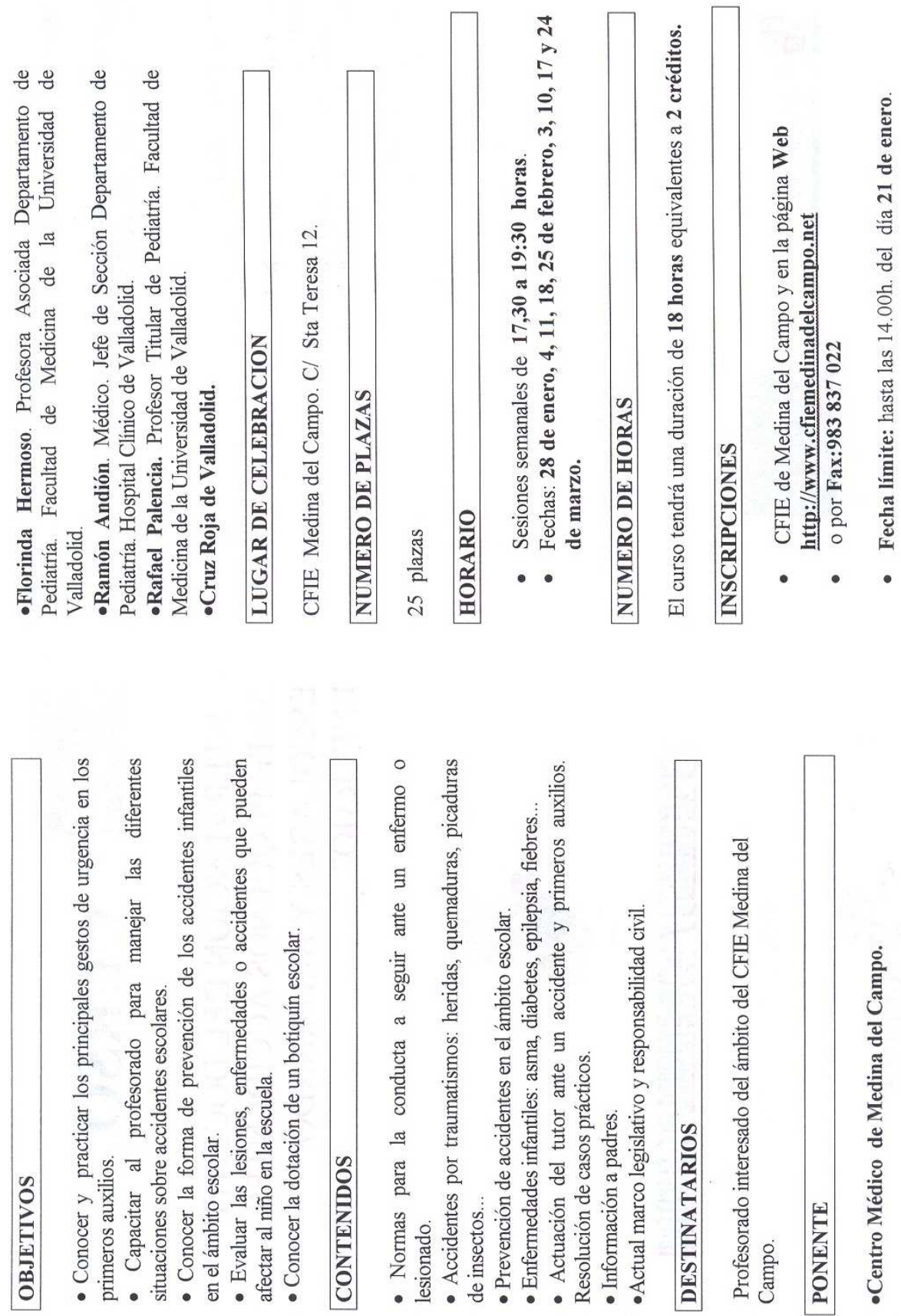

हू. 


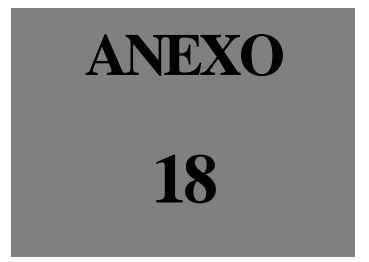

JORNADAS REGIONALES DE INTERCAMBIO DE EXPERIENCIAS DE EDUCACIÓN FÍSICA 


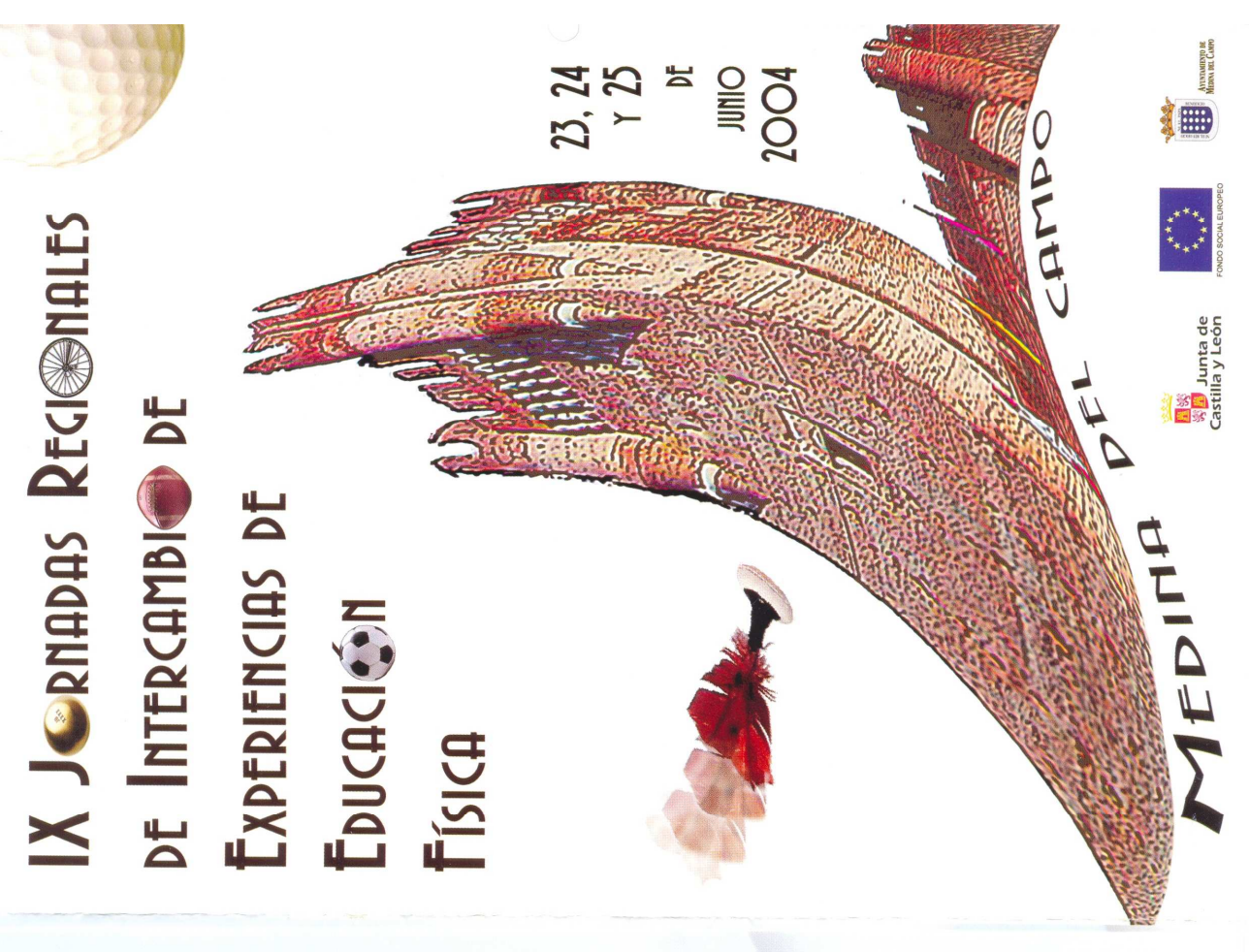

\begin{tabular}{|c|c|c|c|c|c|c|c|c|c|c|c|c|c|c|}
\hline 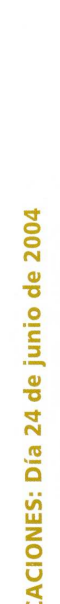 & 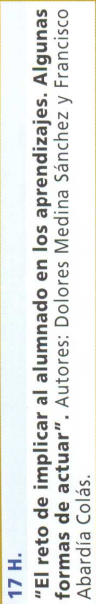 & 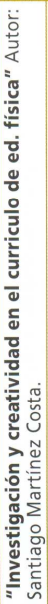 & 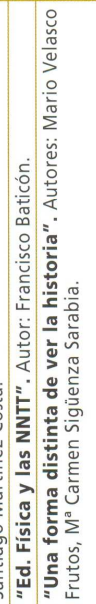 & 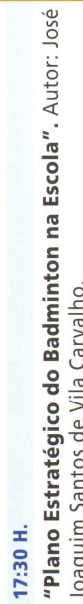 & 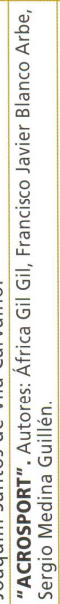 & 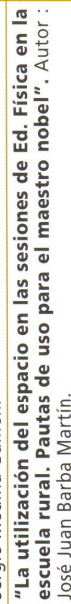 & 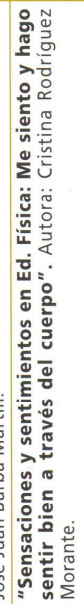 & 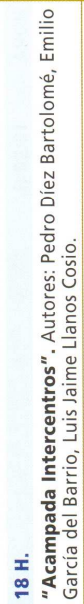 & 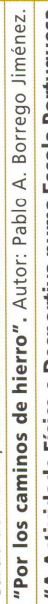 & 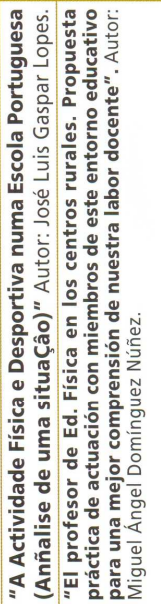 & 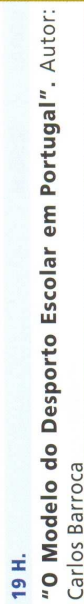 & 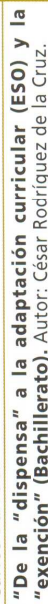 & 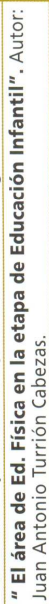 & 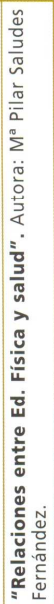 \\
\hline 方 & 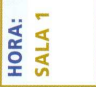 & $\begin{array}{l}n \\
\mathbb{3} \\
\mathbb{a} \\
\vdots \\
n\end{array}$ & 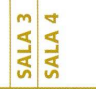 & 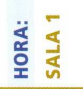 & $\mid \begin{array}{l}n \\
\vdots \\
\frac{a}{a} \\
n\end{array}$ & $\begin{array}{l}m \\
\vdots \\
\frac{a}{a} \\
n\end{array}$ & 政 & 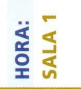 & 离 & 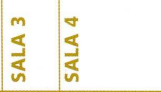 & 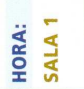 & 永 & $\begin{array}{l}m \\
\vdots \\
a \\
a \\
n\end{array}$ & 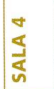 \\
\hline
\end{tabular}



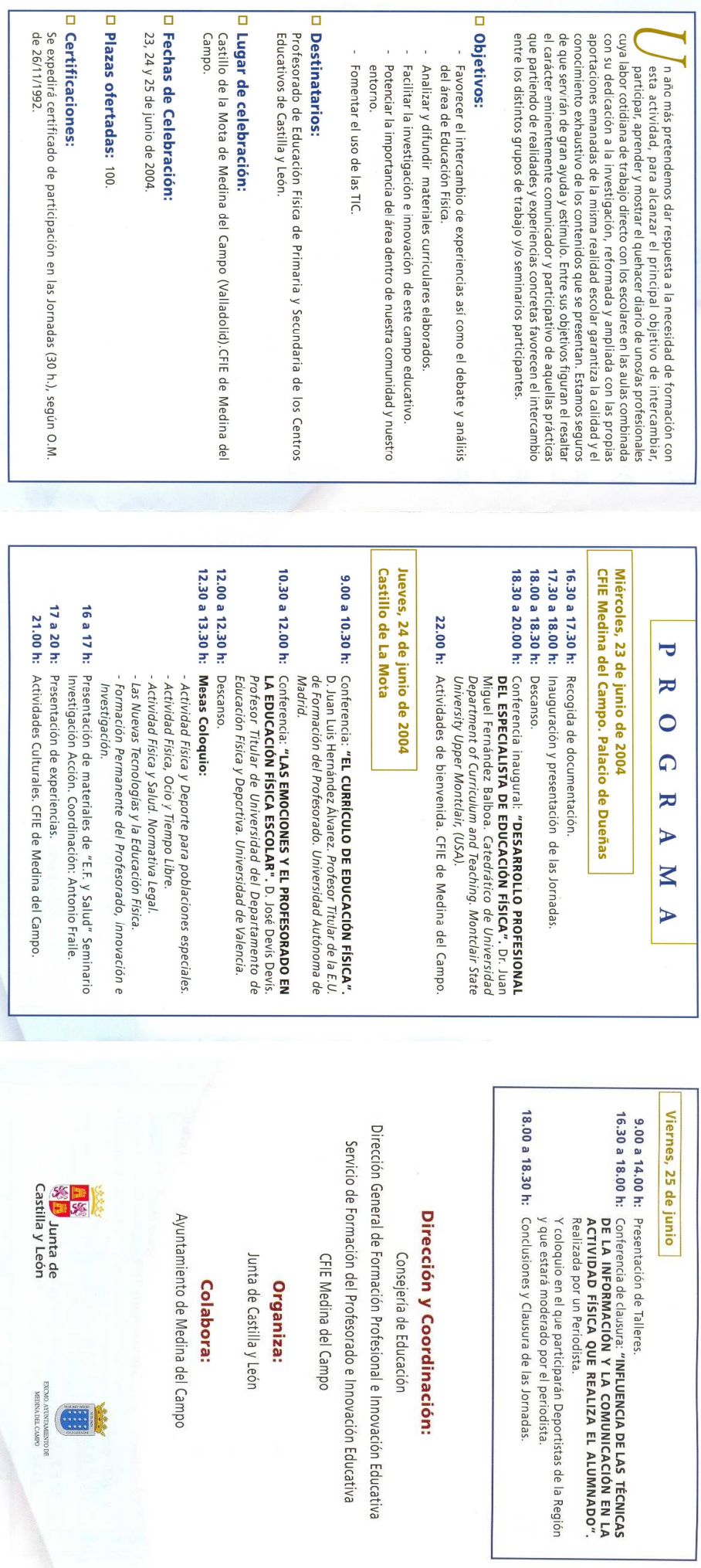


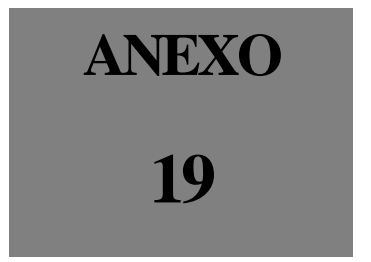

CURSO ESTRATEGIAS DIDÁCTICAS DE EDUCACIÓN FÍSICA EN LA ESCUELA RURAL 

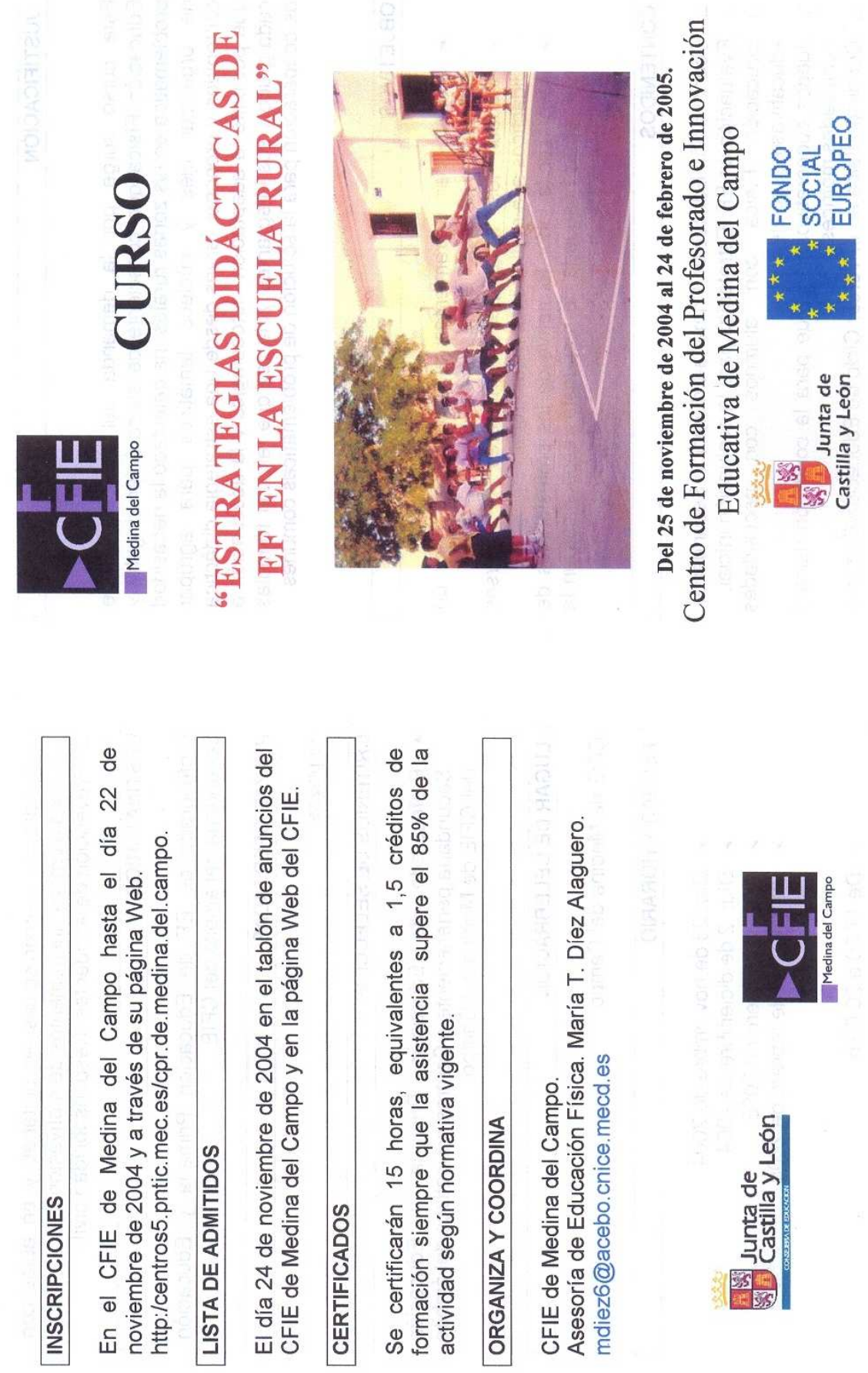

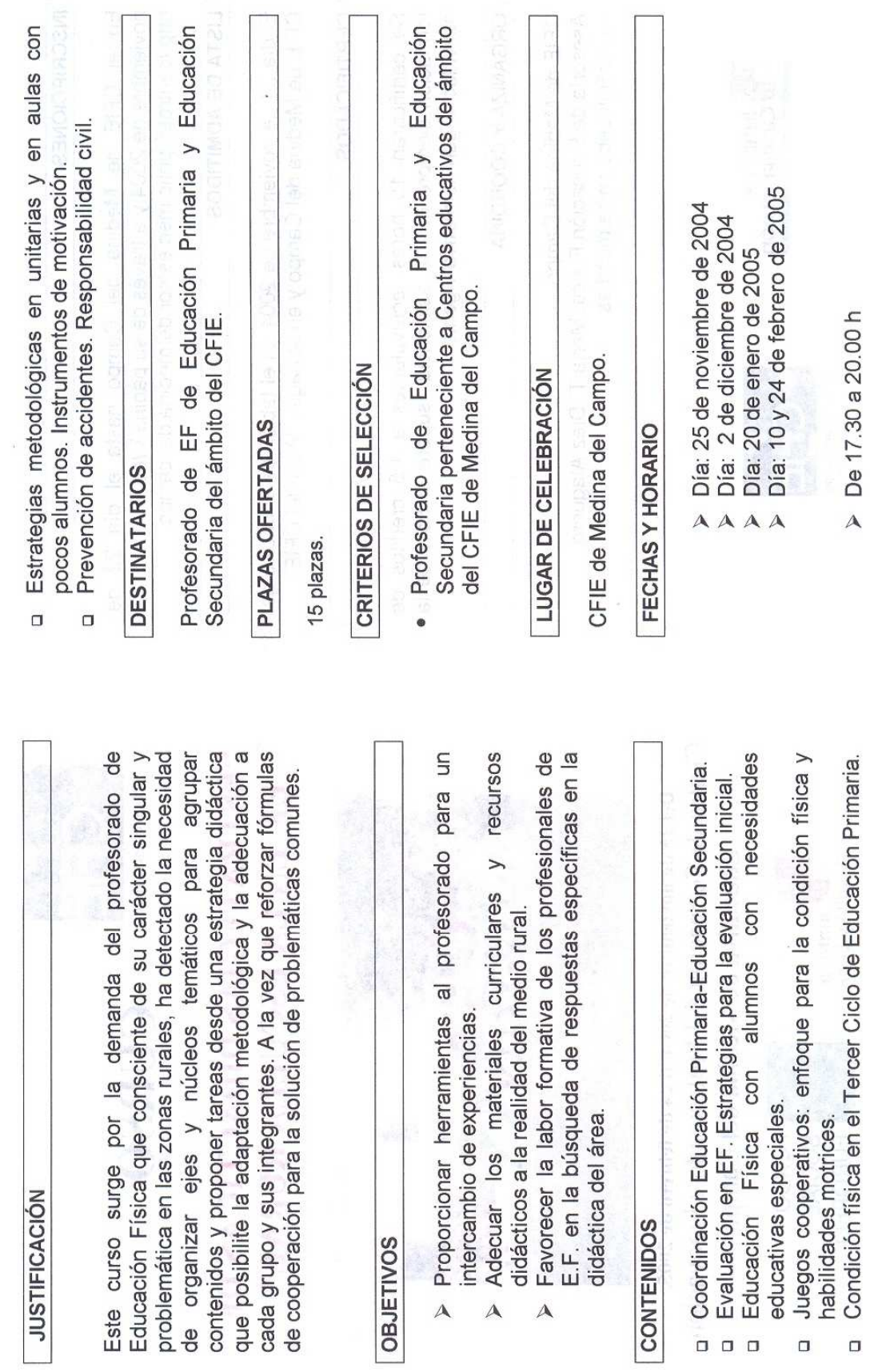


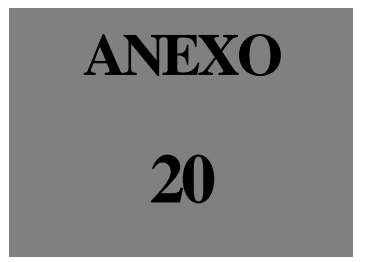

SOLICITUD DE INDEMNIZACIÓN POR RESPONSABILIDAD

PATRIMONIAL 
D./D."

y domicilio en

C.P.

$\mathrm{C}$

adre/madre/representante legal del alumno/ $\mathrm{a}^{(1)}$

según se acredita en la documentación que se adjunta,

EXPONE:

Con fecha ........................................., a las .............................. horas, y con ocasión de actividades en el Centro

el referido alumno/a sufrí un accidente en los términos que a continuación se describe

1. Descripción de los hechos.

2. Lesiones producidas (detallada descripción de las mismas e indicar si precisó o no asistencia médica)

3. Presunta relación de causalidad entre la lesión producida y el funcionamiento del servicio público educativo (justificación de las razones por las que Ud. considera que el accidente pudo preverse o evitarse).

4. Evaluación económica de la responsabilidad patrimonial (justificación detallada de la cantidad que se reclama).

En virtud de lo expuesto y de conformidad con los arts. 131 y siguientes de la Ley 30/1992, de 26 de noviembre, de Régimen Jurídico de las Administraciones Públicas y del Procedimiento Administrativo Común, así como el Real Decreto 429/1993, de 26 de marzo, por el que se aprueba el Reglamento de los procediy consiguientemente se me indemnice en la cantidad de Ptas./Euros ${ }^{(1)}$ como consecuencia de los daños y perjuicios causados por el funcionamiento del servicio público educativo, de acuerdo con los hechos, circunstancias y documentos antes mencionados.

$$
\text { Documentos que deben aportar: }
$$

En

$\square$ Fotocopia compulsada del Libro de Familia o documento judicial de representación del menor

$\square$ Certificado/s médico/s de lesiones

$\square$ Documentos justificativos de los gastos

$\square \operatorname{Otros}^{(2)}$

(1) Táchese lo que no proceda.

(2) Con carácter facultativo podrá acompañar cuantas alegaciones, documentos e informaciones se estimen oportunos y de la proposición de prueba, concretando los medios de que pretenda

EXCMO. SR. CONSEJERO DE EDUCACIÓN Y CULTURA. 


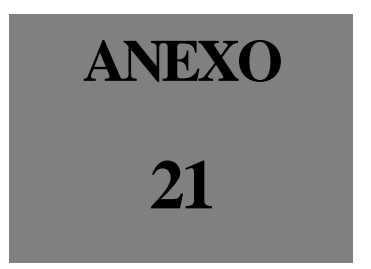




\section{紫 Junta de}

\section{Castilla y León}

COMUNICACIÓN

CONSEERADDE EDUCACGONY CULUURA

\section{DE ACCIDENTE ESCOLAR}

1. DATOS DEL ALUMNO/A

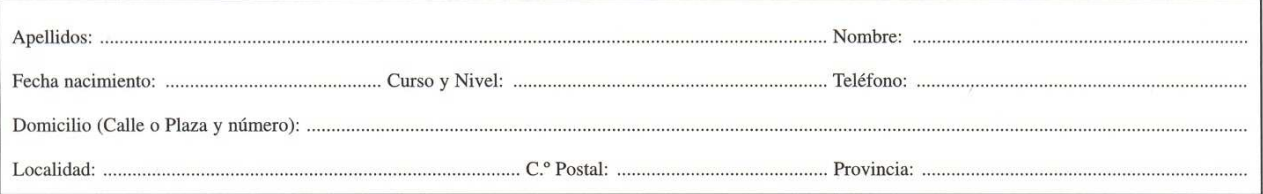

2. DATOS DEL PADRE, MADRE O REPRESENTANTE LEGAL

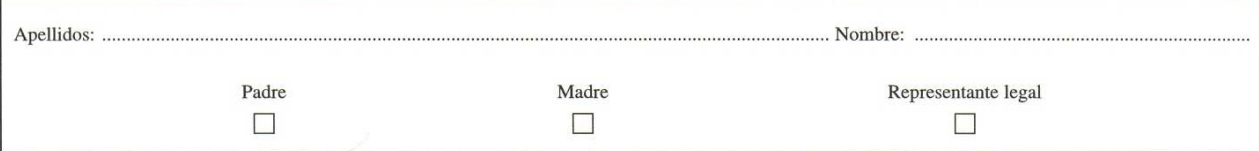

3. DATOS DEL CENTRO ESCOLAR

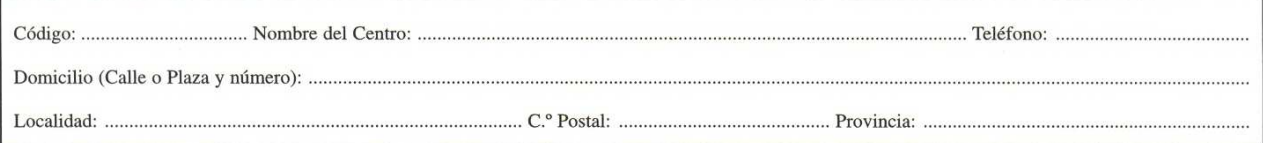

4. DESCRIPCIÓN DEL ACCIDENTE

Fecha: .............................................. Hora: ........................ Lugar: ........................................ Actividad:

Personas presentes:

Daños sufridos:

Relato de los hechos:

(1)

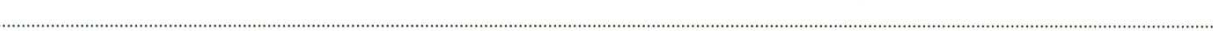

$\square$

NO Precisó asistencia médica.

$\square \quad$ Se considera de particular gravedad por:

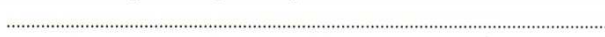

5. OBSERVACIONES

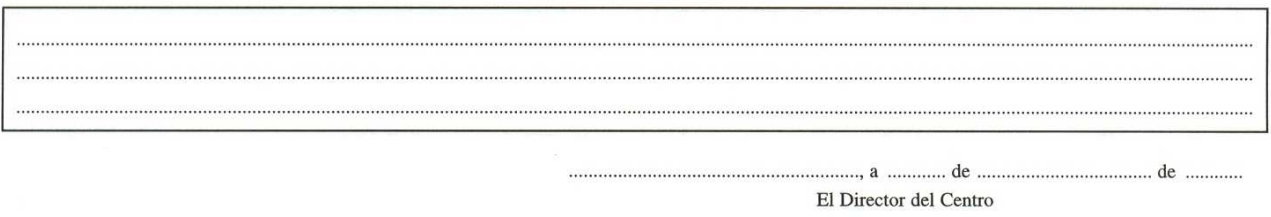

SELLO DEL CENTRO

SR. DIRECTOR PROVINCIAL DE EDUCACIÓN DE 


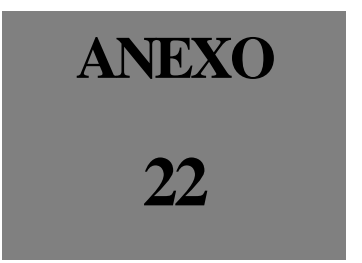

CURSO RIESGOS, ACCIDENTES Y RESPONSABILIDAD EN LA PRÁCTICA DOCENTE DE LA EDUCACIÓN FÍSICA 


\section{Título: RIESGOS, ACCIDENTES Y RESPONSABILIDAD EN LA PRÁCTICA DOCENTE DE LA EDUCACIÓN FÍSICA}

Organiza: Viceconsejería del Deporte de la Consejería de Educación y Ciencia de la Junta de Comunidades de Castilla-La Mancha

Lugar: Albacete

Fechas: 7 y 8 de octubre

Duración: 15 horas

Inscripción: 30 euros

Programa:

- Responsabilidad jurídica del profesor de Educación Física.

- Control de los riesgos de accidente en la clase de Educación Física.

- Instalaciones, materiales y equipamientos adecuados en las instalaciones deportivas escolares.

- Ejercicios desaconsejados en la clase de Educación Física.

- Tratamiento de los "exentos" y grupos especiales, obesos, asma, etc.

- Servicios y prestaciones de un centro de medicina deportiva para alumnos con dificultades en la práctica de actividad física.

- Papel del profesor en el control de riesgos en la clase de Educación Física.

Dirección:

- D. Pedro Bodas Gutiérrez.

- D. Julio Tomás Larrén.

\section{Profesores:}

- D. Pedro Ángel López Miñarro.- Profesor de la Universidad Católica de San Antonio de Murcia.

- D. Fernando Jiménez Díaz. Profesor de la Universidad de Castilla-La Mancha. Especialista en Medicina del Deporte.

- D. José Sánchez Martínez. Centro de Medicina del Deporte San Javier (Murcia)

- D. Jaime Vallejo.- Presidente del Consejo General de llustres Colegios Oficiales de Licenciados en Educación Física y en Ciencias de la Actividad Física y el Deporte.

- D. José Manuel Lara Pérez. Profesor Universidad Castilla-La Mancha.

- D. Antonio Martínez Marhuenda.- Instituto Biomecánico de Valencia.

- D. Miguel Angel González Halcones.- Profesor de la Universidad de CastillaLa Mancha. 
"Riesgos, accidentes y responsabilidad en la práctica docente de la Educación Física"

Albacete, 7 y 8 de octubre de 2005

Lugar de celebración:

Delegación Provincial de la Junta de Comunidades

(Antigua Fábrica de Harinas)

Paseo de la cuba, 27

TIf. 967-195-727

Viernes 7 de octubre de 2005

\begin{tabular}{|c|c|}
\hline 15.45 a $16.15 \mathrm{~h}$. & $\begin{array}{l}\text { Recepción de los participantes } \\
\text { Entrega de documentación }\end{array}$ \\
\hline 16.15 a $16.30 \mathrm{~h}$. & Presentación del curso \\
\hline $16: 30$ a $17.45 \mathrm{~h}$. & $\begin{array}{l}\text { Prestaciones de un centro de medicina deportiva para alumnos con dificultades en la práctica } \\
\text { de actividad física } \\
\text { D. José Sánchez Martínez }\end{array}$ \\
\hline 17.45 a $19.00 \mathrm{~h}$. & $\begin{array}{c}\text { Valoración inicial de la condición física y de la salud de los jóvenes deportistas } \\
\text { D. Fernando Jiménez Díaz }\end{array}$ \\
\hline 19.00 a $19: 30 \mathrm{~h}$. & Descanso \\
\hline 19.30 a $20.45 h$. & $\begin{array}{c}\text { Riesgos de una práctica inadecuada de ejercicio físico } \\
\text { D. Pedro Luis Rodríguez García }\end{array}$ \\
\hline $20: 45$ a $21: 15 \mathrm{~h}$. & Coloquio \\
\hline
\end{tabular}




\section{Sábado 8 de octubre de 2005}

\begin{tabular}{|c|c|}
\hline 9.00 a $10.00 \mathrm{~h}$. & $\begin{array}{l}\text { Papel del profesor de Educación Física en el control de riesgos en la clase de } \\
\text { Educación Física } \\
\text { D. José Manuel Lara Pérez }\end{array}$ \\
\hline 10.00 a $11.00 \mathrm{~h}$. & $\begin{array}{c}\text { Tratamiento de los "exentos" y grupos especiales de riesgo en las } \\
\text { clases de Educación Física } \\
\text { D. Miguel Angel González Halcones }\end{array}$ \\
\hline 11.00 a $11.30 \mathrm{~h}$. & Descanso \\
\hline 11.30 a $12.45 \mathrm{~h}$. & $\begin{array}{c}\text { Responsabilidad civil en la práctica docente de la Educación Física y jurisprudencia } \\
\text { al respecto } \\
\text { D. Jaime Vallejo López }\end{array}$ \\
\hline 12.45 a $14.00 \mathrm{~h}$. & Coloquio \\
\hline
\end{tabular}

\begin{tabular}{|c|c|}
\hline 16.15 a $17.30 \mathrm{~h}$. & $\begin{array}{c}\text { Ejercicios desaconsejados en la clase de Educación Física } \\
\text { D. Pedro Angel López Miñarro }\end{array}$ \\
\hline 17.30 a $18.30 \mathrm{~h}$. & $\begin{array}{l}\text { Control de riesgos en la clase de educación física } \\
\text { D. Pedro Angel López Miñarro }\end{array}$ \\
\hline 18.30 a $19.00 \mathrm{~h}$. & Descanso \\
\hline 19.00 a $20.00 \mathrm{~h}$. & $\begin{array}{c}\text { Instalaciones, equipamientos y materiales adecuados en las zonas deportivas } \\
\text { escolares } \\
\text { D. Javier Gámez Paya }\end{array}$ \\
\hline 20.00 a $20.45 \mathrm{~h}$. & Coloquio \\
\hline 20.45 a $21.00 \mathrm{~h}$. & Clausura y Entrega de Diplomas \\
\hline
\end{tabular}




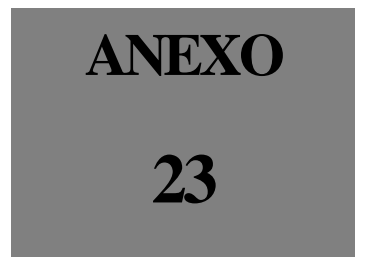

CURSO CONTROL DE LESIONES Y ACCIDENTES EN LA PRÁCTICA EDUCATIVA. RESPONSABILIDAD DOCENTE 


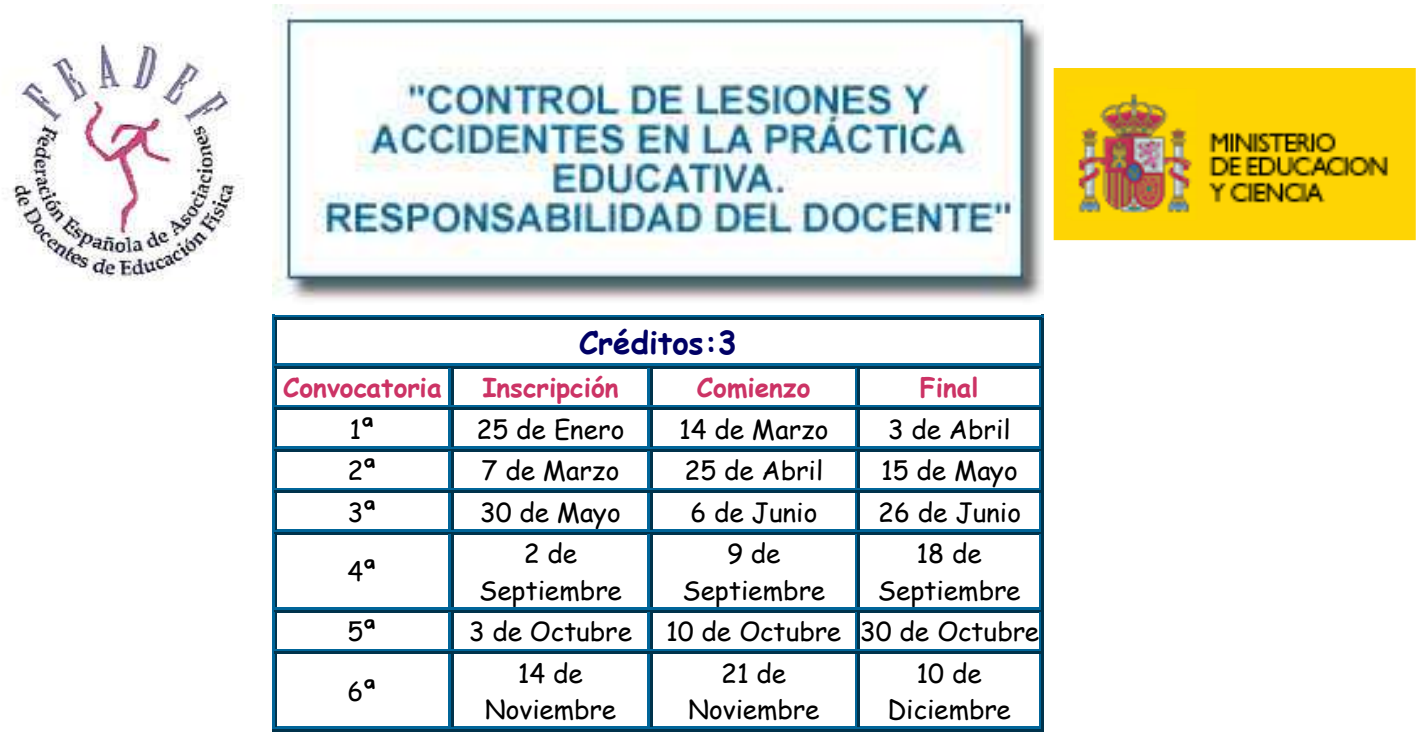

Información
Tarifas
Calendario
Inscripción
Criterios de
selección

Nivel/área

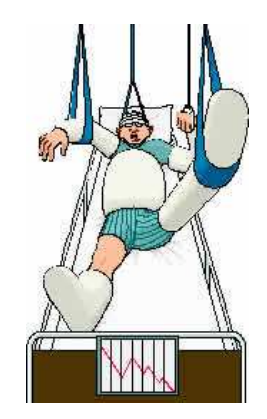

\section{Información}

\section{$1^{\circ}$ Asociados a FEADEF}

$2^{\circ}$ Docentes que imparten cualquier nivel de enseñanza.

$3^{\circ}$ Personas que tienen la titulación adecuada para impartirlo.

$4^{\circ}$ Orden de presentación de instancias de matrícula.

\section{Nivelárea}

INTERNIVELES: Infantil, Primaria, Secundaria. INTERÁREAS.

\section{DIRECTOR PEDAGÓGICO DEL CURSO:}

Ignacio Antolín Ruiz (Director) Licenciado en Historia y profesor de Educación Física en el C.P. "José Escandón" de Soto de la Marina de Santander y Francisco Ruiz Juan (Coordinador) Doctor en Psicopedagogía profesor titular del área de Didáctica de la Expresión Corporal de la Facultad de Humanidades de la Universidad de Almería.

* Cada grupo reducido de alumnos tendrá un Tutor específico para todo tipo de consultas.

* La tutorización será a través de correo electrónico, de correo ordinario, tutoría presencial ó consulta telefónica en día y hora prefijada para cada tutor.

\section{Justificación}

Siempre unido a la actividad y más concretamente a la actividad física los docentes demandan una formación específica para poder solventar cuantas contingencias, lesiones o accidentes pueden a surgir en su tarea diaria, en cualquier momento o circunstancia.

La modalidad a distancia permite a todos aquellos que les es dificultoso adquirir estos conocimientos, tan necesarios, de la manera tradicional, y precisamente a ellos y ellas van dirigido el curso.

\section{Objetivos}

1. Conocer los aspectos metodológicos que deben regir el correcto desarrollo de una actividad física saludable del niño en relación con su desarrollo psico- biológico.

2. Conocer y controlar aquellas contingencias presentes durante las clases de Educación Física y que pueden suponer un 
riesgo de accidente.

3. Interpretar los indicadores básicos de salud a través del informe inicial de valoración de la condición física saludable.

4. Conocer los elementos básicos de responsabilidad del docente así como jurisprudencia al respecto.

5. Seleccionar actividades físicas saludables que no impliquen riesgo de lesión.

6. Descubrir los mitos más habituales en el deporte.

7. Seleccionar los materiales adecuados.

8. Ampliación Profesional en la formación permanente e inicial de los diplomados, licenciados y estudiantes de la Educación Física y los diplomados en general.

9. Abordar la prevención de lesiones desde la perspectiva de la actividad física en el ámbito escolar y el deporte base.

10. Conocer aspectos relacionados con la actividad deportiva y su repercusión sobre la salud de los jóvenes.

11. Valorar las situaciones de riesgo en el deporte y su prevención.

12. Desarrollar pautas a seguir en caso de precisar los primeros auxilios ante las lesiones deportivas más habituales

13. Conocer la función y la estructura de las partes del organismo humano implicadas en las lesiones deportivas más habituales.

14. Conocer los servicios, prestaciones y organización de un Centro de Medicina Deportiva.

\section{Contenidos}

1. SALUD Y ACTIVIDAD FÍSICA: Se pretende que el alumno especule sobre lo saludable o no de la actividad físico deportiva.

2. BASES ANATÓMICAS Y FÍSICAS DE LA LESIÓN. Conocer la anatomía y mecánica de la lesión para entender el funcionamiento de las estructuras corporales y conocer sus límites de movilidad y carga

3. TIPOLOGÍA Y CAUSAS DE LA LESIÓN. Adquirir un vocabulario básico para definir los tipos de lesiones y distinguirlas en la práctica.

4. PREVENCIÓN (FÍSICA, PSICOLÓGICA Y AMBIENTAL). Conocer la influencia de lo emocional en la prevención o aparición de la lesión, así como en su recuperación.

5. INTERVENCIÓN. Atención primaria a un lesionado. Pautas de intervención.

6. RECUPERACIÓN. Sistemas de recuperación. Medicina oficial y terapias alternativas

7. RESPONSABILIDAD JURÍDICA DEL DOCENTE. Conocer los derechos y deberes en el ámbito educativo y de responsabilidad sobre grupos de menores. Responsabilidad jurídica en caso de accidente. Cómo evitar ser denunciado y en caso de serlo cómo actuar.

8. GRUPOS DE ATENCIÓN ESPECIAL: Alumnos con Necesidades Educativas Especiales o de alto riesgo de lesión.

\section{Metodologia}

-Guía Didáctica Informativa.

- Textos legales

-Información sobre cómo realizar el curso.

- Usuario y contraseña de acceso al curso.

-Sesión presencial inicial en la sede provincial de FEADEF, más próxima al del alumno, con el tutor o tutores asignaos al efecto para ese grupo de alumnos.

-Realización del trabajo a desarrollar: comprensión y asimilación de los contenidos, elaboración de material de aplicación a partir del contenido del curso y trabajo final sobre el proceso, resultados, problemas, soluciones, etc.

- Análisis crítico del material remitido y de la web.

- Toma de contacto e ideas previas sobre lesiones y su prevención.

- Confección de una planilla de observación del entorno del lugar de trabajo y su posible influencia en la lesión y planilla de datos de accidentes y estudio estadístico

-Planilla de evaluación de conocimientos sobre los bloques temáticos teóricos

- Diseño de sesión saludable y preventiva

-Análisis teórico o práctico de alguno de los aspectos estudiados.

TUTORIAS: El intercambio de información y de consulta se realizará por correo electrónico, por correo ordinario y teléfono, en horario a designar para cada tutor. 


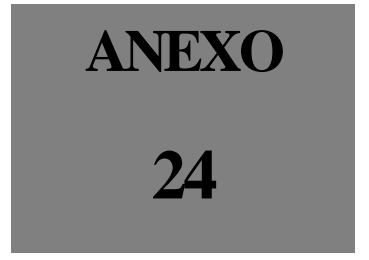




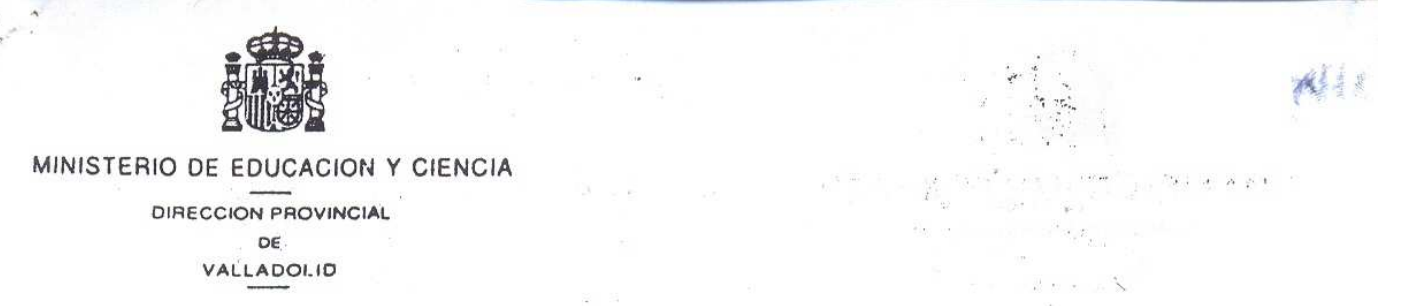

A la atención del Médico que atiende al alumno:

Dentro del enfoque de la asignatura de Educación Fisica como un área que incide decididamente en una concepción de educación para la salud (conocimiento del proplo cuerpo, efectos sobre la salud y calidad de vida), el Ministerio de Educación y Ciencia, preocupado porque el profesorado pueda obtener asesoramiento adecuado para adaptar la materia a las enfermedades temporales o discapacidades permanentes, solicita de Ud. que indique de la relación que se adjunta qué actividades no puede realizar el alumno atendido.

La Dirección Provincial

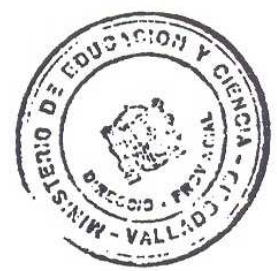



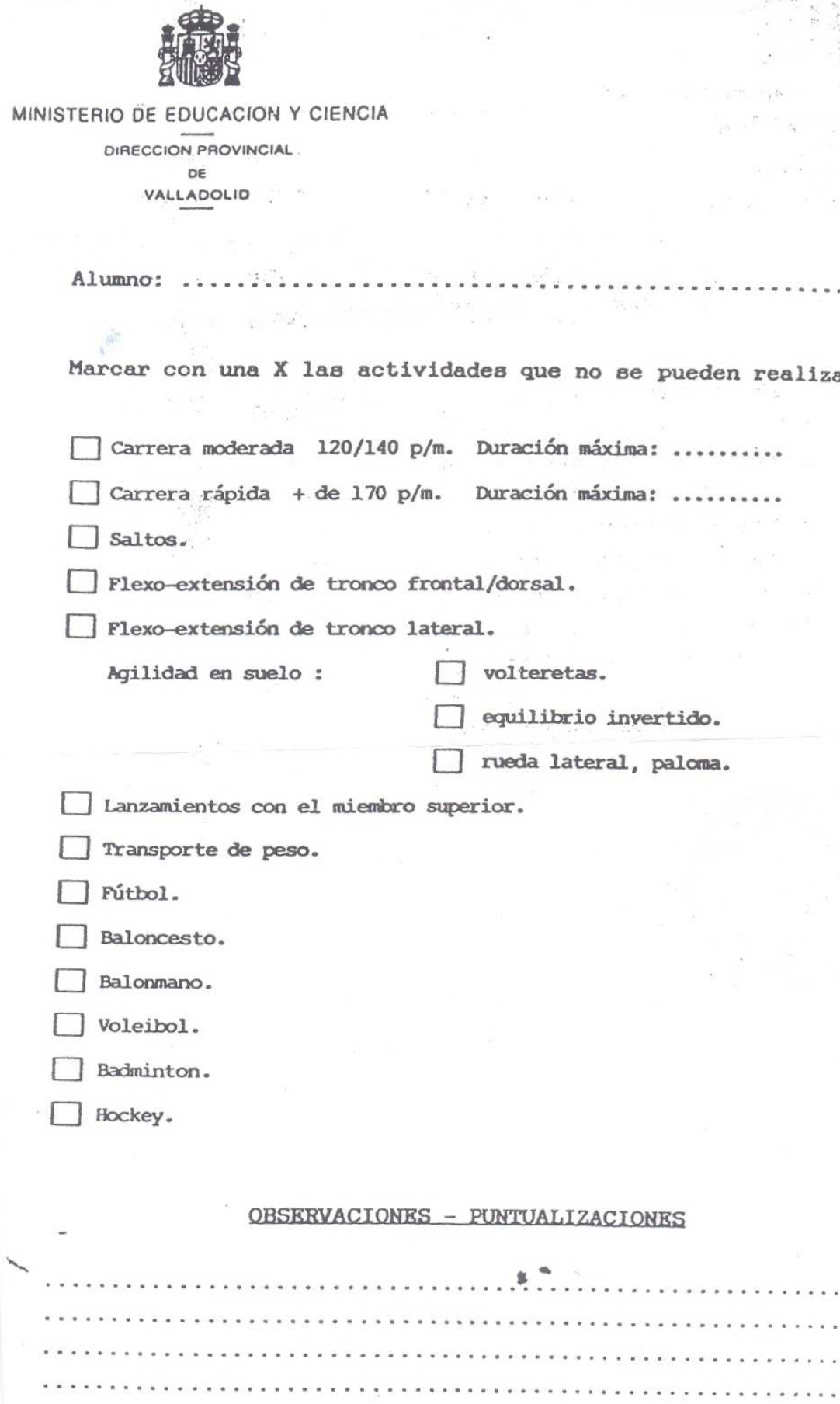


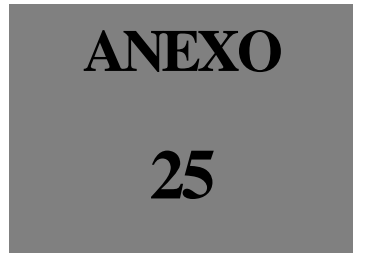

FICHA MÉDICA INDIVIDUAL PARA EDUCACIÓN FÍSICA 


\section{FICHA MÉDICA INDIVIDUAL PARA EDUCACIÓN FÍSICA}

Apellidos del alumno/a:

Curso:.

Fecha de nacimiento:

Nombre:

Rodee con un círculo la respuesta que considere verdadera en las siguientes preguntas. En el caso de respuestas afirmativas, explique lo más detalladamente posible en la línea siguiente a cada pregunta.

$\left.1^{\circ}\right)$ ¿Tiene su hijo/a problemas cardiovasculares (corazón)? SI NO Explicar en caso afirmativo.

$\left.2^{\circ}\right)$ ¿Padece algún tipo de alergia? SI

NO Explicar en caso afirmativo.

$\left.3^{\circ}\right)$ ¿Tiene su hijo/a alteraciones sanguíneas? SI

NO Explicar en caso afirmativo.

$\left.4^{\circ}\right)$ ¿Manifiesta algún problema de huesos y/o articulaciones? SI NO Explicar en caso afirmativo.

$\left.5^{\circ}\right)$ ¿Padece alguna deformación de los pies (planos, cavos)? SI $\mathrm{NO}$ Explicar en caso afirmativo.

$\left.6^{\circ}\right)$ ¿Padece alguna alteración en la columna vertebral? SI NO Explicar en caso afirmativo.

$\left.7^{\circ}\right)$ ¿Tiene dificultades respiratorias $($ asma,...)? SI NO Explicar en caso afirmativo.

$8^{\circ}$ ) Especifique aquellas enfermedades y traumatismos que haya padecido que requieran un cuidado especial:

$\left.9^{\circ}\right)$ Oros problemas que considere explicar: 


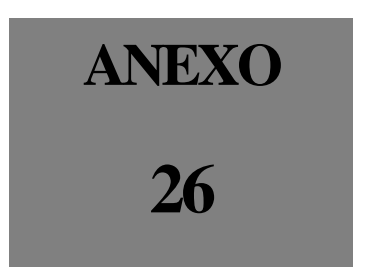

CUESTIONARIO ACERCA DE ASUNTOS RELACIONADOS CON LA RESPONSABILIDAD DEL PROFESORADO 


\section{INSTRUCCIONES}

El cuestionario que tienes entre tus manos formará parte de una Tesis Doctoral que tiene por objetivo, entre otros asuntos, estudiar y analizar la responsabilidad civil del profesorado en el trabajo diario con alumnos/as de la E.S.O. y el Bachillerato.

Rodea con un círculo la respuesta elegida. Al final del cuestionario puedes realizar las aclaraciones que consideres oportunas. Una vez completado, entrégalo en cualquier conserjería del Centro. Gracias por tu colaboración.

1.- En alguna ocasión, durante el desarrollo de tus clases, ¿algún alumno/a ha sufrido un accidente o lesión?

$$
\text { Sí No }
$$

2.- Estando de guardia, ¿has tenido que hacerte cargo de un grupo porque su profesor/a tuviera que ausentarse para trasladar a un alumno/a accidentado durante su clase?

$$
\text { Sí No }
$$

3- En caso afirmativo a la anterior, ¿sabrías decir en qué materias se produjo el accidente?

\section{MATERIAS:}

4.- Valora, en una escala del 1 (poco) al 10 (mucho), el grado de probabilidad de aparición de lesiones o accidentes en las siguientes materias:

$\begin{array}{lcccccccccc}\text { TECNOLOGÍA } & 1 & 2 & 3 & 4 & 5 & 6 & 7 & 8 & 9 & 10 \\ \text { MATEMÁTICAS } & 1 & 2 & 3 & 4 & 5 & 6 & 7 & 8 & 9 & 10 \\ \text { PLÁSTICA Y VISUAL } & 1 & 2 & 3 & 4 & 5 & 6 & 7 & 8 & 9 & 10 \\ \text { MÚSICA } & 1 & 2 & 3 & 4 & 5 & 6 & 7 & 8 & 9 & 10 \\ \text { LENGUA Y LIT. } & 1 & 2 & 3 & 4 & 5 & 6 & 7 & 8 & 9 & 10 \\ \text { EDUCACIÓN FISICA } & 1 & 2 & 3 & 4 & 5 & 6 & 7 & 8 & 9 & 10 \\ \text { C. SOCIALES } & 1 & 2 & 3 & 4 & 5 & 6 & 7 & 8 & 9 & 10 \\ \text { IDIOMAS } & 1 & 2 & 3 & 4 & 5 & 6 & 7 & 8 & 9 & 10 \\ \text { FISICA Y QUIMICA } & 1 & 2 & 3 & 4 & 5 & 6 & 7 & 8 & 9 & 10 \\ \text { C. NATURALES } & 1 & 2 & 3 & 4 & 5 & 6 & 7 & 8 & 9 & 10\end{array}$

5- ¿Crees necesario que el profesorado cuente con un seguro de Responsabilidad Civil?

$$
\text { Sí NO }
$$

6.- Por el cauce que sea (colegiación, afiliación sindical...), ¿lo tienes contratado?

$$
\text { Sí No }
$$


7.- ¿A través de cualquier medio de comunicación has tenido conocimiento de algún accidente producido dentro del horario escolar de cualquier otro centro educativo?

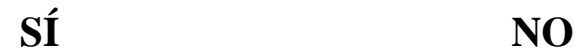

8.- En caso afirmativo a la anterior, ¿sabrías decir en qué materias se produjo?

MATERIAS:

9.- ¿En alguna ocasión te has planteado el tema de la responsabilidad civil en tu trabajo con alumnos/as?

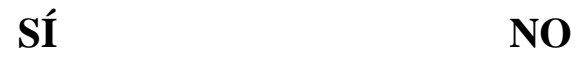

10.- ¿Has asistido a cursos, seminarios... en los que se abordasen cuestiones relacionadas con la responsabilidad civil del profesorado?

\section{SÍ NO}

11.- ¿Crees conveniente que en el centro se realice alguna charla o ponencia informativa al respecto de la responsabilidad civil?

$$
\text { SÍ NO }
$$

12.- En caso de que tengas hijos/as, ¿han sufrido algún accidente o lesión durante el horario escolar?

$$
\text { SÍ NO }
$$

13.- En caso afirmativo a la anterior, ¿sabrías decir en que materia o momento se produjo?

$\begin{array}{rrrr}\text { EDUCACIÓN FÍSICA } & \text { TECNOLOGÍA } & \text { MÚSICA } & \text { C.NATURALES } \\ \text { FÍSICA Y QUÍMICA } & \text { C.SOCIALES } & \text { MATEMÁTICAS } & \text { LENGUA } \\ \text { PLÁSTICA } & \text { IDIOMA } & \text { OTROS }\end{array}$

14.- ¿Crees que estamos debidamente respaldados o protegidos por la Administración en cuestiones de responsabilidad civil?

$$
\text { SÍ NO NO SÉ }
$$

15.- Si lo deseas, puedes realizar las observaciones que creas convenientes en relación con estos asuntos de la responsabilidad civil del profesorado. 


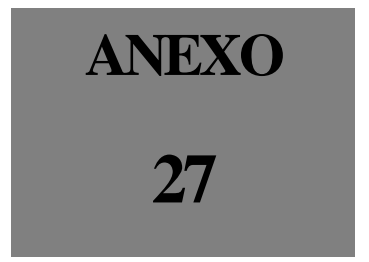

FICHA PARA LA RECOGIDA DE DATOS DEL CUESTINARIO ACERCA DE ASUNTOS RELACIONADOS CON LA RESPONSABILIDAD DEL PROFESORADO 


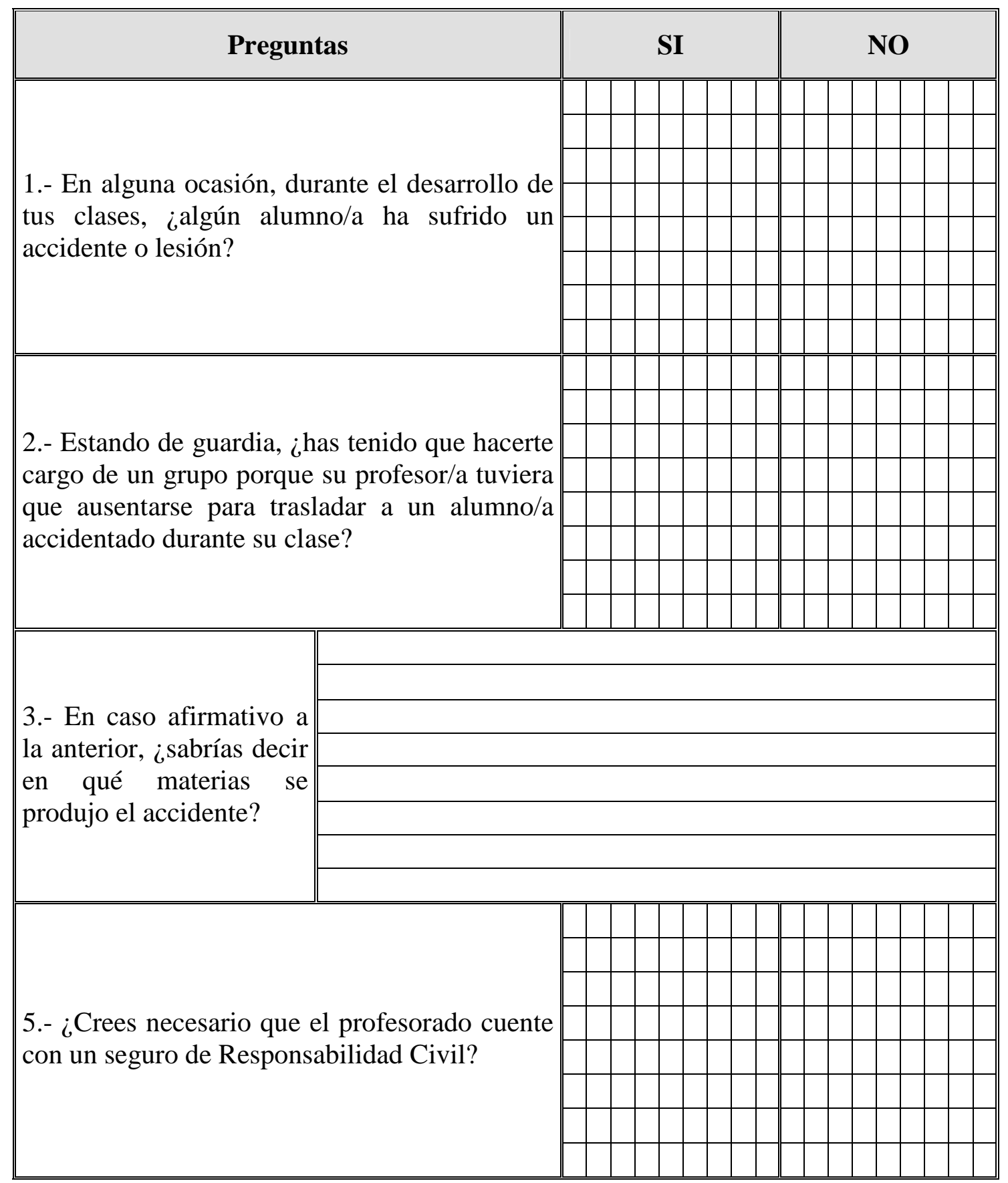




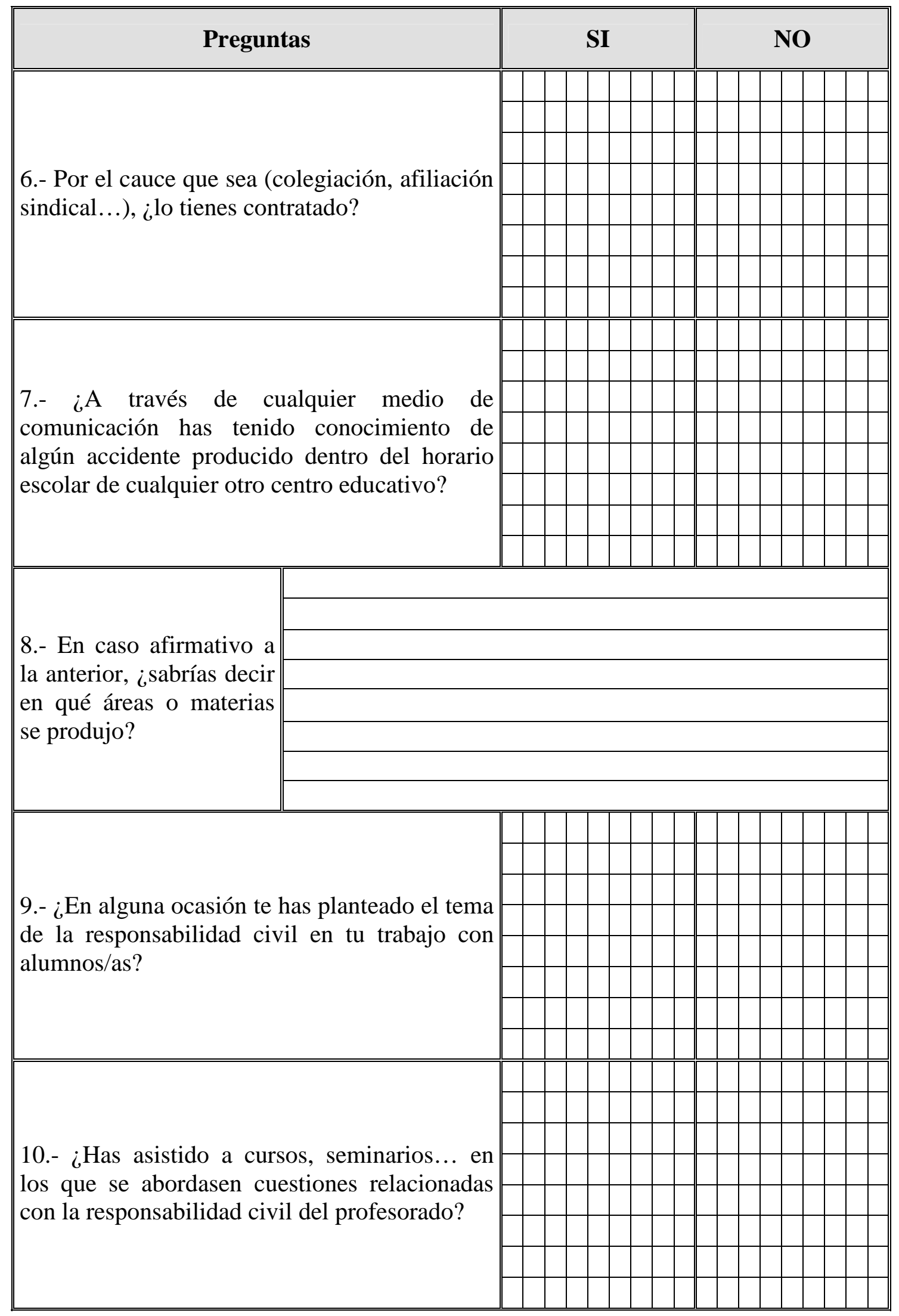




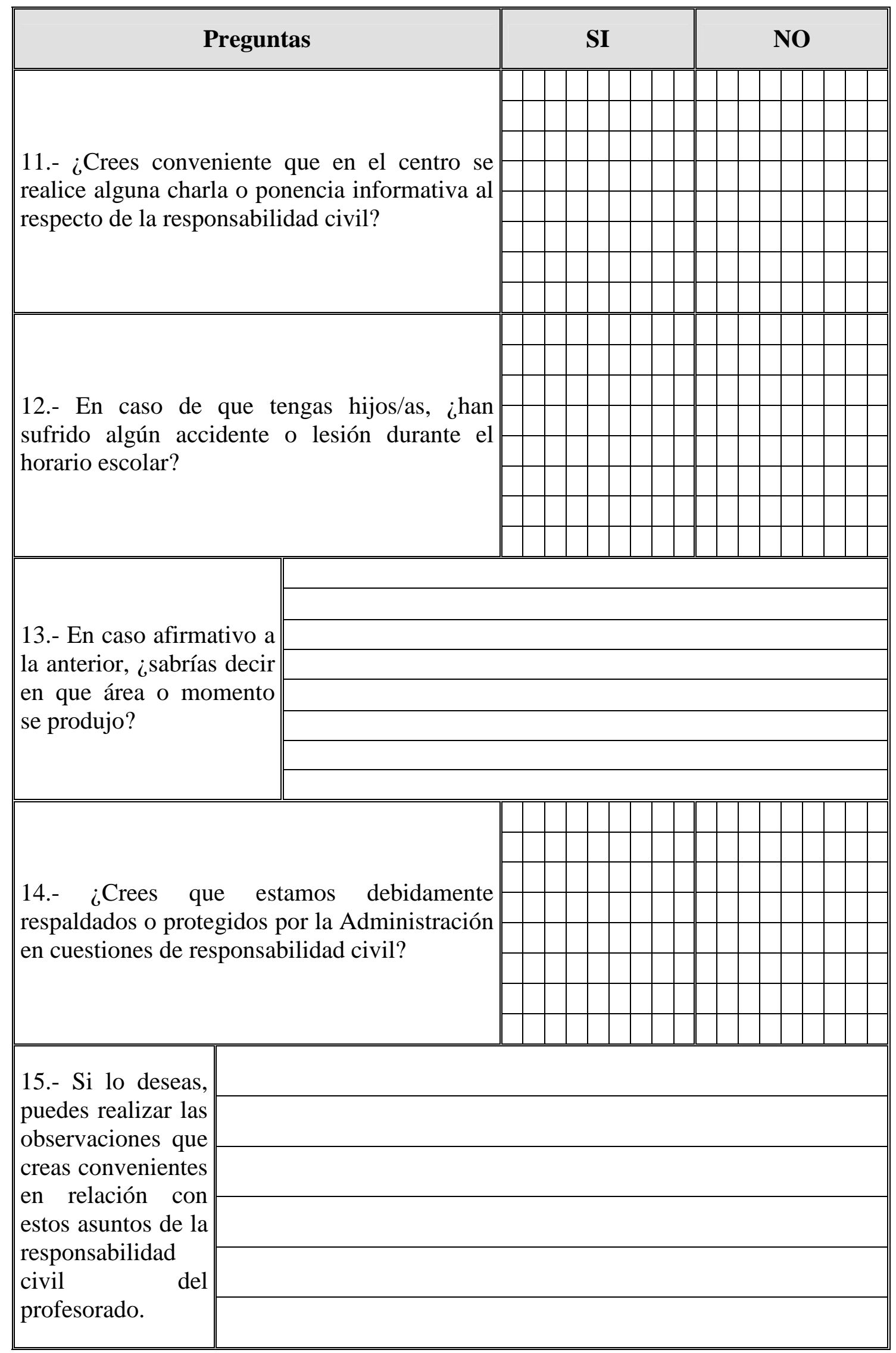




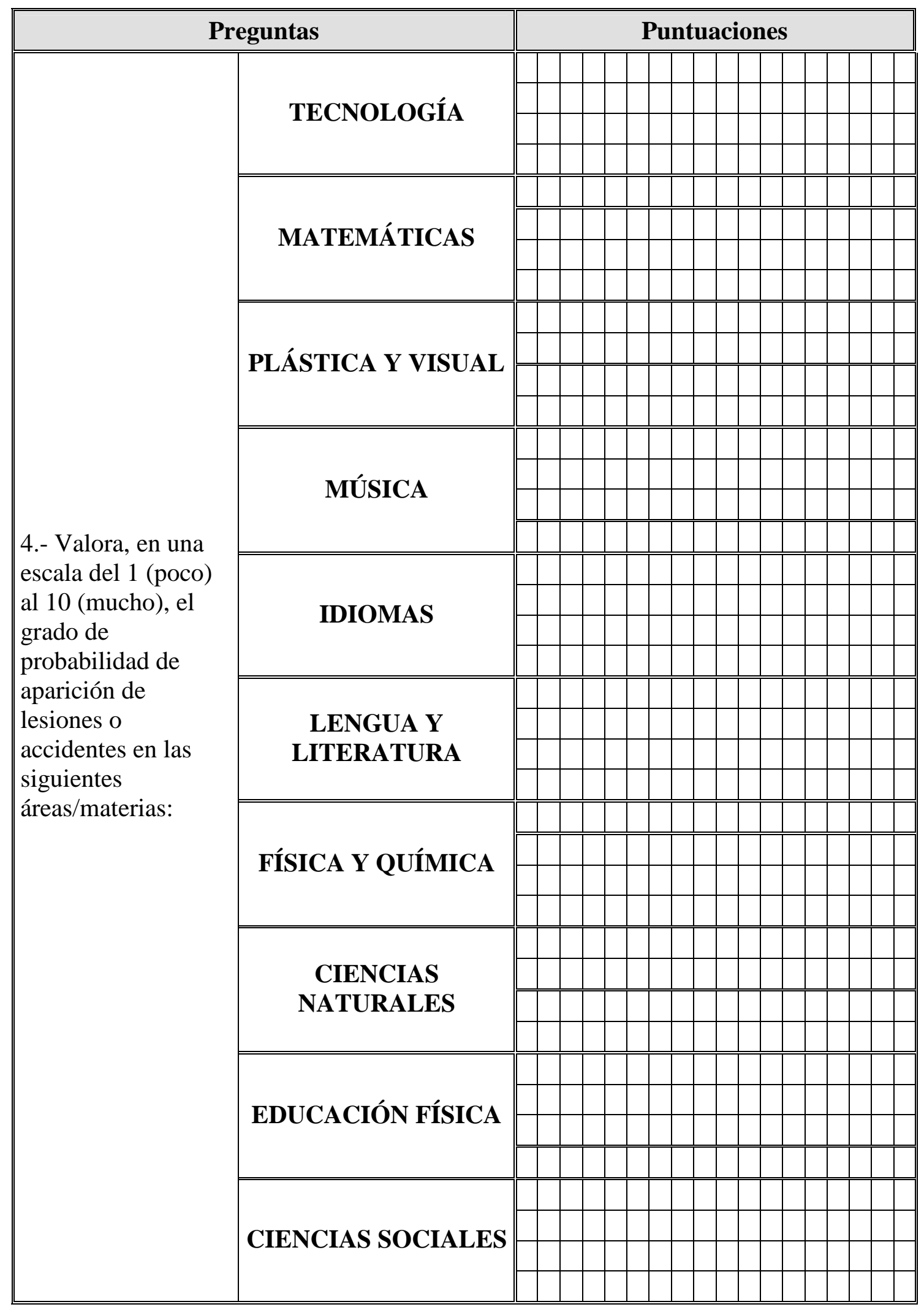




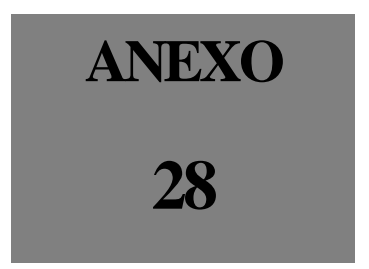


AUTOINFORME FINAL

NOMBRE: CURSO: “ ”

ACLARACIÓN PREVIA: Puedes hacer las diferencias que creas oportunas para los diferentes deportes o contenidos trabajados e, incluso, por evaluaciones.

A) Señala cómo ha sido tu trabajo en clase: asistencia, participación, interés, ayuda a los compañeros, esfuerzo, respeto por el material, por los compañeros, por el profesor, comportamiento y actitud, faltas de ropa, etc.

B) Aprendizaje: si has aprendido cosas nuevas, si haces ejercicios que antes no hacías, qué prácticas deportivas has logrado, si has superado miedos, si has intentado practicar fuera de clase para mejorar, en definitiva, ¿qué has aprendido este año?, ¿Para qué te ha servido la Educación Física? ¿Ha merecido la pena?

C) Cuaderno: trabajado diariamente, completo (sesiones, fotocopias...) implicación real, interés personal, ¿qué opinión te merece? ¿Lo has entregado siempre que se te ha pedido? ¿Has entregado todos los trabajos que se han pedido (corrección de errores, contestación de preguntas...)? ¿Te ha servido de algo el corregir los errores? ¿Cómo te ha servido para la prueba escrita? ¿Qué has aprendido de las fotocopias?

D) ¿Comprendes lo que hacemos y explicamos en clase? ¿Qué no entiendes o te resulta difícil? ¿Qué has aprendido?

E) Opinión sobre las clases: organización, compañeros, instalaciones, horario, actividades...

F) Profesor: las explicaciones, ejemplos o ejecuciones, ayudas ofrecidas, resolución de dudas o problemas, actitud, motivación que da, forma de evaluar...

G) ¿Qué te ha gustado más y qué menos? ¿En qué habría que mejorar?

H) Comentarios, opiniones, dudas y aclaraciones que quieras añadir.

I) Sugerencias que se puedan hacer para $1^{\circ} B A C H$, y aquellas que creas que habría que modificar de $4^{\circ}$ ESO (contenidos a trabajar, horarios, instalaciones, evaluación, cuaderno, materiales, profesor, etc.) ¿Podrías analizar tu paso por la Educación Física a lo largo de cada curso de la ESO? ¿Qué destacarías de cada uno de ellos? ¿En cuál has aprendido más? ¿Cómo han influido los profesores en cada uno de ellos?

J) AUTOCALIFICACIÓN: se trata de hacer el balance final de lo que ha sido este curso, no te limites solo a la tercera evaluación. Intenta ser lo más sincero/a posible. Se trata de cuantificar (poner nota) a todo lo que has escrito antes.

TRABAJO DIARIO (60\% de la nota final)

CUADERNO (30\% de la nota final)

CONOCIMIENTOS [lo que has aprendido y cómo lo dominas] (10\% nota final) 


UNIVERSIDAD DE VALLADOLID

FACULTAD DE EDUCACIÓN Y TRABAJO SOCIAL 